UNIVERSIDADE DE SÃO PAULO

INSTITUTO DE FÍSICA DE SÃO CARLOS

\title{
PARAlelismo em Visão Natural e ARTIFICIAL
}

\section{Odemir Martinez Bruno}

Tese apresentada ao Instituto de Física de São Carlos, da Universidade de São Paulo, para a obtenção do título de Doutor em Ciências: Física Aplicada (Física Computacional).

Orientador: Prof. Dr. Luciano da Fontoura Costa

DEPARTAMENTO DE FÍSICA E INFORMÁTICA

São Carlos

2000 

Bruno, Odemir Martinez

Paralelismo em Visão Natural e Artificial / Odemir Martinez Bruno. São Carlos, 200.

$391 \mathrm{p}$.

Tese (Doutorado) - Instituto de Física de São Carlos, 2000.

Orientador: Prof. Dr. Luciano da Fontoura Costa

1. Visão Cibernética. 2. Computação Paralela. I. Título 

À minha esposa Adriana e aos meus pais Orlando e Maria Candida. 



\section{AGRADECIMENTOS}

À minha esposa Adriana e aos meus pais Orlando e Maria Candida, pelo incentivo, colaboração, carinho e apoio.

Ao Prof. Luciano, pela orientação científica, amizade e pelas valiosas oportunidades de aprendizado.

Aos meus amigos, colegas e colaboradores Alan Salvany Felinto e Jander Moreira, pela cooperação nos trabalhos referentes ao sistema Cyvis-1 e pelo auxílio na validação e testes do CVMP, além da convivência pessoal.

A Luís Augusto Consularo, pelo trabalho em conjunto, pelo auxílio nos testes do CVMP e pela amizade.

A Roberto César Marcondes Junior, pelo trabalho em conjunto no projeto ¿ynergos e convivência pessoal.

À Cristina Algodoal Martins, pelas valiosas sugestões em botânica e pela amizade.

Ao Prof. Hilton Thadeu Zarate do Couto da ESALQ-USP, pelas indicações e informações referentes aos herbários.

À Estação Ecológica de Moji-Guaçu do Instituto Florestal do Estado de S. Paulo, pelo fornecimento de amostras de plantas arbóreas utilizadas neste trabalho. Em especial a Eduardo Amaral Batista, pesquisador chefe da unidade e José Carlos de Lima, auxiliar de apoio à pesquisa.

À Wladerez A. G. Caiado, por sua competência e constante bom humor, nos auxiliando ao longo desses anos nas questões burocráticas.

Ao pessoal da biblioteca do Instituto de Física de São Carlos, pela competência e presteza. 
A todos os colegas do Grupo de Pesquisa em Visão Cibernética pela amizade, fraternidade, cooperação e pelas produtivas discussões.

Aos técnicos do Grupo, Marcos Roberto Gonçalves e Alexandre Rodrigues da Silva, pelo auxílio e suporte.

A todos os professores e pesquisadores com quem pude aprender e debater nesses anos.

A todos que, direta ou indiretamente, prestaram seu apoio e/ou sua colaboração na realização deste trabalho.

Ao CNPq pelo suporte financeiro.

E finalmente quero deixar meus profundos agradecimentos ao Instituto de Física de São Carlos da Universidade de São Paulo, pela infra-estrutura e excelente ambiente para a pesquisa científica, onde tive a honra de estudar, pesquisar, trabalhar e conhecer grandes amigos. 


\section{RESUMO}

Nesta tese são abordados, de maneira integrada, aspectos de paralelismo em visão natural e artificial, com discussões críticas das diversas áreas relacionadas. O paralelismo é discutido no sistema visual dos primatas, assim como suas principais contribuições e motivações incentivando a incorporação de paralelismo em sistemas de visão artificial. Um dos objetivos principais é fornecer as bases de paralelismo para o desenvolvimento do projeto Cyvis-1, uma proposta do Grupo de Pesquisa em Visão Cibernética (IFSC-USP) para visão versátil, com forte motivação biológica e baseada no córtex visual dos primatas. Para tanto, foi introduzida e implementada a proposta CVMP (Cybernetic Vision Message Passage), um conjunto de ferramentas para o desenvolvimento de aplicações paralelas em visão, tanto para sistemas distribuídos como para máquinas multiprocessadores. Baseada em programação orientada a objetos, interação homem-máquina, engenharia de software e programação visual, a proposta prima pelo desenvolvimento de forma simples e amigável. O CVMP é testado, avaliado e validado quanto a aspectos de funcionalidade e utilização, através da implementação paralela de diversos algoritmos de visão computacional e de processamento de imagens (operadores locais, transformada de Hough e transformada de Fourier, entre outros) os quais, além de ilustrar a utilização da ferramenta, são discutidos em termos de arquitetura e balanceamento de carga. São apresentadas três aplicações reais de sistemas paralelos de visão computacional, implementadas através do CVMP, demonstrando a eficiência da ferramenta, na implementação paralela, na utilização e cooperação de trabalho. Duas destas aplicações (integração de atributos visuais no projeto Cyvis-1 e um modelo de complexidade com base na percepção humana), foram desenvolvidas em conjunto com outros pesquisadores do Grupo de Pesquisa em Visão Cibernética. A terceira aplicação apresenta uma proposta do autor para um sistema automático de reconhecimento de plantas arbóreas (Botânica). 


\section{ABSTRACT}

This thesis addresses, in an integrated way, the concept and usage of parallelism in natural and artificial vision. It starts by revising the primate visual system, and discussing how its principles and solutions can be extended to computational systems. One of the main objectives is to supply the parallelism backbone for the development of the Cyvis-1 System, which is a proposal of the Cybernetic Vision Research Group (IFSC-USP) for versatile vision, presenting a strong biological motivation, especially regarding the primate visual cortex. In order to achieve these objectives, the CVMP - Cybernetic Vision Message Passage - had to be developed, representing a set of simple and friendly parallel tools for computer vision applications in distributed and parallel (multiprocessor) systems, which is based on object oriented programming, human-machine interaction, software engineering and visual programming. The CVMP is tested, evaluated and validated with respect to functionality and utilization through the parallel implementation of several algorithms in computer vision and image processing (local operators, Hough transform, Fourier transform, etc.) which, in addition to illustrating the tools, are also discussed as far as their architecture and load balancing is concerned. Three applications of parallel computer vision systems to real situations are presented and implemented by using CVMP, corroborating the effectiveness of the tools in the parallel implementation, usage, and researcher integration. Two such applications (visual attributes integration in Cyvis-1 and a human complexity model) have been developed in collaboration with other researchers at the Cybernetic Vision Research Group. The third application presents the author's proposal for an automated system for arboreal plants recognition (Botany). 


\section{ÍNDICE}

CAPÍTULO 1 - INTRODUÇÃO

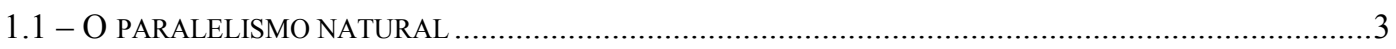

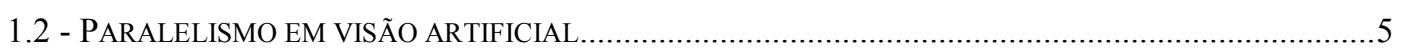

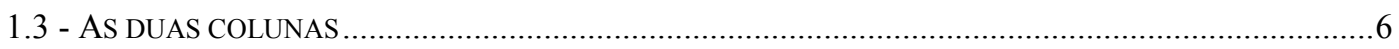

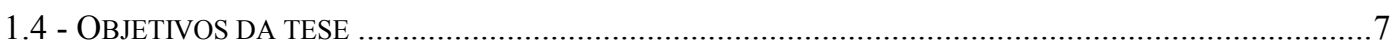

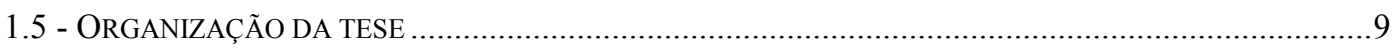

CAPÍTULO 2 - COMPUTAÇÃO PARALELA - HARDWARE .................................................13

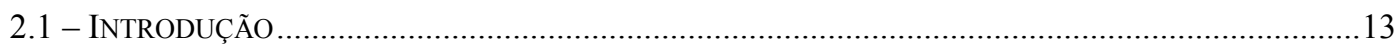

2.2 - PrincíPIOS HISTÓRICOS DA COMPUTAÇÃo PARALELA..............................................................13

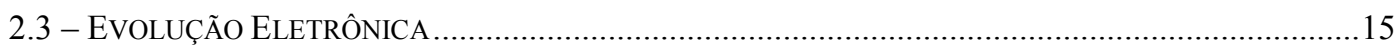

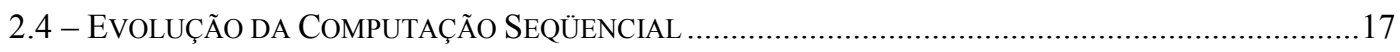

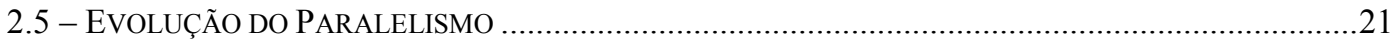

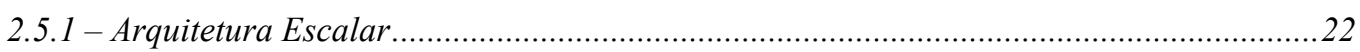

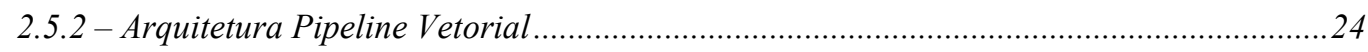

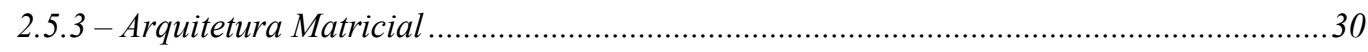

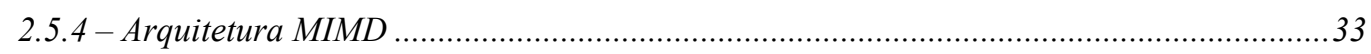

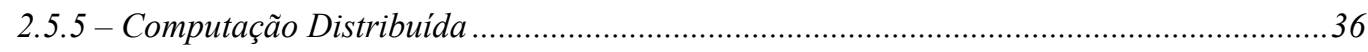

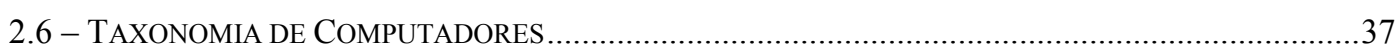

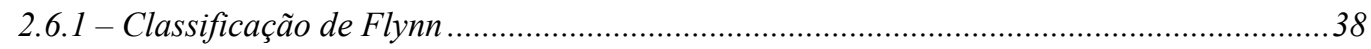

2.6.1.1 - SISD - Um fluxo de instrução e um fluxo de dados ................................................................ 40

2.6.1.2 - MISD - Múltiplos fluxos de instrução e um fluxo de dados ....................................................... 41

2.6.1.3 - SIMD - Um Fluxo de Instrução e Múltiplos Fluxos de Dados.................................................. 42

2.6.1.4 - MIMD - Múltiplos fluxos de instrução e Múltiplos fluxos de dados ........................................ 43

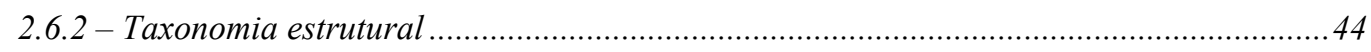

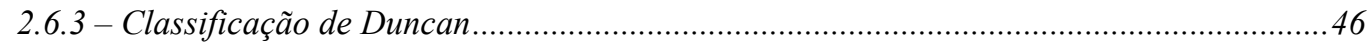

CAPÍTULO 3 - COMPUTAÇÃO PARALELA - SOFTWARE ......................................................51

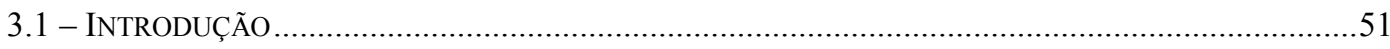

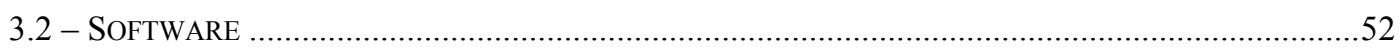

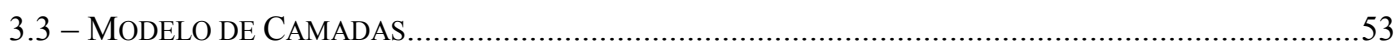

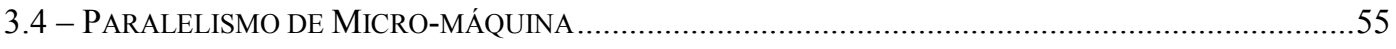

3.5 - PARALELISMO NO NÍVEL CONVENCIONAL ................................................................................. 56

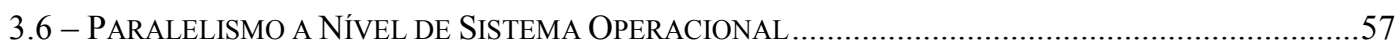

3.7 - Paralelismo A Nível de Linguagens de ProgramaÇão......................................................64

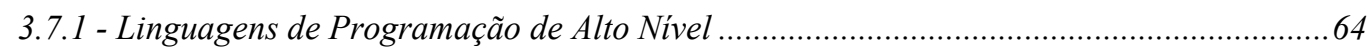

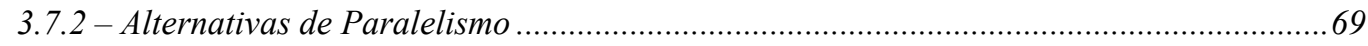


3.7 .3 - Mecanismos de Exploração de Paralelismo.......................................................... 71

3.8 - Ferramentas de Passagem de Mensagem em Sistemas Distribuídos ........................... 76

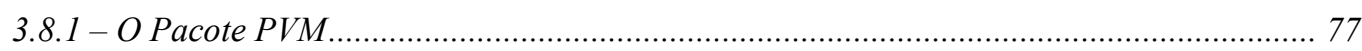

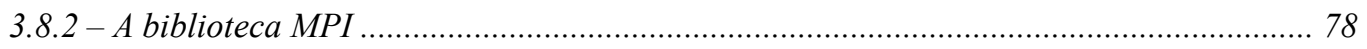

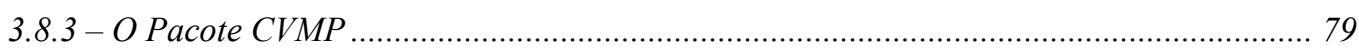

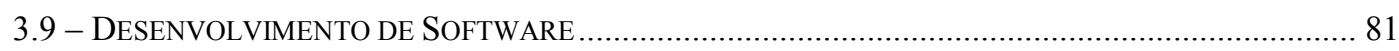

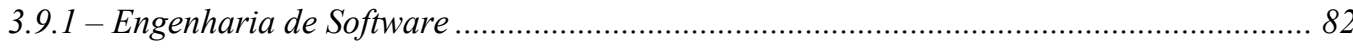

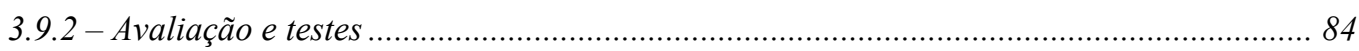

3.9 .3 - Programação Orientada a Objetos .......................................................................... 85

3.9 .4 - Interface Gráfica com o Usuário (GUI) .................................................................. 87

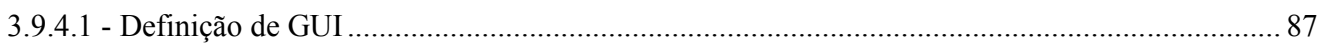

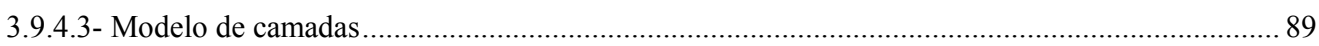

3.9.4.4- Fundamentos de Programação em GUI................................................................................. 91

3.9 .5 - Programação Visual............................................................................................ 92

3.9.6 - Análise Estatística, Gargalos e Desempenho de programas paralelos......................... 93

3.9.7 - Engenharia da Utilização...................................................................................... 98

CAPÍTULO 4 - OS CAMINHOS PARALELOS DA VISÃO_.............................................. 105

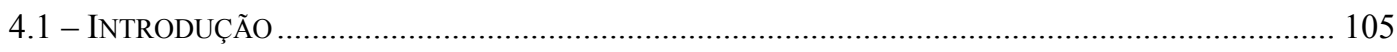

4.2 - INFORMAÇÃO, EVOLUÇÃO, VISÃO ................................................................................... 105

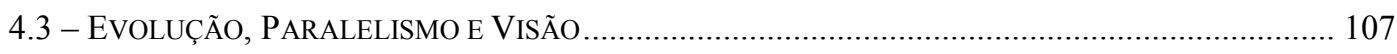

4.4 - O ESTUDO DO CÉREBRO E DA VISÃO .............................................................................. 110

4.4 .1 - As especializações funcionais corticais................................................................... 110

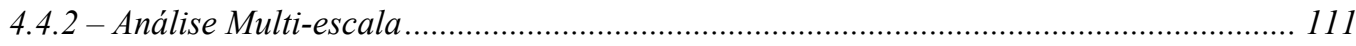

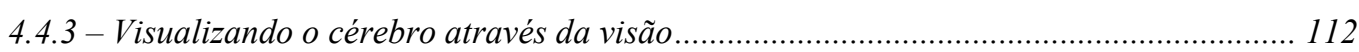

4.4 .4 - Visão - Uma área Multidisciplinar .................................................................... 113

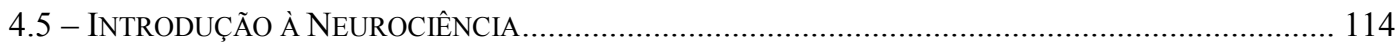

4.5.1 - Sistema Nervoso ............................................................................................. 114

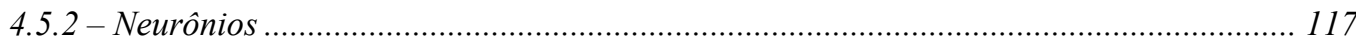

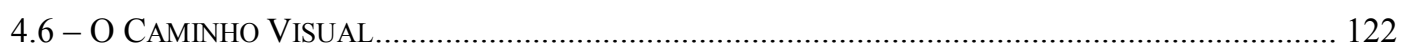

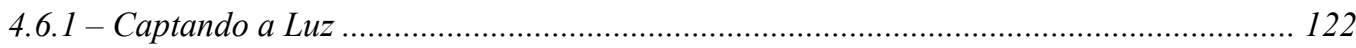

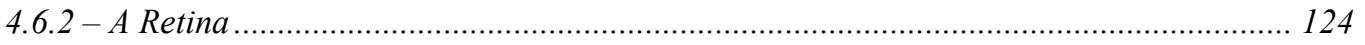

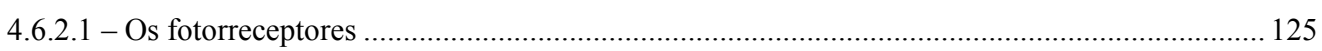

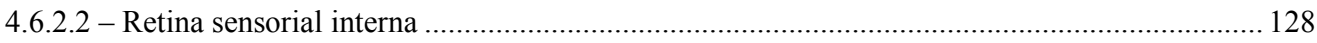

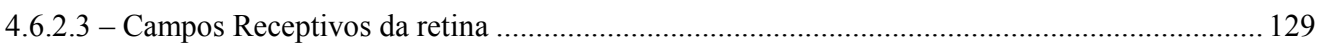

4.6.3 - Conexões entre a retina e o córtex .............................................................................. 130

4.6.3.1 - Núcleo Geniculado Lateral ........................................................................................................ 133

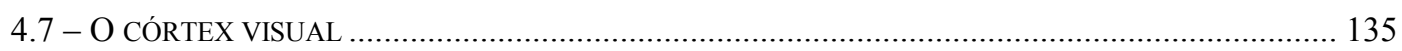

4.7.1 - Especialização funcional do Córtex visual................................................................ 136

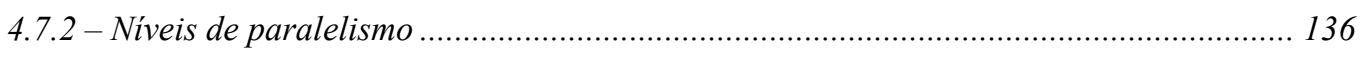




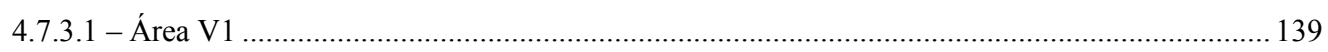

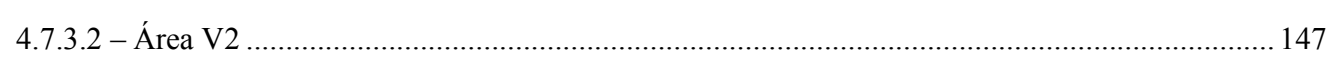

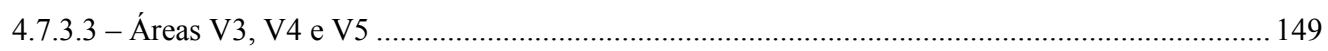

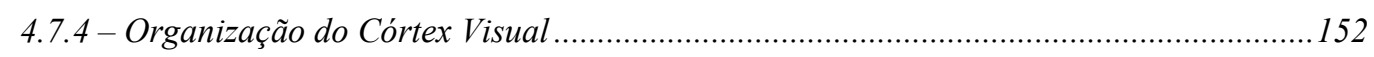

4.7.5 - Estratégias de integração da informação ao longo do percurso visual..........................157

4.7.6 - Integração da informação dos dois hemisférios........................................................... 160

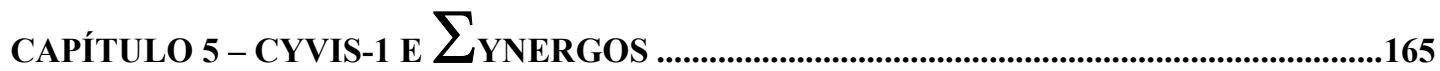

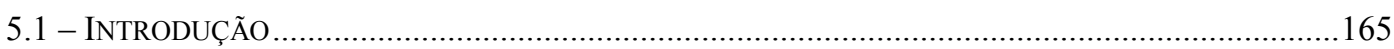

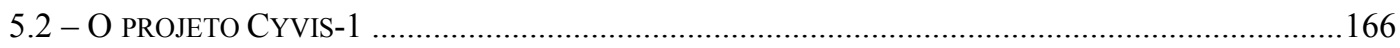

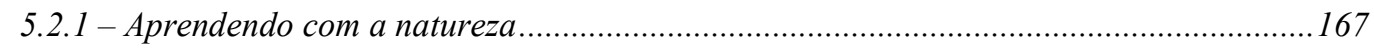

5.2.1.1 - Paralelismo, distribuição de processos e Troca de Mensagens ................................................. 168

5.2.1.2 - Alta resolução para a representação de imagens ..................................................................... 169

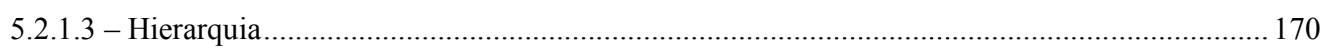

5.2.1.4 - Tráfego da informação em sentido duplo ............................................................................. 170

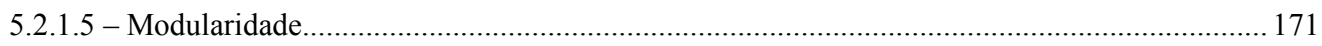

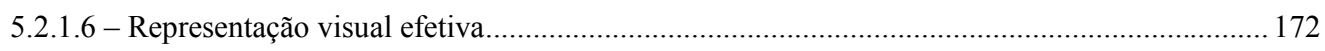

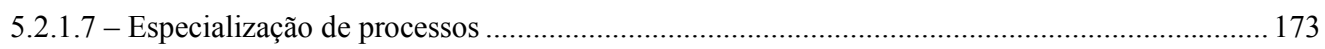

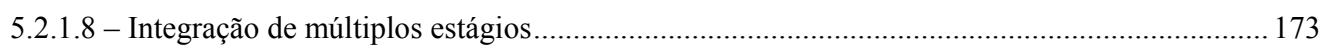

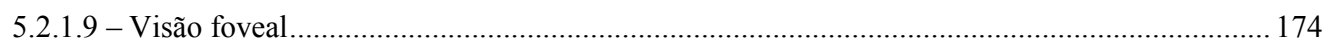

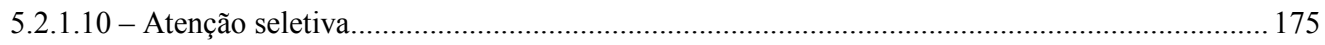

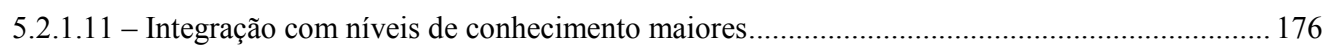

5.2.2 - O Sistema de Visão Cibernética - Cyvis-1 ..................................................................176

5.2 .3 - Implementação, requisitos e necessidades ................................................................... 180

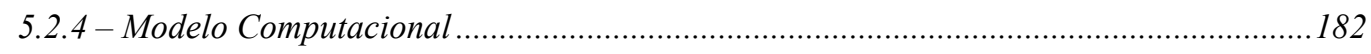

5.3 - SISTEMAS E MODELOS DE VISÃO E SUAS COMPARAÇÕES COM O CYVIS-1 .............................187

5.3 .1 - Sistema Inteligente para segmentação baixo nível de imagens ...................................187

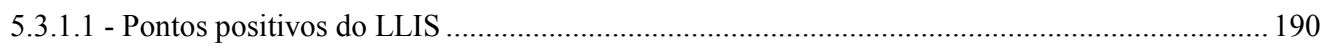

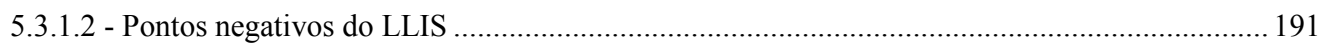

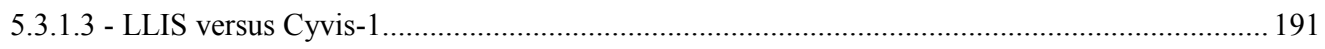

5.3.2 - Sistema de Visão do MIT (Massachussetts Institute of Technology)...............................192

5.3.2.1 - Cyvis-1 versus máquina de visão …………......................................................................... 195

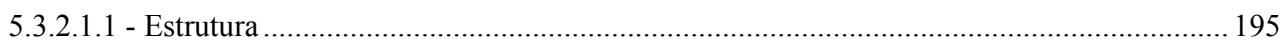

5.3.2.1.2 - Organização e transferência de Dados.......................................................................... 196

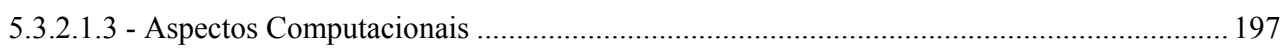

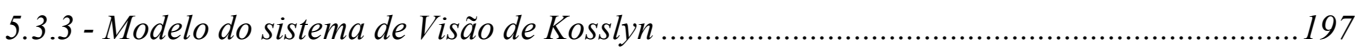

5.3.3.1 - O modelo de Kosslyn e o Cyvis-1 ...................................................................................... 201

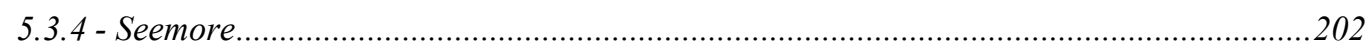

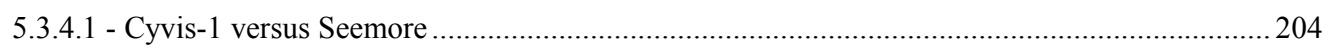


5.4 - O PROJETO $\sum_{\text {YNERGOS }}$

5.5 - PARALELISMO E VISÃO, UM DESAFIO .............................................................................. 207

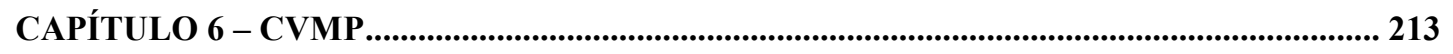

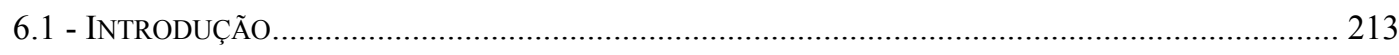

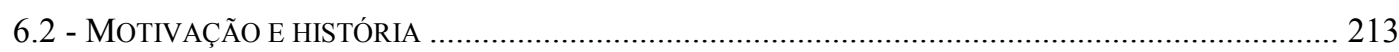

6.3 - CVMP - CYBERnETIC VISION MESSAGE PASSAGE …..................................................... 216

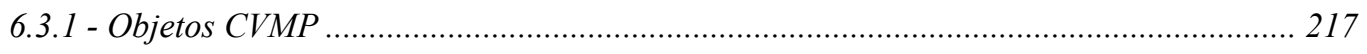

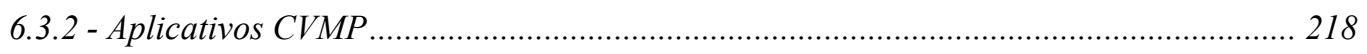

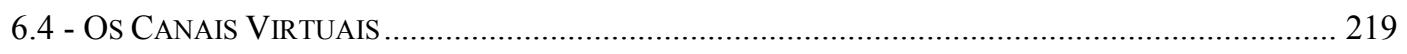

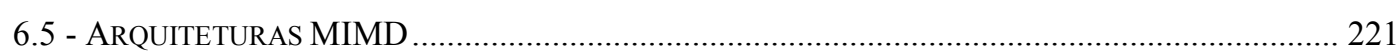

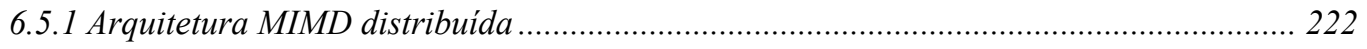

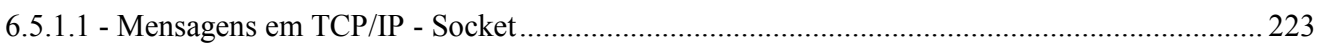

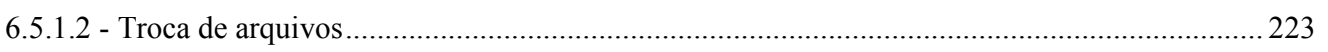

6.5.1.3 - Comparação entre plataformas de troca de mensagens .............................................................. 223

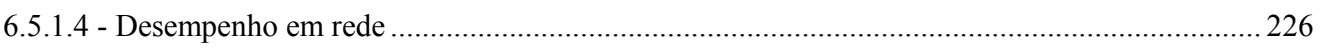

6.5 .2 - Arquitetura MIMD compartilhada ..................................................................... 228

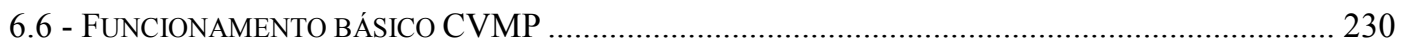

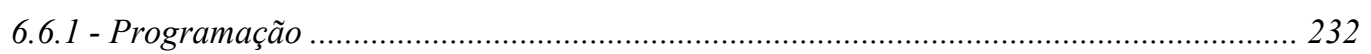

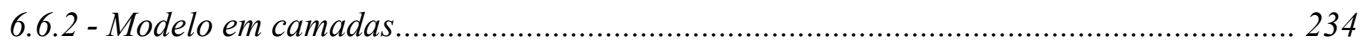

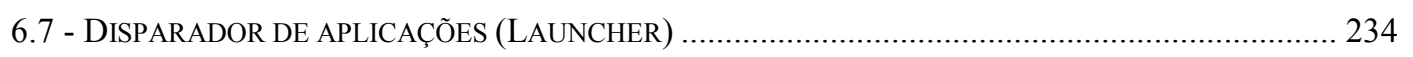

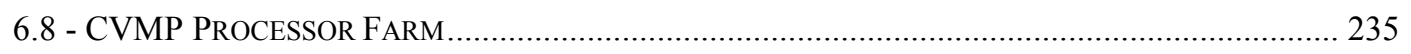

6.9 - ANÁLISE DE DESEMPENHO E ESTATÍSTICAS ................................................................ 240

6.9 .1 - Ferramentas para análise estática .............................................................................. 241

6.9 .2 - Ferramentas para análise dinâmica ................................................................. 243

6.10 - COMPONENTE VISUAL PARA OPERAÇÕES BÁSICAS DE PROCESSAMENTO DE IMAGENS .......... 245

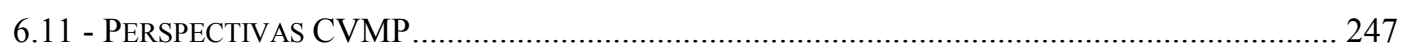

\section{CAPÍTULO 7 - ESTUdOS DE ALGORITMOS PARALELOS PARA VISÃO E SUA}

IMPLEMENTAÇÃO COM CVMP ............................................................................................ 251

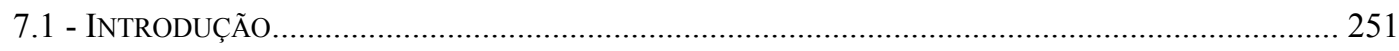

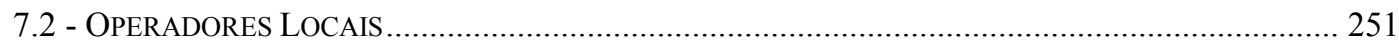

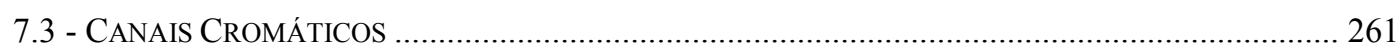

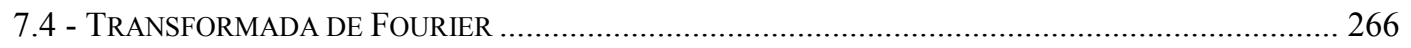

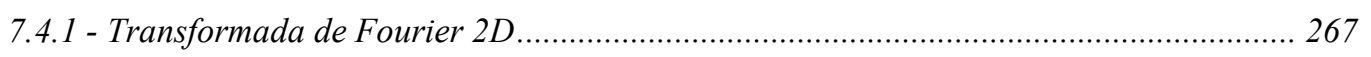

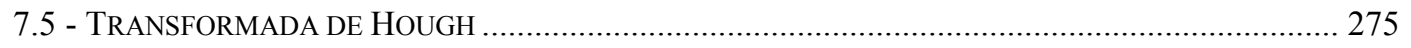

7.5.1 - Rastreamento do arranjo acumulador (backmapping) ............................................ 284

7.6 - RESTAURAÇÃO DE IMAGENS BASEADO EM CAMPOS RANDÔMICOS MARKOVIANOS.................. 288

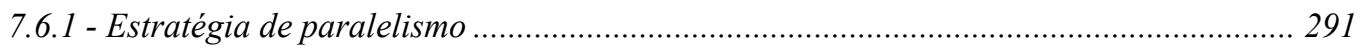




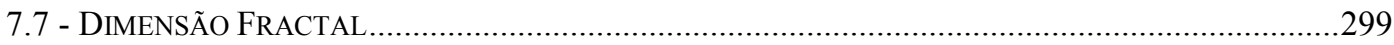

CAPÍTULO 8 - APLICAÇÕES PARALELAS EM VISÃO ........................................................305

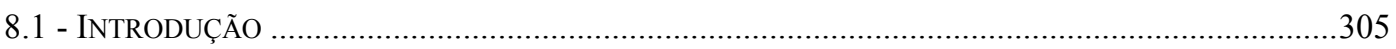

8.2 - INTEGRAÇÃO DE COR E ESTÉREO NO PROJETO CYVIS-1 …..........................................................305

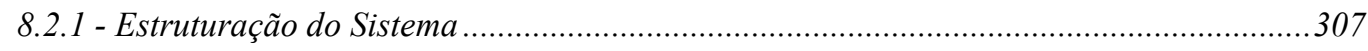

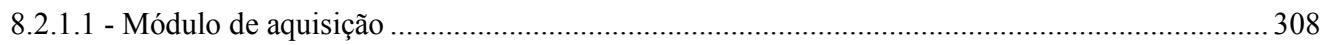

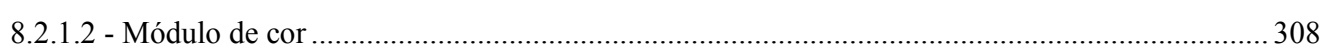

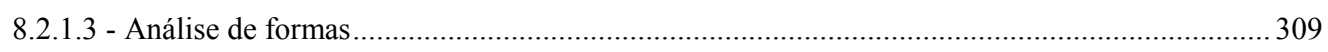

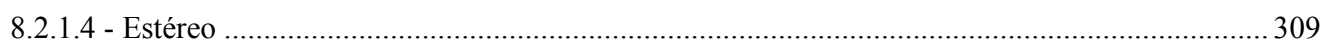

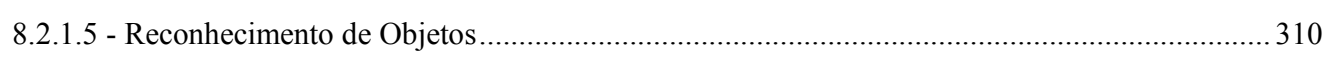

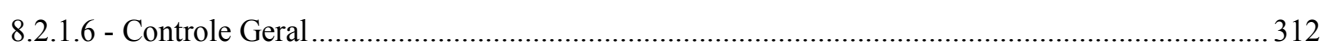

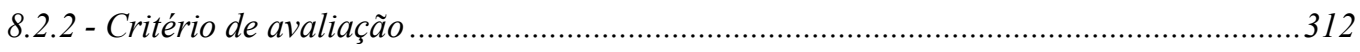

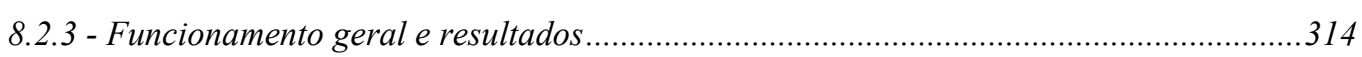

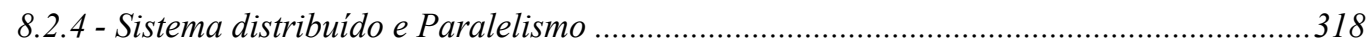

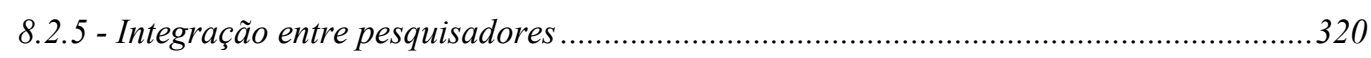

8.3 - $\Sigma$ YNERGOS - INVESTIGAÇÃO DA PERCEPÇÃO HUMANA NA COMPLEXIDADE DAS FORMAS..........321

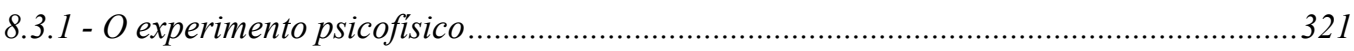

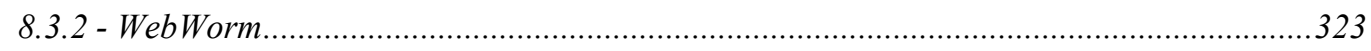

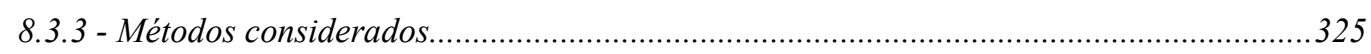

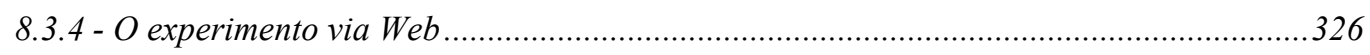

8.3.5 - Algoritmo Genético Paralelo - Análise e modelagem dos dados experimentais..............327

8.3 .6 - Eficiência da implementação paralela ...........................................................................330

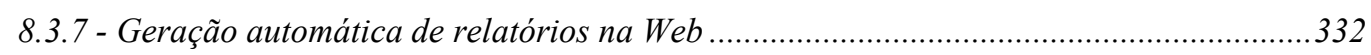

8.4 - TREEVIS - UM SISTEMA PARALELO DE VISÃO PARA ANÁLISE E RECONHECIMENTO ARBÓREO.332

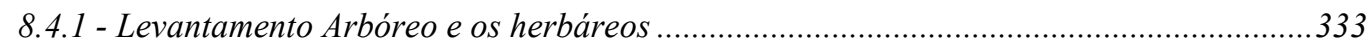

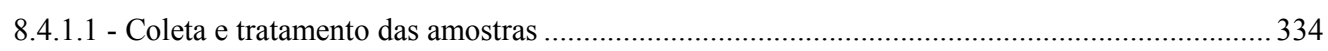

8.4.1.2 - Classificação através de herbários.......................................................................................... 335

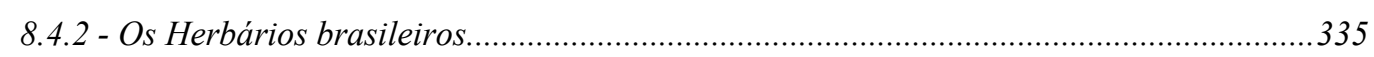

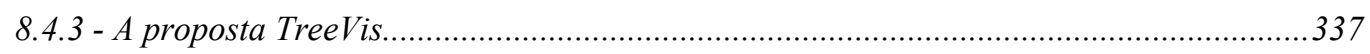

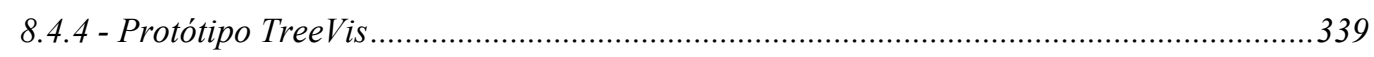

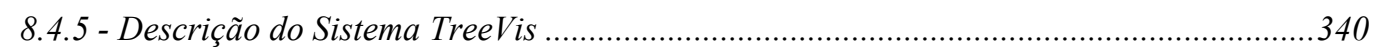

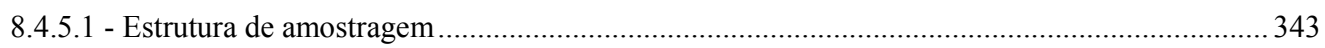

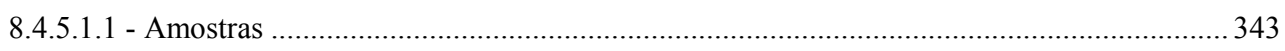

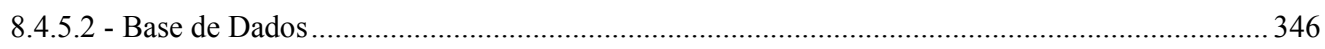

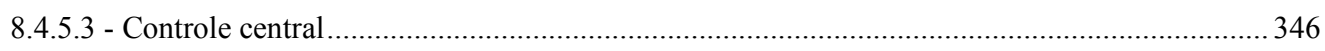

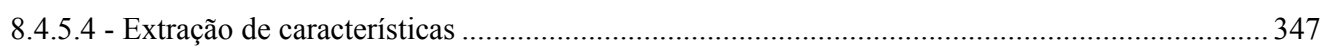

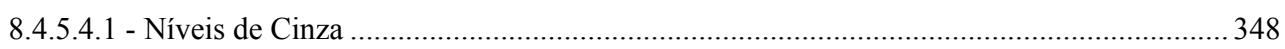

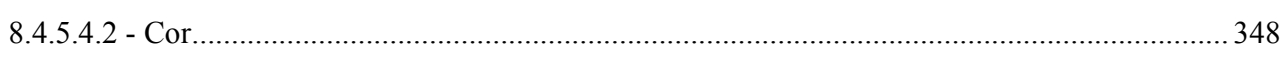

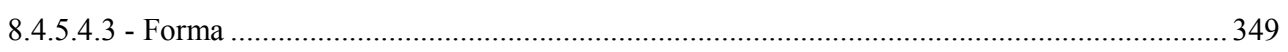




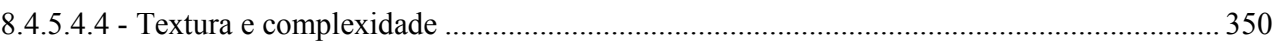

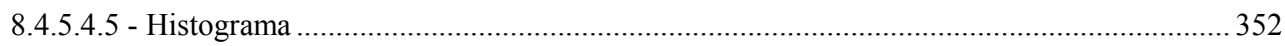

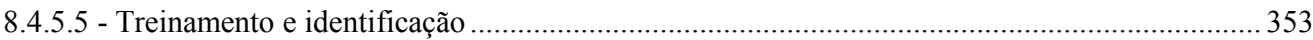

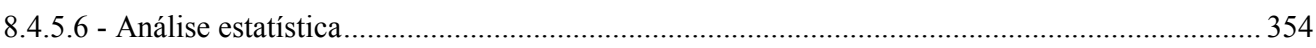

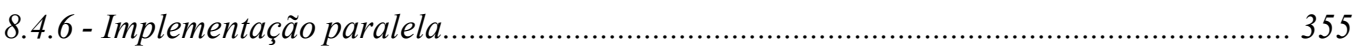

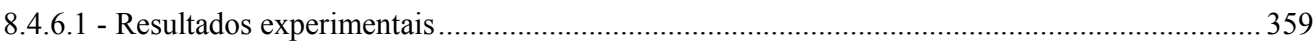

8.4 .7 - Reconhecimento de plantas arbóreas.............................................................................. 362

CAPÍTULO 9 - CONCLUSÃO ............................................................................................................... 367

9.1 - COMENTÁRIOS FINAIS E CONTRIBUIÇÕES …….................................................................. 367

9.2 - SÍNTESE DAS PRINCIPAIS CONTRIBUIÇÕES ............................................................................ 372

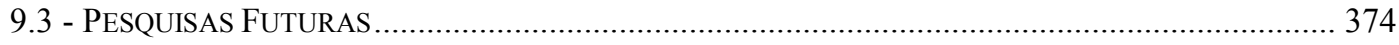

9.3.1 - Estudos de paralelismo em visão natural e artificial ................................................... 374

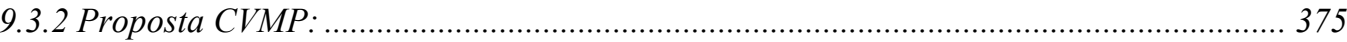

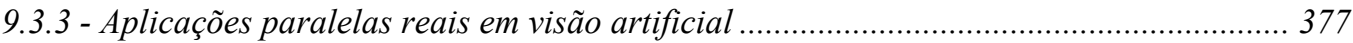

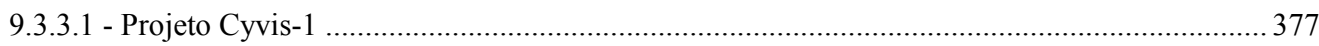

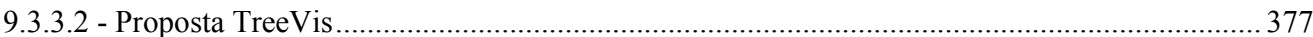

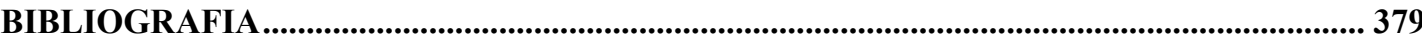




\section{LISTA DE FIGURAS}

FIG. - 2.1 - GERAÇÕES DE COMPUTADORES.

FIG. 2.2 - TÍPICA PIPELINE DE INSTRUÇÕES DE ARQUITETURA RISC. 20

FIG. 2.3 - BENEFÍCIO PROPORCIONADO PELO PARALELISMO NA ARQUITETURA DO PENTIUM.................21

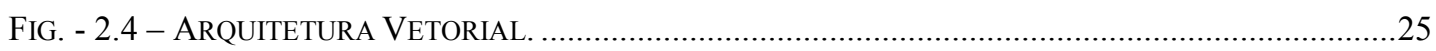

FIG. - 2.5 - COMPARAÇÃO ENTRE CÓDIGOS FORTRAN................................................................26

FIG. - 2.6 - DIAGRAMAS DAS ARQUITETURAS DOS COMPUTADORES CYBER205 E ETA-10..................27

FIG. - 2.7 - DIAGRAMA DE ARQUITETURA DO COMPUTADOR CRAY - 1 .........................................28

FIG. - 2.8 - DIAGRAMA DE ARQUITETURA DO COMPUTADOR CRAY X-MP/2 .................................29

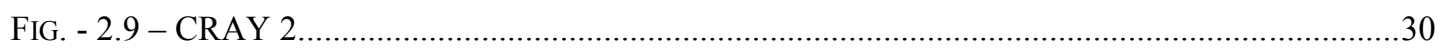

FIG. - 2.10 - FAMÍLIA DOS COMPUTADORES DE ARQUITETURA MATRICIAL. OS NÚMEROS EM CONCHETES SÃO AS PERFORMANCES MÁXIMAS ESTIMADAS EM MFLOPS...................................................... 31

FIG. - 2.11 - DIAGRAMA DE ARQUITETURA DO COMPUTADOR ILLIAC IV ...........................................32

FIG. - 2.12 - CONFIGURAÇÃO DA REDE DE ELEMENTOS DE PROCESSAMENTO (EP). .............................32

FIG. - 2.13 - MEMÓRIA COMPARTILHADA VERSUS MEMÓRIA DISTRIBUÍDA. ............................................34

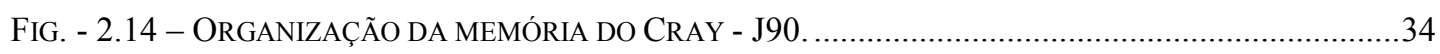

FIG. - 2.15 - DIAGRAMA EM BLOCOS DO PROCESSADOR TRANSPUTER IMS T800................................35

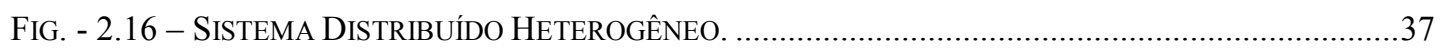

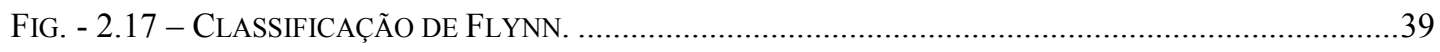

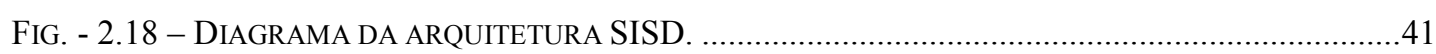

FIG. - 2.19 - DIAGRAMA DA ARQUITETURA MISD. .......................................................................4

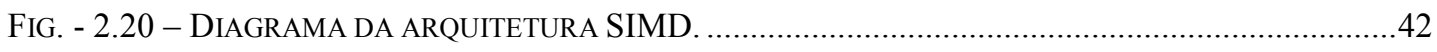

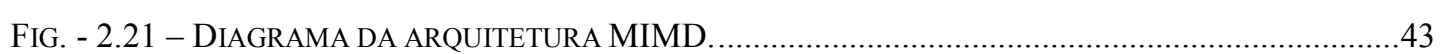

FIG. - 2.22 - DIAGRAMA DA CLASSIFICAÇÃO ESTRUTURAL......................................................... 44

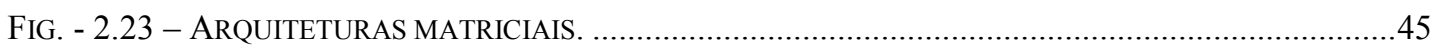

FIG. - 2.24 - CLASSIFICAÇÃO ESTRUTURAL PARA MIMD. ..................................................................46

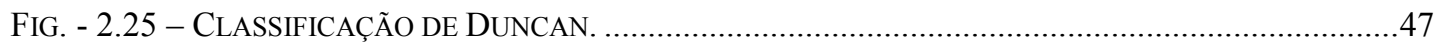

FIG. - 3.1- ORGANIZAÇÃO GENÉRICA EM CAMADAS DOS COMPUTADORES...........................................53

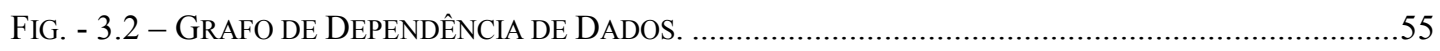

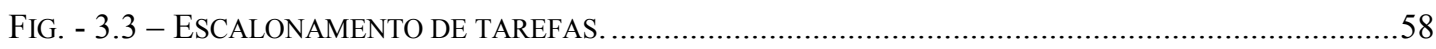

FIG. - 3.4 - COMPARAÇÃO ENTRE O SISTEMA OPERACIONAL UNIX COM E SEM A CAMADA GUI. ..........59

FIG. - 3.5 - ARQUITETURA DO SISTEMA OPERACIONAL DISTRIBUÍDO AMOEBA. ..................................62

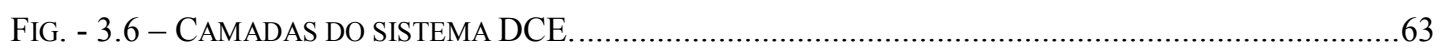

FIG. - 3.7 - GENEALOGIA DAS LINGUAGENS DE PROGRAMAÇÃO...........................................................68

FIG. - 3.8 - COMPARAÇÃO ENTRE PARBEGIN/PAREND E FORK/JOIN, DUAS ALTERNATIVAS DIFERENTES PARA CONTROLAR A EXECUÇÃO PARALELA [ALMASI \& GOTTLIEB, 1994] ...................................73

FIG. - 3.9 - ÁRVORE DE EXECUÇÃo PARALELA. EXEMPLO DE DISPAROS DE PROCESSOS REALIZADOS A

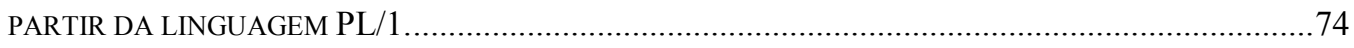


FIG. - 3.10 - EXEMPLO GENÉRICO DE UMA APLICAÇÃO PARALELA COM COORDENAÇÃO DE PROCESSOS E

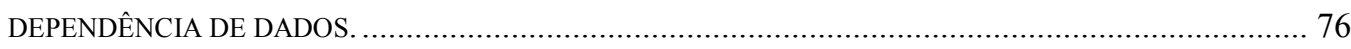

FIG. - 3.11 - CICLO DE VIDA CLÁSSICO DE UM SOFTWARE.............................................................. 83

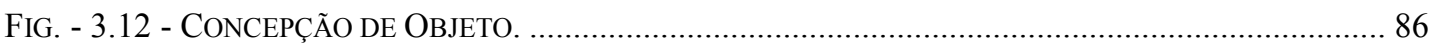

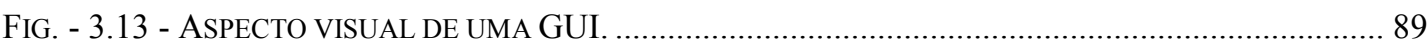

FIG. - 3.14 - MODELO EM CAMADAS DE UMA GUI. .......................................................................... 90

FIG. - 3.15 - DIAGRAMA COMPARATIVO DE CAMADAS DE GUI.................................................... 91

FIG. - 3.16 - COMPARAÇÃO ENTRE A VAZÃO DE FLUXO EM UM SISTEMA DE ENCANAMENTO E O

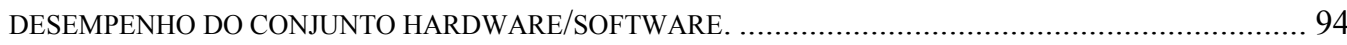

FIG. - 3.17 - MAPA DE DESEMPENHO DAS DIFERENTES ETAPAS DE UM PROGRAMA E A ELIMINAÇÃO DE UM GARGALO ATRAVÉS DE SUA PARALELIZAÇÃO................................................................. 96

FIG. - 4.1 - VISÃO, UMA CIÊNCIA FORMADA PELA INTEGRAÇÃO DE MUITAS OUTRAS. ......................... 114

FIG. - 4.2 - SUBDIVISÕES DO SISTEMA NERVOSO [COSTA, 1996] .................................................... 115

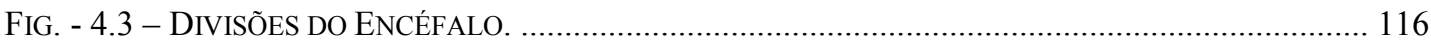

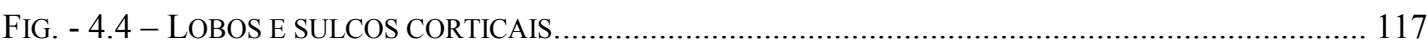

FIG. - 4.5 - ESTRUTURA DE UM NEURÔNIO TÍPICO. ...................................................................... 118

FIG. - 4.6 - (A) ILUSTRAÇÃO DE UMA SINAPSE. (B) FENDA SINÁPTICA. [DOWLING, 1992] .................. 119

FIG. - 4.7 - SINAPSES EXCITATÓRIA, SINAPSES INIBITÓRIA, PPSE E PPSI...................................... 120

FIG. - 4.8 - MODELO MATEMÁTICO TÍPICO DE UMA CÉLULA NEURAL.............................................. 121

FIG. - 4.9 - ESPECTRO DA RADIAÇÃO ELETROMAGNÉTICA COM DESTAQUE PARA A PORÇÃO VISÍVEL. 122

FIG. - 4.10 - OLHO HUMANO, CORTE LATERAL....................................................................... 123

FIG. - 4.11 - MúSCULOS DE SUSTENTAÇÃo DO GLOBO OCULAR. (A) GLOBO OCULAR VISTA DORSAL. (B) DISPOSIÇÃO DOS MÚSCULOS NA CAVIDADE OCULAR............................................................ 124

FIG. - 4.12 - CORTE DA RETINA (A) E MAPA DA DISTRIBUIÇÃO VASCULAR DOS CAPILARES NA MÁCULA

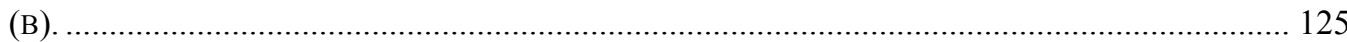

FIG. - 4.13 - DISTRIBUIÇÃO DOS CONES E BASTONETES AO LONGO DA RETINA................................... 126

FIG. - 4.14 - SENSIBILIDADE DOS TRÊS TIPOS DE CONES DA RETINA DOS PRIMATAS. ........................ 127

FIG. - 4.15 - (A) DIAGRAMA ESQUEMÁTICO DOS FOTORRECEPTORES (CONES E BASTONETES) [TOVÈE, 1996]. (B) IMAGEM MICROSCÓPICA APRESENTANDO OS FOTORRECEPTORES (EM DESTAQUE CONE) [DOWLING, 1992].

FiG. - 4.16 - CAMPOS RECEPTIVOS DAS CÉLULAS GANGLIONARES DA RETINA. (A) “ON-CENTER” EXCITAÇÃO NA REGIÃO CENTRAL E INIBIÇÃO NA REGIÃO PERIFÉRICA. (B) “OFF-CENTER” INIBIÇÃO NA REGIÃO CENTRAL E EXCITAÇÃO NA REGIÃO PERIFÉRICA. (C) “ON-OFF” - RESPOSTAS A MOVIMENTOS.

FIG. - 4.17 - CAMINHO ÓPTICO: TRAJETÓRIA DOS SINAIS VISUAIS, DA RETINA AO CÓRTEX VISUAL PRIMÁRIO,

FIG. - 4.18 - DIAGRAMA DA ESTRATÉGIA DE MAPEAMENTO DA IMAGEM AO LONGO DO CAMINHO ÓPTICO.

FIG. - 4.19 - NúCLEO GENICULAdO LATERAL [HUBEL, 1995] 134

xii 
FiG. - 4.20 - PARALELISMO EM MULTI-ESCALA.

FIG. - 4.21 - FATIA DO CÓRTEX VISUAL, APRESENTANDO SUAS ÁREAS [ZEKI, 1993].

FIG. - 4.22 - MICROGRAFIA DO CÓRTEX VISUAL PRIMÁRIO [DOWLING, 1992]. 140

FIG. - 4.23 -DIAGRAMA APRESENTANDO AS PRINCIPAIS CONEXÕES DAS CAMADAS DO CÓRTEX VISUAL PRIMÁRIO [HUBEL, 1995].

FIG. - 4.24 - COLUNAS DE DOMINÂNCIA OCULAR NA CAMADA 4C (PROJEÇÃO 2D), MARCADAS POR DOIS DEOXIGLUCOSE [HUBEL, 1995].

FIG. - 4.25 - DIAGRAMA ILUSTRANDO O CAMPO RECEPTIVO DAS CÉLULAS SIMPLES, SUA COMPOSIÇÃO A PARTIR DE CÉLULAS CENTRO-PERIFERIA DO LGN E AS SUAS RESPOSTAS A ESTÍMULOS DE DIFERENTES ORIENTAÇÕES [ZEKI, 1993].

FIG. - 4.26 - MODELO DAS HIPERCOLUNAS DE HUBEL E WIESEL 145

FIG. - 4.27 - (A) CORTE LONGITUDINAL DO CÓRTEX ESTRIADO, COM TRATAMENTO DE CITOCROMO OXIDASE. (B) DETALHE DO CORTE PARALELO (LINHA DA IMAGEM A) APRESENTANDO AS CAMADAS 2 E 3. AS ESTRUTURAS EM FORMA DE PONTOS CLAROS SÃO OS "BLOBS" [ZEKI, 1993].

FIG. - 4.28 - REGIÕES V1 E V2 DO MACACO ESQUILO MARCADAS POR CITOCROMO OXIDASE [ZEKI, 1993].

FIG. - 4.29 - COMPARAÇÃO ENTRE OS CAMPOS RECEPTIVOS DAS REGIÕES V1, V2, V3 E V5, DEMONSTRANDO O AUMENTO DO TAMANHO DO CAMPO RECEPTIVO E DA ABSTRAÇÃO, NO SENTIDO DE NÃO OCORRER MAIS PREVISÃO DO TRAJETO DO CAMPO RECEPTIVO EM RELAÇÃO AO TRAJETO DA PENETRAÇÃO DO ELETRODO. (A) REGIÃO EXPLORADA E TRAJETÓRIA DO ELETRODO, (B) DIMENSÃO E DISPOSIÇÃO DOS CAMPOS RECEPTIVOS E (C) TRAJETÓRIA DOS CENTROS DOS CAMPOS RECEPTIVOS. [ZEKI, 1993] 150

FIG. - 4.30 - MAPA SIMPLIFICADO DAS INTERCONEXÕES DO CÓRTEX VISUAL. [ZEKI, 1993] [ZEKI \& ShipP, 1988] [LEVINE \& SHEFner, 1991] [LivingSTONE \& HuBEL, 1988].

FIG. - 4.31 - ESTRATÉGIAS DE INTEGRAÇÃO DE SINAL VISUAL ATRAVÉS DO AUMENTO DO CAMPO RECEPTIVO E DA COMPLEXIDADE DO ESTÍMULO. (A) (RETA) CÉLULAS CENTRO-PERIFERIA DO LGN E CÉlulas SIMPles DE V1. (B) (COR) PROJEÇÃo DAS CÉlULAS dOS "BlOBS" EM V1 PARA FAIXAS FINAS EM V2 E FINALMENTE EM V4, OBSERVAR A PIRÂMIDE DE PROJEÇÃO. (C) (MOVIMENTO) ENQUANTO EM V1 AS CÉLULAS SÃO ESTIMULADAS PELA ORIENTAÇÃO DAS BORDAS INDEPENDENTES (UM VETOR DE DIREÇÃO PARA CADA LADO) OCORRE A INTEGRAÇÃO EM V5, DE MODO QUE SUAS CÉLULAS SÃO CAPAZES DE FORNECER A DIREÇÃO DO OBJETO. [ZEKI, 1993] ...159

FIG. - 5.1 - DiAGRAMA DE UM SISTEMA DE VISÃO ARTIFICIAL CLÁSSICO. .168

FIG. - 5.2 - MOVIMENTO DOS OLHOS DURANTE A PERCEPÇÃO DE UMA FACE. OS TRAÇOS DA FIGURA (B) APRESENTAM A POSIÇÃO DA REGIÃO CENTRAL DOS OLHOS DURANTE O RASTREAMENTO PARA A PERCEPÇÃO DA IMAGEM [DOWLING, 1992] [HUBEL, 1995]. 174

FIG. - 5.3 - IMPORTÂNCIA DO CONTEXTO NA PERCEPÇÃO VISUAL HUMANA. EMBORA SEJAM DO MESMO TAMANHO, NA IMAGEM (B) A FIGURA DA MULHER À DIREITA PARECE MENOR DO QUE A DA IMAGEM (A) [DOWLING, 1992] 
Fig. - 5.4 - DiAGRAMA DE BLOCOS DO MODELO ESTRUTURAL DO SISTEMA CYVIS-1, APRESENTANDO SUA ORGANIZAÇÃo GERAL. ADAPTADO DE [BRUNO \& COSTA, 1997] [COSTA ET AL., 1994] ... 177

FIG. - 5.5 - DIAGRAMA DE BLOCOS APRESENTANDO A ORGANIZAÇÃO DE HARDWARE DO CYVIS -1. NESTE EXEMPLO, CADA ATRIBUTO DE IMAGEM ESTÁ SENDO PROCESSADO EM UMA DIFERENTE MÁQUINA. OS COMPUTADORES ESTÃO CONECTADOS POR REDE. ADAPTADO DE [BRUNO \& COSTA,

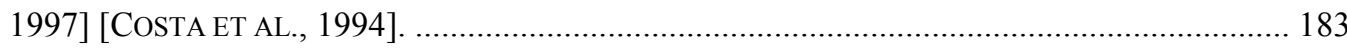

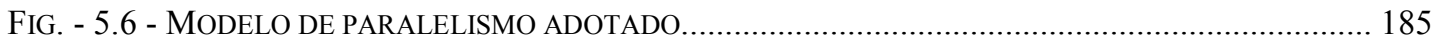

FIG. - 5.7 - DIAGRAMA EM BLOCOS DO SISTEMA LLIS........................................................................ 188

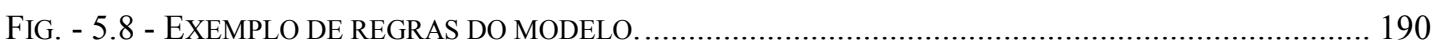

FIG. - 5.9 - DiAGRAMA DA ORGANIZAÇÃO DA MÁQUINA DE VISÃO DO MIT. ........................................ 193

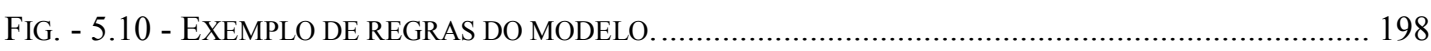

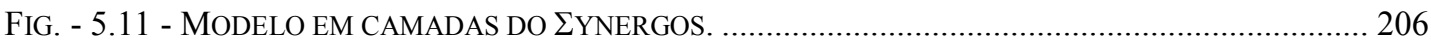

Fig. - 6.1 - PALETA DE COMPONENTES CVMP EM AMBIENTE DELPHI. .............................................. 216

FIG. - 6.2 - EXEMPLO DO CONCEITO MESTRE/ESCRAVO E DA CONEXÃO ATRAVÉS DO CANAL VIRTUAL.

A CAIXA M SIMBOLIZA UM OBJETO CVMP CONFIGURADO COMO MESTRE, ENQUANTO QUE A S, CONFIGURADO COMO ESCRAVO. A BARRA VERTICAL REPRESENTA O CANAL VIRTUAL. ............ 220

FIG. - 6.3 - POSSÍVEIS CONFIGURAÇÕES UTILIZANDO CANAIS VIRTUAIS................................................ 221

FIG. - 6.4 - EXEMPLO DE UMA APLICAÇÃO PARALELA EM UMA ARQUITETURA MIMD DISTRIBUÍDA. 222

FIG. - 6.5 - GRÁFICOS DO DESEMPENHO DE TRANSFERÊNCIA DE PACOTES VIA REDE. (A) CVMP USANDO PROTOCOLO TCP/IP, (B) CVMP USANDO TRANSFERÊNCIA DE ARQUIVO ATRAVÉS DE CHAMADA A API, UTILIZANDO PROTOCOLO NETBEUI E (C) COMPARAÇ̃̃O ENTRE OS RESULTADOS DE (A) E (B). 227

FIG. - 6.6 - EXEMPLO DE UMA APLICAÇÃO PARALELA CVMP EM UMA ARQUITETURA MIMD COMPARTILHADA. NESSE EXEMPLO TEMOS UMA MÁQUINA MULTIPROCESSADA COM 3 PROCESSADORES. 228

FIG. - 6.7 - DiAGRAMA ILUSTRATIVO DO MECANISMO DE TROCA DE MENSAGENS EM SISTEMA MIMD COMPARTILHADO. 229

FIG. - 6.8 - EXEMPLO DE UM ARQUIVO DE CONFIGURAÇÃO DO OBJETO CVMP..................................... 231

FIG. - 6.9 - PRINCIPAIS PRIMITIVAS DE TROCA DE MENSAGENS. ........................................................... 232

FIG. - 6.10 - EXEMPLO DE IMPLEMENTAÇÃO DE UM ALGORITMO PARALELO UTILIZANDO AS PRIMITIVAS CVMP. 233

FIG. - 6.11 - MÓDULO PRINCIPAL DO APLICATIVO CVMP-LAUNCHER. (A) JANELA PRINCIPAL, (B)

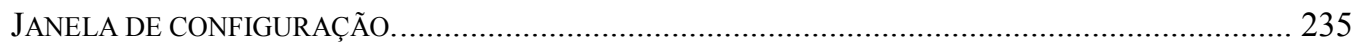

FIG. - 6.12 - DiAGRAMA ILUSTRATIVO DA ESTRATÉGIA DE PARALELISMO PROCESSOR FARM. ............ 236

FIG. - 6.13 - JANELAS DO OBJECT INSPECTOR DO DELPHI, MOSTRANDO AS PROPRIEDADES E EVENTOS DOS OBJETOS CVMP PROCESSOR FARM (A) SUPERVISOR (TPROCFARMM4) E (B) ESCRAVO (TPROCFARMS)

FIG. - 6.14 - EXEMPLO DE CODIFICAÇÃO DO EVENTO ONTASK DO COMPONENTE ESCRAVO DO CVMP PROCESSOR FARM. 
FIG. - 6.15 - EXEMPLO DE CODIFICAÇÃO DOS EVENTOS DO COMPONENTE SUPERVISOR DO CVMP PROCESSOR FARM. (A) EVENTO ONINITASK, DISPARADO ANTES DE SER ATRIBUÍDA A TAREFA PARA UM PROCESSO ESCRAVO. (B) EVENTO ONENDTASK, DISPARADO ASSIM QUE O ESCRAVO FINALIZOU A TAREFA. (C) MÉTODO PARA INICIAR A EXECUÇÃO DO PROCESSAMENTO.

FIG. - 6.16 - JANELA DE CONFIGURAÇÃO AUTOMÁTICA DA DISTRIBUIÇÃO DO SISTEMA, EXIBIDA ATRAVÉS DE CHAMADA AO MÉTODO CONFIG DO COMPONENTE SUPERVISOR .240

FIG. - 6.17 - EXEMPLO DA UTILIZAÇÃO DO COMPONENTE TSTAT. 242

FIG. - 6.18 - JANELAS DA APLICAÇÃO STATVIEWER, APRESENTANDO ALGUMAS DAS DIFERENTES FORMAS DE VISUALIZAÇÃO EM BLOCOS DAS MEDIDAS. AS LINHAS HORIZONTAIS REPRESENTAM OS 4 PROCESSOS PARALELOS, FORMADOS PELOS BLOCOS QUE EXPRIMEM AS TAREFAS. (A) VISUALIZAÇÃO COM BLOCOS SIMPLES, (B) COM BLOCOS PEQUENOS E (C) COM LINHAS. .242

FIG. - 6.19 - JANELAS DA APLICAÇÃO STATONLINE, APRESENTANDO AS MEDIDAS DE PERFORMANCE DE UMA APLICAÇÃO PARALELA (PROCESSOR FARM) COM 4 MÁQUINAS ESCRAVAS. VISUALIZAÇÃO COM BLOCOS(A) E (B) E LISTAGEM DAS MEDIDAS (C).

FIG. - 6.20 - EXEMPLO DE UMA APLICAÇÃO PARALELA UTILIZANDO OS COMPONENTES TSOBELPAR. 246

FIG. - 7.1 - ESTRATÉGIA DE PARALELISMO PARA OPERADORES LOCAIS, PARA QUATRO UNIDADES DE PROCESSAMENTO. (A) DIVISÃO DA IMAGEM EM FAIXAS, (B) DIVISÃO DA IMAGEM EM QUADRILÁTEROS. AS ETAPAS I, II, III, IV E V REPRESENTAM RESPECTIVAMENTE: A IMAGEM ORIGINAL, DIVISÃO DA IMAGEM E SUA DISTRIBUIÇÃO, PROCESSAMENTO DE CADA PARTE DA IMAGEM EM UMA UNIDADE DE PROCESSAMENTO DIFERENTE, RECONSTRUÇÃO DOS RESULTADOS E RESULTADO DO PROCESSAMENTO.

FIG. - 7.2 - DETALHES DA DIVISÃO IMAGEM RESOLVENDO A DEPENDÊNCIA DE DADOS PARA UMA MÁSCARA 3X3. (A) IMAGEM ORIGINAL, (B) FRAÇÕES DA IMAGEM COM A VIZINHANÇA DOS ELEMENTOS DAS LINHAS DIVISÓRIAS (EM CINZA).

FIG. - 7.3 - VARIAÇÃO DA ARQUITETURA PROCESSOR FARM ADOTADA PARA PARALELISMO DO ALGORITMO DOS OPERADORES LOCAIS, ONDE O MESTRE ALÉM DE DISTRIBUIR AS TAREFAS TAMBÉM PROCESSA UMA PORÇÃO DA IMAGEM.

FIG. - 7.4 - DIAGRAMA ILUSTRANDO AS TROCAS DE MENSAGEM E O BALANCEAMENTO DE CARGA DO SISTEMA.

FIG. - 7.5 - EXEMPLO DE FILTRO PASSA BAIXA COM 3X3 ELEMENTOS. 257

FIG. - 7.6 - COMPARAÇÃO ENTRE O TEMPO DE EXECUÇÃO DO ALGORITMO PARALELO E SEQÜENCIAL.257

FIG. - 7.7 - DESEMPENHO DOS ALGORITMOS PARALELOS. 258

FIG. - 7.8 - COMPARAÇÃO ENTRE A PORCENTAGEM DE TEMPO CONSUMIDO ENTRE O PROCESSAMENTO E A TRANSMISSÃO DE DADOS (IMAGEM DE 500X500). .259

FIG. - 7.9 - COMPARAÇÃO ENTRE A PERFORMANCE DO SISTEMA EM REDE DE 10MBITS/S (ETHERNET) E 100MBITS/S (FAST ETHERNET). .260

FIG. - 7.10 - DIAGRAMA ILUSTRANDO AS TROCAS DE MENSAGEM E O BALANCEAMENTO DE CARGA DO SISTEMA. M - MÁQUINA MESTRA; S1 E S2 - MÁQUINAS ESCRAVAS. 262

FIG. - 7.11 - CONFIGURAÇÕES DO SISTEMA: (A) SEQÜENCIAL, (B) PARALELO COM 2 MÁQUINAS E (C) 
PARALELO COM 3 MÁQUINAS.

FIG. 7.12 - TEMPO DE EXECUÇÃO (MÁQUINAS 486DX4-100): (A) EM RELAÇÃO AO NÚMERO DE PIXELS, COMPARAÇÃO ENTRE AS VERSÕES SEQÜENCIAL E PARALELA COM 3 MÁQUINAS E (B) EM RELAÇÃO AO NÚMERO DE PROCESSADORES (P) PARAMETRIZADO PELO NÚMERO DE PIXELS. 264

FIG. 7.13 - GRÁFICOS DE DESEMPENHO EM FUNÇÃO DO NÚMERO DO TAMANHO DA IMAGEM. AS REDES SÃO HOMOGÊNEAS E SÃO BASEADAS EM ETHERNET NE2000 COM TAXA DE 10MBITS/S. (A) REDE FORMADA POR MÁQUINAS 486DX4-100MHz, (B) PENTIUM 225MHz E (C) K6II 375MHz...... 265

FIG. 7.14 - COMPARAÇÃO ENTRE O TEMPO DE EXECUÇÃO DO EXPERIMENTO EM TRÊS DIFERENTES SISTEMAS HOMOGÊNEOS, EM UMA IMAGEM DE 30000 PIXELS. 266

Fig. 7.15 - ESTRATÉGIA DE PARALELISMO DA FFT 2D. EXEMPLO PARA 4 PROCESSOS (MÁQUiNAS OU PROCESSADORES). 269

FIG. 7.16 - ESTRATÉGIA DE PARALELISMO DA FFT 2D. EXEMPLO PARA 4 PROCESSOS (MÁQUINAS OU PROCESSADORES) 271

Fig. 7.17 - TEMPOS DE EXECUÇÃO DO SISTEMA SEQÜENCIAL (1) E MODALIDADES PARALELAS (2, 3, 4 E 5) PARA DIFERENTES TAMANHOS DE IMAGEM. AS MODALIDADES PARALELAS FORAM IMPLEMENTADAS EM SISTEMAS DISTRIBUÍDOS DE 4 MÁQUINAS. 272

FIG. 7.18 - PORCENTAGEM DA UTILIZAÇÃO DE RECURSOS COMPUTACIONAIS ENTRE O PROCESSAMENTO MATEMÁTICO E OS PROCESSOS RELACIONADOS COM AS TRANSFERÊNCIAS DE DADOS. 273

FIG. 7.19 - GRÁFICOS DA TAXA DE DESEMPENHO OU SPEED UP EM FUNÇÃO DO TAMANHO DA IMAGEM (DADO PELO LADO DA IMAGEM QUADRADA). GRÁFICO: (1) DISCO RÍGIDO, (2) DISCO RÍGIDO + COMPACTAÇÃO LZW, (3) RAM E (4) RAM + COMPACTAÇÃO LZW. 273

FIG. 7.20 - GRÁFICOS DA TAXA DE DESEMPENHO OU SPEED-UP EM FUNÇÃO DO TAMANHO DA IMAGEM.

SIMULAÇÃO DE UMA ARQUITETURA DE MEMÓRIA COMPARTILHADA DE 4 PROCESSADORES EQUIVALENTES A AMD K6-2 375 MHz. (A) DESEMPENHO MEMÓRIA COMPARTILHADA FRENTE A VERSÃO SEQÜENCIAL. (B) DESEMPENHO DA MEMÓRIA COMPARTILHADA FRENTE AO MELHOR CASO DA ARQUITETURA DISTRIBUIDA (RAM + LZW). 274

FIG. 7.21 - DEMONSTRAÇÃO DOS PRINCIPAIS ELEMENTOS ENVOLVIDOS NA PARAMETRIZAÇÃO DE RETAS PARA A TRANSFORMADA DE HOUGH. (A) ESPAÇO DE COORDENADAS ORIGINAL. (B) ESPAÇO DE HOUGH 276

Fig. 7.22 - DETECÇÃO DE RETAS ATRAVÉS DA TRANSFORMADA DE HOUGH. (A) IMAGEM ORIGINAL, (B) ARRANJO ACUMULADOR (ESPAÇO DE HOUGH) E (C) RETAS DETECTADAS (COM BACKMAPPING).

FIG. - 7.23 - ESTRATÉGIA DE PARALELISMO PARA A TRANSFORMADA DE HOUGH. AS ETAPAS I, II, III, IV, V E VI REPRESENTAM RESPECTIVAMENTE: A IMAGEM ORIGINAL, DIVISÃO DA IMAGEM E SUA DISTRIBUIÇÃO, PROCESSAMENTO DE CADA FRAGMENTO DA IMAGEM, ARRANJOS ACUMULADOR RESULTANTE DO PROCESSAMENTO DE CADA FRAGMENTO, SOMATÓRIO DOS ELEMENTOS DOS ARRANJOS ACUMULADOR E ARRANJO ACUMULADOR RESULTANTE.

FIG. - 7.24 - DIAGRAMA ILUSTRANDO AS TROCAS DE MENSAGEM E O BALANCEAMENTO DE CARGA DO SISTEMA. 
FIG. - 7.25 - GRÁFICOS DO TEMPO DE EXECUÇÃO EM FUNÇÃO DO NÚMERO DE PROCESSADORES, COM SUAS RESPECTIVAS MODALIDADES DE IMPLEMENTAÇ̃̃O. CADA GRÁFICO É DEFINIDO MEDIANTE UM TAMANHO DE IMAGEM.

Fig. - 7.26 - PorCentagem da UtilizaÇÃo de RECURSOS COMPUTACIONAIS ENTRE O PROCESSAMENTO DA TÉCNICA E OS PROCESSOS RELACIONADOS COM AS TRANSFERÊNCIAS DE DADOS. AS LINHAS HORIZONTAIS CONTÉM OS GRÁFICOS RELACIONADOS AO TAMANHO DA IMAGEM, ENQUANTO QUE AS LINHAS VERTICAIS OS NÚMEROS DE PROCESSADORES.

FIG. - 7.27 - GRÁFICOS DA TAXA DE DESEMPENHO OU SPEED UP EM FUNÇÃO DO NÚMERO DE PROCESSADORES. OS GRÁFICOS APRESENTAM AS TRÊS MODALIDADES IMPLEMENTADAS NO EXPERIMENTO. CADA GRÁFICO É CORRESPONDENTE A UM TAMANHO DE IMAGEM.

FIG. - 7.28 - GRÁFICOS APRESENTANDO O TEMPO DE EXECUÇÃO RELACIONADOS COM O TAMANHO DA IMAGEM, APRESENTANDO UMA COMPARAÇÃO ENTRE AS DIFERENTES VERSÕES DE IMPLEMENTAÇÃO PARALELA PARA OS SISTEMAS DISTRIBUÍDOS COM REDE ETHERNET 10 MB/S.282

FIG. - 7.29 - PORCENTAGEM DA UTILIZAÇÃO DE RECURSOS COMPUTACIONAIS ENTRE O PROCESSAMENTO DA TÉCNICA E OS PROCESSOS RELACIONADOS COM AS TRANSFERÊNCIAS DE DADOS (E AFINS: COMPACTAÇÃO E LISTA DE PICOS). (A) SISTEMA DISTRIBUÍDO 10 MB/s, (B) SISTEMA DISTRIBUÍDO COM COMPACTAÇ̃̃O E (C) SISTEMA DISTRIBUÍDO COM LISTA DE PICOS..283

FIG. - 7.30 - GRÁFICOS DA TAXA DE DESEMPENHO OU SPEED UP. CADA GRÁFICO É CORRESPONDENTE A UM TAMANHO DE IMAGEM. .284

FIG. - 7.31 - ESTRATÉGIA DE PARALELISMO PARA A TÉCNICA DE RASTREAMENTO (BACKMAPPING), PARA QUATRO UNIDADES DE PROCESSAMENTO. I - DIVISÃO DA IMAGEM E DISTRIBUIÇÃO DOS FRAGMENTOS, II - DISTRIBUIÇÃO DO ARRANJO ACUMULADOR RESULTANTE DA TRANSFORMADA DE HOUGH, III - PROCESSAMENTO DO BACKMAPPING A PARTIR DOS DADOS DOS FRAGMENTOS DA IMAGEM E DO ARRANJO ACUMULADOR, IV - TRANSMISSÃO DO ARRANJO ACUMULADOR GERADO PELO RASTREAMENTO PARA O PROCESSO MESTRE, ONDE OS ELEMENTOS DE CADA ARRANJO

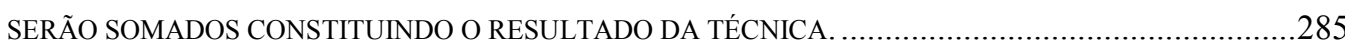

FIG. - 7.32 - GRÁFICOS DO TEMPO DE EXECUÇÃO EM FUNÇÃO DO NÚMERO DE PROCESSADORES. ........286

FIG. - 7.33 - PORCENTAGEM DA UTILIZAÇÃO DE RECURSOS COMPUTACIONAIS ENTRE O PROCESSAMENTO DA TÉCNICA E OS PROCESSOS RELACIONADOS COM AS TRANSFERÊNCIAS DE DADOS.

FIG. - 7.34 - TAXA DE DESEMPENHO EM FUNÇÃO DO NÚMERO DE PROCESSADORES.

FIG. - 7.35 - RESULTADOS DA TÉCNICA DE RESTAURAÇÃO - (A) IMAGEM ORIGINAL 100X100 CORROMPIDA POR UM RUÍDO GAUSSIANO COM $\sigma^{2}=0,5$. OS RESULTADOS SÃO RESPECTIVOS A $\alpha=0,3$ (B), $\alpha=0,5$ (C), $\alpha=0,7$ (D) Е $\alpha=0,9$ (E). .291

FIG. - 7.36 - ESTRATÉGIA BÁSICA DE PARALELISMO DA TÉCNICA MRF. .292

FIG. - 7.37 - ESTRATÉGIA BÁSICA DE PARALELISMO DA TÉCNICA MRF. .293

FIG. - 7.38 - DiAGRAMA DE TRANSFERÊNCIA DAS ESTRUTURAS DE ATUALIZAÇÃO .293

Fig. - 7.39 - Diagrama de TRANSFERÊNCIA DAS ESTRUTURAS DE ATUALIZAÇ̃̃o PARA 6 (A) E 9 (B) ELEMENTOS DE PROCESSAMENTO. 
Fig. - 7.40 - EXEMPLOS DE BALANCEAMENTO DE CARGA, COM 3 ELEMENTOS DE PROCESSAMENTO HETEROGÊNEOS.

FIG. - 7.41 - DIAGRAMA DE EXECUÇÃO DO ALGORITMO MRF PARALELO, PARA QUATRO ELEMENTOS DE PROCESSAMENTO 296

FIG. - 7.42 - DIAGRAMA DE EXECUÇÃO DO ALGORITMO MRF PARALELO EM UM SISTEMA HETEROGÊNEO. 297

FIG. - 7.43 - DiAGRAMA DA TROCA DE MENSAGENS. 298

FIG. - 7.44 - COMPARAÇÕES DE PERFORMANCE ENTRE A VERSÃO PARALELA E SEQÜENCIAL. (A) GRÁFICO DO TEMPO DE EXECUÇÃO EM FUNÇÃO DO TAMANHO DE IMAGEM. (B) GRÁFICO DA TAXA DE DESEMPENHO EM FUNÇÃO DO TAMANHO DE IMAGEM..................................................... 299

FIG. - 7.45 - DOIS EXEMPLOS DE FRACTAIS, TRIÂNGULO DE SIERPINSKI (A) E MANDELBROT (B)....... 300

FIG. - 7.46 - DiAGRAMA DE EXECUÇÃO PARA 4 MÁQUINAS. 302

FIG. - 8.1 - SiSTEMA DE INTEGRAÇÃO ENTRE COR E ESTÉREO, SEGUNDO SUA ESTRUTURA MODULAR [MOREIRA, 1999]. 308

FiG. - 8.2 - MODELO DE ARESTAS DOS OBJETOS QUE CONSTITUEM O UNIVERSO DE RECONHECIMENTO DO SISTEMA (CUBO, TETRAEDRO E PRISMA). 310

FIG. - 8.3 - EXEMPLOS DE CENAS REAIS, NAS QUAIS O SISTEMA REALIZOU A IDENTIFICAÇÃO DOS OBJETOS [MOREIRA, 1999] 311

FiG. - 8.4 - MOdElo DE ARESTAS DOS OBJETOS QUE CONSTITUEM O UNIVERSO DE RECONHECIMENTO DO SISTEMA (CUBO, TETRAEDRO E PRISMA).

FiG. - 8.5 - EXEMPLOS DE SEGMENTAÇÃO DO MÓDULO COR. (A) IMAGEM DIREITA DO PAR ESTÉREO, ADQUIRIDA PELO MÓDULO DE AQUISIÇÃO. (B) RESULTADO DA SEGMENTAÇÃO DO MÓDULO COR (MAPAS AUTO-ORGANIZÁVEIS). (C) SEGMENTAÇÃO POR SOBEL COM FINALIDADE COMPARATIVA.

FiG. - 8.6 - SEGMENTOS DE RETAS DETECTAdOS EM DIFERENTES PONTOS DE VISTAS DE UMA MESMA CENA (FIGURA A ESQUERDA) 316

FIG. - 8.7 - EXEMPLOS DE RECONHECIMENTO DE OBJETOS. NA COLUNA ESQUERDA É APRESENTADA A IMAGEM DIREITA DO PAR ESTÉREO E NA COLUNA DIREITA, O MODELO OBTIDO DO OBJETO SOBREPOSTO AO MODELO RECONHECIDO DO BANCO DE DADOS

Fig. - 8.8 - EXEMPLO DE PIPELINE DE 5 ESTÁGIOS ENTRE OS MÓDULOS DO SISTEMA (AQUISIÇÃO, COR,

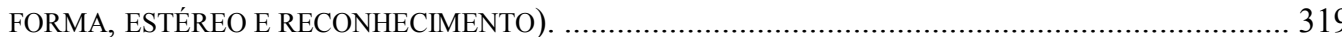

FIG. - 8.9 - DIAGRAMA APRESENTADO AS INTERAÇÕES DO WEBWORM. ............................................... 324

FIG. - 8.10 - EXEMPLO DE NAVEGAÇÃO DO WEBWORM........................................................ 325

FIG. - 8.11 - DIAGRAMA ILUSTRATIVO DA ESTRATÉGIA DE PARALELISMO DO ALGORITMO GENÉTICO DISTRIBUÍDO COM ARQUITETURA CVMP PROCESSOR FARM.

FIG. - 8.12 - RESULTADOS DA CORRELAÇÃO DO ALGORITMO GENÉTICO PARA OS MODELOS DE COMPLEXIDADE UTILIZADOS. REFERENTE A COMBINAÇÃO LINEAR (A) E LOGARÍTMICA (B). ... 329

FIG. - 8.13 - GRÁFICOS APRESENTANDO O TEMPO DE EXECUÇÃO DA IMPLEMENTAÇÃO PARALELA DO ALGORITMO GENÉTICO. 
FIG. - 8.14 - DiAgrama EM BLOCOS APRESENTANDO OS MÓdULOS QUE COMPÕE O SISTEMA TREEVIS, E SUAS RESPECTIVAS CONEXÕES.

FIG. - 8.15 - EXEMPLO DO ALINHAMENTO DA IMAGEM, NA QUAL A NERVURA PRINCIPAL DA FOLHA DEVERÁ ESTAR ORIENTADA NA VERTICAL.

FIG. - 8.16 - PROCEDIMENTO PARA AQUISIÇÃO DA IMAGEM AMPLIADA DE TEXTURA. NESTE EXEMPLO FOI UTILIZADA A FOLHA DA HYMENEA COURBARIL (JATOBÁ).

Fig. - 8.17 - AMOSTRA COMPLETA DA ORMOSIA ARBOREA (OLHO DE CABRA), NO AMBIENTE GRÁFICO DO SISTEMA TREEVIS. DA ESQUERDA PARA A DIREITA: LADO A (SOL), LADO B (SOMBRA) E IMAGEM AMPLIADA DE TEXTURA.

FIG. - 8.18 - AMBIENTE GRÁFICO COM O USUÁRIO DO TREEVIS. EXEMPLO DE VISUALIZAÇÃO DE TÉCNICAS E MÉTODOS DE PROCESSAMENTO DE IMAGENS E VISÃO.

FIG. - 8.19 - VISUALIZAÇÃO DO CÁlCULO DE CURVATURA. CONTORNO DA FOLHA DA CARINIANA ESTRELLENSIS (JEQUITIBÁ), OBTIDA ATRAVÉS DA DETECÇÃO DE BORDAS DA IMAGEM BINARIZADA. (B) JANELA DE CONTROLE, APRESENTANDO A PROJEÇÃO DO CONTORNO NO EIXO X, Y E O GRÁFICO DE CURVATURA. (C) PROJEÇÃo DO GRÁFICO DE CURVATURA SOBRE O CONTORNO (3D). .349

FIG. - 8.20 - NERVURAS DA FOLHA, CONSIDERADAS NA TRANSFORMADA DE HOUGH. IMAGEM SEGMENTADA (A), NERVURAS CONSIDERADAS PARA A TRANSFORMADA (B) E REFERÊNCIA DO ÂNGULO DETERMINADO PELA ANÁLISE (C). 350

FIG. - 8.21 - VISUALIZAÇÃO DO DOMÍNIO DA FREQÜÊNCIA (REAL) DA IMAGEM DE AMPLIAÇÃO DE TEXTURA DE 4 ESPÉCIES DIFERENTES, APRESENTANDO AS DIFERENÇAS QUE CARACTERIZAM OS DESCRITORES.

FIG. - 8.22 - HiSTOGRAMAS DE FOLHAS DE 4 DIFERENTES ESPÉCIES, ILUSTRANDO A VARIAÇÃO PRESENTE NA DISTRIBUIÇÃO DOS HISTOGRAMAS.

FIG. - 8.23 - TREEVIS COM A ESTRATÉGIA DE PARALELISMO PROCESSOR FARM. .356

FIG. - 8.24 - TREEVIS - EXPLORAÇÃO DE PARALELISMO ATRAVÉS DA PARTIÇÃO DO MÓDULO EXTRAÇÃO DE CARACTERÍSTICAS EM 3 PARTES, EXECUTADAS SIMULTANEAMENTE EM PROCESSADORES DIFERENTES.

FIG. - 8.25 - TREEVIS - EXPLORAÇÃO DE PARALELISMO ATRAVÉS DA PARTIÇÃO DO MÓDULO EXTRAÇÃO DE CARACTERÍSTICAS EM 6 PARTES, EXECUTADAS SIMULTANEAMENTE EM PROCESSADORES DIFERENTES.

FIG. - 8.26 - GRÁFICO DO TEMPO DE EXECUÇÃO DA VERSÃO PARALELA (PROCESSOR FARM). NOVE AMOSTRAS FORAM PROCESSADAS.

FIG. - 8.27 - GRÁFICOS DO TEMPO DE EXECUÇÃO, COMPARANDO AS VERSÕES PARALELA E SEQÜENCIAL DO TREEVIS. (A) EXECUÇÃO DE TRÊS AMOSTRAS NA VERSÃO PARALELA (FRAGMENTAÇÃO DO MÓDULO DE EXTRAÇÃO DE CARACTERÍSTICAS). (B) EXECUÇÃO DE UMA AMOSTRA NA VERSÃO SEQÜENCIAL.

FIG. - 8.28 - GRÁFICO DO TEMPO DE EXECUÇÃO DA VERSÃO PARALELA (PROCESSOR FARM) EM SISTEMA DISTRIBUÍDO COM 6 MÁQUINAS. DOZE AMOSTRAS FORAM PROCESSADAS. 
FIG. - 8.29 - GRÁFICOS DO TEMPO DE EXECUÇÃO, COMPARANDO AS VERSÕES PARALELA E SEQÜENCIAL DO TREEVIS. (A) EXECUÇÃO DE TRÊS AMOSTRAS NA VERSÃO PARALELA (FRAGMENTAÇÃO DO MÓDULO DE EXTRAÇÃO DE CARACTERÍSTICAS). (B) EXECUÇ̃̃o DE UMA AMOSTRA NA VERSÃO SEQÜENCIAL 


\section{LISTA DE TABELAS}

TABELA 4.1 - PRINCIPAIS DIFERENÇAS ENTRE AS CÉLULAS MAGNO E PARVOCELULAR. 134

TABELA 4.2 - COMPOSIÇÃO CITOARQUITETURAL DE CADA CAMADA DO CÓRTEX VISUAL PRIMÁRIO...141

TABELA 7.1 - TIPOS DE VARIÁVEIS DO OBJECT PASCAL (DELPHI 4) E A MEMÓRIA UTILIZADA. ............270

TABELA 7.2 - EXEMPLOS DE CRITÉRIOS OBTIDOS EM TERMOS DE $\alpha$.

TABELA 8.1 - HERBÁRIOS BRASILEIROS E NúMEROS DE EXEMPLARES [PEIXOTO \& BARBOSA, 1998]. 336

TABELA 8.2 - OS DOZE HERBÁRIOS BRASILEIROS QUE MAIS DETÊM INFORMAÇÕES [PEIXOTO \& BARBOSA, 1998].

TABELA 8.3 - ESPÉCIES UTILIZADAS NO EXPERIMENTO. .363

TABELA 9.1 - SÍNTESE DAS PRINCIPAIS CONTRIBUIÇÕES DESTA TESE. .373 


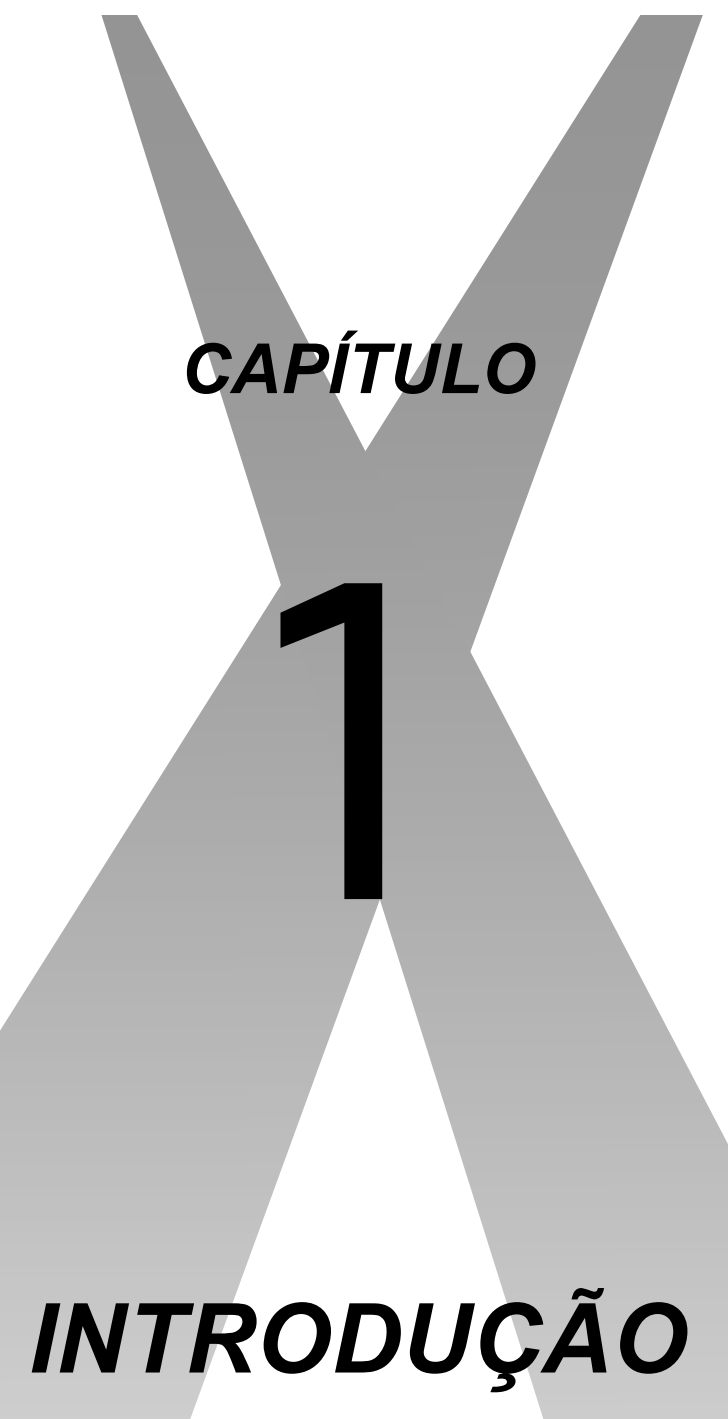

"I think computer viruses should count as life. I think it says something about human nature that the only form of life we have created so far is purely destructive. We've created life in our own image." 
CAPÍTULO 1 


\section{CAPÍTULO 1 - INTRODUÇÃO}

\section{1 - O PARALELISMO NATURAL}

Desconhecemos a exata razão da natureza ao evoluir os diversos seres vivos, mas sabemos entretanto, que como resultado, eles se tornam mais adaptados ao meio e consequentemente mais complexos. Devemos lembrar que a adaptação não compreende apenas a modelagem do indivíduo ao meio físico, mas também seu relacionamento com outros seres e muitas vezes a competição entre as espécies e indivíduos. Embora vários fatores sejam relevantes na adaptação de um ser ao meio, tais como: locomoção, mecanismos de alimentação e dispositivos de ataque (predadores) e defesa (presa), sem dúvida o mais importante é a informação, uma vez que é através dela que o indivíduo vai poder se locomover, alimentar, defender ou atacar, enfim realizar sua integração ao meio.

No decorrer de bilhões de anos, inúmeros mecanismos foram desenvolvidos pela natureza a fim de que os seres vivos pudessem extrair informações do meio. Esses mecanismos são denominados sentidos, estando presentes no ser humano em cinco diferentes modalidades: audição, visão, olfato, paladar e tato. O que determina a eficácia de um sentido é a quantidade e a qualidade das informações através dele percebidas. Foi através da percepção das ondas eletromagnéticas que a natureza desenvolveu uma das suas obras mais incríveis, o mecanismo mais poderoso e sofisticado para a aquisição de informação: a visão.

Mais do que apenas uma maneira de obter informações sobre o meio, a visão é um complexo sistema de processamento de sinais, no qual as imagens são convertidas em informações compreensíveis para o indivíduo. É razoável que um sistema de processamento tão intrincado e sofisticado tenha um elevado custo. De fato, nos animais que possuem a visão mais evoluída, como é o caso dos primatas, cerca de $60 \%$ dos neurônios corticais estão envolvidos com este processo. Entretanto, num mundo onde a competição é sinônimo de sobrevivência, não basta obter informação abundante e de qualidade sobre o meio, é necessário também que ela seja adquirida em tempo real, uma vez que essa condição na maioria das vezes pode significar a diferença entre a vida ou morte para grande parte dos seres vivos. 
Sem dúvida, o principal mecanismo encontrado na natureza para agilizar o processamento das informações é o paralelismo. A maior prova disso é a natureza paralela e distribuída do sistema de visão dos primatas, os animais mais evoluídos. Contudo, não é apenas para a velocidade de resposta que o paralelismo contribui. $\mathrm{Na}$ verdade, o sistema de visão dos primatas tem no paralelismo sua base de estruturação em todos os seus níveis. Como propõem Zeki e Shipp [Zeki \& Shipp, 1988], o paralelismo permite não somente a integração dos atributos visuais, mas também de cada um dos submódulos que os compõe.

O paralelismo foi uma escolha realizada pela natureza ao longo da evolução, o qual iniciou com o aparecimento dos seres pluricelulares. Se pensarmos em cada célula como um elemento individual de processamento da vida, todo ser vivo pluricelular é composto por uma estrutura de processamento paralelo. Nesse contexto, o paralelismo vai se intensificando à medida que os seres se tornam mais complexos e começam a surgir os tecidos e órgãos, culminando no sistema nervoso central, a máquina de processamento paralelo mais poderosa que conhecemos. Em visão, assim como no sistema nervoso, a base estrutural do processamento está fundada no paralelismo.

Podemos considerar que o paralelismo na visão se inicia nos dois órgãos responsáveis pela captação da luz, os olhos, que possuem autonomia e independência, operando em concorrência. O paralelismo dos olhos se acentua quando consideramos suas retinas. Além de possuírem hemisférios de percepção autônomos (campo visual direito e esquerdo), as retinas possuem dois conjuntos de fotorreceptores (cones e bastonetes) que constituem o início de sistemas independentes que captam informações distintas (caminho parvo celular e magno celular). A informação proveniente da retina é replicada e distribuída para diversas regiões do córtex visual, caracterizando um sistema massivamente paralelo com arquitetura distribuída constituído por módulos independentes responsáveis pelo processamento de informações específicas. Cada um dos módulos que constituem o sistema visual é ainda subdividido em estruturas hierárquicas que realizam processamento paralelo. Deste modo, o paralelismo apresenta-se no sistema visual em multiníveis, mostrando-se como uma das bases de sua arquitetura.

É dentro do fascinante universo da visão que reside o objeto de estudo desta tese multidisciplinar: o estudo do paralelismo no sistema de visão dos primatas e sua inspiração para que possamos desenvolver sistemas paralelos de visão artificial mais eficientes. 


\section{2 - PARALELISMO EM VISÃO ARTIFICIAL}

Embora seja de conhecimento da neurociência que os sistemas biológicos de visão estejam fundamentados em estruturas distribuídas e paralelas de processamento, não encontramos, como era de se esperar, na visão artificial (visão computacional) a mesma concepção. De fato, observando a literatura da área, esse assunto, embora de extrema importância, tem sido pouco explorado. Se tomarmos algumas das bases bibliográficas mais importantes, poderemos constatar que o paralelismo não é nem ao menos citado, na sua grande maioria. Como exemplo podemos sugerir o famoso livro "Vision" de David Marr, o qual é consagrado por ser uma das bíblias da área. Marr não faz nem ao menos uma citação em sua obra sobre a importância do paralelismo em visão.

Ainda que a visão artificial seja uma área cuja inspiração biológica é amplamente incentivada, não sabemos qual é o motivo da lacuna que incide sobre o tema do paralelismo. Podemos supor alguns fatores responsáveis pela exclusão do paralelismo nas bases da visão artificial. Uma das possibilidades seria o processamento seqüencial historicamente utilizado pela ciência da computação para resolver seus problemas, que pode ter contribuído para que o paralelismo tenha sido abandonado em visão artificial.

Uma diferença entre os elementos de processamento natural e biológico é a velocidade de processamento. Sendo os neurônios lentos, se comparados com a freqüência de operação dos microprocessadores atuais, existe uma necessidade intrínseca de paralelismo para realizar processamento em tempo real. Talvez este fator tenha levado a uma crença onde, ao contrário da visão natural, o estudo de visão artificial não tivesse a necessidade de se preocupar com os assuntos de paralelismo, uma vez que num futuro próximo, os sistemas computacionais poderiam chegar a possuir poder computacional suficiente para efetuar os métodos e técnicas de visão computacional e processamento de imagens em tempo real. Entretanto, devemos lembrar que na visão natural o paralelismo não possui apenas esse caráter.

Outra possibilidade seria a dificuldade no desenvolvimento de aplicações paralelas, devido à impopularidade da computação paralela levando a uma falta de ambientes de desenvolvimento amigáveis, a necessidade de um profundo conhecimento em computação paralela exigida para sua programação e sistemas de computação complexos e pouco amigáveis entre outras. Esses fatores têm 


\section{CAPÍTULO 1}

mantido a computação paralela restrita aos especialistas da área. Sendo visão um assunto multidisciplinar envolvendo além de cientistas da computação, engenheiros, matemáticos, físicos, biólogos, neurocientistas e outros, o alto custo com o aprendizado e utilização das técnicas de computação paralela estariam assim conduzindo à opção seqüencial.

Seja qual for a possibilidade, podemos concluir que a principal barreira que impõe uma abordagem paralela em visão artificial é a dificuldade de implementação paralela e o direcionamento de suas ferramentas para o restrito grupo dos especialista da área. Observando a história da computação, vemos a grande importância da interação usuário/máquina e de sua simplificação. Deste modo, tornar as tecnologias mais fáceis de utilizar, além de auxiliar os usuários inexperientes, também beneficia os expertos, uma vez que [Hayes, 1990] [Baber et al., 1993]. Bons exemplos desta linha de raciocínio são: a tecnologia GUI (Grafical User Interface), a programação visual e a programação orientada a objetos, cujo principal objetivo é simplificar o relacionamento entre o homem e a máquina.

Deste forma, acreditamos que a principal solução para a ausência de paralelismo em visão artificial seria eliminar a barreira da dificuldade de utilização da tecnologia de computação paralela, através de metodologias e ferramentas que possibilitassem uma simplificação da implementação de aplicativos, permitindo assim que toda a gama de pesquisadores relacionados com visão pudessem facilmente incorporar paralelismo em seus projetos.

Assim sendo, o problema do paralelismo em visão artificial se transforma numa questão inserida no seio da ciência da computação: a adoção do paralelismo com uma filosofia de interação homem-máquina, objetivando o acesso fácil e amigável aos recursos da computação paralela.

\section{3 - AS DUAS COLUNAS}

O paralelismo é inerente à visão natural, possibilitando além de grande performance (processamento em tempo real), as bases para a integração entre os diferentes atributos visuais e seus respectivos módulos [Zeki \& Shipp, 1988] [Livingstone \& Hubel, 1988] [Zeki, 1993] [Hubel, 1995] [Levine \& Shefner, 1991]. Seguindo as lições da natureza, o estudo do paralelismo em visão artificial, é vital para o desenvolvimento de modelos mais realísticos de visão auxiliando na elaboração de sistemas mais complexos, que permitam a integração de atributos 
visuais (cor, estéreo, textura, forma, etc.) e diferentes técnicas de visão, assim como sua execução em tempo real, uma vez que a performance está condicionada à filosofia paralela.

Além de melhorias nos sistemas de visão artificial, a adoção de modelos mais realísticos do ponto de vista biológico permite uma melhor compreensão dos sistemas de visão natural, e consequentemente do funcionamento do cérebro como um todo. Essa realimentação de conhecimento constitui uma das bases da Visão Cibernética, que caracteriza o estudo da visão como um assunto multidisciplinar correlacionado.

Esta tese está fundada em duas colunas: (i) o estudo do paralelismo em visão natural e artificial e (ii) a proposta de uma ferramenta de desenvolvimento paralelo, baseada na interação entre usuário e máquina, que facilite a implementação de algoritmos paralelos de visão.

$\mathrm{Na}$ primeira parte que compõe este trabalho realizamos uma revisão, discussão e análise do paralelismo em visão natural e artificial. São abordadas as bases do paralelismo na visão natural, enfocando o sistema de visão dos primatas. Em visão artificial são tratados os possíveis benefícios do paralelismo, através de sistemas paralelos de visão, concentrando o assunto sobre o projeto Cyvis-1 (Cybernetic Vision 1), sistema de visão versátil em desenvolvimento no nosso grupo. O Cyvis-1 é baseado no modelo de especialização funcional proposto por Zeki \& Shipp [Zeki \& Shipp, 1988], apresentando deste modo, assim como os sistemas de visão natural, uma arquitetura que possui paralelismo inerente.

Conforme discutimos na seção anterior, acreditamos que a principal razão que impele a utilização de paralelismo em massa em visão computacional é a dificuldade de utilização, de implementação e o longo treinamento requerido para a implementação paralela. Na tentativa de solucionar esse problema, sobretudo dentro do nosso grupo de pesquisa, a segunda parte desta tese introduz uma nova metodologia de implementação paralela, baseada na simplicidade de utilização e programação e na reutilização de código.

\section{4 - OBJETIVOS DA TESE}

Nesta seção vamos apresentar ao leitor uma síntese dos principais objetivos deste trabalho, permitindo uma perspectiva sobre os assuntos discutidos e abordados ao longo da tese. 
Como primeiro passo, este trabalho pretende realizar um levantamento crítico e abrangente das diversas áreas relacionadas ao paralelismo em visão natural e artificial. Uma vez que o paralelismo em visão artificial está vinculado à computação paralela, intencionamos realizar uma substancial revisão à computação paralela, de modo a fornecer ao leitor as bases para as discussões do assunto sob o ponto de vista da visão. Em visão natural, o objetivo é realizar uma revisão sobre o assunto, culminando em uma discussão do paralelismo no sistema visual dos primatas. A integração entre as duas modalidades de visão ocorre através de uma análise crítica de sistemas de visão artificial com motivação biológica.

Um dos objetivos principais deste trabalho é fornecer as bases de paralelismo e integração entre pesquisadores para o desenvolvimento do projeto Cyvis-1, uma proposta de visão versátil, que vem sendo desenvolvida pelo nosso grupo. Com forte motivação biológica, o Cyvis-1, é baseado na especialização funcional do córtex visual dos primatas proposta por Zeki \& Shipp [Zeki \& Shipp, 1988], possuindo como principais características a integração dos atributos visuais, o paralelismo em visão e o trabalho cooperativo entre os diversos pesquisadores envolvidos no projeto.

De forma a viabilizar o item anterior e na tentativa de preencher a lacuna do paralelismo em visão artificial, pretendemos desenvolver um conjunto de ferramentas para o desenvolvimento, de forma simples e amigável, de aplicações paralelas em visão que, auxilie tanto os programadores sem conhecimentos em paralelismo como os expertos. Deste modo, permitirá a qualquer pesquisador de visão com o mínimo conhecimento de programação, a utilização de recursos de paralelismo em seus projetos, e aos especialistas, o desenvolvimento mais ágil. Denominado CVMP (Cybernetic Vision Message Passage), o conjunto de ferramentas em questão é voltado para a plataforma Windows NT/9X e para o ambiente de desenvolvimento Delphi, que constituem uma das bases de desenvolvimento computacional do nosso grupo.

Uma vez implementado, é necessário realizar a avaliação e validação do CVMP, tanto nos aspectos de funcionalidade quanto em utilização. Assim, um dos objetivos do trabalho foi a implementação de versões paralelas de diversos algoritmos de visão computacional e de processamento de imagens. Dentre os algoritmos, serão abordados casos clássicos em visão e processamento de imagens, tais como os operados locais, transformada de Hough [Hough, 1959] e 
transformada de Fourier [Brigham, 1988], amplamente discutidos na literatura, algumas vezes até mesmo sob o ponto de vista do paralelismo, além de uma técnica de segmentação inédita baseada em campos aleatórios de Markov [Bruno \& Costa, 2000]. Os algoritmos foram analisados através dos módulos de estatística do CVMP, o qual permitiu um estudo sobre seu comportamento, eficiência e performance.

Outro objetivo é o desenvolvimento de situações reais em visão artificial que utilizem os recursos da computação paralela, através do CVMP. Para tanto serão apresentadas 3 aplicações inéditas desenvolvidas nesse trabalho: (i) estruturas de paralelismo da integração dos atributos cor e estéreo do projeto Cyvis-1, (ii) um experimento para um modelo de complexidade baseado na percepção humana (projeto $\Sigma$ ynergos) e (iii) uma proposta para um herbário digital e automático (proposta TreeVis). As duas primeiras aplicações fazem parte de projetos em desenvolvimento no nosso grupo (Grupo de Pesquisa em Visão Cibernética), nos quais além do autor participam outros integrantes do grupo, possibilitando a validação do CVMP tanto na simplicidade de utilização (manuseio amigável), como na reutilização de código e integração entre pesquisadores. A outra aplicação apresenta um protótipo de uma proposta do autor para um sistema de reconhecimento automático de plantas arbóreas, com o intuito de fornecer aos botânicos uma ferramenta complementar aos tradicionais herbários.

\section{5 - ORGANIZAÇÃO DA TESE}

Esta tese prossegue com uma revisão dos conceitos básicos de computação paralela, permitindo ao leitor familiarizar-se com o assunto. No Capítulo 2 são apresentados alguns aspectos teóricos de arquiteturas paralelas e, no Capítulo 3, o tema continua com uma abordagem em software.

No Capítulo 4 é realizada uma revisão de visão natural, com enfoque no sistema de visão dos primatas. O capítulo é complementado por uma discussão do assunto sob o prisma do paralelismo. No Capítulo 5 são apresentados os sistemas de visão artificial Cyvis-1 e Eynergos, em desenvolvimento no Grupo de Visão Cibernética deste instituto. Dentre eles devemos destacar o Cyvis-1, sistema fortemente motivado pela inspiração biológica, que possui como coluna dorsal o paralelismo, sendo uma das bases de estudo deste trabalho. Ainda nesse capítulo será realizada uma análise comparativa entre o sistema Cyvis-1 e outros sistemas 
artificiais encontrados na literatura.

Esta tese introduz um conjunto de ferramentas visuais, que simplificam a implementação de aplicações paralelas, denominado CVMP. Embora o CVMP tenha sido idealizado para a visão computacional, sua utilização é genérica, permitindo virtualmente que qualquer programador Delphi desenvolva uma aplicação paralela, bastando para isto um conhecimento rudimentar de paralelismo. O conjunto de ferramentas CVMP é apresentado e discutido no Capítulo 6.

O Capítulo 7 apresenta diversas técnicas e métodos paralelos de visão computacional e processamento de imagens, desenvolvidos através de CVMP. Cada caso é discutido, abordando as questões teóricas do assunto, assim como os resultados da implementação paralela e ainda sua comparação com as versões seqüenciais. Dentre as técnicas apresentadas salientamos a implementação paralela do algoritmo de segmentação de imagens, baseado em campos aleatórios de Markov, cuja metodologia foi desenvolvida neste trabalho.

No Capítulo 8 são apresentadas três inéditas aplicações paralelas em visão artificial, implementadas através de CVMP. A primeira delas é um protótipo do sistema de visão Cyvis-1, na qual é realizada a integração dos atributos de cor e estéreo, a partir do paralelismo. Na seguinte, é discutido um experimento de psicofísica realizado a partir do projeto $\Sigma$ ynergos, visando a obtenção de um modelo de medida de complexidade, baseado na percepção humana. Na última aplicação temos um sistema paralelo de visão para auxiliar no levantamento e estudo das plantas arbóreas de florestas tropicais, que funciona como um herbário digital, cuja proposta e implementação foi introduzida nesta tese.

Finalmente esta tese é concluída no Capítulo 9, onde são discutidas as contribuições deste trabalho e as possíveis pesquisas científicas que podem ser realizadas na sua continuação. 


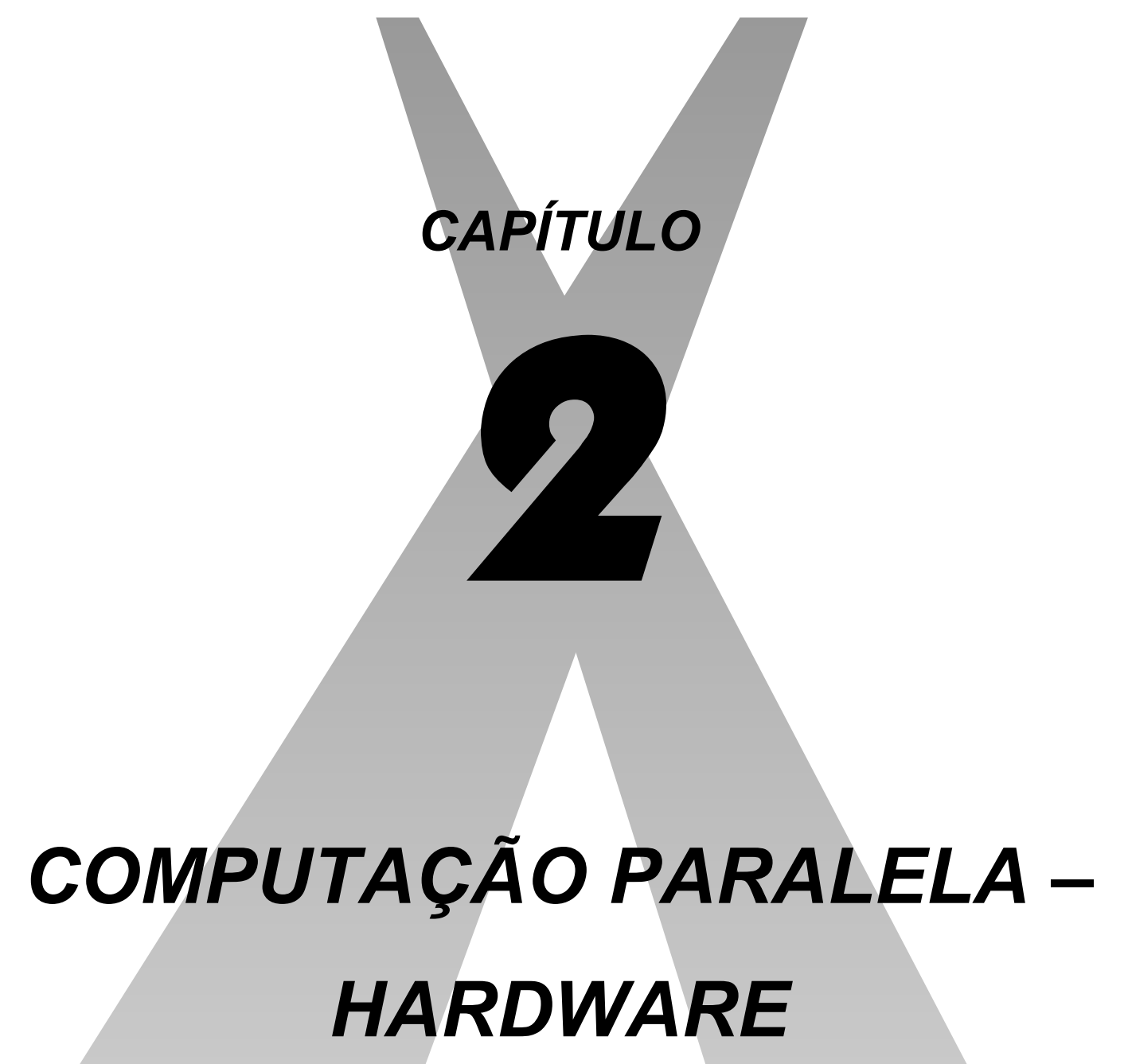

... toda ciência é melhor conhecida a partir de sua história, do mesmo modo que as maiores edificações apresentam as bases mais sólidas ... 
CAPÍTULO 2 


\section{CAPÍTULO 2 - COMPUTAÇÃO PARALELA - HARDWARE}

\section{1 - INTRODUÇÃO}

Partindo da premissa de que toda ciência é melhor conhecida a partir de sua história, do mesmo modo que as maiores edificações apresentam as bases mais sólidas, iniciamos esse capítulo com uma breve revisão da história da computação paralela, a fim de que possamos, a partir da base, traçar as perspectivas para os avanços de uma das áreas mais importantes da Ciência da Computação. Seguindo esse princípio, discorreremos sobre a evolução da computação seqüencial e a seguir apresentaremos a evolução da computação paralela abordando alguns elementos clássicos, de modo a gerar as bases para sua melhor compreensão.

Como podemos deduzir através do título desse capítulo, estaremos discutindo a computação paralela sob o ponto de vista do hardware. Após a abordagem histórica da computação paralela, apresentada na Seção 2.2, na seguinte, iremos tratar da evolução da eletrônica, e apresentar o perfil tecnológico da evolução do hardware. Continuando, trataremos na Seção 2.4 da evolução da computação seqüencial, demonstrando as tendências de paralelismo nos computadores seqüenciais. $\mathrm{Na}$ Seção 2.5 apresentaremos a evolução da computação paralela através de uma jornada evolutiva sobre as principais arquiteturas não convencionais, e finalmente concluímos o capítulo apresentando alguns métodos para a taxionomia de computadores.

\section{2 - Princípios Históricos dA Computação PARALELA}

A história da computação paralela é tão antiga quanto a história do computador moderno. O próprio John von Neumann, criador da arquitetura von Neumann, arquitetura fundamental para a maioria dos computadores desenvolvidos 


\section{CAPÍTULO 2}

até hoje, desenvolveu trabalhos na década de 40 que discutiam a possibilidade de algoritmos paralelos para a solução de equações diferenciais [Breton, 1991]. Com isso podemos concluir que a história da computação paralela vem transcorrendo em paralelo com a própria história da computação moderna, e como poderemos observar, aparenta ser uma evolução natural à computação.

Sem desmerecer as contribuições de importantes nomes da história da computação, como Blaise Pascal [Goldstine, 1993], Gottfried Wilhelm von Leibniz [Breton, 1991], Charles Babbage [Spufford \& Uglow, 1997] e Allan Turing [Hodges, 1992], assim como toda a era pré-moderna da história da computação, podemos dizer que a computação moderna, teve seu início com o projeto ENIAC (Electronic Numerical Integrator and Computer) [Goldstine, 1993] [Breton, 1991], iniciado na década de 40. O projeto ENIAC iniciou-se na era das grandes calculadoras. Embora seus coordenadores Eckert e Mauchly estivessem dispostos a inovar, em seu projeto inicial, o ENIAC não passava de uma calculadora, e a teoria utilizada ainda era muito semelhante à máquina de Babbage e mesmo à Pascalina. Em agosto de 1944, com a incorporação de John von Neumann no projeto do ENIAC, o rumo da história mudaria. Infelizmente o ENIAC já estava em fase bem adiantada e não apresentaria muitas das propostas revolucionárias de von Neumann, mas ainda assim o ENIAC seria o primeiro computador eletrônico de uso geral. Mesmo sendo um precursor dos computadores modernos, o ENIAC já possuía caráter paralelo, uma vez que era disposto em vários módulos independentes, descentralizados e que poderiam realizar operações simultaneamente.

John von Neumann propôs uma nova forma de organizar os sistemas de computação, que deu origem à arquitetura von Neumann e marcou o início da computação moderna. Um dos principais conceitos apresentados por von Neumann foi a memória e a idéia de programa armazenado. A partir da influência direta das idéias de von Neumann nasceram os primeiros cinco computadores modernos (sistema de memória) da história, que foram o EDVAC (o primeiro projeto de computador moderno), a máquina IAS, o BINAC, o EDSAC e o Manchester MARK I (o primeiro computador a funcionar na história). Esses computadores foram de caráter acadêmico ou militar, porém seus sucessos fizeram com que logo começassem a ser produzidos computadores comerciais.

Um fato bastante curioso nessa história, e que nos liga novamente à história da computação paralela, é que uma das características que inviabilizavam o ENIAC era o seu aspecto paralelo, onde diversas partes de sua arquitetura funcionavam 
independentes e em paralelo. Com o paralelismo era necessária a supervisão humana, já que a máquina não possuía uma unidade central autômata. [Breton, 1991].

Com os princípios de memória e programa armazenado, von Neumann implementava a máquina de Turing universal, e com isso, o computador assumia agora um papel genérico, todo e qualquer (salvo limitações) problema computável possuía um programa capaz de resolvê-lo; porém essa nova organização possuía um controle centralizado e tarefas seqüenciais. A partir da definição de computador moderno, a história dos computadores pode ser dividida em três partes, que vão caminhando simultaneamente. Primeiramente temos a revolução tecnológica, à medida que a eletrônica se desenvolvia, computadores mais poderosos e velozes surgiam. Ao mesmo tempo que avançava a eletrônica, que está intimamente ligada à história da computação, ocorriam também progressos na própria computação, em termos de arquitetura, "hardware" e "software". Na computação ocorreram dois caminhos simultâneos: por um lado temos os computadores de uso geral ou comerciais, que adotaram a tradicional máquina de von Neumann como arquitetura básica, por outro lado temos os denominados supercomputadores.

A necessidade de velocidade é inerente à computação, e a solução natural para essa questão é a paralelização. Portanto, os supercomputadores são projetos que tentam alternativas à arquitetura seqüencial de von Neumann, e buscam aumentar a performance da máquina através do paralelismo. Em geral essas máquinas são de uso específico, voltadas a problemas determinados, e de caráter científico.

\section{3 - EVOLUÇÃO ELETRÔNICA}

Do ponto de vista da eletrônica, a história pode ser dividida em cinco partes ou gerações. À medida que a tecnologia eletrônica evoluía, novos computadores mais velozes e poderosos surgiam, baseados na nova tecnologia. Por um lado a velocidade de comutação dos dispositivos aumentava a cada geração e por outro as tecnologias de miniaturização e de integração evoluíam e proporcionavam computadores menores em tamanho, porém com um número cada vez maior de dispositivos de processamento (transistores) e memória. A Figura 2.1 apresenta um diagrama sobre as gerações e seus respectivos períodos.

A primeira geração de computadores (1938-1953), iniciou-se com os primeiros 


\section{CAPÍTULO 2}

computadores pré-modernos (máquinas de calcular), que utilizavam dispositivos eletromecânicos (Reles) e estendeu-se até que surgiram os primeiros computadores eletrônicos, sendo essa fase o período áureo da primeira geração: a utilização de válvulas para o desenvolvimento de computadores eletrônicos. Neste período os computadores possuíam arquitetura bit-by-bit, onde não existia o conceito de palavra (byte) e o processador utilizava um intervalo de relógio para processar cada bit.

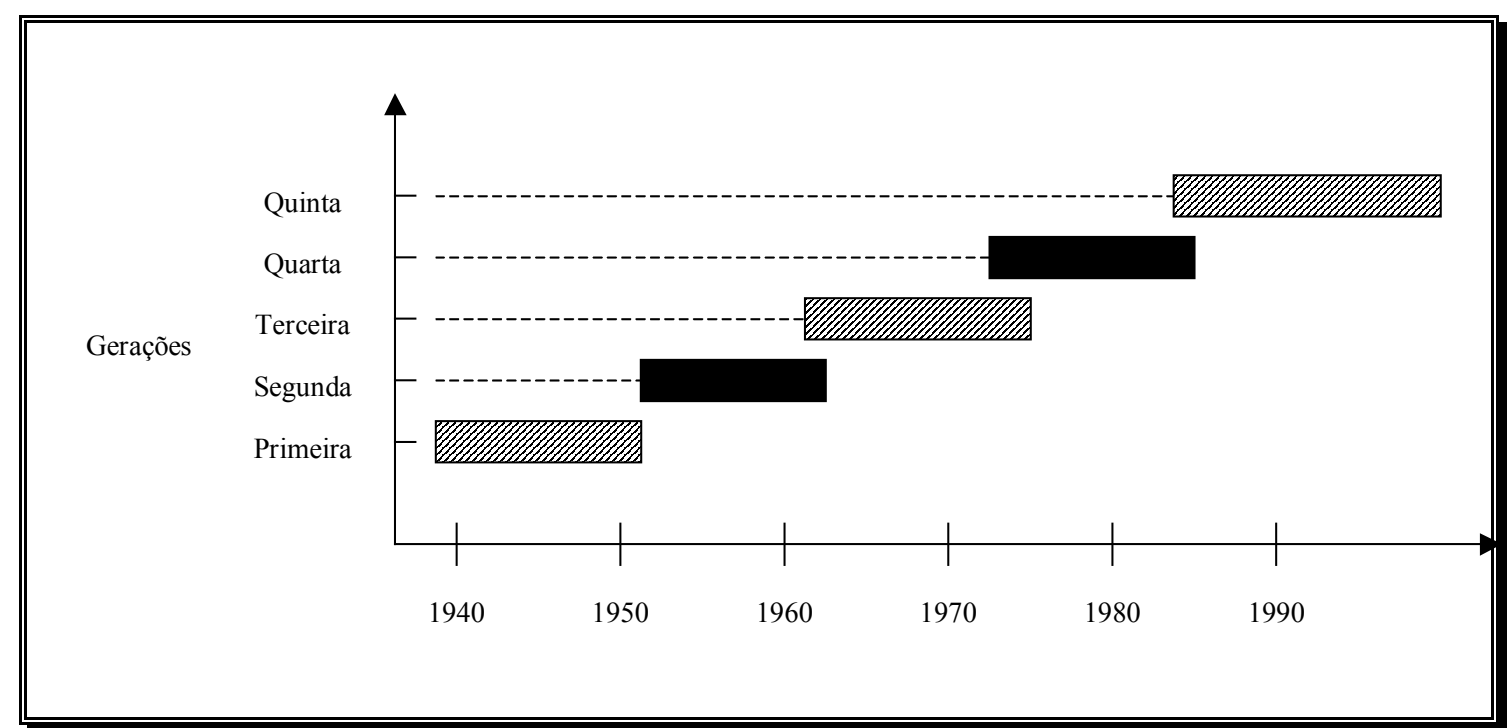

Fig. - 2.1 - Gerações de Computadores.

Os transistores foram inventados em 1948, e com eles surge uma nova evolução na eletrônica. A confecção de computadores utilizando transistores marca a segunda geração de computadores (1952-1963). O primeiro computador a utilizar essa nova tecnologia foi o TRADIC, construído pela Bell Laboratories em 1954. O TRADIC utilizava 800 transistores. Nesse período surge o circuito impresso e a memória magnética.

Ainda nessa época começam a surgir as primeiras linguagens de alto-nível, como o Fortran (do inglês, formula translation) em 1956, o Algol (do inglês, algorithmic language) em 1960 e o COBOL (do inglês COmmon Business Oriented Language) em 1959, e começam também a aparecer processadores específicos para processamento de entrada e saída de dados.

A terceira geração de computadores (1962-1975) surge com o aparecimento dos circuitos integrados SSI (pequena escala) e MSI (média escala). Nessa época surge a memória de estado sólido. Nesse período as linguagens de alto-nível são 
favorecidas com compiladores inteligentes. Começam a ser empregadas as tecnologias de multiprogramação e memória virtual.

Nessa geração surge o microprocessador, através de um projeto de calculadora, Ted Hoff da Intel, projeta um circuito integrado para uso geral em calculadoras e então nasce o microprocessador. O microprocessador é uma unidade central de processamento construída em um único circuito integrado. Esse foi um importante passo na história, surge então o microcomputador e somente a partir daqui os computadores podem ser difundidos e construídos em larga escala. Inicia-se a popularização da informática.

A partir de 1972, utilizando a nova tecnologia de circuitos integrados LSI, surge a quarta geração de computadores (1972 a 1985). Nessa fase os computadores utilizam os novos circuitos integrados em seções de processamento e memória. Surgem os supercomputadores escalar e vetoriais, assim como as extensões de linguagens tradicionais como o Fortran para utilizarem seus novos recursos de paralelismo. A maioria dos sistemas operacionais desta geração utilizam compartilhamento de tempo ("time-sharing") e memória virtual. No final desta geração surge uma corrida por paralelismo, concentrando esforços tanto das porções acadêmicas quanto comerciais.

A atual geração de computadores (quinta geração - 1985 até hoje) iniciouse com o aparecimento da tecnologia de integração VLSI. Esta época marca a continuidade da corrida por paralelismo. Surgem sistemas de computação massivamente paralelos com mais de 64000 unidades de processamento. Este período marca também a fase áurea do Transputer, um microprocessador desenvolvido especificamente para projetos em computação paralela.

Surgem também as estações de trabalho, e com elas a tecnologia RISC e a adoção de paralelismo nos computadores tradicionalmente seqüenciais. Atualmente, a maioria dos microprocessadores convencionais tradicionais incorpora alguns mecanismos de paralelismo. Populariza-se o conceito de rede de computadores e com ele surge um novo sistema de paralelização - computação distribuída, que é o enfoque deste trabalho.

\section{4 - EVoluÇão da COMPUTAÇÃo SEQÜENCIAL}

Entre os anos 50 até meados dos anos 60 , a computação passa por uma fase confusa, onde os padrões ainda não estão estabelecidos, e os fabricantes e 


\section{CAPÍTULO 2}

pesquisadores iniciam diversos projetos distintos, em geral o computador fica uma máquina de uso muito específico, destinado a poucos problemas [Bruno, 1995]. A partir dos anos 60, os computadores começam a proliferar e a generalizar o seu uso. A partir desse ponto, a história da computação pode ser dividida em duas partes: por um lado temos os computadores comerciais (na maioria) de uso geral e por outro lado temos os denominados supercomputadores, que eram destinados normalmente a problemas específicos e voltados mais à área científica ou militar, esses em usualmente tinham como requerimento básico a velocidade.

Quanto aos computadores seqüenciais (de uso geral), um consenso adotou a arquitetura de von Neumann como padrão, e isso não se alterou. Até meados da década de sessenta, a arquitetura dos processadores não foi muito alterada. Um dos primeiros passos rumo ao paralelismo foi o conceito de palavra (byte). Anteriormente o processador possuía uma arquitetura bit-by-bit, onde deveria processar um bit por vez (a cada passo do relógio). Com o conceito de palavra, uma única instrução possibilitava ao processador carregar uma palavra de oito bits a um único passo (clock).

Juntamente com os avanços de arquitetura, o software também evoluía. Um dos primeiros passos foi o aparecimento das linguagens de alto nível, tornando a programação mais simples, deste modo aumentando mais a quantidade de programas e do mesmo modo as aplicações e o uso.

A partir da terceira geração, observou-se que a unidade de processamento ficava ociosa com o acesso a dispositivos de entrada e saída de dados, e pouco a pouco foram sendo acrescentadas novas unidades de processamento nos dispositivos de entrada e saída de dados. O aumento de desempenho proporcionado por essa abordagem aumentou a motivação para essa estratégia e cada vez mais dispositivos do sistema (excluindo UCP - Unidade Central de Processamento) foram ganhando unidades de processamento independentes, autômatas e capazes de trabalhar simultaneamente à UCP. Essa abordagem deu origem ao conceito de interrupção e se difundiu, chegando aos sistemas de computação atuais, que mesmo sendo seqüenciais apresentam várias unidades de processamento (microcontroladores). Podemos citar como exemplos atuais desta abordagem os controladores de Vídeo, interfaces de controle de disco e demais dispositivos de armazenamento de dados, portas seriais (mouse) e paralelas (impressora), controlador DMA (acesso direto a memória), assim como uma série de outros dispositivos incorporados nos atuais sistemas de computação. 
Ainda na segunda e terceira gerações, muitas melhorias beneficiaram o desempenho dos computadores. Enquanto a eletrônica inovou com circuitos mais rápidos e potentes, a computação desenvolve sistemas e melhorias na arquitetura, a fim de deixar o computador mais poderoso e veloz. Surgem então, entre outras melhorias, a memória cache (disco e RAM), a multitarefa, a multiprogramação e a memória virtual.

A partir da terceira e quarta gerações de computadores utiliza-se o circuito integrado. Como resultado, a redução do custo faz com que o microcomputador popularize-se e comece a proliferar. Até o final da década de 70 o microcomputador estaria consolidado como bem de consumo. Na década de 80 , o microcomputador atinge o ápice. Com o lançamento do microcomputador da IBM PC, o microcomputador começa sua escalada, e rapidamente ocorre o chamado "downsizing", fenômeno onde o microcomputador ocupa os lugares dos computadores de grande porte, e faz com que estes tornem-se obsoletos.

No início da informática, os computadores eram programados através da conexão de cabos. Um contato mais íntimo entre o homem e a máquina tornaria sem dúvida o computador mais fácil de ser utilizado pelo homem. Muitas descobertas e invenções contribuíram para a evolução das interfaces. O primeiro passo seria os cartões perfurados, logo a seguir teríamos as "teletypewrites" (dispositivos que se assemelhavam a máquinas de escrever). A primeira grande inovação nesse contexto viria no final da década de 60 , com o uso do terminal de vídeo, que adotava a interface CLI (do inglês command line interface); bons exemplos são o UNIX, o VAX-VMS, o AppleDOS e o próprio MS-DOS [Hayes, 1990].

Durante toda a década de 70, um importante consórcio coordenou os rumos da computação para a próxima década. Não poderíamos narrar a história da computação atual sem considerar as importantes contribuições da XEROX e de seu centro de pesquisas PARC (Palo Alto Research Center). Desde o início da década de 70 o PARC iniciou pesquisas para tornar o relacionamento entre o homem e a máquina mais íntimo. Durante uma década de pesquisas, o PARC chegou a um sistema muito próximo ao que denominamos atualmente de GUI (do inglês graphical user interface) [Peddie, 1992]. Através dessa pesquisa foi descoberto o mouse (dispositivo apontador), o paradoxo de orientação a mensagens e a eventos e adotado o conceito de orientação a objeto, que viria a marcar definitivamente os rumos da computação no final da década de 80 e na década de 90 [Bruno, 1995]. 
A partir da utilização das interfaces gráficas (GUI) e suas novas tecnologias, surgem as estações de trabalho, e com elas se popularizam as redes de computadores. Embora as redes de computadores tenham também uma longa história, foi apenas nos anos 80 através das estações de trabalho que ocorreu sua popularização na computação.

A nível de hardware, as estações de trabalho trouxeram o paralelismo para os microprocessadores seqüenciais. Isto ocorreu inicialmente com o conceito de arquitetura RISC (do Inglês Reduce Instruction Set Computer). A nova geração de microprocessadores RISC incorporava a arquitetura pipeline [Gimarc \& Milutinovic, 1987]. A Figura 2.2 apresenta um exemplo de pipeline de instruções em microprocessadores RISC. [Gimarc \& Milutinovic, 1987] [Ryan, 1992]

\begin{tabular}{|c|c|c|c|c|c|}
\hline Busca & Decodificação & Execução & Escrita & & Tempo \\
\hline Instrução 1 & & & & Ciclo 0 & \\
\hline Instrução 2 & Instrução 1 & & & Ciclo 1 & \\
\hline Instrução 3 & Instrução 2 & Instrução 1 & & Ciclo 2 & \\
\hline \multirow[t]{4}{*}{ Instrução 4} & Instrução 3 & Instrução 2 & Instrução 1 & Ciclo 3 & \\
\hline & Instrução 4 & Instrução 3 & Instrução 2 & Ciclo 4 & \\
\hline & & Instrução 4 & Instrução 3 & Ciclo 5 & \\
\hline & & & Instrução 4 & Ciclo 6 & \\
\hline Fluxo das instr & & & & $\longrightarrow$ & $\nabla$ \\
\hline
\end{tabular}

Fig. 2.2 - Típica pipeline de instruções de arquitetura RISC.

A velocidade e o poder de processamento alcançados por esse novo conceito proporcionaram uma corrida dos desenvolvedores de microprocessadores para o mundo do paralelismo (a nível de instrução). Atualmente vivemos uma forte tendência onde as pesquisas de arquiteturas paralelas estão sendo aproveitadas para o desenvolvimento dos novos microprocessadores "seqüenciais", que se tornam mais paralelos a cada geração. Um bom exemplo dessa perspectiva é o microprocessador Intel Pentium, que como podemos observar pela Figura 2.3 superou a expectativa tecnológica de desempenho graças à utilização de conceitos de computação paralela. Atualmente a grande maioria dos microprocessadores comerciais incorporam pipeline e outros mecanismos de paralelismo em seus microprocessadores convencionais [Ryan, 1992]. 


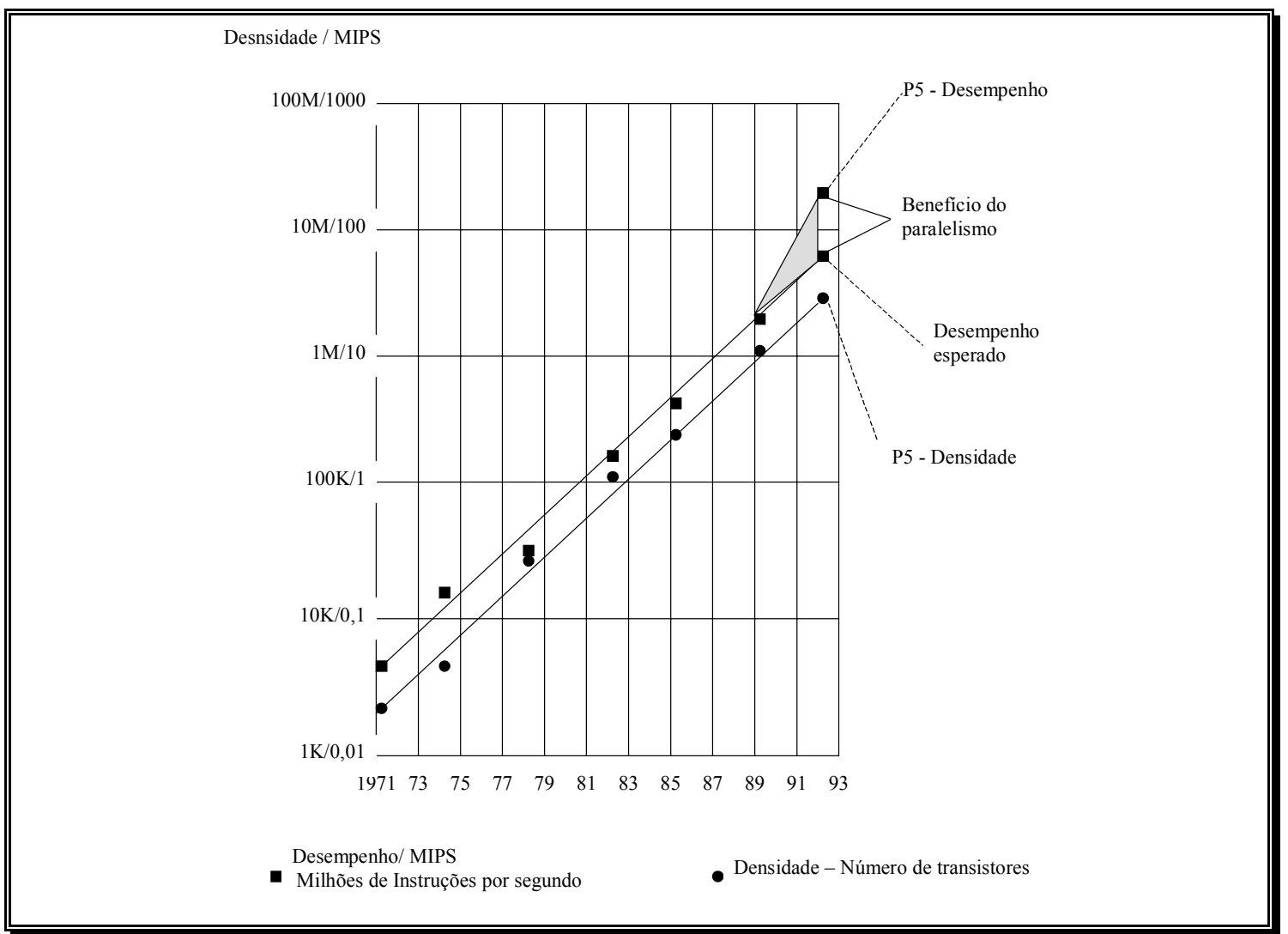

Fig. 2.3 - Benefício proporcionado pelo paralelismo na arquitetura do Pentium.

\section{5 - EVOLUÇÃo do PARALELISMO}

Até a década de 60 , os computadores eram projetados para resolver problemas específicos, isto porém apresentava um obstáculo para a evolução da computação. À medida que a computação evoluía e o universo de aplicações que poderiam utilizar computadores crescia, os computadores começaram a ser úteis para uma gama cada vez maior de problemas. Tornava-se bem claro o rumo dos fabricantes de computadores: desenvolver computadores de uso genérico, que possam ser utilizados nas mais diversas formas de aplicações [Bruno, 1995]. Para esse fim ficou consagrada a arquitetura de von Neumann e com ela os computadores seqüenciais.

A demanda por velocidade é inerente à computação. Assim, nem todos os usuários ficaram satisfeitos com a generalização. Muitos problemas, a grande maioria de caráter científico ou científico-militar, exigiam um desempenho computacional maior que o fornecido pelas máquinas de uso genérico. A resposta 


\section{CAPÍTULO 2}

para aumentar o desempenho dos computadores estava muito clara: paralelismo. $\mathrm{O}$ paralelismo porém acarretaria um custo muito maior em diversos aspectos, tais como: desenvolvimento de hardware específico, multiplicação de recursos (multiplicação de custos consequentemente), desenvolvimento de software específico, desenvolvimento personalizado (sem utilizar as vantagens da produção em massa). Mesmo sendo o paralelismo o resultado de projetos onerosos, existia um nicho disposto a pagar seu preço. Deste modo surge a computação paralela ou supercomputação [Hockney \& Jesshope, 1988].

Embora presente desde o ENIAC na história da computação moderna, somente a partir da década de sessenta a computação paralela assume o seu papel. Devido ao desempenho e aplicações das máquinas paralelas, a computação paralela passa a ser denominada de supercomputação. A partir dessa demanda surgiram diversos projetos de arquiteturas paralelas, apresentando cada vez mais alternativas de paralelização.

\subsection{1 - ARQUITETURA ESCALAR}

Uma das primeiras arquiteturas paralelas que surgiram foi a arquitetura escalar, que deu origem aos denominados computadores escalares rápidos. A longa história do desenvolvimento dos computadores escalares inicia-se na década de 60 e seu desenvolvimento prolonga-se por toda a década de 70 . A evolução dos computadores escalares é basicamente semelhante à própria história da computação paralela, onde o paralelismo vem surgindo e evoluindo pouco a pouco, baseado em máquinas convencionais.

Os computadores escalares, também denominados de computadores pipeline [Hwang et al., 1984] são máquinas que apresentam elementos de processamento duplicados. A grande diferença em termos de instrução entre os computadores escalares e os computadores vetoriais (que trataremos mais tarde) é o tratamento dos dados. As instruções dos computadores escalares trabalham com dados individuais, enquanto que os computadores vetoriais trabalham com grande quantidade de dados ordenados (vetores) por instrução. Um dos primeiros computadores escalares que surgiram foi o IBM 7090.

Um computador que influenciou a história tanto em arquitetura quanto em software foi o ATLAS. Embora seu projeto tenha-se iniciado na Universidade de Manchester por volta de 1956, a primeira produção dessa máquina ocorreu apenas 
em 1963, pela Ferranti. Em termos de software, o ATLAS foi o pioneiro na utilização de sistema operacional multiprogramado. Com aproximadamente 80000 transistores, o ATLAS dispunha de vários dispositivos de I/O com processamento independente, que solicitava o processador apenas quando necessário. Além do pioneirismo em termos de organização, o ATLAS incorporava paralelismo para aumentar seu desempenho computacional.

O ATLAS utilizava quatro bancos independentes de memória, que permitiam acesso simultâneo (em um único clock). Utilizando esses blocos, o ATLAS possuía uma arquitetura funcional com duas unidades aritméticas, de modo que em combinação com seu arranjo de memória, ele poderia (em casos muito favoráveis) executar duas instruções aritméticas em um único clock. Além da arquitetura funcional, o ATLAS também possuía um arranjo pipeline entre as seguintes fases da execução de instruções: busca de instrução, cálculo de endereçamento, busca de operando e execução aritmética.

Para fazer melhor uso de suas características paralelas (múltiplas unidades aritméticas, registradores e memória) e de seus recursos computacionais, seria necessário um sistema que previsse as futuras instruções e determinasse quais instruções poderiam ser executadas concorrentemente sem alterar a lógica do programa. Embora o ATLAS não possuísse nenhum mecanismo de previsão, dois aspectos foram considerados posteriormente por Keller (1976) e Kuck (1978) e incluídos nos computadores escalares CDC6600 e IBM 360/91.

A introdução gradual do paralelismo funcional e pipeline nos computadores seriais pode ser bem observada através dos computadores da Control Data (empresa sob influência direta de Seymour Cray). O seu computador CDC 6600, lançado em 1964, foi o primeiro computador escalar a utilizar o paralelismo funcional como sua característica mais importante de projeto. O modelo seguinte da Control Data, que tomaria o lugar do CDC 6600, viria a ser o CDC 7600, lançado posteriormente em 69. Estas duas máquinas estão entre os supercomputadores de maior sucesso da história, possuindo um parque em sua época com mais de 70 máquinas instaladas. O sucesso comercial bem como o computacional foram tão grandes, que a IBM não conseguia superar sua concorrente. A IBM lançou sua corrida aos supercomputadores através do projeto STRETCH, do laboratório de computação científica de Los Alamos, que pretendia projetar um computador 100 vezes mais rápido que o IBM 704. A versão comercial do STRETCH sairia mais tarde através do IBM 7030, porém não obteve sucesso comercial. Os 


\section{CAPÍTULO 2}

supercomputadores da série CDC eram imbatíveis. Em 1964 a IBM anuncia a série de supercomputadores IBM 360, que segundo a IBM teria performance comparável ao CDC 6600.

A IBM perdia a cada dia o parque de computação científica para sua rival. Em resposta a essa situação, em 1967 a IBM lançou o IBM 360/91, que possuía uma performance cerca de duas vezes maior que o CDC 6600. Essa máquina possuía unidades de execução separadas para operações com números reais e cálculo de endereçamento de memória (inteiro), as instruções eram executadas em paralelo através de arquitetura pipeline.

A corrida continuaria e em 1969 a Control Data lançava a série CDC 7600, com um desempenho cerca de duas vezes maior que o IBM 360/91. A disputa comercial trouxe muitos benefícios para a arquitetura de computadores. Em 1970 a IBM utilizaria o conceito de memória caché [Zuffo, 1978] [Tabak, 1990], que já teria sido utilizado desde o vagaroso ATLAS, e lança o IBM 360/195, superando mais uma vez a Control Data.

Ainda nas arquiteturas escalares, não poderíamos deixar de citar as máquinas da Amdahl corporation. Essa companhia foi fundada por Gene Amdahl, chefe da equipe de arquitetura da séria IBM 360. Amdahl desenvolveu computadores baseados na arquitetura IBM 360. Com isso, suas máquinas além de serem compatíveis com os periféricos IBM, também poderiam utilizar software e sistema operacional desenvolvidos para as máquinas IBM. Isso foi muito importante, pois nesse período os fabricantes tomavam as interfaces com dispositivos de entrada e saída como segredos industriais. Empresas como a Amdahl, quebraram esses segredos e contribuíram muito com a história da portabilidade [Bruno, 1995]. Um outro fator muito importante foi a utilização da nova tecnologia de integração LSI. Com isso a máquina AMDAHL 470V/6 era cerca de um terço do tamanho de sua equivalente a IBM 360/168.

\subsection{2 - ARQUITETURA PIPELINE VETORIAL}

Em 1972, Seymour Cray deixou a Control Data com o propósito de fundar sua própria empresa, a Cray Research. A principal meta dessa empresa era desenvolver o supercomputador mais rápido do mundo. Em apenas quatro anos a Cray estaria não apenas lançando o computador mais rápido do mundo, o CRAY-1 (1976), como também revolucionando a arquitetura dos supercomputadores e 
virando uma nova página na história da computação paralela. O CRAY-1 marcava um estágio evolucionário aos projetos CDC 6600 e CDC 7600 e através dele surgia um novo conceito em arquitetura, a arquitetura vetorial.

Em geral, os problemas científicos mais freqüentes, com grande demanda computacional, realizam de algum modo operações com matrizes ou vetores. A estratégia de paralelismo da arquitetura vetorial parte exatamente desse princípio. $\mathrm{Na}$ arquitetura vetorial, diversos elementos de processamento são replicados e arranjados de modo a favorecer o processamento de estruturas de dados vetoriais. Esses elementos são controlados por uma única unidade de controle, e muitas vezes com uma única instrução podem ser feitas operações em vetores inteiros.

A Figura 2.4 apresenta um esquema genérico de uma arquitetura vetorial. Neste modelo, é apresentada uma arquitetura vetorial real, onde os elementos são realmente replicados. Na prática, a idéia da arquitetura vetorial verdadeira é transposta para pipeline. Com o pipeline os elementos não são replicados realmente, ocorrendo então paralelismo temporal ao invés de espacial [Almasi \& Gottlieb, 1994].

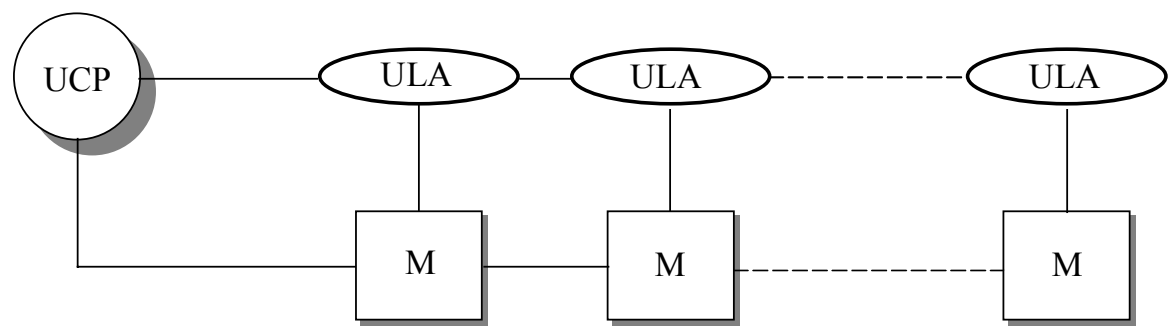

UCP - Unidade Central de Processamento e de Controle

Fig. - 2.4 - Arquitetura Vetorial.

Em relação ao software, o programador pode perceber diretamente o potencial da arquitetura vetorial através das instruções. A arquitetura vetorial permite que ocorram instruções voltadas para vetores, que possam operar diretamente através desses sem a necessidade de indexadores.

A Figura 2.5 apresenta uma comparação entre dois códigos para multiplicação de matrizes com 100 elementos, escritos em Fortran. No código para máquinas seriais, podemos observar a multiplicação realizada a partir de uma 


\section{CAPÍTULO 2}

estrutura de laço (loop), que incrementa o indexador dos vetores. Através de uma máquina vetorial, em uma única instrução pode ser realizada essa operação, como podemos observar no código paralelo, escrito em Fortran 90 [Almasi \& Gottlieb, 1994].

\begin{tabular}{||cc||}
\hline Código em Fortran seqüencial & $\begin{array}{c}\text { Código em Fortran 90, otimizado } \\
\text { para máquinas vetoriais }\end{array}$ \\
$\mathrm{A}(1: 100)=\mathrm{B}(1: 100){ }^{*} \mathrm{C}(1: 100)$
\end{tabular}

Fig. - 2.5 - Comparação entre códigos Fortran.

Embora o CRAY-1 tenha marcado a era das máquinas vetoriais, existiram outras duas máquinas anteriores ao CRAY-1, o CDC STAR 100 e o TIASC (Texas Instruments Advanced Scientific Computer).

O projeto da STAR 100 iniciou-se em 1967, porém apenas em 1973, após um processo de gestação de seis anos, foi desenvolvida uma STAR 100 operacional. Embora utilizasse uma arrojada arquitetura pipeline voltada para cálculos vetoriais, a STAR 100 foi implementada utilizando memória de núcleo magnético, uma tecnologia anterior às memórias de semicondutores. Devido ao atraso tecnológico, o acesso à memória era demasiadamente lento comparado com as memórias semicondutoras, o que fazia com que o seu desempenho se equiparasse ao das máquinas seqüenciais de uso geral contemporâneas. Apenas em vetores muito longos, da ordem de centenas a milhares de elementos, e com o código muito bem elaborado, o STAR era mais rápido que seus contemporâneos de uso geral. Com isso, seu projeto foi um completo fracasso, não ocorrendo nenhuma venda comercial da máquina (apenas foram vendidas quatro máquinas que haviam previamente sido encomendadas pelo governo americano).

Fato semelhante aconteceu com o TIASC. Seu projeto iniciou-se em 1966, porém apenas em 1973 estava operacional. Por ter sido projetado com uma tecnologia obsoleta, não possuía um bom desempenho e tornou-se um fracasso comercial. A Texas Instruments não deu continuidade ao projeto de máquinas vetoriais e deste modo não houve prosseguimento ao TIASC.

No entanto, o projeto STAR foi completamente reconstruído em tecnologia LSI e entrou em 1979 novamente no mercado com o nome de CYBER203E, que após pequenas alterações ficou conhecido como CYBER205 (Figura 2.6). Essa 
máquina tornou-se competitiva com o CRAY-1, embora tenha sido lançada três anos após o lançamento daquele.

Embora o CYBER205 seja uma máquina vetorial, sua arquitetura possui uma estratégia para adaptação de recursos de máquina genérica. Enquanto o CRAY-1 possuía registradores vetoriais e também uma arquitetura totalmente otimizada para o cálculo vetorial, o CYBER 205 processava os vetores diretamente da memória, e sua estrutura pipeline podia ter características de uso geral.

Tanto o CRAY-1 quanto o CYBER 205 deram continuidade a sua revolucionária arquitetura vetorial, e seguiram caminhos semelhantes de evolução, através da replicação de processadores. O CYBER 205 foi base para o supercomputador ETA-10, lançado em 1986. O ETA-10 foi a máquina mais rápida de sua época, possuía uma performance de pico de $10 \mathrm{Gflop} / \mathrm{s}$ (flop/s - operações com ponto flutuante por segundo).

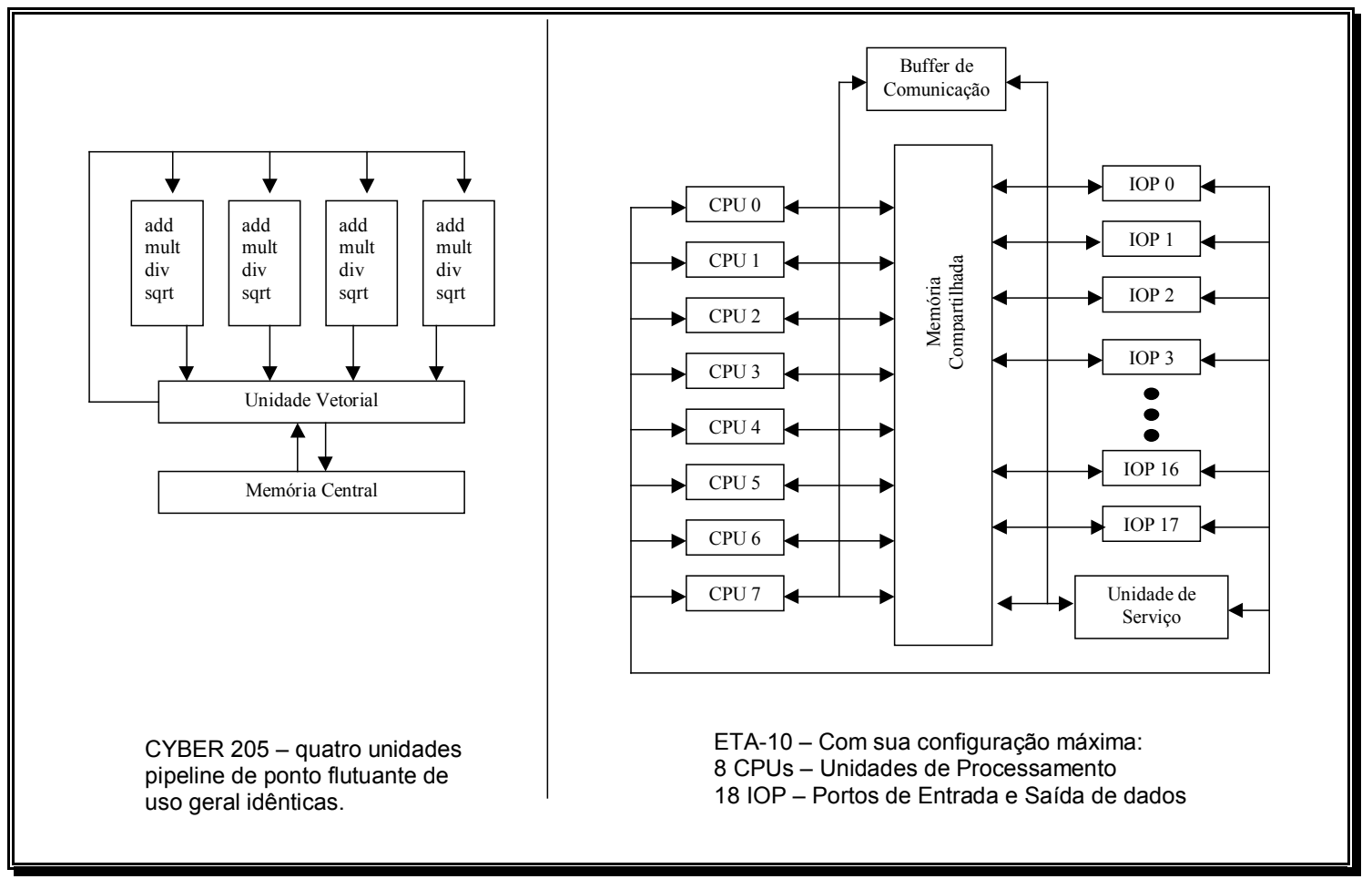

Fig. - 2.6 - Diagramas das arquiteturas dos computadores Cyber205 e ETA-10.

A Figura 2.6 apresenta um diagrama da arquitetura do ETA-10. O ETA-10 podia possuir 2, 4, 6 ou 8 unidades de processamento, onde cada um desses processadores possuía a mesma arquitetura do Cyber-205, cuja arquitetura também é apresentada na Figura 2.6. O ETA-10 podia possuir também de 2 a 18 portos de entrada e saída, através dos quais era possível a comunicação com 
periféricos padrão, como discos, tapes e rede, e uma memória compartilhada de 64 , 128, 192 ou 256 Mwords (64-bits).

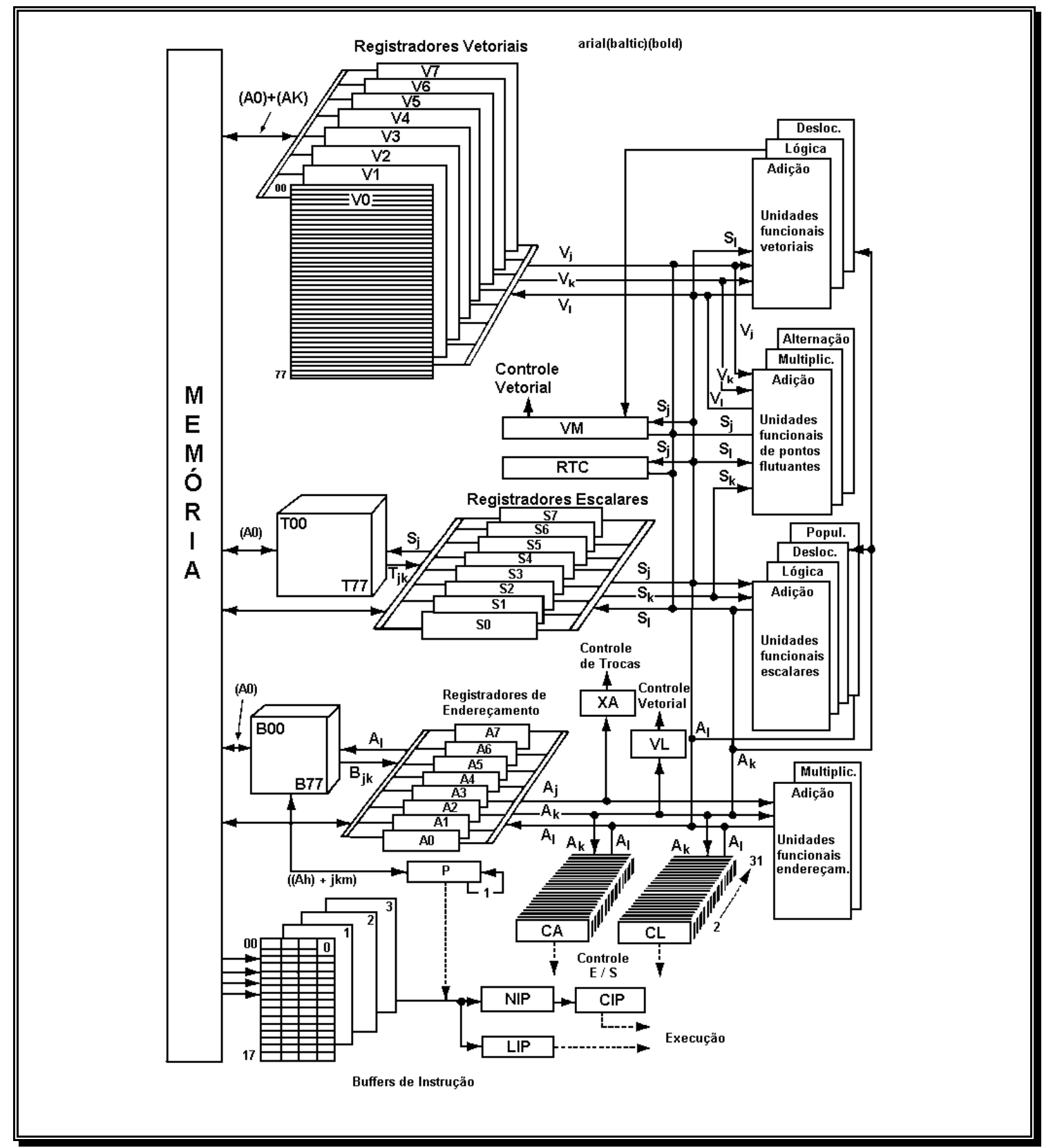

Fig. - 2.7 - Diagrama de arquitetura do computador CRAY - 1.

O CRAY-1 foi a base para a evolução da família de computadores CRAY. A Figura 2.7 apresenta um diagrama da arquitetura do CRAY - 1, onde podemos observar os registradores específicos para vetores, e as pipelines assim como toda sua estrutura vetorial. Os primeiros modelos baseados no CRAY-1 foram o CRAY $\mathrm{X}-\mathrm{MP}$ e o CRAY-2. Ambos, do mesmo modo que o ETA-10, seguiram o passo de 
multiprocessamento, e multiplicaram seu poder replicando os processadores. O CRAY X-MP foi lançado com dois processadores em 1982 e a versão com quatro processadores em 1984.

A Figura 2.8 apresenta o arranjo esquemático de um CRAY X-MP, com sua versão de 2 processadores. Como podemos observar, o CRAY X-MP nada mais é do que a duplicação de recursos computacionais do CRAY-1, uma vez que esse possui dois processadores CRAY-1. É importante observar que os computadores Cray X-MP, Cray 2 e Eta-10 são exemplos de arquitetura MIMD, e foram aqui apresentados apenas para elucidar a evolução de sua família. Porém os núcleos desses permanecem como bons exemplos de arquitetura SIMD (arquitetura vetorial).

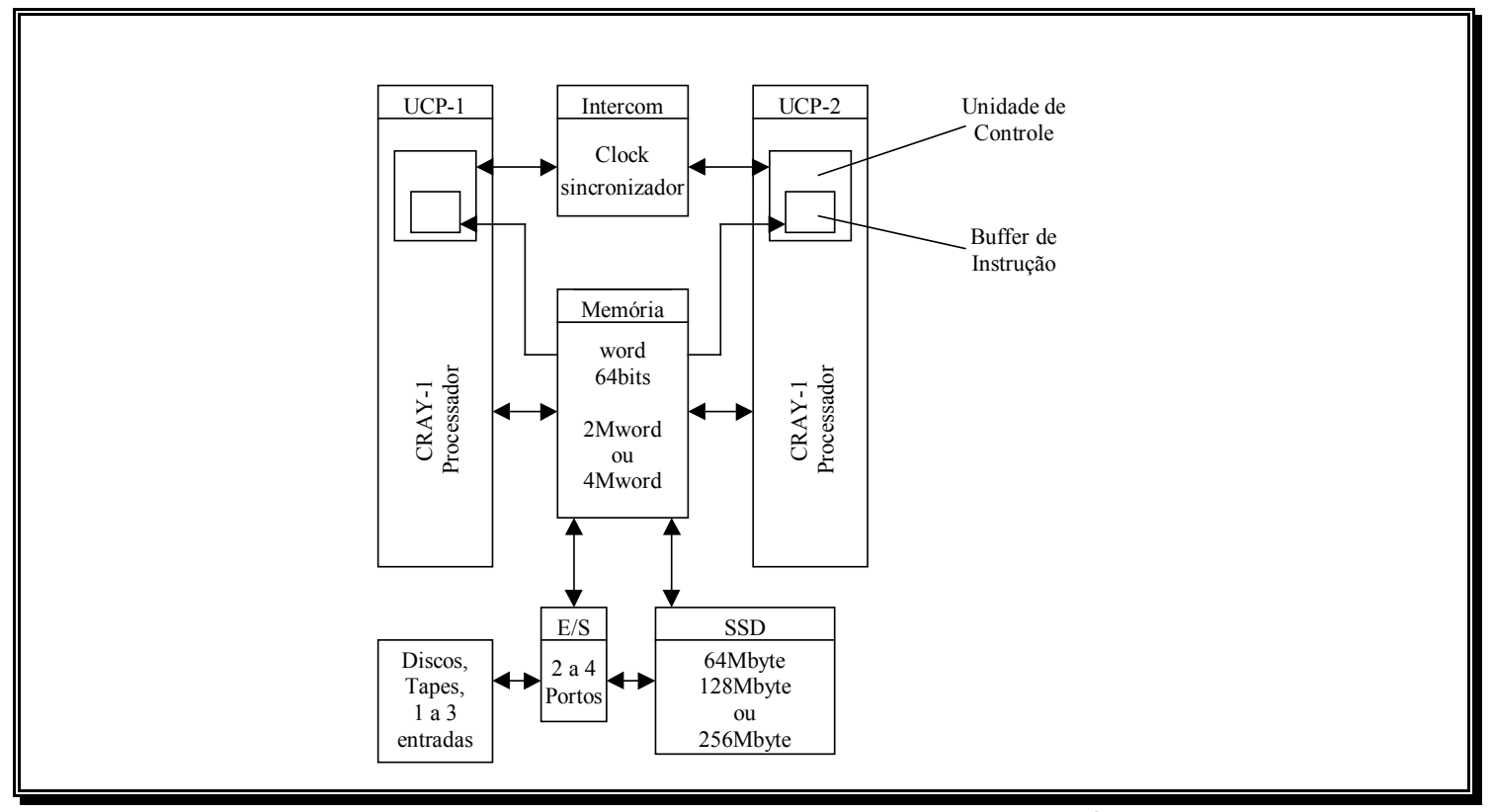

Fig. - 2.8 - Diagrama de arquitetura do computador CRAY X-MP/2.

O CRAY-2 também seguiu a mesma linha evolutiva do CRAY X-MP, porém foi seu caráter tecnológico que recebeu maior destaque em seu projeto (em comparação ao CRAY X-MP). A compactação e a utilização de processadores com alta freqüência foram suas principais características. Devido a esses fatores, o CRAY-2 gerava $195 \mathrm{~kW}$, que era aproximadamente a mesma quantia gerada pelo CRAY X-MP, porém sua dimensão reduzida restringia a dissipação de toda essa energia. Para solucionar esse problema, um sofisticado sistema de refrigeração foi adotado, onde todos os circuitos dos processadores, memória e fontes ficavam imersos num líquido inerte e dielétrico de fluorcarbono. A Figura 2.9 apresenta o 
computador CRAY-2. Seu extravagante sistema de refrigeração proporcionava um aspecto inédito ao computador. Seus circuitos podiam ser observados imersos em líquido borbulhante através do vidro, dando um ar fictício ao computador.

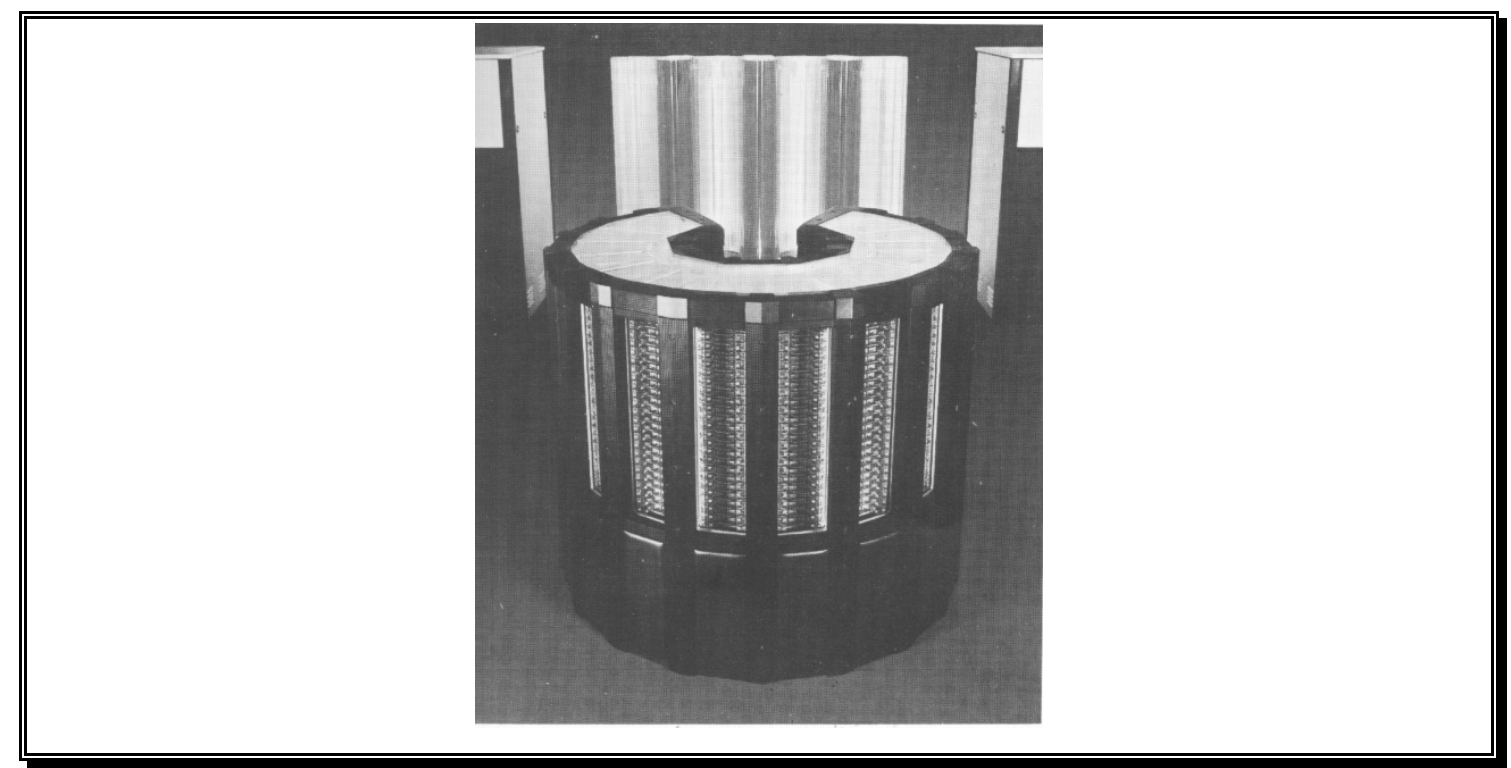

Fig. - 2.9-CRAY 2.

Atualmente a CRAY Research faz parte da Silicon Graphics, dando uma ênfase maior à visualização científica e computação gráfica na utilização das máquinas científicas CRAY.

\subsection{3 - ARQUITETURA MATRICIAL}

Diferentemente da arquitetura vetorial, que apresentava apenas uma evolução lógica dos computadores seqüenciais voltada para o cálculo vetorial, a arquitetura matricial marcou uma mudança radical na concepção da computação paralela. A arquitetura matricial nasceu basicamente a partir de um único artigo de 1962 [Hockney \& Jesshope, 1988], intitulado "The SOLOMON Computer", cujo nome SOLOMON é um acrônimo derivado de "Simultaneous Operation Linked Ordinal Modular Network". O trabalho descreve uma matriz bidimensional de $32 \mathrm{x}$ 32 elementos de processamento, onde cada um desses elementos contém uma memória de 128 posições de 32 bits e uma unidade aritmética. Toda essa estrutura está sob o controle de uma única unidade de controle e fluxo de instrução. Embora SOLOMON tenha sido a origem das arquiteturas matriciais, houve ainda um artigo anterior no qual foi inspirado, o computador espacial, publicado por Unger em 1958 
[Unger, 1958].

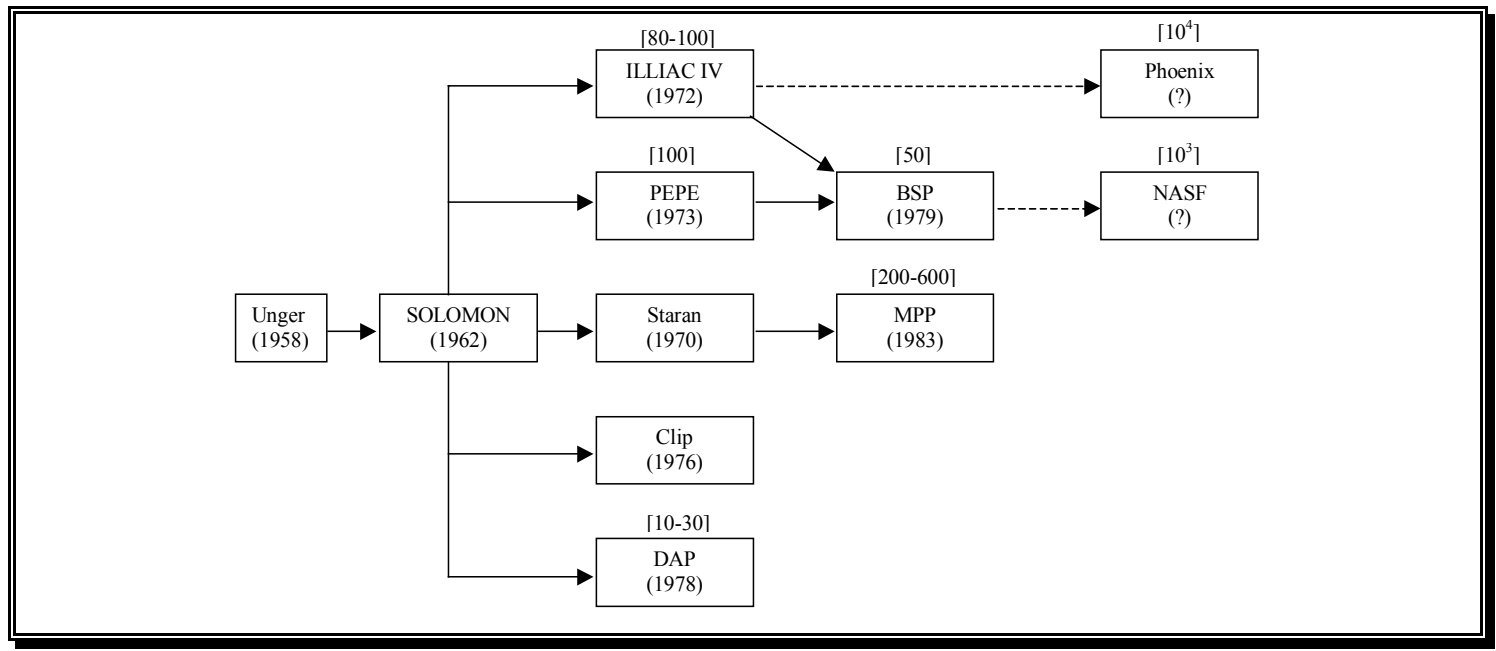

Fig. - 2.10 - Família dos computadores de arquitetura matricial. Os números em conchetes são as performances máximas estimadas em mflops.

Embora o conceito SOLOMON tenha sido uma revolução em arquitetura de computadores, seu projeto nunca foi construído exatamente como descrito no artigo de 1962. Porém deu origem aos clássicos computadores ILLIAC IV, Burroughs PEPE, Goodyear Aerospace STARAN e ICL DAP entre outros (ver Figura 2.10).

Em 1966, a Universidade de Illinois, contratada pelo departamento de defesa americano (ARPA), iniciou o projeto de um computador baseado no SOLOMON. Nascia então o clássico ILLIAC IV (Figura 2.11 e 2.12), que possuía quatro quadrantes com uma unidade de controle e interpretação de instruções para os 64 elementos de processamento de ponto flutuante. Cada um dos elementos de processamento tinha uma memória com 2000 posições de 64 bits. Cada elemento de processamento e memória, em cada quadrante, eram conectados por uma matriz de $8 \times 8$, e os quadrantes eram conectados por um barramento paralelo, o qual era também responsável pela interface de uma unidade de disco, que era a unidade secundária do sistema. Embora o projeto inicial possuísse quatro quadrantes, o ILLIAC IV foi construído utilizando apenas um, pela Burroughs Corporation 1969-73, conforme apresenta a Figura 2.11. 


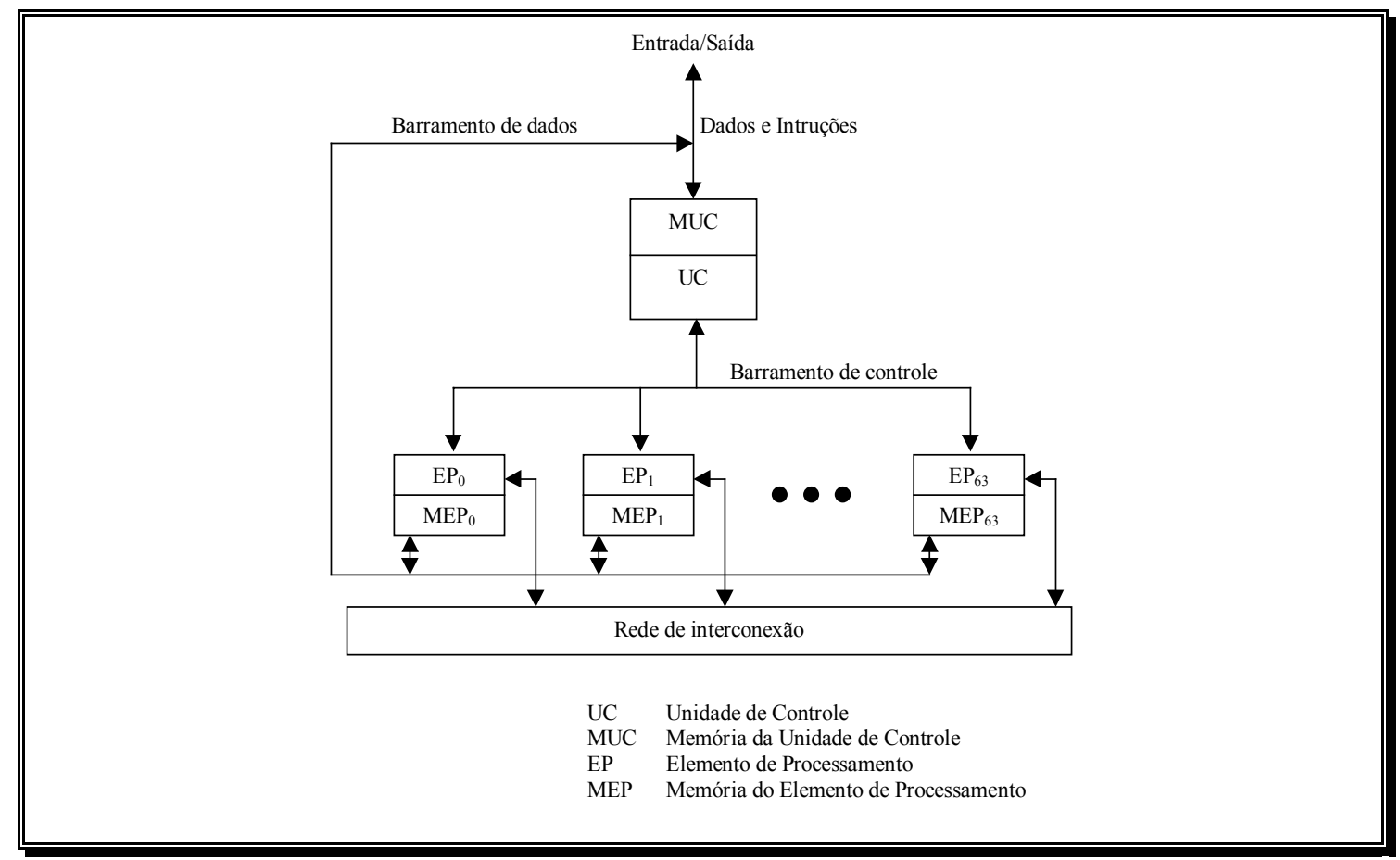

Fig. - 2.11 - Diagrama de arquitetura do computador ILLIAC IV.

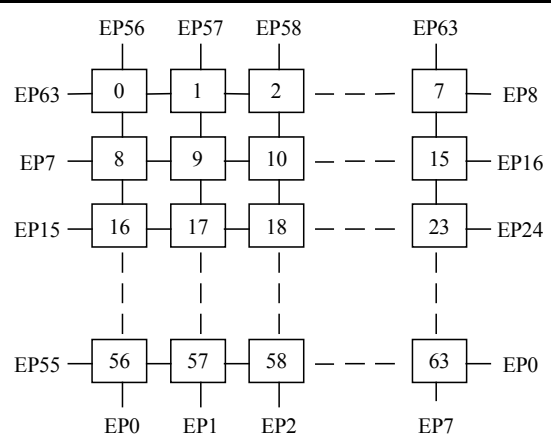

Fig. - 2.12 - Configuração da rede de elementos de processamento (EP).

Pela primeira vez despontava a problemática do software paralelo. Um amplo investimento em software fez com que o ILLIAC IV possuísse seu próprio sistema operacional, assim como quatro linguagens de programação específicas ( TRANQUIL e GLYPNIR - derivadas do ALGOL, ACTUS - derivada do PASCAL e CFD FORTRAN).

O projeto ILLIAC IV foi seguido pelo PEPE, computador encomendado à Burroughs com finalidades militares, e ao computador científico comercial BSP, e ainda ao Phoenix, projeto da NASA para substituir o ILLIAC IV. Classificado como múltiplo-SIMD, o Phoenix possuía basicamente 16 máquinas ILLIAC IV, onde cada uma executava seu próprio fluxo de instruções, sob o controle de uma única 
unidade de controle.

A arquitetura matricial marcou era na computação paralela, tornando possível a incorporação de muitas unidades de processamento em máquinas (milhares). Contribuiu também para a pesquisa em software paralelo, que talvez venha a ser o maior desafio da computação paralela.

\subsection{4 - ARQUITETURA MIMD}

O termo MIMD, derivado do inglês "Multiple Instructions Multiple Data", é proveniente do clássico artigo de taxonomia de computadores, proposto por Flynn [Flynn, 1966]. Nas arquiteturas anteriores à MIMD, somente algumas partes da UCP são replicadas, ou ainda, são replicados pseudo-processadores, (ex: elementos de processamento da arquitetura matricial), onde existe um controle único externo, que em geral é ainda responsável pelo fluxo de instruções. $\mathrm{Na}$ arquitetura MIMD no entanto, UCPs (unidade central de processamento) são inteiramente replicadas, e em certos casos computadores inteiros. Deste modo a arquitetura MIMD é verdadeiramente uma coleção de computadores formando uma única máquina paralela.

A arquitetura MIMD despontou no início da década de 80 , devido à queda de preço dos microprocessadores, assim como ao aumento da performance desses a partir da tecnologia VLSI. A arquitetura MIMD demonstrou ser a tecnologia integradora e evolutiva das arquiteturas SIMD. A maioria do prosseguimento de projeto das tecnologias vetoriais e matriciais acabaram por se tornar arquiteturas MIMD replicadoras de SIMD. Como exemplos, temos as arquiteturas Phoenix, Cray 2, Cray X-MP e Eta 10, descritas anteriormente como SIMD (modo didaticamente evolutivo), mas que na verdade são máquinas MIMD paralelizando SIMD. A arquitetura MIMD amadureceu, chegando até os dias de hoje, onde é a mais utilizada tanto em pesquisa quanto comercialmente.

O maior desafio para os projetos de arquiteturas MIMD está exatamente na comunicação entre os computadores. Na maior parte dos casos, os processadores utilizados são comerciais de larga difusão e de uso genérico, porém a consolidação da tendência MIMD fez com que surgissem processadores específicos para projetos de máquinas MIMD. Entre eles podemos citar a linha Transputer da Inmos e os processadores de processamento de sinais da Texas Instruments.

A partir da comunicação ou integração dos processadores, podemos 
classificar a arquitetura MIMD basicamente em memória compartilhada e memória distribuída, conforme apresenta a Figura 2.13. A diferença básica entre os dois modelos é que enquanto os sistemas de memória compartilhada utilizam uma única memória acessível a todos os processadores, e a utilizam para trocar informações, nos sistemas de memória distribuída, por outro lado, cada um dos processadores possui sua própria memória, inacessível para os demais, e utilizam troca de mensagens via rede ou barramento para efetuar a comunicação.

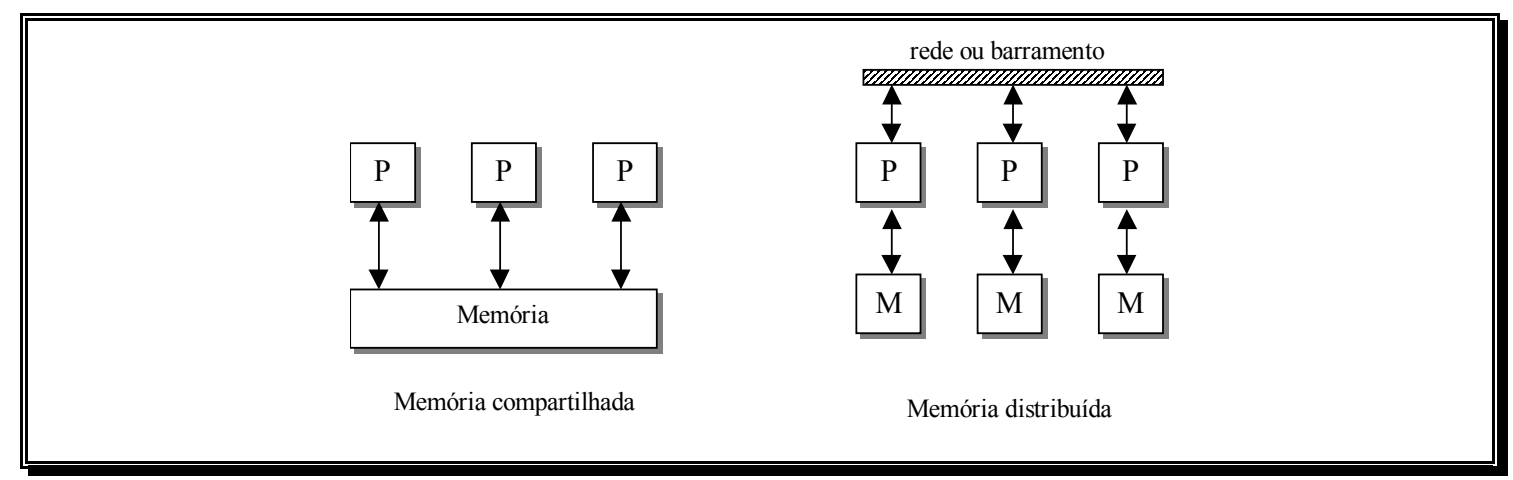

Fig. - 2.13 - Memória compartilhada versus memória distribuída.

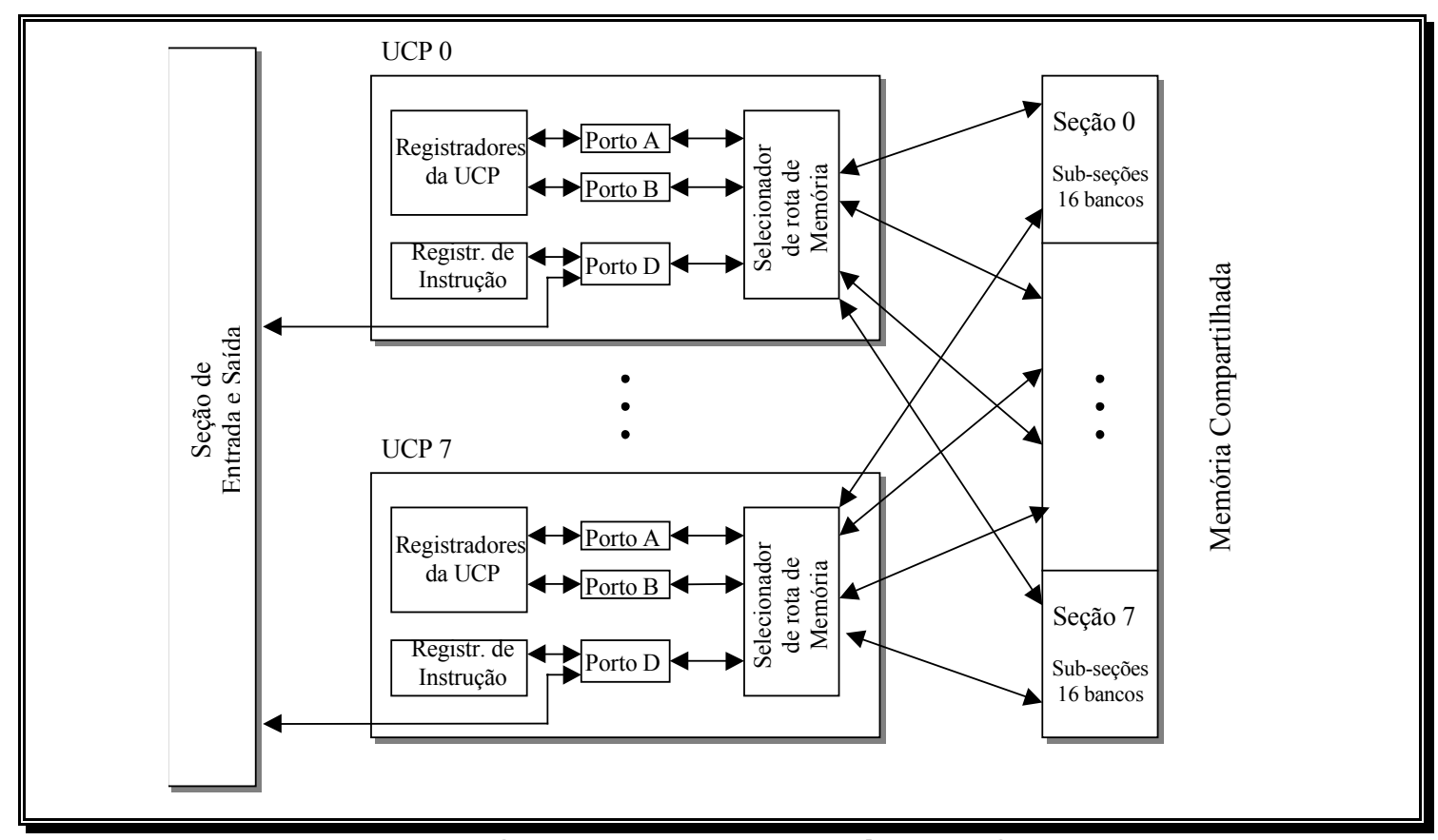

Fig. - 2.14 - Organização da memória do Cray - J90.

Entre as máquinas MIMD de memória compartilhada atuais podemos citar: as séries $\mathrm{J90}$ e T90 da Cray, a AlphaServer da Digital, a série Hitachi S3800, o NEC SX-4, a Starfire E10000 da Sun, Connection Machine CM-5, etc. A Figura 2.14 
apresenta um diagrama da arquitetura da máquina Cray - J90 uma típica MIMD de memória compartilhada.

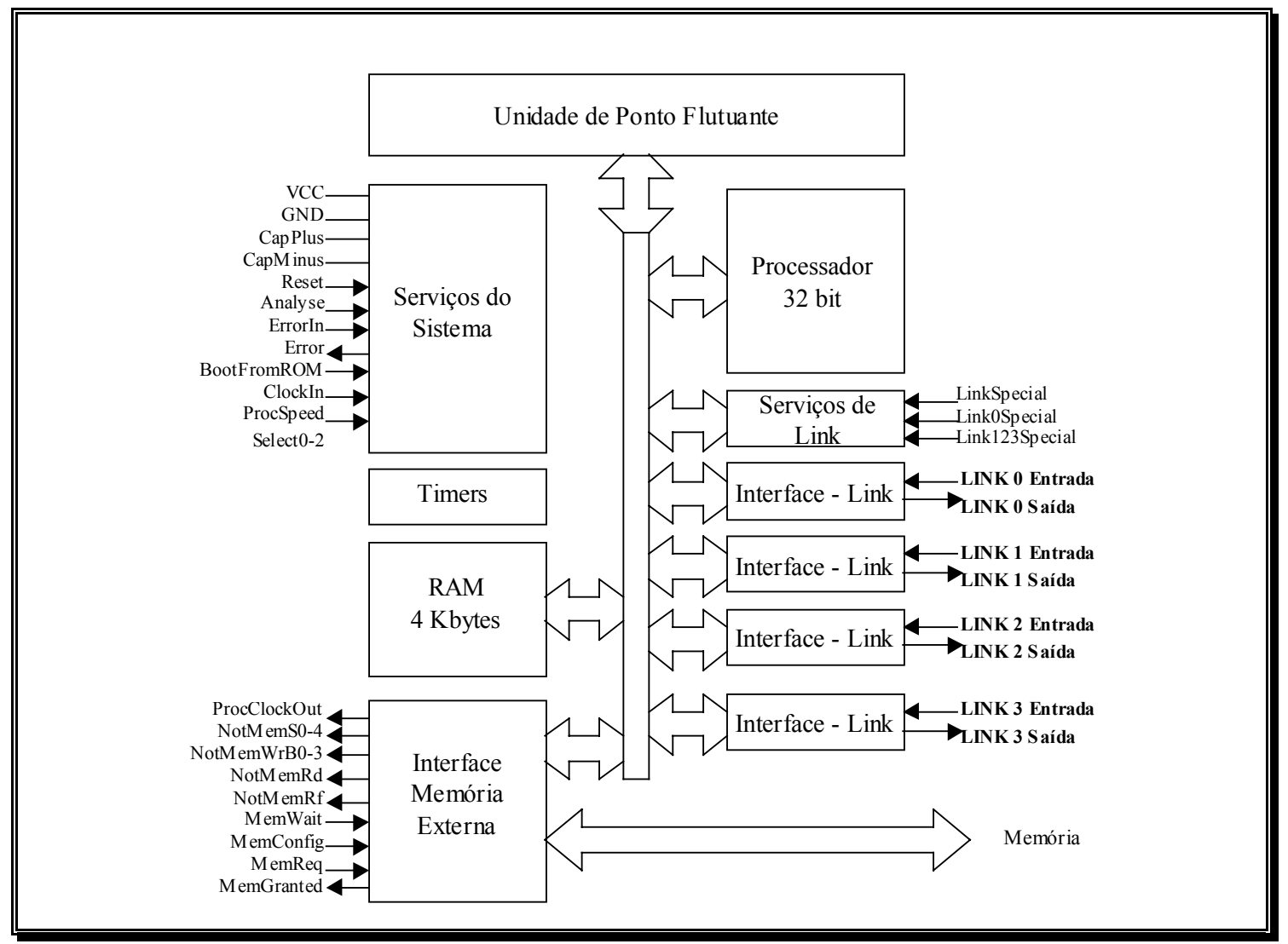

Fig. - 2.15 - Diagrama em blocos do processador Transputer IMS T800.

As máquinas MIMD de memória distribuída, obtiveram uma atenção maior a partir da metade da década de 80. A arquitetura MIMD de memória distribuída, praticamente começou com um projeto Cosmic Cube da Caltech. Esse projeto introduziu toda a pesquisa em torno de redes de conexão de processadores (hipercubos) [Almasi \& Gottlieb, 1994]. O Cosmic Cube foi uma máquina baseada no processador 8086 e seu coprocessador de ponto flutuante 8087 (famosos devido aos microcomputadores pessoais), que integrava 64 pares de processadores (8086 e 8087), conectados com arquitetura de hipercubo [Hockney \& Jesshope, 1988]. A partir de 1985, com o lançamento do Transputer (Inmos), um processador destinado ao desenvolvimento de arquiteturas paralelas, houve uma grande difusão da pesquisa e utilização de arquitetura MIMD. Devido ao fato de ser especificamente voltado ao desenvolvimento de sistemas paralelos, o Transputer tornava os projetos paralelos simples e com custos competitivos. Além de contar com uma série de ferramentas e linguagens que realizavam o suporte de programação. A Figura 2.15 apresenta o diagrama do processador Transputer 
[Inmos, 1988].

Dentre o universo das máquinas MIMD distribuídas podemos citar: Intel iPSC, Intel Paragon, Cray T3E, Avalon A12, nCUBE 2S, As máquinas baseadas em Transputer (ex: IBM - Victor), IBM 9076 SP2, etc.

\subsection{5 - COMPUTAÇÃO DISTRIBUÍDA}

No final da década de 80 , devido ao desenvolvimento e proliferação da tecnologia de redes de computadores e do mesmo modo à diminuição do custo dos microcomputadores, surgiu uma nova arquitetura paralela denominada de Computação Distribuída. Ao invés de desenvolver hardware específico, o conceito de Computação Distribuída utiliza computadores padrão (ou não) conectados por rede de computadores (ethernet ou outra), ficando todo o mecanismo de paralelização sob a responsabilidade das camadas de software [Tanenbaum, 1990], sendo essa em nível de sistema operacional, através de sistemas operacionais distribuídos [Tanenbaum, 1995], ou ainda através de ferramentas de troca de mensagens tais como PVM [Geist et al., 1996], MPI [Pacheco, 1997] ou ainda CVMP apresentada nesta tese.

Embora a velocidade de comunicação das redes de computadores seja muito mais lenta do que através dos mecanismos desenvolvidos em hardware, a simplicidade e baixo custo fizeram com que os Sistemas Distribuídos viessem a se tornar a mais difundida utilização de arquiteturas paralelas, somando a utilização comercial e científica [Almasi \& Gottlieb, 1994].

Segundo a classificação de Flynn [Flynn. 1972], a Computação Distribuída é considerada MIMD de memória distribuída [Almasi \& Gottlieb, 1994], seguindo a mesma heurística de arquitetura e software. Assim como ocorrem em algumas máquinas de arquitetura MIMD, que podem ser compostas por elementos de processamento com arquiteturas paralelas diferentes, como por exemplo o CRAY J90 (MIMD com processadores SIMD), os sistemas distribuídos podem integrar um único sistema e possuir diversas arquiteturas paralelas diferentes, trabalhando juntas. Além de possuir tal característica heterogênea, os Sistemas Distribuídos ainda podem possuir um número de unidades de processamento variáveis, caracterizando sua utilização em sistemas tolerantes a falha. Para caracterizar um aglomerado de estações como Sistema Distribuído (Computação Distribuída), basta que exista um mecanismo de integração das máquinas e que através desse 
mecanismo de troca de mensagens sejam capazes de realizar uma mesma tarefa (ou diferentes partes de uma mesma tarefa). O número de máquinas (elementos de processamento) de um Sistema Distribuído varia muito, indo desde 2 a mesmo milhares de máquinas. A Figura 2.16 apresenta um diagrama de um Sistema Distribuído heterogêneo, onde juntos podem operar estações de trabalho de diversas plataformas diferentes (PCs, estações de trabalho RISC) assim como supercomputadores MIMD e ou SIMD, conectados por rede.

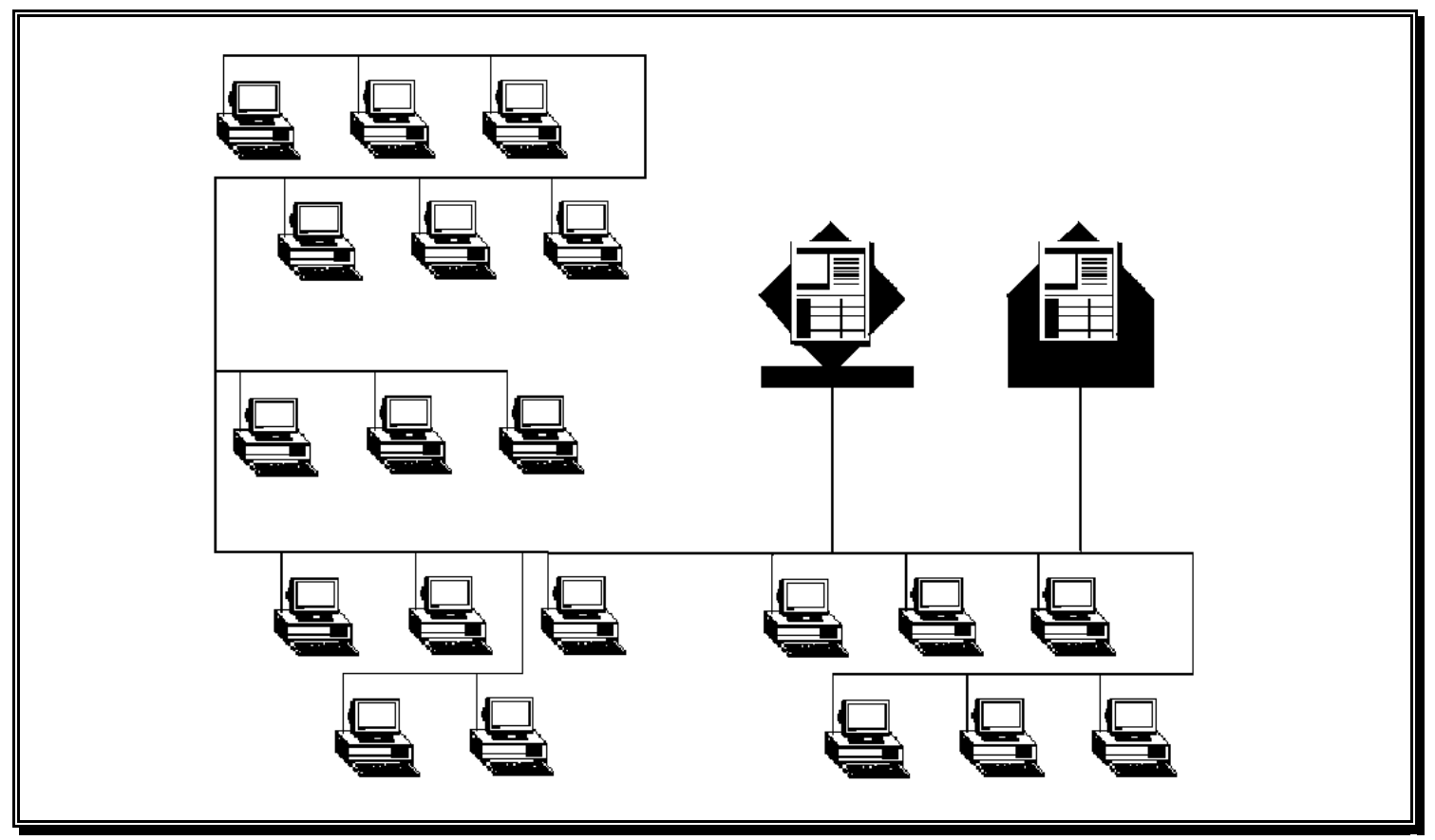

Fig. - 2.16 - Sistema Distribuído Heterogêneo.

\section{6 - TAXONOMIA DE COMPUTADORES}

Anteriormente, descrevemos uma série de tecnologias apresentadas com sua evolução no tempo. Obviamente, não abordamos todo o universo das arquiteturas paralelas, apenas traçamos um breve perfil da evolução da computação paralela, com o intuito de formar bases para as noções de arquitetura de computadores requeridas nesta tese.

As inúmeras possibilidades de organização dos computadores, assim como a diversidade de processadores, geram a necessidade da classificação dos computadores, a fim de encontrarmos famílias as quais podem ser agrupadas, melhor estudadas e comparadas. Existem inúmeras propostas encontradas na literatura para classificar as diferentes arquiteturas e organização dos 


\section{CAPÍTULO 2}

computadores, podemos citar entre elas: Flynn [Flynn, 1966], Feng [Hwang et al., 1984], Händler [Hwang et al., 1984], Gajski [Amorin et al.,1988], Shore [Hockney \& Jesshope, 1988], Estrutural [Hockney \& Jesshope, 1988], Kuck [Almasi \& Gottlieb, 1994], Treleaven [Almasi \& Gottlieb, 1994], Duncan [Duncan, 1990], etc. Nesta seção vamos apresentar três delas: classificação de Flynn, taxonomia estrutural de Hockney e classificação de Duncam.

A classificação de Flynn é a mais divulgada pela literatura, embora seja bastante antiga, originária a partir de um artigo de 1966. A tradição e a popularização tornaram-na a mais importante taxonomia de computadores, permanecendo a mais utilizada atualmente, mesmo com suas falhas e dúvidas [Bogni \& Marrone, 1991]. Devido à sua importância, trataremos esta classificação com maiores detalhes que as demais.

$\mathrm{Na}$ tentativa de realizar uma classificação bastante abrangente, foi proposta a taxonomia estrutural de Hockney. Esta classifica tanto os computadores (históricos) seqüenciais, quanto os paralelos (até os atuais). A maior característica da taxonomia estrutural é a sua diversidade de classes. Embora seja bastante abrangente, essa classificação é pouco conhecida e utilizada. Apresentaremos sucintamente a taxonomia estrutural na Seção 2.6.2.

Com o surgimento de novas tecnologias e com o decorrer de décadas de pesquisa houve uma diversificação das arquiteturas de computadores paralelos, muitas das quais não poderiam ser classificadas através da taxonomia clássica. Tendo em vista esse problema, Duncan propôs uma classificação extensiva à classificação de Flynn, através do artigo "A Survey of Parallel Computer Architectures" [Duncan, 1990]. Finalizaremos a seção Taxonomia de Computadores apresentando sucintamente a proposta de Duncan, na Seção 2.6.3.

\subsection{1 - CLASSIFICAÇÃO DE FLYNN}

O primeiro método de classificação de computadores foi inicialmente proposto por Flynn, em seu célebre artigo de 1966, intitulado "Very High Speed Computing Systems" [Flynn, 1966], mais tarde apresentado com maior formalidade, em 1972 [Flynn, 1972]. O método consiste nas possibilidades de combinação entre uma ou mais seqüências de instruções atuando sobre uma ou mais seqüências de dados.

O princípio básico do funcionamento de um processador é a busca de 
operandos na memória principal, seguindo da execução das instruções compostas por esses operandos e finalmente no armazenamento dos resultados obtidos na memória. Assim sendo, as etapas distintas associadas ao processamento de uma instrução constituem o ciclo de instruções. Deste modo um ciclo de instrução é composto por:

Encontrar o endereço da instrução

Buscar a instrução

Decodificar a instrução

Gerar os endereços referentes aos operandos

Executar a instrução

Armazenar os resultados

A visualização da seqüência da execução das instruções pode ser comparada a um fluxo ou corrente. O fluxo de instruções dirigi-se da memória para o processador. A partir da execução das instruções, são solicitados dados, armazenados na memória, cuja visualização pode igualmente ser comparada a um fluxo ou corrente (fluxo de dados). O fluxo de dados por sua vez, possui uma dupla corrente, indo e vindo da memória para o processador e do processador para a memória.

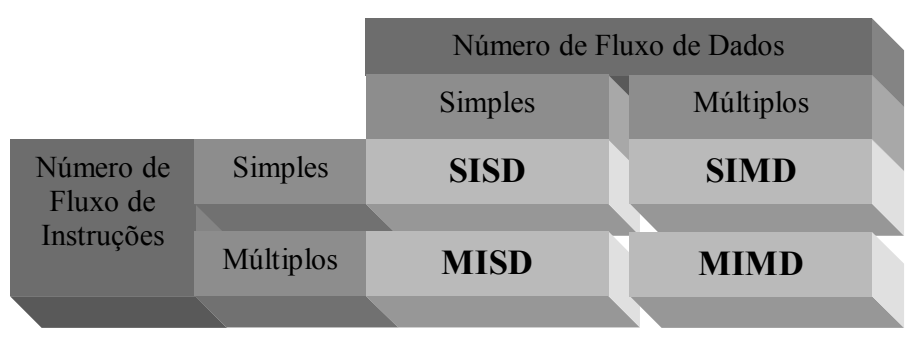

Fig. - 2.17 - Classificação de Flynn.

Baseado no fluxo de instruções e no fluxo de dados, Michael J. Flynn realizou uma classificação de computadores, sugerindo combinações de classes de fluxos de dados versus fluxo de instruções. A partir dessas combinações, Flynn sugeriu quatro classes de computadores: Um fluxo de instrução e um fluxo de dados - SISD (do inglês "Single Instruction stream Single Data stream"), um fluxo 
de instrução e múltiplos fluxos de dados - SIMD (do inglês "Single Instruction stream Multiple Data stream"), múltiplos fluxos de instrução e um fluxo de dados MISD (do inglês "Multiple Instruction stream Single Data stream") e múltiplos fluxos de instrução e múltiplos fluxos de dados - SISD (do inglês "Multiple Instruction stream Multiple Data stream"). (ver Figura 2.17).

Apresentaremos cada um dos casos a seguir, e um diagrama correspondente à arquitetura classificada. Em cada um dos diagramas mostrados serão apresentadas apenas três espécies de componentes de sistema: Unidade de Controle (UC), Unidade de Processamento (UP) e Memória (M) (Figuras 2.18, 2.19, 2.20 e 2.21).

Unidade de Controle (UC) - Responsável pela decodificação das instruções e pelo envio das instruções decodificadas ao processador.

Unidade de Processamento (UP) - Executa as instruções e armazena os resultados na memória.

Memória (M) - Armazena os dados.

Além dos componentes do sistema também serão apresentados os fluxos de dados (FD) e os fluxos de instruções (FI). Observando as Figuras 2.18, 2.19, 2.20 e 2.21, devemos notar que cada fluxo de instruções é gerado por uma unidade de controle independente.

\subsubsection{1 - SISD - UM FLUXO DE INSTRUÇÃO E UM FLUXO DE DADOS}

A classe SISD classifica as arquiteturas convencionais, ou de von Neumman, ou seja os computadores seqüenciais, que compõem a maioria do nosso parque atualmente. Embora a maioria dos microprocessadores atuais SISD possuam mais do que uma unidade funcional e pipeline de instrução [Gimarc \& Milutinovic, 1987], todas as suas unidades funcionais estão sob a supervisão de uma única unidade de controle, classificando-os deste modo como SISD (Figura 2.18). 


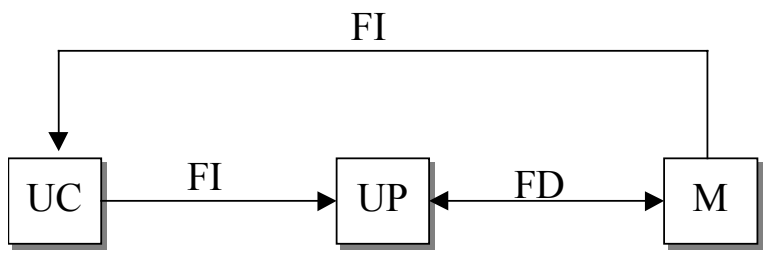

Fig. - 2.18 - Diagrama da arquitetura SISD.

2.6.1.2 - MISD - MÚlTIPLOS FLUXOS DE INSTRUÇÃO E UM FLUXO DE DADOS

A Figura 2.19 apresenta um diagrama conceptual da arquitetura MISD. Não existe nenhuma implementação real desse tipo de arquitetura, ocorrendo então uma falha de classificação do modelo de Flynn [Almasi \& Gottlieb, 1994] [Duncan, 1990].

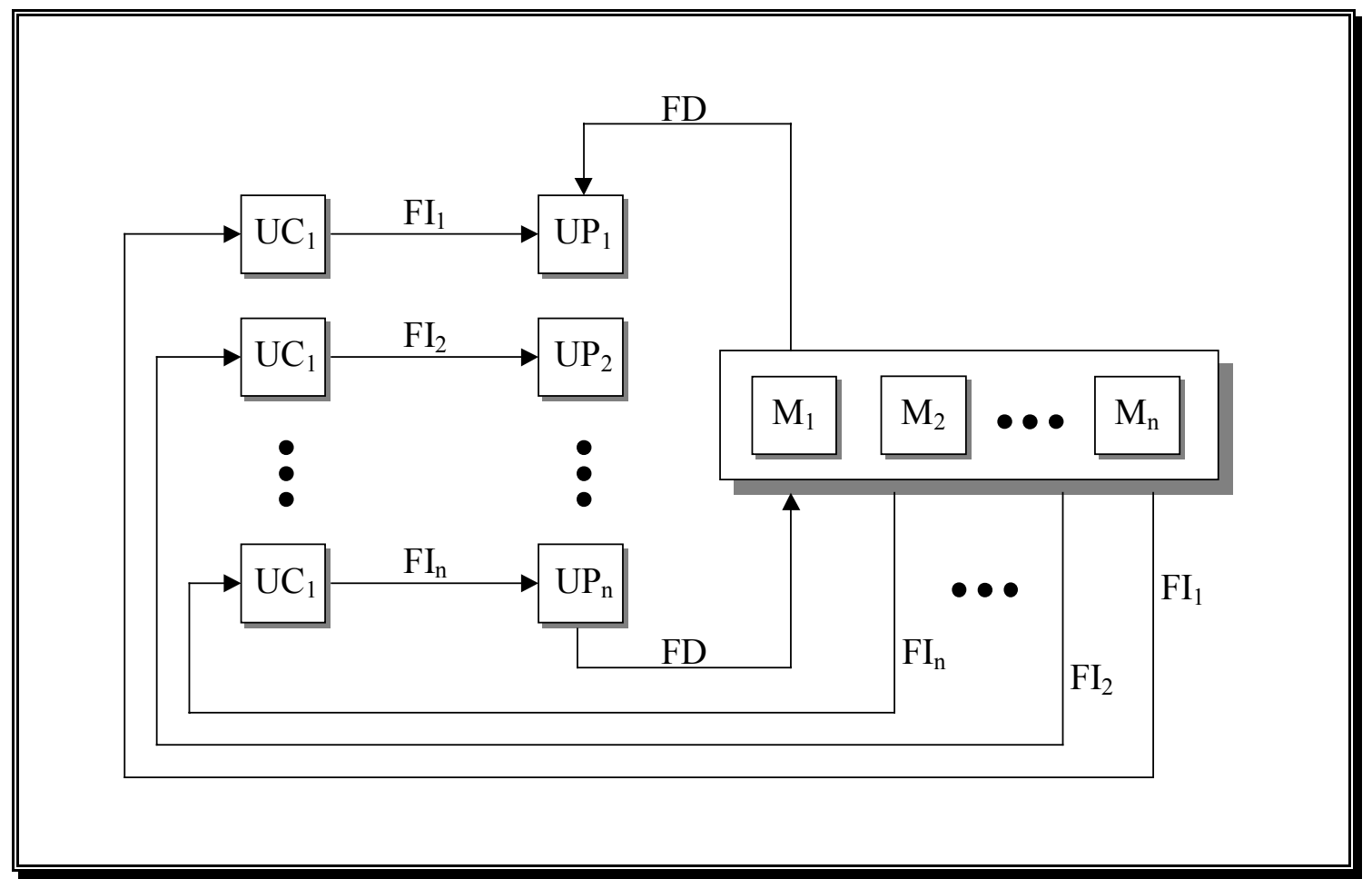

Fig. - 2.19 - Diagrama da arquitetura MISD. 
2.6.1.3 - SIMD - UM FLUXO DE INSTRUÇÃO E MÚLTIPLOS FLUXOS DEDADOS

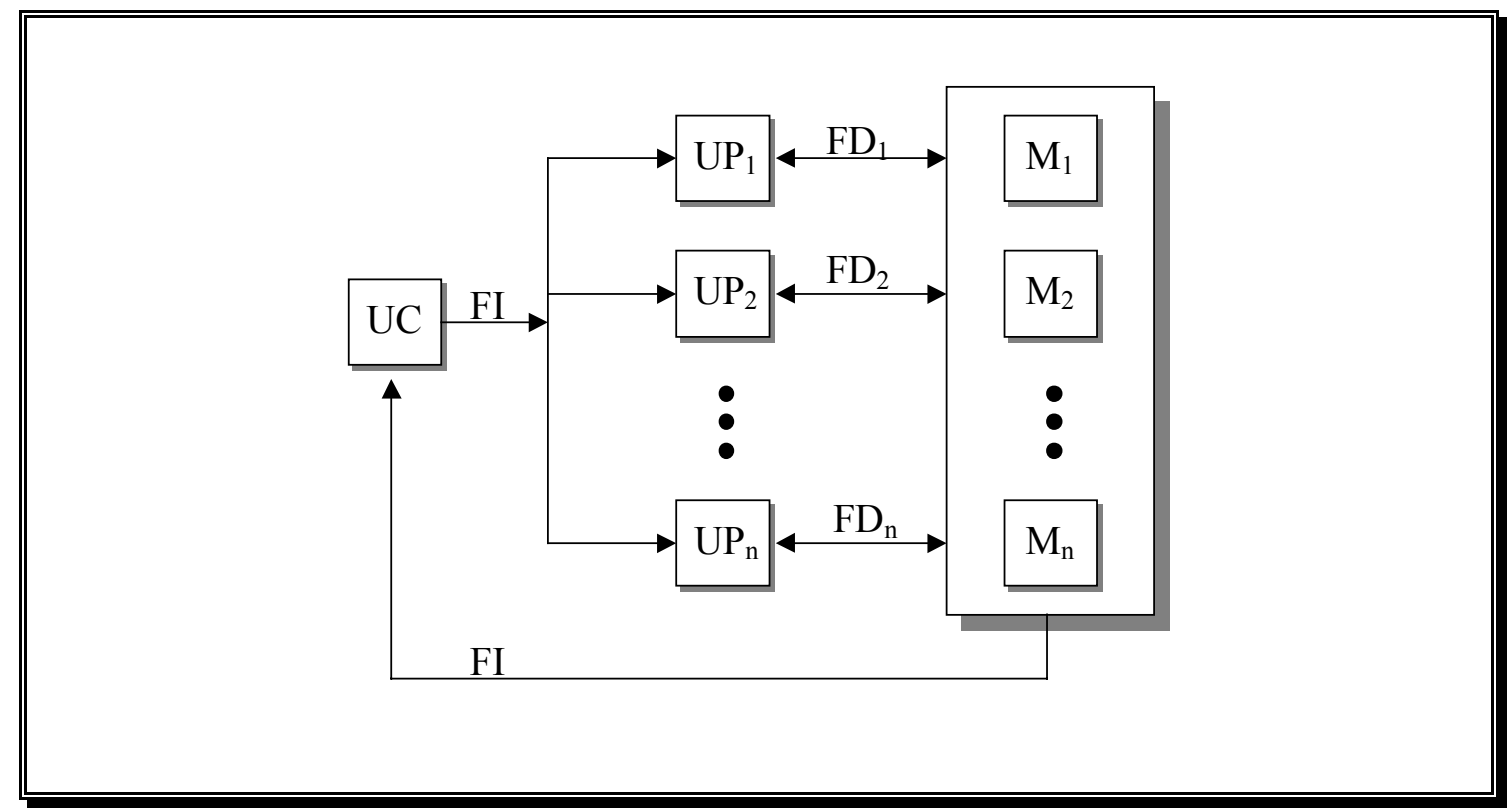

Fig. - 2.20 - Diagrama da arquitetura SIMD.

A classe SIMD corresponde aos computadores matriciais e vetoriais. Conforme podemos observar na Figura 2.20, existem muitos elementos de processamento sendo supervisionados por uma única unidade de controle. Todos os elementos de processamento recebem a mesma instrução, transmitida pela unidade de controle, porém operam as instruções sobre distintos fluxos de dados.

Na prática, a classificação SIMD levanta algumas dúvidas e polêmicas. $\mathrm{Na}$ literatura podemos encontrar alguns autores que classificam máquinas vetoriais pipeline (ex: Cray-1, Cyber-205) como SIMD [Almasi \& Gottlieb, 1994] [Hockney \& Jesshope, 1988], enquanto outros autores as classificam como SISD [Hwang et al., 1984] [Bogni \& Marrone, 1991]. 


\subsubsection{4 - MIMD - MÚlTIPLOS fLUXOS DE INSTRUÇÃO E MÚLTIPLOS FLUXOS DE DADOS}

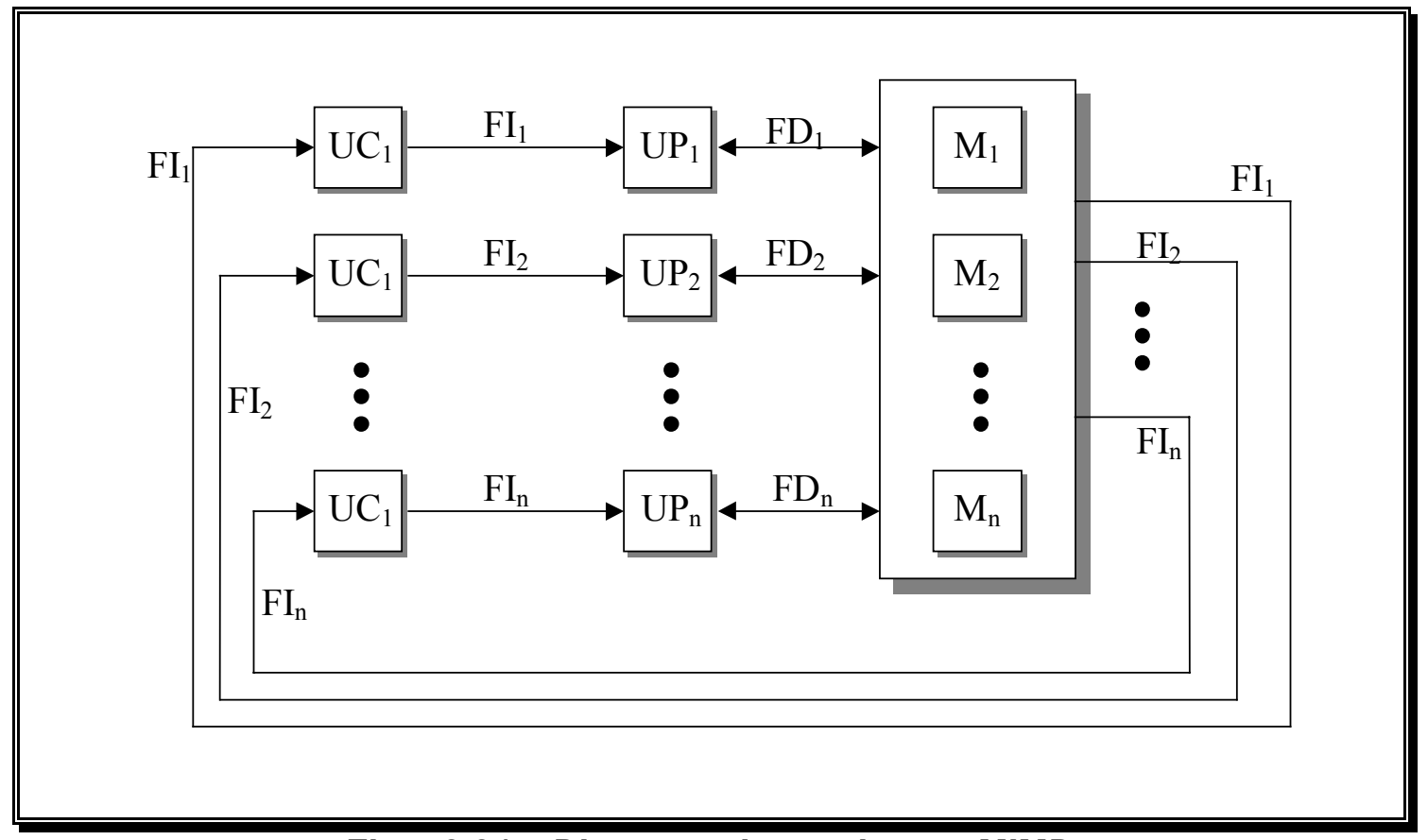

Fig. - 2.21 - Diagrama da arquitetura MIMD.

A Figura 2.21 apresenta um diagrama conceptual da arquitetura MIMD. A maioria dos sistemas paralelos atuais podem ser classificados nessa categoria, gerando deste modo uma sobrecarga a esta classe, que abrange tanto as máquinas multiprocessadores (memória compartilhada) quanto os sistemas multicomputadores (memória distribuída). Deste modo, segundo a organização da memória, a classe MIMD é diretamente dividida em MIMD memória compartilhada e MIMD memória distribuída (Figura 2.13). 


\subsection{2 - TAXONOMIA ESTRUTURAL}

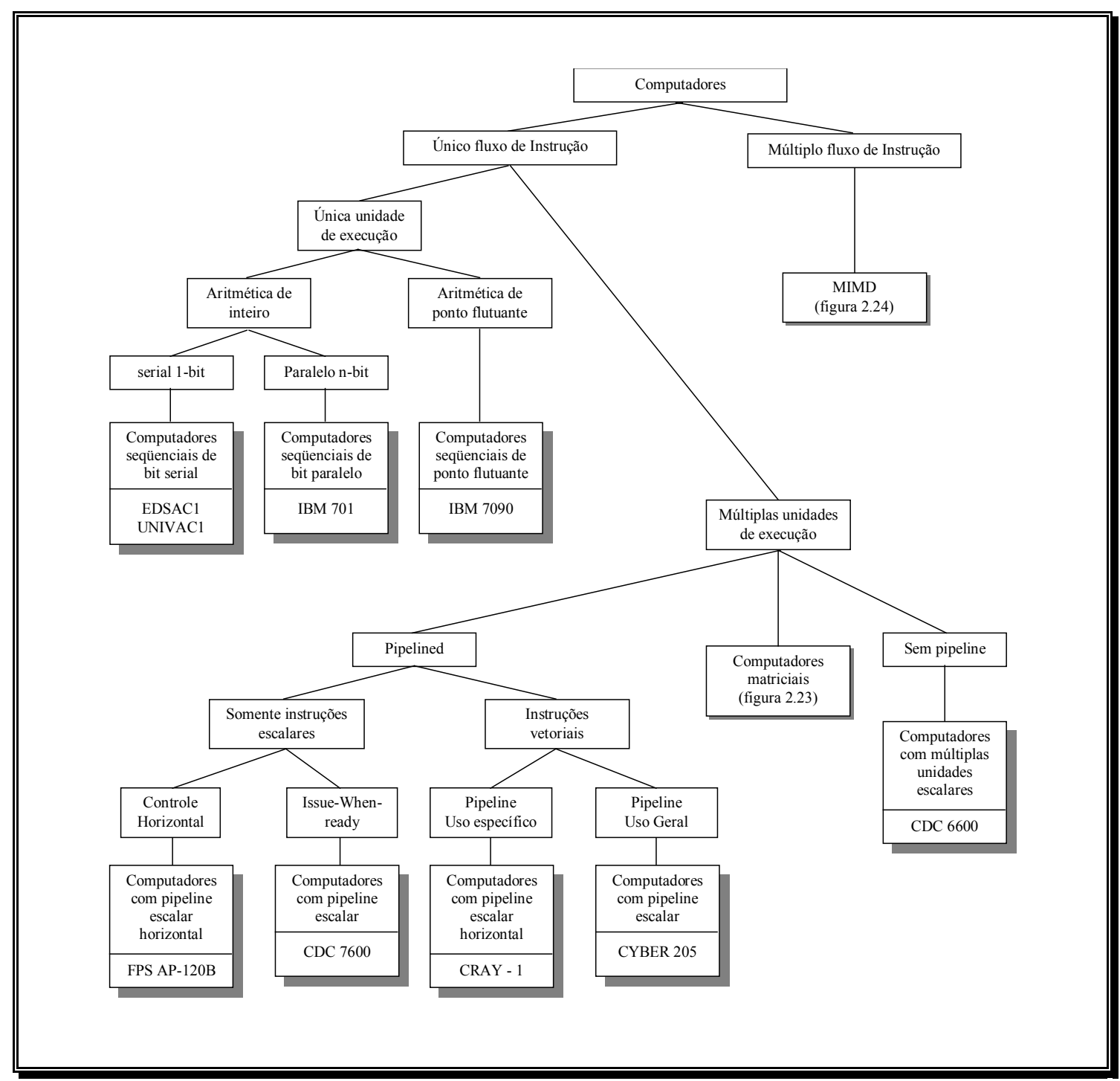

Fig. - 2.22 - Diagrama da classificação estrutural.

A taxonomia estrutural proposta por [Hockney \& Jesshope, 1988] é uma classificação bastante abrangente tanto para os computadores seqüenciais quanto para os paralelos. As Figuras 2.22, 2.23 e 2.24 apresentam o diagrama da classificação, que correspondem respectivamente à classificação geral, máquinas matriciais e MIMD.

A primeira estratégia utilizada para a classificação é a divisão dos computadores em dois grandes grupos: computadores com um único fluxo de instrução e computadores com diversos fluxos de instrução. Através dessa primeira etapa, é separado o universo dos computadores MIMD (diversos fluxos de instrução) dos demais (único fluxo de instrução - seriais e SIMD). A classe dos 
computadores com único fluxo de instruções é então dividida em: única unidade de execução e múltiplas unidades de execução. A primeira classe agrupa os computadores seqüenciais clássicos. A classe de computadores com múltiplas unidades de execução é dividida em pipeline, máquinas matriciais e múltiplas unidades de execução sem pipeline. A partir dessa divisão podemos notar a grande abrangência da taxonomia estrutural, observando a classificação da classe pipeline e matricial. O diagrama da classificação das máquinas matriciais é apresentado na Figura 2.23.

As máquinas matriciais são divididas em duas classes: máquinas com unidades de execução de ponto flutuante e máquinas com unidades de execução com poucos bits (computadores ortogonais e associativos).

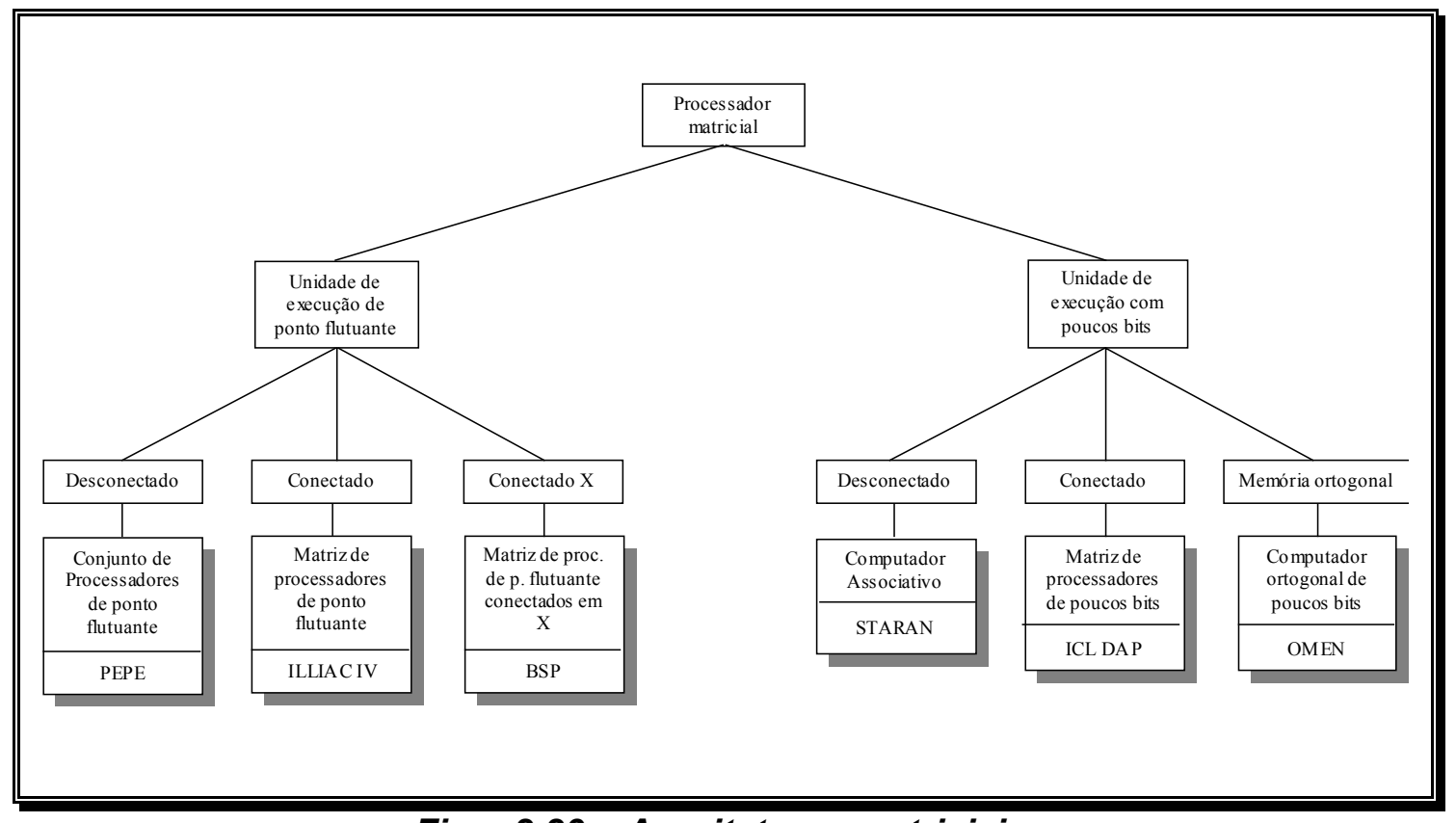

Fig. - 2.23 - Arquiteturas matriciais.

Como comentamos anteriormente, a primeira divisão da taxonomia estrutural separa os computadores MIMD dos demais. As classes de computadores MIMD são apresentadas no diagrama 2.24, que é uma continuação da Figura 2.22. Diferentemente da divisão: memória distribuída e memória compartilhada; denotação essa largamente utilizada na literatura, a taxonomia estrutural de Hockney divide as máquinas MIMD primeiramente entre máquinas com comutadores e máquinas com redes. As máquinas MIMD de memória compartilhada tornam-se então uma subclasse das máquinas com comutadores. 
Devemos observar novamente a divergência da classificação, onde temos grupos para cada topologia, no caso de redes, assim como diferentes classes para as diferentes estruturas de comutadores, para as classes de máquinas com comutadores.

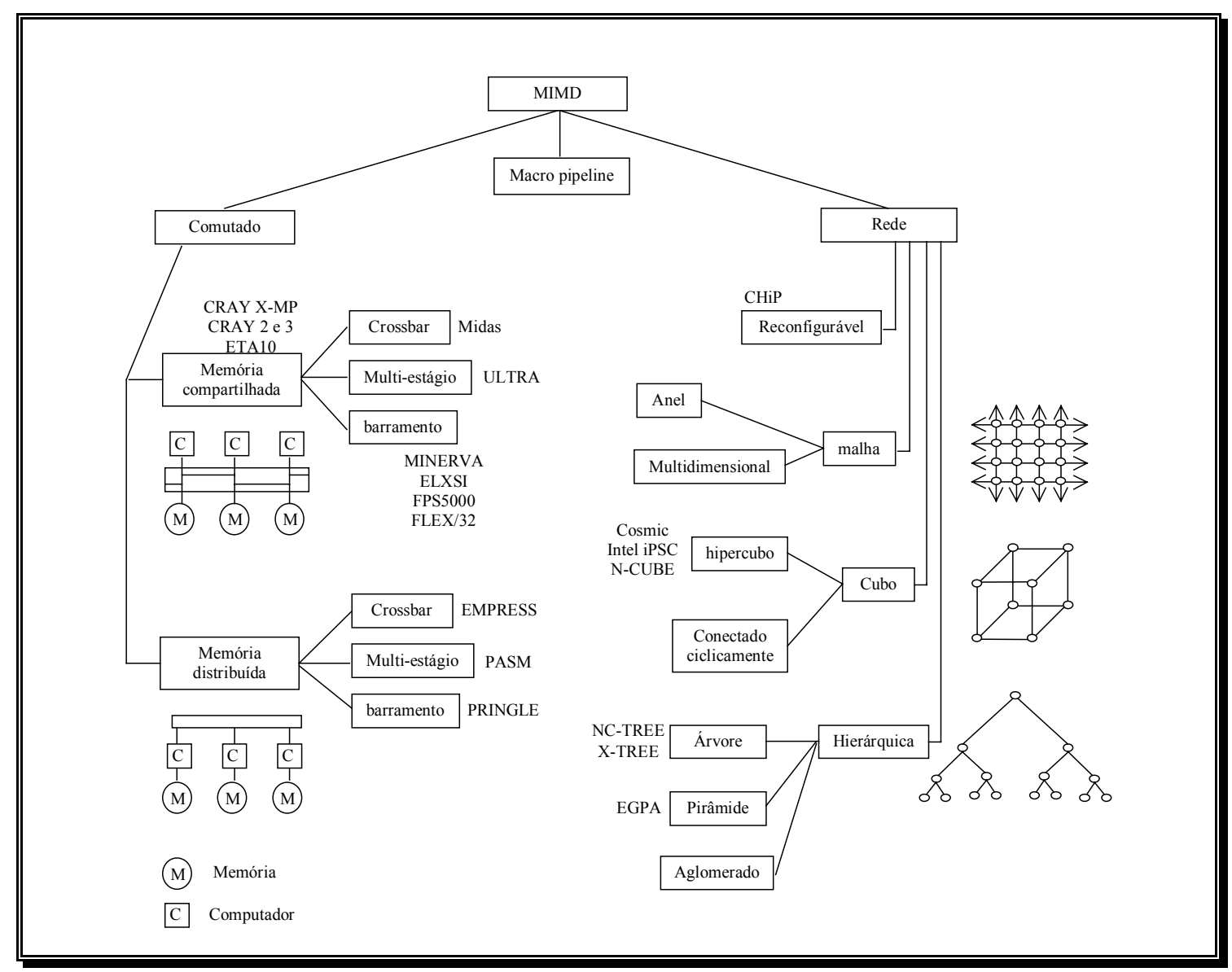

Fig. - 2.24 - Classificação estrutural para MIMD.

\subsection{3 - CLASSIFICAÇÃO DE DUNCAN}

Segundo Duncan [Duncan, 1990], a década de 1980 foi marcante para a computação paralela devido a sua proliferação e popularização. As recentes descobertas e a proliferação da tecnologia de processamento paralelo introduziram novas arquiteturas ao contexto da computação paralela. Deste modo tornou-se difícil a compreensão e a classificação das arquiteturas paralelas baseadas na taxonomia clássica (Flynn).

Tentando resolver o problema da classificação de máquinas paralelas 
Duncan, propôs sua taxinomia baseado no seguinte conjunto de imperativos:

Excluir as arquiteturas que utilizem somente mecanismos de paralelismo de baixonível (comuns nos microcomputadores atuais: Pentium, RISC, etc...).

Continuar adotando os elementos baseados em fluxo de dado e instruções da classificação de Flynn.

Incluir processadores vetoriais (pipeline), e outras arquiteturas que intuitivamente deveriam receber o mérito de pertencer às classes de computadores paralelos. Conforme vimos anteriomente na classificação de Flynn, essas arquiteturas são classificadas como SISD e não como SIMD por alguns autores.

A Figura 2.25 apresenta um diagrama da classificação sugerida por Duncan. As arquiteturas são divididas em três classes: Síncronas, Assíncronas ou MIMD e não convencionais. A classe Síncrona contém uma extensão da classe SIMD de Flynn. A esta classe, além de pertencer as arquiteturas SIMD, foram formalmente inseridas as arquiteturas vetoriais assim como arquiteturas sistólicas [Duncan, 1990], devido a sua característica síncrona. A subclasse SIMD foi ainda dividida em processadores matriciais e memória associativa.

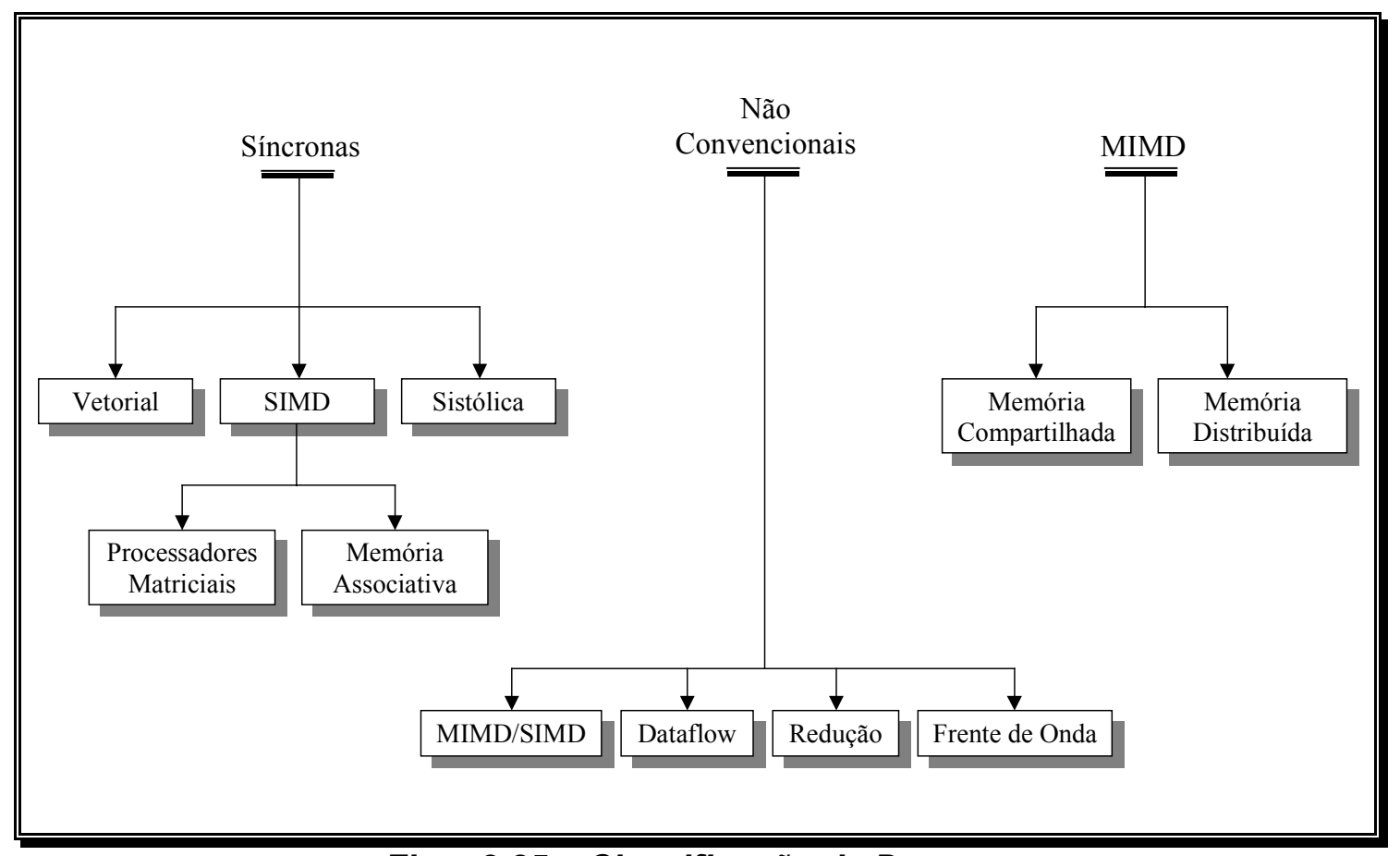

Fig. - 2.25 - Classificação de Duncan.

A classe de arquitetura MIMD (assíncrona) permaneceu com as mesmas 
subdivisões clássicas: Memória Compartilhada e Distribuída. Duncan porém apresenta uma nova classe, para atender as arquiteturas mais modernas. A classe de arquiteturas não convencionais classifica os novos paradigmas introduzidos à arquitetura paralela. Embora sejam todas derivadas da arquitetura MIMD, as arquiteturas híbridas MIMD/SIMD (exemplo: DADO e o Non-von [Almasi \& Gottlieb, 1994]), máquinas de redução (Newcastle Reduction Machine, Utah Applicative Multiprocessing System [Duncan, 1990]), matrizes de frente de onda (implementações assíncronas de arranjos sistólicos [Kung et al., 1987]) e fluxo de dados (MDM - Manchester Dataflow Machine [Almasi \& Gottlieb, 1994] e MIT Tagged Token Dataflow [Duncan, 1990]) são difíceis de enquadrar em uma classificação convencional. 


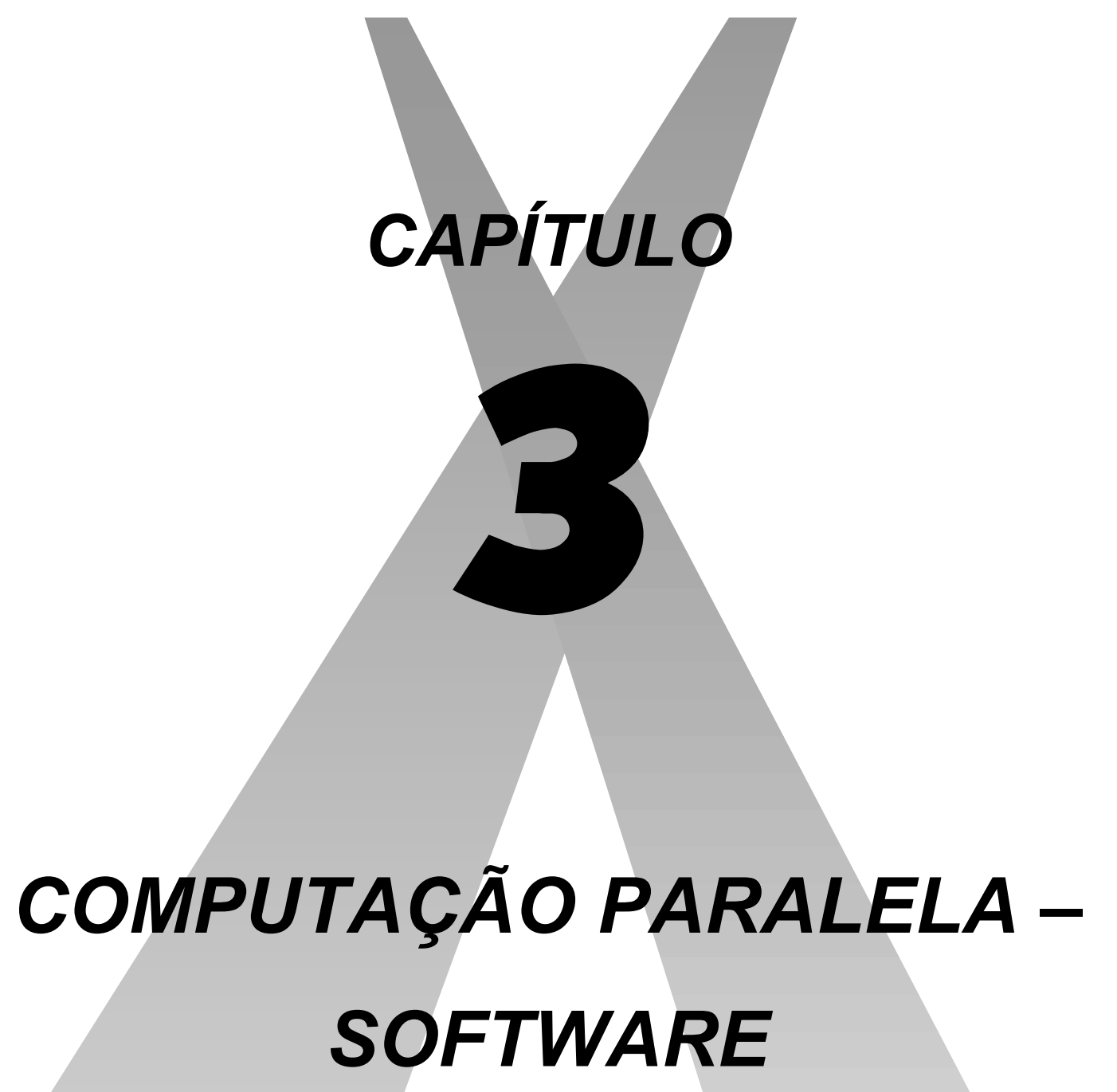

À medida que paralelizamos nossos algoritmos, multiplicamos nossos problemas.

(pensamento do autor) 
CAPÍTULO 3 


\section{CAPÍTULO 3 - COMPUTAÇÃO PARALELA - SOFTWARE}

\section{1 - INTRODUÇÃO}

No capítulo anterior abordamos a computação paralela e os sistemas distribuídos sob o prisma do hardware. Iremos agora discorrer sobre o mesmo assunto através do ponto de vista do software. O software é um importante conceito abstrato, responsável por toda a base da ciência da computação. Somente a partir do conceito de programa armazenado (software), proposto por John von Neumann em meados de 1950, o computador moderno passou a existir, fechando definitivamente o capítulo das super calculadoras da história da ciência da computação.

O conceito abstrato de software ou programa permitiu o aparecimento dos computadores de uso genérico. As primeiras máquinas parecidas com o que hoje denominamos "computador", eram construídas para fins específicos. A partir da teoria da computabilidade [Penrose, 1989], surgiu o conceito de programa. Assim, os computadores passaram a resolver todo e qualquer problema, desde que fosse ele computável, bastando para isso apenas alterar o conteúdo de sua memória de programa. Embora pareça trivial, esse conceito solidificou as bases da computação moderna, construindo toda a sua história.

$\mathrm{Na}$ computação paralela, um dos maiores desafios é o desenvolvimento de software paralelo. Atualmente, grande parte da pesquisa da computação paralela encontra-se destinada a esse aspecto. Embora em muitos casos o paralelismo seja realizado unicamente pelo hardware, ficando transparente às camadas de software (ex: pipeline), em outros, como por exemplo os sistemas distribuídos, toda a abstração das máquinas virtuais, assim como seus mecanismos de paralelismo, são inteiramente realizados pelo software.

Trataremos neste capítulo do conceito de software em linhas gerais, em todos os níveis da máquina (Figura 3.1), enfocando principalmente a exploração do paralelismo em cada um desses níveis.

Iniciaremos a discussão com o conceito de software e logo depois 


\section{CAPÍTULO 3}

apresentaremos o modelo em camadas do computador moderno. Para cada uma dessas camadas discutiremos a atuação do software, assim como a exploração de paralelismo através deste. Finalmente, concluiremos o capítulo apresentando alguns conceitos e ferramentas voltados para o desenvolvimento e utilização de software.

\section{2 - SOFTWARE}

Aproveitando a característica multidisciplinar desta tese, vamos apresentar uma parábola para ilustrar melhor a distinção entre software e hardware nos computadores, comparando-os com os sistemas nervosos biológicos, mais especificamente com o cérebro humano. Através desse paralelo entre homem e máquina, podemos denominar de hardware, todas as características físico-químicas dos neurônios, que são as células nervosas que compõem o sistema nervoso; seguindo a mesma linha de raciocínio, o software, seria todo o sistema de aprendizado. Como sabemos, o aprendizado é vital para o funcionamento do cérebro, ele é responsável pela definição da forma e modo de processamento realizado por cada uma das diferentes regiões cerebrais (hardware). Deste modo, podemos dizer que é o software que determina a forma e o modo de manipulação do hardware, e ainda podemos concluir que sem o aprendizado (software) a parte física do cérebro (hardware) seria apenas um aglomerado de células, e você caro leitor, jamais estaria lendo esta tese.

Vamos continuar essa discussão no próximo capítulo, entretanto, a finalidade dessa simples comparação foi ilustrar a importância do software. Embora extremamente dependente das bases do hardware, a sofisticação evolutiva (instinto, decisão, razão, sentimento, etc.) fica sob a responsabilidade do software. O mesmo ocorre nos computadores. Embora necessite de um meio físico (hardware) para concretizar-se, o software é o elemento responsável pelo comportamento da máquina. É através dele que os computadores modernos são capazes de executar suas funções.

Agora que já observamos sua importância, vamos à sua definição: Software pode ser definido como uma abstração compreendida por algoritmos, instruções, dados e informações responsáveis pelo controle, supervisão e manipulação do hardware.

Como podemos observar através do modelo de camadas apresentado na 
Figura 3.1, muitas vezes o limiar entre software e hardware é bastante sutil, de modo que a sua diferenciação sob determinados níveis de máquina é bastante complexa. No entanto, em termos gerais, podemos definir o hardware como a parte física do computador e o software como a abstração responsável por sua manipulação.

\section{3 - MODELO DE CAMADAS}

Um importante conceito que devemos levar em conta na organização dos computadores é a vinculação das camadas de software ao hardware. A partir do modelo de camadas [Tanenbaum, 1990], os computadores são definidos como composições de hardware e software. Levando em conta o hardware e o software ao definirmos os computadores, estamos acrescentando o conceito de plataforma. Deste modo, uma mesma máquina pode, em função das camadas de software (principalmente Sistema Operacional), pertencer a diferentes plataformas. Um bom exemplo dessa abordagem são os computadores pessoais PC. Embora o hardware seja o mesmo, a máquina pode pertencer a diferentes plataformas, e deste modo modificar seu comportamento, bastando para isso alterar seu sistema operacional (ex: UNIX, Windows, Windows NT, DOS e OS/2). A partir desse conceito o software passa a constituir parte da arquitetura dos computadores.

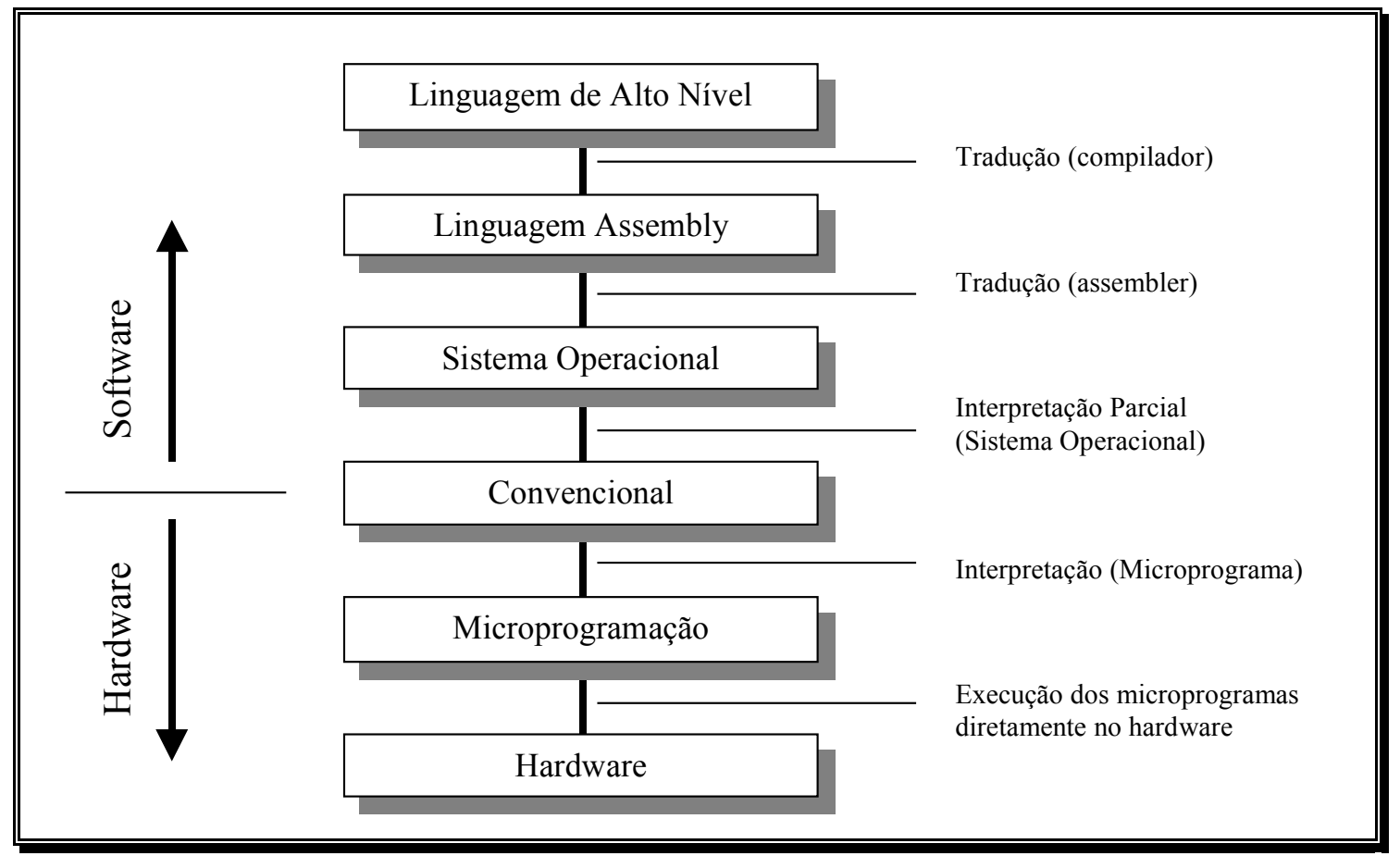

Fig. - 3.1- Organização genérica em camadas dos computadores. 
A Figura 3.1 ilustra a clássica divisão em camadas na organização dos computadores proposta por Tanenbaum [Tanenbaum, 1990]. Esse modelo pode variar muito de computador para computador, tanto em número de camadas quanto em sua diferença. Nesta figura, representa-se um típico computador CISC (do inglês Complex Instruction Set Computer) [Gimarc \& Milutinovic, 1987]. Devemos observar também que o desempenho de cada camada é afetado diretamente pelas camadas inferiores.

A primeira camada do modelo apresentado pela Figura 3.1 representa hardware. Nesta seção não abordaremos o paralelismo contido nessa camada, uma vez que já foi bastante discutido no capítulo anterior. A segunda camada é constituída pela micromáquina ou microprogramação. Em computadores CISC, compete à micromáquina controlar os recursos do hardware. Deste modo, cada instrução do nível convencional, ao ser processada, é interpretada e dividida pela unidade de controle em microinstruções. A micromáquina apresenta uma memória especial denominada de memória de controle (tabela de controle), onde são armazenados os sinais de controle. As microinstruções são convertidas em sinais, através dessa tabela, que controlam diretamente o hardware. Embora essa camada possua o conceito de programa, geralmente não a classificamos como software, uma vez que é transparente ao programador. Discutiremos sucintamente na Seção 3.4 algumas abordagens paralelas utilizadas nessa camada.

A terceira camada é composta pelo nível convencional, também conhecida por linguagem de máquina. No nível convencional é realizada a primeira interface entre o software e o hardware. Esta camada é constituída pelo conjunto de instruções do processador, registradores, dispositivos funcionais (ALUs, deslocadores, etc.), do espaço de endereçamento e de outros recursos de hardware "visíveis" ao programador. Através da interpretação das instruções e sua execução (microprogramação), é realizado o processamento da memória, interrupções e os processos de entrada e saída para periféricos. Apresentaremos o paralelismo a nível convencional na Seção 3.5.

As camadas seguintes: sistema operacional, linguagem assembly e linguagens de alto nível constituem as camadas de software "puro". Iremos tratar desses assuntos nas Seções 3.6 e 3.7.

Finalizaremos a discussão do modelo de camadas com as bibliotecas de troca de mensagens, assunto da Seção 3.8 onde apresentaremos algumas das principais ferramentas disponíveis atualmente e também introduziremos a 
ferramenta CVMP, no decorrer desta tese.

\section{4 - PARALELISMO DE MICRO-MÁQUINA}

Compete à micromáquina controlar os recursos do hardware através dos sinais que são enviados aos pontos de controle. Para isso, a micromáquina interpreta cada instrução executada pelo nível convencional e as transforma em microinstruções. A micromáquina apresenta uma memória especial denominada de memória de controle, onde são armazenados os sinais de controle, para isso, as microinstruções são organizadas em campos de um ou mais bits, chamados de microordens, onde cada uma destas especifica o sinal a ser produzido a fim de executar o hardware.

Mesmo apresentando o conceito de programa, não podemos caracterizar a micromáquina como uma camada de software, pois sua programação não pode ser alterada (hardware) e ela é completamente transparente ao usuário. Deste modo, a programação da micromáquina é realizada pelo fabricante do hardware. Como estamos tratando de paralelismo de software, nesta seção não entraremos em detalhes sobre a implementação paralelas da microprogramação.

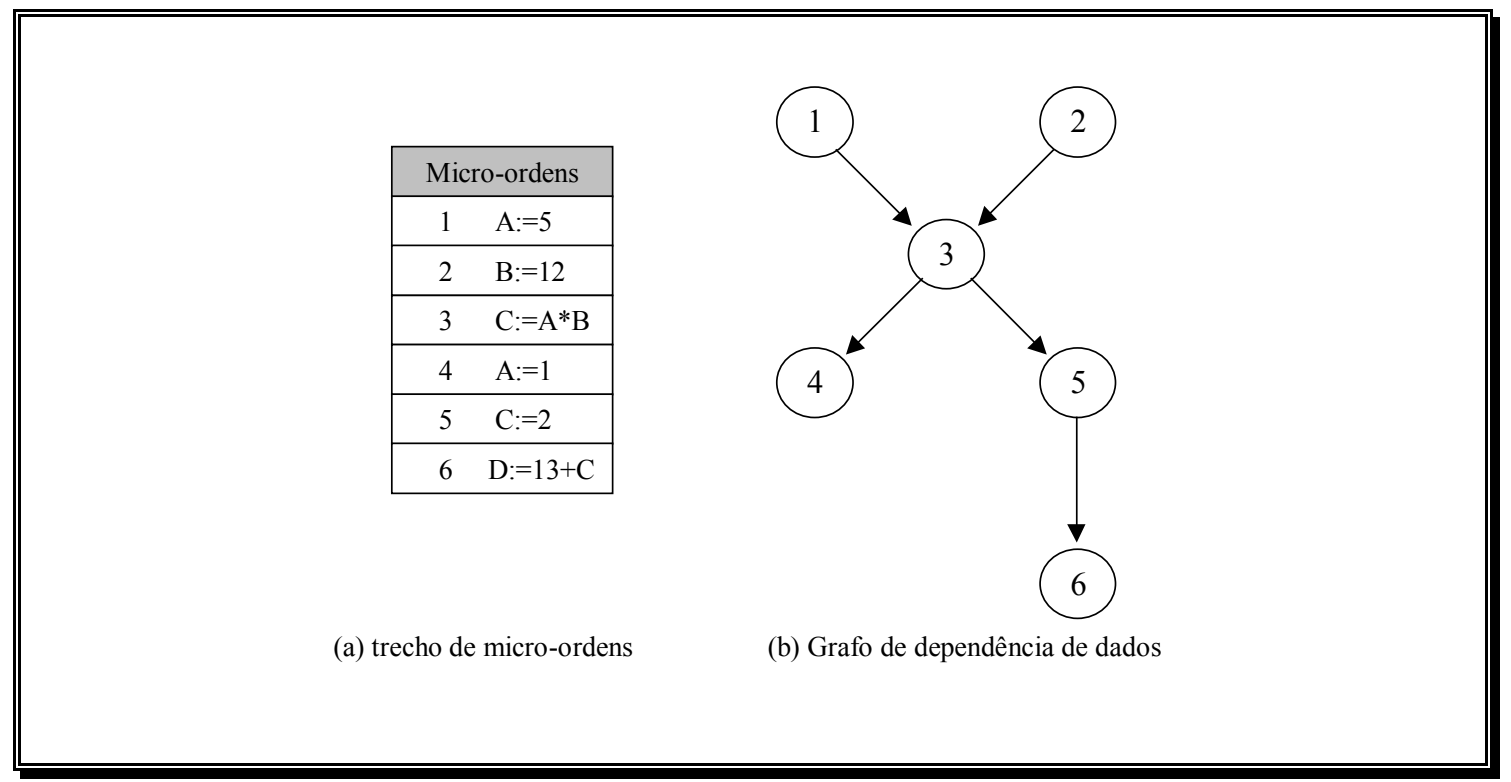

Fig. - 3.2 - Grafo de Dependência de Dados.

As máquinas com microinstruções verticais [Hwang et al., 1984] [Amorin et al.,1988] são capazes de executar diversas microinstruções simultaneamente. A 
heurística da exploração de seu paralelismo consiste basicamente na verificação da dependência de dados. Desta forma, seu algoritmo deverá percorrer as microinstruções e verificar quais poderão ser executadas em paralelo, gerando um grafo de execução. A Figura 3.2 apresenta um exemplo mostrando um grupo de microinstruções e seu respectivo grafo. Observa-se que, devido à dependência de dados, a microinstrução 3 foi executada seqüencialmente.

\section{5 - Paralelismo no Nível Convencional}

A camada de nível convencional também conhecida por linguagem de máquina (embora essa denominação seja incorreta [Tanenbaum, 1990]) é a camada onde se realiza a primeira interface entre o software e o hardware. Ela é caracterizada pelo conjunto de instruções do processador, registradores, dispositivos funcionais (ALUs, deslocadores, etc.), do espaço de endereçamento e de outros recursos de hardware "visíveis" ao programador.

Embora possamos discutir o paralelismo no nível convencional sob o ponto de vista dos registradores, dispositivos funcionais, espaço de endereçamento e etc., vamos enfocar a discussão no conjunto de instruções que compõe a linguagem de máquina.

A exploração do paralelismo das camadas inferiores ao nível convencional ocorre completamente transparente ao programador. Um bom exemplo disso são as máquinas com pipeline de instrução. Do ponto de vista do programador, as instruções de linguagem de máquina são executadas seqüencialmente, porém a unidade de controle realiza o paralelismo do hardware através do pipeline, fazendo com que diversas instruções possam estar sendo executadas simultaneamente, independentemente do conhecimento ou controle do programador.

Existe ainda um determinado tipo de máquina onde essa forma de paralelismo não é transparente ao programador do nível convencional. É o caso das máquinas com múltiplas unidade funcionais (como por exemplo as máquinas escalares CDC 6600, CDC 7600 e IBM 360 [Hwang et al., 1984]). Nesse caso, o paralelismo de hardware somente pode ser explorado quando não ocorre dependência de dados entre as instruções (ver Figura 3.2), ficando sob a responsabilidade do programador (ou mesmo do compilador) a tarefa de gerar o código de linguagem de máquina otimizado.

A principal estratégia de paralelismo dentro do nível convencional é 
encontrada nas arquiteturas VLIW (do inglês "Very Long Instruction Word") [Amorin et al.,1988]. Esse tipo de máquina possui instruções com palavras muito longas, e exploram o paralelismo de hardware através da replicação dos recursos da UCP (unidade central de processamento).

As arquiteturas VLIW são constituídas de uma única unidade central de processamento e foram projetadas para executar as instruções seqüencialmente, do mesmo modo como ocorre na tradicional máquina de von Neumann. O paralelismo nessas máquinas, porém, está contido dentro de cada instrução, que contém informação suficiente para explorar todo o potencial paralelo de suas unidades funcionais replicadas. Devido à sua complexidade, as instruções possuem a capacidade de especificar as unidades funcionais que irão executar seus respectivos operandos.

\section{6 - Paralelismo a nível de Sistema OPERACIONAL}

O sistema operacional é a primeira das camadas que compõem um computador, sendo constituído inteiramente por software. É responsável pela interface entre os aplicativos (programas) e o computador. Compete ao sistema operacional controlar e supervisionar os dispositivos de entrada e saída de dados, organizar e gerenciar a memória, interpretar parcialmente os programas ao serem executados, etc. [Tanenbaum, 1992].

Em sistemas operacionais o processo é um importante conceito de exploração do paralelismo, sendo constituído por todas as partes necessárias de um programa em execução, ou seja: código objeto, o valor das variáveis do programa ("stream") e conteúdo dos registradores e indicadores. Através dele, o sistema operacional é capaz de isolar os programas em execução. Através deste princípio, o sistema operacional é capaz de executar diversas atividades em concorrência, ainda que utilizando um único processador, técnica que recebe a denominação multitarefa ("multitasking"). O conceito de processo exige um sofisticado gerenciamento de memória, interrupções e de controle total sobre a camada convencional. 


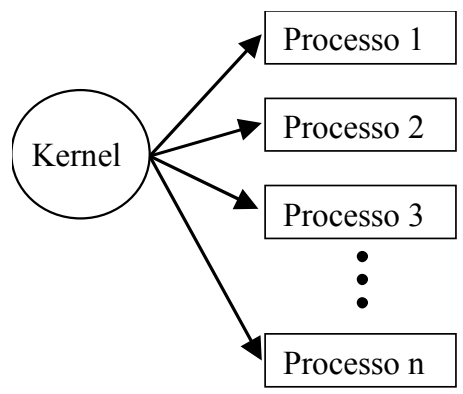

Fig. - 3.3 - Escalonamento de tarefas.

Multitarefa é um mecanismo do sistema operacional, que, utilizando o conceito de processo, alterna os processos (ou tarefas), permitindo a execução de programas simultaneamente (em concorrência). A Figura 3.3 ilustra o escalonamento das tarefas. Neste exemplo, "n" processos estão sendo executados de forma alternada no tempo, sob supervisão do kernel (camada do sistema operacional responsável pelo controle da multitarefa). Assim, o kernel habilita a execução do processo A por um breve período de tempo, a seguir interrompe a execução e começa a executar o próximo processo. Ao final da lista de processos, o kernel volta a executar o primeiro processo e assim sucessivamente até que todos sejam terminados. Esse procedimento gera a ilusão ao usuário de que diversos programas estão sendo executados ao mesmo tempo.

Essa técnica auxilia a programação concorrente, uma vez que permite ao programador executar seus programas em concorrência. Mesmo sendo esse contexto adotado em computadores seqüenciais, sua noção de paralelismo permite ao programador desenvolver sistemas que emulem paralelismo. Do ponto de vista da utilização, a multitarefa somente faz sentido efetivo quando é empregada em sistemas operacionais com interface gráfica com o usuário (GUI).

Durante toda a década de 70 , uma série de pesquisas em ciência da computação viria a mudar o conceito de sistema operacional, através do paradigma das interfaces gráficas com o usuário - GUI (do inglês "graphical user interface") [Bruno, 1995]. Podemos atribuir quase que inteiramente ao Xerox PARC (Palo Alto Research Center) todo o desenvolvimento do conceito de GUI. A camada GUI não é apenas uma simples contribuição ao método de realizar a interface entre o computador e o usuário, mas sim um novo conceito inserido ao sistema operacional [Bruno, 1995], que contribuiu com o desenvolvimento da ciência da computação. 
Entre os benefícios acrescidos pelo conceito podemos citar: a programação orientada a objetos [Cox, 1986] e a programação orientada a eventos [Bruno, 1995]. A Figura 3.4 apresenta como exemplo um diagrama das camadas entre as aplicações e o sistema operacional UNIX com e sem GUI. Com a popularização e proliferação do conceito GUI, atualmente a maioria dos sistemas operacionais disponíveis possuem essa camada embutida.

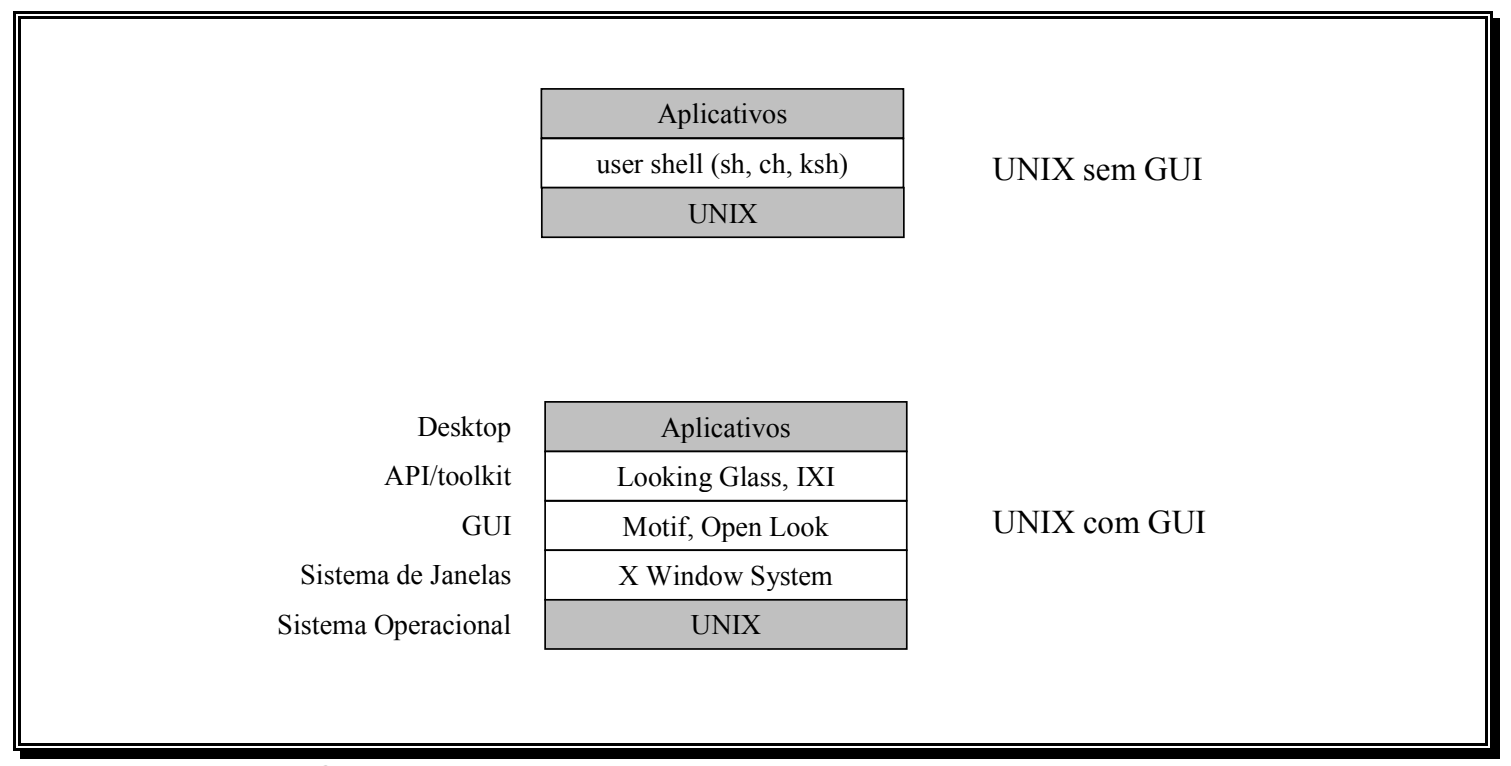

Fig. - 3.4 - Comparação entre o sistema operacional UNIX com e sem a camada GUI.

Além da multitarefa, que possibilita a concorrência de processos, os sistemas operacionais genéricos atuais (UNIX, Windows NT/9X, Mac OS e etc.) apresentam também um outro conceito muito útil para o desenvolvimento de programas concorrentes, denominado Thread. O conceito de Thread é bastante parecido com a multitarefa. Porém agora, ao invés de processos, temos parte de programas (podendo ser de um mesmo programa ou não) sendo executados em concorrência.

Um outro conceito muito importante para a computação paralela é a adoção do sistema de arquivo para redes de computadores [Tanenbaum, 1992]. Essa nova camada permite que o sistema de arquivos do sistema operacional seja expandido aos dispositivos de armazenamento conectados pela rede. Somente a partir dessa camada foi possível a implementação de sistemas operacionais distribuídos.

As estratégias até aqui comentadas, embora relacionadas ao paralelismo, são diretamente associadas aos computadores seqüenciais. Discutiremos a seguir 


\section{CAPÍTULO 3}

de forma abreviada, os sistemas operacionais desenvolvidos especificamente para computação paralela.

O objetivo principal dos sistemas operacionais consiste na interface entre 0 usuário (programador) e a aplicação (computador). Deste modo, o sistema operacional cria uma camada de software que simplifica toda a complexidade do hardware da máquina, possibilitando sua operação e disponibilizando a base para o desenvolvimento e execução das aplicações (programas). Seguindo esse princípio, o sistema operacional funciona como uma máquina virtual [Tanenbaum, 1992], simples de utilizar, compreender e programar, tornando todo o complexo conjunto de dispositivos que constituem o computador (memória, relógios, terminais, controladores de discos rígidos, controladores de discos flexíveis, interfaces de rede, dispositivos de entrada e saída, processador, etc.) transparentes ao usuário.

Sendo o sistema operacional definido como uma máquina virtual, conforme comentamos anteriormente, torna-se bastante natural a transposição desse conceito para as máquinas paralelas. Deste modo, os sistemas operacionais paralelos procuram tornar as características paralelas igualmente transparentes. Assim, foram desenvolvidos os sistemas operacionais distribuídos [Tanenbaum, 1995].

Segundo Tanenbaum [Tanenbaum, 1995], um sistema operacional distribuído consiste de uma camada de software capaz de fazer com que uma coleção de computadores independentes aparentem para o usuário como um único computador. Entretanto, essa definição é apenas teórica. Embora existam diversos sistemas operacionais distribuídos, o atual estado da arte da ciência da computação ainda não permite a implementação efetiva desse conceito. Mais uma vez, o software é a grande barreira do paralelismo. Não sabemos como projetar, implementar ou usar software distribuído de modo a desenvolver um sistema operacional que com eficácia distribua uma aplicação em diversas unidades de processamento.

O atual estado da arte em sistemas operacionais distribuídos ainda não permite paralelizar automaticamente os programas e aplicações, o que seria de se esperar de um sistema operacional distribuído ideal. No entanto, esses sistemas são capazes de deixar transparente e automática a exploração dos recursos paralelos, através da distribuição de processos e threads pelos processadores espalhados na rede. O usuário, ao utilizar um sistema operacional distribuído (ex: Amoeba [Tanenbaum, 1995]), tem a idéia de estar utilizando um sistema 
operacional multitarefa convencional ao invés de um conjunto de máquinas integradas pelo sistema operacional distribuído. Deste modo, quando o usuário executa diversas aplicações, o sistema operacional distribui estas para máquinas distintas, de modo transparente ao usuário, que tem a impressão de estar utilizando um sistema operacional convencional multitarefa com alta performance computacional.

Basicamente existem três possibilidades de implementar um sistema operacional distribuído:

Desenvolvimento completo - Consiste em desenvolver um sistema operacional distribuído específico, partindo do ponto zero, ou seja sem utilizar nenhum outro sistema operacional existente como base de desenvolvimento.

Modificando um sistema operacional convencional - Resume em utilizar as bases de um sistema operacional convencional (normalmente UNIX), alterando-o e incrementando-o até transformá-lo em um novo sistema operacional com características de sistema operacional distribuído.

Utilizando um sistema operacional convencional - Consiste no desenvolvimento de uma camada de software adicional sobre um sistema operacional já existente, ficando entre o usuário / aplicações e o sistema operacional, de modo que a partir dessa nova camada o conjunto todo se comporte como um novo sistema operacional distribuído.

É importante comentar que, embora o conceito de sistemas operacionais distribuídos seja bastante interessante, e que existam mesmo algumas implementações, esse tipo de abordagem não se popularizou. A grande maioria das implementações desses sistemas são de caráter acadêmico e os exemplos que se tornaram comerciais são bastante raros; entre eles podemos citar o Chorus, sistema operacional distribuído desenvolvido a partir do UNIX, no INRIA (Instituto Francês de Pesquisas) e posteriormente comercializado pela Chorus Sistèmes [Tanenbaum, 1995].

A Figura 3.5 apresenta um arranjo da arquitetura do sistema operacional distribuído AMOEBA [Mullender et al., 1990] [Tanenbaum, 1995]. Seguindo a estratégia de desenvolvimento completo, o Amoeba foi desenvolvido totalmente sem utilizar nenhuma base (sistema operacional) previamente implementada. Originado na Vrije Universiteit, Amsterdã, sua primeira versão ficou operante em 


\section{CAPÍTULO 3}

1984. O sistema possui dois objetivos básicos: constituir um sistema operacional distribuído totalmente transparente ao usuário e fornecer as bases para desenvolvimento de programação paralela e distribuída.

Quanto ao primeiro objetivo, o Amoeba tem o propósito de fazer com que as características paralelas sejam transparentes ao usuário. Um interessante conceito do sistema está na opção de não existir máquina-mãe para processos ou usuários. Deste modo, quando um usuário entra no sistema, está entrando no sistema como um todo e não em uma determinada máquina que compõe o sistema. Assim, quando é apresentado a interface (shell) para o usuário entrar no sistema, ela é executada em um processador arbitrário.

O outro objetivo, é fazer com que o Amoeba forneça as bases para pesquisas em programação paralela e distribuída. Se operado por um usuário sem intenções de desenvolver aplicações paralelas, devido à sua transparência, aparenta ser um sistema operacional multitarefa (multitasking) executado em um supercomputador seqüencial. Porém, o Amoeba também possui ferramentas, linguagens e aplicações específicas para a exploração do paralelismo, como a linguagem Orca, voltada exclusivamente para o desenvolvimento de aplicações paralelas [Tanenbaum, 1995].

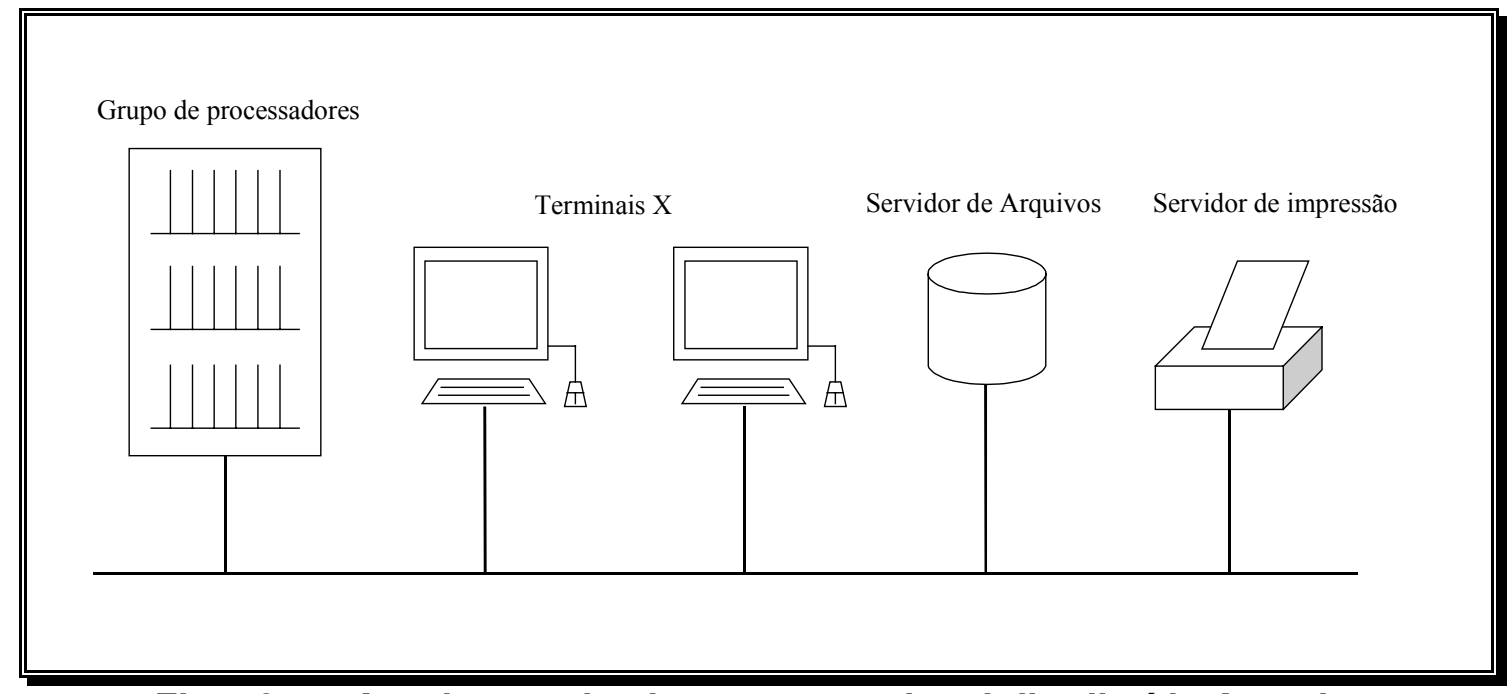

\section{Fig. - 3.5 - Arquitetura do sistema operacional distribuído Amoeba.}

Conforme podemos observar através da Figura 3.5, o Amoeba é composto basicamente por três partes: grupos de processadores, terminais $\mathrm{X}$-Windows e servidores. Os grupos de processadores possuem um substancial número de UCPs, as quais possuem sua própria memória local e conexões de rede. O sistema 
permite também processadores utilizando memória compartilhada. Neste caso, a troca de mensagens é otimizada através da comunicação memória para memória ao invés de trocar mensagens pela rede. As UCPs de um grupo podem pertencer a diferentes arquiteturas, como por exemplo uma mistura entre $680 \times 0$, família Intel, ou máquinas SPARC. As máquinas pertencentes ao grupo de processadores podem ser máquinas completas (com teclado, mouse e monitor) ou simplesmente a placa de processamento com a conexão de rede e memória. As máquinas completas no entanto possuem o inconveniente de serem sub-utilizadas, uma vez que não podem ser utilizadas como terminais.

A outra parte que compõe o sistema Amoeba são os terminais X-Windows. Além destes, podem ser utilizados computadores pessoais ou estações de trabalho como terminais, que no entanto serão sub-utilizados, uma vez que não poderão participar do processamento. A terceira parte do sistema consiste dos servidores, máquinas que executam tarefas específicas (Ex: servidores de arquivos e de impressão).

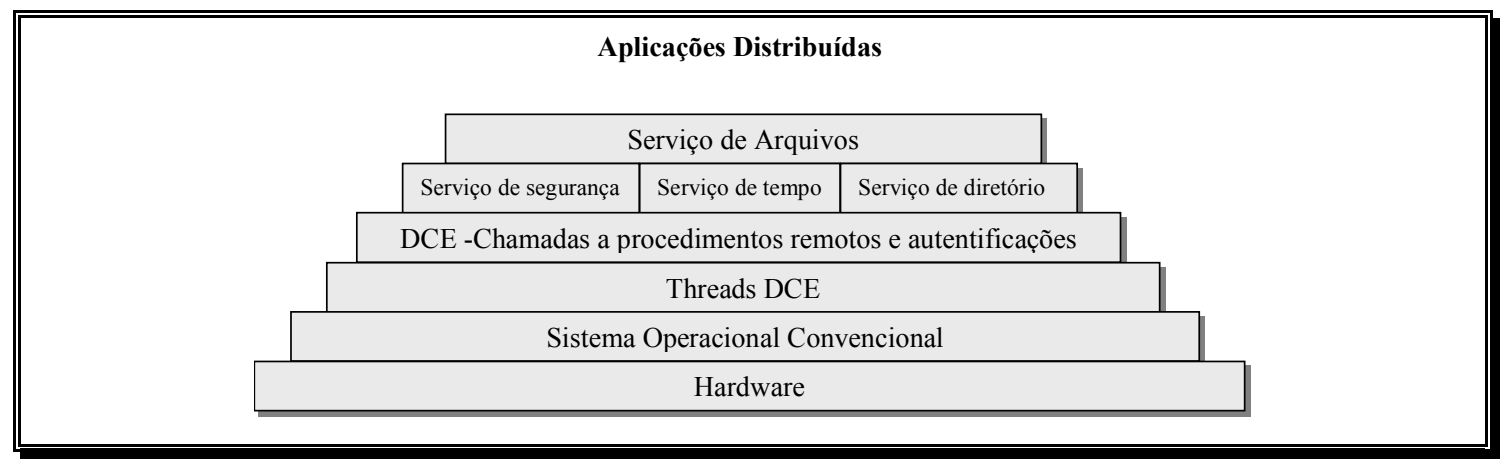

Fig. - 3.6 - Camadas do sistema DCE.

Como exemplo da terceira abordagem de implementação de sistemas operacionais distribuídos, podemos citar o DCE (do inglês Distributed Computing Environment) [Rosenberry et al., 1992]. Utilizando máquinas com sistemas operacionais convencionais e adicionando uma aplicação, que funciona como uma camada de software adicional, o DCE, transforma um conjunto de máquinas em sistema operacional distribuído. A Figura 3.6 apresenta o modelo de camadas do DCE. Inicialmente desenvolvido para rodar em plataforma UNIX, o DCE foi portado para as plataformas VMS, Windows e OS/2. Uma outra característica que chama a atenção é seu caráter comercial, que constitui a base de seu projeto desde a origem. 


\section{7 - Paralelismo a Nível de linguagens de PRogRamação}

Antes de discutirmos sobre o paralelismo a nível de linguagens de programação, é interessante definirmos o que vem a ser uma linguagem de programação. A linguagem de programação de alto nível consiste em um método desenvolvido pela ciência da computação para transformar o modo de programar deixando-o mais abstrato e menos dependente da máquina. Através de um compilador ou interpretador, os programas escritos em linguagens de alto nível são convertidos em linguagem de máquina, e deste modo, transformam-se em novas aplicações (ver Figura 3.1).

O conceito de linguagem de programação de alto nível auxiliou o desenvolvimento da ciência da computação em dois níveis: simplicidade no desenvolvimento de programas e portabilidade. A simplicidade de desenvolvimento de programas é uma das questões mais importantes da computação. A informática somente conseguiu atingir seu estado de popularização através da crescente variedade de aplicações. Se os programas fossem desenvolvidos em linguagem de máquina, a complexidade e o tempo de trabalho fariam com que o software tivesse um custo tão elevado que impossibilitaria a generalização do uso do computador. A portabilidade é uma questão extremamente importante na história da computação [Bruno, 1995]. Com o conceito de linguagem de programação de alto nível, os programas puderam ser portáteis. Deste modo, os programadores podem desenvolver um programa e transpô-lo para qualquer máquina, sem se preocupar com o conjunto de instruções ou com a sua linguagem de máquina ou assembly, bastando que a nova máquina (com arquitetura diferente) possua um compilador para a linguagem em que foi escrito o programa. Em [Bruno, 1995] são encontrados detalhes sobre a história da computação sob os aspectos da portabilidade.

\subsection{1 - Linguagens de Programação de alto NÍVEL}

Sendo o objetivo das linguagens de alto nível a abstração técnica e a representação dos problemas de modo mais facilitado para os programadores, como seria de se esperar, a linguagem de alto nível é desenvolvida com base na 
classe de problemas que procura atender. Verificando o universo das linguagens de programação de alto nível, podemos constatar seu caráter de orientação ao problema. A seguir vamos apresentar algumas das linguagens mais populares de programação com suas respectivas especificações. Apresentamos também na Figura 3.7 um diagrama da genealogia de algumas dessas linguagens.

Fortran - (FORmula TRANslation) Projetada para aplicações técnicas e científicas, mais especificamente para cálculos matemáticos, pode ser considerada como origem de todas as linguagens de programação de alto nível. Embora não possua muita abstração e seja mais voltada para simplificar o trabalho de compilação do que o de programação, o Fortran é uma das linguagens que mais evoluiu, possuindo novas versões a cada década. É amplamente utilizado até os dias de hoje, principalmente em super computação. Existem muitas ferramentas e extensões para exploração de paralelismo em Fortran.

Algol - (ALGOrithmic Language) O Algol foi a primeira linguagem de alto nível realmente preocupada com a abstração (mais voltada ao programador que à estrutura da máquina). Designado para uso geral, introduziu, entre outros, os conceitos de estrutura de blocos, procedimentos e variáveis locais (declaradas dentro dos procedimentos). O Algol influenciou teoricamente a grande maioria das linguagens.

COBOL - (COmercial Business Oriented Language). Primeira linguagem de computadores designada especificamente para uso comercial, o Cobol é ainda hoje uma das linguagens mais utilizadas em todo o mundo. A principal atividade de suas aplicações é a manipulação de arquivos.

Lisp - (LISt Processing language). Foi a primeira linguagem declarativa. Projetada para problemas em inteligência artificial, assim como em outras áreas com estruturas de dados irregulares que são melhor representadas através de listas, introduziu o conceito de recursividade que não era permitido pelo Fortran. Atualmente, existem algumas extensões e implementações do Lisp para a exploração de paralelismo.

BASIC - (Beginner's All-purpose Symbolic Instruction Code). Linguagem de uso geral, utilizada por iniciantes em linguagens de programação. Popularizou-se a partir de meados da década de 70 , por se tornar padrão como linguagem de alto nível para os primeiros microcomputadores. Atualmente o Visual Basic constitui uma evolução da linguagem BASIC, adicionando características de programação 


\section{CAPÍTULO 3}

visual ao BASIC, tornando-se a linguagem que mais desenvolveu aplicativos para a plataforma Windows.

Pascal - Possui essa denominação em homenagem ao matemático e filósofo Blaise Pascal. Caracterizado como um estágio evolutivo da linguagem Algol, foi inicialmente projetado para o ensino de linguagens de programação em nível superior. Devido a sua modularidade e estruturação, assim como sua simplicidade, popularizou-se o Pascal, que se tornou uma das principais linguagens dos computadores de terceira geração. Tendo sido projetado para uso geral, muitos compiladores e sistemas operacionais forma escritos em Pascal. Atualmente o Pascal possui diversas extensões paralelas. A atual ferramenta de desenvolvimento Delphi [Calvert, 1999], estimulou a utilização do Pascal, adicionando características de orientação a objetos [Cox, 1986] e visuais.

C - É uma linguagem de alto nível de uso geral, cuja principal característica é a habilidade de acessar o hardware, comportando-se como linguagem de baixo nível. Embora possua tais características, os programas escritos em $\mathrm{C}$ possuem alta portabilidade podendo ser recompilados em diversas plataformas. Essas condições fazem com que a linguagem $C$ seja voltada ao desenvolvimento de sistemas operacionais (UNIX é escrito em C). Com a popularidade do UNIX em sistemas paralelos, consequentemente a linguagem $\mathrm{C}$ ganhou diversas extensões paralelas.

Smalltalk - O Smalltalk é uma linguagem de programação visual, que inspirou tanto a programação visual quanto o emprego da tecnologia de orientação a objetos. Desenvolvida para suportar os paradigmas dos projetos PARC [Bruno, 1995], motivou diversas outras linguagens por seus conceitos inovadores.

Modula 2 - A linguagem Modula 2, também foi inspirada pelas novas concepções do projeto PARC da Xerox [Bruno, 1995]. baseada em Pascal, foi designada para ser a linguagem de alto nível base para as novas estações de trabalho.

C++ - Devido à popularização do conceito de programação orientada a objetos, foi desenvolvido o $\mathrm{C}++$, que é uma extensão da linguagem C. O C++ acrescenta o conceito de orientação a objetos ao C. As características $\mathrm{OO}$ (orientação a objetos) trouxeram a estrutura de classes ao $\mathrm{C}++$ e todas as suas vantagens de reutilização de código e facilidades para projetos extensos.

Prolog - (PROgramming LOGic). O Prolog é uma linguagem de alto nível de abstração. Projetado para ser utilizado em inteligência artificial e sistemas 
inteligentes, é uma linguagem declarativa, baseada em predicados lógicos.

Ada - Denominação para homenagear a primeira programadora de computadores Augusta Ada Lovelace, aluna de Charles Babbage [Spufford \& Uglow, 1997]. A linguagem de programação ADA é uma linguagem de alto nível, muito parecida com o Pascal, foi encomendada pelo departamento de defesa americano e desenvolvida para computação numérica, programação de sistemas, aplicações em tempo real e programação concorrente. ADA é uma linguagem robusta com bibliotecas nativas para diferentes especificações, incluindo a exploração de paralelismo.

JAVA - Criada pela Sun Microsystens, a linguagem Java foi criada para atender as necessidades da Internet, possuindo caraterísticas que facilitam a utilização de suas aplicações em diversas plataformas de computação diferentes assim como sua integração com as metodologias de navegação da Internet. É uma linguagem de uso geral com estruturas muito parecidas ao $\mathrm{C}++$.

Linguagens Visuais - $O$ conceito de linguagem visual foi introduzido primeiramente pelo Smalltalk. Na plataforma Windows, esse conceito foi introduzido pela linguagem Visual Basic, que consiste num ambiente de programação que, através de ferramentas CASE [Bruno, 1995], é capaz de gerar código através de interação visual entre o programador e o sistema, facilitando o desenvolvimento e diminuindo o tempo de programação. O Visual Basic popularizou-se rapidamente, tornando-se a linguagem mais utilizada e que possui o maior número de aplicações para plataforma Windows. Atualmente, existe uma forte tendência na utilização do conceito de linguagem visual, gerando inúmeras extensões visuais das linguagens tradicionais, como por exemplo: Delphi (Pascal), $\mathrm{C}++$ Builder e Visual $\mathrm{C}++(\mathrm{C}++)$, Jbuilder e Visual J++ (Java), Visual Fortran (Fortran) e etc. 


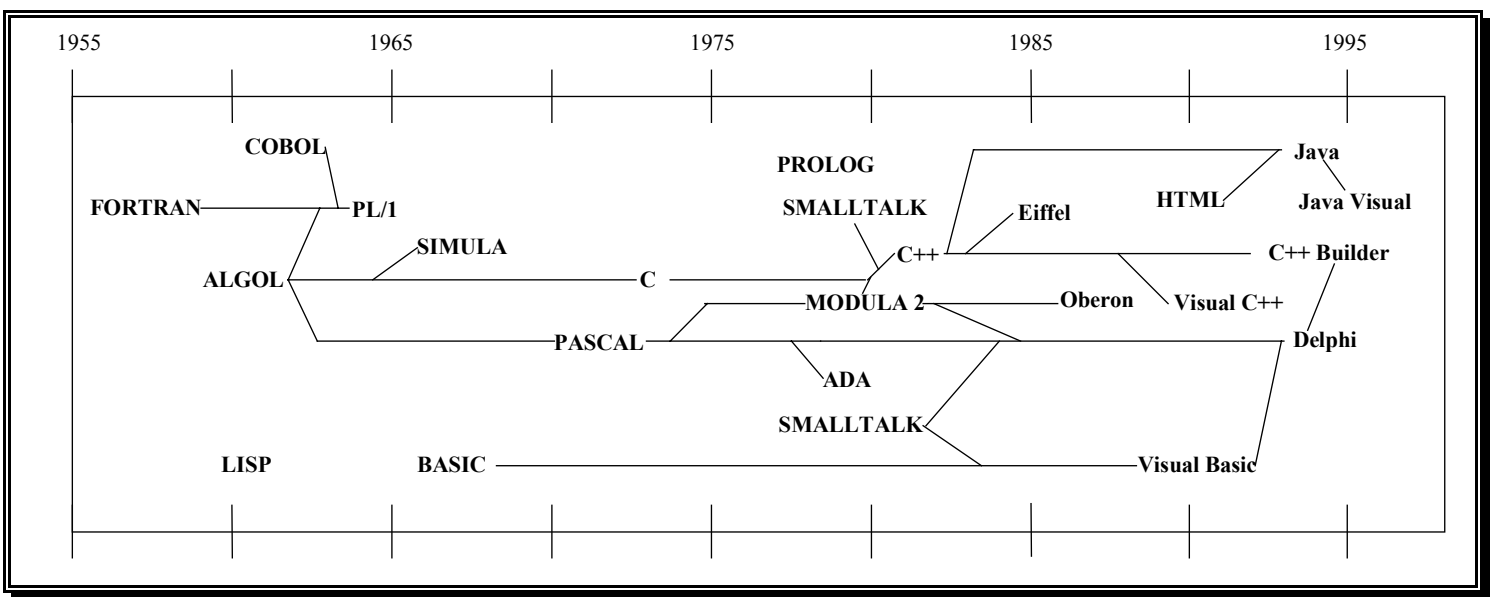

Fig. - 3.7 - Genealogia das Linguagens de Programação.

Podemos dividir as linguagens de programação em duas classes principais: DECLARATIVAS e IMPERATIVAS [Hudak, 1989] [Gregory, 1987]. A semântica para programas imperativos consiste em uma série de comandos obedecidos de forma seqüencial, que embora possuam abstração, ainda são baseados na estrutura dos computadores. Alguns exemplos são o BASIC, O Pascal, Algol, $\mathrm{COBOL}, \mathrm{C}, \mathrm{C}++, \mathrm{ADA}$, Fortran, etc. As linguagens imperativas possuem natureza inerente ao modelo de computação de von Neumann e uma história de evolução e desenvolvimento de 40 anos. Não é de estranhar que essa classe seja a mais difundida e utilizada pela grande maioria dos programadores de todos os níveis. $\mathrm{O}$ advento da computação paralela trouxe uma série de extensões paralelas para as linguagens imperativas, a fim de que estas pudessem explorar o paralelismo, e compiladores paralelos, que tentam extrair 0 paralelismo das linguagens imperativas seqüenciais.

As linguagens declarativas constituem-se de uma série de funções ou predicados lógicos. Como exemplos podemos citar o Prolog, o Lisp, Sisal e etc. Embora considerada por alguns autores [Hockney \& Jesshope, 1988] como menos eficiente que o estilo imperativo de programação, por não ser fundada na estrutura von Neumann, é também considerada de natureza mais paralela, e consequentemente apresenta soluções paralelas mais naturais [Almasi \& Gottlieb, 1994]. Uma outra característica que deve ser atribuída às linguagens declarativas é o seu rigoroso formalismo matemático, que pode auxiliar na temática da complexidade dos programas atuais.

A discussão sobre as vantagens e desvantagens das duas classes ou estilos de linguagem de programação atinge patamares filosóficos, e não podemos 
com certeza designar uma ou outra como a melhor solução para programas complexos ou não, lineares ou paralelos. Embora as linguagens declarativas clamem sua superioridade pelo seu formalismo, elas encontram uma barreira constituída por 40 anos de evolução.

\subsection{2 - ALTERNATIVAS DE PARALELISMO}

Discutiremos a seguir algumas abordagens para explorar o paralelismo através das linguagens de programação (ver Figura 3.1).

Quando um programador tenciona desenvolver um aplicativo paralelo, ele possui quatro possibilidades básicas: paralelismo automático, extensões paralelas para linguagens imperativas, bibliotecas de paralelismo e linguagens não imperativas paralelas.

O paralelismo automático consiste no desenvolvimento de compiladores capazes de analisar o código seqüencial de um programa e paralelizá-lo. Esse tipo de compilador é tipicamente voltado aos programas escritos em Fortran [Almasi \& Gottlieb, 1994]. Embora essa abordagem seja a mais cômoda para o usuário, que não precisa alterar seu código fonte, aprender ferramentas e extensões de linguagens ou ainda aprender linguagens diferentes ou técnicas e estratégias de desenvolvimento de programas paralelos, a performance obtida pelos compiladores, na maioria dos casos, não é satisfatória. A semântica de paralelização demonstra não ser trivial, uma vez que a natureza dos algoritmos para a exploração de paralelismo possui lógica, estrutura e estratégias muito complexas e depende das condições de paralelismo das camadas inferiores. Assim, encontrar um compilador capaz de transformar um programa seqüencial em paralelo com eficiência é um desafio que se algum dia for atingido, exigirá a dedicação de muitas mentes brilhantes. Sem dúvida, essa linha de pesquisa é a mais cobiçada pelos pesquisadores e pela sociedade da computação paralela como um todo, vindo a ser a pedra filosofal do paralelismo.

Uma outra estratégia utilizada para o desenvolvimento de programas paralelos consiste na utilização de extensões paralelas em linguagens imperativas convencionais. Embora essa abordagem requeira maior esforço do programador, que deverá aprender sobre computação paralela e sobre o funcionamento das ferramentas adicionais, por outro lado não será necessário aprender outra linguagem, podendo reutilizar muitas de suas bibliotecas e programas. Deste modo, 


\section{CAPÍTULO 3}

o programador pode utilizar a linguagem com a qual está familiarizado e através do acréscimo de comandos e estruturas específicas para funções paralelas será capaz de explorar o paralelismo. Ainda que esta estratégia seja muito criticada, por manter vínculos com a programação von Neumann, é a mais utilizada atualmente. Através desse tipo de abordagem, pode-se conseguir excelentes performances, dependendo da estratégia de paralelismo adotada pelo programador, que deverá conhecer muito bem a semântica de paralelismo, assim como a estrutura da plataforma paralela utilizada.

Ainda uma alternativa é a utilização de bibliotecas de funções e procedimentos voltadas ao desenvolvimento paralelo. Neste caso, as bibliotecas são utilizadas em linguagens de programação seqüencial permitindo o desenvolvimento de aplicações paralelas.

A última opção que apresentamos é a utilização de uma linguagem não imperativa, com nenhum ou quase nenhum vestígio da estrutura von Neumann. Embora muitos acreditem ser essa a resposta mais pródiga, é também a mais custosa para o programador, que deverá aprender uma nova linguagem, com uma heurística diferente da qual ele está familiarizado, e ainda reescrever todo o seu código para essa nova linguagem.

Podemos considerar dois tipos de linguagens que não apresentam vestígios da arquitetura von Neumann: as linguagens baseadas em predicados lógicos como o Prolog e as linguagens funcionais como o Sisal e outras linguagens voltadas para arquiteturas DataFlow [Duncan, 1990]. Embora existam situações em que a performance do Sisal sobressai ao Fortran, na maioria das vezes a melhor performance obtida é através da utilização de extensões paralelas em linguagens imperativas, entretanto esta é uma área com uma crescente força de pesquisa [Almasi \& Gottlieb, 1994].

Existem linguagens desenvolvidas exclusivamente para a exploração de paralelismo, mas que apresentam estruturas e comandos baseados em linguagens imperativas (Occam [Inmos, 1988]). Este tipo de linguagem é classificada como extensão de linguagens imperativas. 


\subsection{3 - MECANISMOS DE EXPLORAÇÃO DE PARALELISMO}

Dentre as quatro estratégias de paralelismo que apresentamos na seção anterior, estaremos preocupados principalmente em apresentar técnicas voltadas às extensões paralelas das linguagens convencionais $e$ as bibliotecas de paralelismo.

Antes de começarmos a discutir as técnicas básicas de paralelismo, devemos discutir a definição de máquina paralela. Segundo a definição de Almasi e Gottlieb [Almasi \& Gottlieb, 1994], uma máquina paralela é um conjunto de elementos de processamento, capaz de comunicar e cooperar para resolver problemas mais rapidamente. Utilizando-se dessa definição e observando o modelo de camadas do computador moderno apresentado na Figura 3.1, devemos nos lembrar da grande complexidade envolvida na exploração do paralelismo. Abaixo da camada de linguagem de alto nível existem diversas outras camadas que podem, cada uma ao seu modo, executar a exploração do paralelismo. Desse modo, devemos concluir que não existe uma regra ou modelo único capaz de descrever as bases da exploração de paralelismo. Para cada uma das possíveis combinações de exploração de paralelismo, em cada uma das camadas, existem técnicas e estratégias de programação mais adequadas que outras. Desse modo, o conjunto das técnicas de programação é tão vasto quanto o conjunto das combinações de paralelismo das camadas inferiores à sua. Assim, estaremos limitando a discussão deste item às máquinas MIMD genéricas. Devemos lembrar que o universo das máquinas MIMD é bastante abrangente, ocorrendo diversas situações (ex: máquinas MIMD formadas a partir de SIMD - Cray J-90 [Hockney \& Jesshope, 1988]) em que as bases de exploração de paralelismo são um pouco adversas.

Segundo Pratt [Pratt, 1984], em sua forma mais simples, um programa para computador von Neumann é composto por um conjunto de linhas contendo cada uma um único comando, sendo executadas uma após a outra. Existe, no entanto, uma série de procedimentos que nos auxiliam a eliminar essa visão estritamente seqüencial e construir programas mais interessantes. Esses conceitos estão presentes na grande maioria das linguagens atuais de programação e são conhecidas como estruturas de programação. As estruturas de programação permitem que as linhas de programação sejam integradas em estruturas. Dentre 


\section{CAPÍTULO 3}

elas, podemos citar as estruturas de condicionamento (ex: if then else; case), as estruturas de repetições (ex: for; while; repeat), assim como o agrupamento de estruturas ou linhas em blocos ou sub-programas (ex: procedimentos e funções). A diferença entre os comandos e as estruturas de programação são responsáveis pela caracterização das linguagens de programação.

Embora os conceitos de programação estruturada e a aglomeração de linhas em blocos e sub-rotinas sejam bastante conhecidos e importantes na computação seqüencial, são eles também que constituem as bases para a elaboração de programas paralelos. Sem tais conceitos, praticamente seria impossível o desenvolvimento de aplicações paralelas, pois não haveria como realizar a caracterização formal das tarefas a paralelizar.

Os algoritmos correspondentes a um problema geralmente são implementados através das estruturas de programação de forma seqüencial, testados e somente então são paralelizados. Isso ocorre devido à dificuldade de implementação e depuração de programas paralelos. Em termos gerais, as bases para a paralelização de um algoritmo seqüencial obedecem às seguintes tarefas:

Definir quais conjuntos de sub-tarefas podem ser executados em paralelo (dependência de dados).

Quando e como iniciar e finalizar sua execução.

Coordenar e especificar sua interação enquanto estão executando.

A dependência de dados ocorre quando um comando ou operação depende do resultado de outro. Em geral, a sua a análise gera um grafo no estilo do apresentado pela Figura 3.2. Após verificar a dependência de dados, deve-se então decidir quando e como iniciar e finalizar as tarefas paralelas. Existem algumas primitivas básicas comuns, tanto em bibliotecas de extensão paralelas como em linguagens de programação paralelas. São elas: fork/join, parbegin/parend e doall. A Figura 3.8 apresenta um exemplo de comparação entre a estratégia parbegin/parend e fork/join.

Tanto o fork/join quanto o parbegin/parend, possuem o mesmo objetivo: controlar a execução paralela. Na Figura 3.8 podemos observar a diferença entre as duas abordagens. Se por um lado a alternativa parbegin/parend oferece um código mais elegante e simples, sua exploração de paralelismo não é tão flexível quanto fork/join. Outra primitiva bastante comum, que apresenta uma estratégia um 
pouco diferenciada, é a primitiva doall e similares (forall, pardo, etc.), que são voltadas às repetições com exploração de paralelismo. Por serem principalmente empregadas no cálculo de vetores e matrizes, são comuns em linguagens científicas como algumas extensões paralelas do FORTRAN. Embora a abordagem doall seja bastante útil e poderosa, existe um grande número de problemas envolvendo operações com matrizes e vetores, nos quais ocorrem dependência de dados, inviabilizando, deste modo, sua paralelização através desta abordagem.

parbegin/parend

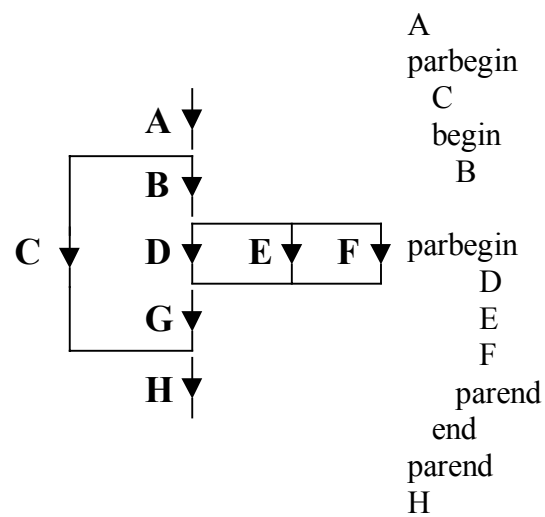

fork/join

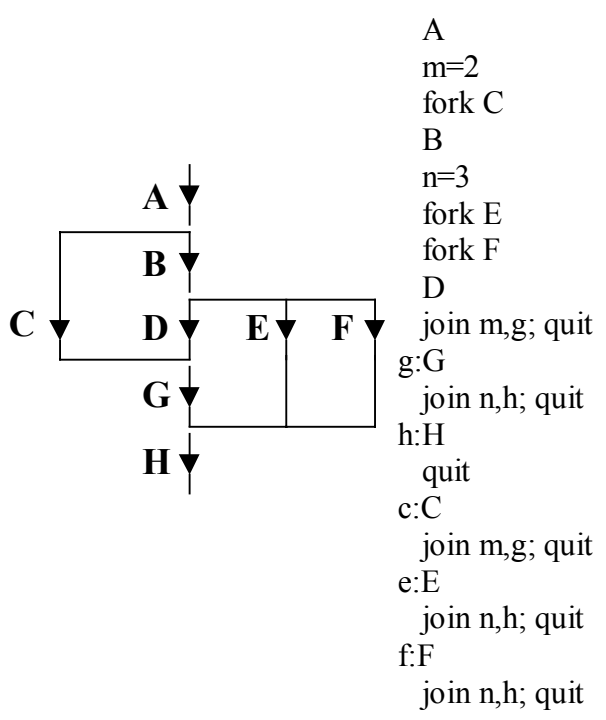

Fig. - 3.8 - Comparação entre parbegin/parend e fork/join, duas alternativas diferentes para controlar a execução paralela [Almasi \& Gottlieb, 1994].

Um conceito igualmente poderoso, que além de ser utilizado em linguagens paralelas ou com extensões paralelas pode ser utilizado em linguagens convencionais, com mecanismos de troca de mensagens (como no caso do CVMP apresentado nesse trabalho), é o conceito de sub-programas paralelos ou subrotinas paralelas. Nesse caso, um programa é capaz de ativar um ou mais subprogramas de modo a gerar execução paralela ou concorrente. Em geral, esses mecanismos utilizam o conceito de processos e "threads" providos pelo sistema operacional, comentados na Seção 3.6. A Figura 3.9 apresenta uma árvore de execução paralela, ilustrando este conceito. Nela podemos observar os processos representados por retângulos. O processo principal executa diversos outros sub- 
processos. Este exemplo foi implementado utilizando a concepção de chamada de processos da linguagem PL/1. PL/1 foi uma das primeiras linguagens que possibilitou a execução de processos concorrentes, porém ela não viabilizava nenhuma espécie de controle, sincronismo ou coordenação dos processos, o que inviabilizava o desenvolvimento de aplicações paralelas. Atualmente a linguagem PL/1 não é mais utilizada, apresentando apenas interesse histórico e didático.

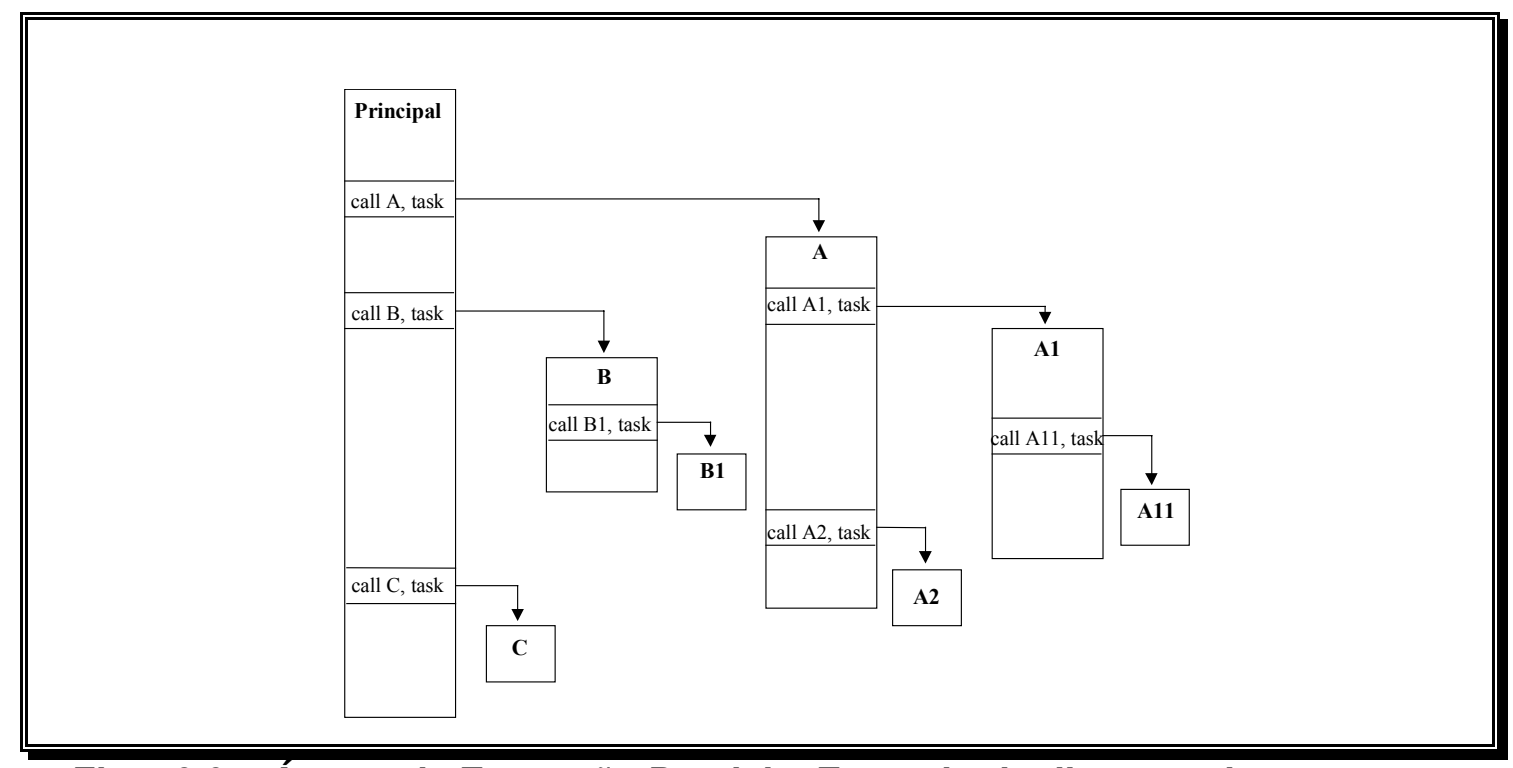

Fig. - 3.9 - Árvore de Execução Paralela. Exemplo de disparos de processos realizados a partir da linguagem $P L / 1$.

A necessidade de sincronismo ou coordenação dos processos paralelos surge devido à necessidade de uma melhor exploração do paralelismo e principalmente pela dependência de dados entre os processos. Além da coordenação dos processos, um outro fator muito importante na exploração do paralelismo é a comunicação entre processos, permitindo a estes trocar informações referentes à dependência dos dados durante sua execução.

Existem diversas estratégias de coordenação de processos e tarefas. Discutiremos sucintamente algumas estratégias utilizadas para a comunicação e sincronismo em máquinas MIMD com memória distribuída e MIMD com memória compartilhada. Caso o leitor deseje entrar em detalhes, encontrará uma ampla abordagem em: [Almasi \& Gottlieb, 1994] [Amorin et al.,1988] [Brawer, 1989] [Codenoti \& Leoncini, 1994] [Foster, 1995] [Krishnamurthy, 1989] [Quinn, 1987].

As técnicas utilizadas para comunicação são, na grande maioria das vezes, 
utilizadas para o sincronismo, variando de acordo com as camadas de hardware. Em máquinas de memória compartilhada, o meio mais usual de comunicação consiste nas variáveis compartilhadas. As variáveis compartilhadas são variáveis de processos diferentes, declaradas no mesmo endereço de memória, que permitem, aos diferentes processos ou tarefas (em diferentes processadores ou não) trocar informações. Devido à sua arquitetura, os processadores das máquinas de memória compartilhada podem ter acesso aos mesmos endereços de memória, e graças a esta possibilidade é viabilizado o mecanismo de comunicação via variável compartilhada.

As máquinas que possuem memória distribuída, devido à sua arquitetura, não permitem que diferentes processadores acessem o mesmo endereço de memória, e portanto não permitem variáveis compartilhadas. Entretanto, a comunicação nas máquinas de memória distribuída é realizada através de uma técnica denominada de passagem de mensagens. A passagem de mensagens consiste na transferência de informações através da rede (ou memória, no casos de sua utilização em sistemas de memória compartilhada) que faz a conexão entre os processadores (ou computadores). Os processos são capazes de efetuar a comunicação via passagem de mensagens na rede através das primitivas SEND e RECEIVE. É importante observar que algumas linguagens possuem suporte para uma única abordagem (ex: Occam [Inmos, 1988b]) ou ainda para as duas abordagens, como é o caso da técnica Rendezvous da linguagem Ada [Naiditch, 1995].

Através dos mecanismos de comunicação são realizados o sincronismo e a coordenação dos processos paralelos. Em termos gerais, a coordenação de processos é realizada através da sincronização. Segundo Andrews e Schneider [Andrews \& Schneider, 1983], o sincronismo entre processos concorrentes pode ser visto como um paradigma de ação e reação. Em outras palavras, o sincronismo ocorre quando um processo envia uma mensagem (memória distribuída) ou atribui determinado valor a uma variável compartilhada (memória compartilhada) e um outro processo executa uma determinada ação mediante a detecção dessa ordem (alteração do valor de uma variável ou mensagem). Através dessa concepção podemos conceber os mecanismos de sincronização de processos como um mecanismo de espera na execução dos processos, que são disparados mediante eventos.

Existem uma série de estratégias de sincronismo de processos, entre elas: 
testa e continua, semáforos, barreiras, RPC, monitores e etc. Não iremos abordálas aqui, porém essas estratégias podem ser melhor estudas em [Almasi \& Gottlieb, 1994] [Amorin et al.,1988] [Brawer, 1989] [Codenoti \& Leoncini, 1994] [Foster, 1995] [Krishnamurthy, 1989] [Quinn, 1987]. O princípio básico dessas estratégias é a atualização e a verificação de variáveis, que indicam a condição ou ordem de outro ou outros processos, sendo possível implementá-las utilizando técnicas de passagem de mensagem ou memória compartilhada.

A Figura 3.10 apresenta um exemplo genérico de aplicação paralela que utiliza o conceito de processos paralelos coordenados. Neste exemplo temos uma máquina composta por três processadores. Os processos são representados pelas caixas cinzas, e a comunicação e sincronismo entre os processos pelas setas. É importante observar a dependência de dados entre os processos.

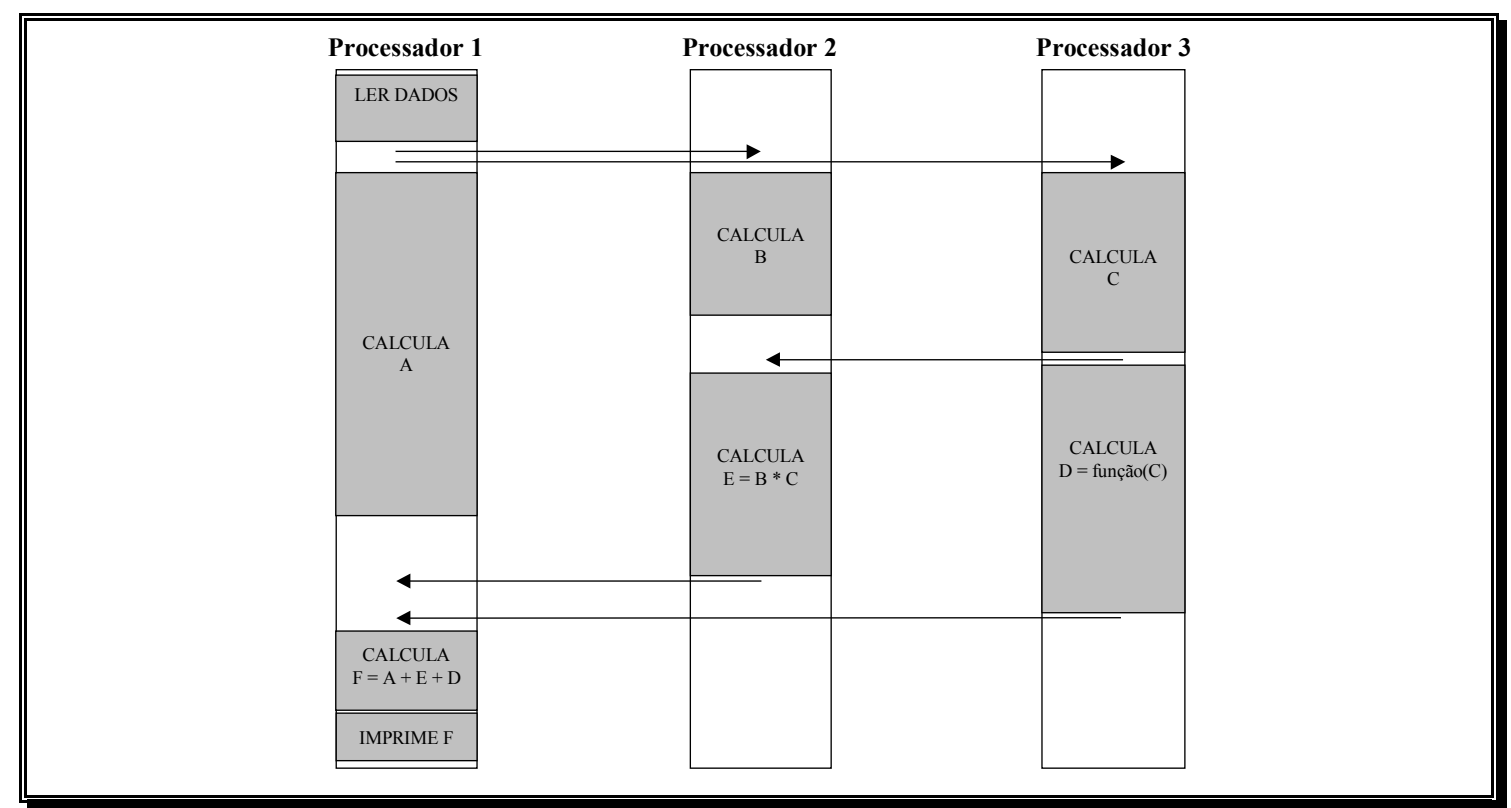

Fig. - 3.10 - Exemplo genérico de uma aplicação paralela com coordenação de processos e dependência de dados.

\section{8 - FerRamentas de Passagem de Mensagem EM SISTEMAS DISTRIBUÍDOS}

Conforme comentamos na Seção 2.5.5, sistemas distribuídos são conjuntos de computadores conectados por rede, que podem executar um trabalho cooperativo explorando o paralelismo. Para implementar uma aplicação distribuída, 
ou seja, uma aplicação que aproveitará o recurso computacional do sistema distribuído, é necessário utilizar ferramentas que realizem a comunicação através da rede. Denominadas ferramentas de passagem de mensagem, são de modo geral, extensões ou bibliotecas, que permitem ao programador utilizar linguagens de programação convencionais e efetuar a troca de mensagens entre as máquinas. Existem diversas ferramentas de troca de mensagens, dentre as quais podemos citar: P4, PVM, MPI, Express, e PARMACS [Geist et al., 1996] [Foster, 1995] [Pacheco, 1997] [Almasi \& Gottlieb, 1994], além do CVMP, introduzido nesta tese. Vamos discutir sucintamente as ferramentas mais populares: PVM e MPI. Depois faremos uma pequena introdução ao CVMP.

\subsection{1 - O PACOTE PVM}

O PVM, cujo nome provem do inglês "Parallel Virtual Machine", foi inicialmente desenvolvido em 1989 no Oak Ridge National Laboratory (ORNL). Trata-se de um pacote de software que permite utilizar uma coleção heterogênea de computadores conectados em rede como se fossem uma única máquina paralela (sistema distribuído) [Geist et al., 1996]. Uma das principais propostas de sistema heterogêneo formulada pelo PVM é a integração de máquinas seqüenciais, paralelas e vetoriais formando uma única enorme máquina de memória distribuída.

O pacote PVM é dividido em duas partes: um controlador de processos denominado de daemon (ou simplesmente pvmd) e uma biblioteca de rotinas. $\mathrm{O}$ pvmd é uma aplicação que deve rodar em todas as máquinas, a fim de implementar a integração destas. Funciona basicamente como um servidor de recursos residente em cada uma das máquinas, e é através dele que as rotinas PVM são capazes de se comunicar. Deste modo, a principal função do módulo pvmd é implementar o conceito de máquina virtual paralela. A biblioteca de rotinas PVM consiste de um conjunto de primitivas para a comunicação, coordenação de processos e conversão de dados. Ela funciona como uma biblioteca de extensão para uma linguagem de programação convencional, de modo que as chamadas para rotinas PVM são usadas em conjunto com o código fonte original. A biblioteca PVM possui dezenas de funções, constituindo um complexo de comunicação de processos.

Embora o pacote PVM tenha sido originalmente desenvolvido para rodar em máquinas com sistema operacional UNIX, atualmente existem pacotes para 0 


\section{CAPÍTULO 3}

sistema operacional Windows NT/9X, além de encontrar-se em desenvolvimento uma versão baseada em Java [PVM]. Em relação à sua biblioteca de rotinas, o PVM não pode ser utilizado por qualquer linguagem de programação, possuindo atualmente versões para as linguagens $\mathrm{C}, \mathrm{C}++$ e Fortran.

O modelo computacional do PVM é baseado na noção de que uma aplicação consiste em muitas tarefas e cada tarefa é responsável por uma parte do trabalho computacional da aplicação. O paralelismo ocorre na execução em concorrência dessas tarefas, através de diferentes processos sendo executados em diferentes máquinas num ambiente de troca de mensagens. Deste modo, o PVM foi projetado para promover um ambiente de troca de mensagens, onde diversos processos podem se comunicar (granularidade preferivelmente grande). Uma característica das aplicações PVM é a sua preferência pelo modelo SPMD (do inglês "Single Program Multiple Data"). Dentro dessa abordagem, em cada processador o mesmo programa é executado, porém processando dados diferentes.

\subsection{2 - A BIBLIOTECA MPI}

O MPI [Pacheco, 1997] [Foster, 1995], cujo nome é derivado do inglês "Message Passing Interface", é o resultado de uma tentativa de implantar um padrão nas interfaces de passagem de mensagem. O MPI foi criado a partir de um consórcio envolvendo cerca de quarenta organizações da comunidade de processamento paralelo mundial (sendo a grande maioria dos Estados Unidos e da Europa), contando com representantes de diversas áreas: indústria, comércio e universidade. Em 1992 iniciou-se o desenvolvimento do MPI, surgindo sua primeira versão funcional em 1994. O MPI é similar ao PVM, trata-se de uma ferramenta voltada a comunicar máquinas heterogêneas em plataforma UNIX conectadas via rede, gerando um ambiente de troca de mensagens. A principal diferenciação entre as duas ferramentas é que o MPI é composto apenas por uma biblioteca de rotinas, não possuindo nenhum outro componente.

A biblioteca MPI é um conjunto complexo de 129 funções, das quais muitas apresentam numerosos parâmetros e variantes, que caracterizam seu poder e sua complexidade. Do mesmo modo que o PVM, o MPI possui variantes para apenas três linguagens de programação, sendo elas a linguagem $C, C++$ e Fortran.

No modelo de programação MPI, a computação compreende em um ou 
mais processos que se comunicam através de chamadas à biblioteca de rotinas (MPI). Essas rotinas são utilizadas para enviar e receber mensagens para outros processos. Na maioria da implementações MPI, um número fixo de processos é criado no início do programa, onde cada processo pertence a um determinado processador ou máquina.

Os sistemas MPI apresentam um número fixo de processos. Existem diferentes abordagens para a comunicação entre os processos, podendo haver comunicação individual e coletiva. Na comunicação individual, ou ponto a ponto, os processos enviam mensagens para outros determinados processos através da comunicação individual. Na comunicação coletiva, um único processo ou um grupo de processos enviam mensagem para um grupo de processos. Além dessas características de comunicação, uma interessante abordagem adotada pelo MPI é o conceito de modularidade. Esse conceito é bastante importante, principalmente sob o ponto de vista da engenharia de software. Um mecanismo denominado de comunicador permite que o programador MPI possa definir módulos que incorporem estruturas internas de comunicação.

\subsection{3 - O PACOTE CVMP}

Nesta seção vamos fazer uma breve apresentação do pacote CVMP, que será abordado ao longo desta tese.

O nome CVMP é derivado do inglês "Cybernetic Vision Message Passage", tratando-se de um pacote de exploração de paralelismo similar ao MPI e ao PVM, onde são fornecidas ferramentas de programação para auxiliar o desenvolvimento de aplicações paralelas. O CVMP foi desenvolvido ao longo de nosso trabalho no Grupo de Pesquisa em Visão Cibernética do IFSC/USP com o intuito de auxiliar no desenvolvimento dos projetos que necessitem da exploração de paralelismo. No decorrer da pesquisa de nosso grupo, observou-se a necessidade de desenvolvimento de sistemas e aplicações paralelas, devido à grande demanda de poder computacional exigida pelos experimentos nas áreas de Visão Computacional e Processamento de Imagens. Embora existam diversos pacotes de exploração de paralelismo, nossa pesquisa constatou a necessidade da elaboração de um pacote de simples utilização, adequado ao parque de computadores pessoais e à plataforma Windows, e que fosse nativo a uma linguagem de programação visual, para facilitar ao máximo a sua programação, além de conter 


\section{CAPÍTULO 3}

ferramentas específicas para a pesquisa em Visão Computacional e Processamento de Imagens.

Procurando atender a essas premissas, as quais não foram encontradas integralmente em nenhum pacote de exploração de paralelismo atual, decidimos implementar o CVMP. Deste modo, o CVMP é um pacote de exploração de paralelismo baseado em troca de mensagens, de simples utilização, capaz de efetivar a comunicação, controle e sincronismo em: (i) ambientes distribuídos constituídos por computadores pessoais em plataforma Windows 95/NT conectados via rede e (ii) máquinas multiprocessadas. A proposta CVMP busca a simplicidade de desenvolvimento de aplicações paralelas, sendo os principais objetivos do projeto:

\footnotetext{
Simples utilização - prover a possibilidade de implementação paralela a programadores sem experiência ou especialidade em computação paralela e sistemas distribuídos, mas que necessitem desenvolver aplicações paralelas (característica da maioria dos pesquisadores em visão e processamento de sinais);
}

Ser nativo para a plataforma Windows NT/9X - Utilizada pela grande maioria dos usuários;

Operacionalidade em ambientes de programação visual - Os ambientes de programação visual (Delphi, Visual Basic e etc.) proporcionam ferramentas para facilitar o desenvolvimento de aplicações, facilitando o processo de programação. Deste modo possuem a importante característica de proporcionar uma boa ferramenta de programação para todo o universo de programadores (inexperiente / experiente );

Prover mecanismos para facilitar o desenvolvimento de algoritmos de Visão Computacional e processamento de sinais em paralelo.

Com base nesses objetivos e nas necessidades dos projetos do grupo, desenvolvemos o pacote CVMP, através do qual, o usuário é capaz de implementar uma aplicação paralela, realizar análise de performance e localizar gargalos.

A comunicação dos processos através do CVMP está baseada no conceito de Canal Virtual. O Canal Virtual, é um conceito de canal de comunicação, inspirado nos processadores Transputer [Inmos, 1988] [Inmos, 1989]. Através dos Canais Virtuais, os objetos CVMP podem trocar mensagens e deste modo 
possibilitar a comunicação entre os processos. Os Canais Virtuais são estabelecidos a partir de um par de objetos CVMP, onde um componente é mestre e o outro é escravo. Uma vez estabelecido, o Canal Virtual não poderá mais ser alterado. Essa característica simplifica bastante o controle e a programação do ponto de vista do usuário [Bruno \& Costa, 2000] [Bruno \& Costa, 1996] [Bruno \& Costa, 1997].

Os componentes ou objetos CVMP são VCLs (Visual Component Library) [Konopka, 1997] compatíveis com os ambientes de programação Borland Delphi [Calvert, 1999] e C++ Builder [Calvert, 1997]. Possuem características de programação orientada a objetos, podendo ser programados visualmente e deste modo ser simples de usar. Funcionam em computadores com plataforma Windows NT/9X, conectados via rede (ethernet, fast-ethernet ou ATM) através dos protocolos de rede TCP/IP [Bennett, 1997] e IPX/SX [Chappell, 1998], assim como em máquinas multiprocessadas, através de variáveis compartilhadas.

Diferentemente do PVM e MPI, o CVMP possui caráter homogêneo. Do ponto de vista da plataforma, todos os micros deverão estar executando Windows 9X/NT. A sua principal característica é a simples utilização do pacote, permitindo a pesquisadores e programadores de diversas áreas a exploração de paralelismo em seus algoritmos. Essa característica se acentua para algoritmos voltados para Visão Computacional e Processamento de Sinais.

\section{9 - DESENVOLVIMENTO DE SOFTWARE}

Nesta seção iremos abordar brevemente algumas técnicas, conceitos e ferramentas, que auxiliam no desenvolvimento de software. De um modo geral, os conceitos genéricos de desenvolvimento de software paralelo são similares aos de software seqüencial. Iniciaremos a discussão através de uma breve apresentação da engenharia de software, que constitui de uma série de ferramentas, métodos e procedimentos para formalizar o desenvolvimento de software. Em seguida comentaremos um pouco sobre a avaliação e teste de software, apresentando o revolucionário conceito de programação orientada a objetos, e passando para interfaces gráficas com o usuário e programação visual. Finalmente terminaremos esta seção discutindo técnicas de análise de desempenho de programas paralelos e a engenharia da utilização. 


\subsection{1 - ENGENHARIA DE SOFTWARE}

As primeiras décadas da história da computação marcaram o domínio do hardware, quando este era considerado o maior desafio da Ciência da Computação, deixando o software em segundo plano. O conjunto de normas, organização, ferramentas e metodologias utilizadas no desenvolvimento de hardware foi denominado de Engenharia de Hardware, que na realidade tratava-se de mais uma especialização da Engenharia Elétrica. Através da Engenharia de Hardware, o custo e o tempo de desenvolvimento de um novo sistema podia ser objetivamente calculado e estimado.

De um modo geral, não havia a comercialização e industrialização do software, como conseqüência, este era desenvolvido dentro das empresas, pelas mesmas pessoas que iriam utilizá-los e em caso de erros corrigi-los. Esse tipo de abordagem permitia que o desenvolvimento de software fosse realizado sem qualquer tipo de formalismo, métodos, normas e documentação. Dentro desse ambiente, o mundo do software estava completamente indisciplinado, acarretando na crise do software (final da década de 1970), responsável pela improdutividade, alto custo, insatisfação dos consumidores, longo período de desenvolvimento, baixa qualidade, difícil manutenção, etc. [Pressman, 1988]

$\mathrm{Na}$ tentativa de ordenar a criação, implementação e manutenção de software, surgiu a Engenharia de Software, que compreende uma série de metodologias, critérios, conceitos, ferramentas, que possibilitaram a formalização do software.

Segundo Pressman [Pressman, 1988], o software pode ser definido como:

Instruções (programas de computadores) que quando executadas fazem com que o hardware proceda de acordo com a sua programação.

Estrutura de dados que permitem aos programas manipular adequadamente informações.

A documentação que descreve a operação e a utilização dos programas.

Dentro da filosofia da engenharia de software, os projetos são desenvolvidos em ciclos. Esta abordagem é denominada de Paradigma de Engenharia de Software [Pressman, 1988]. Cada projeto possui um paradigma apropriado, sendo escolhido de acordo com sua natureza e de sua aplicação. Embora existam 
diversos paradigmas diferentes, apresentamos na Figura 3.11 um modelo clássico de ciclo de vida de um software.

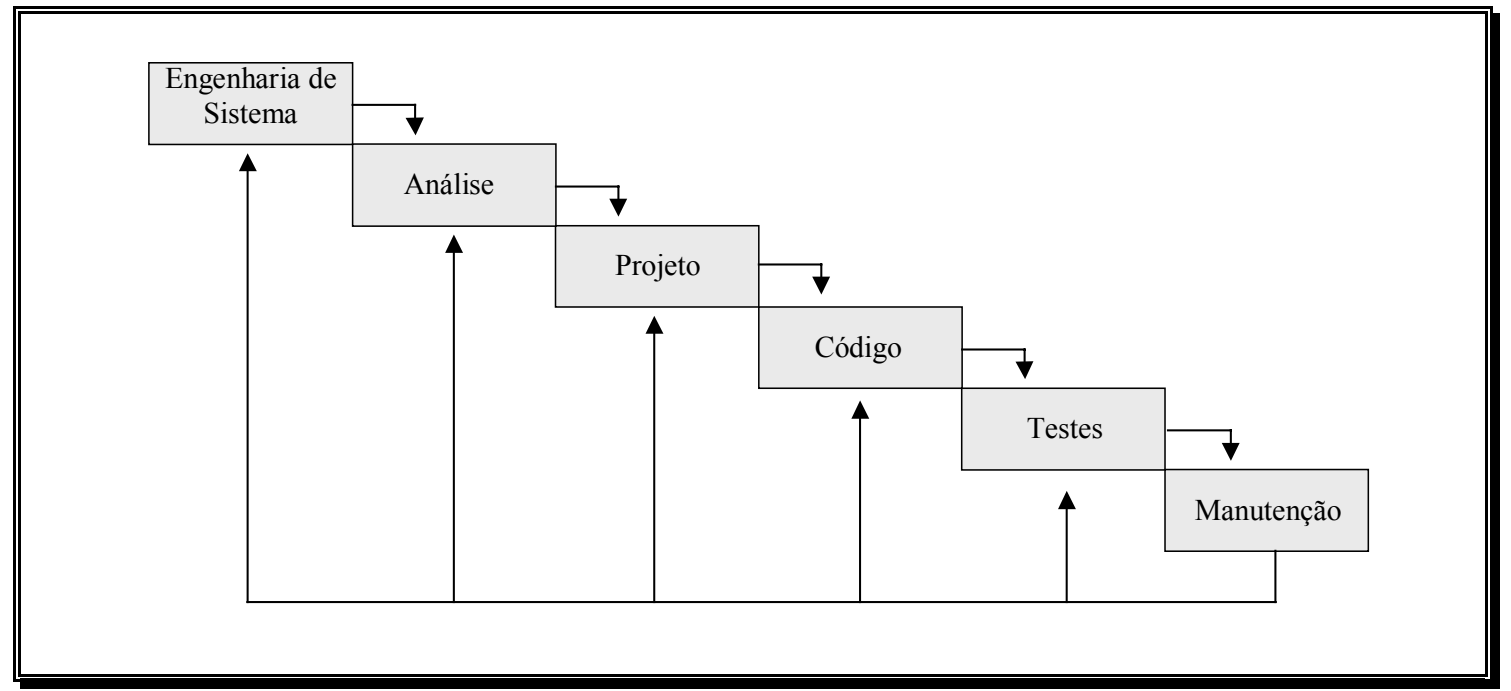

Fig. - 3.11 - Ciclo de vida clássico de um software.

O projeto de software é dividido em três fases: definição, desenvolvimento e manutenção. Cada uma destas fases possuem diversas metodologias, procedimentos, análises e ferramentas. Segundo a Engenharia de Software tem demonstrado, a forte formalização dos processos de criação, produção e manutenção do software, faz com que o projeto de software apresente uma previsão de tempo, custo e qualidade previamente determinados, assim como nas demais áreas da engenharia.

A engenharia de software tem também como objetivo o desenvolvimento de ferramentas de auxílio à modelagem e desenvolvimento de software. Dentre estas, devemos comentar o CASE (do inglês "Computer Aided Software Engineering"). Através de ferramentas CASE, algumas tarefas repetitivas de programação podem ser substituídas pela geração automática de código. Dentre as ferramentas CASE, destacam-se as voltadas ao desenvolvimento de software que utilizam base de dados e também as ferramentas de geração automática de interfaces para aplicações direcionadas para ambientes GUI [Bruno, 1995]. As ferramentas CASE voltadas para base de dados possibilitam a geração de código a partir da diagramação de metodologias de análise de dados (DFD) [Pressman, 1988].

As ferramentas CASE voltadas à interfaces, embora possuam versões voltadas a ambientes CLI [Hayes, 1990] são especialmente úteis em ambientes GUI (veja Seção 9.4). Conforme é apresentado por [Bruno, 1995], as aplicações 
voltadas para ambientes GUI por mais simples que sejam envolvem uma complexa programação de sua interface, uma vez que se preocupam muito mais com o usuário. A complexidade do tratamento da interface faz com que muitas linhas de código sejam necessárias para implementar uma simples aplicação GUI, tornando as ferramentas CASE vitais, uma vez que geram o código da camada de interface automaticamente, poupando o programador dessa tarefa maçante e muitas vezes repetitiva.

Através de ferramentas CASE para GUI originou-se o conceito de programação visual, que é tratado na Seção 3.9.5.

\subsection{2 - AVALIAÇÃO E TESTES}

A avaliação e testes de um software é uma das etapas que mais tomam tempo no projeto (cerca de $40 \%$ do tempo total [Pressman, 1988]). Em alguns casos extremos, como controle de vôo ou reatores nucleares, a fase de teste pode custar três a quatro vezes mais que todas as outras etapas juntas. Os principais objetivos para a realização dos testes nos projetos de software é a qualidade e o funcionamento correto do software

Conforme podemos observar na Figura 3.11, a etapa de avaliação e testes de um software é uma das últimas a ser realizada num projeto de engenharia de software. Na fase de testes são localizados os erros cometidos nas fases anteriores do projeto. Uma vez localizados, deve-se voltar à fase onde estes ocorreram, alterá-los e repetir os testes novamente, fazendo com que a depuração desenvolva um ciclo.

Existem duas alternativas para a realização da fase de testes: manual e automática. Enquanto na manual o software é analisado por usuários, a automática consiste de um outro software, capaz de efetuar a análise de forma automática. Devido à complexidade de implementação do software de análise, também conhecido como CASE de teste ou depuração, a grande maioria dos testes é realizado manualmente.

Quando um erro é detectado indicando alguma falha de programação, pode ser facilmente localizado ou não através do código fonte. Quando os erros não são facilmente detectados a partir da análise do código, o programador utiliza algumas ferramentas de auxílio à programação, tais como o "debbuger" e o "trace", disponíveis na grande maioria dos ambientes de programação. 
Em computação paralela, o teste do software é uma tarefa ainda mais trabalhosa, uma vez que as situações de análise não estão mais dispostas de modo seqüencial. Cada código distribuído entre os processadores do sistema deve ser analisado em conjunto, e em algumas situações as falhas não são claramente detectadas independentemente. Atualmente, a maioria dos sistemas de computação paralela, especialmente os de computação distribuída, não possuem ferramentas específicas para a depuração de erros, utilizando versões como as dos sistemas seqüenciais, tornando a análise e teste de software paralelo bastante complexa.

\subsection{3 - PROGRAMAÇÃo ORIENTADA A OBJETOS}

A programação orientada a objetos ou OOP (abreviação do inglês "ObjectOriented Programming"), embora tenha sido iniciada com o Simula, despontou juntamente com os projetos do PARC (Palo Alto Research Center) da Xerox. O PARC percorreu toda a década de 70 pesquisando e obteve em meados da década de 80 um novo conceito de interface entre homem-máquina, a interface gráfica com o usuário, também denominada de GUI (abreviação do inglês "Graphical User Interface"). Embora intimamente ligada, ao conceito de GUI, a programação orientada a objeto não depende necessariamente desse conceito, uma vez que é um paradigma ligado ao modo de programação.

O principio básico da OOP é abstrair o software e modelá-lo a partir do conceito de objetos, existente no mundo real [Cox, 1986] [Pressman, 1988]. A Figura 3.12 apresenta o paradigma OOP segundo o Smalltalk [Hurson et al., 1993]. Vamos a seguir apresentar alguns conceitos básicos sobre OOP. Um objeto é, basicamente, um pacote de informações (dados) e as descrições de suas formas de manipulação (métodos). Uma das principais características dos objetos é a encapsulação, ou seja, os dados de um objeto são protegidos do mundo exterior, sendo inacessíveis. O único meio de obter acesso a esses dados é através do envio de mensagens aos seus métodos, onde a mensagem é definida como uma especificação para um método do objeto. O método é uma entidade (como um procedimento) que descreve uma seqüência de ações a serem realizadas. Algumas mensagens possuem a característica de requerer um retorno, nesses casos, após a execução do método, a informação solicitada é retornada. Os objetos são definidos e agrupados através de classes [Bruno, 1995], as quais são constituídas por 
declarações formais.

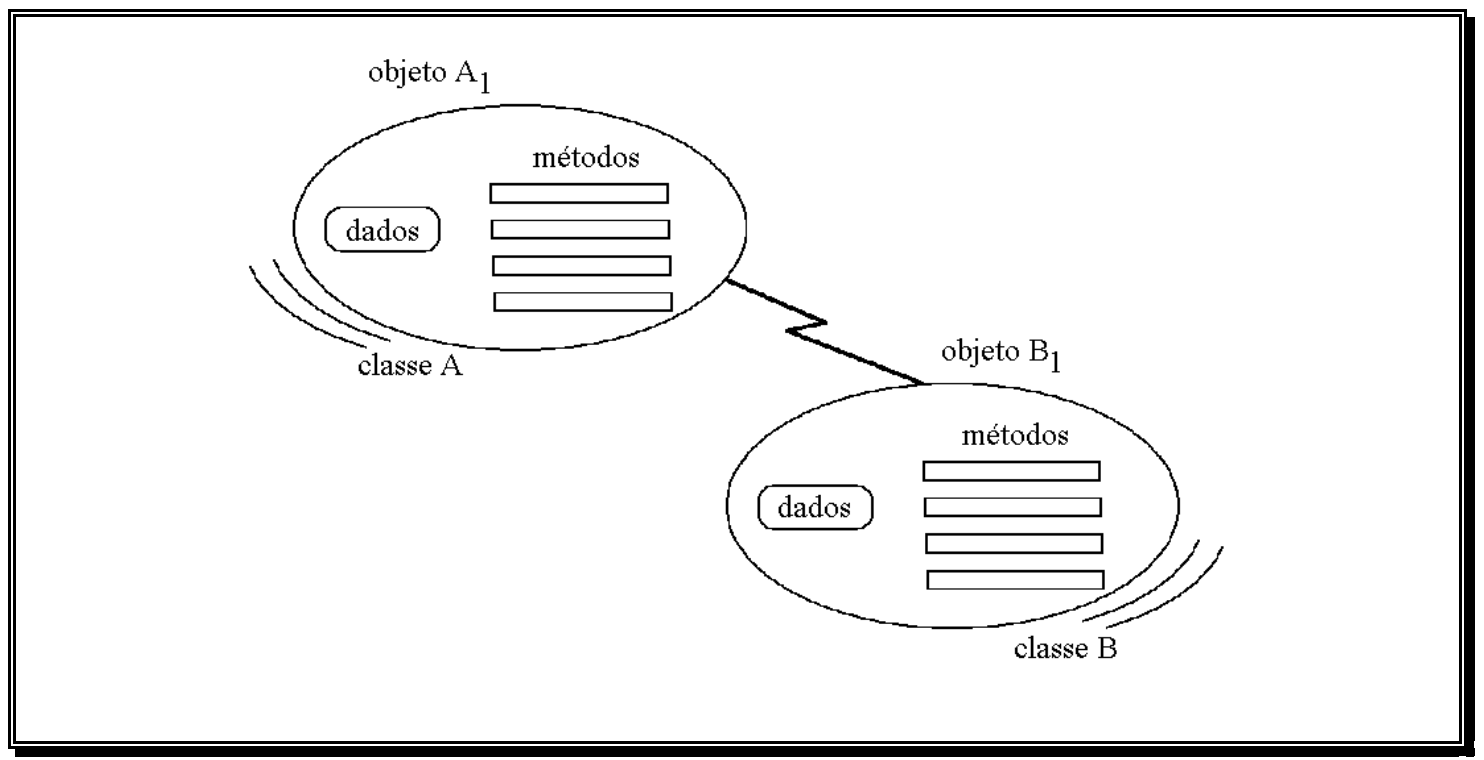

Fig. - 3.12 - Concepção de Objeto.

A OOP possui diversas características tais como: organização hierárquica, herança, polimorfismo, facilidade de agrupamento ordenado, abstração de dados, reutilização de código, encapsulação, entre outras.

A OOP possibilita um grande auxilio à engenharia de software, através da abstração de dados, encapsulação e reutilização de código. Essas características tornam o paradigma OOP muito vantajoso para grandes projetos, facilitando a independência entre os programadores e a integração de trabalho no desenvolvimento do software e proporcionando também a reabilitação e reciclagem de software.

Uma outra característica muito relevante da OOP, especialmente para o assunto deste capítulo, é sua abordagem paralela. Devido à arquitetura encapsulada e orientada às mensagens, o paradigma OOP é caracterizado por apresentar uma abordagem natural ao paralelismo. Se observarmos os modelos de arquitetura MIMD distribuídos (ver Seção 2.5.5) poderemos constatar que são muito semelhantes ao modelo OOP, especialmente no que se refere ao encapsulamento dos dados e a comunicação entre objetos por troca de mensagens.

Outra característica do paradigma que beneficia a implementação de aplicações paralelas, é a facilidade e a versatilidade para modelar situações complexas, uma vez que as aplicações paralelas envolvem algoritmos complexos. Este fato deve ser bastante considerado, já que um dos maiores obstáculos para o 
desenvolvimento de programas paralelos está exatamente na sua complexidade e dificuldade de implementação.

\subsection{4 - INTERFACE GRÁFICA COM O USUÁRIO (GUI)}

Nesta seção vamos abordar a revolucionária interface gráfica com o usuário (GUI). Durante toda a década de 70 e início da década de 80 este novo conceito de interface entre homem-máquina foi pesquisado pelo PARC (Palo Alto Research Center) da Xerox. Atualmente utilizado em larga escala na maioria das plataformas dos computadores, a GUI tem a sua principal característica no conceito de utilização do dispositivo de exibição de forma virtual, possibilitando que o usuário interaja virtualmente com a máquina arrastando ícones, clicando botões e manipulando dispositivos de controle diretamente na tela.

\subsubsection{1 - DEFINIÇÃO DE GUI}

O primeiro dispositivo que forneceu uma interface interativa homem máquina, largamente utilizado nos primórdios da computação (décadas de 50 e 60), foram as "teletypewriters" (TTYs), terminais baseados em caracteres, onde cada caracter digitado era impresso em papel. Com o aprimoramento tecnológico, tornaram-se disponíveis os terminais de vídeo (baseados em caracteres). Pela incontestável superioridade de interação sobre os TTYs, os terminais de vídeo rapidamente tornaram-se uma norma na computação [Hayes, 1990]. Nestes sistemas baseados em caracteres, a interface com o usuário adotada era a interface de linhas de comando (CLI do inglês "command-line interface"), que vem sendo utilizada até os dias de hoje.

Os sistemas operacionais com interface CLI, como o DOS ou o UNIX, vêm sendo criticados ao longo do tempo pela complexidade de suas interfaces com o usuário. Desenvolvido para ser utilizado em minicomputadores, o UNIX foi criado como um conjunto de aplicações compartilháveis, que dispunham de uma interface orientada a linha (CLI). Esta interface foi revolucionária em seu tempo, por sua simplicidade e poder. O UNIX introduziu o conceito de "shell", um interpretador de comandos, que lê e executa as linhas de comando provenientes do teclado [Peddie, 1992]. O DOS foi implementado mediante este conceito muitos anos depois.

Os pesquisadores do Xerox PARC, contudo, estavam trabalhando com uma idéia diferente. Pesquisavam uma interface que substituísse as linhas de comando 


\section{CAPÍTULO 3}

e as telas de caracteres, por telas gráficas com grandes mapas de bits, através das quais os comandos seriam exibidos graficamente (na forma icônica). Assim a interface com o computador seria de forma "visual" [Peddie, 1992] [Petzold \& Yao, 1996].

Para isso, os pesquisadores do PARC precisaram revolucionar o conceito de monitor de vídeo. Antigamente, o monitor de vídeo, era utilizado somente para reproduzir o texto que o usuário digitava no teclado. Com a nova concepção o monitor, através de um apontador (no caso o "mouse", também criado na Xerox PARC), transformava-se numa verdadeira fonte de entrada de dados [Petzold \& Yao, 1996]. A tela do monitor de vídeo passa agora a exibir objetos gráficos na forma de ícones e janelas com dispositivos que são verdadeiros comandos "virtuais", como botões, barras de rolagem, menus, etc. Esses são manipulados virtualmente pelo usuário, através do apontador e também do teclado. A Figura 3.13 apresenta o aspecto visual de uma interface gráfica com o usuário (GUI).

Os gráficos fazem uma utilização melhor da tela, transmitindo informações de maneira visual mais rica. $\mathrm{E}$ a combinação da exibição rica com a manipulação virtual dos gráficos fez das GUls uma nova etapa evolutiva da interface homemmáquina. Deste modo com evolução de CLls para GUls, trabalhamos com um computador menos abstrato e mais "real" [Peddie, 1992] [Petzold \& Yao, 1996].

Durante décadas, pesquisas tem sido realizadas com o intuito de desenvolver arquiteturas que aproveitem melhor o "software". Nestas pesquisas apareceram questões em relação a prioridades; as interfaces devem ser projetadas a fim de que os usuários experientes tirem, ao máximo, o proveito das máquinas, ou a fim de otimizar a curva de aprendizado dos iniciantes ? [Hayes, 1990].

As interfaces gráficas com o usuário demostraram ser uma resposta efetiva para as questões de prioridade, na interface homem - máquina [Hayes, 1990]. Com esta nova tecnologia, a utilização da máquina satisfaz todos os níveis de usuários: [Peddie, 1992]

usuário iniciante, através da simplicidade de utilização, interação e conceitos intuitivos, imediatamente torna-se hábil para utilizar alguns recursos da máquina. O treinamento torna-se então rápido e eficaz, não necessitando de leitura de manuais extensos, e o aprendiz rapidamente está hábil a ser "mestre".

usuário casual, que executa várias diferentes aplicações diariamente, encontra a consistência do padrão entre as diferentes aplicações.

E o usuário experiente ("power user"), também é beneficiado por executar suas 
tarefas com maior interação. Ele se beneficia do maior número de recursos providos com o novo sistema (ex: multitarefa).

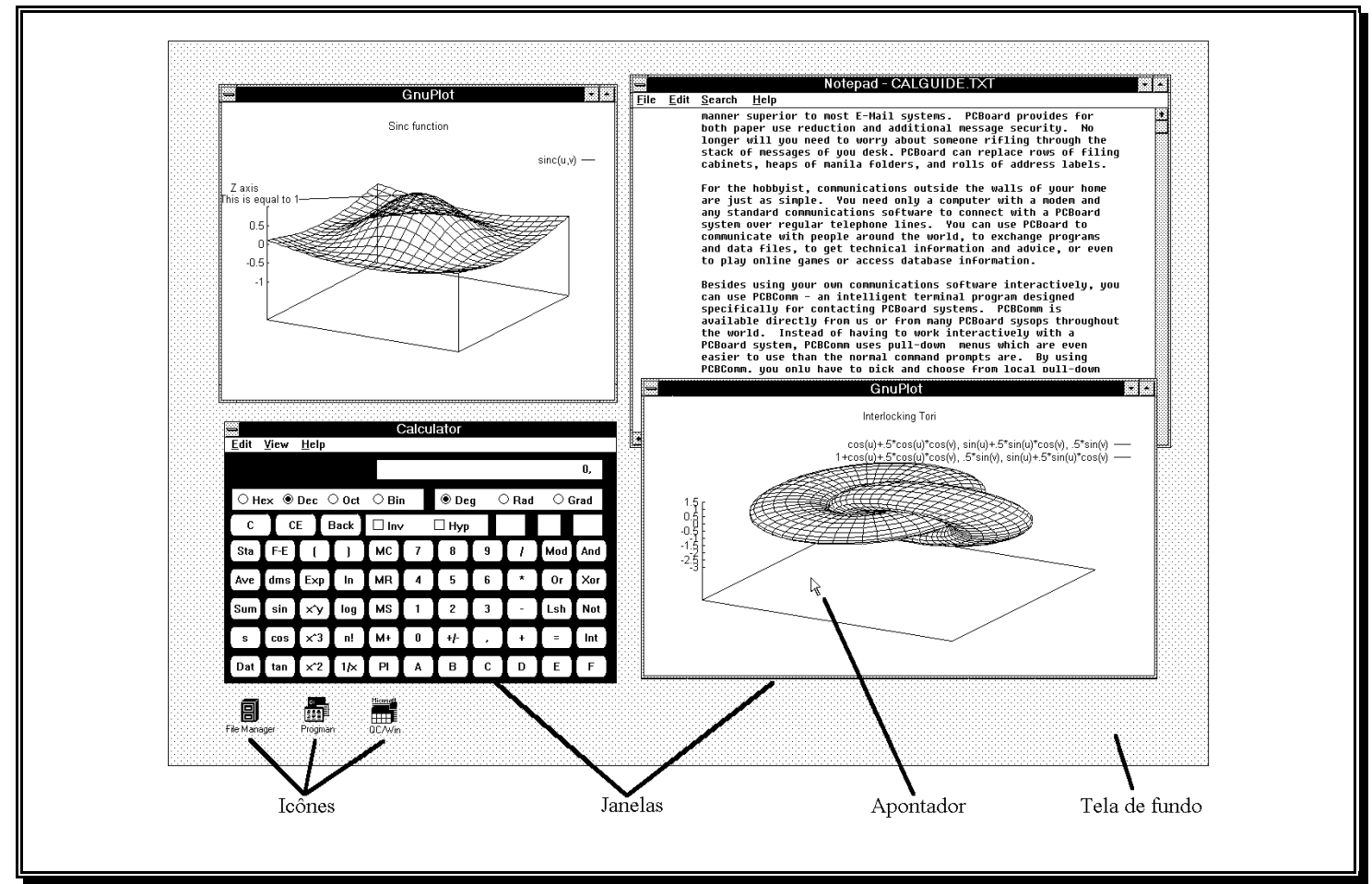

Fig. - 3.13 - Aspecto visual de uma GUI.

\subsubsection{3- MODELO DE CAMADAS}

Atualmente existe uma grande variedade de GUls, diferindo em várias características. Além das diferenças em relação à interface, podem variar também quanto ao seu nível de integração com o sistema operacional. Certas GUls são fortemente agregadas ao sistema operacional (Macintosh), enquanto que outras são visivelmente colocadas sobre o sistema operacional (Windows, e das GUls para o UNIX).

A definição do que faz parte ou não de uma GUI varia de um fabricante para outro. Apresentaremos um modelo genérico das camadas de uma GUI que tem como objetivo mostrar seus componentes (Figura 3.14). O modelo apresentado nesta figura ilustra uma GUI que é colocada sobre o sistema operacional, entretanto existem casos em que o sistema operacional é parte integrante da GUI [Peddie, 1992].

O modelo de GUI da Figura 3.14 é composto por cinco camadas, as quais serão comentadas a seguir: 
Modelo de objetos: O caminho pelo qual as aplicações reagem entre si freqüentemente, envolve o uso de um modelo de objetos. O modelo "Object Link \& Embedding (OLE)" é um exemplo desta camada. Existem algumas GUI que não possuem um modelo de objetos.

API: A Abreviação é oriunda do inglês "Application Program Interface". Esta camada é um conjunto de funções que são utilizadas pelos programas para se comunicarem com a GUI. O programador precisa especificar quais funções (ex: janelas, menus, barras de rolagem, ícones e etc.) são utilizadas e quando.

GUI: Como mencionado outrora, o que faz parte ou não de uma GUI varia de fabricante para fabricante. A camada GUI é onde as ações e elementos da tela residem.

Sistema de janelas: Esta camada é tão difícil de definir quanto a camada GUI. Por exemplo, o X-Window é apenas um sistema de janelas, ao passo que o Windows é um sistema de janelas e uma GUI construídos juntamente.

Modelo de imagem: Enquanto o sistema X-Window não tem um modelo de imagem, algumas GUI suportam mais de um modelo de imagem. É o caso do NeWS da Sun Microsystem, que suporta um modelo similar ao modelo de imagem Display PostScript (DPS); porém, diferente do DPS, ele pode também trabalhar com um modelamento complexo como o PHIGS ou GKS para controle de programas de CAD (“Computer Aided Design").

\begin{tabular}{|c|}
\hline Aplicasao \\
\hline Modelo de objetos \\
\hline API \\
\hline GUI \\
\hline Sistema de janelas \\
\hline Modelo de imagem \\
\hline Sistenin op piracional. \\
\hline 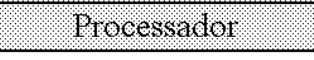 \\
\hline
\end{tabular}

Fig. - 3.14 - Modelo em Camadas de uma GUI.

É bastante difícil obter um modelo genérico de representação para todas as GUls, que diferem muito. Na Figura 3.14 foi apresentado um modelo que tenta ser o mais genérico possível.

Na Figura 3.15 são apresentadas algumas GUls diferentes, possibilitando a comparação de uma para outra. Não obstante, nem todas as GUls possuem as 
camadas descritas no modelo genérico. Existem algumas que apresentam camadas externas, como o caso do NeXTstep, que não é fundamentado numa plataforma orientada ao objeto. Neste caso, o modelo de objeto, quando usado nesse sistema, é externo.

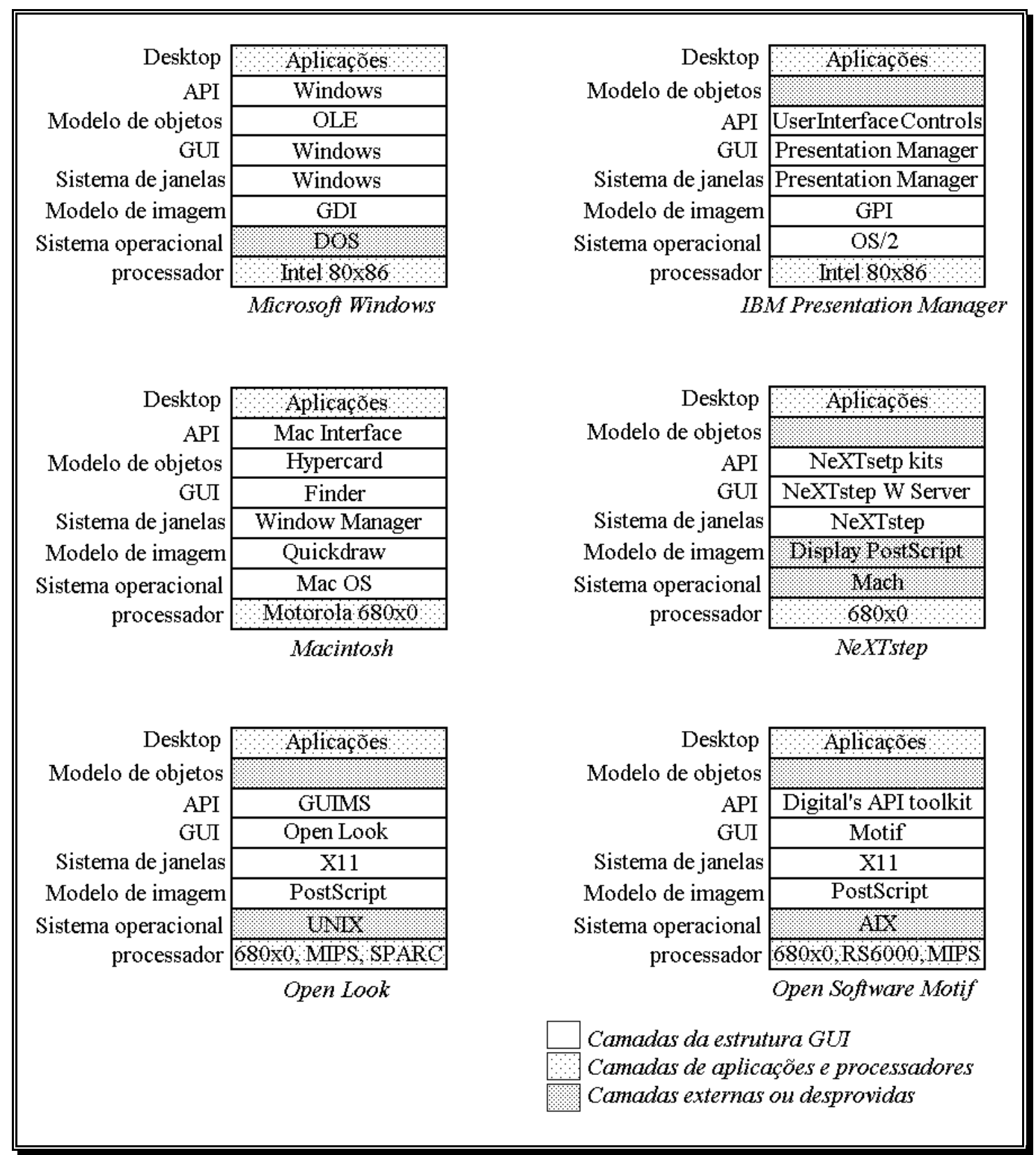

Fig. - 3.15 - Diagrama comparativo de camadas de GUI.

\subsubsection{4- Fundamentos de PROGRAMAÇÃo EM GUI}

Com o conceito GUI, várias novas tecnologias de programação foram 


\section{CAPÍTULO 3}

adotadas ou criadas para dar consistência à nova interface homem-máquina.

Ao contrário da filosofia CLI, a plataforma GUI é voltada para o usuário, e não para o programador. Com isto, a tarefa de programar (utilizando um compilador tradicional) para um ambiente GUI, não é tão simples como num ambiente CLI, cuja filosofia facilita ao programador. Nos primórdios do ambiente GUI, a programação de aplicativos era uma tarefa extremamente difícil e trabalhosa, pois embora o sistema gerenciasse as janelas e facilitasse sua criação, uma boa parte do trabalho era destinado ao programador. Atualmente, essa tarefa é realizada automaticamente através de CASE ou da programação visual, liberando o tempo e esforço do programador para outras atividades importantes [Bruno,1995].

\subsection{5 - PROGRAMAÇÃO VISUAL}

A idéia de programação visual surgiu com o famoso projeto Vivarium, no qual crianças utilizavam o Smalltalk para desenvolver um ambiente e então o povoavam com animais virtuais. Se crianças podem gerar um "mundo" simplesmente movimentando objetos, não poderíamos utilizar a mesma abordagem para desenvolver aplicativos ? [Bonner, 1995].

A idéia básica da programação visual seria desenvolver uma ferramenta na qual fosse possível gerar um aplicativo sem escrever nenhuma linha de código. Porém, o que ocorre é que na programação visual os elementos da interface com o usuário, suas características e controle são gerados visualmente (através do apontador) e a estes elementos é ligado o código que implementa a ação ("software") que provoca o elemento. Este código não é implementado visualmente, ficando como tarefa das linguagens convencionais (ou não) de programação.

Atualmente, parece predominar a tendência de ferramentas de programação visual. Fortemente ligada aos conceitos GUI e OOP, a larga difusão dessas duas tendências tem arrastado consigo a programação visual, a qual tem influenciado muitos ambientes de linguagens de programação convencionais.

O conceito de programação visual tem base na inversão da ênfase da programação. Nas interfaces baseadas em caracteres (CLI), e nos compiladores tradicionais de linguagens procedimentais, a ênfase da programação residia no projeto das estruturas de dados e na tradução lógica de uma atividade para o código do programa. O projeto da interface com o usuário ficava normalmente em segundo plano. As ferramentas de programação visual invertem esta equação: o 
processo de programação começa com a interface com o usuário, e permanece centralizado nela [Bonner, 1995].

Com isso surge uma nova filosofia de codificação, onde o código do programa fica ligado diretamente aos objetos da interface com o usuário. Isto só é possível em ambiente onde o compilador e o CASE estejam integrados.

Dentre as ferramentas de programação visual para ambiente Windows disponíveis atualmente, podemos citar como exemplos de compiladores que possuem ferramentas de programação visual o Borland Delphi e o C++ Builder assim como o Microsoft Visual Basic. Estes compiladores possuem um parque estabelecido de usuários, tornando um forte padrão para a programação em ambiente Windows. As suas principais vantagens estão na simplicidade de elaboração de protótipos e construção automática de interfaces, além da utilização de componentes visuais, que tornam facilmente acessíveis, através de objetos (OOP), poderosos recursos de programação.

\subsection{6 - ANÁlise Estatística, gargalos E DESEMPENHO DE PROGRAMAS PARALELOS}

Conforme comentamos anteriormente, a principal motivação para a exploração de paralelismo nas máquinas, seja via hardware ou software, é o aumento da performance. A grande questão é avaliar a performance de um software. Mesmo nos softwares seqüenciais, avaliação de performance é muito complexa, chegando a ser subjetiva, uma vez que interação entre as camadas inferiores (ver Figura 3.1) exerce papel fundamental no desempenho em questão. Normalmente, a avaliação de performance é feita através da comparação de desempenho entre as aplicações. Esse método é conhecido como benchmark [benchmark].

No entanto a confiabilidade nas medidas de benchmark são questionáveis, uma vez que a comparação entre os algoritmos e sua performance pode dar resultados completamente diversos dependendo da arquitetura na qual a aplicação está sendo executada. Como exemplo, se compararmos dois algoritmos que utilizam estratégias adversas para solucionarem o mesmo tipo de problema, e utilizarmos duas plataformas diferentes, é bastante freqüente ocorrer que um algoritmo possua uma performance superior a seu concorrente em uma plataforma, e esse resultado se inverta completamente na outra plataforma. Isso ocorre devido 


\section{CAPÍTULO 3}

à interação entre as camadas inferiores à aplicação.

A complexidade da avaliação de desempenho de um software aumenta muito quando tratamos de computação paralela, especialmente no caso dos sistemas baseados em computação distribuída, que ainda podem ser compostos por plataforma heterogêneas. Em computação paralela, além de avaliar o desempenho como um todo, é essencial que seja analisado o desempenho de cada uma das etapas de execução dos programas, da comunicação entre processos, acesso a disco, etc. Somente através da análise de performance e tempo despendido em cada uma das etapas é que podemos localizar os gargalos, ou seja regiões responsáveis pelo comprometimento da performance.

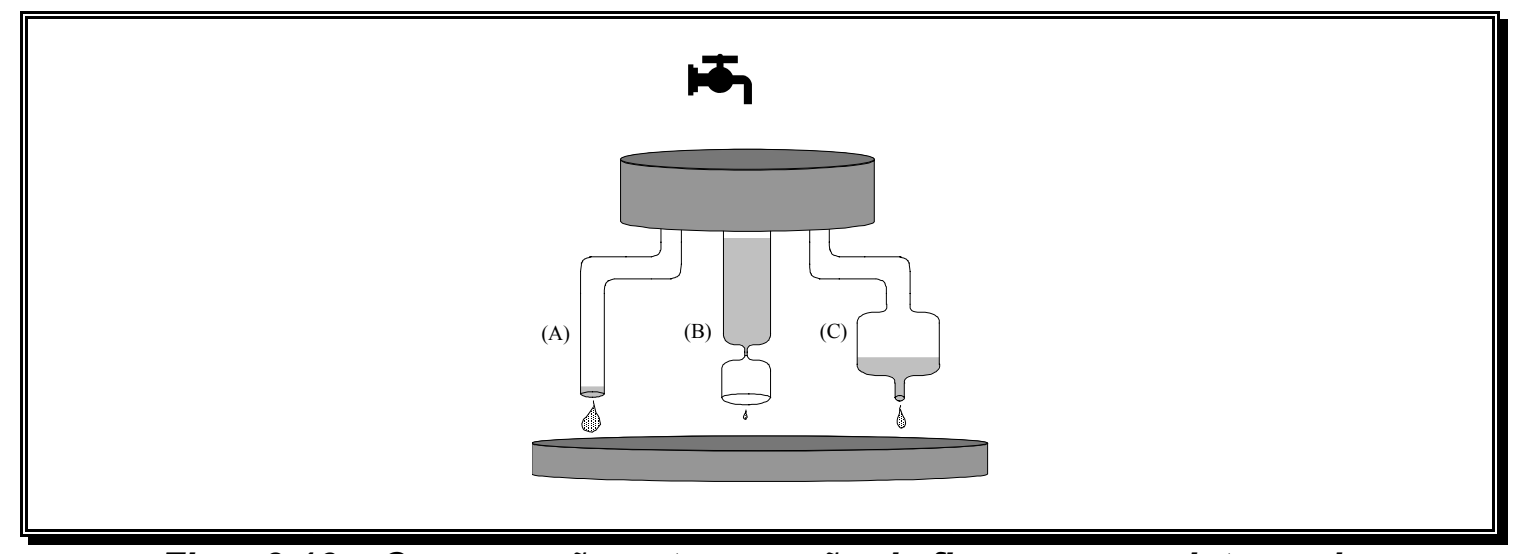

Fig. - 3.16 - Comparação entre a vazão de fluxo em um sistema de encanamento e o desempenho do conjunto hardware/software.

O conceito de gargalo em software é similar ao gargalo em fluxo de fluídos. Podemos comparar o fluxo de execução do software à vazão de fluídos em um sistema de encanamento. A Figura 3.16 apresenta um exemplo que ilustra a comparação entre a execução de software paralelo e vazão em sistema de encanamento. Devemos observar que o término de execução ou vazão ocorre quando não há mais fluido em nenhum ducto. Na representação devemos observar que cada ducto corresponde a um conjunto hardware/software e o fluído ao fluxo de processamento. Devemos observar ainda que o diâmetro do ducto corresponde ao desempenho computacional de cada conjunto hardware/software, com isso, quanto maior o diâmetro do ducto, maior será a sua vazão ou desempenho. Porém de, modo similar ao que ocorre nos fluídos, existem regiões, onde o estreitamento do ducto compromete sua vazão. Essas regiões são denominadas de gargalos. O gargalo limita a vazão do ducto como um todo, não importando seu diâmetro 
anterior, do mesmo modo, no conjunto hardware/software, não importa o poder computacional anterior ao gargalo, dependendo de quão estreito seja o gargalo, todo o desempenho do conjunto será comprometido.

Desse modo, observamos que embora o ducto $(B)$ tenha um poder de vazão maior que os ductos $(A)$ e $(C)$, devido ao gargalo que possui, sua vazão é muito menor que a vazão de $(A)$ ou de $(C)$. Em termos do conjunto hardware/software, o ducto (B) poderia ser comparado a um sistema com um processador mais poderoso, porém em algum ponto de seu programa existe um intensivo acesso a um dispositivo de hardware lento (acesso a disco ou rede) ou ainda algum tipo de processamento dispendioso. Podemos observar também, que simultaneamente ao momento em que ocorre o gargalo no ducto(B), o ducto (C) aumenta seu diâmetro. Isso seria equivalente a uma sub-utilização de seus recursos computacionais num dado momento. A partir da análise de gargalo, o programador pode rever a estratégia de paralelização de modo a balancear a carga de processamento da etapa crítica (gargalo) de (B) com a fase de sub-utilização de (C), eliminando o gargalo e consequentemente, aumentando o desempenho do sistema como um todo.

Como vimos, a localização e a eliminação dos gargalos é vital para o desempenho do software (o mesmo se aplica ao hardware). Embora na computação seqüencial a análise e localização de gargalos sejam importantes, elas são cruciais na computação paralela, que deve sua existência principalmente à velocidade. Sem a localização e a eliminação de estreitos gargalos, um sistema paralelo com diversos processadores pode possuir a mesma velocidade, ou ainda pior, ser mais lento que seu equivalente seqüencial, tornando-se completamente ineficiente e sem sentido.

Basicamente, a técnica utilizada para localizar os gargalos de um software consiste no mapeamento de todas as suas etapas, registrando a performance individual de cada uma. Embora existam algumas ferramentas para auxiliar a medida de cada uma das etapas (Engenharia de Software), na maioria dos casos essa tarefa é realizada pelo programador, que deve fazer uma análise estatística do tempo de execução de cada uma delas. No caso do CVMP, implementamos ferramentas específicas para a localização de gargalos e análise de desempenho de software, que serão comentadas no Capítulo 6.

A partir do mapa de desempenho, pode-se localizar com precisão os gargalos dos sistemas paralelos e deste modo auxiliar sua eliminação. Uma outra 
estratégia seria analisar diferentes etapas de algoritmos lineares, e após localizar as etapas mais custosas, traçar uma estratégia de paralelização mais eficiente antes mesmo da implementação da versão paralela. Como exemplo dessa abordagem, a Figura 3.17 mostra um diagrama que representa uma análise de desempenho em uma aplicação seqüencial e posteriormente sua versão paralela.

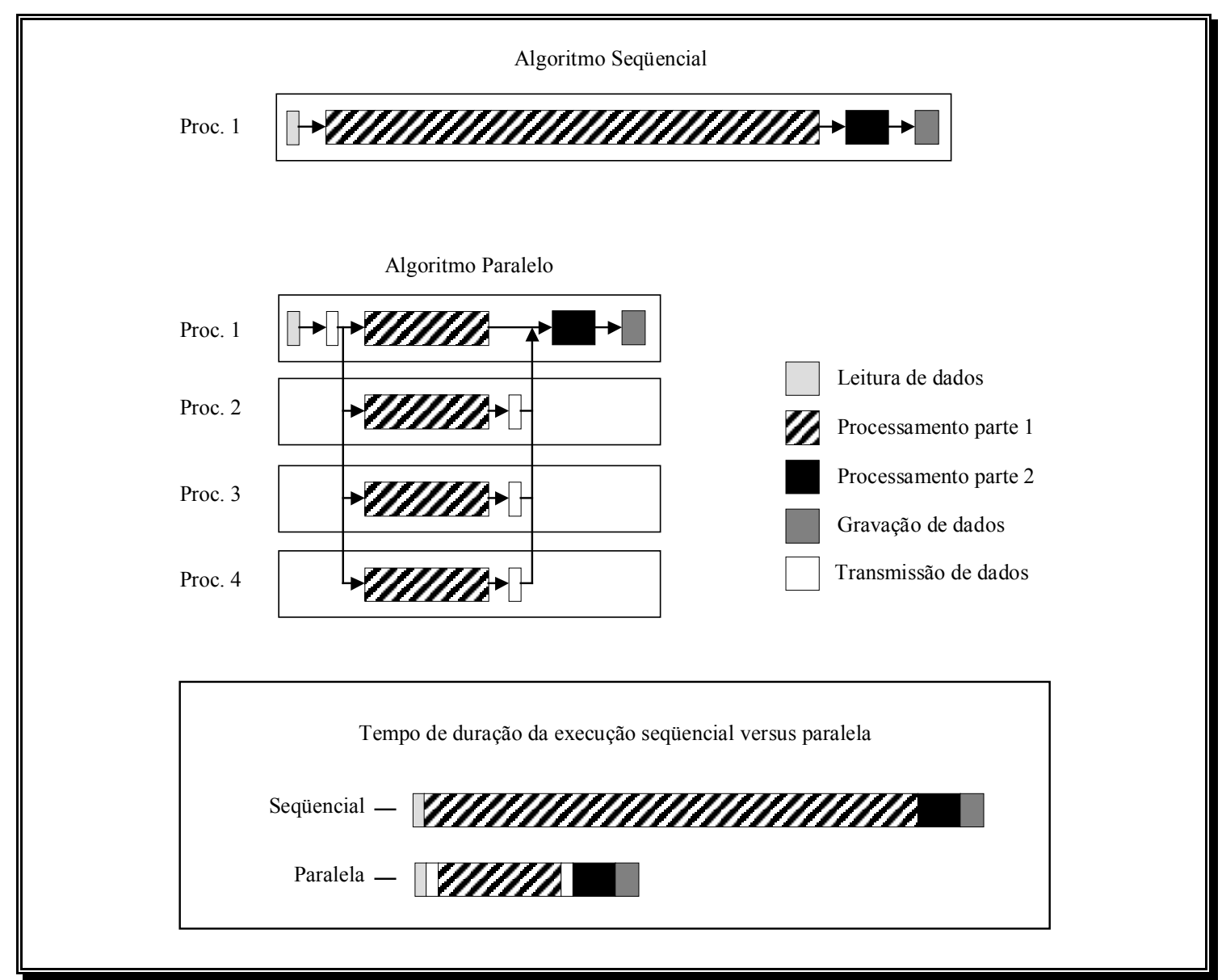

Fig. - 3.17 - Mapa de desempenho das diferentes etapas de um programa e a eliminação de um gargalo através de sua paralelização.

Como podemos observar, neste exemplo a aplicação foi dividida em quatro etapas: leitura de dados, processamento parte 1, processamento parte 2 e escrita de dados. Segundo constatamos ao observar o diagrama, a etapa processamento parte 1 é onde se localiza o gargalo do programa e supondo que essa etapa não possua uma grande dependência de dados e seja simples de paralelizar, podemos dividi-la em quatro partes, através da paralelização. Embora essa divisão acrescente mais etapas, responsáveis pela transferência de dados entre os processadores ou máquinas, o principal gargalo do sistema é eliminado e 
consequentemente ocorre um ganho no desempenho. No caso do exemplo, para quatro processadores, o tempo de execução do programa paralelo é da ordem de 2,5 vezes menor.

Devemos observar, entretanto, que quando concentramos esforços ou recursos computacionais apenas em um único ponto do problema, ocorre que o gargalo é transferido para uma outra etapa. Na Ciência da Computação esse paradoxo é conhecido como lei de Amdahl [Hockney \& Jesshope, 1988]. Tomando o nosso exemplo, se aumentarmos o recurso computacional, ou seja, se aumentarmos o número de processadores na versão paralela, a um determinado momento, o gargalo será deslocado para outras etapas do programa, e a partir desse momento não faria mais sentido aumentar os recursos computacionais para essa fase, havendo então necessidade de eliminar os outros gargalos para aumentar o desempenho de forma efetiva.

Ainda quanto à análise, é possível medir objetivamente a performance e desempenho de um software paralelo em relação a seu equivalente seqüencial. Essa medida, denominada de "speed-up" (Sp), é dada pela razão entre o tempo de execução do programa seqüencial $(t s)$ pelo tempo de execução do programa paralelo (tp) (Equação 3.1). Ainda em termos de desempenho, é importante também saber a eficiência da paralelização, ou seja, se foi realizado um balanceamento de cargas efetivo, e consequentemente sem gargalos. A eficiência é dada pela razão entre o tempo em que o programa utiliza os recursos computacionais ( $t u$ - tempo de processador em uso) e o tempo total de execução (tt) (Equação 3.2). Embora existam outras formas de mensurar o desempenho de software paralelo, o "speed-up" e a eficiência são as mais genéricas [Costa \& Slaets, 1991] [Faber et al., 1987].

$$
\begin{aligned}
& S p(N)=\frac{t s}{t p(N)} \\
& E=\frac{t u}{t t}
\end{aligned}
$$




\subsection{7 - ENGENHARIA DA UTILIZAÇÃO}

O projeto PARC (Palo Alto Research Center) da Xerox, influenciou a ciência da computação em diversos aspectos diferentes, dentre os quais podemos citar: a interface gráfica com o usuário (GUI), a descoberta do apontador (mouse), a virtualidade do monitor (através de eventos e botões GUI), a programação visual, a programação orientada a objetos, a estação de trabalho, etc. Observando a computação atual, e a importância desses conceitos podemos concluir que grande parte da história da computação moderna foi escrita no PARC [Bruno, 1995]. Dentre as novas idéias apresentadas pelo PARC, uma das mais importantes foi a consagração do computador e do software como uma ferramenta de trabalho. Embora esse conceito não tenha sido diretamente ditado pelo PARC, foram suas novas idéias que impulsionaram o surgimento dessa tendência.

A tendência de assumir o computador como uma ferramenta de trabalho surgiu através da revolução da micro-informática. Com a queda dos computadores de grande porte (mainframes) e o aparecimento dos microcomputadores, esses começaram a proliferar e a informática iniciou sua jornada de influência em todas as áreas de nossa sociedade. A partir desse momento, a concepção da utilização dos computadores começou a mudar. Inicialmente, os computadores existiam em número reduzido, eram caríssimos e as poucas corporações que desfrutavam dessas máquinas possuíam uma equipe de profissionais altamente treinados para operá-los. Neste contexto, não havia a necessidade de se preocupar com a dificuldade de manipular ou programar os computadores, uma vez que estes eram operados e programados apenas por profissionais altamente especializados e treinados. A complexidade dessas tarefas não era um problema, era apenas uma característica do perfil das profissões ligadas à computação, uma vez que tais profissionais eram os únicos usuários dos computadores.

Com o surgimento da micro-informática e com a proliferação dos microcomputadores, o perfil dos usuários mudou drasticamente. Ao invés de especialistas altamente treinados, os usuários passaram a ser pessoas comuns, dispostas a utilizar os computadores para auxiliar de alguma forma suas tarefas. Dentro desse novo contexto não há lugar para a complexidade e a sobrevivência de um produto (computador ou software) passou a depender também de sua simplicidade e objetividade para o usuário.

É claro que essa transição não foi imediata. Nenhuma evolução ou 
revolução envolvendo o caráter humano ocorre do dia para noite. O período de transição entre o complexo e o simples na história da informática vem ocorrendo desde o final da década de 70 , e ainda continuamos vivenciando esse processo. Através da simplificação da manipulação dos computadores surgiu o conceito de ferramenta de trabalho, onde o computador e a informática são vistos como uma ferramenta para auxiliar o trabalho humano.

Esse novo conceito não é apenas uma tendência, mas sim um novo postulado na Ciência da Computação. Atualmente contamos com novas áreas tais como Interação Homem - Máquina e Engenharia da Utilização que basicamente estão preocupadas com essas questões.

Comentamos anteriormente, as novas concepções apresentadas pelo PARC (Palo Alto Research Center) da Xerox foram essenciais para formar as bases da concepção de ferramenta de trabalho. O conceito de interface gráfica com o usuário (GUI) fez com que o método de utilização do computador se tornasse simples ao usuário inexperiente e ágil ao usuário experto, como podemos constatar pela análise feita por Hayes [Hayes, 1990].

No dia-a-dia, podemos observar que a questão da utilização é importante não apenas para a informática mas também para todas as demais áreas. Se tivermos que escolher entre dois abridores de latas automáticos, que executam a mesma função com a mesma qualidade e eficiência, sendo que um deles possui apenas um botão, bastando pressioná-lo para abrir a lata e o outro apresenta uma interface com o usuário bem mais complicada, com dezenas de ajustes, botões e alavancas, qual dos dois abridores seria a ferramenta mais útil ?

Como conseqüência da tendência de simplificar a manipulação dos computadores, descobrimos que não apenas as aplicações voltadas ao usuário final apresentam-se com mais vantagens quando analisadas e pensadas sob o ponto de vista da engenharia da utilização, mas também as ferramentas, ambientes e linguagens de desenvolvimento. A razão para isso é bastante simples, quando utilizamos ferramentas complicadas, normalmente temos que perder tempo em treinamentos desnecessários ou ainda executarmos um número demasiado de procedimentos para realizar apenas uma tarefa. Ao passo que utilizando ferramentas simples, a situação é completamente diferente, poucos procedimentos são necessários para realizar as tarefas assim como o tempo desperdiçado com treinamentos é menor.

Alguns conceitos foram essenciais para o desenvolvimento de ferramentas, 


\section{CAPÍTULO 3}

ambientes e linguagens de desenvolvimento de software mais adequados sob o ponto de vista da engenharia de utilização [Preece et al., 1994]. Através da programação orientada a objetos, interface gráfica com o usuário e programação visual (PARC), assim como de conceitos extraídos da engenharia de software, tais como ferramentas CASE e reutilização de código, temos hoje uma série de linguagens visuais, sistemas operacionais com GUI e ferramentas de desenvolvimento, que obedecem às regras da engenharia da utilização e são simples e eficazes para os programadores.

A engenharia da utilização é uma área da Ciência da Computação responsável pelo estudo da maneira mais adequada de se utilizar e desenvolver interfaces entre o homem e a máquina. Através de análise estatística sobre o comportamento humano ao utilizar um determinado software, é possível encontrar o modo mais adequado para que o software em questão torne-se uma ferramenta simples, intuitiva e eficaz [Preece et al., 1994].

À medida que aumenta a sofisticação das aplicações, dos programas e dos sistemas fica cada vez mais óbvio a necessidade de ferramentas de desenvolvimento que utilizem os conceitos de engenharia da utilização e se tornem mais simples, intuitivas e eficazes. Isso fica claro especialmente para o desenvolvimento de aplicativos em GUI. O autor apresentou em sua dissertação de mestrado [Bruno, 1995] um exemplo entre um ambiente visual e um compilador tradicional. Observando o código fonte e a diferença entre procedimentos, podemos constatar a importância de utilizar uma ferramenta adequada, que simplifica o trabalho, sem perder a eficiência e qualidade. Enquanto no compilador tradicional o programador deveria escrever o código para todo o sistema de interface, ao invés de concentrar seu esforço na implementação do algoritmo principal, através do ambiente visual, o programador simplesmente desenha a interface, e através de ferramenta CASE é gerado o código, economizando assim seu tempo. É muito mais vantajoso o programador concentrar o tempo de programação em seu algoritmo principal do que programando a interface.

O exemplo do ambiente de programação visual é apenas uma demonstração do emprego da filosofia da engenharia da utilização sob o aspecto macro (sistema como todo), no entanto a engenharia da utilização preocupa-se também com os detalhes, ou seja, interfaces, gráficos, ícones e nomes de funções e modo de utilização de bibliotecas de funções, visando tornar as ferramentas mais intuitivas e fáceis de utilizar. 
Pelo que observamos ao longo de nossa pesquisa, normalmente as ferramentas voltadas para a computação paralela não se preocupam com as questões da engenharia de utilização, sendo na maioria dos casos complexas, exigindo treinamento amplo e geralmente necessitando ser manipuladas por especialistas da área. A história nos mostra a importância da engenharia de utilização e do mesmo modo a importância de ferramentas simples e eficientes.

Não estamos questionando a eficiência das ferramentas de desenvolvimento paralelo, mas sim sua simplicidade e sua preocupação com a utilização (ser amigável com o usuário). Temos observado que existe uma latência na computação paralela para a adoção dos princípios da engenharia da utilização. Conforme comentamos anteriormente, um dos grandes problemas da computação paralela é o desenvolvimento e manutenção de software. Existem muitos fatores responsáveis pela complexidade desses itens, porém acreditamos que um deles é a falta da adoção dos princípios da engenharia da utilização e consequentemente com a falta de preocupação com o usuário, que embora normalmente seja um especialista da área, poderia ser favorecido com tais conceitos.

Visando esses fatores, um dos principais objetivos desta tese é o desenvolvimento de uma ferramenta intuitiva e simples de utilizar, voltada para a computação paralela, a qual, através de sua simplicidade, pode ser utilizada mesmo por programadores com o mínimo de conhecimento em computação paralela. Portanto, uma das principais bases do pacote CVMP que será apresentado no Capítulo 6 é a sua abordagem sob o ponto de vista da engenharia de utilização. De acordo com a evolução natural da computação é vital a existência de uma ferramenta para desenvolvimento de aplicações paralelas que obedeça aos requisitos da engenharia da utilização, sendo desse modo intuitiva, fácil de usar, simples e eficiente. 
CAPÍTULO 3 


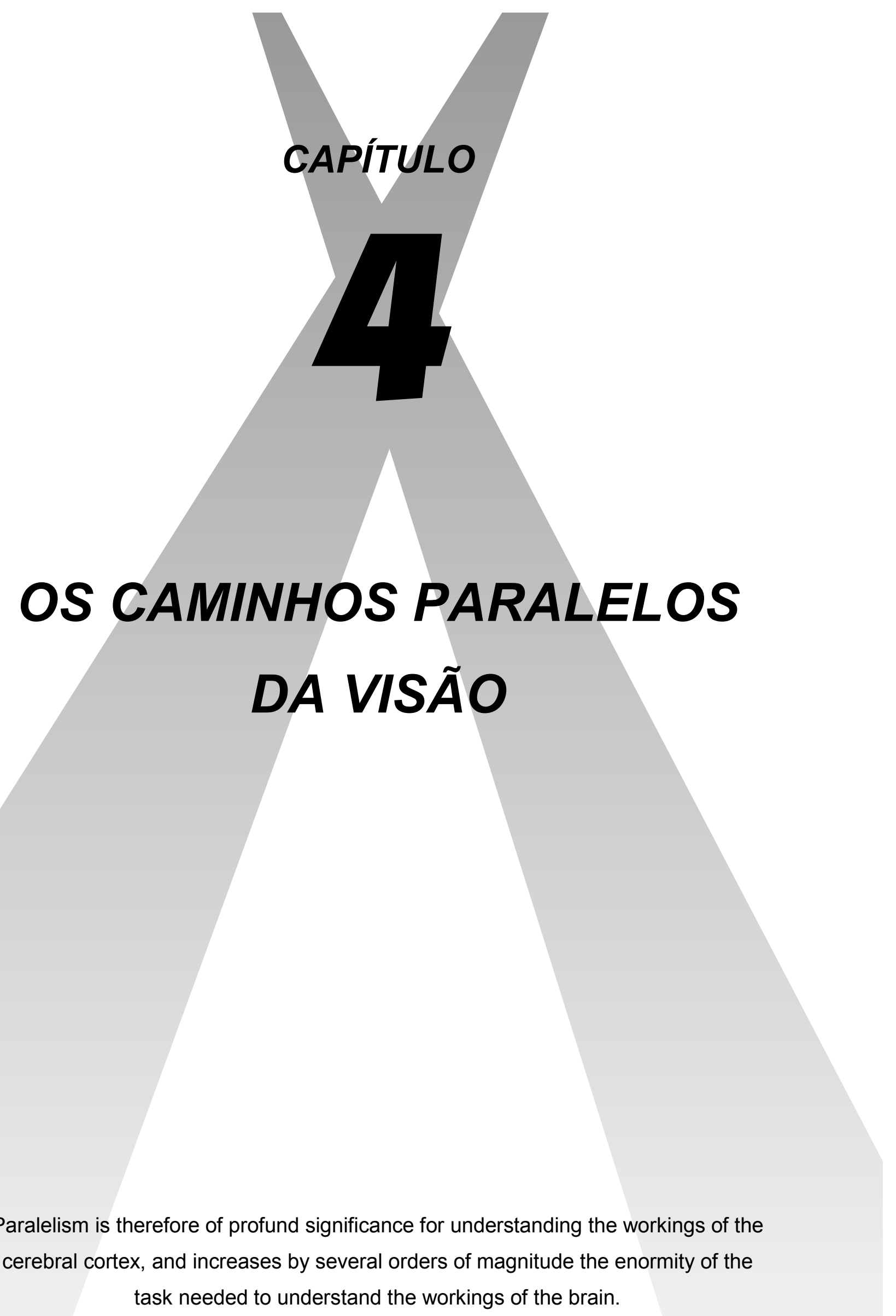

Semir Zeki 
CAPÍTULO 4 


\section{CAPÍTULO 4 - OS CAMINHOS PARALELOS DA VISÃO}

\section{1 - INTRODUÇÃO}

Neste capítulo estaremos abordando a visão biológica, o mais eficiente sistema de aquisição de informação criado pela natureza, com enfoque em seu paralelismo. Iniciaremos nossa discussão abordando a evolução em função da informação e do paralelismo, correlacionando esses tópicos. A seguir, discorreremos um pouco sobre as técnicas de estudo de visão e apresentaremos uma breve introdução à neurociência e finalmente discutiremos o sistema de visão natural dos primatas, apresentando o percurso da informação visual dentro do maquinário neural enfocando o paralelismo.

\section{2 - INFORMAÇÃO, EVOLUÇÃO, VISÃO}

Quando lemos um livro, estamos alimentando nossa memória com informações e, deste modo, aprendendo. Normalmente, atribuímos esse aprendizado à nossa inteligência e nos esquecemos da importância da aquisição de informações nesse processo. Para salientá-la, podemos fazer as seguintes perguntas:

\section{Existe inteligência sem a informação ?}

Um indivíduo que não possui nenhum sentido, ou seja, cujo cérebro não possui conexão alguma com o meio exterior possui inteligência?

Se refletirmos um pouco sobre essas questões, logo podemos chegar à conclusão de que tanto a razão quanto a inteligência não existem sem a informação, e ainda mais, podem ser definidas simplesmente como a interpretação, aprendizado e compreensão da informação. A palavra inteligência tem sua origem do latim intelligentia, e sua definição, segundo o tradicional dicionário Aurélio da língua portuguesa, é a faculdade de aprender, apreender ou compreender; 


\section{CAPÍTULO 4}

percepção, capacidade de compreender e adaptar-se facilmente e ainda maneira de interpretar ou entender. Devemos observar que não podemos aprender, compreender ou perceber sem a informação, e, deste modo, podemos concluir que não existe inteligência sem informação.

A importância da informação é tamanha que, durante bilhões de anos, a natureza vem aprimorando os sentidos dos seres vivos, para que possam de maneira mais eficiente se adaptar ao meio e, deste modo, sobreviver. Em algum ponto da história da vida neste planeta, começou a competição entre as espécies, e a informação passou a desempenhar um papel importante, senão vital, para a sobrevivência. Vamos imaginar as primeiras espécies deste planeta a procura de alimento, ou seja, garantindo sua sobrevivência. No início, essas criaturas primitivas não possuíam sistemas sofisticados de aquisição de informação (sentidos), portanto seus métodos de procura por alimentos eram bastante ineficientes. Muitas vezes essas criaturas estavam próximas ao alimento e, devido à falta de informação, não localizavam-no e deste modo desperdiçavam as oportunidades.

Vamos supor que algumas espécies, através da evolução [Darwin, 1859], tivessem desenvolvido algum tipo de sistema de aquisição de informação, através do qual pudessem encontrar alimento de maneira mais eficaz que as demais. No primeiro momento em que houvesse escassez de alimento no "habitat" no qual concorriam, as espécies que possuíssem o sistema de aquisição mais eficiente, certamente sobreviveriam, ao passo que as outras sucumbiriam.

A informação passa a ser ainda mais vital quando, além da competição por alimento, estão envolvidas também as atividades predatórias. A vitória da luta entre presa e predador é dada, praticamente, pela informação. Para o predador, é fundamental um sistema de aquisição de informação que localize a presa, enquanto que para a presa é vital a informação sobre o predador. A natureza desenvolveu dispositivos tanto para a presa quanto para o predador com o intuito de obter informações (sentidos) ou ocultá-las (camuflagem).

Neste ciclo de adaptação, luta e sobrevivência, basicamente girando em torno da informação, a natureza desenvolveu, ao longo de bilhões de anos de evolução, um sistema poderoso para obter informação: a visão.

Dentre todos os sentidos que a natureza desenvolveu, a visão consegue absorver a maior quantidade de informação. A visão pode ser definida como a capacidade fisiológica de ver e perceber $o$ mundo. Através de órgãos especializados, os olhos, as ondas eletromagnéticas são captadas e direcionadas 
para sensores capazes de senti-las, ou seja, converter a informação proveniente em sinais neurológicos. Além disso, a visão também consiste no processamento e interpretação desses sinais, e foram exatamente nesses processos que a natureza encontrou seus maiores desafios e, atualmente, nossa ciência também: como funciona a visão?

\section{3 - EVolução, Paralelismo e Visão}

Nesta seção vamos discorrer sobre a evolução, o paralelismo e a visão. Embora essa combinação possa inicialmente parecer muito estranha e sem razão, veremos que seu sentido surge a partir dos paradoxos da evolução.

De acordo com a teoria da evolução de Darwin, a vida na terra começou a partir de uma forma de vida primitiva. Não podemos provar com certeza como era a sua consistência e composição exata, porém teoricamente supomos que essa forma primordial de vida era constituída por uma única célula, ou seja estamos falando de um ser unicelular. Não sabemos por que, nem qual é o objetivo último da evolução, mas é claro o seu anseio por formas de vida mais adaptadas e muitas vezes, em conseqüência disso, complexas.

$\mathrm{Na}$ busca da adaptação, e consequentemente da complexidade, em algum momento da evolução surgiu um indivíduo cujo organismo era formado por mais de uma célula, surgiram assim os indivíduos pluricelulares. Podemos observar aqui a primeira escolha da natureza pelo paralelismo, se nesse caso considerarmos a célula como uma unidade de processamento biológico. Mas por que teria a evolução optado em criar seres vivos compostos por diferentes unidades celulares? Por que a evolução não optou por desenvolver os seres unicelulares e deixá-los cada vez mais complexos e adaptados, porém permanecendo unicelulares?

Pensando nessas respostas, verificamos que a evolução optou realmente pelo paralelismo, e o quanto ela favoreceu os indivíduos unicelulares. Se observarmos os seres mais evoluídos, podemos constatar que todos são pluricelulares. Mas poderíamos conjecturar que o fato dos seres terem mais de uma célula não significa nada em termos de paralelismo, ou ainda que correlação teria o paralelismo com isso. Se pensarmos em termos de microorganismos, o conceito de paralelismo não é tão óbvio, mas e se pensarmos num mamífero ?

No caso de um mamífero qualquer, cada uma dos bilhões de células possui o mesmo programa genético e funções independentes, sem falar ainda nos 


\section{CAPÍTULO 4}

processos fisiológicos tais como respiração, reprodução, excreção, etc. Se pensarmos agora em termos de órgãos, o paralelismo fica ainda mais óbvio. Qualquer mamífero possui uma série de órgãos, responsáveis por uma determinada tarefa essencial à vida. Estes, por sua vez, são compostos por células operando em paralelo, e ainda exercem suas funções paralelamente em relação aos outros demais órgãos. Como exemplo, podemos pensar no coração, pulmão, órgãos do sistema digestivo e sensorial, todos executando suas tarefas no mais absoluto paralelismo. Podemos concluir que os seres pluricelulares são sistemas de vida paralelos, e que quanto maior o seu grau de evolução, maior a escala de paralelismo envolvida.

Agora que concordamos com o paralelismo envolvendo os seres pluricelulares, voltamos a perguntar: Se os seres unicelulares satisfazem a condição básica de vida, por que razão a evolução optou pelo desenvolvimento de seres paralelos (pluricelulares) ? Por que não existem seres unicelulares com alto grau de evolução ? A resposta parece ser um conjunto de fatores, envolvendo a natureza química e física da vida. Infelizmente nosso conhecimento ainda é muito limitado, e não sabemos como se comportaria a vida em condições adversas à nossa. Não sabemos nem ao menos se existe vida evoluída fora da terra. Não sabemos responder se existe apenas um universo, se as leis da física regem nosso universo como um todo ou ainda se existe outro ou outros universos. Agora, hipoteticamente falando, se houver outro universo, a probabilidade das leis físicas serem exatamente iguais as nossas é remota. Poderia em situações adversas, a natureza desenvolver vida com alto grau de evolução sem a multiplicação de unidades básicas de vida ? Ou seja poderia a natureza escolher como caminho de evolução seres unicelulares?

As respostas a essas perguntas e conjecturas parecem estar longe do nosso alcance. No entanto, na natureza nada é por acaso, bilhões de anos de evolução não foram em vão e, como a natureza optou pelo paralelismo em massa, o melhor a fazer é compreender e estudar suas vantagens.

Compreendemos que a natureza encontrou no paralelismo celular um ótimo mecanismo na busca da complexidade, adaptação e evolução, mas aonde entraria a visão nesse contexto ? Por que estaria a natureza preocupada com sistemas de visão paralelos?

Como comentamos anteriormente a visão está ligada à necessidade dos seres vivos de obter informações do meio. Quando indivíduos competem no mesmo 
habitat, e concorrem pela alimentação, qualquer informação a esse respeito é vital para a sobrevivência, e aquele que obtiver mais informação será favorecido na luta da sobrevivência. Até este ponto apenas a qualidade da informação foi levada em conta, no entanto a situação é um pouco diferente: além da qualidade, um outro fator crucial nessa questão é a velocidade, pois além de saber onde está e como chegar até o alimento, é necessário também que o indivíduo obtenha essa informação antes dos demais. Vamos imaginar duas espécies concorrentes, disputando o mesmo alimento escasso. Supondo que a principal fonte de informação de ambas seja a visão, e ainda que uma das espécies possua um sistema de visão lento e a outra um sistema de visão veloz. Se a diferença básica entre as duas espécies fosse essa qual sobreviveria ? Parece-nos bastante óbvio que a espécie que obtivesse a informação de modo lento pereceria, uma vez que os concorrentes chegariam ao alimento antes.

A necessidade de velocidade na percepção visual se torna ainda mais crítica quando levamos em conta a disputa entre predador e presa. Neste caso, é fundamental para ambos, presa e predador, obter informações a respeito de seu oponente. Embora a visão não seja a única fonte de informação numa tal disputa, que conta com outros estímulos (olfato, audição, etc.), podemos dizer que a informação pela visão ainda assim tem uma relevância fundamental, e até mesmo primordial em algumas espécies. É claro que a natureza ao longo desses anos tem encontrado diversos mecanismos para contornar e iludir o sistema de informação do oponente, como a camuflagem, mas a velocidade do reconhecimento e localização da presa ou do predador é fundamental para a sobrevivência.

Como vimos nos capítulos anteriores, a história da computação demonstra que a resposta para o desempenho de sistemas de informação artificiais é o paralelismo. Desde sua opção pelo paralelismo, no desenvolvimento de seres pluricelulares, a natureza se tornou mestra na arte de paralelizar, não seria de se espantar que ela usasse essa mesma arte para aprimorar os sistemas de visão biológicos, e é exatamente isso que o estudo da visão tem constatado. Neste capítulo apresentaremos uma revisão sobre os sistemas de visão biológicos, com enfoque nos primatas, e finalizaremos apresentando alguns estudos que demonstram a adoção do paralelismo já nas primeiras fases do processo visual.

Visão artificial é hoje um tema de pesquisa de ponta, e tentamos a todo custo desenvolver sistemas artificiais de visão. No entanto, por maior esforço que realizemos e por maior o número de áreas científicas envolvidas, não conseguimos 
sequer igualar a eficiência de nossos sistemas com o sistema de visão dos seres mais primitivos. Tendo a natureza encontrado no paralelismo uma escolha ao longo de bilhões de anos, por que nós, que possuímos um conhecimento tão limitado (funcionamento cortical), iríamos discordar?

\section{4 - O ESTUdO do CÉREBRO E DA VISÃo}

Embora a ciência tenha se esforçado arduamente durante todo este século, o cérebro ainda permanece uma caixa preta. Se considerarmos o estudo do cérebro como um livro, nosso conhecimento científico atual corresponderia apenas às primeiras páginas. Devemos observar a grande complexidade envolvida nesta questão. A uma primeira instância o estudo do cérebro pode parecer pertencer a algumas poucas áreas científicas, mais especificamente a áreas fundamentadas em biologia. No entanto, uma tendência científica atual vem unindo diversas áreas na construção do imenso quebra-cabeça no qual se relacionam este estudo. Assim sendo, o estudo do cérebro está reunindo, concentrando e integrando diversas áreas científicas, possuidoras de caminhos históricos bastante diferentes. Nenhum outro tema científico reuniu áreas tão distintas, e talvez, graças ao desafio de desvendar nosso próprio cérebro, nossa ciência altere seu curso separatista na história.

\subsection{1 - AS ESPECIALIZAÇÕES FUNCIONAIS CORTICAIS}

Até o século passado o cérebro era visto como uma caixa preta, dividida apenas em duas partes: áreas de projeção e áreas de associação [Machado, 1993]. $\mathrm{Na}$ metade do século passado o neurologista francês Pierre Paul Broca, iniciou um estudo que expandiria a divisão dualista do cérebro [Broca, 1861]. Através de um caso clínico de um paciente que perdeu a capacidade de falar e, realizando autopsia após seu óbito, Broca constatou que uma área específica do cérebro era responsável pelo caso clínico, mas foi duramente criticado pelo meio científico de sua época. Porém seu trabalho introduziu a noção de que o córtex cerebral era composto de áreas distintas diferenciadas por sua especialização. No entanto, a crença na dualidade cerebral perduraria, especialmente pela dificuldade de localizar regiões anatomicamente distintas no córtex, assim como a questão da plasticidade cerebral. 
Uma grande diversidade de trabalhos científicos viriam a consolidar a divisão do córtex em áreas distintas classificadas mediante a função, entre eles devemos destacar os trabalhos de Fritsch e Hitzig [Fritsch \& Hitzig, 1870], que conseguiram provocar movimentos em determinadas partes do corpo através de estímulos elétricos em áreas específicas no córtex do cão.

A divisão do córtex em áreas funcionais possibilitou que a clássica estratégia de dividir e conquistar fosse aplicada à neurociência, permitindo a canalização de diferentes estudos relativos a função de suas áreas determinadas. Com isso, ao estudarmos uma determinada função específica do córtex, podemos concentrar esforços na sua região cortical correspondente.

\subsection{2 - ANÁLISE MULTI-ESCALA}

Uma questão muito importante no estudo cortical é a sua complexidade multi-escalar. O córtex deve ser explorado sob diferentes prismas relativos a escala. Deste modo, do ponto de vista multi-escala, podemos dividir a análise cortical em três partes [Costa, 1996]:

Microscópica: Dentro dessa abordagem o córtex é estudado em nível celular. São estudadas as células que o compõe: neurônios, fibras e glias. Além do comportamento do estudo histológico dos componentes de cada célula, nessa escala são ainda estudadas as ramificações dendríticas e axonais. As técnicas de estudo nessa escala são histológicas / anatômicas (empregam corantes, dissecações e são feitas in vitro).

Intermediária: Nesta classe são estudados grupos de células e suas conexões. O comportamento das árvores dendríticas e como são compostas as redes neurais. São ainda exploradas as conexões neurais dentro de uma região cortical. Um exemplo do estudo cortical nessa escala são as visualizações de redes neurais e de seu comportamento nas regiões V1 e V2 do córtex visual. Através das técnicas de citoarquiteturas, citochromo oxidase e mieloarquiteturas é possível a visualização das sub-regiões de cataventos em V1 (blobs e inter-blobs) e das subregiões em forma de faixas em V2 ("thin stripe", "inter stripe" e "thick stripe") [Zeki, 1993] [Hubel, 1995].

Macroscópica: A esta categoria pertence o estudo de regiões inteiras do córtex. Embora essa escala possa ser explorada do ponto de vista anatômico, o maior interesse reside na sua pesquisa fisiológica. A principal característica da 


\section{CAPÍTULO 4}

exploração fisiológica é que esta envolve aspectos funcionais da parte estudada e são executadas in vivo. Assim, temos como exemplo da escala macroscópica os estudos cirúrgicos (como o de Broca), tomografia por ressonância magnética e PET (Positron-Emition Tomography).

Devemos lembrar que não existe uma divisão distinta entre as escalas. Ninguém sabe exatamente onde uma escala começa ou termina. Essa classificação tem como único objetivo apresentar as características multi-escala do estudo do córtex.

\subsection{3 - VISUALIZANDO O CÉREBRO ATRAVÉS DA VISÃO}

Como vimos anteriormente, o cérebro sempre foi visto como uma caixa preta (em especial o córtex). Do ponto de vista anatômico tradicional, quando analisamos o córtex, este se apresenta como uma estrutura uniforme, diferenciando-se apenas pelas depressões, intituladas sulcos, que delimitam os giros e lobos. Entretanto, a existência dos sulcos não dizem nada em termos da funcionalidade do córtex, eles são apenas uma estratégia utilizada pela natureza que permite aumento da superfície sem grande aumento do volume (no homem, cerca de dois terços do córtex está "escondido" pelos sulcos) [Machado, 1993]. Desta forma, o córtex apresenta-se singular: uma única matéria uniforme enrugada (sulcos e giros). Devido a essa característica uniforme, Semir Zeki [Zeki, 1993] sugere que, embora o córtex seja diferenciado pela funcionalidade de cada região, deva existir uma estratégia única ou geral para o seu funcionamento. Deste modo, se explorarmos e desvendarmos o funcionamento de uma região cortical, teremos conhecimentos suficientes para desvendar as demais regiões.

Nessas últimas décadas, a visão recebeu uma atenção especial. Nenhum outro sentido ou região cerebral foi mais explorado do que a visão. Embora tenha sido alvo da pesquisa científica, tem revelado muito pouco sobre o seu funcionamento.

Assim, o estudo da visão está trazendo evidências de como funciona o cérebro como um todo, e aproveitando o trocadilho proposto pelo título do livro $A$ Vision of the Brain, de Semir Zeki [Zeki, 1993], fornecendo uma poderosa ferramenta de visualização do funcionamento do cérebro.

Embora esta subseção seja destinada ao estudo do cérebro, vamos a partir daqui enfocar a visão: o sentido e a região mais explorados do córtex. 


\subsection{4 - VISÃO - UMA ÁREA MULTIDISCIPLINAR}

Dentre as áreas do conhecimento cientifico, talvez a que envolva a maior diversidade de disciplinas seja a visão. É fácil verificar esta suspeita. O estudo da visão pode ser dividido em visão natural e artificial. Em visão natural, os objetos de estudos são os sistemas biológicos de visão, ao passo que no segundo caso, temos as ciências exatas tentando reproduzir artificialmente o processo de interpretação visual do mundo realizado pelos sistemas biológicos. O verdadeiro fascínio dessa ciência ocorre na integração de suas duas partes: visão natural e artificial, integrando as ciências exatas com as ciências biológicas. Se por um lado a biologia tenta desvendar a arquitetura e funcionamento do cérebro, a cibernética desenvolve modelos baseados nos sistemas biológicos e experimentam sistemas artificiais. Embora aparentemente estejam percorrendo caminhos diversos, a integração ocorre na realimentação do conhecimento científico.

No entanto, a visão é muito mais complexa e contém um número maior de áreas de conhecimento envolvidas do que a versão dualista anteriormente apresentada. Para explorar algumas dessas áreas envolvidas, vamos considerar a definição de visão utilizada por David Marr. Segundo Marr [Marr, 1982], visão é o processo de descobrir através de imagens o que está presente em nosso mundo e suas respectivas posições. Seguindo essa abordagem, o primeiro estágio da visão é a aquisição de imagens. Assim, os olhos captam energia eletromagnética na forma de luz e a converte em impulsos nervosos através de células fotorreceptoras. A visão é um mecanismo neurológico, baseado em estímulos do universo físico, necessitando deste modo, para sua compreensão de conhecimentos em ambos universos científicos (compreensão física e neurológica).

Nesse patamar a complexidade da questão fica bastante evidente, assim como a diversidade de áreas científicas envolvidas. Num primeiro plano temos as neurociências, através das quais são estudados os mecanismos neurais. O entendimento dos processos de percepção, compete à psicologia, assim como entramos em questões de interesse filosófico quando levantamos a questão da consciência envolvida em todo o processo. Se ponderarmos sobre a questão do comportamento do sistema visual em resposta ao ambiente, assim como do processo evolutivo que levou ao desenvolvimento do sistema de visão natural, devemos considerar a ecologia e o darwinismo. Encerrando o processo do estudo da visão temos a matemática e a física desenvolvendo os modelos formais das 
interpretações encontradas para o processo visual e finalmente a computação auxiliando no desenvolvimento de experimentos, fazendo análises abstratas ou não das simulações e modelagens, e desenvolvendo sistemas artificiais correspondentes (Figura 4.1).

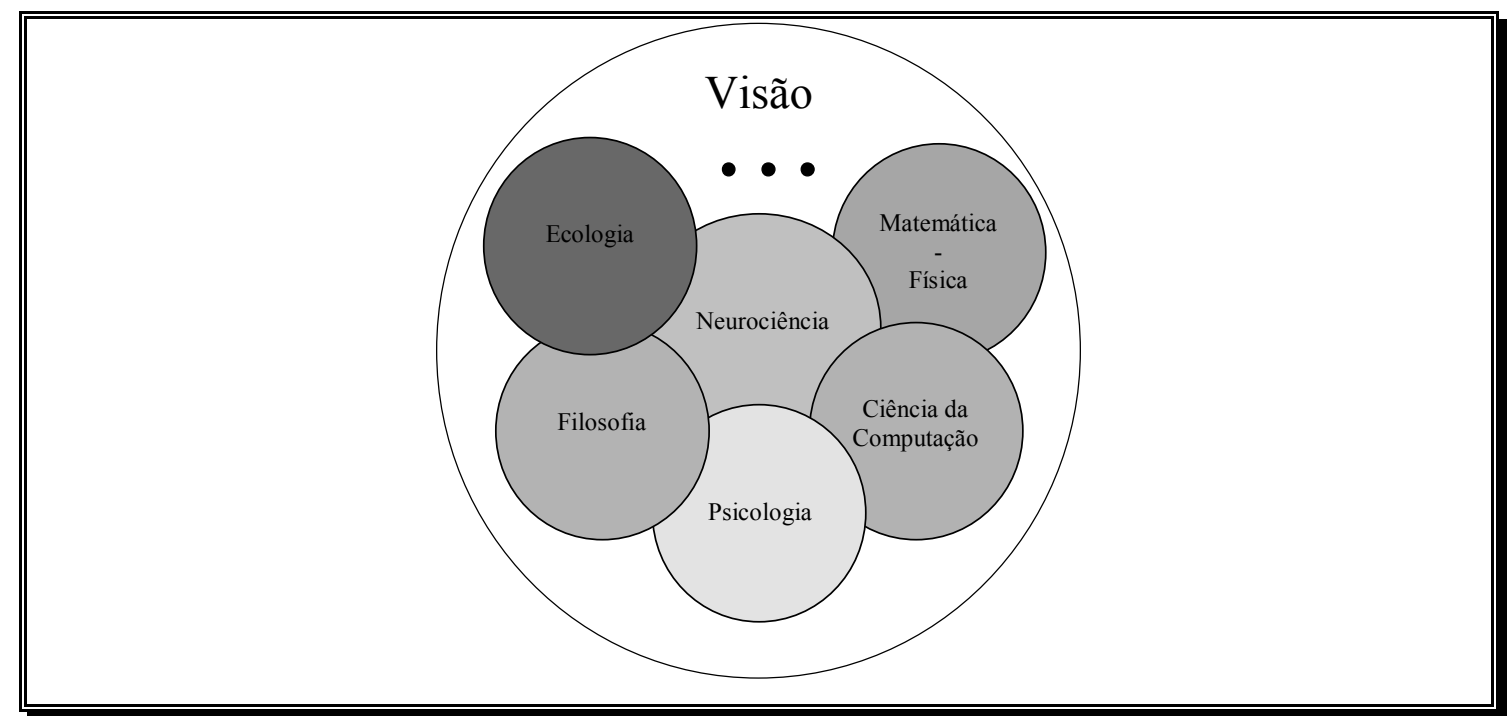

Fig. - 4.1 - Visão, uma ciência formada pela integração de muitas outras.

\section{5 - INTRODUÇÃO À NEUROCIÊNCIA}

Nesta seção iremos discutir sucintamente as bases da neurociência, para que possamos no contexto desse capítulo discorrer sobre o funcionamento do córtex visual. O sistema nervoso é constituído basicamente por dois tipos de células: células neurais ou neurônios e glias ou neuróglias. Enquanto os neurônios são células especializadas na condução e processamento de sinais eletroquímicos, as glias tem como finalidade o revestimento ou isolamento, modulação da atividade neural e defesa [Machado, 1993]. Nesta seção iremos enfocar nossa discussão nos neurônios, uma vez que estamos nos limitando ao perfil de processamento de informações.

\subsection{1 - SISTEMA NERVOSO}

Em termos evolutivos, a complexidade do sistema nervoso dos seres vivos determina sua escala hierárquica. Assim, quanto mais primitivo, mais rudimentar é o seu sistema nervoso, se comparado com o sistema nervoso dos vertebrados e 
mais ainda se compararmos com os representantes do ápice da pirâmide evolutiva, os primatas. No entanto, todos eles possuem uma unidade fundamental, as células neurais ou neurônios [Kovács, 1997]. Os sistemas nervosos são constituídos por aglomerados dessas células (gânglios, núcleos e córtices). Através de seus sistemas nervosos, os seres vivos são capazes de agir e reagir a eventos no ambiente, e muitas vezes até mesmo a modelá-lo.

O sistema nervoso dos vertebrados costuma ser dividido em duas porções com características distintas: o sistema nervoso central, localizado dentro do esqueleto axial (cavidade craniana e canal vertebral) e o sistema nervoso periférico localizado fora do esqueleto axial. O sistema nervoso central é formado pelo cérebro, medula espinhal e retina do sistema visual, ao passo que o periférico é composto pelas fibras aferentes e suas conexões com os órgãos sensoriais e pelas fibras eferentes, conexas com os músculos [Machado, 1993] [Costa, 1996]. A Figura 4.2 apresenta um esquema detalhado das divisões do sistema nervoso.

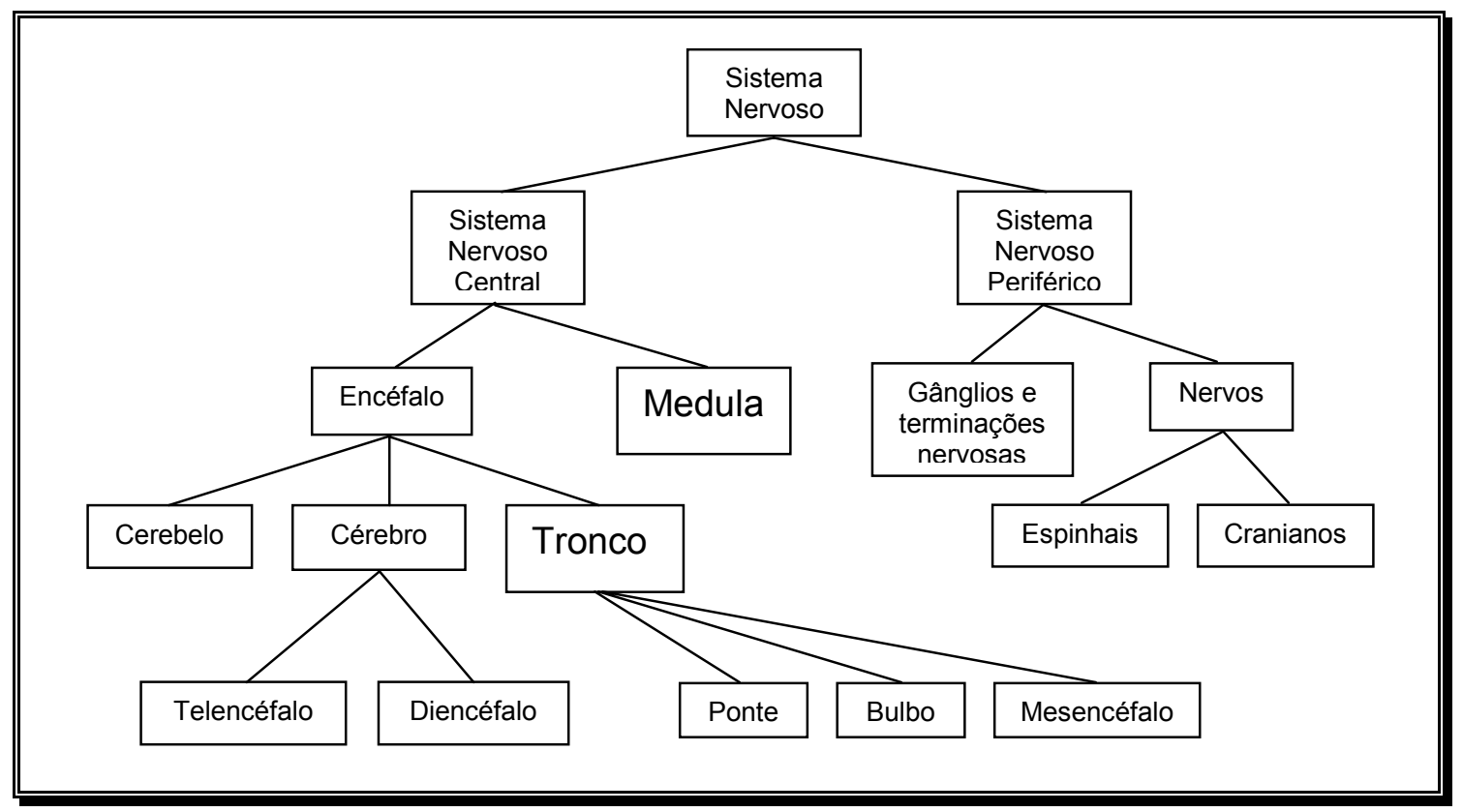

Fig. - 4.2 - Subdivisões do Sistema Nervoso [Costa, 1996].

Neste trabalho estaremos mais interessados no cérebro, que é composto pelo diencéfalo e telencéfalo. Na Figura 4.3 encontramos uma ilustração das divisões do encéfalo onde podemos encontrar essas duas regiões. $O$ diencéfalo fica localizado na base do telencéfalo. Um dos componentes do diencéfalo é o tálamo, que é composto por duas regiões localizadas simetricamente em sua porção láterodorsal. A grande maioria dos caminhos sensoriais fazem conexões ao tálamo, entre 
eles o caminho visual, uma vez que o núcleo geniculado lateral faz parte do complexo do tálamo.

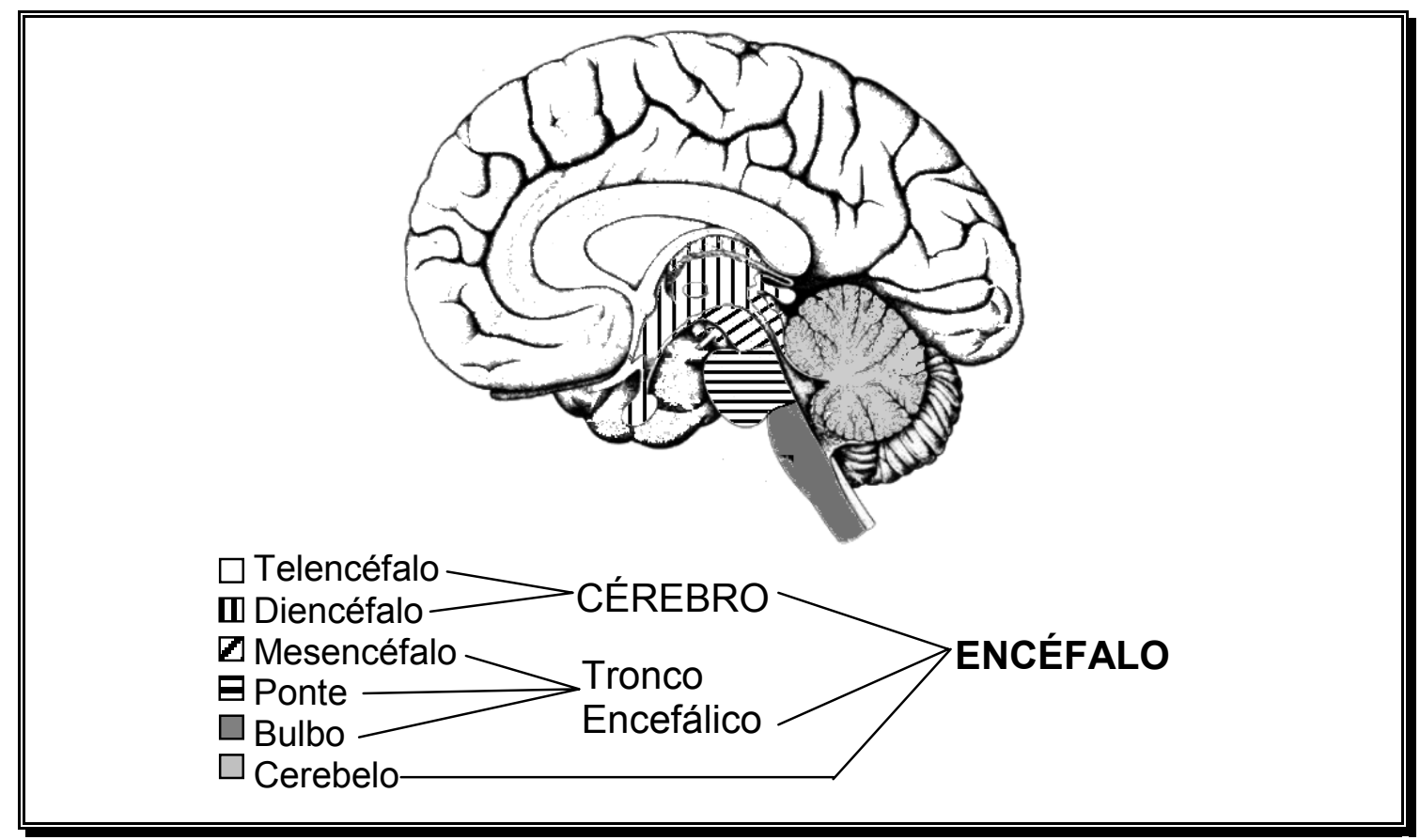

Fig. - 4.3 - Divisões do Encéfalo.

O telencéfalo por sua vez é composto pelos dois hemisférios cerebrais (direito e esquerdo) e pelo corpo caloso, através do qual os hemisférios são interconectados. Os hemisférios podem ser divididos em duas partes: o córtex cerebral e o centro branco medular. O córtex é aonde estão concentrados a grande maioria dos neurônios de todo o sistema nervoso, também denominado de matéria cinza, que possui cerca de $2 \mathrm{~mm}$ de espessura nos mamíferos. Devido à sua natureza superficial, o córtex é alojado dentro da cavidade craniana assemelhandose a um jornal amassado. Desta maneira, formam-se diversos sulcos, giros e lobos (Figura 4.4). Conforme já comentado, essa foi uma estratégia encontrada pela natureza a fim de que o córtex ocupasse uma área menor e possibilitando deste modo ficar contido dentro do crânio. O córtex reveste o centro branco medular, que é constituído pelos axônios que interconectam as regiões corticais e também pela conexão das regiões corticais com os centros subcorticais (ex: tálamo, que funciona como uma estação de distribuição dos sinais sensoriais). 


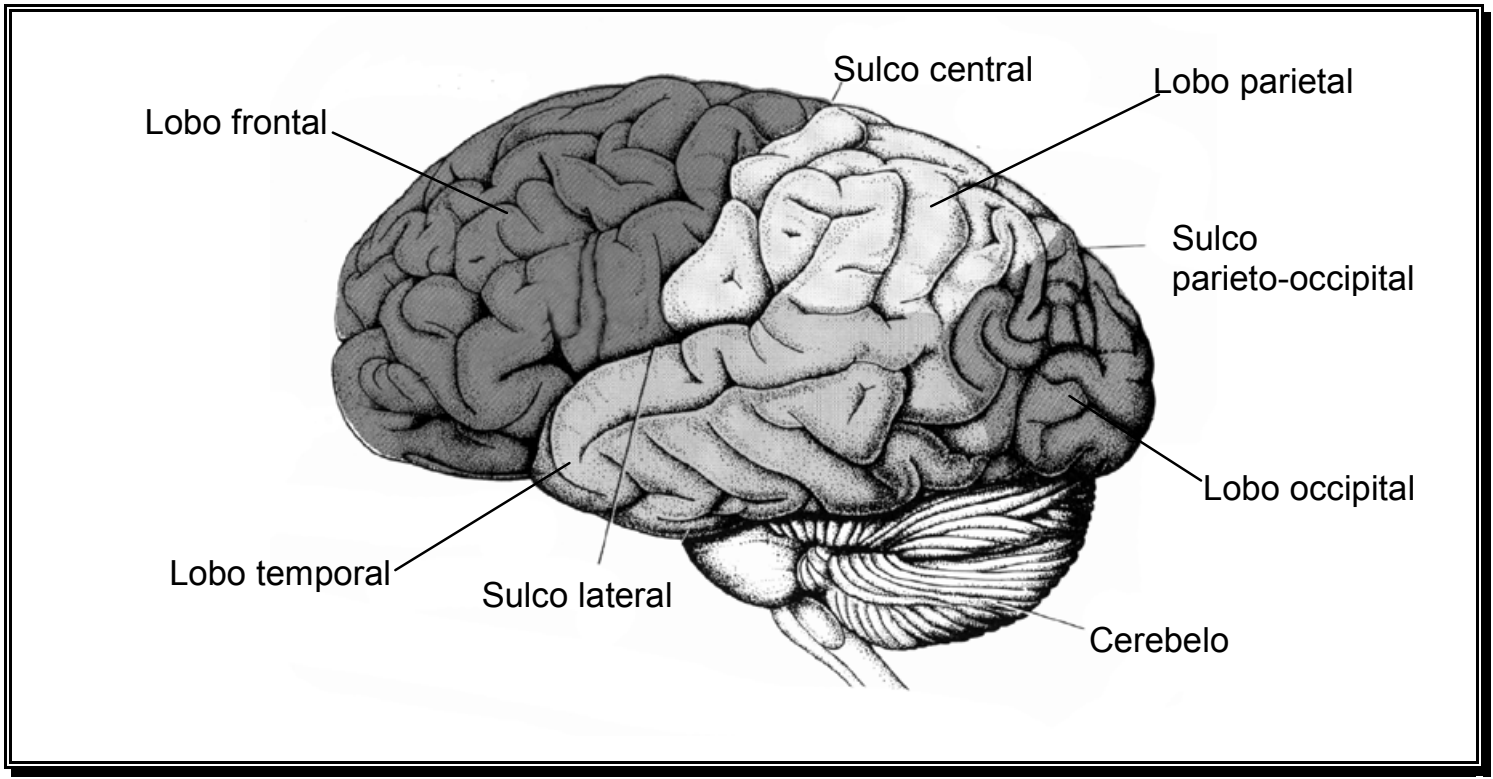

Fig. - 4.4- Lobos e sulcos corticais.

\subsection{2 - NEURÔNIOS}

A Figura 4.5 apresenta um neurônio típico transmitindo sinais eletroquímicos a outras três células neurais. Os neurônios são células especializadas na condução e processamento de sinais eletroquímicos. Embora exista uma grande quantidade de classes de neurônios, que são agrupados através de suas características funcionais e morfológicas, a base de seu comportamento eletroquímico é a mesma para todas as classes [Costa, 1996]. Os neurônios são delimitados por uma membrana celular e são constituídos basicamente de um corpo celular ou soma, um filamento alongado denominado axônio e dendritos (caracterizados pela sua natureza arborizada).

As dimensões, formas e localização do soma em relação à árvore dendrítica variam muito entre os diversos tipos de neurônios. Os diâmetros podem ir da ordem de 2 mícrons a mais de 0,5 milímetros. Em geral os neurônios apresentam apenas um único axônio. Sua função básica é a transmissão de sinal, resultante do processamento de informações recebidas pelos dendritos, através de pulsos elétricos. $\mathrm{O}$ axônio se caracteriza por ser um filamento de diâmetro uniforme que se projeta do neurônio percorrendo distâncias que vão desde centenas de mícrons até mais de um metro. O diâmetro dos axônios está relacionado à velocidade de transmissão: quanto maior o diâmetro, maior é a taxa de transmissão do sinal [Costa, 1996]. No Sistema Nervoso Periférico, axônios aferentes [Machado, 1993] transportam a informação proveniente dos sensores para o Sistema Nervoso 
Central. O caminho inverso também ocorre, quando as informações são transmitidas pelos eferentes ao organismos. Os axônios podem se agrupar em feixes. Quando agrupados no Sistema Nervoso Periférico, esse conjunto recebe o nome de troncos nervosos ou nervos, que podem conter desde poucas unidades a dezenas de milhares de axônios. No Sistema Nervoso Central, os agrupamentos são denominados de tractos [Kovács, 1997].

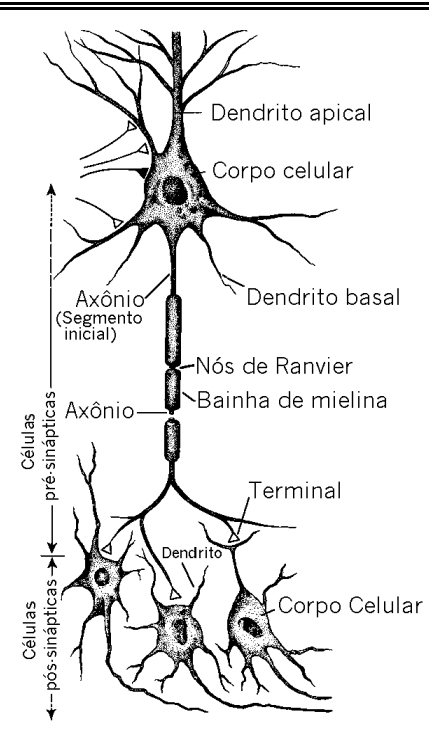

Fig. - 4.5 - Estrutura de um neurônio típico.

Nos vertebrados a maioria dos axônios são revestidos por uma cobertura gordurosa denominada de capas de mielina (bainha de mielina). Essa substância é produzida por células neurogliais de Schwamm [Kovács, 1997]. Este tipo de arranjo permite $\mathrm{o}$ isolamento elétrico das fibras aumentando a sua velocidade de transmissão e diminuindo seu diâmetro. Estima-se que nosso cérebro seria dez vezes maior caso não fosse adotada as capas de mielina [Dowling, 1992]. Os invertebrados, em geral, não possuem esse mecanismo, o que indica que a mielinização dos axônios foi um passo evolutivo, que aumentou a velocidade de propagação dos impulsos nervosos e diminuiu a dimensão das fibras nervosas, oferecendo uma significativa vantagem competitiva.

Se por um lado os axônios têm como função a transmissão dos impulsos nervosos, cabe aos dendritos a sua recepção. Os dendritos são prolongamentos filamentares de arranjo arbóreo, constituindo a parte receptiva dos neurônios. Sua natureza de ramificação arbórea tem como finalidade possuir uma ampla área para a recepção dos sinais. A transmissão do sinal entre os axônios e dendritos ocorre 
em estruturas de contato denominadas sinapses. Embora as sinapses freqüentemente ocorram entre axônios e dendritos (axodendríticas), elas podem ocorrer também entre axônios e a soma (axossomáticas), e em casos mais raros entre: axônio-axônio (axoaxônicas), dendrito-dendrito (dendrodendríticas), dentritosoma (dendrossomáticas), soma-soma (somatossomáticas), soma-dendrito (somatodendríticas) e soma-axônio (somatoaxônicas) [Machado, 1993].

(a)

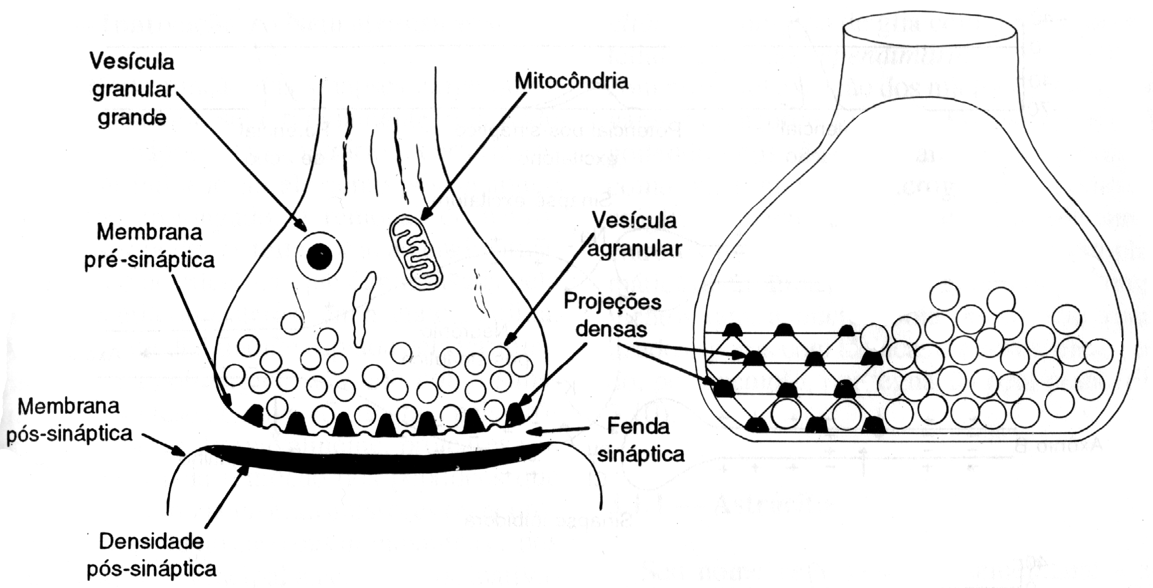

(b)

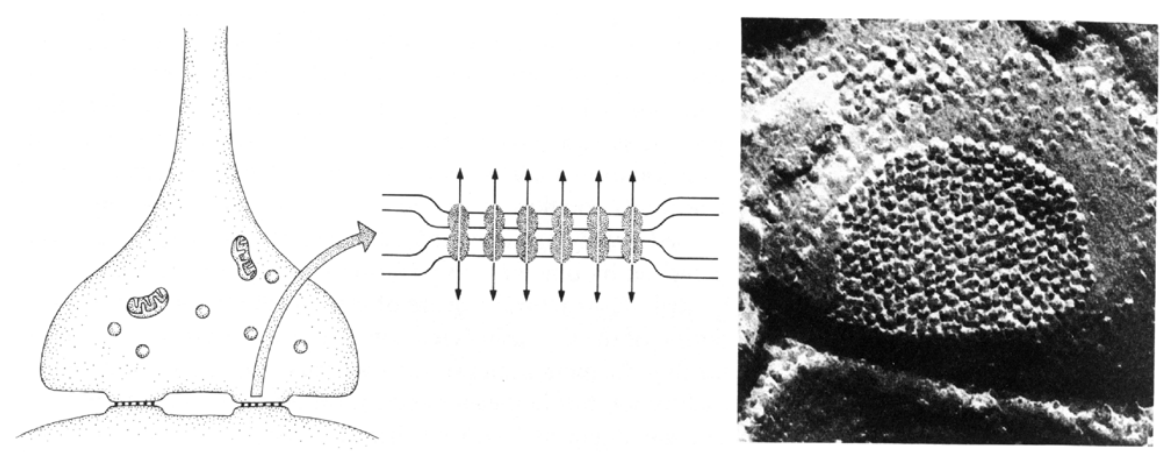

Fig. - 4.6 - (a) Ilustração de uma sinapse. (b) Fenda sináptica. [Dowling, 1992]

A Figura 4.6a apresenta uma sinapse. Nela podemos observar duas membranas: pré-sináptica e pós-sináptica. A membrana pré-sináptica transmite o sinal, enquanto que a pós-sináptica o recebe. Ambas as membranas sinápticas são separadas por uma fenda denominada de fenda sináptica, que podemos observar na Figura 4.6b. Quando um pulso nervoso chega pelo axônio até a membrana présináptica, esta libera vesículas com mediadores químicos, denominados de neurotransmissores (Figura 4.6), que através da fenda sináptica, chegam à 


\section{CAPÍTULO 4}

membrana pós-sináptica, provocando alteração em sua polaridade. Uma característica fundamental da sinapse é a de propagar sinais em um único sentido: da membrana pré-sináptica para a membrana pós-sináptica.

Quanto à função, podem ocorrer dois tipos de sinapses: excitatória e inibitória. De acordo com as características químicas dos neurotransmissores pode haver uma despolarização ou hiperpolarização da membrana pós-sináptica, onde a despolarização desta é denominada de potencial pós-sináptico excitatório (PPSE) e a hiperpolarização denominada potencial pós-sináptico inibitório (PPSI) [Coelho, 1998]. A Figura 4.7 ilustra as sinapses excitatória e inibitória assim como as PPSE e PPSI.

Cada sinapse (PPSE ou PPSI) produz um efeito mínimo no neurônio. No entanto os neurônios apresentam muitas sinapses, segundo Kovács [Kovács, 1997] a ordem de sinapses é de 5000 nos neurônios motores da medula e pode chegar até mesmo a 95000 nas células de Purkinje (neurônio do córtex cerebelar) e que para cada milímetro cúbico do córtex cerebral existam $10^{5}$ neurônios e $10^{9}$ sinapses. Assim, o neurônio funciona como um integrador de sinais, de modo que o conjunto dos sinais sinápticos determinará a resposta do neurônio.

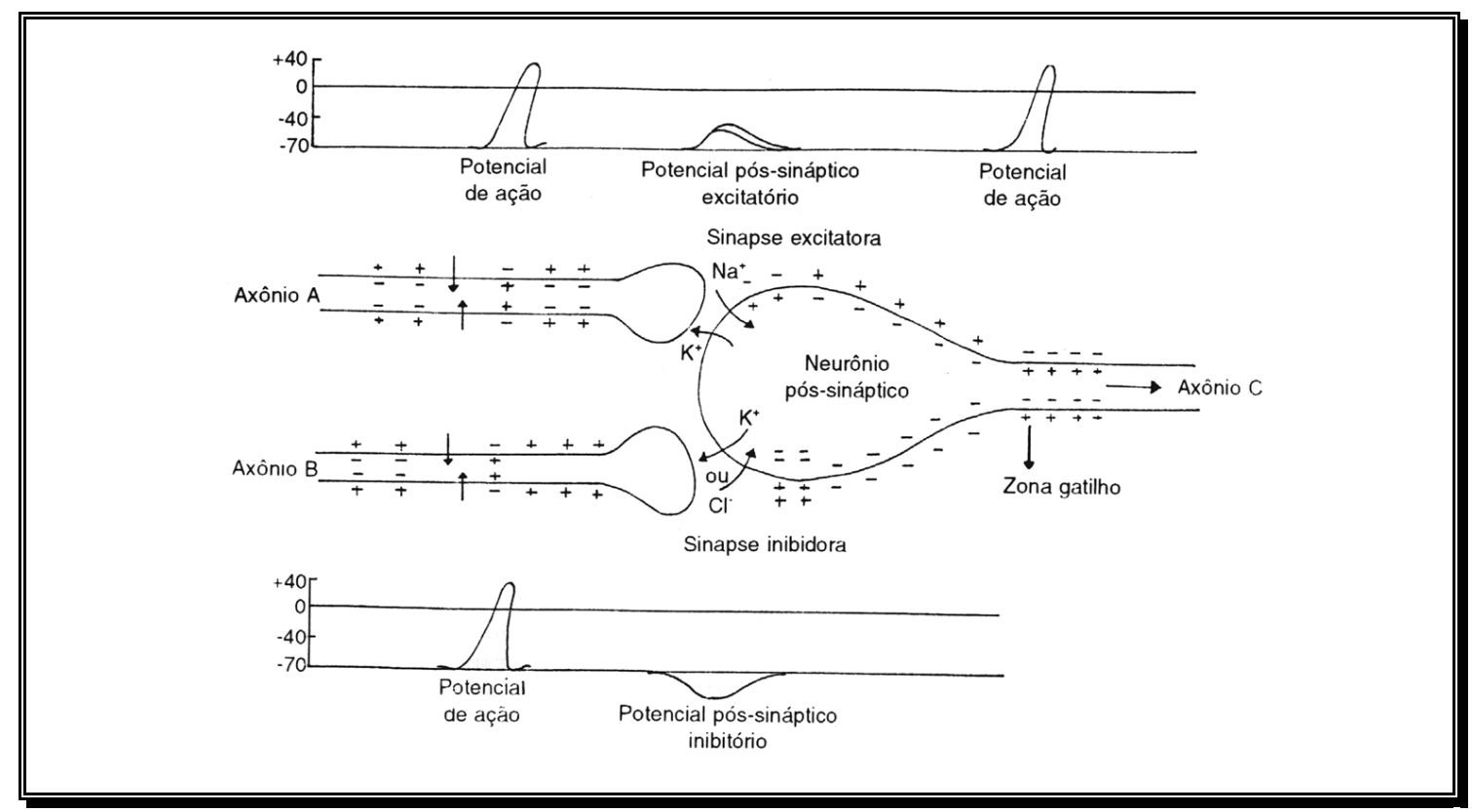

Fig. - 4.7 - Sinapses excitatória, Sinapses inibitória, PPSE e PPSI.

Cada sinapse pode produzir polarizações diferentes, que são determinados por um conjunto de fatores, tais como: tamanho da sinapse, quantidade de neurotransmissores liberados, distância do ponto sináptico ao soma e tipo da 
sinapse (PPSE - despolarização e PPSI - polarização) [Kovács, 1997] [Costa, 1996]. Para que o neurônio responda ao estímulo, a somatória da polarização das sinapses deve produzir uma despolarização suficiente para ultrapassar um limiar, conhecido como limite de disparo. Acontecendo isso, a membrana despolariza em questão de microsegundos muito além do limiar, e o estímulo é transmitido pelo axônio, fazendo que deste modo a polarização da membrana retorne lentamente (em relação ao disparo) à sua polarização original. Este fenômeno é denominado potencial de ação. A velocidade de transmissão do impulso nervoso é de algumas dezenas de centímetros por segundo em fibras não mielinizadas e até 150 metros por segundo em fibras mielinizadas [Kovács, 1996].

Existe um grande número de modelos matemáticos de neurônios e redes neurais. A motivação inicial da modelagem de neurônios artificiais ocorreu em 1943 com o trabalho de McCulloch e Pitts [McCulloch \& Pitts, 1943]. Por algumas décadas essa idéia não teve muitos seguidores até emergir novamente na década de 80 com força renovada nas linhas de pesquisa. A Figura 4.8 apresenta um modelo matemático típico de um neurônio. Nele os estímulos $X_{1} \ldots X_{n}$ são integrados com o produto interno de seus respectivos pesos $W$ produzindo $s$, que sofre uma transformação não linear implementada pela função $f$. Transpondo essa representação para o modelo biológico temos cada entrada $X$ representada por uma sinapse, que apresenta "pesos" diferentes sob determinados aspectos [Costa, 1996], cuja despolarização é integrada pela soma celular que, caso exceda o limiar, dispara um impulso nervoso representado por $\mathrm{y}$.

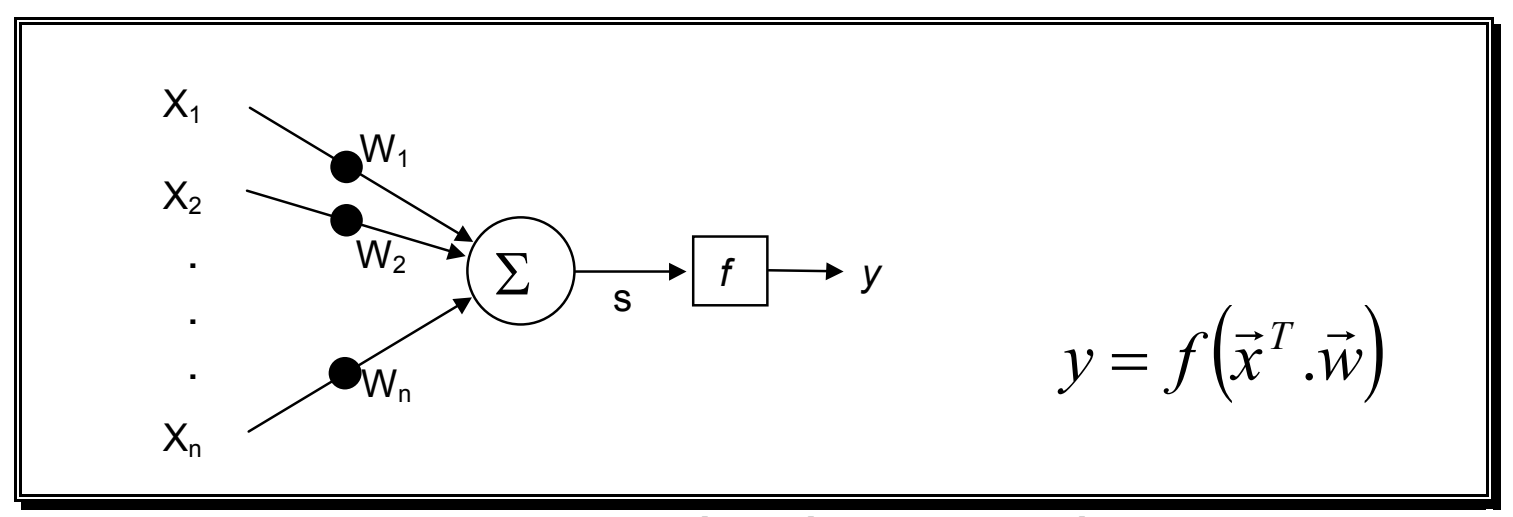

Fig. - 4.8 - Modelo matemático típico de uma célula neural. 


\section{6 - O CAMINHO VISUAL}

Assim como os demais sentidos, a visão tem como objetivo a percepção, compreensão e até mesmo (nos seres mais evoluídos) a modelagem do meio ambiente e dos objetos a sua volta. A diferença básica entre a visão e os demais sentidos é a quantidade de informações que são adquiridas por este sentido e sua complexidade. A importância, assim como sua complexidade, é tamanha que $60 \%$ de todo o mecanismo neural do córtex é utilizado para esse sentido [Hubel, 1995] [Tovée, 1996] [Levine, 1985]. Nesta seção vamos discutir o caminho visual, que se inicia com a luz refletindo nos objetos e sendo transformada em impulsos nervosos pelos fotorreceptores e finaliza com a abstração e percepção dos sinais nervosos processados pela retina e córtex visual primário.

\subsection{1 - CAPTANDO A LUZ}

Os olhos têm como função básica captar a luz e focalizá-la na retina, uma fina camada localizada na parede posterior interna composta de neurônios especializados em converter os sinais eletromagnéticos em neurológicos. Entendese por luz visível a região do espectro da radiação eletromagnética visível pelos seres humanos. Embora possua um sistema de visão eficiente, o homem é cego à grande maioria das ondas eletromagnéticas. A Figura 4.9 apresenta o espectro da radiação eletromagnética, destacando a porção percebida pelo nosso sistema de visão.

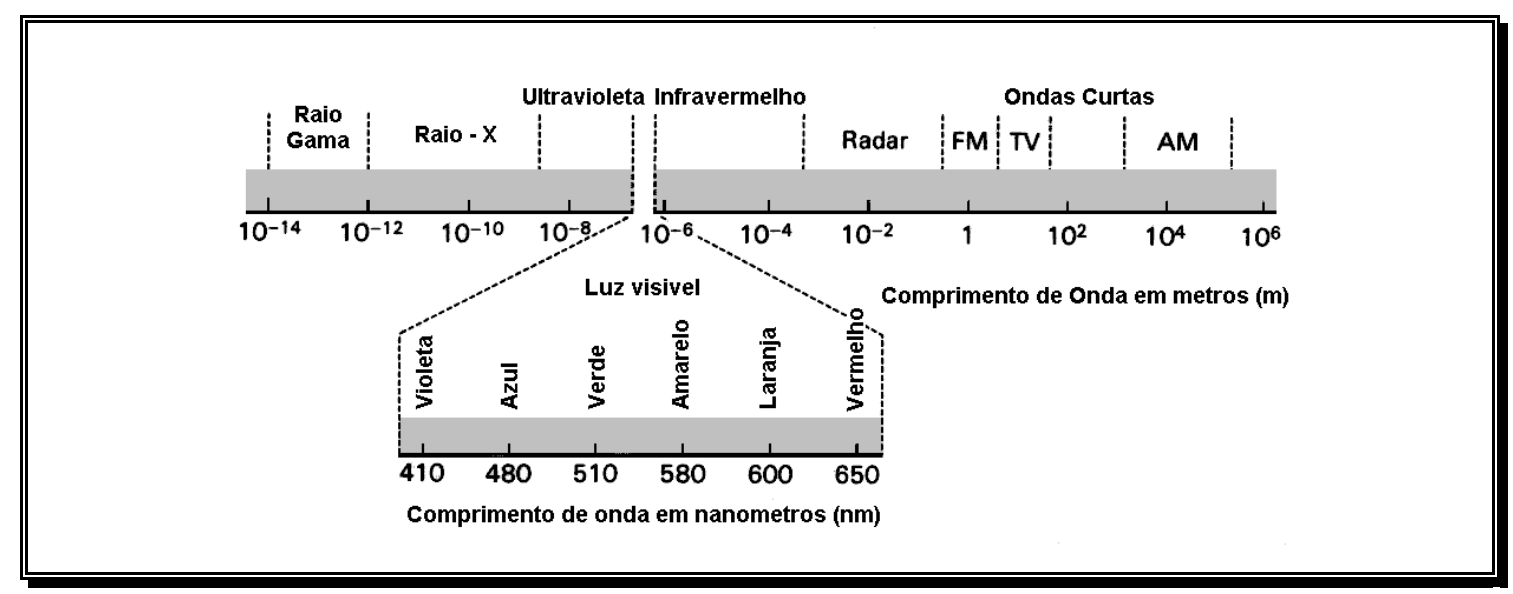

Fig. - 4.9 - Espectro da radiação eletromagnética com destaque para a porção visível. 
A Figura 4.10 apresenta a estrutura geral do olho humano. O olho apresenta funcionamento semelhante a uma câmara fotográfica, através do seu sistema de lentes, composto pela córnea e pelo cristalino, focaliza a imagem na retina. A luz é inicialmente refratada pela córnea, que através de sua superfície côncava, converte os raios luminosos para o interior do olho. Após os raios refratados terem passado pela córnea e pelo humor aquoso, atingem a superfície curva anterior da lente do cristalino e então a superfície curva posterior (lente convexa). Deste modo os raios luminosos são refratados em três locais diferentes e através dessas refrações são convergidos e focados na retina. O cristalino é flexível e pode ser alongado e comprimido pela ação dos músculos ciliares. Através dessa alteração da forma do cristalino a dioptria do sistema óptico é alterada, possibilitando focar objetos localizados em distâncias diferentes. Enquanto o cristalino é responsável pelo ajuste fino do foco, a córnea é a maior responsável pela convergência dos raios, cerca de $70 \%$ da refração é realizada por ela [Tovée, 1996]. Uma outra forma de alterar a dioptria de um sistema óptico seria o deslocamento do cristalino, do mesmo modo como é utilizado nas câmaras fotográficas. Embora esse método não seja utilizado pelos primatas, alguns animais, como por exemplo a rã, adotam essa estratégia [Schmidt, 1980].

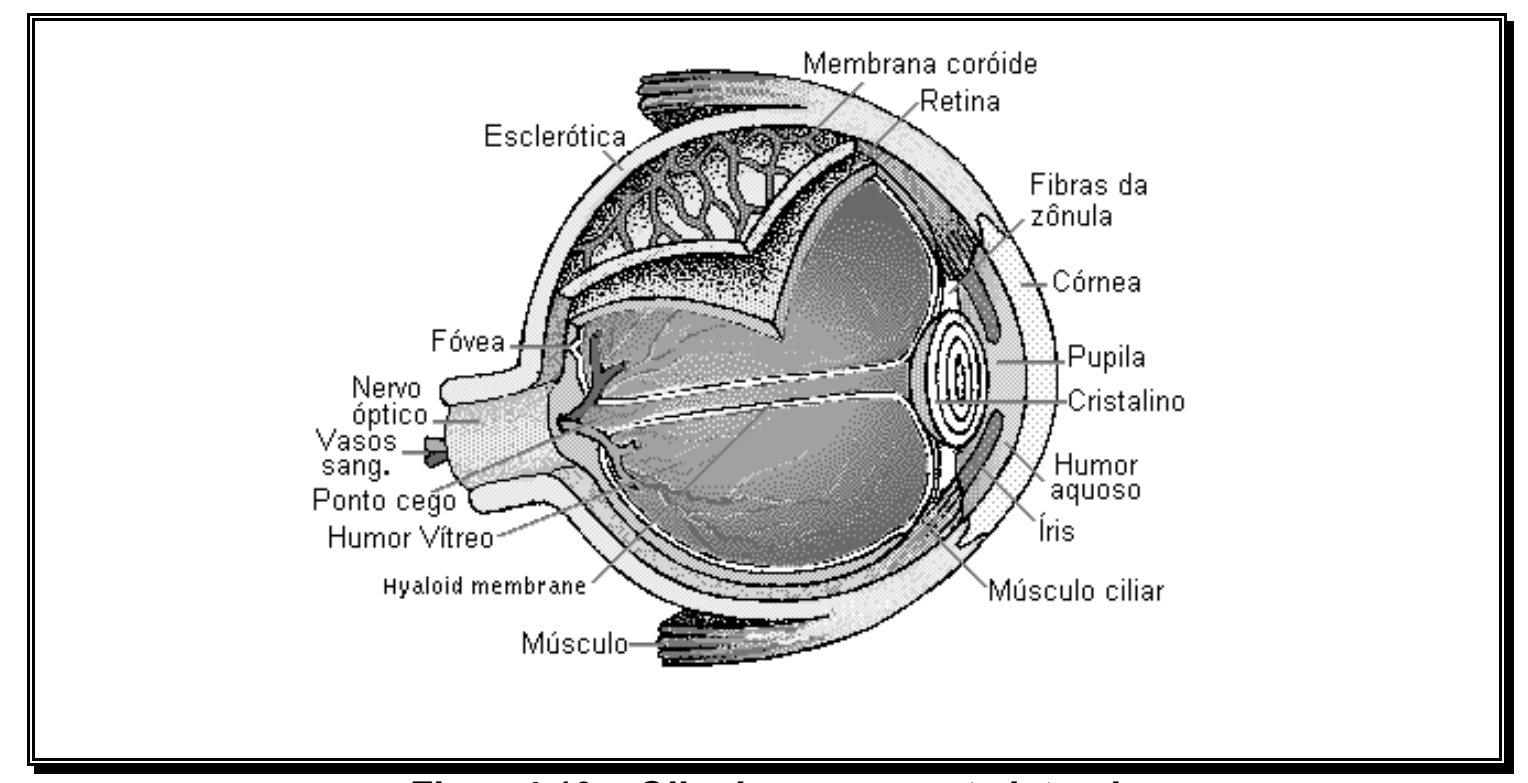

Fig. - 4.10 - Olho humano, corte lateral.

O globo ocular é sustentado por três pares de músculos, que são responsáveis por sua movimentação, conforme mostra a Figura 4.11. Os músculos de cada pa trabalham em oposição e são responsáveis pelo movimento em relação 
a três planos perpendiculares. Os movimentos do globo ocular possuem precisão da ordem de um minuto de arco e podem fornecer um ângulo de visão de no mínimo $140^{\circ}$ [Braham, 1996]. O sistema de movimentação do globo ocular trabalha em conjunto com uma coleção de reflexos precisamente sintonizados, incluindo os que controlam a posição da cabeça [Hubel, 1995].

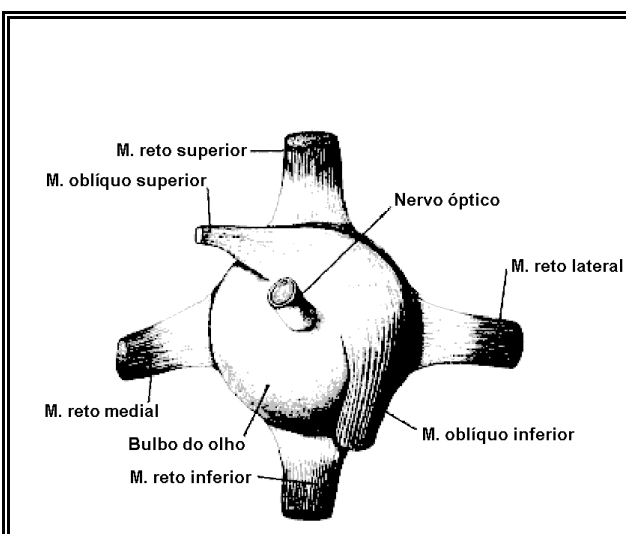

(a)

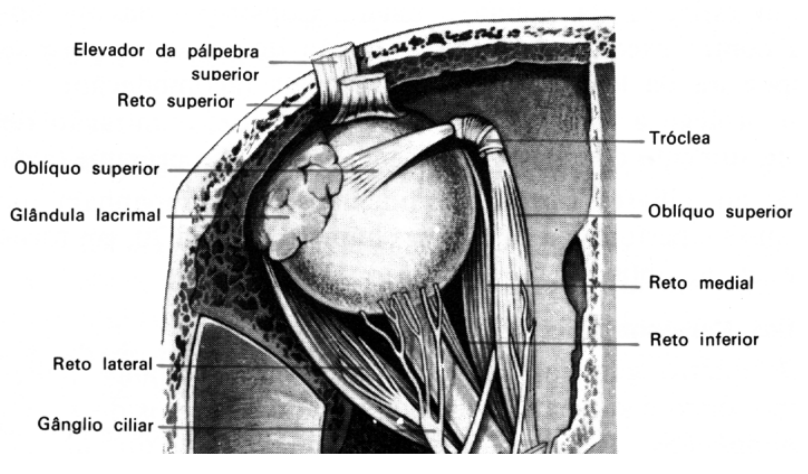

(b)

Fig. - 4.11 - Músculos de sustentação do globo ocular. (a) Globo ocular vista dorsal. (b) Disposição dos músculos na cavidade ocular.

\subsection{2 - A RETINA}

A retina, localizada na parede posterior do olho, recebe toda a luz captada pelo sistema óptico. Uma vez focalizada a imagem na retina, inicia-se o processo de transformação da luz em impulso nervoso.

A retina é uma parte do cérebro que se desprendeu através da evolução e permaneceu conectada através do nervo óptico. Ela é composta por três camadas de corpos de células nervosas separadas por duas camadas de sinapses, compostas por axônios e dendritos. As estruturas da retina encontram-se altamente organizadas. A retina tem a forma de uma placa ou camada e encontra-se depositada na parede posterior do olho, possuindo uma espessura de aproximadamente 0,25 mm [Hubel, 1995]. A Figura 4.12 apresenta uma ilustração contendo um olho e a retina ampliada apresentando suas estruturas. Curiosamente a última camada da retina é composta pelos fotorreceptores, células nervosas sensoriais capazes de converter a luz em sinal nervoso. Deste modo a luz atravessa todas as demais estruturas da retina até chegar nos fotorreceptores. 


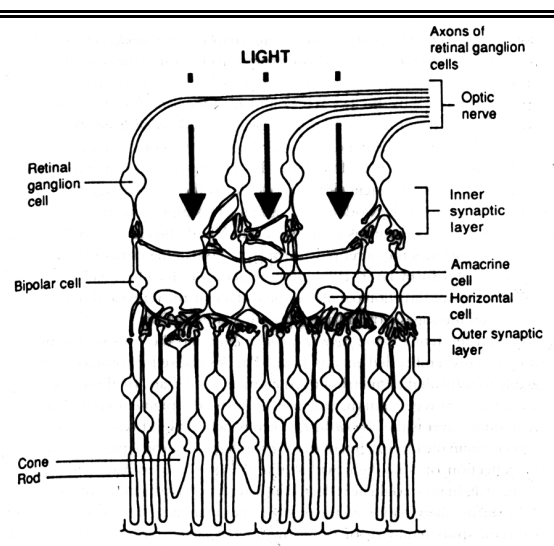

(a)

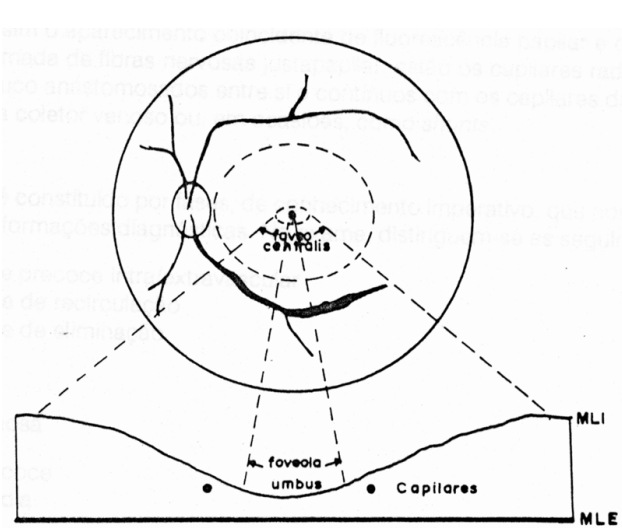

(b)

Fig. - 4.12 - Corte da retina (a) e mapa da distribuição vascular dos capilares na mácula (b).

A retina costuma ser considerada em duas camadas: a neurossensorial e o epitélio pigmentar. A retina sensorial é uma estrutua celular complexa, estratificada, composta pelas células fotorreceptoras, ganglionares, interneurais (bipolar, horizontal, amácrina e interplexiforme) e glias. A retina sensorial subdividi-se em duas partes: (i) interna, englobando a membrana limitante até a nuclear interna (todas as células de processamento neurológico descritas anteriormente) e (ii) externa constituindo da plexiforme externa aos fotorreceptores. A retina sensorial interna é vascularizada a partir dos vasos sangüíneos oriundos da artéria central da retina, ao passo que a retina externa é avascular, sendo nutrida pela coróide (a nutrição atravessa o eptélio pigmentar) [Bruno, 1999].

\subsubsection{1 - OS FOTORRECEPTORES}

Os fotorreceptores são células nervosas adaptadas, responsáveis pela conversão do sinal luminoso em sinal nervoso. Existem dois tipos de fotorreceptores na retina: os cones e os bastonetes. A retina humana contém cerca de 120 milhões de bastonetes e 6 milhões de cones [Tovée, 1996]. A Figura 4.13 apresenta um gráfico que ilustra a distribuição dos cones e bastonetes ao longo da retina. Como podemos observar, os cones estão concentrados na região central da retina. Sua concentração apresenta um pico numa região denominada fóvea. Os bastonetes por outro lado, se concentram mais nas regiões periféricas, tendo uma presença praticamente nula na região foveal. 


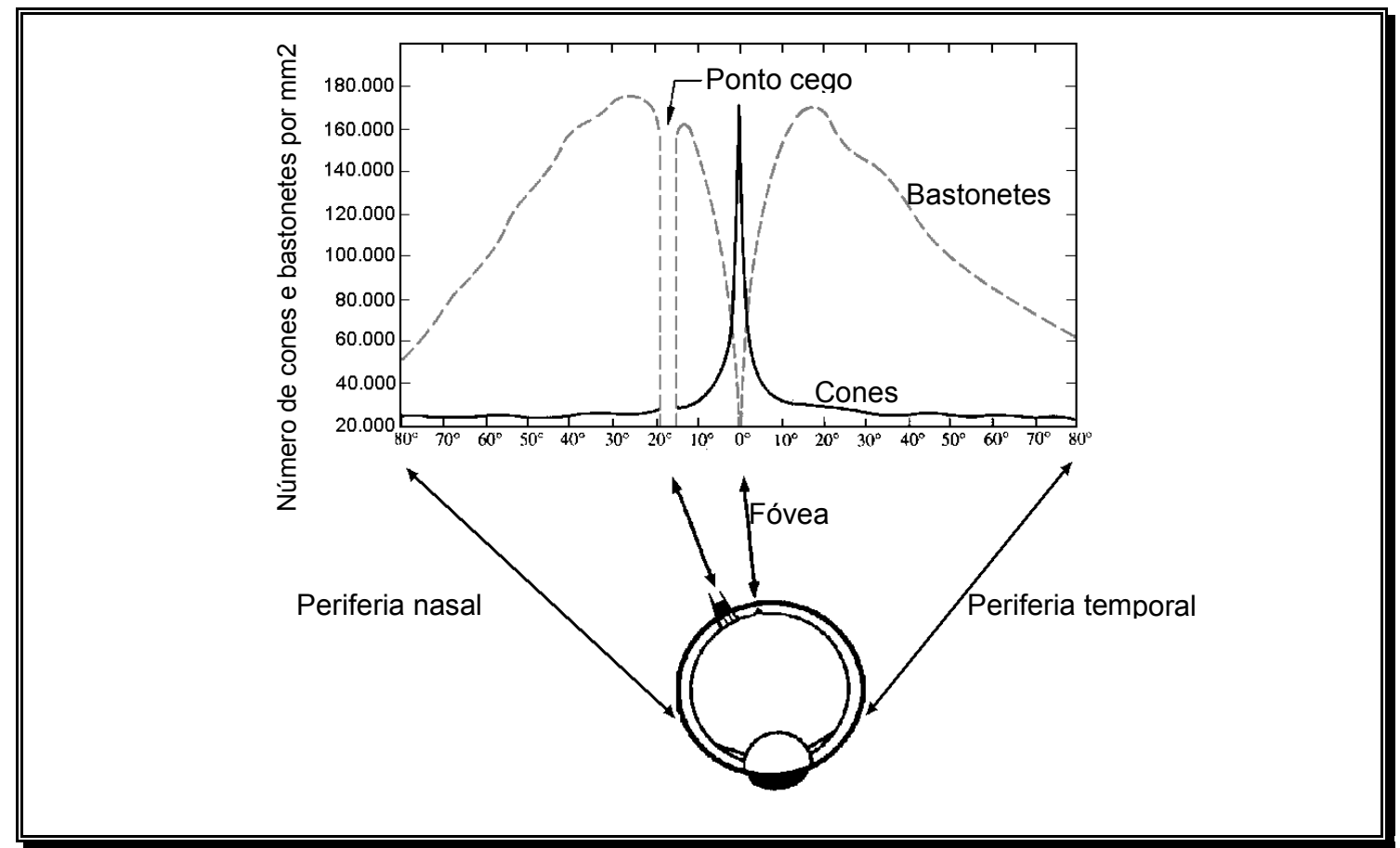

Fig. - 4.13 - Distribuição dos cones e bastonetes ao longo da retina.

Ainda observando a distribuição dos fotorreceptores na retina, podemos observar o ponto cego, que constitui a região por onde chega a vascularização até a retina e também a região por onde sai o nervo óptico, conjunto de axônios que levam as informações processadas na retina ao córtex.

Além da distribuição ao longo da retina, os cones e bastonetes também se diferenciam quanto a forma e função. Os bastonetes são mais sensíveis à luz que os cones, possuindo uma maior percepção para locais com pouca iluminação ou visão noturna, entretanto sua resolução é menor. Os cones por outro lado são os sensores utilizados para a visão diurna com alta precisão. Alguns primatas, entre eles o homem, possuem três tipos de cones, sensíveis a diferentes freqüências eletromagnéticas: ondas curtas (azul), médias (verde) e longas (vermelho). Sendo assim, os cones são responsáveis pela visão cromática. A Figura 4.14 apresenta as curvas sensibilidade a freqüência para cada classe.

A grande maioria dos cones se encontra na fóvea, devido a este fato, essa região da retina é responsável pela visão de precisão. Cerca de $5 \%$ a $10 \%$ do cones, respondem ao azul. Eles ficam distribuídos na região periférica da fóvea, formando assim uma estrutura anular. Os cones que respondem ao vermelho e verde são arranjados de forma bastante regular, estabelecendo padrões na retina. A razão entre os cones sensíveis ao vermelho e verde é de 2 para um [Tovée, 


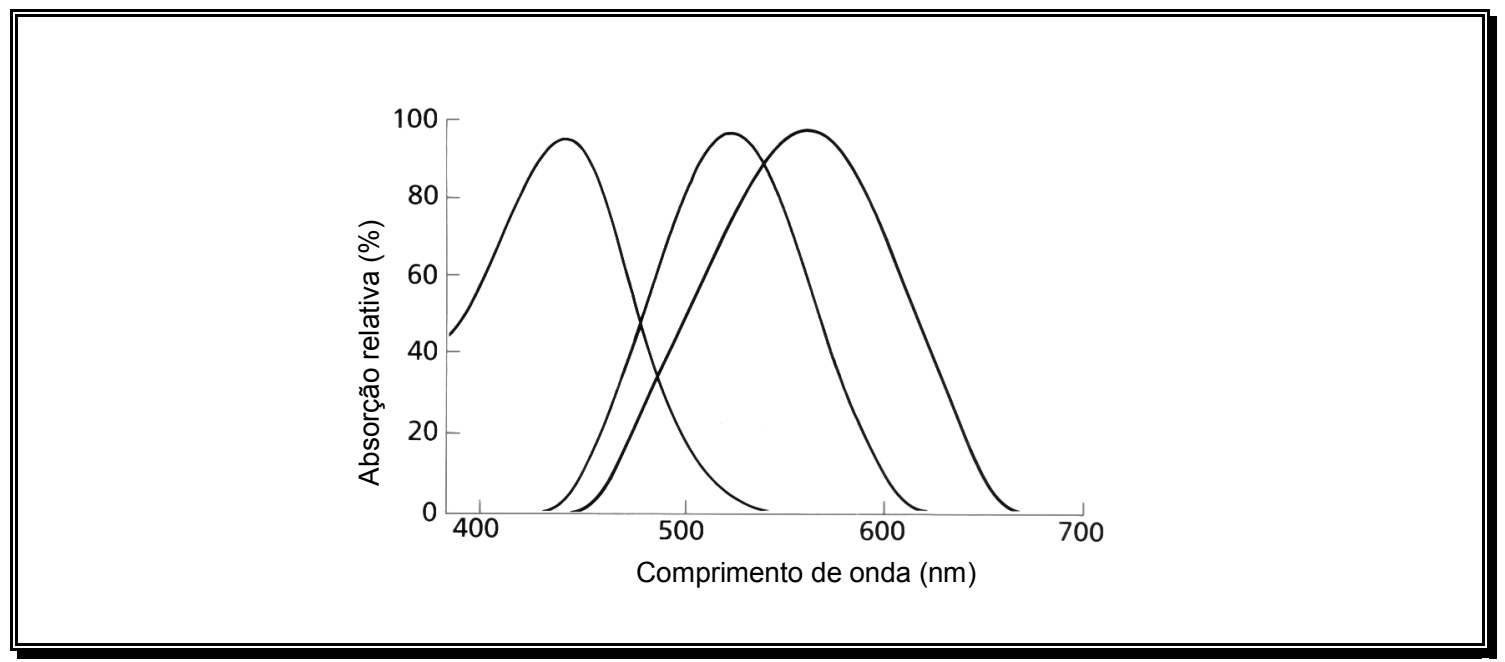

Fig. - 4.14 - Sensibilidade dos três tipos de cones da retina dos primatas.

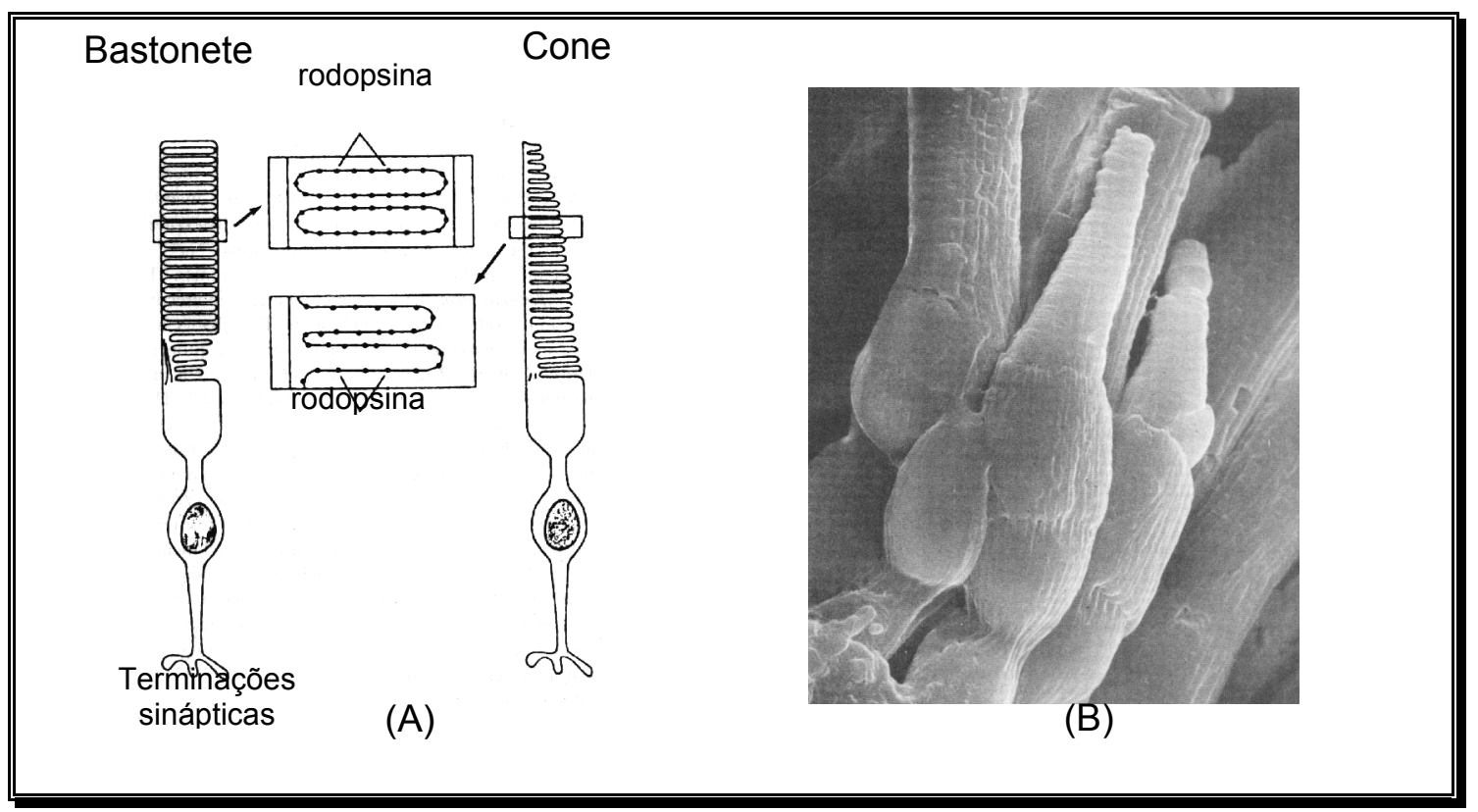

Fig. - 4.15 - (A) Diagrama esquemático dos fotorreceptores (cones e bastonetes) [Tovèe, 1996]. (B) Imagem microscópica apresentando os fotorreceptores (em destaque cone) [Dowling,1992].

Tanto os cones quanto os bastonetes, possuem funcionamentos semelhantes, baseados em moléculas sensíveis à luz, intituladas rodopsinas. $O$ conjunto das moléculas rodopsinas, localizadas no segmento exterior das células fotorreceptoras é responsável por sua excitação, um único bastonete humano contém cerca de 100 milhões de moléculas, que são interligadas proximamente, 


\section{CAPÍTULO 4}

cuja distância entre moléculas possui cerca de 20 nm [Tovèe,1996]. A Figura 4.15a apresenta uma comparação entre um cone e um bastonete em relação à forma assim como a disposição das moléculas de rodopsina e a Figura 4.15b apresenta uma imagem dos fotorreceptores.

\subsubsection{2 - RETINA SENSORIAL INTERNA}

Há algumas décadas atrás acreditava-se que a única função da retina era converter a luz em sinais nervosos e transmiti-los para o córtex. No entanto, existem cerca de 126 milhões de fotorreceptores na retina, cada um transmitindo informações sobre a luz absorvida em um determinado ponto da retina. A informação é transmitida para o córtex através do nervo óptico, que é o conjunto dos axônios das células ganglionares, e existem apenas 1 milhão deste. A relação 126 milhões para 1 milhão, deixa bastante clara a existência de processamento nas células da retina sensorial interna.

As evidências indicam que a retina realize os primeiros processamentos da informação visual [Goldstein, 1989] [Hubel, 1995], destacando a detecção de bordas [Marr, 1982] [Bruce \& Green, 1990]. Além da detecção de bordas, uma outra função importante implementada na retina é o início da divisão dos caminhos visuais (parvo e magno), que será comentada mais adiante.

A retina sensorial interna é formada por quatro tipos de células neurais: células bipolares, células horizontais, células amácrinas e células ganglionares (ver Figura 4.12). Embora essas células tenham sido vastamente estudadas, estaremos interessados neste trabalho nas células ganglionares, que são a última camada de células nervosas na retina, sendo que seus axônios formam o nervo óptico.

Nas células ganglionares da retina de primatas foram encontrados dois tipos distintos de células : M e P (Magno e Parvo) [Shapley \& Perry 1986]. As células M tem como características um campo dendrítico pequeno na região foveal, que aumenta em tamanho de forma linear quanto mais as células se distanciam da fóvea ao passo que as células $P$ são muito mais numerosas e possuem um campo dendrítico pequeno, que se mantém de tamanho constante ao longo de toda a retina. Essas células irão originar os caminhos Magnocelular e Parvocelular, caminhos independentemente correlacionados que percorrem quase todo o sistema visual. Conforme veremos em breve (Seção 4.6.3.1) as propriedade dos caminhos Parvocelular e Magnocelular sugerem uma correlação direta entre as células ganglionares $\mathrm{M}$ e $\mathrm{P}$ e as duas classes de fotorreceptores (cones e bastonetes). 


\subsubsection{3 - CAMPOS RECEPTIVOS DA RETINA}

O campo receptivo se caracteriza por uma região sensorial que influencia uma célula específica. Os campos receptivos são encontrados e estudados em diversos pontos do caminho visual. Na retina, os campos receptivos são classicamente estudados a partir das células ganglionares. Deste modo cada célula ganglionar possui uma região na retina (fotorreceptores) que a influencia.

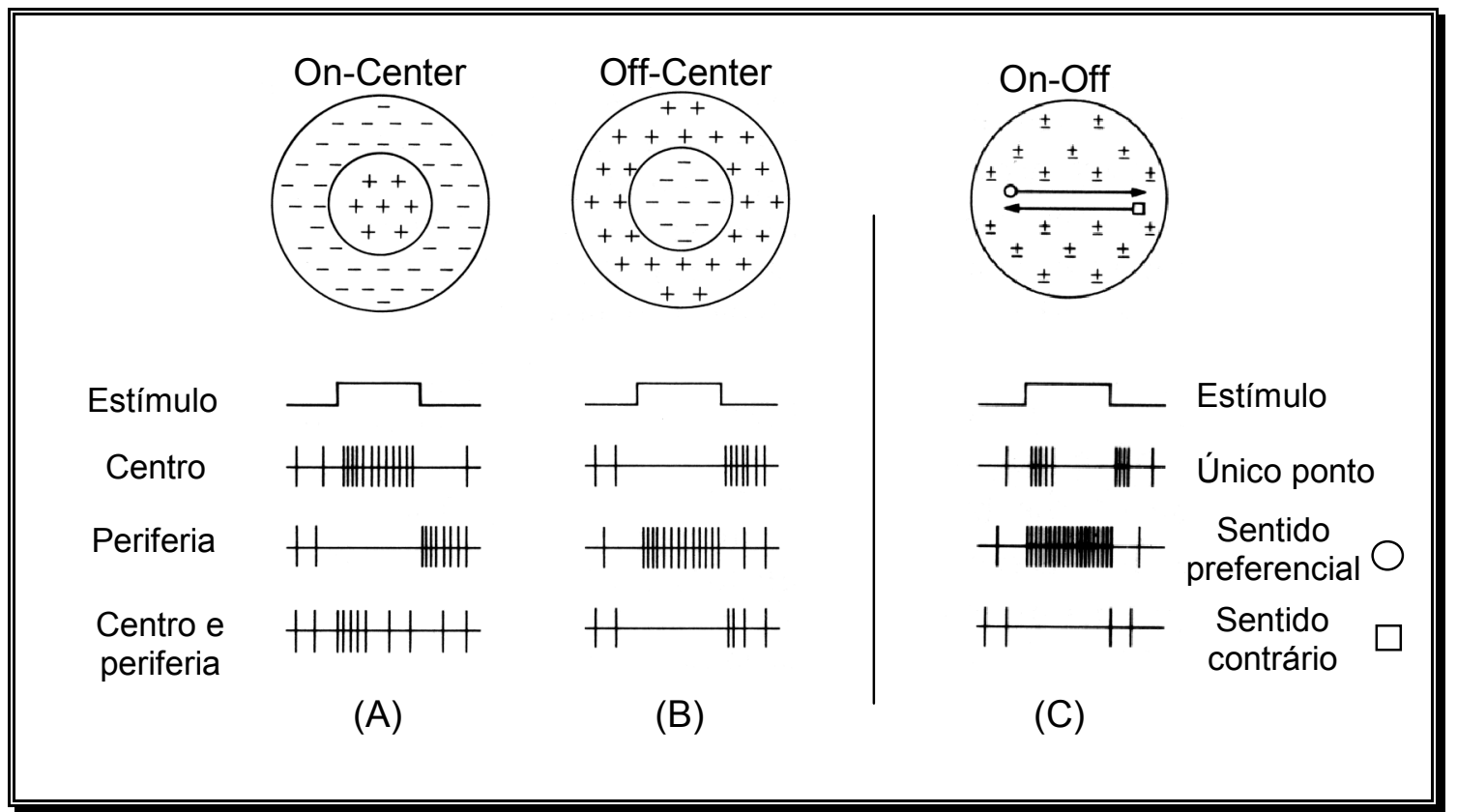

Fig. - 4.16 - Campos receptivos das células ganglionares da retina. (a) "OnCenter" - excitação na região central e inibição na região periférica. (b) "OffCenter" - inibição na região central e excitação na região periférica. (c) "OnOff' - respostas a movimentos.

$\mathrm{Na}$ retina os campos receptivos se caracterizam por formarem estruturas concêntricas conhecidas como centro-periferia, apresentando basicamente três tipos quanto a funcionalidade: "On-Center", "Off-Center" e "On-Off". Na Figura 4.16 temos exemplos das respostas das células em relação aos estímulos em seus campos receptivos. As células com campos receptivos "On-Center" (Figura 4.16a) disparam quando o centro do campo receptivo é iluminado, ao passo que com as células com campos "Off-Center" (Figura 4.16b) ocorre justamente o contrário. As células com campos receptivos "On-Off" (Figura 4.16c) são sensíveis ao movimento, respondendo quando um ponto luminoso percorre uma direção e sentido preferencial [Dowling, 1992] [Coelho, 1998] [Costa, 1996]. 
É importante observar que os campos receptivos se sobrepõem, de modo que uma célula fotorreceptora da retina pode fazer parte de muitos campos receptivos de diferentes células ganglionares [Hubel, 1995]. Quanto ao tamanho dos campos receptivos, este difere de uma célula para outra, tendo em média tamanhos menores quando o campo receptivo está nas regiões foveais e maiores na periferia. David Marr [Marr, 1982], descreve uma modelagem matemática dos campos receptivos da retina, que se tornou um clássico na literatura, sendo conhecida como filtro de Marr-Hildreth, que é descrita pelo laplaciano da gaussiana (Equação 4.1). Segundo tal modelo, os campos receptivos ganglionares são excelentes detectores de bordas.

$$
\nabla^{2} G(r)=\frac{-1}{\pi \sigma^{4}}\left(1-\frac{r^{2}}{2 \sigma^{2}}\right) e^{\frac{-r^{2}}{2 \sigma^{2}}}
$$

\subsection{3 - CONEXÕES ENTRE A RETINA E O CÓRTEX}

O próximo passo no caminho visual é a transmissão da informação processada na retina para o córtex visual. As informações luminosas capturadas e processadas na retina são enviadas até o LGN (Núcleo Geniculado Lateral). A conexão entre a retina e o LGN é realizada pelo nervo óptico, que nada mais é do que o conjunto de axônios das células ganglionares. Pode-se dizer que a retina é mapeada topograficamente nas células do LGN [Zeki, 1993], o que ocorre entretanto é que o mapeamento obedece a sofisticadas estratégias, que privilegiam a fóvea e fazem a integração das imagens obtidas pelas duas retinas.

A Figura 4.17 apresenta um diagrama do caminho óptico. A imagem é focalizada na retina e então processada e transmitida através do nervo óptico. Após passar pelo quiasma óptico, o nervo óptico recebe a denominação de trato óptico, chegando até o LGN ou núcleo geniculado lateral. Deste ponto a informação é finalmente transmitida até o córtex, através dos axônios das células do LGN, fibras que são denominadas radiação óptica. 


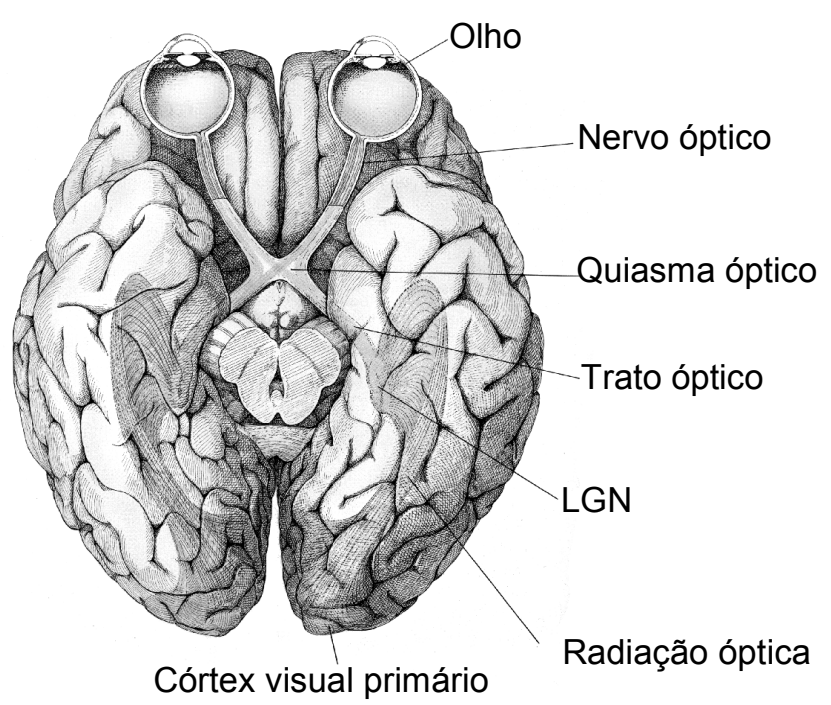

Fig. - 4.17 - Caminho óptico: trajetória dos sinais visuais, da retina ao córtex visual primário.

Vamos comentar agora a estratégia de mapeamento que propicia a integração das imagens obtidas nas retinas assim como a priorização da região foveal no percurso óptico. Antes de prosseguirmos, devemos lembrar que cada retina é dividida em quatro partes ou quadrantes [Zeki,1993], e que quando o olho focaliza uma imagem, esta é sobreposta nos quadrantes de cada retina (Figura 4.18).

A Figura 4.18 apresenta um diagrama que demonstra o mapeamento da imagem formada na retina em cada etapa do caminho óptico. Para compreendermos melhor esse diagrama, devemos observar o campo visual e a sua projeção e sobreposição em cada uma das retinas, onde a região central do campo visual (coloração mais escura) corresponde à região da imagem que será projetada na região foveal da retina, assim como as regiões periféricas do campo de visão respectivamente na periferia da retina.

O primeiro tipo de mapeamento da imagem vai ocorrer já na própria retina que, como dissemos anteriormente, possui na região foveal uma concentração maior de fotorreceptores (cones). Como a dimensão dos campos receptivos ganglionares é menor nessa região, de modo a favorecer o tamanho dessa região no mapa, ocorre uma distorção ampliando essa região no mapa. 


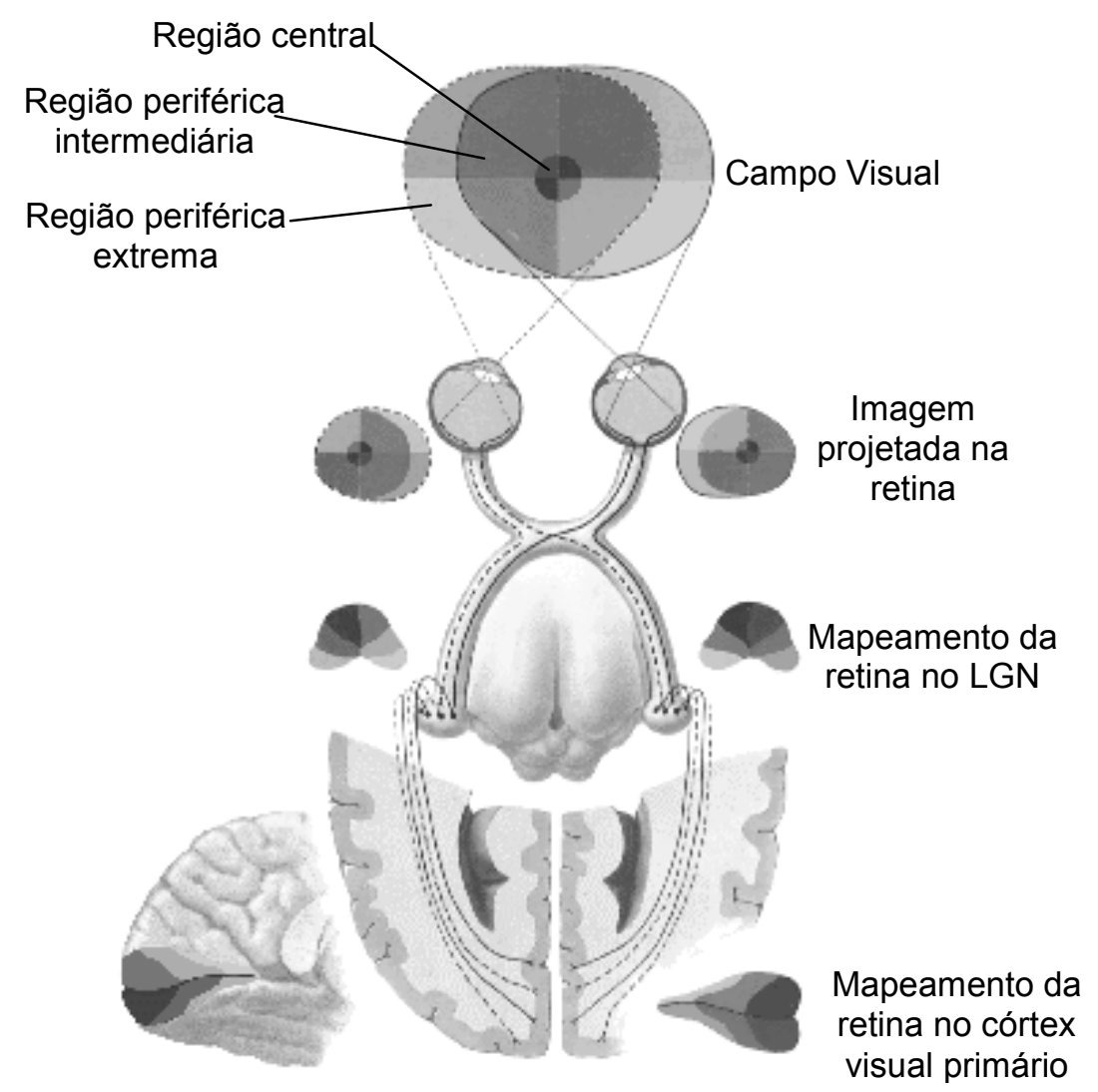

Fig. - 4.18 - Diagrama da estratégia de mapeamento da imagem ao longo do caminho óptico.

No quiasma óptico ocorre a integração dos dois mapas visuais. Se dividirmos o campo visual em duas partes (direita e esquerda), a parte esquerda do campo visual é projetada na porção nasal da retina do olho esquerdo e na temporal da retina do olho direito ao passo que a parte direita do campo visual na porção nasal da retina do olho direito e na temporal da retina esquerda. Deste modo, teremos em cada retina informação sobre as duas partes do campo visual (direita e esquerda). Quando o nervo óptico de cada uma das retinas chega até o quiasma óptico, as imagens do campo visual são integradas e o mapa de cada retina separado, de forma que toda a informação referente ao lado esquerdo do campo visual, integrada com informações de ambas retinas, se dirija ao hemisfério direito do cérebro, acontecendo o mesmo com o outro lado, que se integra e dirige-se para o hemisfério esquerdo.

Os mapas correspondentes a cada lado do campo visual (esquerdo e 
direito), são então enviados até o LGN pelo trato óptico. Nas células do LGN a retina continua mapeada, embora esse mapeamento seja relativo ao topográfico, a sua distribuição difere, devido à quantidade maior de células voltadas a região central (mácula e fóvea). A partir do LGN, as informações visuais são transmitidas para o córtex visual primário. As células do córtex visual continuam mapeando topograficamente a retina. Esse mapeamento é demostrado a partir da análise de lesões de V1 [Zeki, 1993], assim como dos campos receptivos. No caso dos campos receptivos, verifica-se que células adjacentes em V1 apresentam campos receptivos adjacentes, comprovando a manutenção do mapeamento da retina no córtex, sempre lembrando que ocorre uma distorção devido a uma superrepresentação celular da região foveal. Além de V1 outras regiões do córtex visual também apresentam em suas células o mapeamento topográfico da imagem correspondente à retina, no entanto observa-se que à medida que a informação caminha de V1 para as regiões seguintes, os campos receptivos, embora continuem adjacentes, aumentam de tamanho, caracterizando uma maior abstração de informação [Zeki, 1993].

\subsubsection{1 - NÚCLEO GENICULADO LATERAL}

O Núcleo Geniculado Lateral ou LGN (do inglês "Lateral Geniculate Nucleus"), é um núcleo talâmico que faz a mediação entre a retina e o córtex visual primário, aqui as informações transmitidas pela retina sofrem a primeira conexão sináptica. Conforme comentamos anteriormente, o mesmo mapeamento celular das informações visuais transmitidas pela retina é mantido nesse núcleo, de forma precisa. Em relação ao processamento realizado pelo LGN, foram detectadas respostas em suas células em relação a impulsos cromáticos e iluminação difusa, no entanto existem evidências de que ocorram outros tipos de processamentos [Costa, 1996].

Nesse trabalho estaremos interessados em duas características do LGN: (i) a segregação dos caminhos parvo e magno iniciados na retina e (ii) a distribuição e replicação do mapa visual para o córtex visual. 


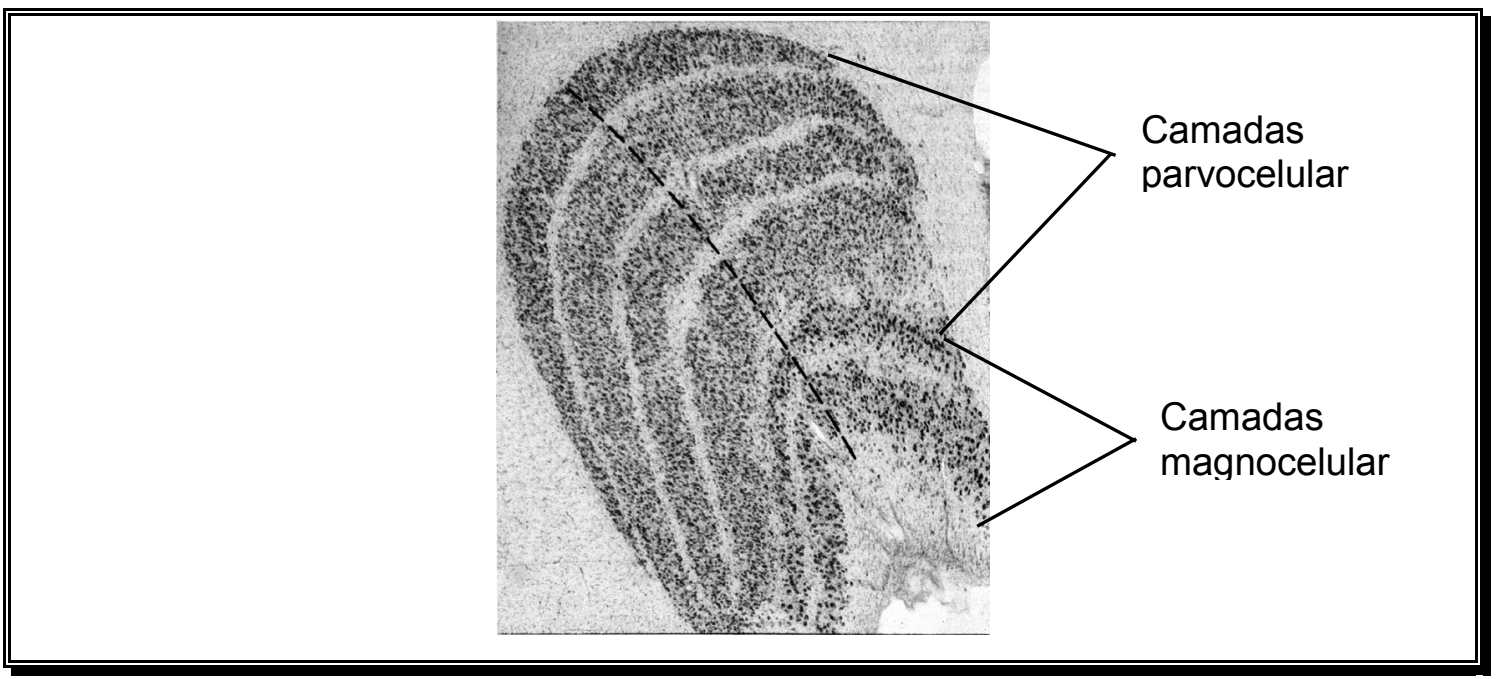

Fig. - 4.19 - Núcleo Geniculado Lateral [Hubel,1995].

Conforme iremos comentar, o caminho visual como um todo é caracterizado pelo dualismo do caminho Parvo e Magno. Embora esses dois caminhos se iniciem na retina, (nas células ganglionares da retina observa-se a existência de duas classes celulares, P e M) a divisão mais marcante ocorre no LGN, a qual pode ser observada não somente através da forma e função celulares mas também no nível da sua organização. O LGN é formado por seis camadas conforme podemos observar na Figura 4.19. Destas seis camadas, quatro são caracterizadas por células pequenas, parvocelulares, e duas camadas por células grandes, magno celulares [Hubel, 1995]. A Tabela 4.1 apresenta um resumo das características entre as células magno e parvo do LGN. Observando as características desta tabela, podemos concluir que o caminho magno possui características menos evoluídas que o caminho parvo. Isto pode ser notado principalmente pela diferença de resolução e velocidade de resposta.

\begin{tabular}{|c|c|c|}
\hline Característica & Magno & Parvo \\
\hline Tamanho do soma & Menor & Maior \\
\hline Sensibilidade a Cor & Não & Sim \\
\hline Resolução & Baixa & Alta \\
\hline Velocidade & Rápidas e Transientes & Lentas e Contínuas \\
\hline Contraste & Mais Sensitivo & Menos Sensitivo \\
\hline
\end{tabular}

Tabela 4.1 - Principais diferenças entre as células magno e parvocelular. 
Como segunda característica do LGN temos a distribuição e replicação do mapa visual para o córtex visual. Como vimos, o LGN é composto de seis camadas (4 parvo e 2 magno), cada olho sendo mapeado em 3 das 6 camadas (2 parvo e 1 magno). Deste modo, a retina é mapeada três vezes no LGN [Livingstone \& Hubel, 1988]. Essa característica é especialmente importante para esse trabalho por evidenciar o paralelismo do sistema visual, onde podemos supor que, assim como nos sistemas computacionais, a natureza foi obrigada a fazer cópias, devido a necessidade de enviá-las a sistemas distintos que trabalharam com as informações de modo independente. A grande maioria das informações correspondentes aos mapas replicados do LGN são transmitidos para camadas distintas do córtex visual primário (V1), embora uma pequena parcela seja projetada em outras regiões [Zeki, 1993].

\section{7 - O CÓRTEX VISUAL}

Embora, o processamento visual se inicie logo após a captação da imagem, nas células nervosas da retina, a grande maioria do processamento visual, ou seja, a abstração da informação visual em algo inteligível para o maquinário neural, é realizado pelo córtex visual. O córtex visual se localiza no lóbulo occiptal, (ver Figura 4.4), que se encontra na região posterior do cérebro ou, segundo a divisão de Broadmann, nas áreas 17 e 18. Possui uma aparência bastante uniforme, podendo a uma primeira instância ser reveladas duas regiões: o córtex estriado e o córtex pré-estriado. O córtex pré-estriado, através de diferentes técnicas (ex: citoarquitetura e citocromo oxidase), quando analisado demonstra ser composto por quatro regiões distintas. Deste modo, o córtex visual é composto por cinco áreas, que apresentam características funcionais bem definidas, sendo cada uma delas respectivamente denominadas de: córtex visual estriado ou V1, córtex visual préestriado ou V2, V3, V4 e V5. Algumas dessas regiões apresentam estruturas bem definidas (como "blobs", colunas, "stripes", etc), que obedecem a uma hierarquia. Ao longo de todo o córtex visual sua espessura é formada por seis camadas de estratificação (citoarquiteturas), que são caracterizadas em termos de tipo e distribuição de células neurais.

Nesta seção discutimos a organização, o funcionamento e as estratégias de paralelismo do córtex visual dos primatas. 


\subsection{1 - ESPECIALIZAÇÃO FUNCIONAL DO CÓRTEX}

\section{VISUAL}

As informações transmitidas pelo LGN são enviadas para a área 17 de Broadmann, também conhecida como córtex visual primário, ou ainda $\mathrm{V} 1$, de onde prosseguem para as demais regiões corticais que constituem o córtex visual. As regiões do córtex visual apresentam uma modularização hierárquica. Entre as teorias a respeito da modularidade do córtex visual destaca-se a teoria da especialização funcional do córtex visual de Zeki e Shipp [Zeki \& Shipp, 1988], segundo a qual o córtex visual é dividido em módulos, que são responsáveis por atributos específicos ou seja, especializados e agregados segundo a função que exercem no processamento visual. Estaremos especialmente interessados na teoria da especialização funcional do córtex visual. Também a levaremos em conta como inspiração biológica para alguns modelos apresentados futuramente neste trabalho.

\subsection{2 - NÍVEIS DE PARALELISMO}

Antes de avançarmos no caminho visual discorrendo sobre a organização do córtex visual comentaremos um pouco a respeito dos prováveis níveis de paralelismo cortical. Conforme veremos, não apenas o córtex visual, mas todo o córtex é massivamente paralelo. Conforme mostrado na Figura 4.20, o paralelismo do córtex visual se apresenta em múltiplas escalas. Na micro escala, ocorre paralelismo entre os neurônios; na escala intermediária entre regiões e sub-regiões corticais; e no topo da escala o macro paralelismo ocorre entre os dois hemisférios cerebrais.

Diversas evidências apresentam o paralelismo em cada uma das escalas. Quanto ao nível celular, o paralelismo não tem novidade alguma, estando presente na própria natureza das células neurais, cuja principal característica é receber e integrar informações que chegam simultaneamente de diferentes células. Além disso, a velocidade de processamento é individualmente lenta nos neurônios, impossibilitando a existência de sistemas seriais complexos e velozes, como encontramos normalmente na maioria dos seres vivos. De fato o paralelismo encontrado na natureza das células nervosas tem motivado intensamente áreas como as redes neurais artificiais.

Quanto ao paralelismo em macro escala, vivenciamos suas evidências todos 
os dias. O simples fato do cérebro possuir dois hemisférios é a maior prova desse paralelismo. Cada hemisfério do cérebro possui processamento independente e, do ponte de vista motor e sensorial, cada hemisfério é responsável por uma metade do corpo. De fato, a nossa própria arquitetura, composta por pares (membros, olhos, ouvidos, etc.), pode estar associada a essa composição. Do ponto de vista da visão cada hemisfério recebe informações e é responsável por uma metade do campo visual. A integração dos dois hemisférios é realizada pelo corpo caloso [Gazzaniga, 1998].

MICRO Entre células

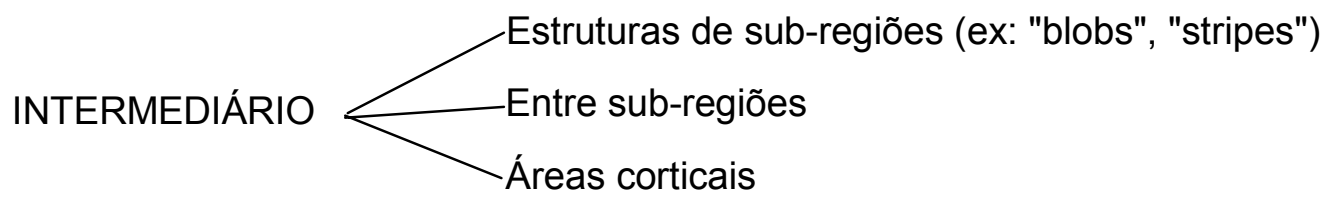

MACRO Hemisférios

\section{Fig. - 4.20 - Paralelismo em multi-escala.}

Neste trabalho estamos especialmente interessados no paralelismo entre regiões e sub - regiões corticais. As evidências que indicam o paralelismo entre as regiões corticais estão presentes nas conexões entre as áreas. Podemos observar que todas as regiões corticais enviam saídas para mais de uma região. A existência de saídas paralelas indicam a replicação de dados e o funcionamento de regiões em paralelo [Zeki, 1993]. Além de ocorrer concentrações nas conexões de saídas entre regiões, o mesmo acontece também entre sub-regiões, demonstrando as evidências de paralelismo nesse nível.

O paralelismo entre as áreas, sub-áreas corticais e micro estruturas ("blobs", "stripes", etc.) visuais está estreitamente relacionado com a teoria da especialização funcional. Assim as regiões especializadas em atributos diferentes estariam executando processamento das informações em paralelo. A primeira evidência para comprovar esse fato ocorre já na conexão do LGN com o córtex visual estriado ou $\mathrm{V} 1$, onde a retina é replicada 3 vezes (2 cópias para o caminho Parvo e 1 para o magno), onde cada cópia é enviada para uma sub-área distinta de V1, comprovando a existência do paralelismo entre suas sub-áreas. 


\section{CAPÍTULO 4}

O mesmo tipo de paralelismo pode ser observado no córtex visual préestriado ou V2. Depois de processado em V1, as informações visuais são enviadas para V2. Novamente, três cópias da retina são enviadas para três regiões distintas em V2, confirmando uma arquitetura semelhante a V1. Observa-se que cada milímetro de $\mathrm{V} 1$ envia fibras anatomicamente separadas para diferentes áreas do córtex pré-estriado. Essas fibras possuem diferentes diâmetros, o que indica que o sinal é transmitido em velocidades diferentes, evidenciando o sincronismo (cada área recebe os sinais em tempos diferentes). Ainda quanto ao paralelismo entre as sub-áreas de V1 e V2 (blobs, interblobs, e faixas) observa-se que estas formam conjuntos de arranjos repetidos, onde cada conjunto é formado por diversas estruturas replicadas, indicando a ocorrência de paralelismo dentro de uma subárea.

Além de enviar sinais para o córtex pré-estriado, o córtex estriado (V1) envia mapas de informação visual para as áreas V3, V4 e V5 simultaneamente. O mesmo ocorre com a área V2, que também transmite para essas regiões. Essa arquitetura de conexões apresenta as evidências de paralelismo entre as áreas. Conforme vamos apresentar futuramente as áreas V1 e V2 apresentam um forte perfil de segregação, separando sinais de diferentes atributos e enviando para as regiões mais especializadas (V3,V4 e V5). Esse tipo de estrutura sugere a existência de uma arquitetura estilo "pipeline" entre as áreas de segregação V1 e V2 e as mais especializadas (V3, V4 e V5), devido a dependência de dados. Devemos observar entretanto, que a comunicação no córtex visual é extremamente complexa, e ainda pouco sabemos a respeito de sua arquitetura. Existem comunicações entre as subregiões de uma mesma área, assim como entre áreas, de forma a favorecer a integração e segregação da informação dos diferentes atributos visuais. Além disso, devemos observar também que não existe um caminho unidirecional. As informações transitam em ambos sentidos de forma que as camadas superiores da hierarquia visual realimentam as primeiras camadas do processo.

Nas próximas seções estaremos discutindo a organização, as conexões e o funcionamento do córtex visual, consequentemente explorando seu provável paralelismo. Para concluirmos esta seção, devemos lembrar a forte correlação existente entre a distribuição da informação e o paralelismo. Desta forma, a busca pelo paralelismo no processamento biológico implica na procura pela distribuição e replicação de sinas. Uma vez que todas as áreas corticais possuem saídas paralelas para outras diferentes áreas, chegamos à conclusão que não apenas o 
sistema visual é um sistema paralelo-distribuído, mas sim todo o cérebro.

\subsection{3 - DIVISÕES DO CÓRTEX VISUAL}

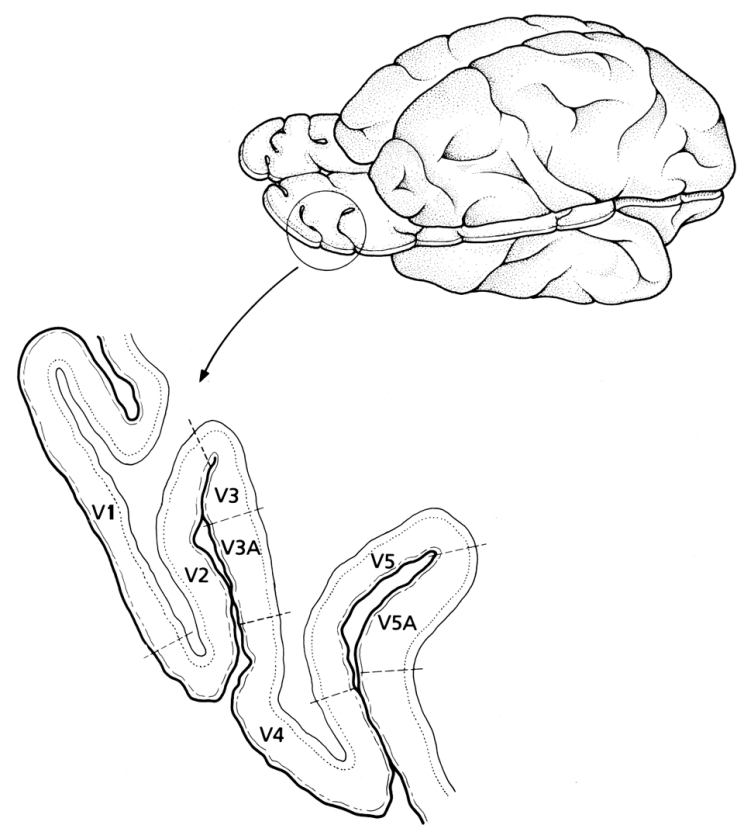

Fig. - 4.21 - Fatia do córtex visual, apresentando suas áreas [Zeki, 1993].

O córtex visual se localiza no lóbulo occiptal, nas áreas 17 e 18 de Bradmann, que se caracterizam pelo seu aspecto, respectivamente como córtex visual estriado e pré-estriado. O córtex visual estriado constitui uma das cinco áreas do córtex visual, também conhecido como V1 ou córtex visual primário, ao passo que o córtex visual pré-estriado é dividido segundo critérios anatômicos e funcionais em quatro áreas (V2, V3, V4 e V5). A Figura 4.21 apresenta uma fatia do córtex na qual podemos observar a localização anatômica de cada uma das áreas do córtex visual. Nesta seção apresentamos cada uma dessa áreas.

\subsubsection{1 - ÁREA V1}

Também conhecida como córtex visual estriado, córtex visual primário ou ainda área 17 de Broadmann, V1 é a região mais estudada e melhor compreendida de todo o córtex. Em V1 são recebidas e processadas todas as modalidades de atributos visuais, sendo que a sua principal função é a segregação e a distribuição 
dos atributos. Conforme comentamos anteriormente, o LGN envia para V1 três mapas que replicam as informações visuais da retina, onde cada mapa é enviado para uma camada cortical específica. É importante observar que V1 é a única área cortical que recebe as informações visuais do LGN. A conexão entre o LGN e V1 é feita ponto a ponto, de modo que encontramos em $\mathrm{V} 1$ mapas topográficos da retina, ou seja células adjacentes em V1 recebem informações de regiões adjacentes da retina. Deste modo as vizinhanças do campo visual são precisamente mantidas, sendo também conhecida como córtex retinal devido a essa característica. Como na retina e em todo o sistema visual, em V1 continua ocorrendo uma superrepresentação da região central do campo visual, onde praticamente metade de V1 é responsável por seu processamento [Costa, 1996].

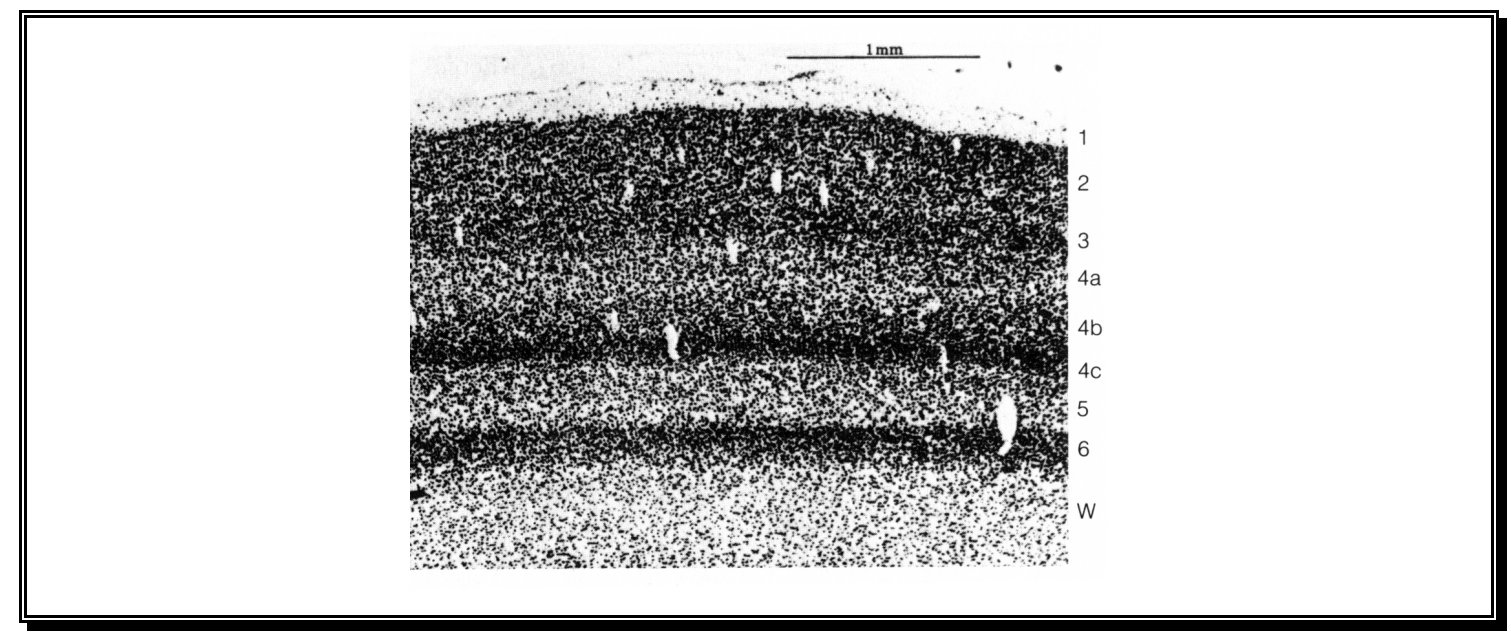

Fig. - 4.22 - Micrografia do córtex visual primário [Dowling, 1992].

Assim como as demais áreas do córtex visual, o córtex visual primário é composto por seis camadas, conforme apresentado na micrografia da Figura 4.22. Observando essa Figura vemos que as camadas 1 e 2 não podem ser distinguidas nessa imagem e que a camada 4 é dividida em 3 sub-camadas: 4a, 4b e 4c. Cada uma dessas camadas apresentam um tipo diferenciado de composição celular que é apresentado na Tabela 4.2.

As fibras que saem do LGN chegam ao córtex visual primário através da matéria branca (representado pela letra W na Figura 4.22). Os axônios provenientes das camadas magno celulares fazem conexão com os neurônios da metade superior da camada 4c, conhecida como $4 \mathrm{c} \alpha$, ao passo que os axônios das camadas parvo celulares se conectam em duas camadas: na outra metade da camada 4c $(4 \mathrm{c} \beta)$ e na camada 4a. A Figura 4.23 apresenta um diagrama 
simplificado das entradas e saídas das conexões de V1 e como podemos observar as camadas corticais não se diferem apenas pela sua natureza celular (Tabela 4.2) mas também por suas conexões.

\begin{tabular}{|c|l|}
\hline Camada & \multicolumn{1}{c|}{ Tipos de células predominantes } \\
\hline 1 & $\begin{array}{c}\text { astrócitos, oligondendrócitos, microgliais e neurônios } \\
\text { com corpos celulares ovais }\end{array}$ \\
\hline 2 & células piramidais de dendritos curtos \\
\hline 3 & células piramidais de tamanho médio e pequeno \\
\hline 4 (a, b e c) & $\begin{array}{l}\text { neurônios estrelados espinhosos e neurônios } \\
\text { poligonais } \\
\text { (provavelmente neurônios piramidais modificados) }\end{array}$ \\
\hline 5 & neurônios poligonais pequenos e médios e células \\
& piramidais \\
\hline 6 & várias células, entre elas, neurônios piramidais \\
& pequenos e médios e células triangulares
\end{tabular}

Tabela 4.2 - Composição citoarquitetural de cada camada do córtex visual primário.

A dualidade do sistema visual, caminhos Parvo e Magno, continua presente em V1, sendo diferenciadas pelas camadas em que realizam suas principais conexões. O caminho Magno após fazer conexão na camada $4 \mathrm{c} \alpha$, envia informações para a camada 4B. Nesta camada, a maioria das células são seletivas a orientação e também algumas de suas células apresentam seletividade para direção e movimento. Alguns desses neurônios ainda são binoculares ou seja necessitam de estímulos de ambos os olhos e apresentam sensibilidade a disparidade retinal (visão estéreo) [Tovée, 1996].

O caminho Parvo, por sua vez, após conectar nas camadas $4 \mathrm{c} \beta$ e $4 a$, envia informações para as camadas superiores de $\mathrm{V} 1$ e divide-se em dois novos caminhos. Onde o primeiro deles está relacionado com cor e é denominado P-B e o outro relacionado com a percepção de formas precisas e orientação do estímulo, conhecido como P-I. 


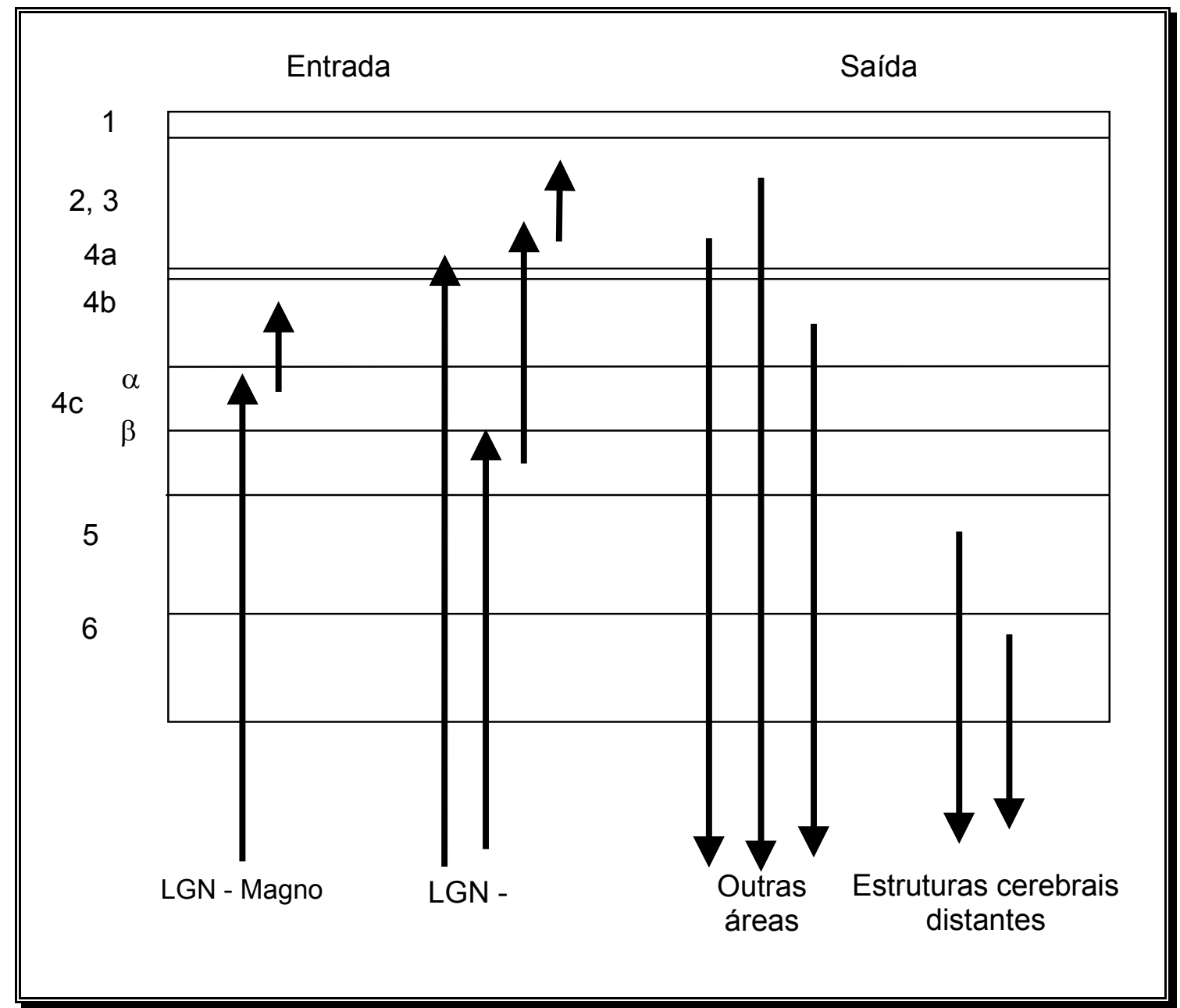

Fig. - 4.23 -Diagrama apresentando as principais conexões das camadas do córtex visual primário [Hubel, 1995].

As camadas do córtex visual apresentam conexões entre camadas, entre as demais áreas do córtex visual ou ainda podem apresentar conexões com regiões mais distantes, sendo corticais ou não. Todas as camadas com exceções de 1, 4a e 4c apresentam conexões para fora do córtex. As camadas 2, 3 e 4B apresentam a grande maioria de suas conexões para as demais áreas do córtex visual, ao passo que as camadas mais inferiores 5 e 6 projetam suas conexões além do córtex, para o colliculu superior e de volta ao LGN respectivamente. Devemos lembrar que essa estratégia de realimentação do LGN realizada pela camada 6 é uma forte evidência do pré-processamento da informação visual realizada no LGN. 


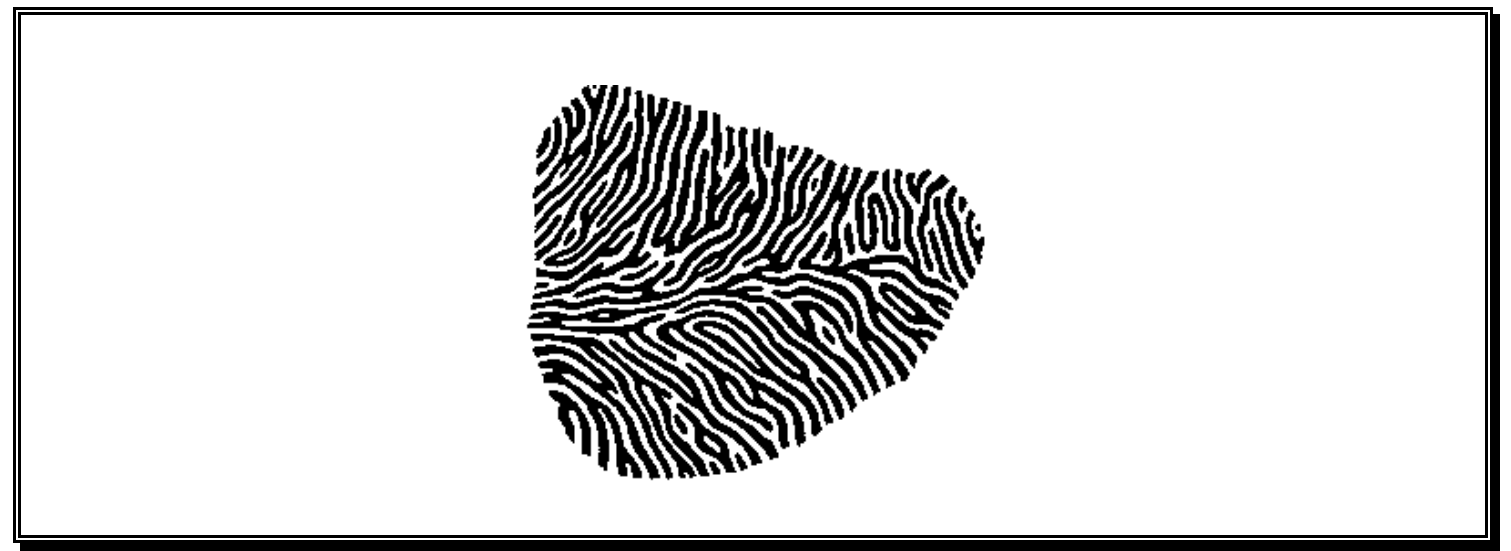

\section{Fig. - 4.24 - Colunas de dominância ocular na camada 4c (projeção 2D), marcadas por dois deoxiglucose [Hubel, 1995].}

Como vimos na Seção 4.6.3, a área V1 de cada hemisfério recebe informações visuais de apenas um lado do campo visual composto pelas metades dos dois olhos, recebendo assim sinais de ambos os olhos. Essa natureza dual da informação visual apresenta estruturas no córtex visual primário denominadas colunas de dominância ocular. As colunas de dominância ocular foram reveladas através de marcações com dois deoxiglucose por Hubel e colaboradores [Hubel et al., 1977] [Hubel \& Wiesel 1977], e se apresentam ao longo de todo o córtex visual estriado. A Figura 4.24 apresenta uma projeção 2D da camada 4C do córtex visual primário, revelando as colunas de dominância. A dominância ocular se mantém constante ao longo da espessura do córtex, apresentando-se no entanto de forma mais graduada a medida que as camadas se distanciam de $4 \mathrm{C}$, camada que recebe os aferentes do LGN. A dominância ocular demonstra evidências de ser um dos mecanismos responsáveis pela integração da informação proveniente de cada olho.

Além de campos receptivos semelhantes aos encontrados na retina e no LGN, V1 apresenta dois novos tipos de campos receptivos, denominados de simples e complexos. Os campos receptivos simples são sensíveis a orientação e posição dos estímulos, e os complexos específicos à orientação, mas os estímulos podem aparecer em diversas posições (movimentos). A Figura 4.25 apresenta um modelo para o mecanismo das células simples [Hubel, 1995], no qual as células centro-periferia de LGN aferem impulsos para as células simples. Através da combinação destes estímulos, ocorre a resposta à orientação. Seguindo essa mesma filosofia, podemos compreender o funcionamento das células complexas. Assim, as células simples de mesma orientação enviam sinais para as células 
complexas. A combinação dos sinais das células simples explicaria o funcionamento das células complexas, que possuem campos receptivos maiores que as simples e respondem a mesma orientação indiferente da posição do estímulo no campo receptivo.

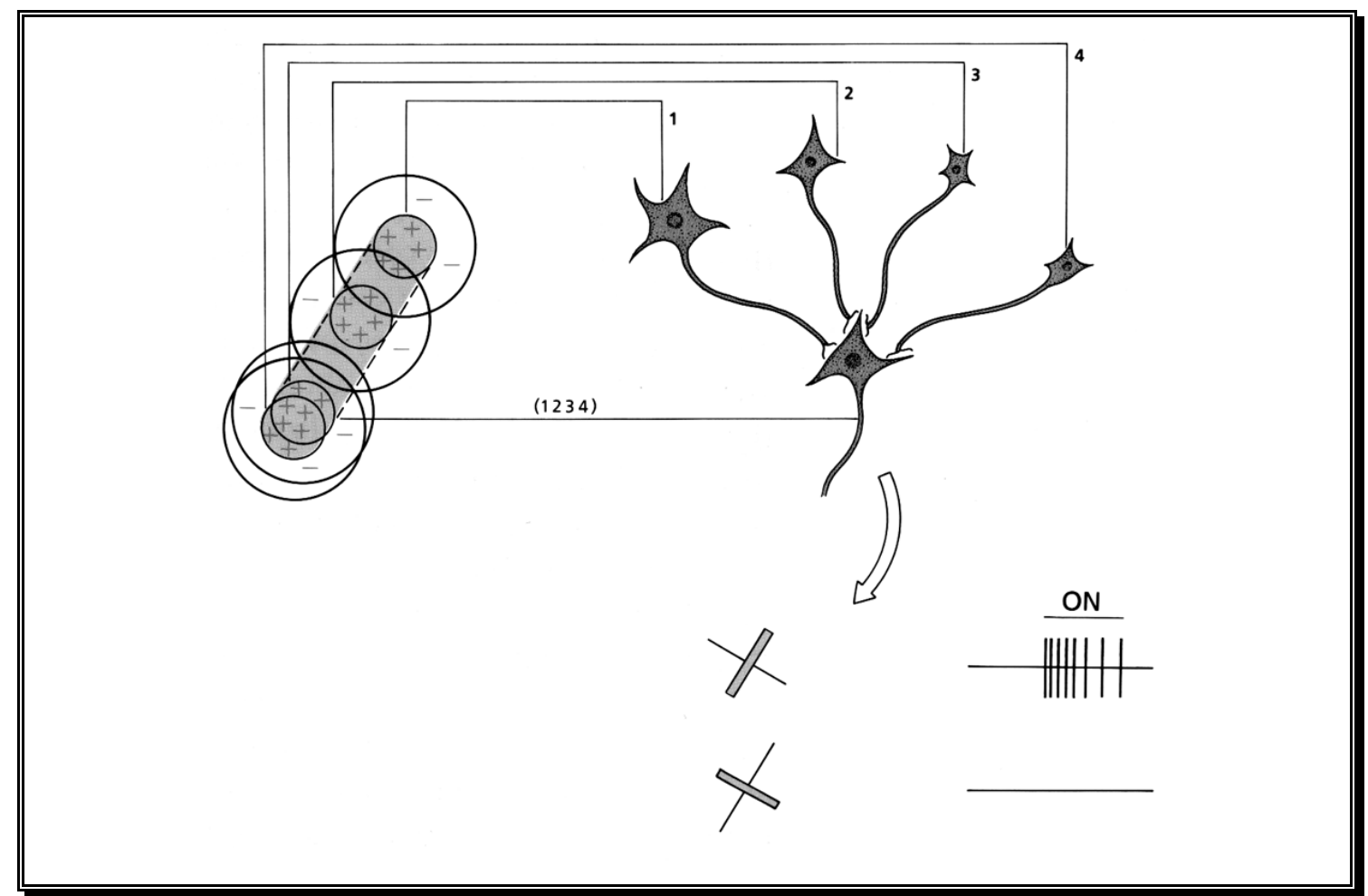

Fig. - 4.25 - Diagrama ilustrando o campo receptivo das células simples, sua composição a partir de células centro-periferia do LGN e as suas respostas a estímulos de diferentes orientações [Zeki, 1993].

Uma outra peculiaridade importante de V1 é o arranjo no qual se encontram as células estimuladas à orientação. Experimentalmente, Hubel e Wiesel [Hubel, 1995] perceberam que quando o eletrodo era introduzido perpendicularmente às camadas, as células mantinham praticamente a mesma orientação, ao passo que quando o caminho de penetração do eletrodo era tangencial, a resposta à orientação das células variavam linearmente ao longo do percurso, embora houvesse algumas variações abruptas inexplicáveis. Estas características inspiram o clássico modelo das hipercolunas, apresentado na Figura 4.26, que integra as colunas de dominância ocular e a distribuição das células de orientação seletiva. 


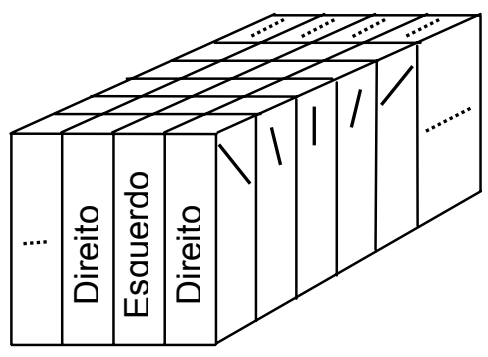

Fig. - 4.26 - Modelo das hipercolunas de Hubel e Wiesel.

Quando marcado com a técnica de citocromo oxidase, o córtex estriado apresenta marcas na forma de pequenas bolhas ("blobs", no inglês), conforme podemos observar na Figura 4.27. Do ponto de vista fisiológico desse arranjo, foi observado que os "blobs" não apresentavam células sensíveis à orientação, mas que por outro lado respondiam a variações do comprimento de onda (cor). No entanto, a região entre os "blobs" apresenta seletividade à orientação. Para corrigir as variações abruptas do modelo de hipercolunas, Braitenberg \& Braitenberg propuseram um modelo teórico que, devido ao seu aspecto, foi denominado catavento [Braitenberg \& Braitenberg, 1979]. Experimentos recentes [Costa, 1996] [Bonhoeffer \& Grinvald, 1991] [Blasdel, 1986] indicam que o modelo teórico do catavento coincide com os "blobs" do citocromo oxidase, de forma que o centro do catavento, insensível a orientação seja o "blob", e a região que o contorna possui a estrutura de orientação seguindo o padrão de cata-vento.

Além de coincidir com o modelo de Braitenberg, os "blobs" também explicam a dualidade do caminho parvo celular (P-B e P-I) que ocorre em V1. O caminho parvo P-B (de Parvo-Blob) privilegia as informações cromáticas e está relacionado com as células pertencentes aos "blobs". O caminho parvo P-I ( de Parvo-Interblob) é voltado a percepção precisa de formas, localizando nas regiões entre os "blobs", contém neurônios que apresentam respostas à orientação (linhas e barras). Uma vez que as células dos "blobs" não respondem à orientação, elas possuem campos receptivos diferentes dos simples e complexos encontrados em V1, e respondem a estímulos envolvendo cromaticidade. Assim como no LGN foram encontradas células com campo receptivo de oponência cromática. Esse mecanismo envolve os pares de cores vermelho/verde e azul/amarelo, que ficam arranjados nas estruturas centro-periferia dos campos receptivos e podem ser observados através de uma série de experimentos psicofísicos [Goldstein, 1989]. 


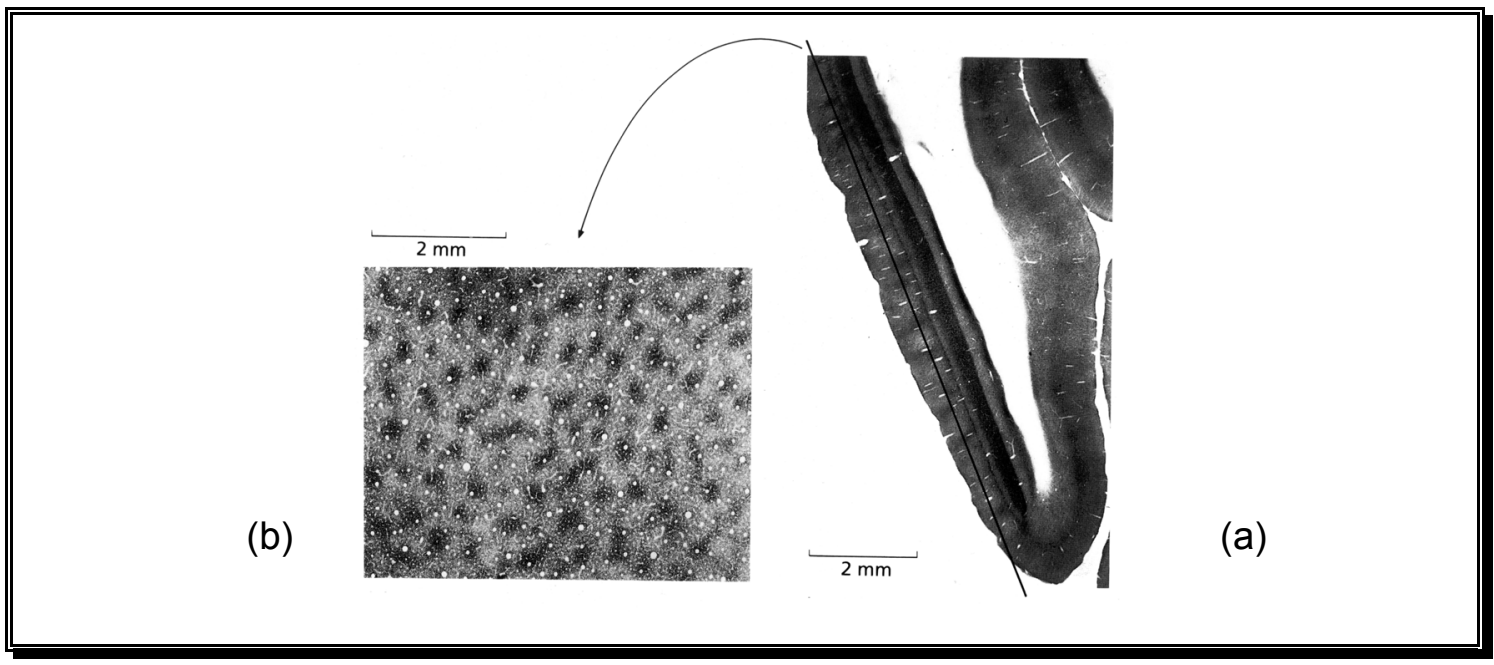

Fig. - 4.27 - (a) Corte longitudinal do córtex estriado, com tratamento de citocromo oxidase. (b) Detalhe do corte paralelo (linha da imagem a) apresentando as camadas 2 e 3 . As estruturas em forma de pontos claros são os "blobs" [Zeki, 1993].

Uma vez que discutimos as estruturas encontradas no córtex estriado visual, comentaremos agora sobre seu funcionamento em termos gerais, enfocando sempre as questões de paralelismo. Uma das principais funções de V1 é a segregação dos sinais visuais. Deste modo, o sinal que vem do LGN é separado de acordo com o atributos e retransmitido para as áreas mais especializadas. Do ponto de vista do paralelismo, a segregação realizada em V1 é uma evidência muito forte do paralelismo entre as diferentes áreas. Nesse perfil, o córtex visual primário tem como função a divisão das tarefas, uma vez que direciona cada atributo para uma área especialista, e além disso o sincronismo de sinas, como já comentamos, V1 possui fibras eferentes com diferentes espessuras indicando velocidades diferentes.

Ainda quanto ao paralelismo, este pode ocorrer em diferentes níveis dentro do córtex estriado (Seção 4.7.2). No nível mais baixo da escala temos o paralelismo entre neurônios, uma forte evidência desse nível em V1 são as células simples e complexas. Como vimos, as células simples recebem sinal das células centroperiferia e as células complexas das células simples, isso evidência o paralelismo entre neurônios em V1, e para que os impulsos sejam integrados pelo neurônio, eles devem ser concomitantes, indicando a ocorrência de células processando paralelamente. Subindo a escala encontramos diversas estruturas replicadas indicando paralelismo entre estas assim como regiões respondendo a diferentes 
orientações. E, finalmente, encontramos em V1 três sistemas distintos: um magno e dois parvos. Sendo responsáveis por diferentes atributos, ocupam espaços físicos separados (embora ocorra conexões entre eles) em estruturas ou camadas diferentes, indicando através dessa independência a existência de paralelismo entre esses sistemas.

\subsubsection{2 - ÁREA V2}

Adjacente à região $\mathrm{V} 1$, e embora não tão explorada quanto esta, V2 é a segunda região mais explorada do córtex visual. Semelhante em diversos aspectos ao córtex visual primário, do qual é o alvo principal das fibras aferentes, essa região segrega as informações visuais distribuindo para áreas mais especializadas e, deste modo, também incorpora todas as modalidades visuais. Outra característica que preserva do córtex estriado é a constância do mapeamento da retina, possuindo as células vizinhas campos receptivos vizinhos no campo visual, uma vez que células adjacentes em $\mathrm{V} 1$ conectam-se com células também adjacentes em V2.

$\mathrm{Na}$ região $\mathrm{V} 2$, além dos campos receptivos que já apresentamos anteriormente, encontramos um novo tipo peculiar, denominado de células hipercomplexas. Esse novo campo receptivo, semelhante as células simples e complexas, é seletivo à orientação. No entanto, além da orientação sua resposta depende do comprimento do estímulo e, assim como as células complexas, é indiferente a posição do estímulo. As células hipercomplexas recebem conexão das células complexas. Devido as suas características devem haver conexões inibitórias operando em conjunto com as excitatórias, a fim de possibilitar a seletividade ao comprimento do estímulo.

Quando marcada com citocromo oxidase, V2 também revela estruturas, no entanto elas são bastante diferentes das estruturas que comentamos na seção anterior. Conforme podemos observar na Figura 4.28, a arquitetura citocromo oxidase de V2 é apresentada na forma de tiras ou faixas paralelas que formam um ângulo quase perpendicular com V1. As faixas são formadas por três conjuntos (finas, grossas e pálidas), que ficam arranjados de forma intercalada. 


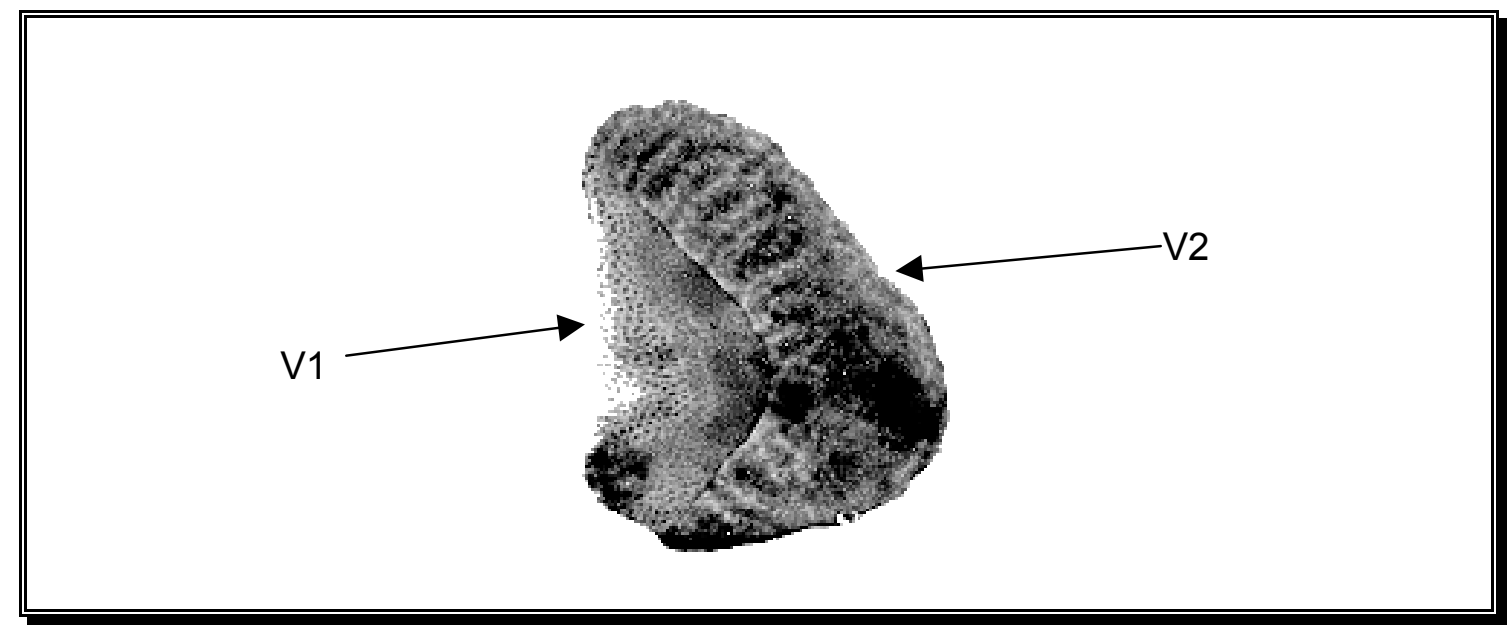

Fig. - 4.28 - Regiões V1 e V2 do macaco esquilo marcadas por citocromo oxidase [Zeki, 1993].

As faixas finas e grossas se caracterizam por suas cores escuras e se diferenciam por sua espessura, a terceira faixa apresenta uma cor mais clara, sendo denominada por essa característica de pálida, sendo também conhecida como estrutura "entre faixas". Os neurônios das faixas grossas recebem a maioria de suas conexões das células da camada 4B de V1 (caminho magno), e suas células possuem características semelhantes às desta camada de $\mathrm{V} 1$, possuindo seletividade a orientação, movimento e também apresentam disparidade ocular, função primordial para a visão estéreo.

As células das estruturas "blobs" de V1 projetam parte de seus axônios para os neurônios das faixas finas. Os neurônios dessa estrutura não são sensíveis à orientação. No entanto, mais da metade deles responde ao comprimento de onda, assim como as células dos "blobs". No entanto, verifica-se a ocorrência de um número maior de células com oponência cromática dupla. Os neurônios das áreas entre "blobs" de V1, enviam parte de suas fibras para as estruturas pálidas ou entre faixas. Essa região possui células que são sensíveis à orientação, mas não apresentam sensibilidade à direção (movimento) ou cor.

Os dois caminhos parvo e o caminho magno encontrados em $\mathrm{V} 1$, continuam presentes em V2. De fato, em V2 a divisão do caminho visual fica ainda mais evidente, uma vez que ela se encontra visível nas estruturas (faixas) desta área. Tal divisão é uma demonstração de paralelismo em V2, que apresenta três mapas com representações distintas, separadas, independentes e praticamente integrais da retina [Zeki, 1993]. Cada mapa corresponde a uma estrutura (faixa) de V2, assim as faixas grossas apresentam um mapa de orientação e movimento (caminho magno), 
as faixas finas um mapa cromático (parvo B) e as pálidas apresentam um mapa de disparidade e orientação relacionada a formas de alta definição (parvo I). Uma demonstração de que cada um dos mapas possui uma representação praticamente integral da retina está no fato de que estruturas adjacentes (faixas finas, grossa e pálidas) apresentam campos receptivos sobrepostos, indicando que representam a mesma região retinal. Cada um dos mapas de V2 é transmitido para áreas especializadas em atributos específicos. Deste modo a V2 assim como V1 continuam exercendo o papel de segregação e distribuição de sinais.

\subsubsection{3 - ÁREAS V3, V4 E V5}

A exploração e mapeamento detalhado que ocorre na áreas V1 e V2 não ocorre em mais nenhuma outra área do córtex visual, uma vez que ainda não foi descoberta nenhuma técnica que permite revelar suas arquiteturas. Deste modo, pouco sabemos a respeito destas áreas. Os estudos fisiológicos, entretanto, demonstram que diferentemente de V1 e V2 que apresentam todas as modalidades dos atributos visuais (cor, movimento, forma e estéreo), essas áreas são mais especializadas, tornando responsáveis por atributos específicos. Esta é a situação de V5, que foi denominado de área de movimento [Zeki, 1993] [Costa, 1996] por possuir mais de $90 \%$ de suas células relacionadas com esse atributo.

Além de ocorrer a especialização de toda a área para um atributo específico observamos também que as representações vão se tornando cada vez mais complexas e abstratas à medida em que o caminho visual vai adentrando as regiões corticais. A representação topográfica da retina não é mais encontrada em nenhuma área, de modo que a previsão do campo receptivo das células vizinhas não é mais tão óbvia quanto em V1 ou V2. Outra característica que vem comprovar o crescente nível de abstração é o tamanho dos campos receptivos, onde o tamanho do campo receptivo de V1 é menor do que o de V2 que é menor do que as demais áreas. A Figura 4.29 contém uma ilustração que apresenta a diferença de tamanho relativo e conseqüente abstração entre os campos receptivos de diferentes áreas do córtex visual.

Quanto ao paralelismo nestas áreas, devido a falta de conhecimento sobre suas arquiteturas, pouco sabemos a respeito da concorrência dentro de uma única área, com exceção de V4, que recebe as duas divisões do caminho parvo (l e B), indicando a existência de no mínimo dois sistemas independentes. Subindo a escala do paralelismo e considerando a concorrência entre as áreas, V3, V4 e V5 
trazem fortes evidências para este nível de paralelismo. Isso pode ser observado se considerarmos a independência entre essas áreas, e suas conexões. Deste modo os mapas das áreas V1 e V2 que, como vimos, são processados paralelamente, se estendem para essas áreas em caminhos distintos e consequentemente paralelos. Entraremos em maiores detalhes sobre esse assunto na próxima seção.

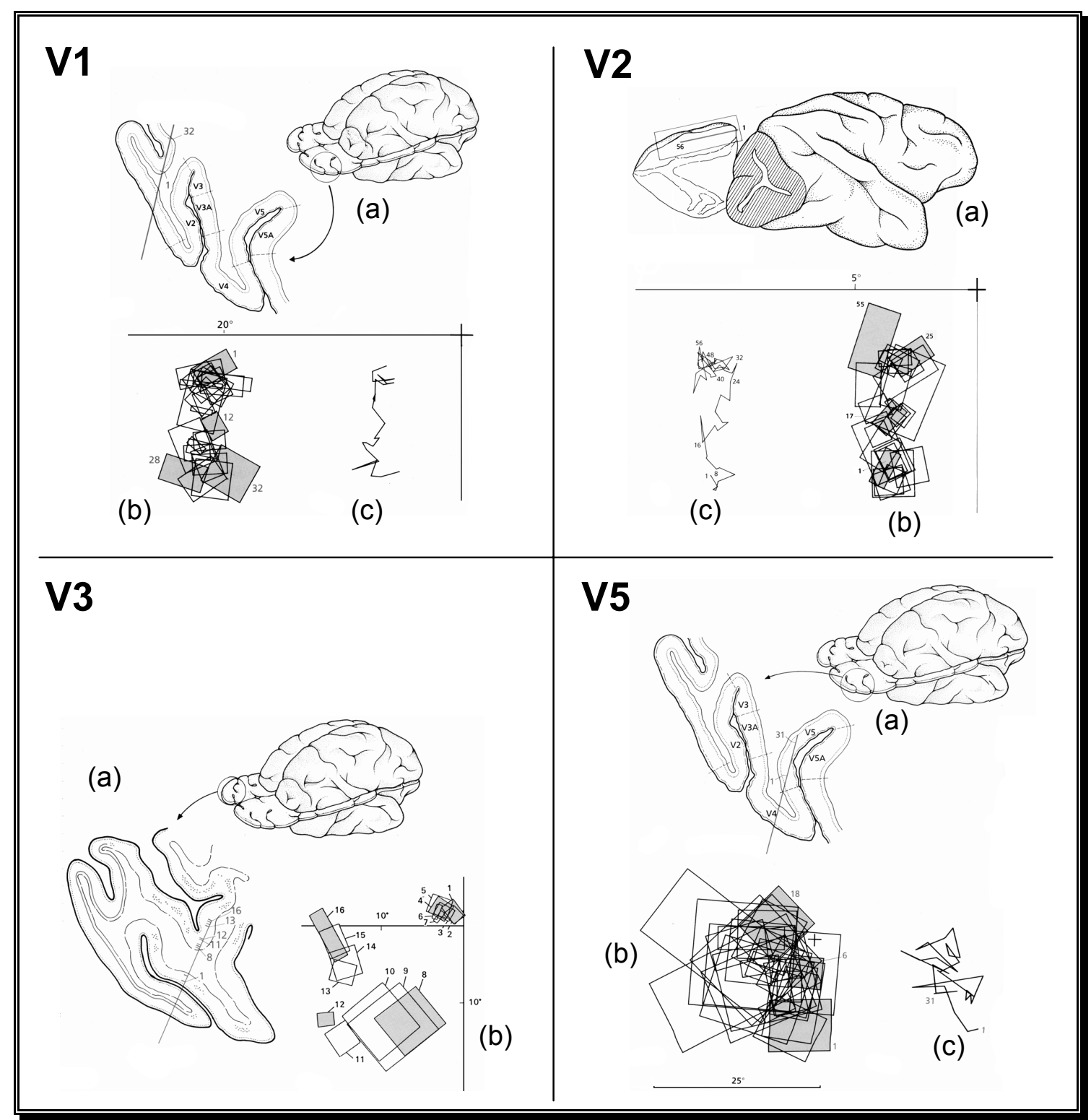

Fig. - 4.29 - Comparação entre os campos receptivos das regiões V1, V2, V3 e V5, demonstrando o aumento do tamanho do campo receptivo e da abstração, no sentido de não ocorrer mais previsão do trajeto do campo receptivo em relação ao trajeto da penetração do eletrodo. (a) Região explorada e trajetória do eletrodo, (b) dimensão e disposição dos campos receptivos e (c) trajetória dos centros dos campos receptivos. [Zeki, 1993] 
Conforme já comentamos, cada uma dessas áreas é responsável por um atributo ou modalidade de visão, o que as diferencia das áreas V1 e V2 que possuem representações de todas as modalidades $e$, consequentemente, designam o papel de segregadoras de sinal. Entretanto, evidências foram encontradas, especialmente na projeção de fibras para diversas áreas corticais, que indicam a ocorrência de segregação de sinal nas áreas especializadas (V3, V4 e V5). Assim, devemos supor que as modalidades representadas por cada uma dessas áreas deve ser ainda dividida em atributos distintos. Essa idéia se torna mais clara à medida em que vão sendo descobertas as áreas satélites (V5 complexa, V4 complexa, etc.) [Zeki, 1993]. As áreas satélites são regiões próximas às áreas especializadas que processam a mesma modalidade da área principal. Em relação ao controle de paralelismo, é importante observar que essas áreas recebem poucas ou nenhuma projeção de $\mathrm{V} 1$, indicando que o controle dessas regiões é realizado pelas regiões especialistas. Deste modo a existência das áreas satélites contribui para a visão modular e estruturada do córtex visual, assim como seu arranjo sob o perfil de estratégias de paralelismo. A seguir vamos comentar as principais características de cada uma dessas áreas:

Área V3 - É adjacente a V2 e recebe conexões das faixas grossas, assim como da camada 4B de V1. Essa área se caracteriza por apresentar a grande maioria de seus neurônios sensíveis à orientação, não possuir células com sensibilidade a estímulos cromáticos e por apresentar indicações de que esteja relacionada com o processamento de forma dinâmicas. Dentre as áreas especializadas, V3 é a que mantém traços de ordenações em relação a topografia da retina. Em alguns primatas, com exceção dos homens, foi encontrada uma subdivisão de V3, denominada de $\mathrm{V} 3 \mathrm{~A}$. A principal diferença entre $\mathrm{V} 3 \mathrm{~A}$ e as demais partes de V3 é que ela não recebe conexões de $\mathrm{V} 1$.

Área V4 - Recebe projeções das faixas finas e das pálidas de V2, assim como dos "blobs" de V1, deste modo as duas subdivisões do caminho parvo (B e I) são contidas nessa área. Embora, como as demais áreas especializadas, apresenta hegemonia quando marcada com citocromo oxidase, é possível traçar as conexões de seus neurônios através da utilização de algumas substâncias (entre elas as enzimas peroxidase). Essas conexões, quando analisadas, sugerem que os dois caminhos parvos continuam divididos, uma vez que geram padrões de conexão 


\section{CAPÍTULO 4}

distintos. Deste modo, acredita-se que a divisão do caminho parvo continue em V4, indicando portanto a existência de dois sistemas independentes.

Encontramos nessas áreas como principais características a seletividade à cor e à orientação apresentadas pela grande maioria das suas células, sendo que os estímulos são bem mais complexos que nas áreas anteriores. Em relação a sensibilidade cromática, em vez de simplesmente responder ao comprimento de onda, as células de V4 respondem à cor. Esse fenômeno é denominado de constância cromática e pode ser exemplificada pela impressão que temos quando um objeto embora iluminado com diferentes fontes de luz (comprimentos de onda diferentes) permanece com a mesma percepção de cor [Goldstein, 1989] [Zeki, 1993]. Quanto à seletividade à orientação, V4 possui características de processamento de formas e objetos, que foram demonstradas através de experimentos realizados em macacos, através de estudos eletrofisiológicos de respostas celulares e lesões [Toveè, 1996]. V4 projeta a maior parte de suas fibras para o córtex visual temporal, onde aparenta ocorrer uma integração entre a cor e a forma dos objetos. Neurônios nessa região demonstraram ser seletivos a padrões e objetos complexos, como rostos [Rolls et al., 1994].

Área V5 - Assim como V3, a área V5 recebe projeções do caminho magno, sendo parte da camada 4B de V1 e parte da faixa grossa de V2. Se caracteriza por possuir praticamente todos os seus neurônios seletivos ao movimento e não apresentar respostas aos estímulos cromáticos. Está associada ao processamento de informações de movimento e estéreo. V5 projeta principalmente para o córtex parietal, que demonstra ser uma região de continuidade do caminho magno, integrando movimento, estéreo e profundidade em representações espaciais.

\subsection{4 - ORGANIZAÇÃO DO CÓRTEX VISUAL}

Já discutimos algumas das áreas que compõem o córtex visual, assim como suas arquiteturas e, embora tenhamos comentado individualmente as conexões entre áreas, estaremos apresentando nesta seção as conexões e a organização do córtex visual como um todo, suas estratégias de paralelismo e de segregação e integração de sinais. 


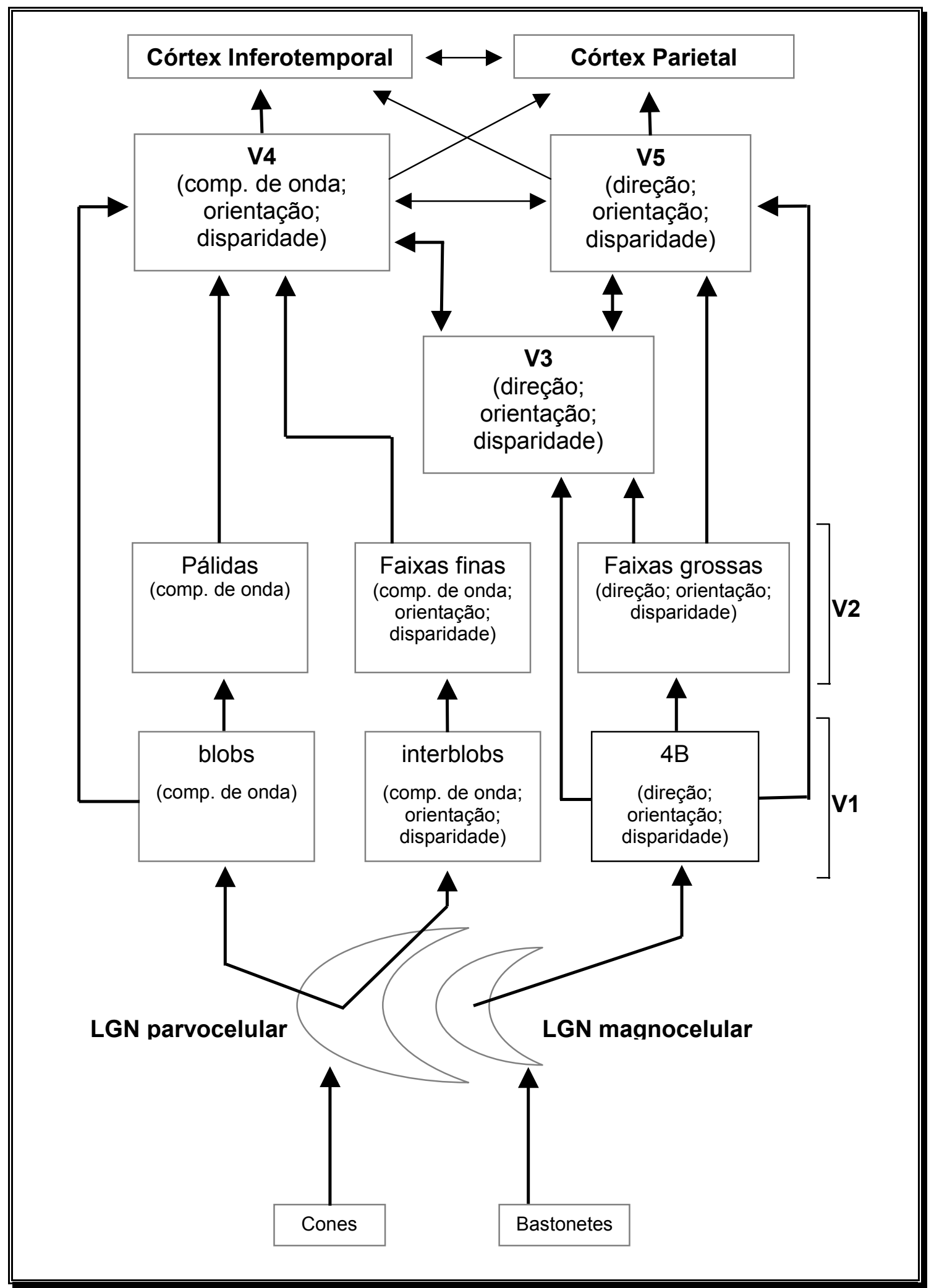

Fig. - 4.30 - Mapa simplificado das interconexões do córtex visual. [Zeki, 1993] [Zeki \& Shipp, 1988] [Levine \& Shefner, 1991] [Livingstone \& Hubel, 1988]. 


\section{CAPÍTULO 4}

A Figura 4.30 apresenta um mapa simplificado das interconexões entre as áreas e sub-áreas do córtex visual. As considerações que faremos no decorrer deste seção serão referentes a ela. A primeira segregação no processo visual se inicia já na retina, que apresenta dois tipos de células especializadas para diferentes informações visuais. Mediante o dualismo dos fotorreceptores, que mantém as suas conexões separadas em camadas distintas do LGN, podemos concluir que além do paralelismo entre as células, a retina também apresenta dois sistemas distintos e independentes no seu maquinário neurológico.

Conforme vimos na Seção 4.6.3, a visão tem um sofisticado mecanismo de integração das informações do campo visual que estão em cada uma das retinas, que ocorre com o cruzamento das fibras do nervo óptico no Quiasma óptico. Depois disso, é realizada a primeira conexão sináptica no núcleo lateral geniculado (LGN) onde, mais uma vez o sinal é segregado e consequentemente ocorre sua distribuição. Como vimos, o LGN possui dois grupos distintos de células (magno e parvo), que estão relacionados com os dois grupos de fotorreceptores da retina. Ele é composto por seis camadas das quais quatro correspondem ao caminho parvo celular e duas ao magno celular, os quais caracterizam três mapas distintos da retina.

Se já tivemos uma divisão de caminhos entre parvo e magno, teremos ainda uma segregação do caminho parvo em LGN. Deste modo, ocorrem três projeções básicas de LGN para V1. As células do caminho magno projetam fibras para V1, que serão relacionadas com o processamento realizado na camada 4B, e as células do caminho parvo, que foram segmentadas em dois mapas replicados da retina, projetam um mapa que será relacionado com as estruturas "blobs" e outro mapa que será relacionado à estrutura entre "blobs".

O mapa da Figura 4.30 é muito simplificado e apresenta apenas as principais conexões realizadas. Embora apresentamos no mapa apenas um sentido para as conexões, essas são na sua grande maioria bi-laterais, sendo essa uma importante característica do processamento visual. Seus dois sentidos de transferência de informações durante o processamento é referenciada muitas vezes na literatura como "top-down" e "botton-up" [Levine, 1985]. O córtex visual primário, por exemplo, projeta fibras de volta para o LGN.

Para cada hemisfério cerebral é enviada uma metade de cada retina que, juntas, compõem um lado do campo visual. O córtex visual primário possui uma arquitetura (colunas de dominância ocular) para o tratamento individual de cada 
uma das retinas (binocularidade), que indica ser um sistema de integração entre as imagens de cada retina. O estímulo celular com preferência binocular não é encontrado em nenhuma outra área cortical, sugerindo que V1 seja realmente a área responsável pela junção desses sinais.

Quanto à organização V1 apresenta três sistemas independentes, que são respectivos aos três caminhos incidentes nesta área ou seja, dois caminhos parvos, recebem o nome de parvo I ("interblob") e parvo B ("blob") e magno. Devido à independência, destino principal individual e seu aspecto funcional, acredita-se que eles sejam paralelos. Além do paralelismo entre os três caminhos, encontramos também, devido ao amplo estudo e exploração de V1, sub-estruturas replicadas para cada um dos caminhos replicados, indicando o paralelismo multi-escalar dentro dessa área.

O córtex visual primário caracteriza-se como um segregador, distribuidor de sinais e provavelmente também como gerenciador ou escalonador, devido à diferença de diâmetro, que consequentemente influencia na velocidade de transmissão de suas fibras. Deste modo, V1 projeta fibras para diversas áreas corticais, dentro e fora do córtex visual, assim como projeções extra-corticais (culículo superior, LGN, etc.). Dentre as principais conexões de V1 destacam-se as projeções para V2 e para as áreas especialistas V3, V4 e V5. As conexões entre as áreas corticais em geral obedecem a padrões restritos, que indicam que os estímulos estão sendo transmitidos em conjunto através de mapas.

$\mathrm{A}$ área $\mathrm{V} 2$ recebe três mapas de $\mathrm{V} 1$, relativos aos três caminhos (magno, parvo I e parvo B). Esses caminhos continuam em V2 como sistemas independentes e são associados a estruturas anatômicas que assemelham a faixas (faixas grossa, finas e pálidas). Assim como V1, V2 projeta fibras para todas as áreas especialistas do córtex visual (V3, V4 e V5). Embora não esteja representado no mapa da Figura 4.30, as áreas V3, V4 e V5 apresentam em suas proximidades áreas satélites, que processam os mesmos atributos e recebem a maior parte das fibras eferentes das áreas principais. As áreas satélites nos apresentam fortes indícios da distribuição de processamento que ocorre nas áreas V3, V4 e V5 [Zeki].

Em função das áreas satélites especializadas, encontramos uma peculiar diferença entre as áreas V1 e V2. Embora possuam características semelhantes, como segregadoras de sinais, e ambas apresentam conexões com todas as regiões especializadas, somente V2 apresenta conexões com as áreas satélites de V3, V4 e V5. 


\section{CAPÍTULO 4}

Os caminhos visuais são projetados a partir de V1 e V2 para as áreas mais especializadas do córtex visual: V3, V4 e V5. Essas áreas se diferenciam de V1 e V2 por lidarem com atributos mais específicos e, consequentemente, por apresentarem apenas representações destes. O caminho magno, correspondente à camada $4 \mathrm{~B}$ de $\mathrm{V} 1$ e faixas grossas de $\mathrm{V} 2$, é projetado para duas áreas especialistas: V3 e V5. A área V3 é principalmente responsável pelo processamento de formas dinâmicas e a área $\mathrm{V} 5$ por movimento. Os dois caminhos parvos ( I e B), entretanto, são projetados para uma única área: V4. Essa área é responsável pelos processamentos cor (Parvo B) e formas de alta definição cromática (Parvo I).

Cada uma das áreas especialistas trocam informações entre si. Essas informações permitem o enriquecimento da informação local com componentes processados pela outra área. Dentre as comunicações entre as áreas especializadas destacam-se as conexões entre V3 e V4. Segundo Zeki [Zeki, 1993], existem indicações que através dessas conexões é realizada a integração de sinais para o processamento de formas. Desta forma, V3, responsável pelo processamento de formas dinâmicas, enriquece seu processamento com os resultados de $\mathrm{V} 4$, responsável por formas cromáticas de alta definição, e viceversa.

A partir das áreas especialistas, a informação visual é transmitida para regiões mais profundas no córtex, ficando cada vez mais complexa e abstrata. Basicamente, encontramos dois caminhos principais que nos levam a dois sistemas de visão localizados respectivamente no córtex inferotemporal e no córtex parietal. Aparentemente essas conexões são extensões dos caminhos parvo e magno e são as bases da famosa doutrina "o que" e "onde". Segundo essa doutrina, as informações visuais são separadas em duas primitivas básicas quando organizadas na memória associativa. Uma delas é responsável pelo processamento e armazenamento de todas as informações relativas à localização no espaço, e a outra, pelo processamento e armazenamento das informações relativas às propriedades físicas dos objetos [Kosslyn, 1996] [Hundert, 1995].

A doutrina "o que - aonde" entretanto não é amplamente aceita no meio científico, sendo duramente criticada por alguns autores. Dentre as críticas, destaca-se a de Zeki [Zeki, 1993], que sugere que a doutrina constitua de um erro sistematicamente histórico, que ocorre na tentativa de neuro-cirurgiões simplificarem as estratégias corticais, devido ao limitado conhecimento de sua 
constituição e funcionamento. Segundo Zeki, o mesmo ocorreu com a teoria da plasticidade cortical, que via o cérebro como uma caixa preta e sem nenhuma modularidade específica e também com a idéia de processamento linear da informação visual, defendida até ser contestada pelos experimentos de Hubel e Wiesel.

\subsection{5 - ESTRATÉGIAS DE INTEGRAÇÃO DA INFORMAÇÃO AO LONGO DO PERCURSO VISUAL}

Os diversos estudos sobre o córtex visual apresentam diversas noções de divisão de trabalho e de segregação funcional. A nossa experiência diária, visualizando um mundo uniforme diferente, nos leva a crer na unidade do campo visual e de sua percepção, onde todos os atributos são processados simultaneamente. Para que essa percepção seja válida devem ocorrer sofisticados métodos e processos de integração de sinais. Levados pela lógica, podemos supor que deveria existir uma região mestre no córtex, que receberia e seria responsável pela integração de todas as informações. No entanto não existe uma região no córtex a qual todas as demais se reportam. Essa afirmativa é válida não apenas para o córtex visual, mas sim para todo o córtex.

Muito pouco sabemos a respeito das estratégias de integração de sinais utilizadas pelo córtex. Mesmo no bem explorado córtex visual, ainda não temos nenhum perfil de integração e, diferentemente dos processos de segregação de sinais que foram vastamente estudados, o que é feito são apenas especulações sobre essas estratégias. Vamos a seguir apresentar algumas supostas estratégias de integração realizada pelo córtex visual. Com base em algumas evidências, podemos supor três estratégias básicas para a integração dos estímulos visuais:

Aumento do tamanho do campo receptivo, e permitindo que as células estejam hábeis a coletar informações de partes maiores do campo visual e que respondam ao conjunto de seus estímulos. Observamos, que à medida que vamos adentrando o percurso visual, percebemos que as células ficam com seus campos receptivos cada vez maiores, de modo que o campo receptivo das células de V1 são maiores que as do LGN, que por sua vez os campos receptivos de $\mathrm{V} 2$ são maiores que $\mathrm{V} 1$ e menores que $\mathrm{V} 3$, que por sua vez é menor que V5. Finalmente quando comparamos os campos receptivos das células do córtex inferotemporal e parietal notamos que são maiores que as das 


\section{CAPÍTULO 4}

áreas do córtex visual.

Aumento da complexidade do estímulo. Ocorre simultaneamente com a primeira (i), uma vez que as células aumentam seus campos receptivos, automaticamente elas tratam com sinais cada vez mais complexos e propriedades mais específicas. A Figura 4.31 apresenta exemplos das estratégias (i) e (ii).

Unificação dos sinais de diferentes fontes, representando diferentes atributos visuais (ex: forma e movimento). A unificação não significa necessariamente que os sinais devam ser direcionados para uma célula específica, uma possibilidade é que a unificação venha a ser realizado por células distantes respondendo em sincronismo a um evento em comum [Zeki, 1993]. 


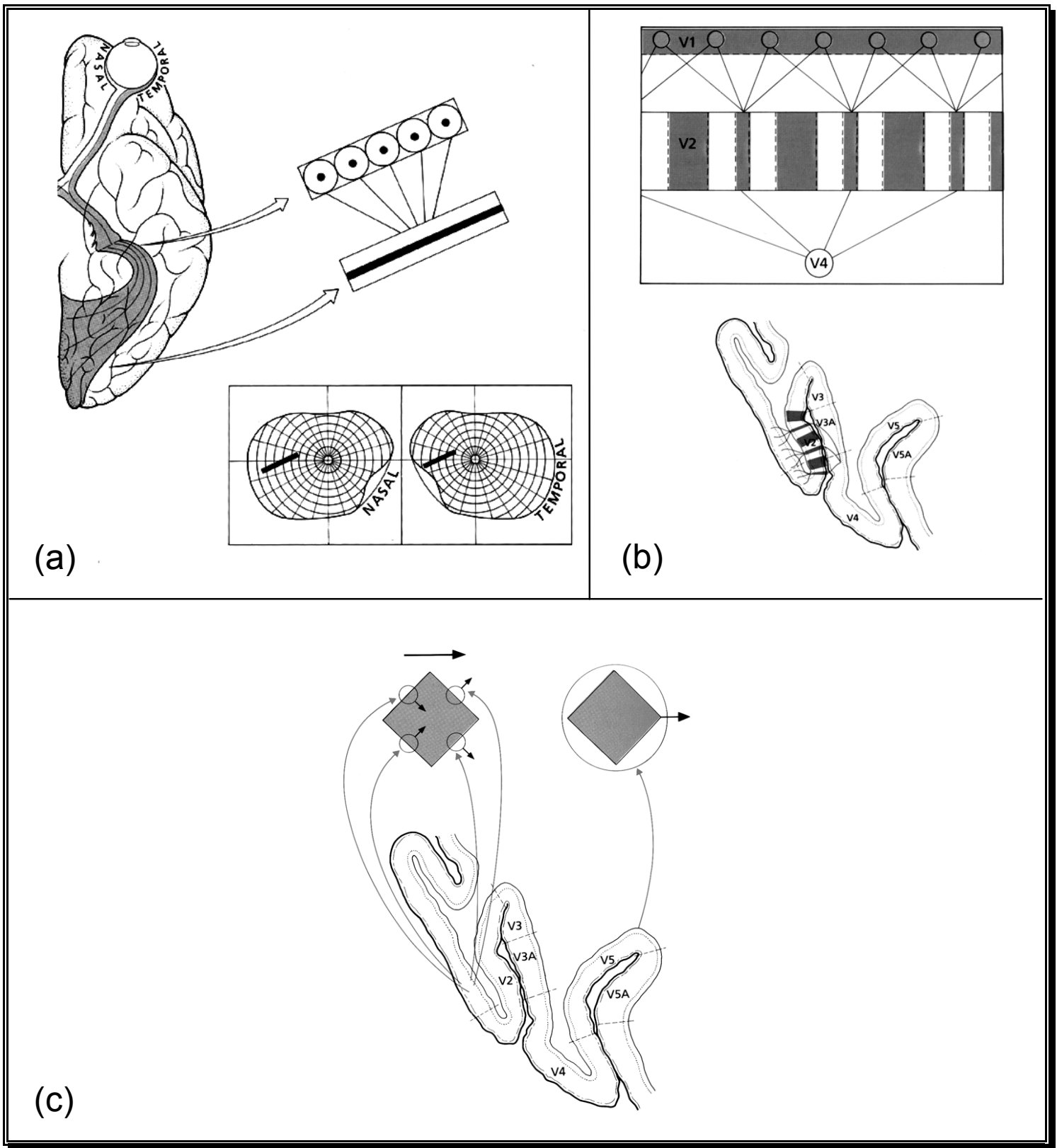

Fig. - 4.31 - Estratégias de integração de sinal visual através do aumento do campo receptivo e da complexidade do estímulo. (a) (reta) Células centroperiferia do LGN e células simples de V1. (b) (cor) Projeção das células dos

"blobs" em V1 para faixas finas em V2 e finalmente em V4, observar a pirâmide de projeção. (c) (movimento) Enquanto em V1 as células são estimuladas pela orientação das bordas independentes (um vetor de direção para cada lado) ocorre a integração em V5, de modo que suas células são capazes de fornecer a direção do objeto. [Zeki, 1993] 


\subsection{6 - INTEGRAÇÃO DA INFORMAÇÃO DOS DOIS}

\section{HEMISFÉRIOS}

O nível mais alto de paralelismo do processamento visual que encontramos no córtex é demonstrado pela divisão do cérebro em dois hemisférios. Como já apresentamos, a aquisição de todo o campo visual é realizada em cada uma das retinas e reorganizadas (quiasma óptico) de modo que o córtex visual de cada hemisfério receba estímulos correspondentes a uma metade do campo visual. Embora exista essa divisão no campo visual, o sistema de visão possui uma integração perfeita, sendo que nos é impossível percebê-la.

O corpo caloso é um corpúsculo formado pela aglomeração de fibras, cuja principal característica é a conexão dos dois hemisférios. Através do corpo caloso as áreas pares de cada hemisfério são interconectadas e assim o cérebro é integrado. Em geral, as conexões são organizadas de forma bem definida e distinta em uma das áreas corticais, formando um bom referencial sobre o número e a divisão destas. Cada área é conectada separadamente com sua correspondente no hemisfério oposto, exatamente porque as duas metades (uma em cada hemisfério) possuem mecanismos que são diferentes das outras áreas e assim requerem conexões separadas.

Como sabemos, o córtex visual estriado possui um mapeamento topográfico preciso da retina. Deste modo, seria de se esperar que apenas as regiões posicionadas na linha divisória do campo visual possuíssem conexões entre hemisférios. De fato é exatamente isso que ocorre nas conexões entre o córtex visual primário e o corpo caloso, onde a sua regularidade traça exatamente a linha do meridiano vertical do campo visual em cada hemisfério.

Como o córtex visual primário, V2 possui um mapeamento topográfico preciso da retina, apresentando também conexões com o corpo caloso, presentes apenas nas células da linha divisória do campo visual. Desta forma, seu traçado corresponde exatamente ao meridiano vertical do campo visual. À medida que avançamos no córtex visual as áreas se tornam mais específicas e abstratas e, consequentemente, seus mapas ficam cada vez mais desorganizados em relação à topografia da retina. Assim, a conexão das áreas com o corpo caloso não formam mais uma trilha de indicação do meridiano do campo visual, já que as células correspondentes a essa região encontram-se espalhadas. Enquanto V1 e V2 apresentam uma estrutura muito definida, traçando o limiar do campo visual, V3 
possui conexões espalhadas e, V4 e V5 não possuem nenhum tipo de ordenação clara na conexão com o corpo caloso.

Além de caracterizar as diferentes áreas espalhadas pelo córtex e definir a precisão do mapeamento topográfico da retina nas diferentes áreas do córtex visual, o corpo caloso também evidencia o paralelismo entre hemisférios e entre áreas. O primeiro caso é bastante óbvio, a simples existência de dois hemisférios por si só é uma prova de paralelismo nesse nível. Em relação ao paralelismo entre áreas, para que ela ocorra é necessário que as diferentes áreas do córtex visual apresentem uma representação completa do campo visual. A conexão com o corpo caloso, independente entre cada uma das áreas é a indicação de que cada área possui sua própria representação completa do campo visual através da conexão com seu par no outro hemisfério, indicando consequentemente sua independência e paralelismo. 
CAPÍTULO 4 


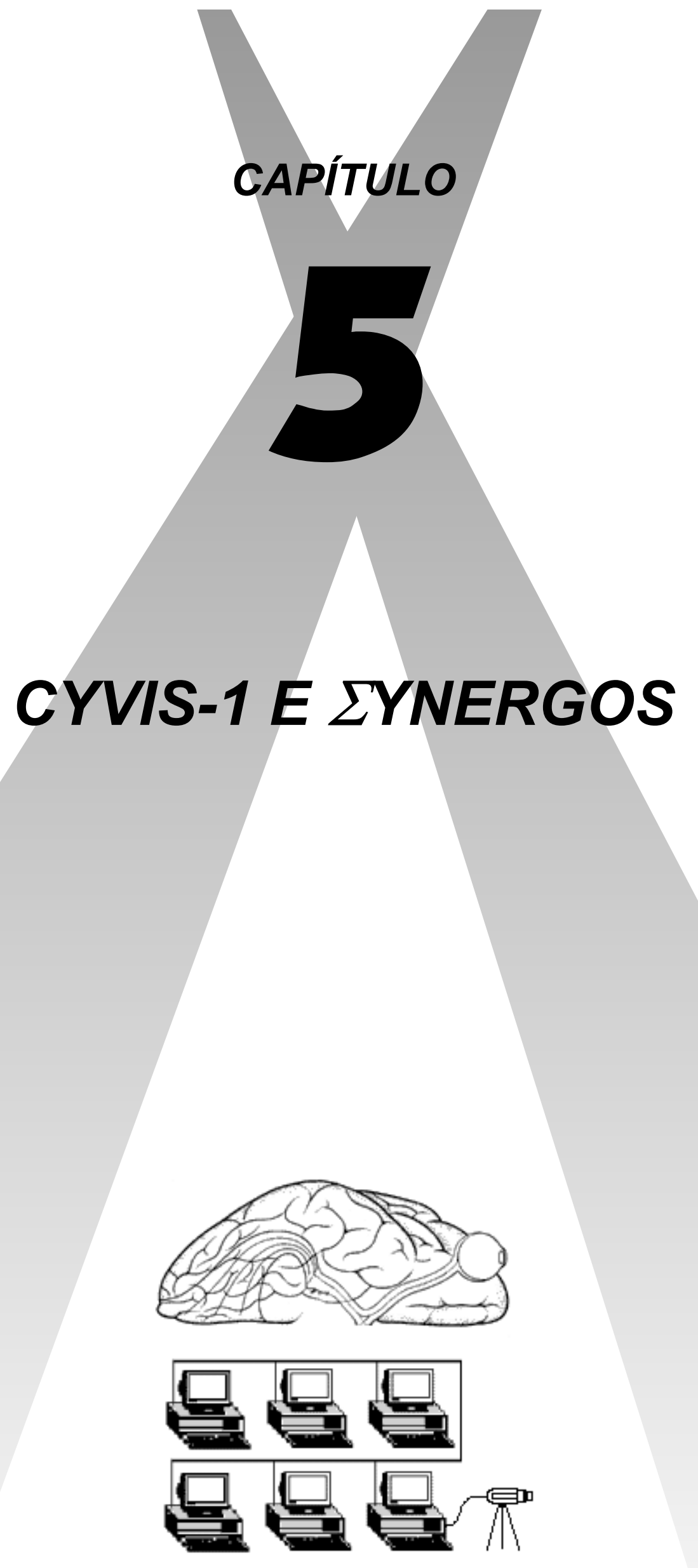


CAPÍTULO 5 


\section{CAPÍTULO 5 - CYVIS-1 E LYNERGOS}

\section{1 - INTRODUÇÃO}

Neste capítulo iremos apresentar os projetos que motivaram e constituíram os princípios para o desenvolvimento do trabalho apresentado nesta tese. Conforme já apresentamos, uma das bases da visão natural é o seu processamento paralelo. Entretanto, a visão artificial não vem utilizando este recurso como prioridade de pesquisa. A vasta maioria da literatura sobre visão computacional, visão artificial e processamento de imagens tem uma forte tendência seqüencial. Isso se deve principalmente aos fundamentos dessas áreas, se tomarmos os livros mais clássicos, e entre eles a bíblia da visão, o livro "Vision" de David Marr [Marr, 1982]. Embora siga a linha da inspiração biológica, Marr, não considerou esse recurso, que como vimos, foi plenamente explorado pela natureza nos sistemas de visão.

Apresentaremos neste capítulo dois projetos audaciosos do grupo de visão cibernética do IFSC - USP. O primeiro é o Cyvis-1, um sistema de visão versátil, fortemente inspirado em biologia, mais especificamente no modelo da especialização funcional do córtex visual. Assim como os sistemas biológicos, o Cyvis-1 se caracteriza pelo perfil modular, onde cada módulo é especializado em um atributo visual. Assim como o modelo biológico, o projeto é baseado em processamento paralelo. Apresentaremos também alguns projetos similares ao Cyvis-1 encontrados na literatura e faremos uma breve comparação explorando as vantagens e desvantagens dos sistemas. O outro projeto, इynergos, é um ambiente e laboratório de desenvolvimento e análise de técnicas de visão e processamento de imagens, que tem como objetivo auxiliar a pesquisa, implementação, caracterização, validação de métodos e realização de experimentos nestas áreas.

Ambos os projetos possuem em comum o processamento paralelo de algoritmos e sistemas de visão. A filosofia de processamento linear agregada a visão, a falta de pesquisas abrangentes de paralelismo nessa área, assim como a necessidade de ferramentas de desenvolvimento, controle e análise de sistemas paralelos para programadores não-especializados em computação paralela, foram 
alguns dos principais fatores de motivação do nosso trabalho, que serão comentados na parte final deste capítulo.

\section{2 - O PROJETO CYVIS-1}

Um dos maiores desafios, senão o maior, na visão artificial, é o desenvolvimento de visão versátil. Entendemos por visão versátil a capacidade de um sistema se adaptar facilmente a diferentes situações e ambientes, assim como realizar o reconhecimento visual de objetos diversos. Ao longo da evolução a natureza desenvolveu uma quantidade enorme e variada de sistemas de visão versáteis, como os sistemas de visão dos vertebrados. A grande maioria dos vertebrados, mesmo os mais primitivos, possuem sistemas de visão capazes de responder a uma grande variedade de objetos, nas mais diversas situações e ambientes. A despeito dos muitos avanços tecnológicos e científicos, os sistemas de visão que somos capazes de construir atualmente, se compararmos sob o aspecto da versatilidade no reconhecimento de objetos, são medíocres em relação aos sistemas de visão dos mais primitivos vertebrados, e até mesmo de invertebrados.

Normalmente a abordagem clássica adotada pelos sistemas de visão é a exploração de poucos atributos e seu tratamento individual, elaborando algoritmos cada vez mais sofisticados, mas isolados. Muito temos que aprender com a natureza, e de fato diversos algoritmos eficientes de visão foram nela inspirados. Entretanto, observando as divergências entre os sistemas naturais e os artificiais, podemos perceber nos sistemas artificiais de visão ausências de algumas estratégias utilizadas pela natureza com êxito, das quais podemos citar:

Estratégias de processamento em duplo sentido, não apenas indo do baixo nível para alto nível, mas também o sentido inverso ("top-down" e "botton-up");

Paralelismo: a biologia investiu ao longo da evolução em estratégias de paralelismo, de modo que elas não apenas possibilitam a execução em tempo real dos sistemas de visão, mas também estão intrinsecamente ligados aos mecanismos de integração e compartilhamento de informações;

Modularidade e integração: estão presentes nos sistemas naturais de visão e são fundamentais para sua grande performance. Estando intimamente associadas às estratégias e arquiteturas paralelas adotadas pela natureza [Costa et al., 1994]; 
Hierarquia: fundamental para a organização da informação e dos processos, ainda mais quando de modo não linear, conforme sugerido pelos itens anteriores; Representação visual efetiva. [Costa et al., 1994]

Cyvis-1, cujo nome é derivado do inglês "Cybernetic Vision System 1" é um ambicioso projeto do nosso grupo de pesquisa, fortemente inspirado na biologia, cujo intuito é o desenvolvimento de um sistema de visão versátil capaz de se adaptar de modo quase automático a diferentes tipos de problemas de visão [Costa et al., 1994]. Uma das bases para o desenvolvimento do Cyvis-1 é o estudo e a incorporação de estratégias de paralelismo, uma vez que a natureza nos demonstra que para o problema de visão não são apenas necessárias sofisticadas representações e algoritmos, mas também estruturas paralelas/concorrentes para, além de atender no menor tempo possível a enorme quantidade de dados necessários para o processamento (especialmente nos níveis mais baixos), força também a constituição de estruturas modulares e hierárquicas, capazes de trocar informações durante o processamento, efetuando deste modo a sua integração.

\subsection{1 - APRENDENDO COM A NATUREZA}

A engenharia reversa realizada em sistemas biológicos é uma linha de pesquisa que, devido ao seu sucesso, está se tornando cada vez mais popular. Deste modo, ao invés de reinventarmos as soluções, analisamos o modo pelo qual a natureza em milhões de anos de evolução solucionou seus problemas. Essa linha de raciocínio é um dos pilares fundamentais da Visão Cibernética, que procura na biologia a solução para os problemas de visão artificial. Seguindo esta estratégia, encontramos a base do sistema de visão artificial Cyvis-1, cuja principal característica é a sua forte inspiração biológica. Nesta seção, vamos apresentar alguns dos principais princípios biológicos de processamento, representação e organização incorporados no projeto Cyvis-1 [Costa et al., 1994].

\subsubsection{1 - PARALELISMO, DISTRIBUIÇÃO DE PROCESSOS E}

\section{TROCA DE MENSAGENS}

Tradicionalmente, os sistemas de visão artificiais são seqüenciais. A figura 5.1 apresenta um diagrama de um sistema de visão artificial clássico, nele encontramos um dispositivo de aquisição de imagens, um módulo de pré- 


\section{CAPÍTULO 5}

processamento, o qual realiza algumas operações de tratamento de imagem, um módulo de processamento primário, o qual extrai características básicas da imagem, como as bordas por exemplo, e um ou alguns poucos módulos de processamento de atributos, que extrai as propriedades da imagem e finalmente 0 módulo de classificação, que recebe os resultados. Ao contrário dessa abordagem, a natureza, ao longo de milhões de anos de evolução, investiu profundamente no paralelismo, e nos ensina que esta é uma solução natural para a questão da visão.

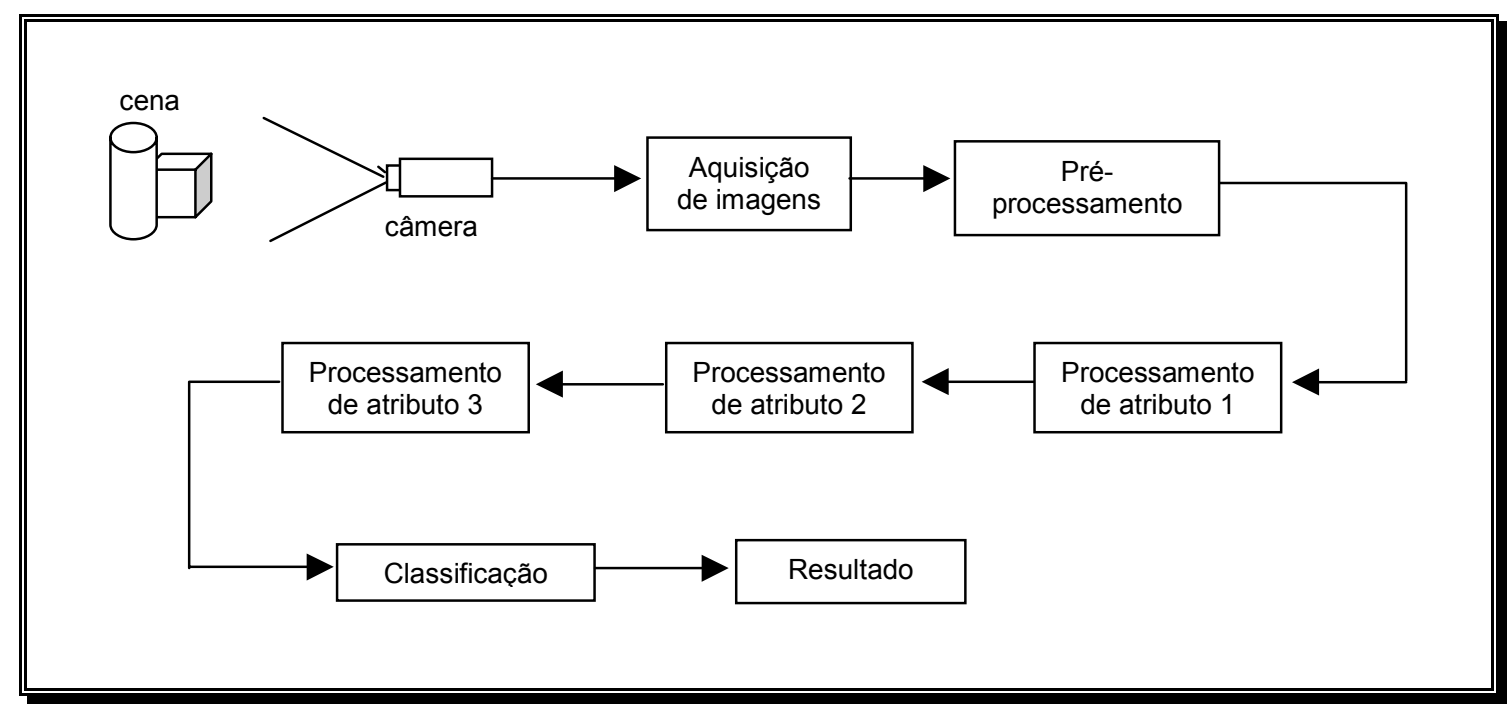

Fig. - 5.1 - Diagrama de um sistema de visão artificial clássico.

Quando pensamos em paralelismo, a primeira questão que nos vem à mente é o desempenho, uma vez que basicamente utilizamos o paralelismo com o intuito de aumentar a performance de sistemas que necessitem de respostas rápidas e demandem grande poder computacional. Sem dúvida alguma, o desempenho é uma questão muito importante. Especialmente para os sistemas de visão versátil que, tentando resolver diversos problemas, tem necessariamente que se defrontar com uma série destes que estão envolvidos diretamente com processamento em tempo real. Nesse contexto, a situação se agrava ainda mais, uma vez que a visão utiliza algoritmos dispendiosos que demandam grande poder computacional, e que se tornam muitas vezes impraticáveis, especialmente com imagens de alta resolução, devido ao tempo de execução prolongado e consequentemente um elevado uso de recursos computacionais.

No entanto, a natureza demonstra que sua opção pelo paralelismo não se deu única e exclusivamente devido ao benefício do aumento de desempenho (uma vez que os neurônios são relativamente lentos). O paralelismo está diretamente 
relacionado com inúmeras outras questões, que juntas caracterizam o sistema visual. A natureza modularizou e distribuiu o sistema visual de modo que os atributos visuais (cor, textura, formas, estéreo, movimento e etc.) pudessem ser executados concomitantemente. Além disso, como discutimos no Capítulo 4, cada um dos módulos é ainda formado por inúmeras estruturas concorrentes. Ademais, os sinais são separados e percorrem caminhos diferentes ao longo de todo o sistema, caracterizando a sua distribuição. Dentro do conceito de módulos e múltiplos caminhos, o paralelismo, a distribuição de processos e a troca de mensagens desempenham um papel fundamental, uma vez que informações são trocadas entre os módulos de diferentes atributos, assim como de diferentes estágios dentro de um mesmo caminho, de modo a aprimorar o processamento visual. Esse tipo de processamento colaborativo não teria sentido em um regime de processamento seqüencial.

Além do trabalho cooperativo entre o processamento simultâneo de diferentes atributos, o córtex também apresenta a integração e colaboração de diferentes níveis de conhecimento. Ao mesmo tempo que as informações são processadas de baixo para alto nível, o mesmo ocorre em sentido inverso, e a troca de mensagens entre esses dois sentidos realiza a integração das informações, aumentando o poder de processamento e reconhecimento de padrões do sistema biológico. Novamente, esse tipo de estratégia não teria sentido sem a utilização de uma arquitetura massivamente paralela.

\subsubsection{2 - AltA RESOLUÇÃo PARA A REPRESENTAÇÃO DE IMAGENS}

Esta é uma das lições mais básicas que a natureza nos ensina. Por questões de desempenho, é ainda raro encontrar um sistema de visão artificial que exceda a dimensão de $512 \times 512$ (262144 pontos), no entanto os sistemas naturais de visão apresentam resoluções de ordens muito maiores. Na retina de cada um dos olhos dos seres humanos, são encontradas cerca de 126 milhões de fotorreceptores. A indicação que podemos tirar dessa grande diferença é de que resoluções mais altas podem aumentar substancialmente a performance da qualidade em reconhecimento de padrões, assim como dos resultados das técnicas de processamento de imagens. 


\section{CAPÍTULO 5}

Evidentemente, o aumento da resolução do sistema aumenta proporcionalmente o custo computacional do processamento, especialmente nos primeiros estágios da visão, que de um modo geral, operam a imagem pixel a pixel e usualmente utilizam métodos que empregam convoluções, tornando ainda mais drástico o tempo de processamento e o consumo de poder computacional, devido ao grande número de multiplicações utilizadas [Levine, 1985]. Para solucionar esse problema, a natureza utiliza o processamento massivamente paralelo, replicando as estruturas de processamento nos módulos, processando diversos módulos simultaneamente e até mesmo desenvolvendo mecanismos de processamento paralelo de sinais intimamente ligados às estruturas de aquisição de imagem (o maquinário neural encontrado na retina). Este é mais um ponto que evidencia a necessidade do paralelismo, que é uma das bases do projeto.

\subsubsection{3 - HIERARQUIA}

Organização hierárquica do processamento sempre foi característica dos sistemas de visão artificiais, sendo talvez uma conseqüência natural do processamento visual. No sistema de visão dos primatas, a hierarquia é bem nítida e pode ser sintetizada pela seqüência: retina, núcleo lateral geniculado, córtex visual e áreas corticais de alto nível. A cada estágio hierárquico a informação visual se torna mais compacta e mais abstrata e complexa, incorporando cada vez mais informações. Assim como os demais princípios apresentados aqui, a hierarquia também está relacionada diretamente com outros tópicos, especialmente com a modularidade, paralelismo e com a representação visual efetiva.

\subsubsection{4 - TRÁFEGO DA INFORMAÇÃO EM SENTIDO DUPLO}

Um princípio que exerce um papel fundamental no desempenho do reconhecimento de padrões dos sistemas biológicos é a realimentação de informações ou o duplo sentido da informação. A vasta maioria dos sistemas de visão artificial apresentam apenas um único sentido no tráfego de imagem, o qual vai dos níveis baixos para os níveis altos de processamento. Entende-se por nível baixo de processamento, os processamentos primários, tais como detecção de bordas, normalização de histograma, suavização e etc. À medida que as informações processadas vão ficando mais complexas (retas, regiões, formas, objetos e etc.), dentro dessa nomenclatura, o processamento vai se tornando de 
nível mais alto.

Nos sistemas de visão biológicos o tráfego das informações é realizado em sentido duplo. Deste modo, tanto os módulos de baixo nível transmitem informações para os de alto nível, como o reverso também ocorre. A grande vantagem dessa estratégia é que as informações processadas de alto nível, armazenadas em processamentos realizados anteriormente, quando enviadas para os módulos de processamento de baixo nível, contribuem para a eficácia e performance de seus processamentos, enriquecendo a informação visual. Ocasionalmente, quando observamos um objeto ou uma cena, e temos uma percepção instantânea que não condiz com a realidade, muitas vezes isto é fruto de um erro concebido pelo fluxo de informações de alto para baixo nível.

\subsubsection{5 - MODULARIDADE}

Principalmente devido à característica de plasticidade apresentada em determinadas situações pelo córtex, nos primórdios da neurociência, acreditava-se que o cérebro, mais especificamente o córtex, era uma massa uniforme, dividida apenas entre regiões de motoras - sensoriais e memória associativa [Zeki, 1993]. Essa antiga crença ainda influencia o âmbito computacional que se inspira em neurociências. Podemos observar que a grande maioria das redes neurais artificiais são caracterizadas por interconexões uniformes constituídas de apenas um único tipo de neurônio artificial. A pesquisa científica, entretanto, elucidou essa questão e pôs fim à crença da uniformidade. Como sabemos o córtex, longe de ser uniforme, apresenta arquiteturas e conexões distintas em diferentes regiões. Tomando apenas o exemplo da córtex visual, o capítulo anterior apresenta diferentes arquiteturas que caracterizam as diferentes áreas do córtex visual.

A modularidade apresenta para os sistemas de visão a utilização de uma organização lógica e estrutural, que proporciona, as bases para o processamento paralelo, assim como inúmeras outras vantagens nos aspectos arquitetônicos, que sob o ponto de vista computacional são vitais. Ferramentas e métodos para a modularização do software e hardware são vitais para a ciência da computação, como bom exemplo disso podemos citar a programação orientada a objetos em software, assim como o desenvolvimento do circuito integrado em hardware. 


\subsubsection{6 - REPRESENTAÇÃO VISUAL EFETIVA}

Uma das questões mais importantes nos sistemas de processamento de dados consiste no modo pelo qual a informação será representada. Esse ponto é importante para os sistemas de processamento visual, uma vez que operam em grandes quantidades de dados, que são armazenados sucessivamente para cada um dos estágios do processamento. No modelo biológico, a preocupação com a representação visual é claramente observável, e aqui vamos tomar como exemplo o sistema visual dos primatas e suas diferentes representações ao longo de sua hierarquia.

A imagem projetada na retina é convertida em sinal nervoso por cerca de 126 milhões de fotorreceptores, dos quais existem duas classes principais (cones e bastonetes) que possuem sensibilidades distintas. De modo, temos dois mapas com representações específicas. Na retina, é realizado um pré processamento de detecção de borda pelo seu maquinário neural, que culmina nas células ganglionares. Os dois mapas são então reorganizados e as suas representações compactadas. Assim as imagens são representadas pelas terminações nervosas de apenas 800 mil células ganglionares, que formam o nervo óptico. Se não ocorresse o pré processamento e uma representação mais efetiva do sinal, o nervo óptico seria muito maior, desperdiçando recursos, que a natureza prima por economizar. Segundo Marr [Marr, 1982], isso é possível devido à riqueza das informações contidas nas bordas, que são suficientes para representar grande parte da cena.

Dos gânglios da retina a informação é então enviada para o LGN, que então redistribui representações distintas para entradas específicas do córtex visual primário, onde é realizado processamento de um nível mais alto. Nessa etapa as informações são representadas de forma a arranjar contextos mais ricos, tais como mapas cromáticos, mapas de segmentos de retas, disparidade e movimento, entre outros. Embora ainda sejam pouco conhecidas as representações em escalas ainda maiores, devido ao comportamento do córtex de elaborar representações mais abstratas e complexas a partir das anteriores, podemos presumir, nessa linha de raciocínio, que existem representações abstratas capazes de conter de forma concisa e precisa, objetos e cenas inteiras.

\subsubsection{7 - ESPECIALIZAÇÃO DE PROCESSOS}

A antiga crença na uniformidade do córtex, além de influenciar as questões 
estruturais e arquiteturais, como vimos na Seção 5.2.1.5, também caracterizou de modo impróprio o seu aspecto funcional. Deste modo, acreditava-se que todas as partes do córtex eram capazes de realizar qualquer tipo de processamento, e que não existiam centros ou regiões repensáveis por determinados atributos. A partir da localização da área Broca [Broca, 1861], esse conceito mudou e, mais tarde, com a descoberta das áreas especializadas no córtex visual, a teoria da especialização funcional do córtex veio a se consolidar. Deste modo além de apresentar módulos com perfil arquitetônico e estrutural distintos, cada um desses módulos possui também funções distintas.

Nos primatas, assim como em outros mamíferos de ordem superior, o processamento dos atributos visuais (movimento, orientação, cor, textura e etc.) é realizado por distintas especializações de processamento [Zeki \& Shipp, 1988] [Livingstone \& Hubel, 1988] [Zeki, 1993] [Hubel, 1995] [Levine \& Shefner, 1991] [Julesz, 1995]. A segregação do sistema visual inicia-se já na retina, além de possuir diferentes células fotorreceptoras possui também caminhos diferentes de processamentos: magnocelular e parvocelular. Esses caminhos são novamente divididos no LGN e no córtex visual, de modo que cada área ou módulo especializado do córtex visual receba um fluxo de sinal principal, proveniente de um caminho com um sinal específico. Essa característica, além de fundamentar o processamento especializado, também o define como distribuído. Deste modo, a especialização de processos e caminhos, do ponto de vista computacional, permite um alto grau de paralelismo.

\subsubsection{8 - INTEGRAÇÃO DE MÚLTIPLOS ESTÁGIOS}

Os princípios discutidos anteriormente, modularidade, hierarquia, paralelismo, troca de mensagens, tráfego de sinais em duplo sentido e especialização de processos, constituem a organização funcional do córtex. Uma de suas principais características é a interconexão entre os módulos e caminhos especializados (atributos específicos) assim como entre os diferentes estágios hierárquicos, e foi denominada por Zeki e Shipp [Zeki \& Shipp, 1988] de Integração de múltiplos estágios. Através dessa estrutura, os módulos especialistas que compõem um caminho ou atributo visual podem trocar informações em qualquer estágio hierárquico com módulos de outros atributos, possibilitando complementar a informação. A colaboração entre os módulos, permite uma precisão e performance melhores no reconhecimento dos objetos ou regiões da imagem. 
A colaboração entre os módulos inspirou profundamente o projeto Cyvis-1 e constitui atualmente um dos maiores desafios, uma vez que pouquíssimos sistemas artificias utilizam características de auxílio mútuo entre módulos, e quase nenhuma referência na literatura apresenta essa integração de atributos em visão artificial.

\subsubsection{9 - VISÃO FOVEAL}

Uma diferença muito grande entre os sistemas artificiais e os naturais está presente na estratégia de aquisição de imagens. Em visão artificial, tradicionalmente, as imagens são captadas por câmeras de vídeo (estáticas), que registram e convertem toda a cena em matrizes lineares de duas dimensões. Deste modo, toda a cena capturada é armazenada e cada um dos pixels da imagens (ou elementos da matriz) são processados igualmente. Conforme comentamos na Seção 4.6.2.1, a distribuição dos fotorreceptores na retina não é linear, e a maior concentração na região central ou fóvea faz com que essa região tenha uma resolução muito maior do que as demais. A região foveal compreende uma pequena porção do campo visual e a maioria do maquinário neural está envolvida especificamente com o seu processamento.

Para a compreensão total de uma cena, o sistema visual utiliza a movimentação dos olhos, e consequentemente da fóvea, por toda a cena, processando-a região por região. A figura 5.2 ilustra essa situação, onde foi registrada o percurso da região foveal humana em uma cena durante sua percepção.

(a)

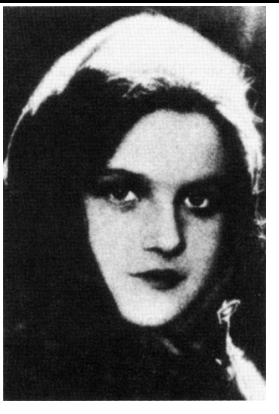

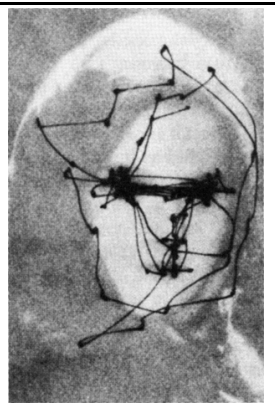

(b)

Fig. - 5.2 - Movimento dos olhos durante a percepção de uma face. Os traços da figura (b) apresentam a posição da região central dos olhos durante o rastreamento para a percepção da imagem [Dowling, 1992] [Hubel, 1995].

Embora a uma primeira instância possa parecer mais objetiva a estratégia de captar toda a cena de uma só vez, com alta resolução em matrizes lineares, esse tipo de abordagem apresenta diversas desvantagens em relação ao sistema 
foveal, entre as quais podemos citar:

Alto custo com hardware e pouca compactação: Se o sistema de visão humano não fosse foveal, certamente o complexo de células do sistema neural não caberia na caixa craniana.

Alto custo computacional: Preferindo uma pequena parte, ao invés de todo o campo visual, o poder computacional é economizado, considerando-se custosos algoritmos de processamento de sinais.

Tempo de processamento: $\mathrm{O}$ elevado custo computacional acarreta num tempo maior de processamento.

Menor interação com a imagem: Uma vez que o tempo de processamento é maior, o sistema tem um tempo de resposta igualmente maior e, deste modo, possui interação menor, necessária especialmente quando se trata de operações que envolvem movimentos.

\subsubsection{0 - ATENÇÃO SELETIVA}

O paralelismo, nos sistemas visuais naturais, possui uma estrutura piramidal, de forma que a base da pirâmide, formada pelos estágios de baixo nível, são massivamente paralelos, e à medida que a escalamos, encontramos estágios de processamento de níveis cada vez mais altos e com menor paralelismo, de modo que no topo da pirâmide os processos são quase seqüenciais.

A atenção seletiva é um mecanismo através do qual os sistemas de alto nível concentram temporariamente a atenção em regiões ou objetos localizados na fóvea, obtendo uma análise detalhada dos elementos da imagem um por um. Assim como na visão foveal, onde a cena é rastreada pela região central da retina através dos movimentos dos olhos e depois integrada como um todo pelo córtex, na atenção seletiva, cada detalhe, região ou objeto localizado na fóvea, é rastreado através de atenção dedicada, um a um, e são integrados pelo córtex formando um conjunto detalhado.

\subsubsection{1 - INTEGRAÇÃO COM NÍVEIS DE CONHECIMENTO MAIORES}

Esse princípio está diretamente relacionado com o alto nível de aprendizado que os sistemas naturais utilizam. Assim, o processo visual através de consultas à 
memória, realiza uma análise de contexto, ambiente, localização e história, comparando a cena com observações anteriores reconhecidas e registradas, o sistema pode receber informações adicionais e deste modo proceder 0 reconhecimento. A figura 5.3 apresenta um exemplo de como nossa percepção é fortemente influenciada pela análise de contexto. A análise das retas do corredor, dão uma informação contextual de distância, de modo que na imagem (a) temos a impressão que uma pessoa está distante da outra, e na (b) ocorre uma situação diferente da percepção normal a que fomos treinados ao longo de nossas vidas, e portanto temos a idéia de que é uma miniatura. Observem também que as duas mulheres têm o mesmo tamanho na imagem, entretanto percebemos que a da imagem (a) é maior.

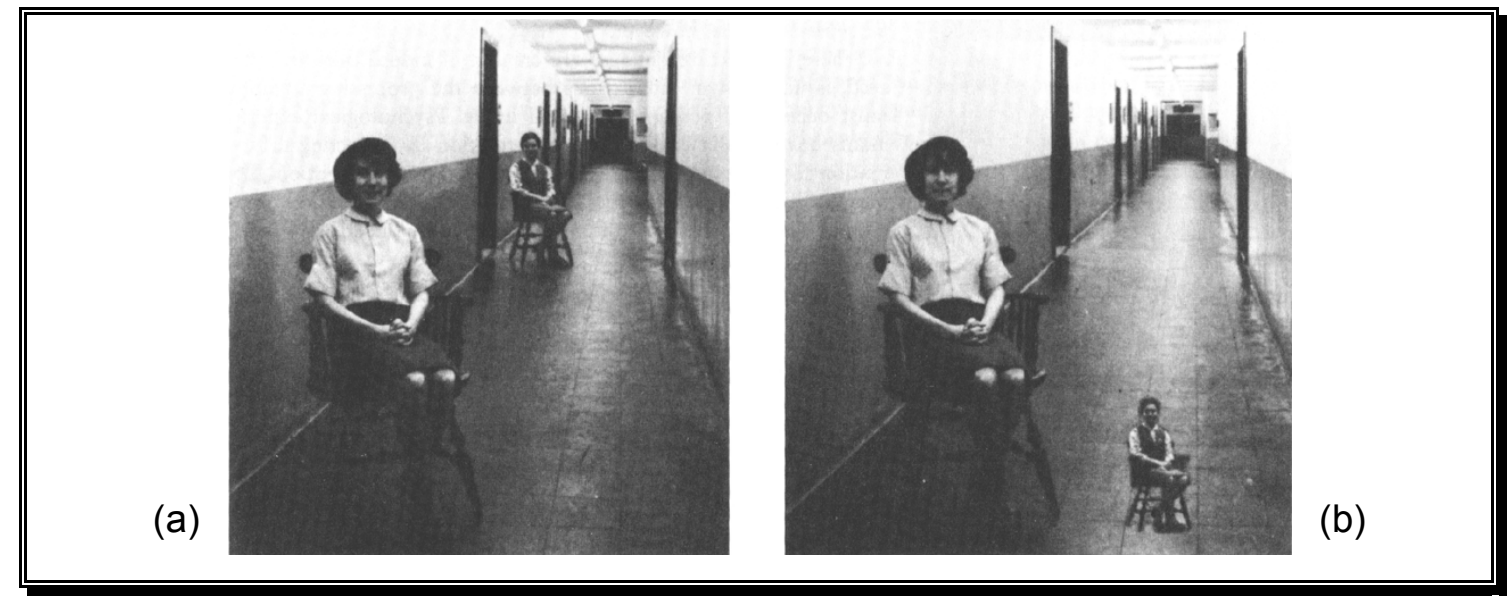

Fig. - 5.3 - Importância do contexto na percepção visual humana. Embora sejam do mesmo tamanho, na imagem (b) a figura da mulher à direita parece menor do que a da imagem (a) [Dowling, 1992].

\subsection{2 - O SISTEMA DE VISÃO CIBERNÉTICA - CYVIS-1}

Com o intuito de prover a visão versátil nasceu um dos mais audaciosos projetos do Grupo de Visão Cibernética, o Cyvis-1, que foi introduzido em 1994 por Costa e colaboradores [Costa et al., 1994]. Com base em modelos de visão biológica, especialmente no modelo de integração de estágios múltiplos do processamento visual do cérebro dos primatas, proposto por Zeki e Shipp [Zeki \& Shipp, 1988], o sistema de visão cibernética Cyvis-1 é um modelo conceitual para a visão versátil em tempo real.

Devido a grande dificuldade proporcionada e ao seu caracter de vanguarda 
e pioneirismo, o projeto foi idealizado num plano de pesquisa de longa duração, do qual participarão diversos pesquisadores. Atualmente, o projeto encontra-se na fase inicial, que consiste na implementação de protótipos, visando o estudo do comportamento de sistemas de visão sob o aspecto de distribuição e integração de tarefas, assim como no desenvolvimento de algoritmos mais eficientes para cada uma das etapas dos módulos de processamento específico. Nesta seção iremos descrever o projeto, assim como alguns itens da sua implementação.

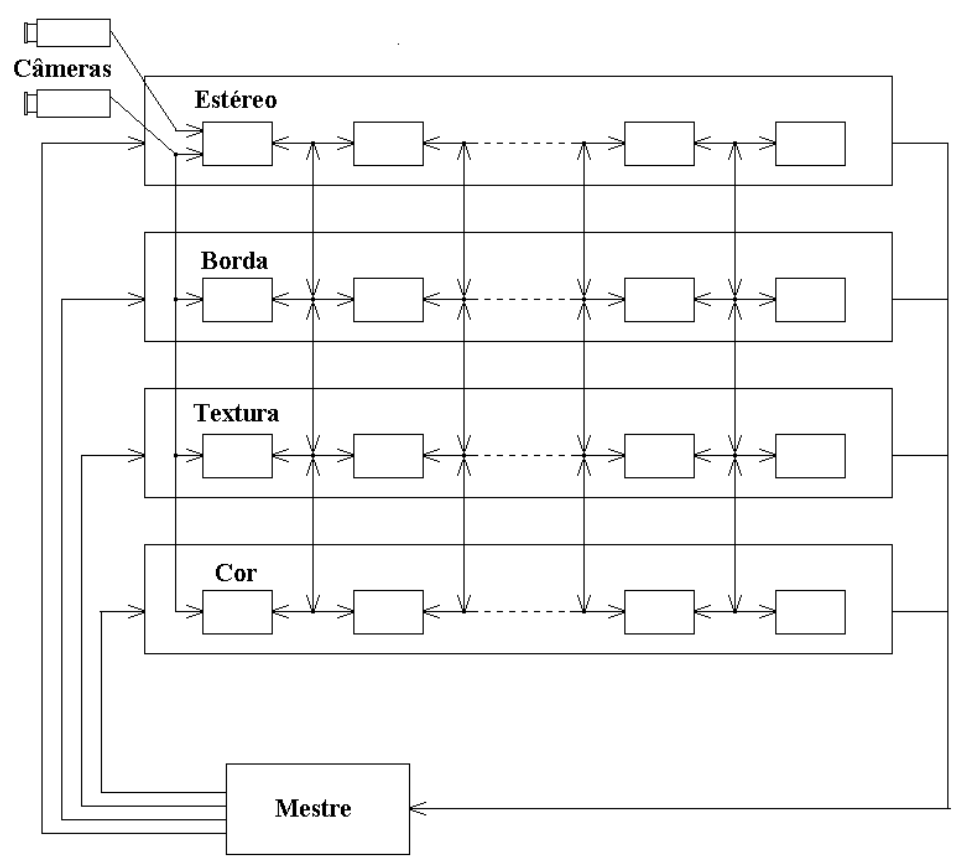

Fig. - 5.4 - Diagrama de blocos do modelo estrutural do sistema Cyvis-1, apresentando sua organização geral. Adaptado de [Bruno \& Costa, 1997] [Costa et al., 1994].

A figura 5.4 apresenta um diagrama de blocos do modelo estrutural do sistema de visão cibernética. A organização geral do Cyvis-1 consiste em um conjunto de sistemas dedicados, responsáveis pelo processamento e análise independente de atributos visuais (cor, bordas, formas, textura, estéreo e etc.), representados pelas barras horizontais, um par de câmeras, responsável pela captura das imagens e o módulo de controle.

Os sistemas dedicados são responsáveis pelo processamento dos atributos visuais específicos. O processamento é dividido em diferentes estágios, que 


\section{CAPÍTULO 5}

obedecem a uma escala hierárquica correspondente ao seu nível de processamento visual. A escala hierárquica de processamento visual possui natureza similar ao caminho visual do sistema de visão biológico, que, como vimos no Capítulo 4, inicia-se com o processamento de baixo nível na retina, onde são extraídas características fundamentais da imagem (ex: bordas) e prossegue pelo processamento no LGN, córtex visual primário, secundário e demais áreas corticais, onde em cada etapa do caminho visual as informações vão se tornando mais complexas, mais abstratas e representativas (exemplo: bordas -> retas -> formas -> objetos). Deste modo, o sistema dedicado é dividido em diversos módulos, sendo que cada um é responsável pelo processamento individual dos níveis do caminho visual do atributo.

Os módulos são representados na figura 5.4 por pequenas caixas no interior das barras horizontais, onde os responsáveis pelos processamento de baixo nível estão à esquerda e os de alto nível à direita. Assim, a imagem capturada pela câmera é transmitida para o módulo de mais baixo nível, e após ser processada, gera um mapa, que é enviado para o próximo módulo da hierarquia e assim sucessivamente até o nível mais elevado. Como nos sistemas biológicos, ocorre também o sentido inverso do fluxo de informação, indicado pelo duplo sentido das conexões entre os módulos. Em algumas ocasiões, o alto nível realimenta os módulos de baixo nível com informações de imagens processadas anteriormente, contribuindo no processamento e reconhecimento da cena.

Assim como nos sistemas biológicos, cada módulo dos sistemas dedicados possui um método de representação de dados particular e estratégia de processamento própria. Deste modo, os módulos de baixo nível possuem representações mais generalizadas, menos abstratas e que necessitam de maior espaço de armazenamento. À medida que subimos nas etapas hierárquicas de processamento, as informações vão ficando mais concisas, específicas e abstratas e consequentemente necessitam de um espaço menor para o armazenamento.

Assim como ocorre uma alteração evolutiva na forma de representação dos dados, o mesmo acontece com a estratégia de processamento. Nos módulos de baixo nível, o processamento é mais localizado, independente e em geral requer um número maior de operações aritméticas, bem como maiores recursos computacionais. Entretanto, devido a sua natureza de processamento disperso e independente, os níveis mais baixos possibilitam estratégias de paralelismo mais eficientes. Por outro lado, os níveis mais altos, envolvem processamentos com 
maior dependência de dados e mais globalizados, tornando-se cada vez menos viável a implementação paralela de seus algoritmos, chegando a níveis predominantemente seqüenciais, como por exemplo, os algoritmos de classificação.

Além das conexões horizontais, que como vimos integram os diferentes módulos de processamento de um atributo específico, o Cyvis-1 possui também conexões verticais, que ligam os sistemas dedicados permitindo a troca de informações entre atributos. É através destas conexões verticais que ocorre a colaboração entre os sistemas dedicados. Como exemplo, vamos explicar a colaboração entre os sistemas dedicados a bordas e cor: suponhamos que o sistema dedicado ao processamento de bordas não consiga definir as bordas de uma determinada região da imagem. Então, o sistema dedicado ao atributo borda, requer ao sistema dedicado ao atributo cor informações adicionais sobre essa região, e, de posse das informações recebidas, as bordas da região, podem ser agora reconhecidas.

Todos os sistemas dedicados são controlados pelo módulo mestre, que além de manipular o fluxo das informações em cada atributo, pode também concentrar temporariamente todo o processamento dos sistemas em uma determinada região da imagem, ou em um atributo específico, assim como a atenção seletiva dos sistemas biológicos. O mestre é também responsável pelo gerenciamento da base de conhecimento global do sistema e pela classificação e reconhecimento final. Para isso, recebe as informações resultantes dos processamentos de cada atributo. Cada sistema dedicado é também provido de uma base de conhecimento local, utilizada para decisões independentes da supervisão do mestre. O fluxo de execução é em parte determinado pelos próprios sistemas dedicados, tomando decisões a partir de sua base de conhecimento local, e em parte pelo mestre, que é responsável pelo processamento total e pelas decisões sobre o foco de atenção.

\subsection{3 - IMPLEMENTAÇÃO, REQUISITOS E}

\section{NECESSIDADES}

Nesta seção iremos abordar os principais requisitos, necessidades e dificuldades de implementação do projeto Cyvis-1, além dos diversos desafios 


\section{CAPÍTULO 5}

científicos e tecnológicos encontrados em: visão computacional, processamento de imagens, computação paralela, sistemas distribuídos, integração de atributos visuais, controle e escalonamento de tarefas, e outros mais. O projeto também se confronta com a difícil tarefa de integrar os recursos humanos envolvidos. Conforme já comentamos, trata-se de um projeto ambicioso de longa duração, que utiliza o trabalho cooperativo de diversos pesquisadores.

O primeiro passo a ser dado para se iniciar a implementação é a definição da plataforma de desenvolvimento. Essa definição engloba a escolha da plataforma de hardware, do sistema operacional e das ferramentas e linguagens de programação. A decisão desses requisitos foi baseada primordialmente nas ferramentas de desenvolvimento. O grupo de Visão Cibernética possui hoje como plataformas de desenvolvimento o MATLAB [Etter, 1995] e o Scilab [Gomes et al., 1999] para o modelagem matemática dos algoritmos, e o Delphi [Cantù,1995] [Calvert, 1999] e o C++ Builder [Calvert, 1997] para a implementação efetiva. Estando todos os membros do grupo familiarizados com estas ferramentas, a escolha óbvia para a plataforma de desenvolvimento do projeto fixou-se nestas alternativas.

As linguagens de cálculo matricial são excelentes ambientes de desenvolvimento, mas podem não atender os requisitos necessários para a implementação do sistema, uma vez que além de lentas (em geral são interpretadas), não possuem toda a versatilidade das linguagens de uso geral. Normalmente, em nosso grupo, os algoritmos desenvolvidos nesses ambientes são convertidos em $\mathrm{C}++$ ou Pascal para sua utilização e consequentemente sua compilação nos ambientes Delphi e C++ Builder. Existem também ferramentas que possibilitam a utilização direta dos algoritmos nestes ambientes, tal como o Matcom, também utilizado pelo grupo [Consularo \& Costa, 1998].

Deste modo, o par Delphi e C++ Builder foi adotado como plataforma de desenvolvimento do projeto, uma vez que essa escolha reduz drasticamente a curva de aprendizado, pois além de serem bastante populares e de fácil aprendizado para novos membros, os pesquisadores atuais do grupo já estão familiarizados com essas ferramentas. E também atendem aos requisitos de performance, versatilidade de manipulação de baixo nível (hardware/sistema operacional), programação orientada a objetos OOP e programação visual efetiva baseada em integração de ferramenta CASE [Bruno \& Costa, 1996] [Bruno \& Costa 1997] [Bruno \& Costa, 2000]. 
Tendo definido a plataforma de desenvolvimento, temos que fazer a escolha dos hardwares e sistemas operacionais. Como escolha de hardware foram adotadas máquinas baseadas no padrão IBM-PC, que possuem baixo custo, são populares, e sua performance atingiu o nível das estações de trabalho (já existem hoje máquinas neste padrão, com múltiplos processadores, cuja freqüência de operação aumenta a cada dia). Quanto ao sistema operacional, tivemos que fazer nossa escolha com base nas plataformas de desenvolvimento. Embora os sistemas operacionais baseados em UNIX para IBM-PC possuam mais vantagens quanto ao desenvolvimento em sistemas de redes e computação científica, atualmente eles possuem um déficit de ambientes de desenvolvimento integrados (como o Delphi e o C++ Builder - programação visual, OOP, Base de dados, etc.). Devido a tais fatores optamos pela utilização do Windows 95/98/NT, escolha esta que num futuro próximo deverá ser estendida, uma vez que o fabricante das ferramentas de desenvolvimento escolhidas está portando-as para UNIX [Kylix].

Como vimos nas seções anteriores, devido a sua inspiração biológica, uma das bases de desenvolvimento do projeto Cyvis-1 é o paralelismo. Defrontamos assim com um grande desafio para a implementação do sistema. Já discutimos a importância do paralelismo na computação e nos sistemas biológicos, e como embora sendo vitais, acarretam uma série de problemas. O desenvolvimento de programas paralelos envolve o aprendizado de linguagens de computação com extensões paralelas assim como de ferramentas de implementação paralela. Um dos grandes problemas nesses casos é que os algoritmos já desenvolvidos deverão ser portados para a nova plataforma de desenvolvimento, e na grande maioria dos casos, adaptados e reescritos. Além das dificuldades encontradas para portar os códigos, encontramos mais um senão. A computação paralela tem sido voltada, no decorrer da história, ao âmbito científico apenas. Com isso sua utilização se limita, na maioria dos casos, a especialistas da área, de modo que pouco se tem pensado para minimizar a curva de aprendizado das linguagens e ferramentas para a computação paralela.

Como já comentamos, uma das principais linhas de desenvolvimento do Cyvis-1 é o trabalho cooperativo realizado por pesquisadores de visão e processamento de imagens. Sendo assim, o objetivo principal é que esses profissionais possam se integrar facilmente no desenvolvimento de um sistema paralelo, aproveitando seus trabalhos já realizados, sem desperdício de tempo com o longo aprendizado exigido para o domínio das ferramentas tradicionais de 


\section{CAPÍTULO 5}

computação paralela. Com a deficiência de ferramentas de desenvolvimento paralelo intuitivas que sejam fáceis de usar, assim como pela insipiência desse aspecto nos ambientes de desenvolvimento utilizados pelo nosso grupo, fomos motivados a desenvolver uma série de ferramentas para prover paralelismo nos ambientes de desenvolvimento Delphi / C++ Builder e no sistema operacional Windows 95/98/NT, a fim de possibilitar o desenvolvimento rápido e efetivo de algoritmos de visão e processamento de imagens paralelos, possibilitando deste modo a integração e cooperação de diferentes pesquisadores para o desenvolvimento do sistema. No Capítulo 6 descreveremos esse conjunto de ferramentas intitulado de CVMP do inglês "Cybernetic Vision Message Passage".

\subsection{4 - MODELO COMPUTACIONAL}

Tendo discutido as principais características conceituais e de implementação, vamos agora apresentar o modelo formal computacional escolhido como base para o desenvolvimento inicial do projeto. A figura 5.5 apresenta um exemplo de um modelo de implementação, nele temos 5 computadores IBM-PC conectados via rede, representados por blocos horizontais. Neste exemplo, cada atributo visual (estéreo, cor textura e borda) é processado por uma máquina específica, que é supervisionada pelo sistema mestre, processado também em uma única máquina distinta. Além dessa função, a máquina mestre possui também uma base de conhecimento e um classificador estatístico. A base de conhecimento é alimentada a cada processamento pelos resultados dos atributos, através dela e das bases locais de cada atributo, o sistema realiza o processamento em sentido inverso, ou seja a partir do nível maior para o menor.

A classificação da imagem também é de responsabilidade do mestre. À medida que é realizado o processamento nos sistemas dedicados de atributos, as características vão sendo extraídas e enviadas para a unidade mestre. De posse das características, o mestre consulta o classificador estatístico, e caso a resposta da consulta seja satisfatória para a classificação, então o sistema finaliza o processamento. Caso contrário, são aguardadas novas características para alimentar o classificador, até que o resultado seja representativo, ou tenham já sido extraídas todas as características. Essa estratégia de classificação por demanda, ou seja, a tentativa de classificação para cada característica extraída, possibilita um aumento de desempenho do sistema, uma vez que alguns objetos são 
reconhecidos com poucas características, e deste modo o sistema não precisa executar todos os seu processos, poupando tempo de execução. Além do desempenho, esta estratégia possibilita também um melhor controle de supervisão para o mestre. Com os resultados obtidos pela classificação, o mestre obtém uma lista das características mais promissoras para uma classificação ágil, e com essa informação, através de supervisão, concentra os recursos para priorizar a extração delas.

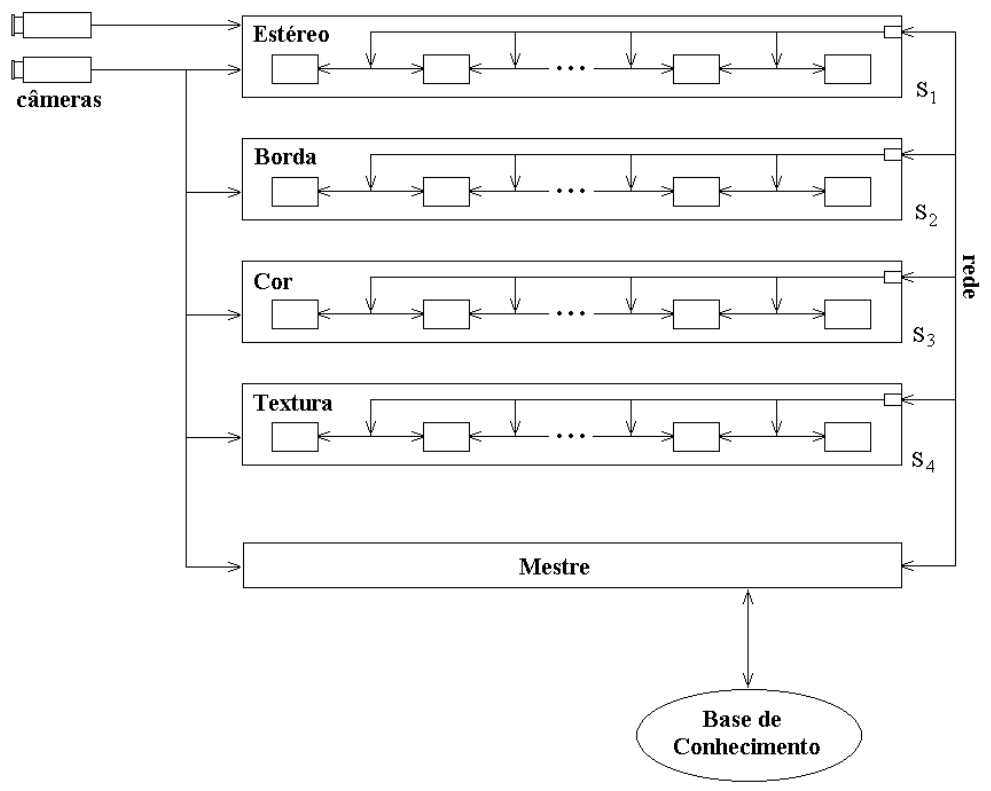

Fig. - 5.5 - Diagrama de blocos apresentando a organização de hardware do Cyvis -1. Neste exemplo, cada atributo de imagem está sendo processado em uma diferente máquina. Os computadores estão conectados por rede. Adaptado de [Bruno \& Costa, 1997] [Costa et al., 1994].

As imagens são capturadas através do par de câmeras que se encontra conectado ao sistema. Apenas o atributo estéreo necessita de visão binocular, sendo que os demais atributos recebem informações provenientes de uma câmera. Poderiam ser utilizadas duas câmeras, trazendo benefícios de informação, porém com maior custo computacional. As câmeras são conectadas diretamente nas máquinas de cada um dos atributos. Embora essa medida exija investimento de hardware, uma vez que as placas de aquisição de imagens deverão ser replicadas para cada uma das máquina, ela reduz drasticamente o gargalo da distribuição de imagens. Nos primeiros experimentos, ao invés da arquitetura apresentada na 


\section{CAPÍTULO 5}

figura 5.5, conectamos as câmeras no mestre, que também ficava responsável pela aquisição e distribuição das imagens [Bruno \& Costa, 1996]. Observamos no entanto que o gargalo gerado pelo processo de distribuição era demasiado, o que comprometia o desempenho do sistema. Através de nossas observações e do trabalho de Cantoni e Lombardi [Cantoni \& Lombardi, 1999] chegamos à configuração atual.

Tendo definido a arquitetura do sistema em termos de hardware e de sua funcionalidade vamos agora apresentar o modelo computacional utilizado para a implementação paralela. Dentre os modelos formais para a abordagem paralela, optamos pelo paradigma da fazenda de processadores (processor farm) [Bruno \& Costa, 1997] [[Inmos, 1989] [Atkin, 1987], que freqüentemente possui uma utilização de processador próxima do ideal. O paradigma da fazenda tradicionalmente envolve um processador mestre, que é conectado, na maioria dos casos através de canais, a um número de processadores escravos. As tarefas, por exemplo subproblemas que podem ser executados independentemente, são distribuídas pelo mestre de acordo com a disponibilidade dos processadores escravos, garantindo assim um bom balanceamento total de carga. Esse paradigma é particularmente apropriado quando a comunicação pode ser realizada em concorrência com o processamento, como ocorre com os Transputers [Inmos, 1988] [Inmos, 1988b] [Inmos, 1989].

No caso específico do Cyvis-1, após algumas análises, optamos por uma abordagem de paralelização baseada em uma versão modificada do paradigma da fazenda (processor farm). Assim como no paradigma da fazenda de processos tradicional, o Cyvis-1 é composto como podemos observar na figura 5.6, de um conjunto de escravos supervisionados por um mestre. Estamos nos referindo aos módulos retangulares, onde temos 4 sistemas dedicados referentes aos atributos cor, borda, textura e estéreo, supervisionados pelo mestre. A primeira diferença entre o modelo adotado e o tradicional é que cada um dos módulos responsáveis pelos atributos, assim como o próprio mestre, são sistemas independentes que também obedecem ao paradigma da fazenda. Assim, cada módulo possui um processo mestre, que controla diversos outros processos escravos. Na figura 5.6 os processos locais mestre e escravos estão representados pelas letras M e $S$ respectivamente. 


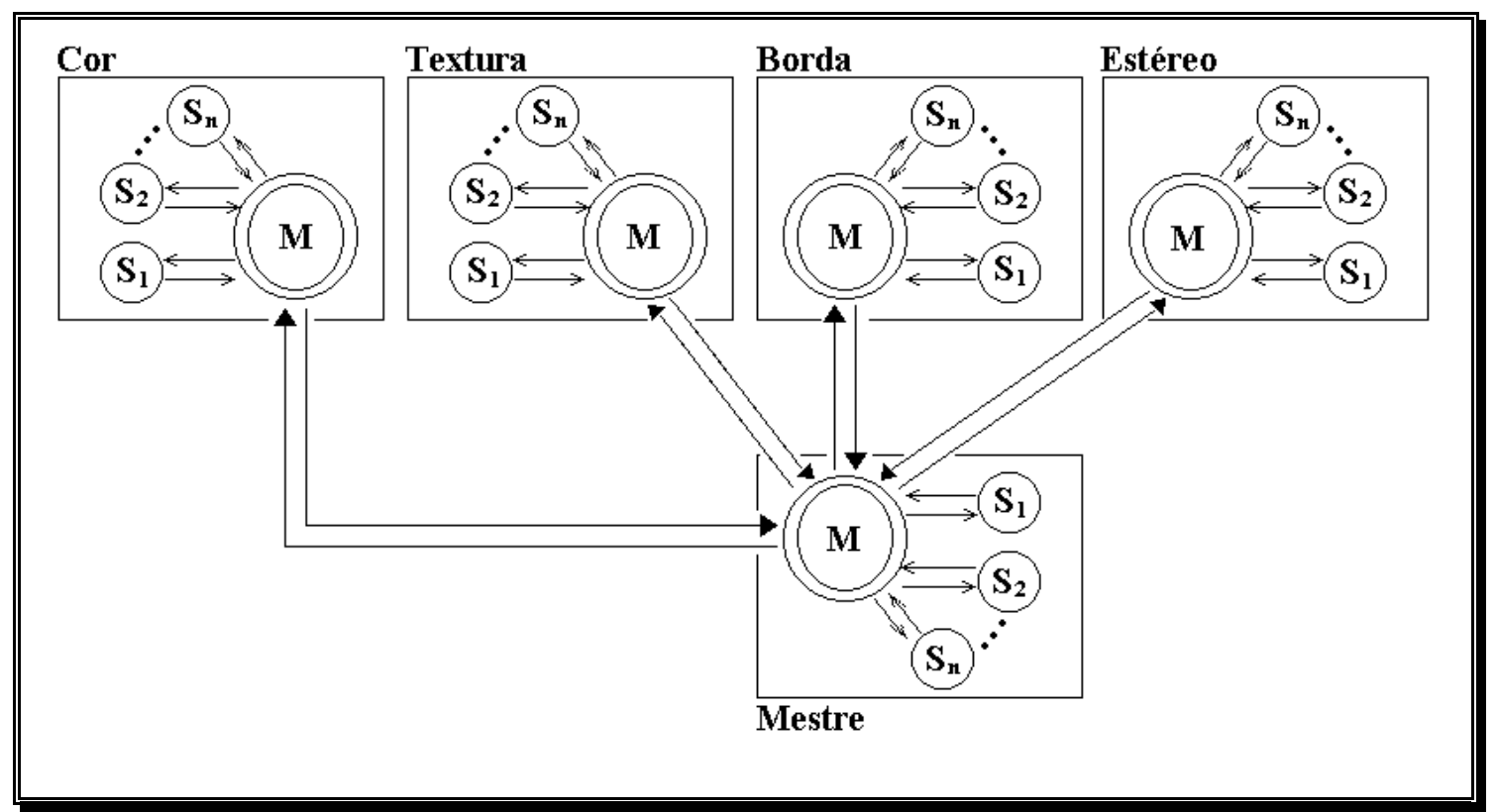

Fig. - 5.6 - Modelo de paralelismo adotado.

Quanto às tarefas, estas são inicialmente divididas de acordo com os atributos, pelo mestre do sistema, e distribuídas para os módulos de atributos. Cada uma dessas tarefas são novamente divididas pelo processo mestre de cada módulo e repassada para os escravos. Assim como nos sistemas biológicos, o Cyvis-1 também possui mecanismo para atenção seletiva [Cantoni \& Lombardi, 1999] [Gonçalves, 1999], que está relacionado com a supervisão e a distribuição de tarefas realizadas pelo mestre do sistema. Deste modo, em determinadas situações, o mestre pode concentrar o processamento do sistema em uma determinada região ou atributo, alojando um número maior de escravos para o mestre do respectivo módulo.

Dentro do sistema estão previstos ainda diferentes tipos de recursos, que se classificam segundo a natureza de execução, entre o seguinte:

Paralelismo de Máquina: são processos que são executados em um único computador conectado pela rede (sistema distribuído).

Paralelismo de Processador: processos que são executados em diferentes processadores de máquinas com múltiplos processadores.

Multitarefa: são processos que são executados concorrentemente, utilizando o mesmo recurso de hardware, através do mecanismo de multitarefa do sistema operacional da máquina.

Específicos: são processos que somente podem ser alojados em máquinas que contém hardware específico. São exemplos desta modalidade máquinas com 


\section{CAPÍTULO 5}

placa de aquisição de imagem ou ainda com dispositivos de processamento de sinais específicos.

Quanto ao alojamento e a distribuição, os recursos computacionais do sistema se dividem em dois grupos:

fixos: recursos que pertencem a um determinado módulo (atributo ou unidade de controle) e executam apenas processos associados a seu módulo, não podendo ser redirecionados para outros fins.

móveis: recursos computacionais que podem ser utilizados por qualquer um dos módulos do sistema, desde que sejam redirecionados.

Os processos mestres de cada um dos módulos são caracterizados por utilizar sempre recursos fixos. O escravos podem ser dos dois tipos, um grupo pequeno de escravos são fixos, e somente podem servir a um determinado módulo. Desse grupo fazem parte os escravos que necessitem de recursos computacionais extra (ex: hardware específico, placa de aquisição de imagem e etc.), aqueles envolvidos com a base de conhecimento local de cada módulo e ainda os escravos fixos por motivos estratégicos, exemplo, encontram-se em condições de se comunicar mais eficientemente com os recursos computacionais de determinado mestre (ex: máquina com processadores múltiplos).

Temos alguns motivos para a mista distribuição de recursos (parte específicos e parte homogêneos), ao invés do clássico conjunto homogêneo de recursos (pool of slaves):

Maior similaridade com o sistema biológico, que não prima pela homogeneidade, arquitetura e processamento diferente para módulos distintos.

Possibilidade de incorporação de hardware dedicado para o processamento específico de determinado atributo visual.

Os módulos podem manter dados localmente armazenados assim como bases de conhecimentos locais.

Sendo o sistema misto, entre um conjunto homogêneo e outro específico, podemos tirar proveito das vantagens dos sistemas com recursos específicos descritos acima e também das vantagens de distribuição, concentração dinâmica de recursos e melhor balanceamento de carga dos sistemas homogêneos.

\section{3 - Sistemas e modelos de VISÃo e suAS}




\section{COMPARAÇÕES COM O CYVIS-1}

Nesta seção vamos apresentar sucintamente alguns sistemas e modelos de visão encontrados na literatura, que possuam características similares ao do Cyvis-1, especialmente a integração de atributos, representação e composição de características da imagem, versatilidade de visão e processamento paralelo. Além da breve descrição de cada sistema, vamos discutir suas similaridades e diferenças relativas ao Cyvis-1.

\subsection{1 - SISTEMA INTELIGENTE PARA SEGMENTAÇÃO BAIXO NÍVEL DE IMAGENS}

O sistema inteligente para segmentação de imagens, ou LLIS (do inglês: Low Level Image Segmentation), proposto por Nazif e Levine [Nazif \& Levine, 1984], é um sistema para a segmentação primária ou segmentação de baixo nível de imagens, e consiste basicamente uma abordagem ao problema que engloba a integração de características para a representação das imagens, lógica e memória associativa.

O primeiro estágio na visão computacional para a compreensão de imagens é a segmentação de baixo nível. Nesta etapa, deve-se extrair algumas características básicas da imagem, que possuem informações a respeito de seu contexto assim como: bordas, linhas, regiões, etc. Em geral, os sistema tradicionais limitam-se a apenas uma abordagem, ou seja, são específicos à extração de uma única característica. O LLIS se preocupa com a integração e representação de diversas características, de modo a formular uma representação mais rica e complexa da informação visual.

Um dos problemas em visão computacional é a modelagem dos dados resultantes do processamento de segmentação de imagem. Como modelar uma estrutura de dados de tal forma que esta seja significante na representação da informação? A maioria dos modelos de segmentação não estruturam ou modelam os dados resultantes, de forma a apresentarem como resposta simplesmente imagens realçadas. Tais resultados, embora demonstram vasta aplicação, não são devidamente significativos quanto ao armazenamento, transporte e aproveitamento de informações (para níveis superiores de processamento), principalmente na 


\section{CAPÍTULO 5}

representação da informação.

O LLIS é um modelo para a segmentação de baixo nível de imagens que procura diferenciar-se dos modelos tradicionais de segmentação de baixo nível por apresentar algumas propostas de motivação biológica, tal como memória associativa e lógica, assim como apresentar uma estrutura de representação efetiva para combinar diferentes atributos visuais de baixo nível, analisar e traçar em tempo de execução estratégias de processamento mais apropriadas para diferentes situações, assim como a geração de uma base de dados, a partir do processamento que realimente o sistema com conhecimento.

O processamento da informação no LLIS é baseado em regras, onde as informações referentes ao processamento são todas analisadas com comparações lógicas: (e) e (não-e). Quando as operações lógicas são verdadeiras então os predicados, ou seja ações aliadas aos operadores, são executados.

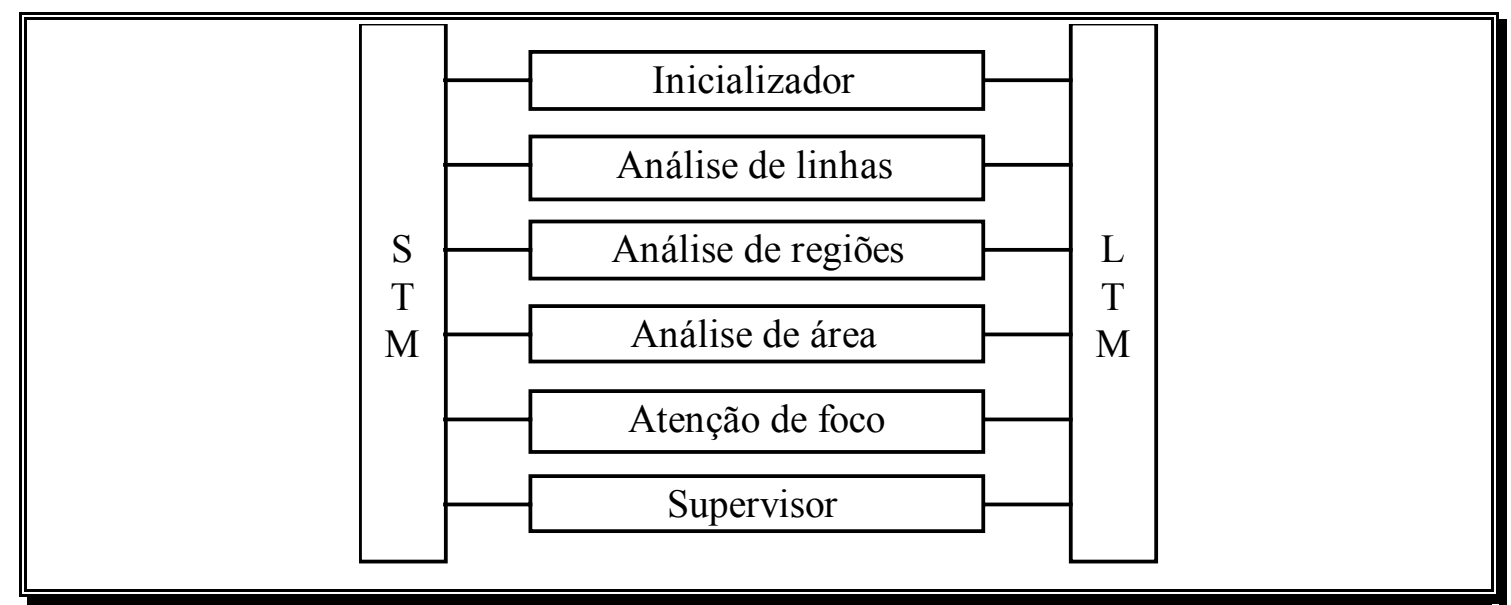

Fig. - 5.7 - Diagrama em blocos do sistema LLIS.

O LLIS é formado de módulos que compõem os processos de controle e segmentação, assim como duas memórias associativas, conforme apresentado na figura 5.7. Os dados referentes à imagem de entrada, segmentação e estrutura de saída são armazenados na memória STM (Memória de curta duração do inglês: Short Term Memory), ao passo que na memória LTM (Memória de longa duração do inglês: Long Term Memory) é armazenado o conhecimento do sistema a respeito do processamento de baixo nível (regras lógicas sobre o comportamento dos dados), assim como as regras referentes as estratégias de controle. Os dados contidos na STM podem ser alterados durante o processamento, apagados ou ainda pode-se inserir dados, ao passo que a memória LTM é fixa, podendo ser 
programada com as regras de comportamento antes do processamento.

Inicialmente a imagem situada na STM é processada e binarizada, resultando pontos que são agrupados em linhas e produzem o primeiro mapa da imagem. Estes resultados são armazenados também na STM. Uma área inicial do mapa é então selecionada, e é realizado o processamento de mais alto nível que determinará características da região, tais como: saturação, cor, posicionamento e relacionamento entre os objetos (linhas e regiões). Este processamento irá resultar em características de análise e comparação tais como: adjacência entre as regiões, relacionamentos como em frente de, atrás, em paralelo, a esquerda, a direita e etc., para as linhas e relacionamento entre linhas e regiões tais como: a região está a esquerda ou a direita da linha, a linha toca ou interseciona a região e etc. E ainda em relação ao comportamento de áreas: com textura, nebulosa e a sua proximidade com linhas, etc.

Após determinadas estas dependências lógicas, que podemos denominar de processamento de baixo nível, é realizado o processamento de alto nível (ao qual é dedicado de fato o LLIS), que é realizado pelo modelo baseado em regras. As regras são divididas em três classes: regras de estratégia, regras de controle e meta regras e regras de conhecimento (região, linha e análise de área), que ficam alojadas na memória LTM. As regras de estratégia, e as regras de controle e meta regras não executam nenhuma alteração na memória STM, elas são destinadas ao controle dos processos de ação, que operam as regras de conhecimento.

As regras de conhecimento são responsáveis pelo processamento da segmentação. Nelas são tomados pares ou conjuntos de informações de propriedades referentes a linhas, regiões e áreas, sendo então comparadas logicamente. Caso as situações lógicas satisfaçam à decisão lógica, então é executada a ação respectiva. O funcionamento das regras é bastante simples, conforme podemos observar na figura 5.8, onde temos o formato e um exemplo de uma regra. Por um lado nós temos um conjunto de combinações lógicas, e do outro, a ação executada caso a condição seja satisfeita. Conforme já comentamos, as regras ficam alojadas na memória LTM e executam ações sobre a memória STM, com dados também armazenados na STM. 


\section{IF: THERE IS A LOW DIFFERENCE IN REGION FEATURE 1 THERE IS A LOW DIFFERENCE IN REGION FEATURE 2 THERE IS A LOW DIFFERENCE IN REGION FEATURE 3 THEN: MERGE THE REGIONS}

Fig. - 5.8 - Exemplo de regras do modelo.

Tendo comentado o modelo baseado em regras, voltemos ao sistema. Após realizada a primeira segmentação (baixo nível) e definidos os mapas, o sistema fica sob controle do módulo supervisor (figura 5.7). O módulo de foco de atenção seleciona uma determinada área, e é realizado o processamento através das regras pelos módulos de análise de linha, região e área (figura 5.7), que irão alterando dados na memória STM que realimenta o sistema. Após finalizado o processamento em uma área de atenção, é iniciado o processamento em uma nova área de atenção, e assim sucessivamente. Após ter visitado todas as áreas de atenção da imagem, o sistema determina então se existe a necessidade de processar novas áreas, e caso afirmativo, repete a visita a essas áreas. Caso o sistema já tenha visitado todos os focos (áreas) de atenção, o sistema processa o mapa da imagem como um todo, e é finalizada a segmentação da imagem.

\subsubsection{1 - PONTOS POSITIVOS DO LLIS}

A primeira característica interessante do sistema é a elaboração de uma estrutura de dados, na qual é armazenado um sistema de conhecimento, que pode ser compartilhado entre diferentes heurísticas. No caso do LLIS informações sobre linhas e regiões compartilham a mesma estrutura de dados. Essa estrutura torna-se ainda mais interessante por apresentar a possibilidade de ser flexível a outras heurísticas. A combinação de heurísticas no processamento, no caso processamento de linha e região é um outro ponto forte da proposta.

Uma outra abordagem muito interessante adotada pelo sistema é a seleção de determinadas áreas da imagem, e a concentração da atenção, ou enfoque de processamento, nestas áreas. Esta abordagem, além de ter fortes bases biológicas [Kosslyn, 1996] [Goldstein, 1989] [Ballard \& Brown, 1982], também possui um interessante mecanismo de realimentação ou fluxo inverso de informações em 
tempo de execução. Como o resultado das regras alteraram a mesma memória em que os dados das características da imagem são armazenados, ocorre então uma realimentação natural do sistema, ocorrendo um somatório de processamento, que pode vir a enriquecer a qualidade de processamento.

\subsubsection{2 - PONTOS NEGATIVOS DO LLIS}

Um dos maiores desafios da visão computacional é a segmentação de baixo nível. Determinar a posição de uma linha, onde ela começa, onde termina, se faz laço, se é paralela a outra, se apresenta descontinuidade, e se uma área apresenta uma determinada textura, ou possui uma segmentação nebulosa, ou ainda obter as características de regiões, é uma tarefa extremamente difícil e que se encontra plenamente aberta para pesquisa. Na proposta do LLIS, é necessário uma présegmentação na imagem, de modo que devolva as propriedades e características de retas e regiões da imagem. Porém, a extração destas informações é algo longe de ser trivial, não existindo ainda algoritmo capaz de fazê-lo com a eficiência exigida pelo suposto modelo.

É nesse aspecto que encontramos as principais falhas no modelo do LLIS. O modelo baseado em regras, não segmenta de fato as imagens, apenas executa operações lógicas de alto nível em dados já extraídos desta. Os autores não comentam como um algoritmo consegue extrair informações da imagem original com performance suficiente, para operar a gramática de regras apresentada no artigo.

\subsubsection{3 - LLIS VERSUS CYVIS-1}

Uma das semelhanças que podemos observar entre a proposta do sistema Cyvis-1 e o LLIS é o uso do processamento modular. O LLIS apresenta módulos de processamento específicos para linhas, regiões e áreas, do mesmo modo como o Cyvis-1, que é dividido em módulos específicos a uma determinada característica (cor, estéreo, borda, textura). Ainda uma outra semelhança é a utilização de um módulo de controle, para supervisionar os módulos de processamento. Embora possuam estas semelhanças, a abordagem difere, uma vez que o Cyvis-1 busca o paralelismo, solução adotada pelo sistema de visão natural (Capítulo 4) para resolver diversas questões, entre elas a integração, sendo que o LLIS é essencialmente serial devido a sua modelagem, baseada em regras e predicados 


\section{CAPÍTULO 5}

de inteligência artificial convencional.

Além de possuírem módulos distintos para diferentes tipos de processamento, uma outra similaridade entre os sistemas é a tentativa de compartilhamento de informações entre os módulos a fim de melhorar a interpretação e processamento da imagem. Porém a maneira com que é realizada a abordagem é um pouco diferenciada. O LLIS tem uma memória global compartilhada (STM) onde os dados do processamento além de estarem compartilhados, ainda dividem a mesma estrutura de dados, ao passo que o Cyvis-1 possui além de uma base de conhecimento geral, uma memória distribuída para cada módulo, onde as informações são trocadas a partir de mensagens entre os módulos e o supervisor.

\subsection{2 - SISTEMA DE VISÃO DO MIT (MASSACHUSSETTS INSTITUTE OF TECHNOLOGY)}

O sistema de Visão do MIT, apresentado por Poggio e Weinshall [Poggio \& Weinshall, 1993], denominado MIT Vision Machine, possui inspiração parecida com o Cyvis-1, sendo também baseado em paralelismo e inspirado pela natureza. Os sistemas biológicos, ao realizarem o processamento visual (em seus primeiros estágios), integram diferentes atributos de processamento da cena para realizar a interpretação. Tal fato é constatado na literatura, e os autores acreditam ser esta a chave para as características de flexibilidade, reaproveitamento e robustez dos sistemas biológicos. Inspirado na integração de diferentes atributos visuais, realizado pelos sistemas biológicos, foi proposto este sistema, sendo sua proposta a integração e desenvolvimento de algoritmos paralelos para visão.

A organização geral do sistema pode ser observada na figura 5.9. Uma das intenções do sistema é explorar o desenvolvimento de algoritmos paralelos para visão. Desta forma, as imagens são processadas paralelamente por diferentes algoritmos e módulos, que correspondem a diferentes propriedades visuais. Além dos módulos responsáveis por diferentes atributos sendo executados em paralelo, ainda cada um dos algoritmos que compõe os módulo são igualmente executados simultaneamente, constituindo uma abordagem altamente paralela. O sistema possui como plataforma um computador massivamente paralelo do MIT, o Connection Machine [Almasi \& Gottlieb, 1994].

Os módulos são caracterizados pelos diferentes atributos de visão 
utilizados, que nesse sistema são: processamento de borda, estéreo, cor, textura e movimento. Os módulos são executados em concorrência e ao final do processamento é gerado um mapa de descontinuidade global ou mapa resultante, que é formado pela integração dos mapas de cada módulo, com as informações complementares de cada um.

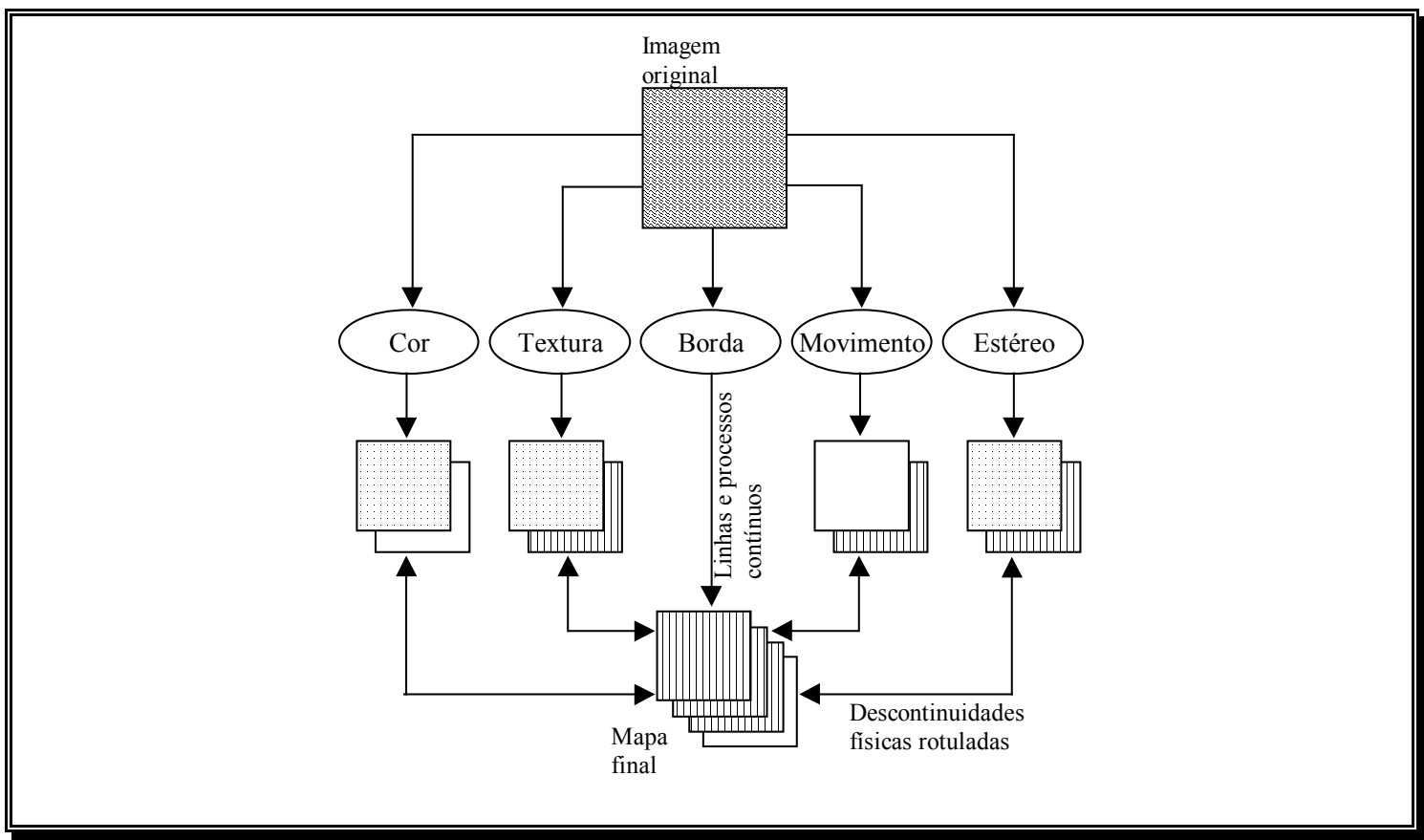

Fig. - 5.9 - Diagrama da organização da máquina de visão do MIT.

A seguir vamos descrever sucintamente cada um dos módulos de processamento do sistema:

Detecção de borda - O módulo de detecção de borda procura encontrar descontinuidades no brilho da imagem. Para realizar este processamento são utilizados dois algoritmos no sistema, o primeiro é o cruzamento por zero do Laplaciano da Gaussiana [Marr, 1982], e o segundo na convolução do template de Canny [Gonzalez \& Woods, 1993] [Parker, 1997]. O cruzamento por zero, pode ser usado pelo módulo de estéreo e movimento, ao passo que o Canny, é a entrada para a integração utilizando os campos markovianos.

Estéreo - Para a realização de processamento de visão Estéreo, o sistema requer dois dispositivos de aquisição de imagem diferentes. Estes deverão focalizar a mesma cena porém através de ângulos diferentes. Embora a cena seja a mesma, 


\section{CAPÍTULO 5}

devido a binocularidade, ocorrerá disparidades entre as imagens. O módulo de estéreo consiste em encontrar essas disparidades nas imagens, gerando deste modo um mapa das disparidades.

Movimento - O módulo de movimento objetiva o cálculo do campo de fluxo óptico. Este procedimento consiste em armazenar um vetor de imagens, e comparar suas disparidades resultantes do movimento. Por exemplo, considere que, temos uma imagem $E(x, y)$ e uma outra imagem, formada no instante seguinte, $E+\Delta t(x, y)$. Logo, quando é encontrada a disparidade entre $E(x, y)$ e $E+\Delta t(x, y)$ é obtido um mapa de descontinuidade contendo as bordas dos objetos em movimento.

Cor - O módulo de cor consiste em encontrar as fronteiras da superfície da função de reflectância espectral, ou seja descontinuidades cromáticas da imagem.

Textura - O módulo de textura dedica-se a encontrar as descontinuidades entre regiões preenchidas por padrões semelhantes. O resultado deste processo converge num mapa das fronteiras das regiões com textura. Nesse módulo, é utilizado uma versão simplificada do algoritmo paralelo de textura desenvolvido por Voorhees e Poggio [Voorhees \& Poggio, 1988].

Os módulos são processados paralelamente originando mapas de descontinuidade. Cada um dos mapas contém informações características (de baixo nível) de cada um dos atributos respectivos a cada módulo. O objetivo do sistema é integrar estes módulos a fim de obter um mapa de descontinuidade geral, enriquecido com cada uma das características específicas de cada um dos atributos (cor, borda, estéreo, movimento e textura). Como resultado desta integração temos um mapa de bordas da imagem original. Embora existam inúmeros algoritmos que obtenham mapas de bordas, a contribuição dada pelo sistema de Visão do MIT é um mapa enriquecido pela integração de inúmeros atributos, contendo deste modo concentrada e filtrada diversas informações. O resultado proveniente do processamento de cada um dos atributos é esparso e ruidoso. Com a adoção do modelo MRF é realizada a integração dos diferentes atributos e simultaneamente a filtragem do ruído, originando um mapa mais confiável. 


\subsubsection{1 - CYVIS-1 VERSUS MÁQUINA DE VISÃO}

Embora tanto o Cyvis-1 quanto o Vision Machine tenham o mesmo propósito, ou seja, incorporar diferentes atributos para realizar o processamento de imagem, a filosofia, estrutura e estratégia de cada um dos sistemas é bastante divergente. Discutiremos as diferenças entre os dois sistemas relativamente aos seguintes tópicos: Estrutura, Hierarquia, Organização de Dados e Aspectos Computacionais.

\subsubsection{1 - Estrutura}

A estrutura dos dois sistemas a grosso modo é bastante parecida: ambos são sistemas de visão computacional de baixo nível, tempo real e com plataforma computacional paralela. Os dois sistemas também processam diferentes atributos da mesma imagem, e tentam integrá-los na obtenção de um único resultado, e para cada um desses atributos, os sistemas adotam módulos e algoritmos independentes. O que realmente diverge, é a organização e transferência de dados, assim como a hierarquia dos sistemas.

No sistema MIT Vision Machine, os módulos não apresentam ordem hierárquica definida. Os módulos são processados paralelamente, sem dependência de dados, de maneira síncrona. Ao final do processamento de todos os módulos é então realizada a integração de seus resultados para obtenção de um mapa de resultados. Nessa abordagem não existe hierarquia de processos nem mesmo de dados. A única preocupação do sistema é a integração estatística dos resultados através do modelo de campos aleatórios de Markov (MRF).

O Cyvis-1 apresenta ordem hierárquica significativa. Os módulos possuem diferentes níveis hierárquicos e ocorre dependência de dados entre eles. Deste modo, por exemplo, um módulo de detecção de borda de nível hierárquico mais alto não poderá ser executado sem o resultado de um módulo de cor, com nível hierárquico inferior, já que num nível hierárquico mais alto, o módulo de detecção de borda necessita de informações cromáticas da imagem.

Deste modo, a estratégia de integração entre os sistemas também é bastante diferenciada. Se no Vision Machine a integração é resolvida num único processo matemático (MRF), no Cyvis-1 a integração é realizada ao longo do processamento de modo mais ameno. Os módulos de hierarquia superior tem como sua entrada de dados os resultados dos módulos de hierarquia inferior. Deste modo é realizada a integração dos diferentes módulos de um mesmo atributo. Além de necessitar dos resultados dos níveis hierárquicos mais baixos (de um mesmo 


\section{CAPÍTULO 5}

módulo), existem módulos que necessitam também de dados provenientes de módulos de atributos diferentes. Estes módulos são responsáveis pela integração de diferentes atributos, que ocorre em diferentes etapas.

Uma outra singularidade no Cyvis-1 é a característica de fornecer caminho inverso na hierarquia de processamento ("back propagation"). Esta propriedade faz com que seja possível a um módulo de alta hierarquia requerer que um módulo de baixa hierarquia seja executado novamente, e passar parâmetros complementares para este. Com isso, é possível obter informações que anteriormente não foram extraídas.

\subsubsection{2 - Organização e transferência de Dados}

Devido à diferença entre a estrutura e hierarquia, a organização e transferência dos dados apresenta também diferentes aspectos em cada sistema. No caso do Vision Machine, a estrutura dos dados é comum entre os módulos. O resultado de cada módulo é constituído de um mapa de descontinuidades, bastante semelhante entre cada um dos módulos. Como não há escala hierárquica, não ocorre dependência de dados. Os resultados de cada um dos módulos de atributo são semelhantes e serão integrados nos mesmos passos. Deste modo, além da transferência dos dados ser unidimensional, também não é estimulada a comunicação entre módulos de diferentes atributos.

A organização dos dados no Cyvis-1 não é uniforme, e sua estrutura varia entre diferentes módulos de atributos, assim como entre os diferentes níveis hierárquicos. A medida que subimos a escala hierárquica, os dados tornam-se mais compactos e as informações mais simbólicas. Nesse modelo, ocorre a dependência de dados entre processos, ou seja, um processo não pode ser executado enquanto não tiver o resultado de um processo e nível hierárquico inferior. Diferente da estratégia utilizada no Vision Machine, em que a integração ocorre num estágio de integração matemática (MRF), no Cyvis-1, a integração na transferência e organização de dados ocorre a cada módulo.

Do mesmo modo que a organização de dados, o fluxo de transferência também se altera no decorrer do sistema. Nos níveis hierárquicos mais baixos, a transferência entre os módulos envolve grande quantidade de dados com uma freqüência baixa. A medida que vamos subindo a escala hierárquica, os pacotes de dados vão diminuindo e o fluxo de transferência aumentando.

\subsubsection{3 - Aspectos Computacionais}


Os dois sistemas utilizam estratégias de paralelização, do ponto de vista computacional. O Cyvis-1 adota uma arquitetura MIMD. Deste modo, foi adotado a utilização de microcomputadores padrão PC, interconectados por rede e multiprocessados. Nesta abordagem, os algoritmos dos sistemas são distribuídos entre as máquinas e então processados de modo síncrono. Esta abordagem, além do desempenho, visa a padronização e baixo custo.

Por outro lado, o MIT Vision Machine adota como plataforma de computação paralela um sistema desenvolvido pelo próprio MIT denominado Connection Machine, um super computador massivamente paralelo [Almasi \& Gottlieb, 1994].

Assim, temos duas abordagens diferentes, por um lado o MIT Vision Machine, utilizando uma plataforma exclusiva que deixa o sistema isolado (sem portabilidade), porém essa plataforma é poderosa e possui características singulares em computação paralela, possibilitando uma pesquisa mais abrangente e, consequentemente, um melhor desempenho.

Em oposição à essa estratégia temos o Cyvis-1, cuja preocupação, além de desempenho, é portabilidade de baixo custo. Deste modo, utiliza uma plataforma bastante popular (PCs) e barata, trazendo assim o benefício da padronização e portabilidade ao seu favor.

\subsection{3 - MODELO DO SISTEMA DE VISÃO DE KOSSLYN}

O modelo de Kosslyn é apresentado no livro Image and Brain [Kosslyn, 1996]. Diferentemente dos modelos convencionais de visão que tratam do assunto sob o ponto de vista da percepção visual, o modelo de Kosslyn refere-se às imagens mentais, que são formadas em nosso cérebro quando mentalizamos simples objetos ou ambientes inteiros.

Quando desejamos consultar a nossa base de dados, a fim de relembrarmos um objeto ou ambiente, precisamos extrair as informações contidas em nossa memória. Essas informações no entanto, são compiladas pelo processamento cerebral, e armazenadas de forma otimizada. Para lembrarmos, por exemplo, as cores da faixa dorsal do famoso fusca de Hollywood, (Herby - Se meu fusca falasse - Walt Disney), temos que encontrar a informação em nossa memória associativa referente a imagem do carro. A fim de compreendermos essa imagem, e lembrarmos de seus detalhes, ela deverá ser "descompilada" e armazenada em nossa memória visual. Agora, com a informação em nossa memória visual 


\section{CAPÍTULO 5}

poderemos "ver" mentalmente a imagem do fusca e então fazer um novo processamento a nível de detalhes a fim de relembrar a forma e coloração das faixas que marcavam o carro, assim como o logotipo formado com seu número. Experimentos demostraram que o fenômeno da formação das imagens mentais possuem essa linha de processamento. Deste modo, podemos constatar o compartilhamento das áreas de processamento visual de alto nível entre percepção e mentalização. A característica biológica de que as conexões que levam informações das áreas processamento de alto nível para níveis superiores existem em número aproximado às que fazem o percurso inverso vem a fortalecer ainda mais o modelo.

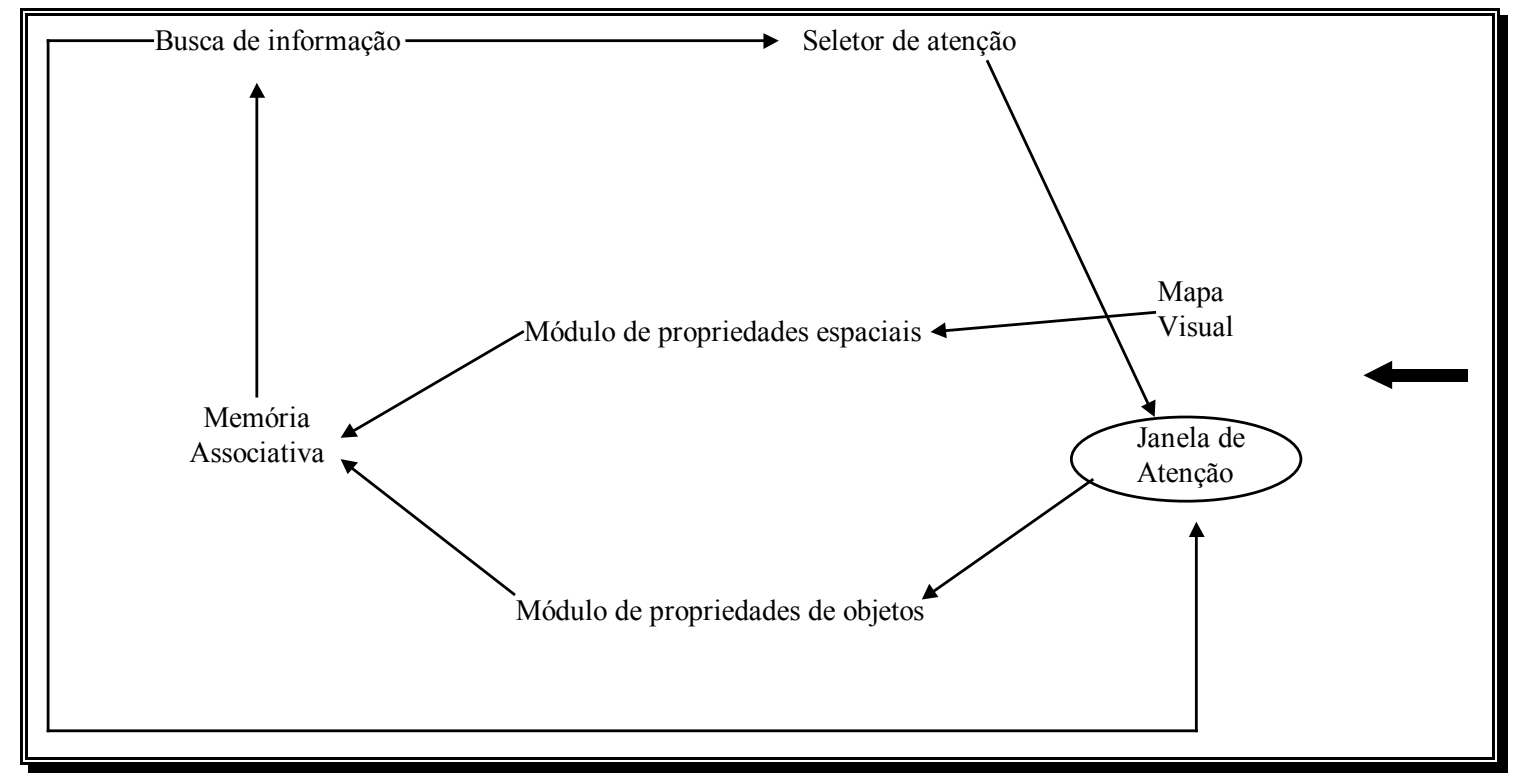

Fig. - 5.10 - Exemplo de regras do modelo.

Kosslyn propõe um interessante modelo de processamento visual de alto nível. A partir desse modelo, ele apresenta de forma empírica o compartilhamento e a reconstrução de imagens mentalizadas. A figura 5.10 apresenta o modelo de Kosslyn o qual, devemos lembrar, se refere a um modelo de identificação de objetos que é compartilhado entre percepção e mentalização.

Vamos agora fazer uma breve descrição de cada um dos elementos do modelo:

Mapa Visual - Entrada de informação provinda dos olhos, porém processada topograficamente pelas regiões de baixo nível. 
Janela de Atenção - Área do Mapa Visual destinada ao processamento detalhado.

Módulo de propriedades de objetos - Ou sistema ventral, são áreas do cérebro do lóbulo occipital inferior para o lóbulo temporal inferior. Em macacos, podemos dizer que o sistema ventral inclui as regiões V3, V4, TEO, TF e TE. As células destas regiões tipicamente respondem as propriedades dos objetos, como forma, cor e textura.

Sua principal função é a codificação dessas informações para o armazenamento na memória associativa.

Módulo de propriedades espaciais - Ou sistema dorsal, são áreas formadas pelas regiões de conexões que vão do lóbulo occipital até o lóbulo parietal. Este sistema também é denominado "O que / Onde", e é responsável pelas informações de localização, navegação. As principais propriedades processadas aqui são localização e tamanho dos objetos. O sistema dorsal funciona simultaneamente ao sistema ventral.

Uma das principais funções do sistema dorsal é codificar informações que são utilizadas primeiramente para guiar ações, como movimento dos olhos.

Memória Associativa - As saídas dos sistemas dorsal e ventral chegam simultaneamente e são armazenadas na memória associativa. Na memória associativa os dados não são armazenados somente como representações de percepção, mas também de modo mais abstrato (nomes, categorias, partes de pronúncia, etc.).

Em alguns casos as informações enviadas pelos sistemas dorsal e ventral são boas o suficiente para selecionar a representação adequada na memória associativa, deste modo a identificação é realizada. Em outros quando não é possível realizar a identificação por falta de dados, o sistema deve então solicitar uma nova coleta de dados.

Busca de informação - Quando os dados codificados pelos sistemas ventrais e dorsais não implicam inicialmente um objeto específico, mais informação deve ser coletada. Nessas circunstâncias, nós não precisamos olhar aleatoriamente para o objeto, para coletar informações adicionais. O sistema de busca de 


\section{CAPÍTULO 5}

informação realiza um processamento "top-down", ou seja ele procura informações na memória associativa relevantes as informações anteriormente obtidas, e o sistema gera então a partir dessas informações um guia para a obtenção das informações auxiliares necessárias para a identificação. Deste modo, o sistema visual saberá exatamente o que procurar na tentativa de reconhecimento.

Seletor de atenção - No processo "top-down", não somente o acesso à informação é necessário, como também o acionamento de mecanismos que dão maior atenção à região visual onde o objeto ou cena possuem as informações características. O mecanismo de atenção seletiva posiciona o corpo, cabeça, olhos e a janela de atenção, onde uma porção da imagem pode ser processada com mais detalhes.

Tendo brevemente discutido os componentes do modelo de Kosslyn, vamos agora descrever o seu funcionamento. Para a percepção, em termos sucintos, a imagem proveniente da retina é processada pelas áreas de processamento de baixo nível, e então transmitida ao mapa visual. A imagem contida no mapa visual deverá ser então codificada para a sua representação na memória associativa. Esse processamento ocorre simultaneamente nos sistemas Dorsal (módulo de propriedades espaciais) e Ventral (módulo de propriedades de objetos), onde respectivamente as propriedades de localização e propriedades de forma, cor, textura, borda, etc., são codificadas. A representação codificada do objeto é então transferida para a memória associativa. Caso as informações estejam satisfatórias e existam dados coerentes ao objeto na memória associativa, então o objeto é reconhecido, caso contrário, o módulo de busca de informação irá pesquisar na memória associativa quais informações características são necessárias. Essas informações são então transmitidas para o seletor de atenção, que posicionará a janela de atenção no mapa visual, e/ou solicitará novos detalhes da imagem para o sistema visual. Caso não tenha necessidade de coletar nova imagem (atenção seletiva), então a informação contida na janela de atenção será processada novamente passando apenas pelo sistema ventral. Esse ciclo é repetido até o objeto ser identificado.

$\mathrm{Na}$ mentalização de imagens, as mesmas áreas são utilizadas. Embora exista o compartilhamento, a utilização do modelo é um pouco diferente. Por exemplo, no caso do Herby, quando perguntamos as cores e formas das listras 
dorsais e logotipos do carro, precisaremos mentalizá-lo a fim de que possamos recordar. O módulo de busca de informação, deverá fazer uma busca na memória associativa a fim de encontrar as representações do carro. Feito isso, a imagem é reconstruída no mapa visual, como se tivesse sido originada pela percepção do sistema óptico. O mecanismo seletor de atenção, posicionará a janela de atenção na porção da imagem que contém as informações necessárias. A imagem será então reprocessada pelo sistema ventral, a fim de que possa ocorrer a identificação das cores e formas das listras. Supondo que não recordamos ainda do logotipo, pois apenas nos lembramos dele na lateral do carro. O mecanismo seletor de atenção irá então posicionar a janela de atenção na posição adequada para detalhar o logotipo. Pelo processamento ventral, e novamente pelas consultas na memória associativa, agora podemos identificar o logotipo, sua forma cor e o número presente.

As principais diferenças entre a percepção e a mentalização de imagens são:

As imagens desaparecem rapidamente no processo de mentalização.

As imagens mentais são criadas a partir de imagens armazenadas. Diferentemente das imagens pelo processo de percepção, que são originadas a partir do mundo exterior.

As imagens mentais, diferentes da percepção, podem ser recriadas com diferentes modos. Por exemplo, podemos rotacionar o objeto, ampliar um detalhe, mudar a distância, movê-lo e etc.

\subsubsection{1 - O MODELO DE KOSSLYN E O CYVIS-1}

Mesmo sendo o modelo de Kosslyn de visão de alto nível, diferentemente do baixo nível do Cyvis-1, podemos fazer algumas comparações entre os sistemas, assim como motivações para o Cyvis-1. O modelo de Kosslyn é estritamente biológico, através do qual é realizada uma modelagem dos processos de alto nível do sistema visual humano. Esse modelo se caracteriza pelo paradigma dos caminhos o que / onde ( what/where ), teoria que se baseia na dualidade dos caminhos de informações visuais no córtex. No entanto esta teoria recebeu duras críticas na literatura, como sendo uma simplificação de um problema complexo [Zeki, 1993].

Dentro do modelo de Kosslyn os sinais (atributos) são agrupados em dois conjuntos e integrados. Assim, os sinais referentes ao caminho o que (cor, linhas, 


\section{CAPÍTULO 5}

formas, etc.), são separados e integrados separadamente dos sinais referentes ao caminho onde (movimento, estéreo, etc.). No Cyvis-1 não é realizado o agrupamento de sinais, assim, pode ocorrer a integração entre qualquer combinação de atributos.

Os mecanismos de atenção seletiva foram bastante explorados no modelo de Kosslyn, conforme podemos observar na figura 5.10, dos 7 módulos que compõe o modelo, 3 são voltados para esta questão. O Cyvis-1 também incorpora a atenção seletiva, que é realizada pelo mestre. No entanto, o modelo de Kosslyn nos sugere que esta questão é complexa e necessita de um mecanismo mais robusto para sua implementação, podendo nos levar no decorrer do projeto Cyvis-1 à incorporação de um módulo específico para essa questão. O que falta no modelo, entretanto, é uma explanação maior sobre os detalhes de cada módulo. Por exemplo, a procura de informações na memória associativa está descrita de forma bastante subjetiva. Ainda em atenção seletiva, o modelo de Kosslyn é fortemente baseado na divisão de sinais onde/o que, uma vez que apenas o caminho o que ou propriedades do objeto estão envolvidas diretamente com o processo.

\subsection{4 - SEEMORE}

Uma abordagem clássica nos sistemas de visão artificial é a análise profunda de uma característica ou atributo marcante para a extração de propriedades para a classificação de objetos. Ultimamente, podemos observar a tendência de seguir a mesma abordagem estabelecida pelos sistemas de visão biológica, ou seja a combinação de diversos atributos para a classificação de objetos. O sistema de visão artificial Seemore, de autoria de Barlett Mel [Mel, 1997], é mais um exemplo de um sistema de visão que combina diferentes atributos da imagem para uma classificação mais efetiva dos objetos.

O funcionamento básico do sistema consiste na extração do maior número possível de características da imagem, e sua eventual classificação através de ferramentas estatísticas. Para analisar o sistema foram treinadas para classificação, 100 imagens, formadas por objetos sólidos rígidos (telefone) e flexíveis (cabo espiral de telefone) assim como imagens complexas de duas dimensões. O Seemore demostrou ser capaz de reconhecer as imagens em diferentes ângulos e escalas variando em fator de 2. Todas as imagens foram capturadas no mesmo ambiente com iluminação normalizada. 
O treinamento do Seemore consiste na captura de 12 a 36 diferentes vistas dos objetos dependendo de sua natureza. Para objetos rígidos, são necessários 12 vistas em diferentes ângulos, variando em intervalos de $60^{\circ} \mathrm{em}$ média em torno da esfera visual do objeto, e mais 3 imagens escaladas para cada vista, tendo $67 \%$, $100 \%$ e $150 \%$ da original. Para objetos flexíveis as vistas são tiradas de modo aleatório em diferentes posições e escalas.

O processamento do sistema Seemore consiste na extração de 102 características da imagem. Cada característica é denominada de canal, e o conjunto dos canais constituem o vetor de características que é a entrada para o classificador estatístico. Deste modo, o banco de dados para cada objeto possui um total de 1224 a 3672 inteiros. Os 102 canais são divididos em 5 grupos:

23 canais de cor, cada um dos quais correspondem a pequenos nódulos parametrizados pela melhor matiz e saturação.

11 canais de cantos, parametrizados pelo ângulo de abertura.

12 canais de características parametrizados pela forma principal (alongada ou arredondada) e pelo tamanho do objeto.

24 canais com características de contorno.

16 canais de textura e forma baseados na saída da função de Gabor [Faugeras, 1996].

O processamento do Seemore é seqüencial, mesmo não existindo dependência de dados entre os 5 módulos e possuindo uma estrutura que permite uma exploração de paralelismo, essa questão não foi levada em conta pelo autor. Deste modo, a execução do sistema é realizada de modo a extrair as características uma após a outra até o montante de 102. Após a extração, as características são enviadas para o classificador estatístico que compara o resultado atual com o banco de dados formado pelo treinamento, para o reconhecimento do objeto.

\subsubsection{1 - CYVIS-1 VERSUS SEEMORE}

Embora combine diversos atributos para o reconhecimento de objetos, o Seemore possui uma estrutura muito mais simples que o Cyvis-1, uma vez que não existe a integração dos atributos, estratégias de paralelismo, análise de dados automática, cooperação entre atributos e análise "top-down" (caminho inverso), entre outras. Numa visão simplificada, podemos resumir o Seemore como um sistema que extrai o maior número possível de características da cena sem análise 


\section{CAPÍTULO 5}

prévia ou direcionamento, e alimenta com um grande número de parâmetros um classificador estatístico. Deste modo o Cyvis-1, em termos de arquitetura de sistema e de visão, tem mais a ensinar do que a aprender com Seemore. Mesmo possuindo uma arquitetura simplificada em termos de visão, os resultados de reconhecimento apresentados revelam uma boa performance do sistema. Ainda quanto aos resultados de reconhecimento, Mel [Mel, 1997], apresentou uma tabela onde compara a performance da classificação do Seemore utilizando apenas um atributo (cor, textura ou forma) e a combinação de atributos. Os resultados demostraram a eficiência da classificação quando alimentada com os dados dos diferentes atributos. Este é um dado relevante para o Cyvis-1, uma vez que além de combinar os atributos, ele também desempenha a integração e cooperação.

A execução do Seemore é seqüencial. Mesmo não possuindo dependência de dados e hierarquia rígida, o que facilita a implementação paralela, essa questão não foi abordada, diferentemente da filosofia do Cyvis-1, que mantém a implementação paralela como um de seus principais objetivos.

\section{4 - O PROJETO LYNERGOS}

No desenvolvimento de sistemas e na realização de experimentos em visão, apresentam-se uma série de dificuldades, que devem ser vencidas pelo esforço, a fim de que o sistema ou experimento em questão possa ser realizado com êxito. Dentre essas dificuldades podemos citar: (i) a validação das técnicas: é bastante trabalhoso certificar que as técnicas e algoritmos estão funcionando perfeitamente; (ii) a implementação correta de algoritmos muitas vezes direcionados a linguagens de modelagem (ex: MATLAB); e (iii) a análise estatística dos dados obtidos a partir do processamento: muitas vezes diversos atributos extraídos de uma imagem classificam-na de modo igual, tornando-se redundantes, assim como em algumas ocasiões os atributos extraídos podem não estar distinguindo adequadamente diferentes classes, sendo necessário a adição de características no sistema.

Normalmente, os pesquisadores desenvolvem algoritmos específicos para a realização de testes e análises, ou estudam através de seus experimentos para uma melhor compreensão dos problemas apresentados acima. No entanto, isso é bastante trabalhoso e custoso, implicando num tempo muito maior para o desenvolvimento de sistemas e experimentos. Esses problemas, comuns na área de visão, motivaram o desenvolvimento de uma ferramenta para auxiliar a 
pesquisa, experimentos e desenvolvimento de sistemas em visão, em nosso grupo.

O projeto $\Sigma$ ynergos [Bruno et al., 2000] [Consularo et al., 1999] [Bruno et al., 1998], tem como objetivo fornecer um ambiente, formado por um conjunto de ferramentas, para auxiliar no desenvolvimento de sistemas e experimentos em visão. O Eynergos é composto por um conjunto de módulos caracterizados por ferramentas que atuam em áreas específicas. Os principais módulos do $\Sigma$ ynergos são:

Pesquisa em Visão Computacional: Este módulo inclui ferramentas tradicionais para visão computacional e processamento de imagens, tais como Fourier e outros métodos de transformação, detecção de bordas, segmentação de imagens, etc.;

Pesquisa em Visão biológica: É composto por ferramentas para diferentes atividades relacionadas à visão biológica, assim como psicofísica e síntese e modelagem de estruturas biológicas.

Análise dos Dados e Classificação: Nesse módulo são tratados os procedimentos de reconhecimento de padrões, análise de classes e funções estatísticas. Sendo útil para auxiliar na validação das características.

Validação e Testes: Este módulo contém métodos para a verificação da integridade das rotinas implementadas, assim como para avaliar e melhorar a performance dos algoritmos.

Base de Dados: Base de dados para imagens e dados genéricos, fornece o alicerce para que diferentes métodos tais como os de performance de algoritmos, validação e selecionador automático de características, possam agir.

Computação Paralela: Esta abordagem é responsável pelo auxílio em implementações de aplicações de tempo real através da paralelização de algoritmos. A base paralela adotada pelo Eynergos é o CVMP (ver Capítulo 6).

Inteligência Artificial: Aqui se encontram as rotinas para aquisição de conhecimento de sistemas especialistas ou de experimentos (exemplo algoritmo genético [Goldberg, 1989]).

Mineração de dados (Data Mining): Este módulo se refere as funções para encontrar regras gerais em conjuntos de dados, que podem ser usadas para modelar estruturas biológicas ou para aquisição de conhecimento em sistemas especialistas, por exemplo.

Visualização e GUI: Módulo responsável pela visualização científica dos dados e da interface entre o usuário e máquina. 


\section{CAPÍTULO 5}

Internet: Interação com a Internet em três diferentes situações: (a) síntese: geração automática de documentos HTML; (b) análise: processamento de imagens e dados provenientes do WWW; (c) processamento: aplicações rodando através da internet (via cgi-bins, Perl ou Java, por exemplo).

Interação com aplicativos externos: Este módulo é responsável por permitir que o Eynergos possa interagir e comunicar com outras aplicações tais como Matlab ou ADOBE PhotoShop, tornando-o um versátil ambiente para a investigação de imagens.

A principal idéia por trás do projeto $\Sigma$ ynergos, além de auxiliar o desenvolvimento de sistemas e experimentos, está o conceito de sinergia, que se exprime pela sentença de que a soma das partes é maior do que o todo. Deste modo o resultado da união de diversos métodos computacionais em um único sistema pode ser maior do que a soma de suas partes, uma vez que as vantagens e desvantagens relativas de cada módulo podem se complementar.

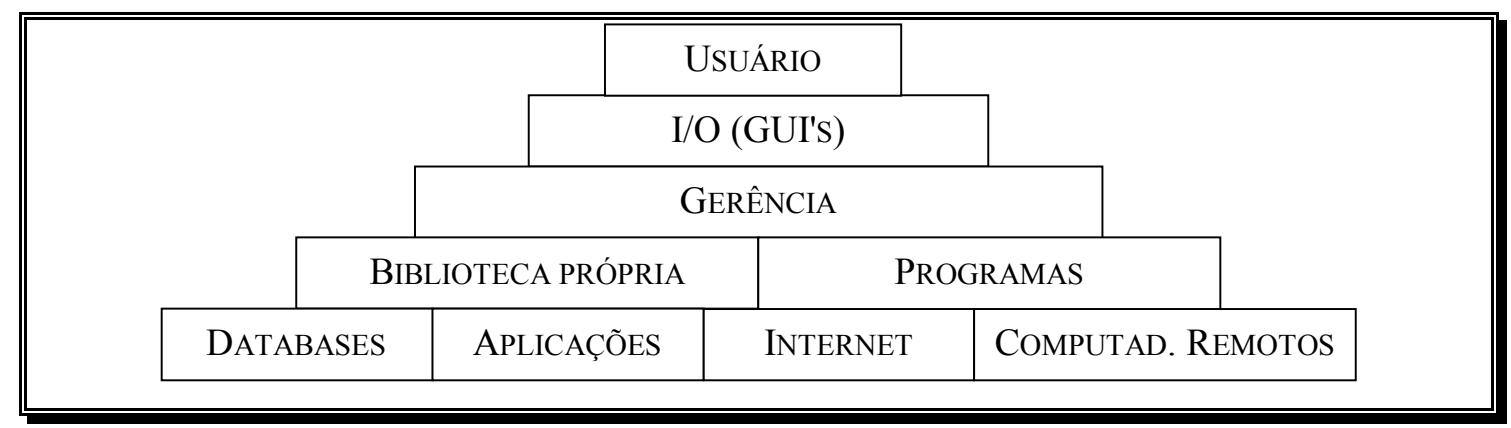

Fig. - 5.11 - Modelo em camadas do Lynergos.

Deste modo, o yynergos pode ser caracterizado como um sofisticado laboratório de visão, através do qual podem ser desenvolvidos poderosos experimentos baseados na interação entre seus módulos. A figura 5.11 apresenta um modelo de camadas que expressa sua arquitetura. O Eynergos está sendo implementado principalmente pelo colega de grupo Luís Augusto Consularo [Consularo et al., 1999], utilizando o ambiente de programação Delphi e a plataforma Windows NT/9X. O ambiente Delphi possui ferramentas para programação visual, bases de dados, programação Internet (cgi-bin) e programação orientada a objetos (OOP), e desse modo tem contribuído para a implementação efetiva dos conceitos envolvidos no projeto.

Uma das características do Eynergos é a sua natureza paralela e distribuída. 
A implementação paralela e distribuída está sendo implementada utilizando as ferramentas CVMP ( Cybernetic Vision Message Passage - ver Capítulo 6), tendo como plataforma computacional máquinas IBM/PC conectadas via rede com um ou mais processadores (multiprocessadas), e sistema operacional Windows NT/9X. A adoção da plataforma PC / Windows foi adotada preferencialmente por: (i) As máquinas IBM-PC atingiram um alto nível de performance (ex: $1000 \mathrm{MHz}$ ), (ii) portabilidade e popularidade tanto do hardware quanto do software e (iii) baixo custo.

\section{5 - Paralelismo e Visão, Um Desafio}

Neste capítulo discutimos e apresentamos alguns sistemas de visão artificial e suas necessidades de paralelismo. Entretanto, a demanda por paralelismo nas áreas relacionadas com a visão computacional é muito mais ampla, uma vez que esta envolve a manipulação de grandes quantidades de dados (imagens) sendo processados por um elevado número de operações aritméticas, o que consequentemente resulta num grande consumo computacional e tempo. Além da questão de desempenho, existe também a integração e colaboração entre atributos visuais. Ainda que esses conceitos estejam em fase inicial de pesquisa, motivados pelos sistemas biológicos, acreditamos estar no paralelismo as soluções para essas questões.

Embora a visão computacional e diversas outras áreas científicas, que necessitem de grande poder computacional, venham a ser beneficiadas com a utilização de paralelismo, algumas barreiras freqüentemente impedem sua adoção, tais como:

Necessidade de escrever novo código voltado para o paralelismo e em muitos casos alterar a estratégia do algoritmo, gerando um aumento de trabalho na implementação dos algoritmos e não permitindo a utilização dos códigos já desenvolvidos.

Os programas paralelos obedecem a princípios de funcionamento e de programação que diferem dos seriais. Isso dificulta sua implementação, uma vez que a formação típica dos programadores é em processamento seqüencial, sendo necessário conhecimento sobre os princípios básicos do paralelismo e ambientação.

O código paralelo é em geral voltado para uma determinada arquitetura paralela, 


\section{CAPÍTULO 5}

reduzindo a portabilidade do código e padronização.

Necessidade de mudar de linguagem e ambiente de desenvolvimento. Poucos ambientes de programação apresentam soluções para a implementação de código paralelo, especialmente os comerciais integrados e visuais (Delphi, C++ Builder, Visual C++ e Visual Basic), sendo necessário em algumas situações a mudança de ambiente de trabalho e até mesmo de linguagem de programação. Com isso, além de não reutilizar o código, os programadores são obrigados a aprender a operar novos ambientes e linguagens e a se familiarizar com eles.

A grande maioria das ferramentas e linguagens de programação voltadas ao paralelismo se caracterizam por serem voltadas aos especialistas em computação paralela, não se preocupando com o programador comum. Com isso dificultam a implementação de programas concorrentes e aumentam drasticamente a curva de aprendizado [Hayes, 1990] [Baber et al., 1993] [Preece et al., 1994].

Alto custo, especialmente para soluções de paralelismo que envolvem computadores com arquiteturas não convencionais.

Analisando as barreiras podemos constatar que os maiores empecilhos para o desenvolvimento de programas paralelos estão relacionados ao trabalho humano. Se observarmos a história da ciência da computação verificaremos a importância da interação entre o homem e o computador, e consequentemente das interação e simplicidade de uso das ferramentas, tanto de operação quanto de programação. As idéias de simplificar o modo de operação e as ferramentas computacionais são conceitos que atingiram seu ápice em relação a pesquisa no projeto PARC [Bruno, 1995] que culminou na tecnologia GUI [Peddie, 1992], na programação orientada a objetos e em linguagens visuais (Smalltalk) [Hurson et al., 1993] [Cox, 1986]. Graças a esses elementos páginas foram viradas na história da computação e a informática teve um grande impulso em sua expansão, chegando a fazer parte direta ou indiretamente de toda as nossas atividades científicas.

A importância de ferramentas simples no desenvolvimento de programas pode ser também observada na popularidade das plataformas computacionais, sendo esse o principal motivo da difusão do Windows, que apresenta diversas ferramentas que possibilitam a criação de aplicativos de maneira simples, destacando o Visual Basic, linguagem para iniciantes, simples de utilizar, e que possui o maior número de aplicativos desenvolvidos. 
Embora os conceitos de interação entre homem e máquina sejam consagrados e amplamente difundidos, eles não foram empregados de forma efetiva na computação paralela. Isso provavelmente se deve a sua natureza científica, uma vez que sua aplicação se restringe ao meio científico e consequentemente aos ecléticos especialistas da computação paralela.

Devido à demanda por paralelismo em visão computacional, e mais especificamente para os projetos do Grupo de Visão Cibernética e carência de ferramentas de simples utilização para a implementação paralela compatíveis com a linguagem e com o ambiente de programação vigentes, fomos motivados a desenvolver um conjunto de ferramentas para implementação de aplicações paralelas que viessem a atender a estas necessidades.

Nasceu assim o CVMP ("Cybernetic Vision Message Passage"), que será apresentado no próximo capítulo. Um conjunto de ferramentas visuais para a implementação de aplicações paralelas, de simples utilização, voltada para a visão computacional. Através do CVMP os pesquisadores do Grupo de Visão Cibernética não necessitam mais mudar de linguagem e ambiente de desenvolvimento para a implementação de programas concorrentes, poupando árduos treinamentos, longos períodos de familiarização e o trabalho de portar códigos. Deste modo, podem de maneira simples e efetiva, através de programação visual e orientada a objetos, desenvolver programas paralelos e se integrar em grandes projetos de visão computacional, que necessitam de paralelismo, tais como o Cyvis-1 e o Eynergos. 
CAPÍTULO 5 


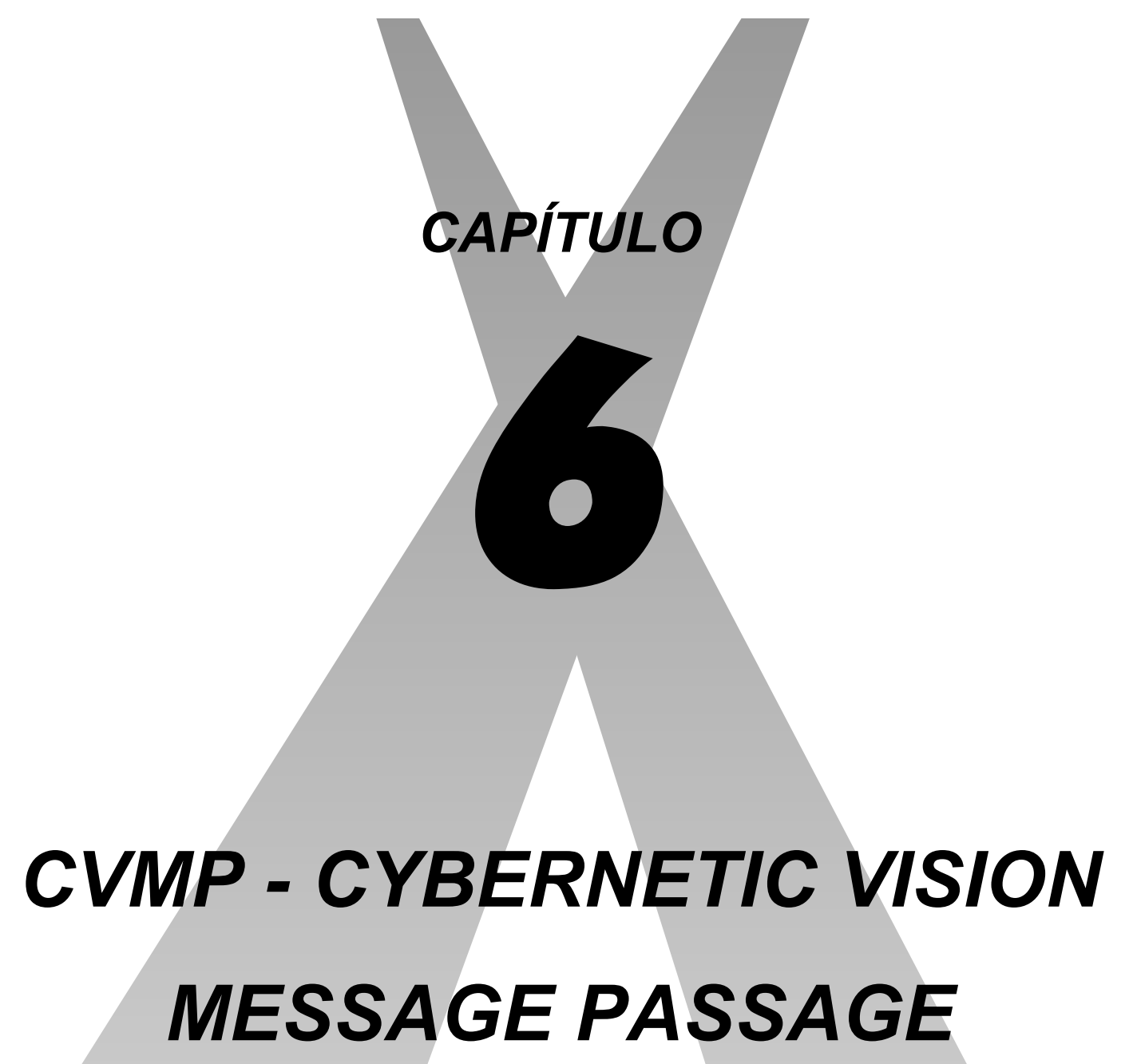

"Todas as coisas complexas estão condenadas à decadência" Buda 
CAPÍTULO 6 


\section{CAPÍTULO 6 - CVMP}

\section{1 - INTRODUÇÃO}

Neste capítulo estaremos apresentando a base para o paralelismo proposta nesse trabalho, o CVMP. Iniciaremos este capítulo comentando os aspectos que nos levaram ao desenvolvimento dessa plataforma, depois estaremos apresentando seus princípios e funcionamento e em seguida suas estratégias de comunicação e seu desempenho, assim como sua disponibilidade de utilização nas plataformas MIMD memória compartilhada e MIMD memória distribuída. Finalizamos o capítulo apresentando o conjunto de ferramentas que constituem o CVMP.

\section{2 - MOTIVAÇÃO E HISTÓRIA}

Como vimos no capítulo anterior, embora a computação paralela traga inúmeros benefícios para as áreas de visão computacional, processamento de imagens e áreas relacionadas, alguns obstáculos impedem sua proliferação. Dentre estes, o principal obstáculo é a dificuldade de implementação de programas concorrentes, uma vez que a maioria das ferramentas para o desenvolvimento de programas paralelos é destinada a especialistas da área. Essa dificuldade aumenta ainda mais devido à necessidade de mudar de ambientes de programação e até mesmo linguagens em determinados casos, de modo que além do tempo gasto com o aprendizado das metodologias paralelas, é necessário também investir tempo no processo de familiarização com as novas ferramentas de programação, além da necessidade de portar ou reescrever o código para outra plataforma.

Observando essas dificuldades, fomos motivados a idealizar uma metodologia para o desenvolvimento de programas concorrentes de forma simples e efetiva. Além da simplicidade de utilização, uma questão primordial para facilitar o desenvolvimento de programas concorrentes é a utilização das linguagens e ambientes de programação integrados (visual) a que os programadores já estejam ambientados, reduzindo assim o tempo de aprendizado e de portar, ou reescrever o 


\section{CAPÍTULO 6}

código. Tendo nosso grupo adotado como plataforma de desenvolvimento o Borland Delphi [Cantù, 1995], que além de bastante popular, obedece as características necessárias de uma plataforma de desenvolvimento moderna (ver 5.2.3), optamos pela utilização deste ambiente.

A história do CVMP é parecida com diversos outros produtos que nasceram derivados de outros projetos. Essa situação é bastante comum na Ciência da Computação, um bom exemplo é o mouse ou o do conceito de orientação a objetos, que surgiram no PARC (Palo Alto Research Center) [Bruno, 1995], através de um grande projeto de interação entre homem e máquina realizado pela Xerox ao longo de toda a década de 70. No caso do CVMP o projeto em questão é o Cyvis-1, que foi apresentado no capítulo anterior. Uma das bases do Cyvis-1 é a adoção de paralelismo em sistemas de visão que, como vimos, além de desempenho, exerce papel fundamental sobre a integração e a corporação de atributos visuais. Uma das características do projeto Cyvis-1 é o número de pessoas envolvidas, pois devido à sua complexidade, o Civis-1 requer o trabalho cooperativo de diversos pesquisadores de visão cibernética, especialistas nas diversas modalidades exigidas pelo sistema, para o seu desenvolvimento.

Sendo os pesquisadores que participam e virão a participar do projeto especialistas em visão e processamento de imagens, defrontamos com a grande barreira da computação paralela. Dentre as inúmeras dificuldades que já mencionamos (ambientes e linguagens diferentes, portar código, dificuldade de implementação, etc.), que acompanham os benefícios da computação paralela, nos defrontamos principalmente com a questão da dificuldade de implementação de sistemas em paralelo. Uma das características que podemos observar na Computação Paralela, que também se manifesta em diversas outras áreas da ciência, é o seu perfil eclético. Dificilmente encontramos sistemas comerciais paralelos. Em geral, a utilização de paralelismo em sistemas de computação repousa no berço da pesquisa científica, encontrando nela o seu principal nicho. Provavelmente por essa razão, não existe uma preocupação efetiva como a interação entre homem e máquina [Preece et al., 1994] nesta área, fato que podemos facilmente comprovar pela natureza complicada de suas ferramentas de implementação, como é o caso das famosas MPI [Pacheco, 1997] e PVM [Geist et al., 1996], que através da dificuldade de utilização, limitam os benefícios do paralelismo aos especialistas da área.

Assim, devido à grande dificuldade de implementação de sistemas 
paralelos, fomos motivados a desenvolver uma ferramenta que trouxesse os benefícios da computação paralela ao mundo da visão computacional e processamento de imagens, de modo simples de usar, possibilitando o desenvolvimento de programas paralelos por pesquisadores da área de visão sem conhecimento específico em computação paralela. Nascia assim a ferramenta de troca de mensagens CVMP. Os principais requisitos que encontramos e atendemos de forma a simplificar ao máximo o desenvolvimento de programas paralelos, foram:

Plataforma de desenvolvimento convencional: Como já comentamos o treinamento com novas plataformas e linguagens de desenvolvimento e o tempo gasto portando programas é um grande empecilho. Por esta razão optamos pela adoção de uma plataforma de desenvolvimento convencional e popular. Optamos pelas ferramentas Borland Delphi e C++ Builder, que além de serem bastante populares, são as ferramentas adotadas pelo grupo de visão, de modo que os pesquisadores possam facilmente desenvolver versões paralelas de seus programas na mesma linguagem e ambiente com os quais já estão familiarizados.

Programação Visual: A programação visual, diretamente associada com o paradigma da orientação a objetos, é uma tecnologia que trouxe inúmeros benefícios para o desenvolvimento de software. Através da programação visual, o tempo de desenvolvimento de aplicativos é menor e a utilização de linguagens de programação mais simples e fácil.

Programação Orientada a Objetos: Inúmeros são os benefícios proporcionados por essa tecnologia. Em termos de operação de computadores, o conceito de programação orientada a objetos surgiu simultaneamente com a interface gráfica com o usuário (GUI), que possibilitou um enorme passo para a popularização da informática. Na engenharia de software, esse paradigma possibilitou benefícios similares ao conceito de circuitos integrados em eletrônica [Cox, 1986]. O conceito de programação orientada a objetos é a coluna dorsal do CVMP, uma vez que este paradigma possibilita além de simples utilização, a reutilização de código e a modelagem de sistemas complexos.

A partir dessas primitivas e outros conceitos que iremos apresentar no decorrer desse capítulo, o conjunto de ferramentas CVMP se transformou na base de desenvolvimento paralelo para o projeto Cyvis-1. A partir da idéia de criar uma 


\section{CAPÍTULO 6}

ferramenta de desenvolvimento de aplicações paralelas, simples de utilizar, e que permite sua utilização por profissionais de diferentes áreas, tem demonstrado ser um interessante meio de tornar os benefícios da computação paralela acessíveis para as demais áreas da ciência da computação.

\section{3 - CVMP - Cybernetic Vision Message}

\section{PASSAGE}

O CVMP é uma abreviação do inglês "Cybernetic Vision Message Passage", que podemos traduzir como ferramenta de troca de mensagens para visão cibernética. Trata-se de um conjunto de ferramentas para o desenvolvimento de programas paralelos em plataforma Delphi / C++ Builder, utilizando os conceitos de programação visual e orientação a objetos. Seu ideal, é o de contribuir com a proliferação da computação paralela e especialmente sua utilização de forma simples em nossa área (visão e processamento de imagens). Atualmente tem demonstrado sua eficiência como plataforma de desenvolvimento paralelo do grupo de visão cibernética, através de sua utilização por diversos pesquisadores no desenvolvimento de projetos que se beneficiem com a paralelismo, sendo de modo especial, a base para o desenvolvimento do Cyvis-1, cujo conceito de paralelismo é vital para o seu modelo.

O CVMP é composto por um conjunto de componentes (VCL - Visual Component Library) nativos em Delphi e alguns aplicativos. Os componentes são compostos por cinco grupos: CVMP básico, CVMP processor farm, CVMP image processing, Estatística e Launcher, e os aplicativos em dois grupos: Estatística e Launcher.

A Figura 6.1 apresenta a paleta de componentes do ambiente Delphi com os componentes CVMP.

File É dit Search View Project Riun Component Database Iools Help

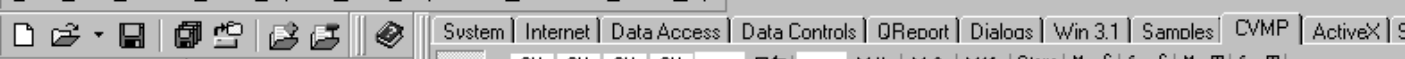

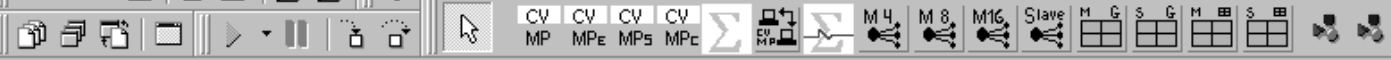

Fig. - 6.1 - Paleta de componentes CVMP em ambiente Delphi. 


\subsection{1 - OBJETOS CVMP}

No decorrer deste capítulo forneceremos maiores detalhes sobre cada um dos componentes e também dos aplicativos que compõe o conjunto de ferramentas CVMP. A seguir vamos apresentar rapidamente cada um dos seus grupos de componentes.

CVMP básico: Esse grupo é composto por dois componentes, que fornecem as primitivas de troca de mensagens, sendo um componente para sistemas MIMD de memória distribuída e o outro para MIMD de memória compartilhada:

CVMP Pro: Contém uma biblioteca de funções e procedimentos e um componente CVMP básico com esta biblioteca encapsulada (CVMP Pro). A biblioteca CVMP Pro contém funções e procedimentos para a manipulação de pacotes de mensagens, para a sincronização da troca de mensagens, semáforos e mecanismos de controle que podem ser utilizadas em conjunto com o CVMP básico, além de suporte para operações básicas com imagens, tais como partição e divisão em blocos.

CVMP processor farm: Contém componentes com a arquitetura fazenda de processadores (processor farm) implementada para até 4, 8 e 16 máquinas escravas. Através do CVMP processor farm, o usuário pode de modo visual implementar facilmente uma aplicação distribuída, sem precisar escrever nenhuma linha de controle para essa estratégia de paralelismo. Cada CVMP processor farm (até 4 e até 8 máquinas escravas) é composto por uma dupla de componentes, um mestre e um escravo. O componente mestre é responsável pela supervisão dos escravos e pela divisão automática de tarefas, enquanto que o componente escravo é responsável pela execução das tarefas.

CVMP Image processing: Cada técnica de processamento de imagem implementada pelo CVMP pode ser facilmente convertida em um novo componente e reutilizado futuramente. Dentro deste conjunto, temos algumas técnicas de processamento de imagem implementadas e prontas para sua utilização, tais como: transformada de Fourier, convolução de máscaras (Sobel) e transformada de Hough. Enfim, esta categoria está sempre em expansão e pode ser implementada pelo próprio usuário, como é o caso do componente personalizado desenvolvido em 


\section{CAPÍTULO 6}

conjunto com Alan Salvany Felinto e Jander Moreira [Moreira et al., 1999], que possui inúmeros protocolos personalizados e um método para aquisição remota de imagens (a partir de placa de aquisição de imagens de vídeo), para o sistema de integração entre cor e estéreo, que apresentaremos futuramente.

Estatística: É composto por dois componentes, um para análise estática e outro análise dinâmica, para auxiliar na análise estatística do comportamento de execução dos programas concorrentes desenvolvidos com o CVMP, tais como fluxo e tempo de execução e o tráfego de mensagens. O componente de análise estática faz as medidas de desempenho diretamente através do código do programa, que deve conter em pontos estratégicos, estipulados pelo programador, chamadas a métodos do objeto. A partir destas chamadas, o componente realiza o cálculo do tempo e o armazena em um arquivo que pode ser visualizado com o aplicativo de estatística, que faz parte do conjunto de ferramentas CVMP. O componente para análise dinâmica possui a mesma estratégia de utilização de seu parceiro, entretanto, ao invés de serem armazenadas em arquivo, as análises são enviadas em tempo de execução para o aplicativo de análise dinâmica, podendo deste modo ser feito a visualização do desempenho, fluxo de execução e troca de mensagens, enquanto o sistema é executado.

Launcher: Composto por um único componente, o CVMP-Launcher, possibilita o disparo de aplicativos nas máquinas da rede. Isto é realizado em conjunto com os aplicativos Launcher. A partir de chamadas aos métodos do objeto, o programa pode disparar a execução de um determinado programa em uma máquina específica da rede.

\subsection{2 - APLICATIVOS CVMP}

Os aplicativos CVMP são programas que auxiliam na utilização ou funcionamento dos objetos CVMP. Os aplicativos se dividem em dois grupos: Análise estatística, contendo aplicativos voltados para a análise de fluxo de execução, desempenho e troca de mensagens e o Launcher, contendo aplicativos que permitem o disparo de programas em máquinas remotas.

Estatística: Existem dois aplicativos para análises estatísticas, sendo um para 
análise estática e outro para dinâmica. O Aplicativo para a análise estática é um utilitário que permite a visualização e análise dos resultados gerados a partir do componente de estatística. O aplicativo para análise dinâmica é mais complexo. Assim como o estático ele também permite a visualização e análise dos resultados, no entanto os resultados são obtidos em tempo de execução. Para isso o aplicativo recebe mensagens do componente através de compartilhamento da memória virtual. A cada mensagem recebida é atualizada a janela de exibição, permitindo desse modo uma análise do comportamento do sistema em tempo real.

Launcher: É composto por dois aplicativos, o módulo central e os disparadores. Os disparadores são aplicativos que ficam na barra de tarefas do windows (tray) e ficam aguardando ordens. Através das ordens que recebem eles executam os programas determinados. O módulo central é um aplicativo que recebe comandos do objeto Launcher, ou entradas diretas pelo usuário. Sua missão é transmitir as ordens para a execução de programas para os disparadores espalhados pela rede.

\section{4 - OS CANAIS VIRTUAIS}

A comunicação entre os objetos CVMP é realizada sempre aos pares, dentro do conceito mestre/escravo, conforme apresenta a Figura 6.2. A partir de um par de objetos CVMP é estabelecido um canal virtual [Bruno \& Costa, 1997] [Bruno \& Costa, 2000]. O conceito de canal virtual é a base da ferramenta CVMP, ele foi inspirado nos canais dos transputer [Inmos, 1988] [Inmos, 1989], famosos processadores utilizados na década de 80 , que impulsionaram forte interesse em paralelismo em sua época, devido à facilidade de implementação de hardware paralelo que eles proporcionavam. Assim como nos canais dos transputers, os canais virtuais são fixos e, uma vez definidos, não podem mais ser alterados. $A$ estratégia de fixar a conexão entre os componentes foi idealizada de modo a simplificar ao máximo sua utilização.

Cada canal virtual conecta dois processos, onde cada processo utiliza um objeto CVMP, que pode através dele enviar e receber mensagens. Os processos podem estar na mesma máquina, sendo executados em concorrência através da multitarefa do sistema operacional, podendo estar também em diferentes processadores de uma máquina multiprocessada, assim como em máquinas conectadas por rede. 


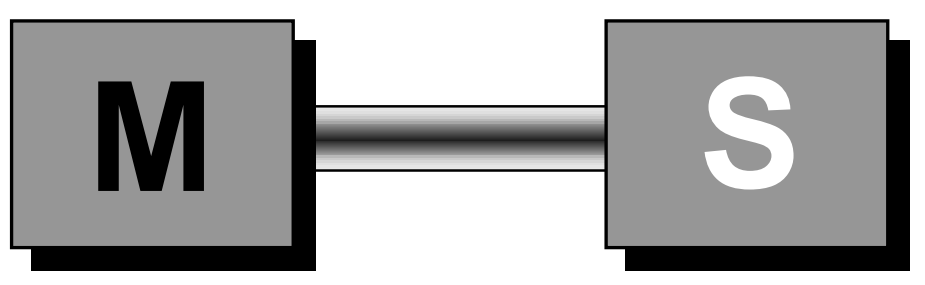

Fig. - 6.2 - Exemplo do conceito mestre/escravo e da conexão através do Canal Virtual. A caixa M simboliza um objeto CVMP configurado como mestre, enquanto que a $S$, configurado como escravo. A barra vertical representa 0 Canal Virtual.

Para a comunicação de processos em diferentes máquinas conectadas via rede (sistema distribuído), o Canal Virtual possui duas conexões, uma para o tráfego de pacotes, com pequena granularidade, e utilizando protocolo TCP/IP, e outra para pacotes, de alta granularidade, utilizando o protocolo NetBeui ou IPX/SX. Essa estratégia permite um desempenho melhor da rede, possibilitando um tráfego de pacotes mais ágil. Comentaremos nas próximas seções esta estratégia de forma mais detalhada.

Em uma primeira instância, pode parecer que, tanto a utilização de canais fixos como a conexão entre pares limitam as possibilidades de conexões. No entanto, não existe um limite para o número de canais virtuais e nem para o número de objetos CVMP utilizados por processo. Deste modo, arquiteturas complexas podem ser facilmente implementadas. A Figura 6.3 apresenta alguns exemplos de configurações permitidas utilizando os canais virtuais, demonstrando sua flexibilidade. As configurações apresentadas são as mesmas tanto para sistemas distribuídos (MIMD distribuído) como para máquinas multiprocessadas (MIMD compartilhado). Em (a) temos uma máquina conectada a outras máquinas utilizando pares de CVMP conectados por Canais Virtuais; em (b) existem dois processos conectados em uma máquina monoprocessada (multitarefa); em (c) temos a combinação de (a) e (b); e em (d) temos uma situação mais complexa, ilustrando a versatilidade do CVMP. 
A )

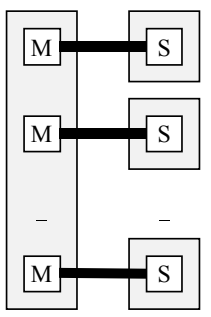

B )

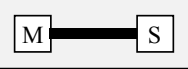

C )

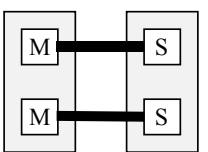

D )

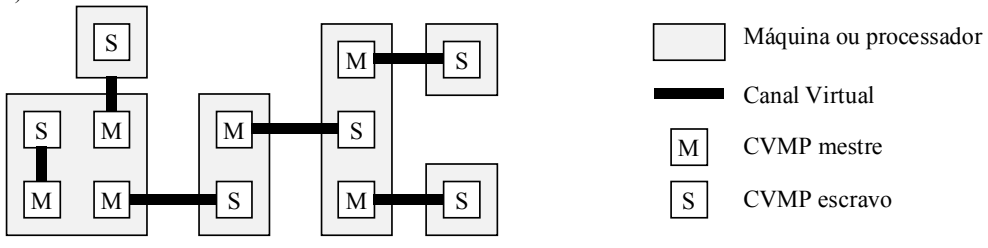

Fig. - 6.3 - Possíveis configurações utilizando canais virtuais.

\section{5 - ARQUITETURAS MIMD}

Nessa seção discutimos as arquiteturas paralelas utilizadas para a implementação de sistemas através do CVMP, assim como as técnicas computacionais utilizadas para a implementação do CVMP em cada uma delas. Como já comentamos anteriormente, o CVMP incorpora duas estratégias de arquitetura paralela: sistemas distribuídos e máquinas multiprocessadas. $\mathrm{Na}$ literatura, o termo sistema distribuído é amplamente empregado, discriminando sistemas operacionais (Amoeba) [Mullender et al., 1990], servidores de bases de dados e sistemas de computação distribuída. No nosso trabalho estaremos empregando esse termo para designar aplicações (ou programas) concorrentes que são executados em diferentes máquinas conectadas via rede, ou seja computação distribuída. Podemos classificar os sistemas distribuídos implementados com CVMP como máquinas MIMD com memória distribuída (ver Capítulo 2). Uma outra possível arquitetura de paralelismo permitida pelo CVMP é o desenvolvimento de programas concorrentes em máquinas multiprocessadas. Máquinas multiprocessadas são sistemas computacionais que apresentam mais de um processador principal. Existe uma grande diversidade de máquinas que se enquadram nesse perfil [Almasi \& Gottlieb, 1994]. No entanto, o CVMP está limitado a sistemas padrão IBM-PC multiprocessados com plataforma Windows-NT. Em 


\section{CAPÍTULO 6}

relação a arquitetura anterior, podemos classificar este tipo de sistema como MIMD memória compartilhada.

\subsubsection{ARQUITETURA MIMD DISTRIBUÍDA}

Dentro do contexto do CVMP, denominamos arquitetura MIMD distribuída um conjunto de máquinas IBM-PC com plataforma Windows NT/9x conectadas em rede, apresentando um conjunto de aplicações, que através de utilização das ferramentas CVMP, conseguem cooperar executando processamento em conjunto. A Figura 6.4 apresenta um exemplo dessa arquitetura, nela temos um sistema paralelo formado por 3 processos alojados em máquinas distintas conectadas por rede, dos quais dois são escravos (extremidades) e um mestre (no centro). Através dos objetos CVMP, representados na figura por pequenos quadrados cinza no interior dos processos, são estabelecidos canais virtuais que possibilitam a troca de mensagens entre os processos.

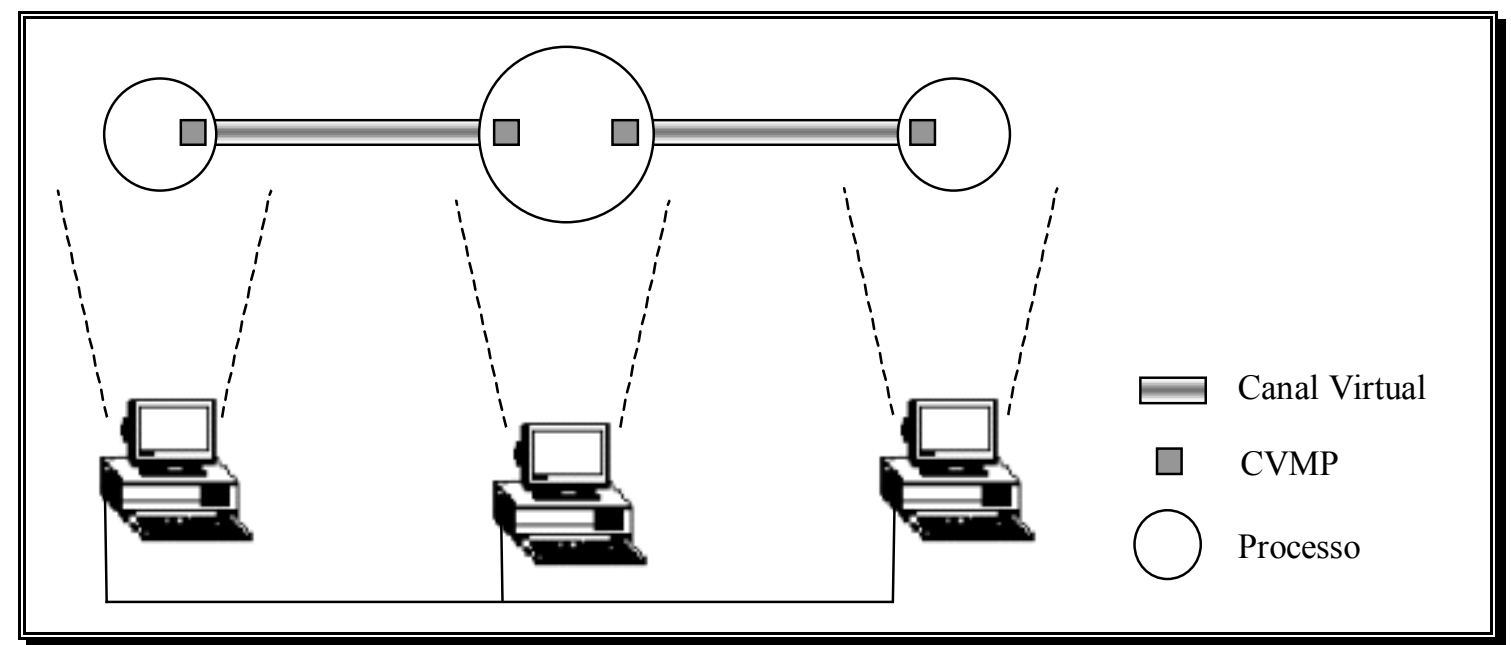

Fig. - 6.4 - Exemplo de uma aplicação paralela em uma arquitetura MIMD distribuída.

Para cada arquitetura, MIMD distribuída e MIMD compartilhada, é utilizado um objeto de base CVMP específico, que implementa as primitivas de troca de mensagens apropriadas e estabelecem os canais virtuais. No modelo MIMD distribuído, existem dois mecanismos de troca de mensagem específicos para pacotes de pequena granularidade, baseada no protocolo de rede TCP/IP e na interface de rede socket e de alta granularidade, baseada na troca de arquivos através dos protocolos NetBeui e IPX/SX. 


\subsubsection{1 - MENSAGENS EM TCP/IP - SOCKET}

Os canais virtuais são estabelecidos através de conexões entre interfaces socket [Dumas, 1995], mecanismo desenvolvido pela Universidade de Berkeley para facilitar a troca de mensagens através do protocolo TCP/IP, sendo nativo para o UNIX, mais especificamente para o BSD (Berkeley Software Distribution). Os ambientes Windows utilizam uma versão do socket de Berkeley denominado de Winsock. Nesses sistemas o Winsock é caracterizado por uma DLL (biblioteca de ligação dinâmica) [Bruno, 1995], que exerce o papel de uma API (interface de programação de aplicativo) que pode ser acessada através de programação.

Embora o Delphi apresente em suas novas versões alguns componentes que simplificam o acesso ao Winsock, o CVMP foi implementado sem a utilização desse recurso, fazendo chamadas diretas à API, para melhorar a performance, possuindo um conjunto de primitivas de troca de mensagens.

\subsubsection{2 - TROCA DE ARQUIVOS}

Observamos que em processamento de imagens e visão computacional, especialmente nos primeiros estágios, é bastante comum a transferência de arquivos com imagens ou dados com grande quantidade de memória. A plataforma Windows, dependendo da configuração das máquinas da rede, não apresenta o melhor desempenho para a troca de pacotes utilizando protocolo TCP/IP. Visando melhorar a performance da rede, foi incorporado uma alternativa no CVMP para este protocolo nas situações de troca de alta granularidade ou seja na troca de arquivos. Deste modo o CVMP também possui uma estratégia de troca e compartilhamento de arquivos através de métodos de API Windows que utilizam os protocolos nativos NetBeui e IPX/SX, determinado pela configuração do Windows que, segundo a configuração, aumenta a performance da troca de pacotes.

\subsubsection{3 - COMPARAÇÃO ENTRE PLATAFORMAS DE TROCA DE MENSAGENS}

O CVMP pode ser visto como uma camada de software adicional à interface socket de acesso ao sistema de redes (CVMP distribuído), cujo objetivo é fornecer um modelo orientado a objetos, simples de usar, flexível e reutilizável para o desenvolvimento de programas concorrentes. Embora exista uma grande 


\section{CAPÍTULO 6}

diversidade de métodos para o desenvolvimento de sistemas distribuídos e programação concorrente, que também constituem-se de camadas de software sobre os protocolos de rede, acreditamos que a principal contribuição do CVMP é a simplificação da metodologia, tornando mais simples e ágil o trabalho do especialista e provendo os benefícios do paralelismo para programadores não especialistas.

Dentre as ferramentas para troca de mensagens, podemos destacar entre as mais populares atualmente: PVM, MPI, DCOM e CORBA. Elas representam duas classes distintas de estratégias de concorrência: bibliotecas de funções e objetos distribuídos. A primeira, classe é composta pelo PVM (Parallel Virtual Machine) [Geist et al., 1996] e pelo MPI (Message Passing Inteface) [Pacheco, 1997], que são baseadas em bibliotecas de funções, contendo primitivas para o desenvolvimento de programas concorrentes, podendo ser incorporados como extensões de linguagens de programação genérica ou específicas ou ainda parte integrante de algumas linguagens paralelas. A outra classe, objetos distribuídos, é caracterizada pelo DCOM (Distributed Component Object Model) [Grimes, 1997] e CORBA (Common Object Request Broker Architecture) [Grimes, 1997]. Nesse caso o paralelismo fica a cargo de uma camada extra de software integrada ao sistema operacional, que é responsável pela distribuição e comunicação dos objetos. Um exemplo mais específico do funcionamento dessa estratégia é apresentado pelo DCOM. O DCOM é um aperfeiçoamento do COM, e por isso denominado na literatura de COM de longo alcance. COM (Component Object Model) [Grimes, 1997] é uma evolução do antigo padrão OLE (Object Linking and Embedding) [Williams, 1994]. Como é uma camada de software que fica acima das APIs do sistema, e possibilita a criação de interfaces em aplicações, que permite que essas se comuniquem com outras em tempo de execução. O DCOM é baseado na mesma filosofia do COM, no entanto ao invés de aplicações da mesma máquina se comunicarem, essa tecnologia permite que aplicações de diferentes máquinas conectadas via rede se comuniquem.

Enquanto as bibliotecas de funções (PVM e MPI) foram desenvolvidas com a finalidade específica de computação científica de alta performance, ou seja voltadas para a computação paralela, a tecnologia dos objetos distribuídos, possue uso mais voltado à integração de aplicações dentro de um ambiente GUI, como é o caso do COM/DCOM, para a plataforma Windows e o CORBA para o projeto GNOME (GNU Network Object Model Environment) [GNOME], para plataforma 
UNIX. Embora possa ser utilizado para programação concorrente, a utilização mais freqüente desta classe se destina a integração de aplicações e interfaces gráficas com o usuário sobre a rede, aplicações de banco de dados e Internet.

Dentre essas duas alternativas as que mais se adequam ao desenvolvimento de programas concorrentes são as bibliotecas de funções para troca de mensagens. Entretanto, a sua utilização apresenta os mesmos problemas comuns à computação paralela como um todo, ou seja a dificuldade de desenvolvimento de programas, limitando seus horizontes de utilização aos especialistas em computação paralela. Embora a computação paralela aparenta possuir um perfil eclético, ou seja concentre seus esforços para os especialistas, dificultando sua utilização para o programador comum, outra razão inviabiliza estudos mais arrojados para torná-las mais amigáveis, uma vez que essas ferramentas possuem uma natureza de programação estruturada por procedimentos, fato que impede a utilização direta dos paradigmas da programação orientada a objetos. Ainda que a tecnologia de objetos distribuídos seja toda baseada no conceito de orientação a objetos, a sua utilização para a computação paralela está muito longe de ser simples para o usuário, especialmente em ambiente Windows. Além de dificuldade de programação das interfaces COM, mesmo sendo parte integrante dessa plataforma, é necessária toda uma configuração dos sistemas em rede para a sua utilização. Outro fator limitante para a utilização dessa tecnologia, é o fato de que apenas as máquinas NT podem ser servidoras DCOM, as máquinas com a plataforma Windows 95 se limitam apenas a serem clientes.

O CVMP, mais do que um conjunto de ferramentas para a implementação de programas paralelos baseados em troca de mensagens, representa um novo conceito, que mostra como a computação paralela pode ser estendida para diversas áreas e utilizada por um espectro de usuários muito maior. Dentro desse prisma, o CVMP nada mais é do que uma camada adicional de software, criada para tornar a programação paralela simples e amigável. Neste contexto o CVMP pode estar baseado em qualquer mecanismo de troca de mensagens, podendo assim, ser uma camada adicional ao PVM e MPI e até mesmo ao DCOM e CORBA. Em algumas situações essas alternativas podem ser especialmente atraentes, uma vez que possibilitariam uma integração imediata com sistemas e programas paralelos já implementados nessas plataformas. 


\section{CAPÍTULO 6}

\subsubsection{4 - DESEMPENHO EM REDE}

Nessa seção vamos discutir alguns resultados do desempenho da transferência de pacotes pela rede. O desempenho da comunicação em rede depende de diversos fatores, que vão desde o hardware até as diversas camadas de software envolvidas na comunicação, a descrição do modelo de camadas da rede e suas funções são apresentados de forma bastante didática por Tanenbaum [Tanenbaum, 1989]. O CVMP é baseado em chamadas diretas às APIs, em ambas as estratégias de troca de mensagens (baixa e alta granularidade), de modo que, embora seja uma camada de software adicional ao sistema de rede, é praticamente desprezível, no cálculo do desempenho, uma vez que é diversas vezes mais leve que as demais camadas envolvidas no processo. Deste modo o desempenho da comunicação CVMP é praticamente igual ao desempenho do Winsock, para pacotes de granularidade baixa e ao protocolo NetBeui - IPX/SX para as granularidades altas.

Os gargalos que influenciam o desempenho da rede, podem ser comparados a uma pirâmide, onde a base (meio físico e hardware) determina o desempenho máximo, que diminui a cada camada adicional. Deste modo a configuração da rede é um fator imprescindível para a eficiência da comunicação. A interface entre o software e o hardware, é um elemento que pode limitar bastante a performance. Essa interface é realizada através de programas conhecidos como device driver. Usualmente os sistemas operacionais possuem device drivers genéricos, que não exploram as características específicas do hardware, e consequentemente comprometem a sua performance.

Realizamos as medidas de desempenho de comunicação do CVMP em uma rede de computadores plataforma Windows com configuração genérica. Uma vez que o CVMP possui um consumo de software desprezível em relação as outras camadas da rede, nossas medidas expressam o desempenho do próprio sistema operacional em uma rede padrão ethernet NE2000 de 10 Mbits/s. 

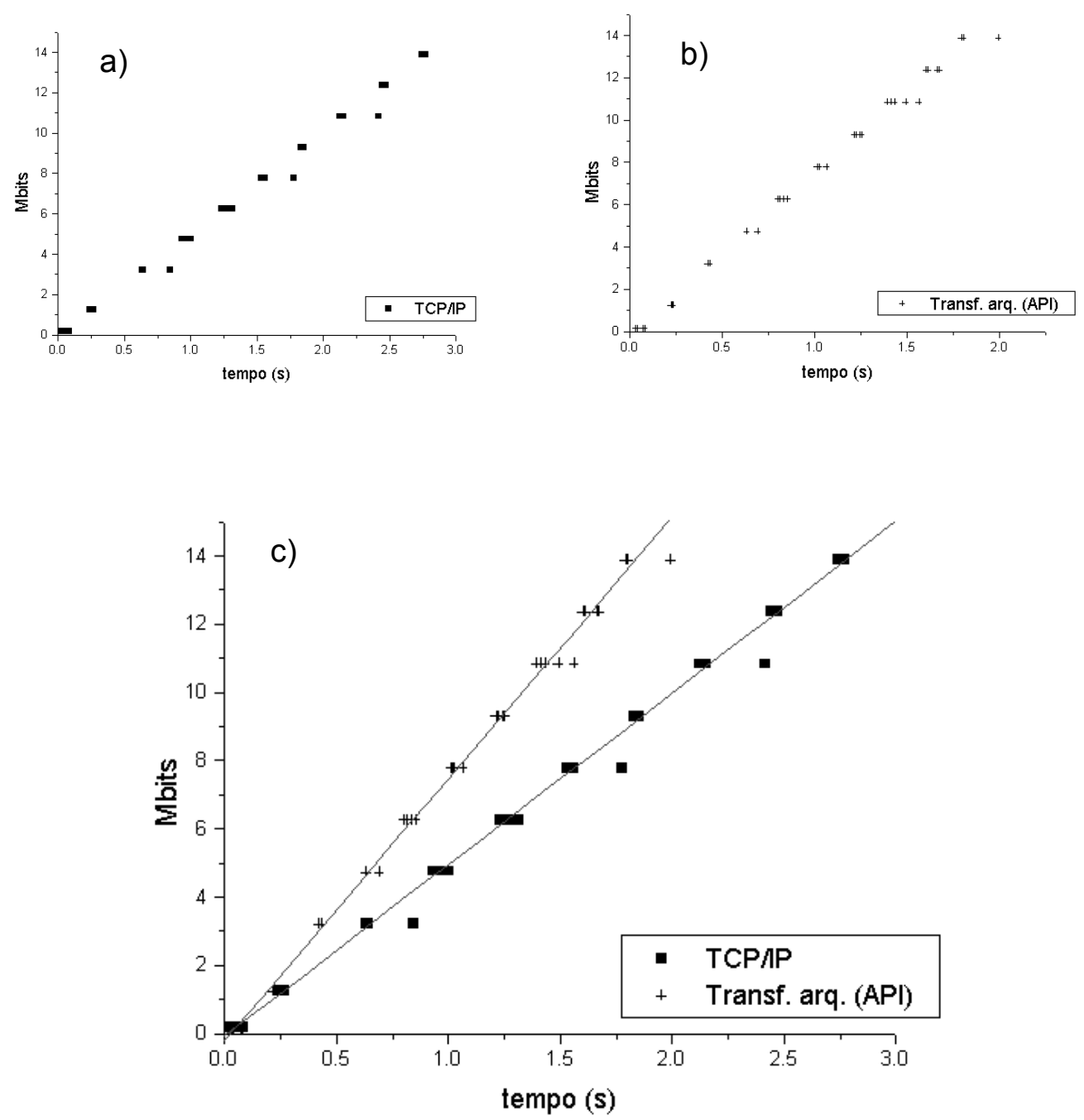

Fig. - 6.5 - Gráficos do desempenho de transferência de pacotes via rede. (a) CVMP usando protocolo TCP/IP, (b) CVMP usando transferência de arquivo através de chamada a API, utilizando protocolo NetBeui e (c) comparação entre os resultados de (a) e (b).

A Figura 6.5 apresenta os gráficos com os resultados obtidos da transferência de diferentes tamanhos de pacotes em função do tempo. Neles são apresentados os resultados dos dois procedimentos de transferência de dados do CVMP. Na Figura 6.5 (a), é apresentado o resultado do desempenho de transferência do Winsock usando TCP/IP, através dos procedimentos do CVMP para baixa granularidade e no gráfico (b) os procedimentos para alta granularidade, que consistem na troca de arquivos através de chamadas a API usando o protocolo 


\section{CAPÍTULO 6}

NetBeui e IPX/SX. Como podemos observar no gráfico (c) os protocolos NetBeui e IPX/SX apresentam um desempenho melhor de transferência de dados que o protocolo TCP/IP em plataforma Windows, o que nos motivou a implementar dois métodos diferentes para troca de mensagens via rede, um para alta e outro para baixa granularidade de pacotes, a fim de otimizar a comunicação. As linhas do gráfico (c) representam o traçado da reta ajustada a partir da regressão linear dos pontos de cada caso, obtivemos como resultados as taxas aproximadas de 5 megabits/s e 8 megabits/s respectivamente para os protocolos TCP/IP e NetBeui.

\subsection{2 - ARQUITETURA MIMD COMPARTILHADA}

A arquitetura MIMD compartilhada, diferente da arquitetura MIMD distribuída, é caracterizada pelo multiprocessamento, ou seja, por uma máquina constituída de diversos processadores que compartilham memória. Assim como os sistemas distribuídos, comentados anteriormente, os processadores dessa arquitetura, podem trabalhar em conjunto, efetuando comunicações através da troca de mensagens. Nesse modelo, os processadores utilizam a memória compartilhada para a comunicação.

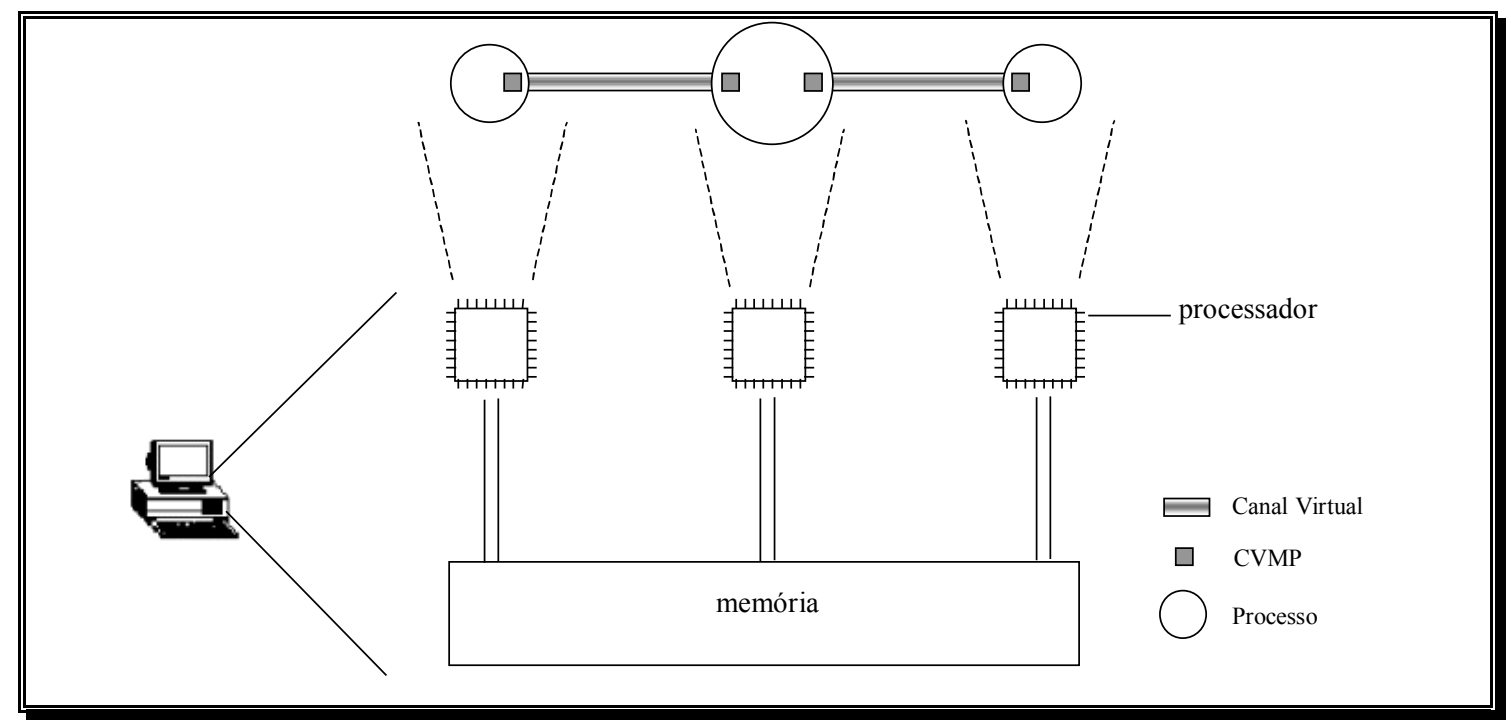

Fig. - 6.6 - Exemplo de uma aplicação paralela CVMP em uma arquitetura MIMD compartilhada. Nesse exemplo temos uma máquina multiprocessada com 3 processadores.

A Figura 6.6 apresenta um exemplo dessa arquitetura, nela temos uma máquina constituída por 3 processadores, que compartilham a mesma memória. 
Em cada um dos processadores está alojado um processo, dos quais os dois da extremidade são escravos e o central é o mestre. Assim como na arquitetura distribuída, através dos objetos CVMP (pequenos quadrados no interior dos processos), são estabelecidos canais virtuais, que possibilitam a troca de mensagens entre os processos.

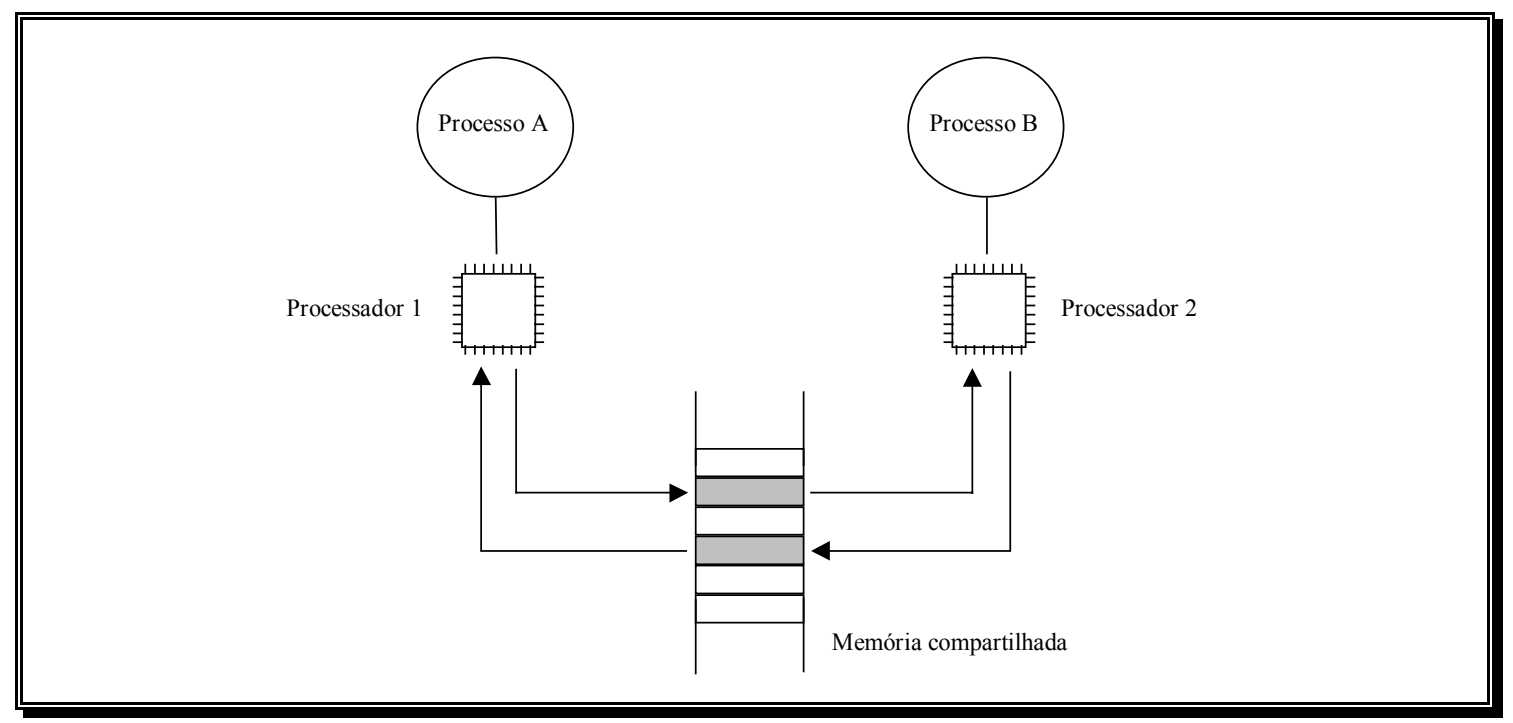

Fig. - 6.7 - Diagrama ilustrativo do mecanismo de troca de mensagens em sistema MIMD compartilhado.

Nos objetos CVMP memória compartilhada, os canais virtuais utilizam a memória compartilhada para trocar mensagens. A Figura 6.7 apresenta uma ilustração desse conceito. Nela temos dois processadores efetuando troca de mensagens a partir de memória compartilhada.

A troca de mensagens através da memória compartilhada é realizada no CVMP através do mecanismo do Windows denominado de "filemapping", que consiste num conjunto de APIs que permitem a manipulação da memória global (memória RAM e memória virtual) com requintes de tratamento de arquivos [Deatz, 1997] [Petzold, 1995] [Petzold \& Yao, 1996] [Richter, 1995]. Através desse mecanismo, são estabelecidos os Canais virtuais, que permitem que diferentes processos, alojados em processadores diferentes ou no mesmo processador, possam realizar a troca de mensagens através de objetos CVMP.

A performance da comunicação nessa arquitetura é muito superior à distribuída, sendo que a taxa de transferência entre processador e memória RAM é incomparavelmente mais alta do que em rede, mesmo se considerarmos a 


\section{CAPÍTULO 6}

transferência através da memória virtual, que pode envolver operações em disco, ainda assim o desempenho seria muito superior ao obtido via rede. Além de taxa de transferência superior, o tempo de acesso também é bastante inferior, diminuindo assim a latência da comunicação. Deste modo, essa arquitetura pode ser bastante promissora para sistemas na área de visão, que demandam considerável troca de dados. Entretanto, o alto custo de hardware, assim como o número relativamente baixo de processadores por máquinas disponíveis no mercado (4 processadores por máquina) ainda inviabilizam essa arquitetura. A combinação das duas arquiteturas, MIMD compartilhado e distribuído aparenta ser uma solução bastante interessante, uma vez que aumenta o número de máquinas no sistema paralelo assim como possibilita estratégias de balanceamento de carga, algoritmos com maior gargalo em troca de mensagens alojados na arquitetura compartilhada e menor na distribuída.

\section{6 - FUNCIONAMENTO BÁSICO CVMP}

O CVMP básico é o objeto elementar da ferramenta CVMP. Trata-se de um componente VCL nativo em Delphi que possui propriedades e métodos que efetuam a troca de mensagens e controle entre processos, sendo composto de duas versões, uma para arquitetura MIMD distribuída (Tcvmp) e outra para arquitetura MIMD compartilhada (Tcvmps).

A operação do CVMP é bastante simples. Como primeiro passo, usualmente nas operações de VCL do Delphi, o programador deve arrastar e soltar o CVMP básico da paleta de componentes CVMP sobre o seu formulário. Efetuado esse procedimento, deve-se então criar um arquivo de configuração do objeto. $\mathrm{O}$ arquivo de configuração é um arquivo em formato ASCIl que contém as informações (a respeito das máquinas, redes e porto socket) necessárias para que o objeto possa estabelecer um canal virtual. A Figura 6.8 apresenta um exemplo típico de um arquivo de configuração.

O arquivo de configuração pode ser criado e editado de diferentes maneiras. O usuário pode criar o arquivo com um editor de textos qualquer ou então utilizar o gerador automático de arquivo de configuração, que acompanha as ferramentas CVMP. O gerador automático é uma aplicação bastante simples, onde o usuário preenche os campos e a partir desses dados são gerados os arquivos de configuração. Ainda outra alternativa é configurar as propriedades do componente 
CVMP diretamente. Isto pode ser feito através de programação, ou ainda pela janela Object Inspector do ambiente Delphi, através das propriedades: master_ip (ip da máquina), master_n (nome e domínio), master_pt (porto socket), slave_ip, slave_n e slave_pt.

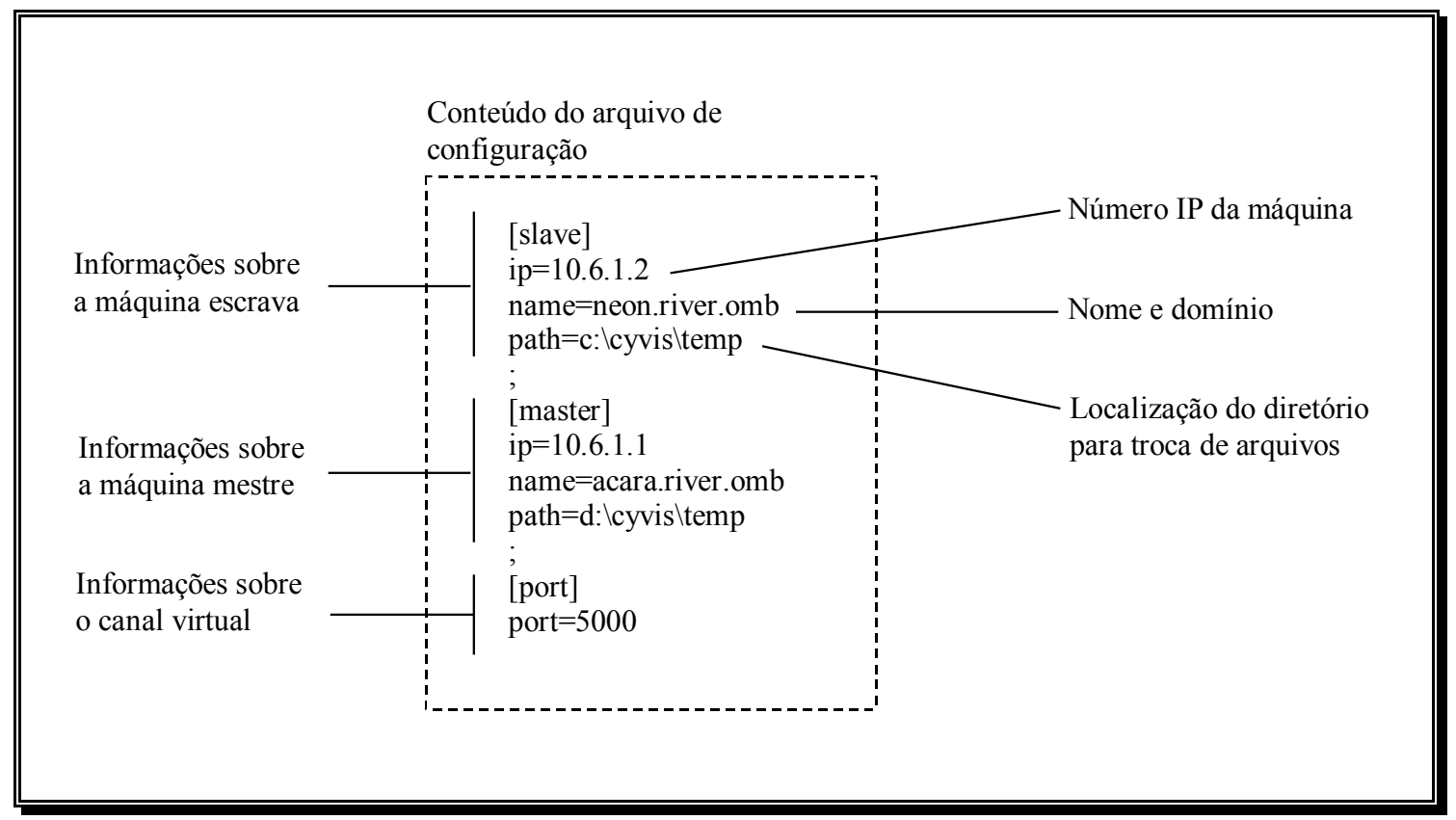

Fig. - 6.8 - Exemplo de um arquivo de configuração do objeto CVMP.

Uma vez editado o arquivo de configuração deve ser atribuído à propriedade $m p \_i n i t$ file o nome e o diretório onde se encontra o arquivo de configuração correspondente ao objeto. Devemos lembrar que cada canal virtual possui dois arquivos de configuração idênticos, um para o objeto mestre e o outro para o escravo. Os arquivos de configuração são idênticos para os objetos CVMP MIMD compartilhado e distribuído. Nos objetos CVMP para arquitetura distribuída, a configuração port define o porto do socket a ser utilizado pelo canal virtual, enquanto que, para a arquitetura compartilhada, o port define os rótulos dos ponteiros para a memória. Não poderão haver mais de um Canal Virtual com o mesmo número de port em uma mesma arquitetura.

Após a configuração dos objetos CVMP, o canal virtual está pronto para ser estabelecido e realizar a troca de mensagens, sendo estas tarefas de programação realizadas a partir da manipulação dos métodos e propriedades do objeto CVMP. No momento do estabelecimento dos canais virtuais, são definidos os papéis de cada objeto. No objeto escravo é executado o método $\mathrm{mp}$ _listen ou mp_slave, 


\section{CAPÍTULO 6}

deste modo, esse objeto ficará aguardando a primeira conexão de seu par mestre para que o canal virtual seja estabilizado. Estando o objeto escravo aguardando a conexão, deve ser então executado, no objeto a ser definido como mestre o método mp_connect ou mp_master. Deste modo está estabelecido um canal virtual entre os dois objetos, permitindo a troca de mensagens entre estes dois componentes (mestre e escravo).

\subsection{1 - PROGRAMAÇÃO}

A programação de aplicações paralelas com o CVMP é realizada a partir de um conjunto de primitivas, que realizam a troca de mensagens, caracterizadas por métodos e propriedades do objeto CVMP. Figura 6.9 apresenta as principais primitivas de troca de mensagens e suas respectivas funções.

\begin{tabular}{|l|l|}
\hline mp_init_file & $\begin{array}{l}\text { Propriedade, determina o nome e a } \\
\text { localização do arquivo de configuração. }\end{array}$ \\
\hline mp_listen, mp_slave & $\begin{array}{l}\text { Método, define o objeto como escravo. } \\
\text { Utilizado para estabilizar o Canal Virtual. }\end{array}$ \\
\hline mp_connect, mp_master & $\begin{array}{l}\text { Método, define o objeto como mestre. } \\
\text { Utilizado para estabilizar o Canal Virtual. }\end{array}$ \\
\hline mp_send(mens:str) & $\begin{array}{l}\text { Método, envia uma mensagem através do } \\
\text { Canal Virtual. }\end{array}$ \\
\hline str:=mp_receive & $\begin{array}{l}\text { Método, função que retorna a primeira } \\
\text { mensagem da fila de mensagens recebidas. }\end{array}$ \\
\hline setblocking & $\begin{array}{l}\text { Método, define se as mensagens são } \\
\text { bloqueantes ou não. }\end{array}$ \\
\hline sendfile(str) & $\begin{array}{l}\text { Método, envia mensagem de alta } \\
\text { granularidade (arquivos). }\end{array}$ \\
\hline receivefile(str) & $\begin{array}{l}\text { Método, recebe mensagem de alta } \\
\text { granularidade (arquivos). }\end{array}$ \\
\hline mp_close & Método, termina o Canal Virtual. \\
\hline
\end{tabular}

Fig. - 6.9-Principais primitivas de troca de mensagens.

A partir da utilização das primitivas é possível desenvolver as aplicações paralelas, programando as diferentes estratégias de paralelismo a partir das trocas de mensagens. Referências para algumas estratégias de paralelismo são encontradas em [Almasi \& Gottlieb, 1994] [Amorin et al.,1988] [Bem-Ari, 1990] [Brawer, 1989] [Codenoti \& Leoncini, 1994] [Foster, 1995].

A Figura 6.10 apresenta um exemplo de um algoritmo concorrente utilizando 
as primitivas CVMP. Nele temos quatro computações sendo realizadas, $A, B, C$ e D, onde os cálculos C e D são obtidos mediante os resultados de A e B. Vamos supor que cada um destes cálculos leva um tempo igual a $t$. Supondo que $t$ é muito maior que o tempo da troca de mensagem realizada (basicamente os resultados e parâmetros da computação), então podemos desconsiderar o tempo tomado pelos processos de comunicação. Caso esse algoritmo hipotético seja implementado de modo seqüencial, o tempo total seria de 4 t. O algoritmo apresentado na Figura 6.10 é uma versão paralela para essa computação tal que os cálculos $A$ e B são executados simultaneamente em duas máquinas, e após a troca de resultados entre os processos, C e D são igualmente processados em concorrência, em cada uma das máquinas. Deste modo temos um tempo total de processamento igual a $2 t$, obtendo uma performance de computação 2 vezes maior. Caso não houvesse a dependência de dados ( $C$ e $D$ necessitarem dos resultados de $A$ e $B$ ), o número de máquinas poderia ser maior, aumentando ainda mais a performance do sistema.

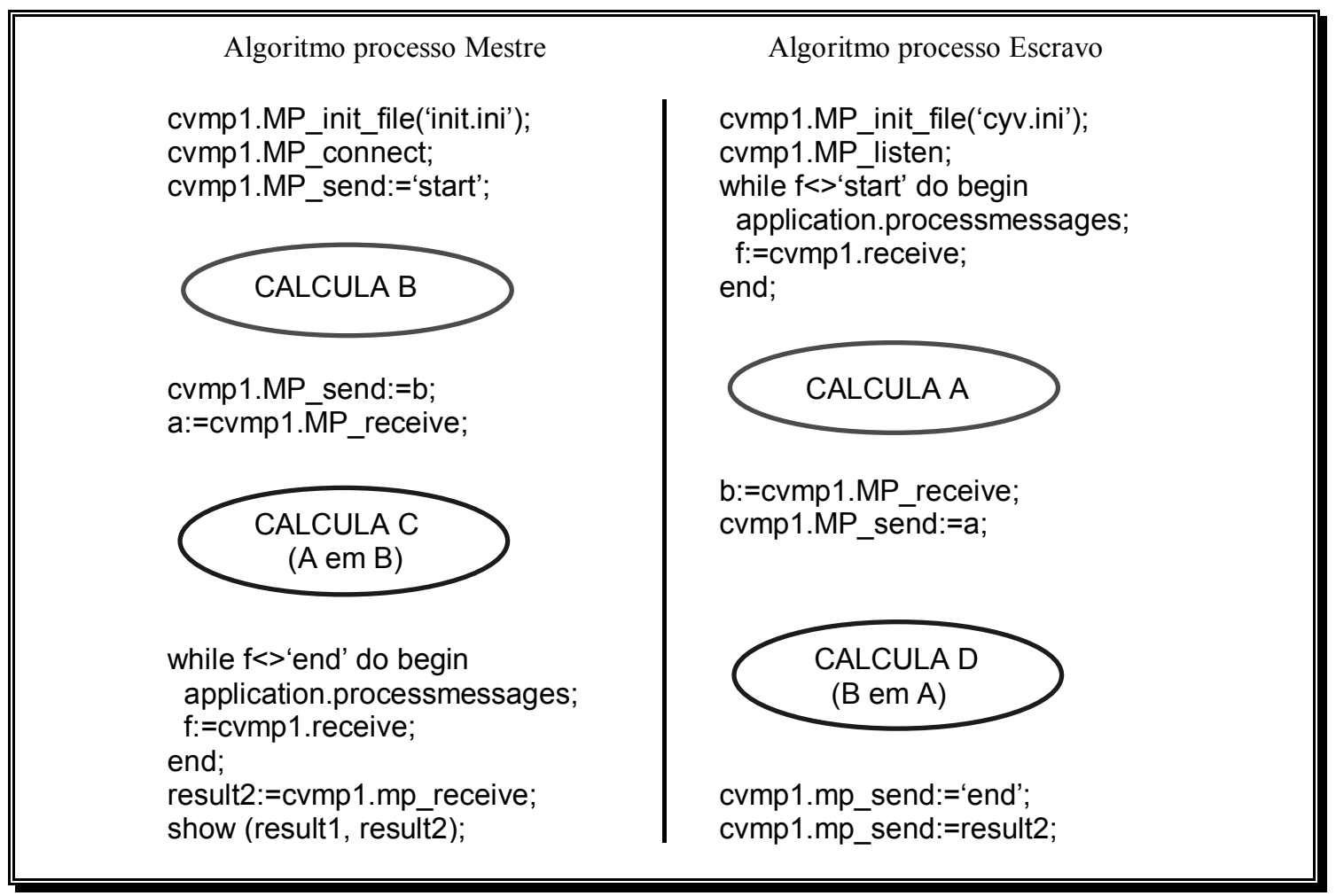

Fig. - 6.10 - Exemplo de implementação de um algoritmo paralelo utilizando as primitivas CVMP. 


\subsection{2 - MODELO EM CAMADAS}

Devido à sua natureza orientada a objetos, o CVMP permite sua reutilização e consequentemente o desenvolvimento de outros objetos, que herdam suas propriedades. Esse conceito é fundamental para a arquitetura do CVMP, permitindo que sejam desenvolvidos outros objetos, com maior nível de especificidade, mais simples de utilizar, programação visual mais desenvolvida e etc. Desta forma, além do desenvolvimento das ferramentas que compõem o conjunto CVMP, também é possível o desenvolvimento personalizado de novos componentes, de acordo com as necessidades do programador. Assim, o CVMP pode ser visto como um modelo de camadas, onde o CVMP básico é a camada básica que permite a inserção de um número ilimitado de camadas adicionais.

Nas próximas seções vamos apresentar uma série de objetos e aplicações que foram desenvolvidas a partir desse princípio. Um exemplo de componente personalizado é o CyComm [Moreira, 1999], desenvolvido em conjunto com Jander Moreira e Alan Felinto. Ele incorpora diversas características, tais como um editor interno para modificar o arquivo de configuração, protocolos adicionais para troca de imagens e servidor de imagem para máquinas com sistema de captura. Esse componente foi utilizado para desenvolver o sistema de comunicação e controle de alguns módulos do sistema descrito no Capítulo 8 desta tese.

\section{7 - DISPARADOR DE APLICAÇÕES (LAUNCHER)}

Launcher ou disparador de aplicações é a denominação que atribuímos à ferramenta responsável pela execução de processos remotos. Através de sua utilização o módulo principal do sistema pode disparar aplicativos, em geral escravos, ao longo da rede. O CVMP-launcher, é composto por dois aplicativos e um componente, sendo que os aplicativos são constituídos pelo módulo principal e pelos disparadores.

Os módulos disparadores possuem um sistema de instalação que altera os registros do sistema operacional de forma que estes são executados toda vez que o Windows é reiniciado, não necessitando que o usuário sequer entre em sua área. Deste modo, mesmo máquinas sendo utilizadas por outros usuários podem ser solicitadas para executar processos do sistema paralelo. Os módulos disparadores são instalados nas diversas máquinas da rede, a serem utilizadas pelo sistema 
distribuído; sua função é aguardar as ordens do módulo principal e mediante elas, disparar processos locais.

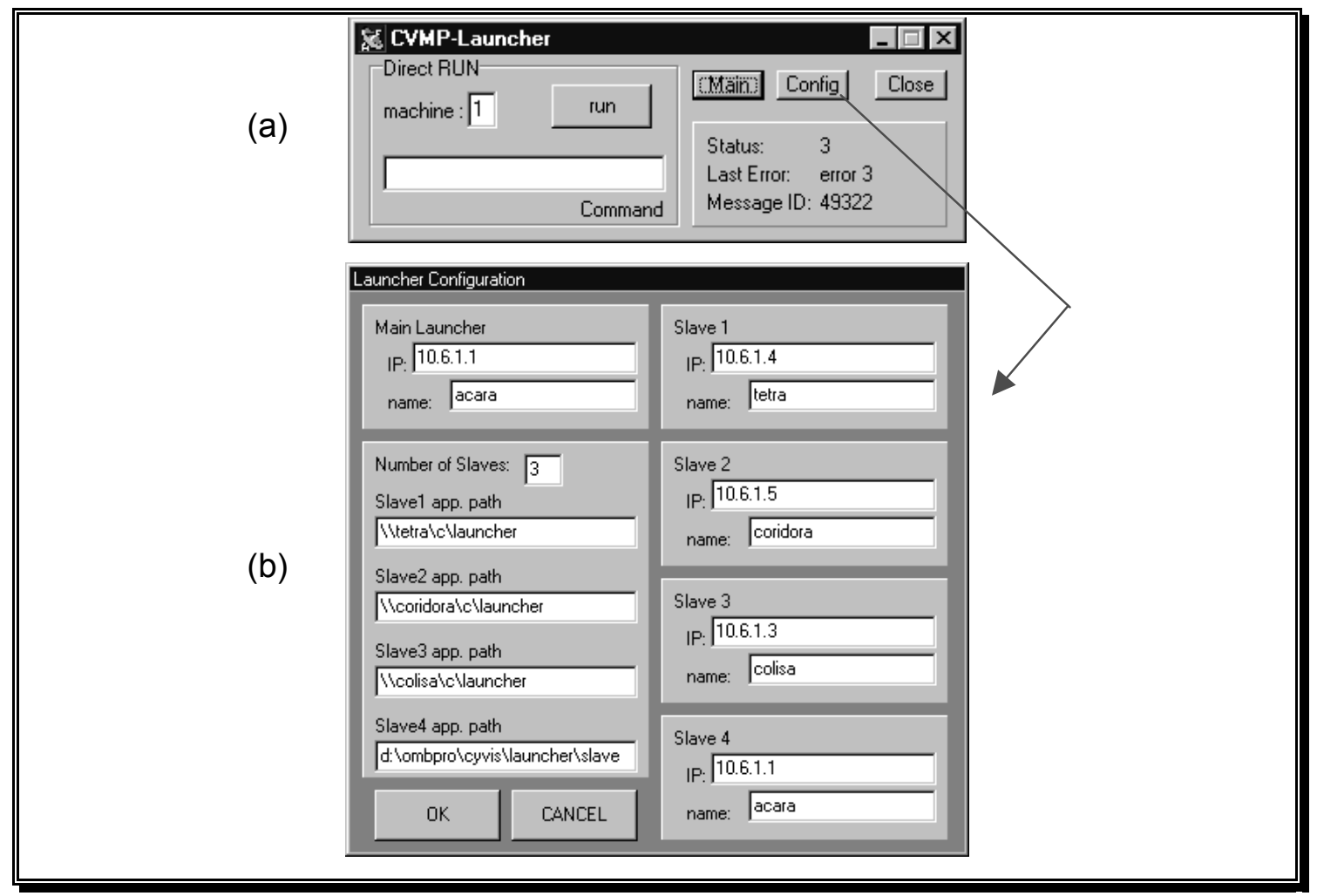

Fig. - 6.11 - Módulo principal do aplicativo CVMP-Launcher. (a) Janela principal, (b) Janela de configuração.

$\mathrm{Na}$ rede pode existir uma ou mais máquinas com módulos principais, em geral essa ou essas máquinas são responsáveis pelo controle do sistema, e vão requerer a execução de processos escravos espalhados pela rede. A Figura 6.11 apresenta a janela do módulo principal, com a respectiva janela de configuração. Os processos remotos podem ser disparados remotamente ou através do objeto Tlauncher, baseado no CVMP para memória compartilhada, esse componente envia mensagens para o modulo principal, ativando o disparo de mensagens para as máquinas remotas, de modo que estas possam executar os processos remotos.

\section{8 - CVMP PROCESSOR FARM}

O CVMP processor farm é constituído de um conjunto de componentes Delphi, desenvolvido sobre o CVMP, que permite a implementação visual de 


\section{CAPÍTULO 6}

aplicativos paralelos que utilizam a estratégia processor farm. Desenvolvido para simplificar a programação de algoritmos paralelos, o CVMP processor farm permite que até mesmo os programadores mais inexperientes possam desenvolver seus próprios sistemas distribuídos.

Dentre as estratégias de paralelismo, observamos que o processor farm (ou fazenda de processadores) é bastante genérico e pode ser amplamente utilizado nos mais diversos algoritmos de visão. Uma característica bastante importante dessa estratégia é o balanceamento automático de carga, através do qual sistemas híbridos, com máquinas com performances diferentes, podem ser prontamente utilizados, sem que o programador se preocupe com a distribuição das máquinas que compõem o sistema e seu poder computacional.

A Figura 6.12 apresenta um diagrama que ilustra essa estratégia. Como podemos observar, o processor farm consiste em um processo de supervisão que controla e distribui tarefas para um conjunto de processos escravos. Os processos escravos são ordenados através de uma fila de processos livres, que fica armazenada no supervisor. Quando for necessário distribuir uma tarefa, o supervisor escolhe o primeiro elemento da fila, atribui a este uma tarefa, e então retira-o da fila. À medida que os processos escravos vão terminando a execução das tarefas, vão sendo inseridos novamente na fila de processos disponíveis. $O$ principal inconveniente dessa estratégia é a sua preferência a sistemas sem dependência de dados. No entanto, através de algumas adaptações, pode-se utilizá-la mesmo em sistemas com relativa dependência de dados.

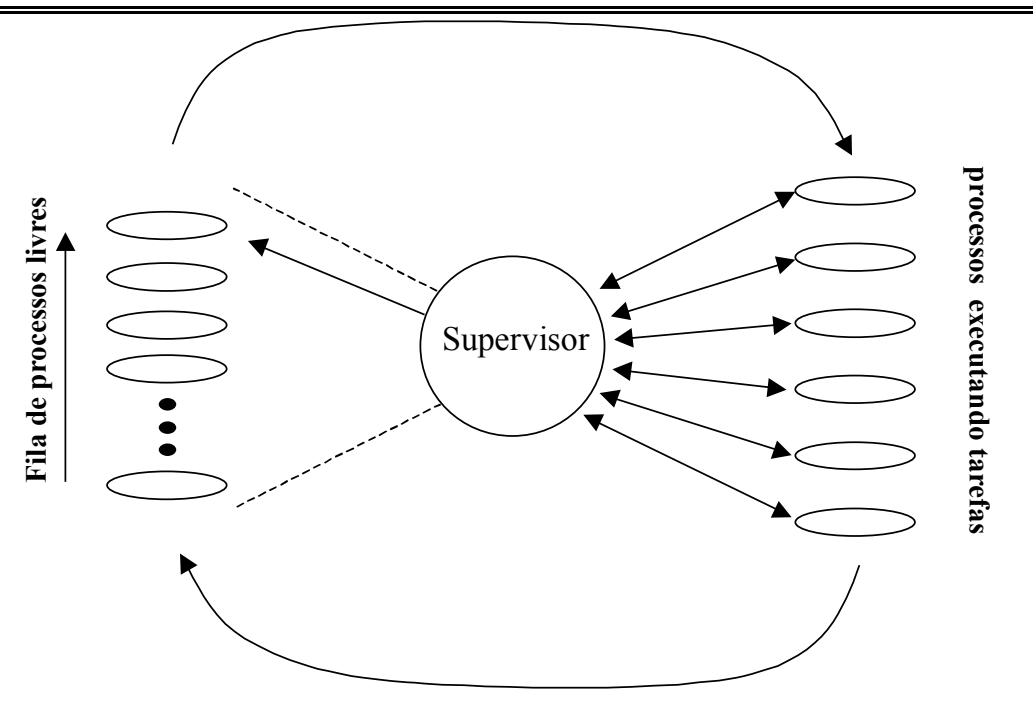

Fig. - 6.12 - Diagrama ilustrativo da estratégia de paralelismo processor farm. 
O CVMP processor farm foi desenvolvido com o intuito de fornecer sofisticados recursos para a implementação de sistema distribuídos e ao mesmo tempo ser simples de usar, de modo que até o mais inexperiente dos programadores possa desenvolver sua aplicação paralela. Assim, o CVMP processor farm é o ponto áureo do CVMP, permitindo o desenvolvimento genérico de aplicações paralelas de modo visual e intuitivo.

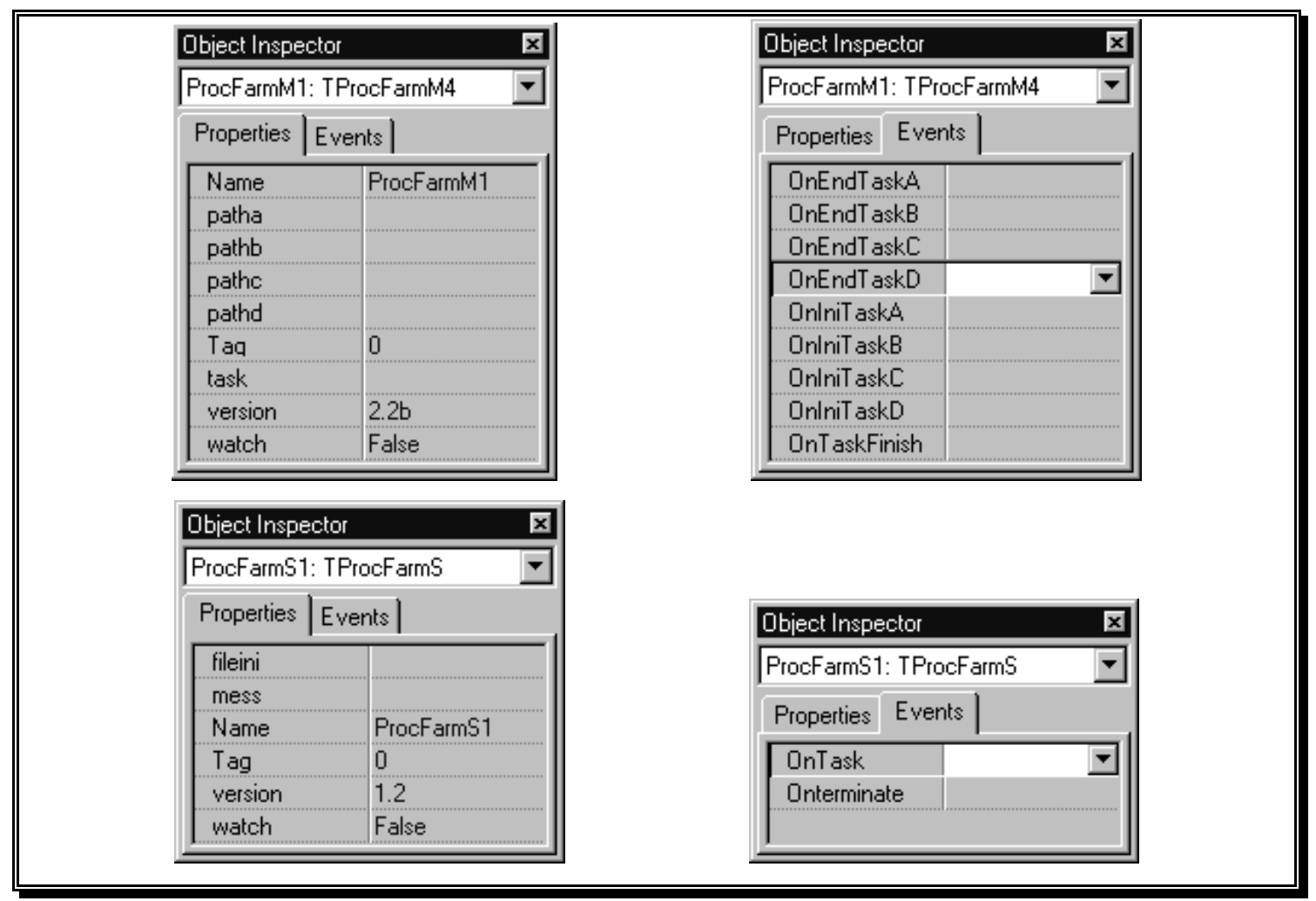

Fig. - 6.13 - Janelas do object inspector do Delphi, mostrando as propriedades e eventos dos objetos CVMP Processor Farm (a) supervisor (TprocFarmM4) e (b) escravo (TprocFarmS).

O CVMP processor farm é constituído basicamente de dois componentes: escravo e mestre (supervisor). Os componentes escravos, assim como o componente mestre, devem ser arrastados e soltos no formulário das aplicações escravas e de supervisão, respectivamente. Através do object inspector, o programador configura alguns poucos atributos e seleciona os eventos a serem programados. A Figura 6.13 apresenta a janela do object browser mostrando as propriedades e eventos dos objetos supervisor e escravo. O objeto supervisor utilizado na Figura 6.13 tem um limite de controle de 4 processos escravos (designados pelos eventos $A, B, C$ e D), no entanto implementamos 3 objetos 


\section{CAPÍTULO 6}

supervisores, para controlar diferentes números máximos de processos escravos (4, 8 e 16 processos).

A sua utilização simplificada permite, conforme vamos demonstrar, que um sofisticado sistema distribuído possa ser implementado mediante alguns cliques de mouse e poucas linhas de código. Para exemplificarmos, vamos imaginar um exemplo bem simples que possa ilustrar a utilização do CVMP Processor Farm. Dada uma função hipotética, a qual vamos chamar de $F$, que a partir de um determinado número de parâmetros $(p)$, realize um cálculo interativo retornando um resultado, vamos presumir que nosso problema necessite dos resultados de diversas chamadas a $F$. Supondo que, toda a vez em que $F$ é executada, um demasiado poder computacional seja demandado; deste modo, uma solução paralela pode aumentar a performance do sistema e consequentemente diminuir o tempo de resolução. Assim, supondo que cada execução de $F$ demore 1 minuto e nosso problema necessite de 120 cálculos, nossa aplicação levará 2 horas para ser executada em uma máquina. Nessa situação, se utilizarmos 4 máquinas iremos reduzir o tempo de execução em 1/4 (30 minutos).

A Figura 6.14 apresenta a principal rotina da máquina escrava. Ela é chamada pelo evento OnTask, que podemos ver na Figura 6.13. Com pequenas linhas de código, o CVMP processor farm permite que o programador extraia os parâmetros, enviados pelo supervisor, para cálculo da função e depois de calculado $F$ retorne o resultado para ele. Em nosso exemplo como temos um único modelo de escravo, não existe necessidade de escrever um código específico para cada máquina, bastando replicar o aplicativo e distribuí-lo na rede.

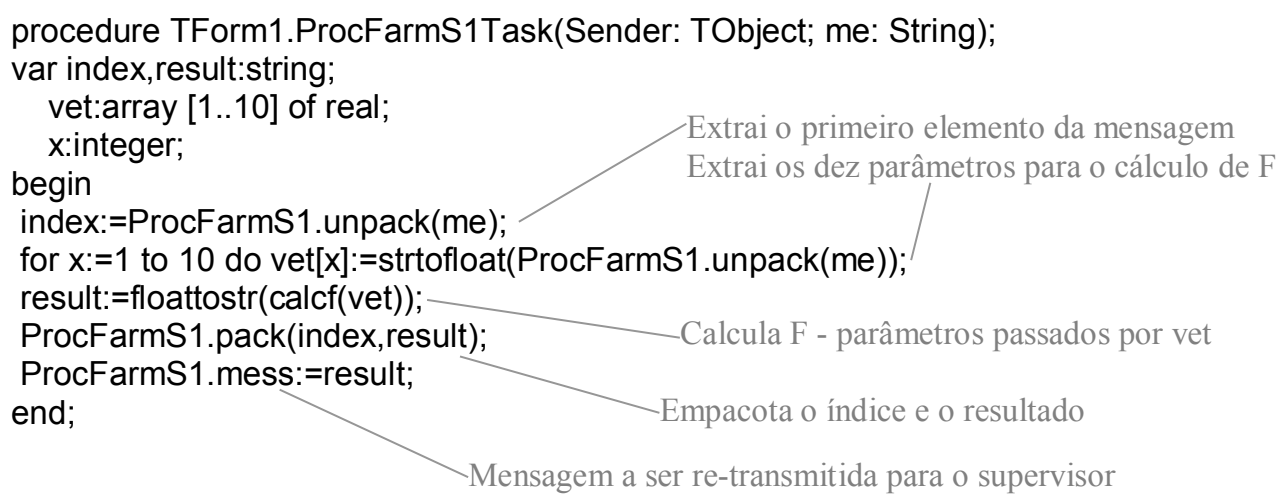

Fig. - 6.14 - Exemplo de codificação do evento OnTask do componente escravo do CVMP processor farm. 
$\mathrm{Na}$ Figura 6.15, temos alguns segmentos de código da aplicação supervisora. Para nosso exemplo, são necessários dois eventos para cada processo escravo, um para a designação das tarefas (OnlniTask) e outro para o término das tarefas e recebimento do resultado (OnEndTask), respectivamente mostrados na Figura 6.15 (A) e (B). Deste modo, como podemos observar através dos códigos, a programação do supervisor é muito simples, necessitando poucas linhas de código. Para iniciar o processamento paralelo, deve ser executado o método descrito em $(C)$, onde o primeiro parâmetro deve conter o número de processos utilizados e no segundo, o número de tarefas a serem distribuídas.

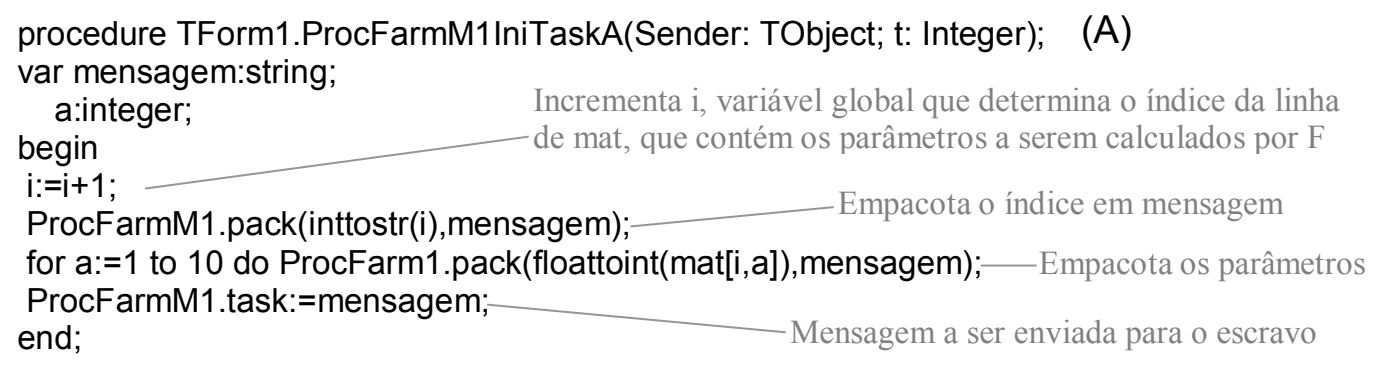

ProcFarmM1.execute(núm. de processos, núm. de tarefas)

(C)

Fig. - 6.15 - Exemplo de codificação dos eventos do componente supervisor do CVMP processor farm. (A) Evento OnIniTask, disparado antes de ser atribuída a tarefa para um processo escravo. (B) Evento OnEndTask, disparado assim que o escravo finalizou a tarefa. (C) Método para iniciar a execução do processamento.

A configuração do sistema também é muito simples e pode ser realizada visualmente pelo próprio usuário, não necessitando ser feita via programação. Para isso deve ser executado o método config (do componente supervisor), que apresenta uma janela em tempo de execução na qual o usuário descrimina os 


\section{CAPÍTULO 6}

nomes, diretórios e IP dos processos escravos, conforme mostrado na Figura 6.16. Esse procedimento gera automaticamente todos os arquivos de configuração do sistema, tanto para o supervisor como para os escravos.

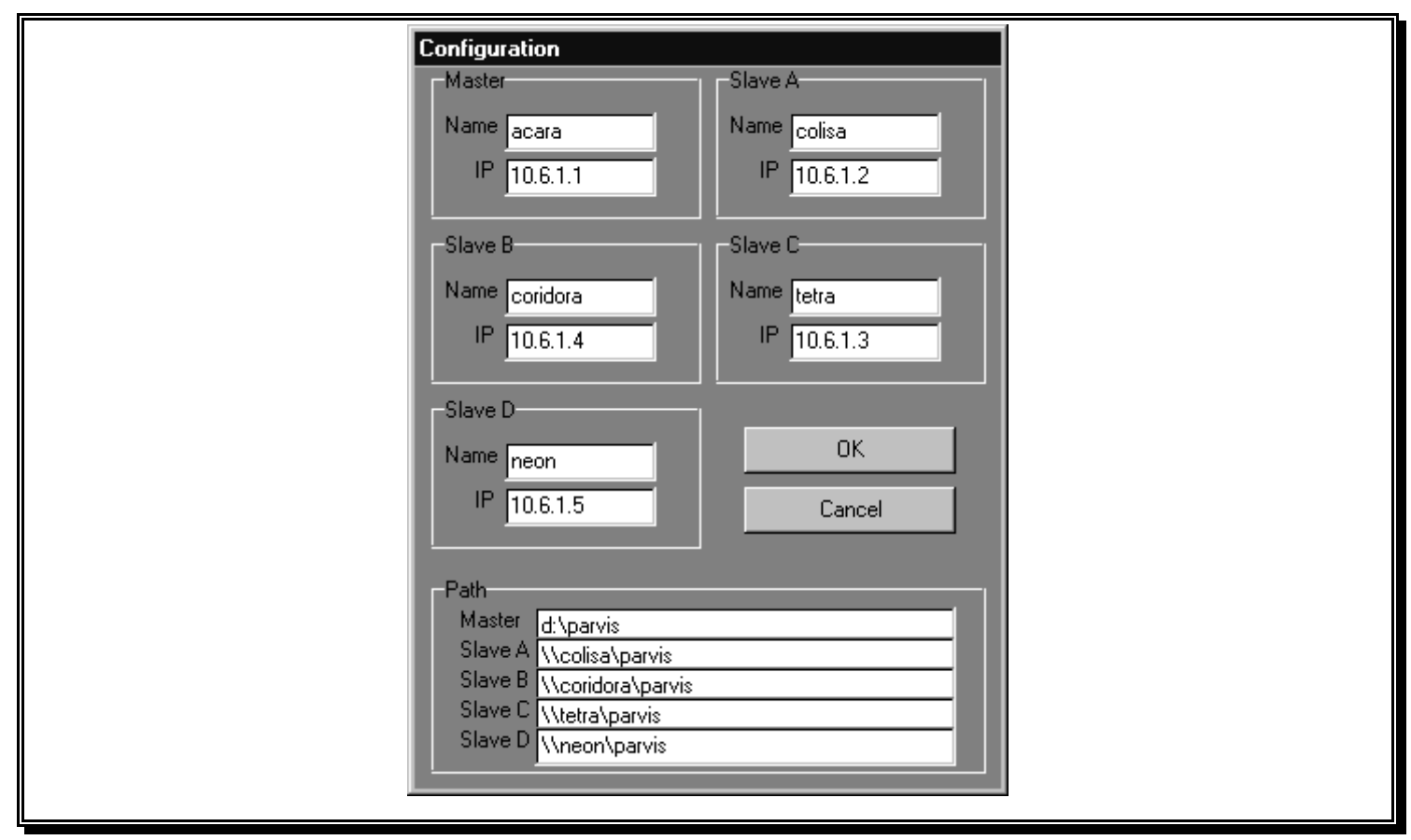

Fig. - 6.16 - Janela de configuração automática da distribuição do sistema, exibida através de chamada ao método config do componente supervisor.

Os componentes possuem ainda mecanismos para visualizar o processamento em tempo de execução. Se a propriedade watch (ver Figura 6.13) estiver atribuída como verdadeiro, então o sistema exibe uma janela que mostra simultaneamente um resumo do tráfego de mensagens enviadas e recebidas pelo objeto. Isso pode ser bastante útil para depurar o sistema, assim como para analisar seu comportamento. O componente supervisor possui também acesso automático à ferramenta de visualização de estatística e desempenho em tempo de execução, descrita na próxima seção.

\section{9 - ANÁLISE DE DESEMPENHO E ESTATÍSTICAS}

Uma tarefa muito importante nos projetos de programas paralelos é a análise de desempenho e estatísticas, através das quais vai ser estimada a performance, o balanço de carga e os gargalos do sistema. Um dos empregos do 
paralelismo consiste em aumentar a performance dos mecanismos computacionais para uma execução mais rápida dos algoritmos. No entanto, os gargalos, a má distribuição das cargas e o emprego incorreto de uma determinada estratégia de paralelização podem fazer com que os sistemas paralelos sejam até mesmo mais lentos que os seqüenciais, perdendo completamente seu sentido de existência.

As medidas de análise de desempenho e suas estatísticas constituem em uma árdua tarefa para o programador, que muitas vezes, devido à escassez de ferramentas apropriadas, tem que desenvolver programas para auxiliá-lo na realização dessas medidas, tomando grande parte de seu tempo. Devido a esses fatores, desenvolvemos algumas ferramentas para extrair medidas de performance, de modo a auxiliar o programador e simplificar esta importante etapa no desenvolvimento de sistemas paralelos.

As ferramentas de análise de desempenho e estatística do CVMP se dividem em dois grupos: análise estática e análise dinâmica.

\subsection{1 - FERRAMENTAS PARA ANÁLISE ESTÁTICA}

As ferramentas para análise estática são compostas por um componente (TStat) e um aplicativo de visualização. O componente TStat, é uma ferramenta de uso genérico para auxiliar as medidas de desempenho de programas seqüenciais ou paralelos. Através dela o programador pode estimar o tempo de duração dos procedimentos, funções, métodos utilizados em seus programas ou até mesmo o tempo de execução de uma linha ou de um conjunto de linhas de código.

A Figura 6.17 contém um exemplo da utilização do TStat, mostrando a utilização do componente para um caso hipotético. Nele são apresentados os métodos do componente TStat:

initialize e terminate: Métodos utilizados para iniciar e terminar as medidas realizadas por TStat. Quando o método initialize é chamado, inicia a contagem do tempo total da medida, sendo concluída com o método terminate.

start e finish: Marcam o tempo das linhas de código entre a chamada aos métodos start e finish.

makefile: Grava um arquivo contendo as medidas realizadas. 


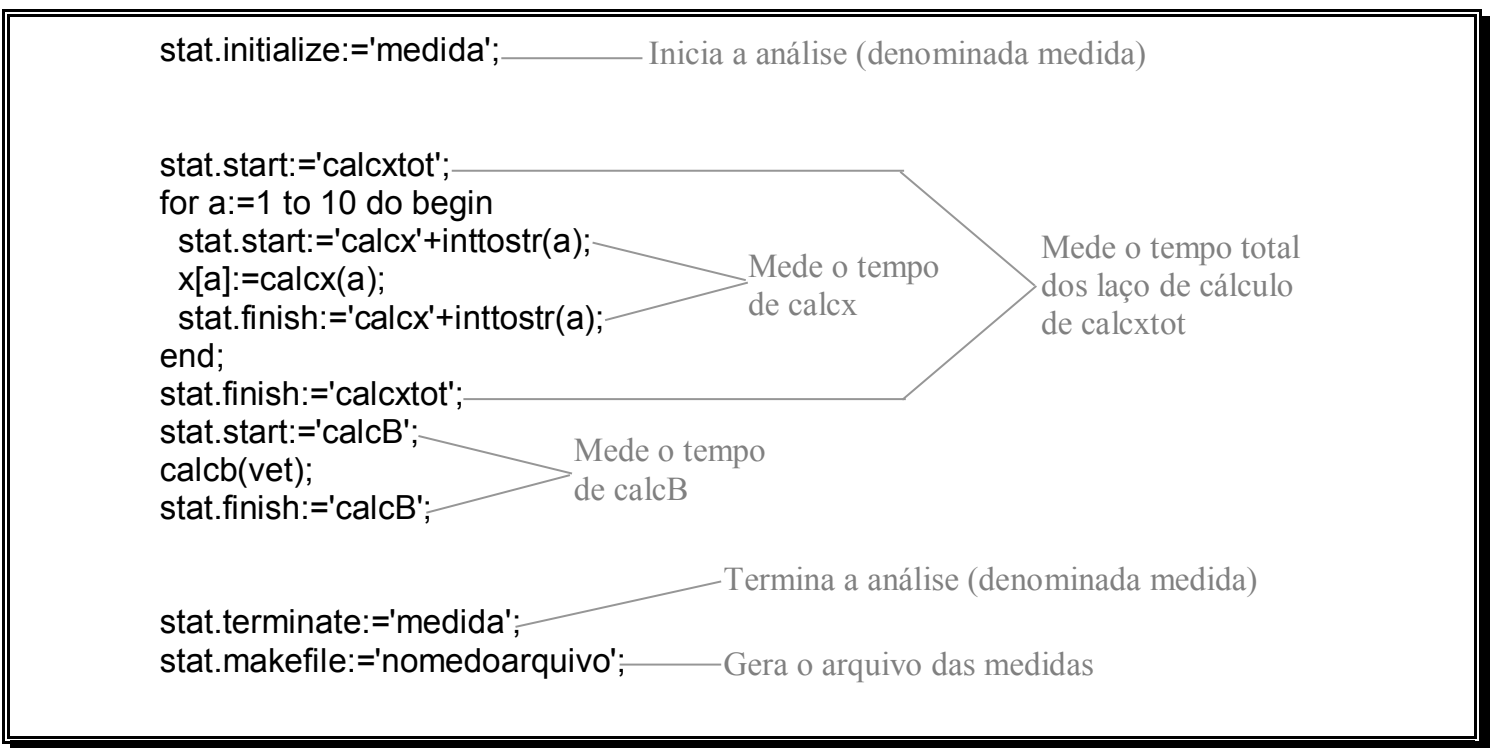

Fig. - 6.17 - Exemplo da utilização do componente TStat.

(a)

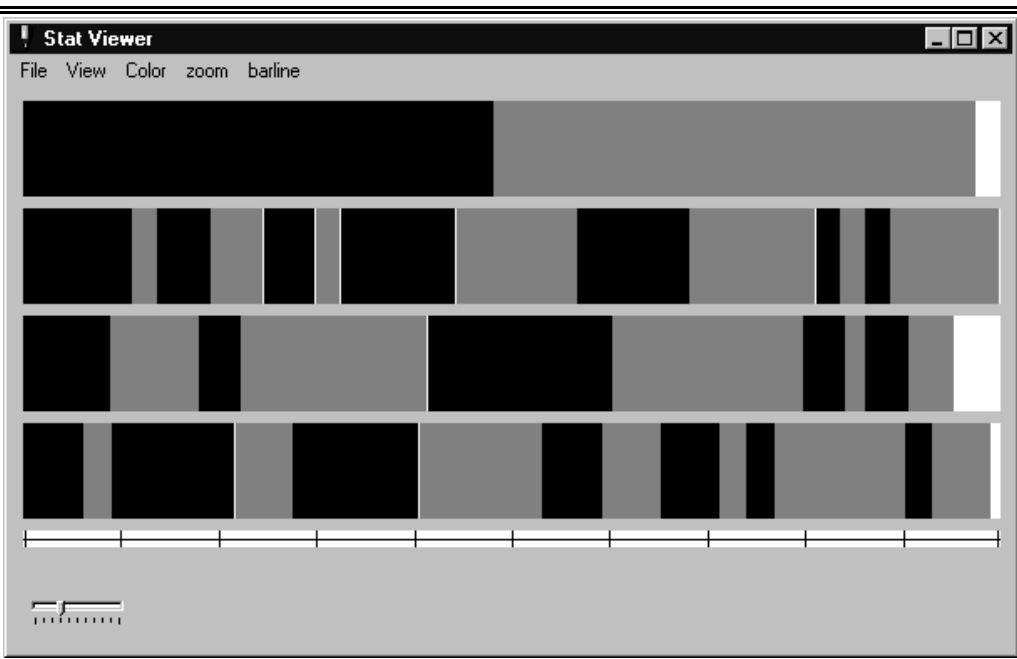

(b)

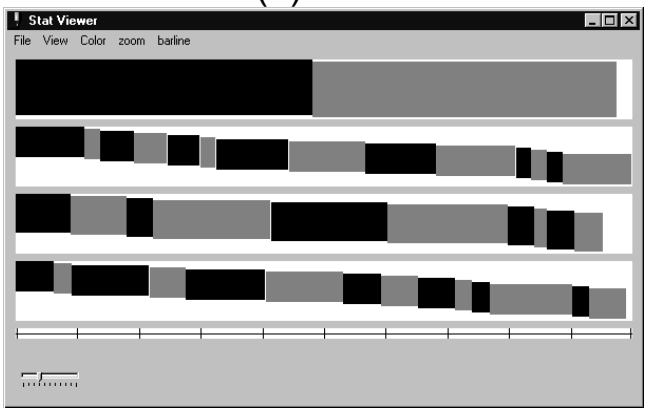

(c)

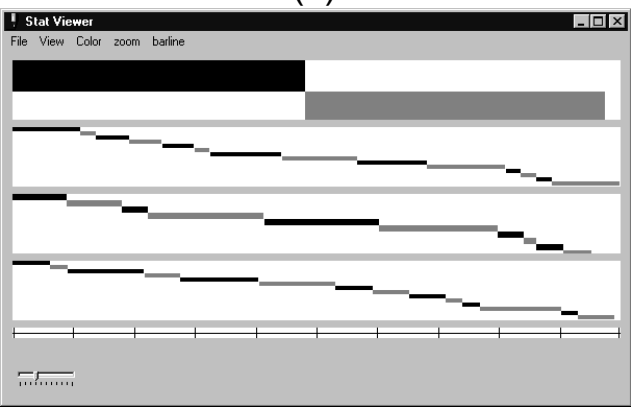

Fig. - 6.18 - Janelas da aplicação StatViewer, apresentando algumas das diferentes formas de visualização em blocos das medidas. As linhas horizontais representam os 4 processos paralelos, formados pelos blocos que exprimem as tarefas. (a) Visualização com blocos simples, (b) com blocos pequenos e (c) com linhas. 
O aplicativo de visualização, denominado StatViewer, apresenta as medidas para o usuário, a partir do arquivo gerado pelo componente TStat. Através de diagramas de barras, as medidas podem ser visualizadas, permitindo a análise da arquitetura paralela e da distribuição dos processos, a localização de gargalos e, deste modo, possibilitando o aprimoramento do projeto e seu consequente aumento de performance. A Figura 6.18 apresenta um exemplo da visualização das medidas através do StatViewer, nela são mostradas 3 janelas com diferentes diagramas de barras que mostram os resultados de um sistema com arquitetura processor farm, composto por 4 máquinas escravas (processos), representadas pelas linhas verticais das janelas. Estas são compostas por blocos, onde cada um corresponde a uma tarefa.

Além de permitir a visualização das medidas, o StatViewer possui uma série de métodos para auxiliar o usuário, entre eles: o zoom, permitindo observar maiores detalhes entre os processos e tarefas; a personalização das cores dos blocos, permitindo destacar ou agrupar blocos com cores específicas, facilitando assim a análise; e a listagem dos processos e tarefas com suas respectivas medidas.

\subsection{2 - FERRAMENTAS PARA ANÁLISE DINÂMICA}

As ferramentas para análise dinâmica se assemelham muito às estáticas, diferenciando-se essencialmente por permitirem a análise do sistema em tempo de execução. Assim como as ferramentas para análise estática, são constituídas por um componente (TStatOnLine) e por uma aplicação de visualização (StatOnLine).

O componente TStatOnLine possui propriedades similares ao TStat, possuindo a mesma metodologia de utilização, no entanto, ao invés de armazenar as medidas e arquivá-las num arquivo, o objeto as envia para a aplicação StatOnLine, permitindo desta maneira sua visualização em tempo de execução. A comunicação entre o componente e a aplicação é realizada a partir do CVMP memória compartilhada, para tanto foi necessário encapsular este objeto no componente StatOnLine. 


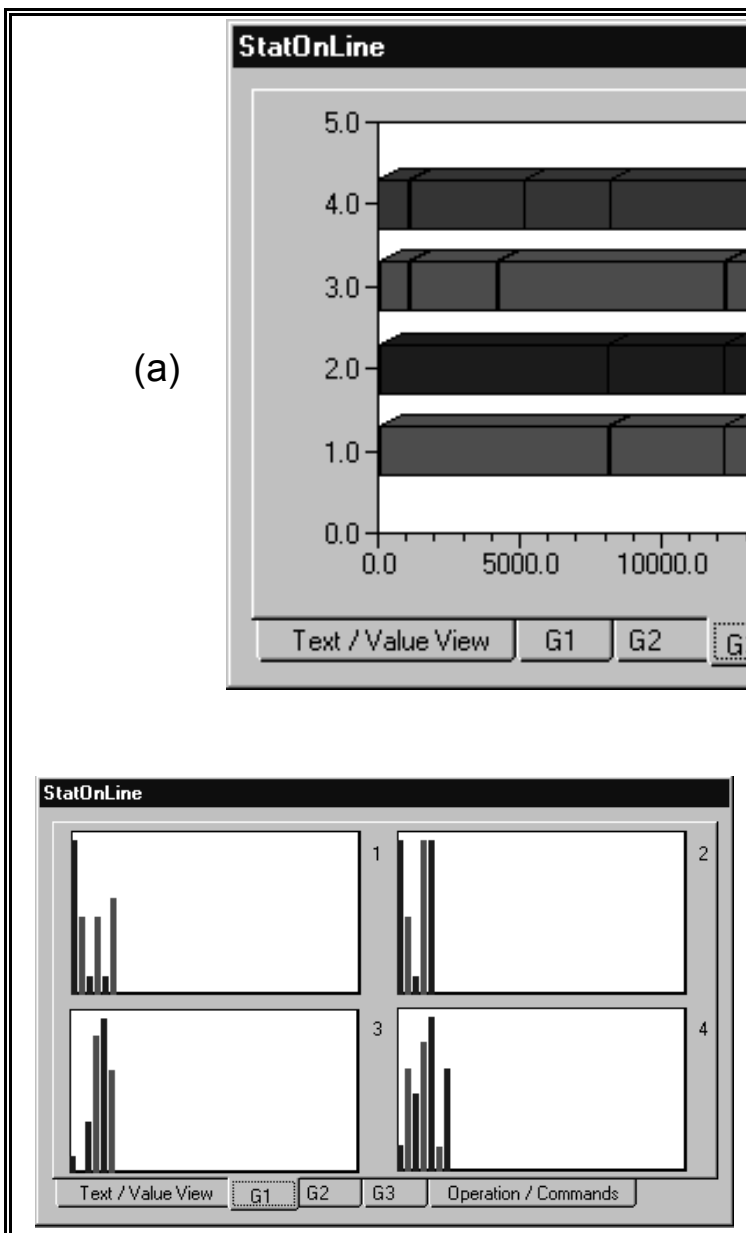

(b)

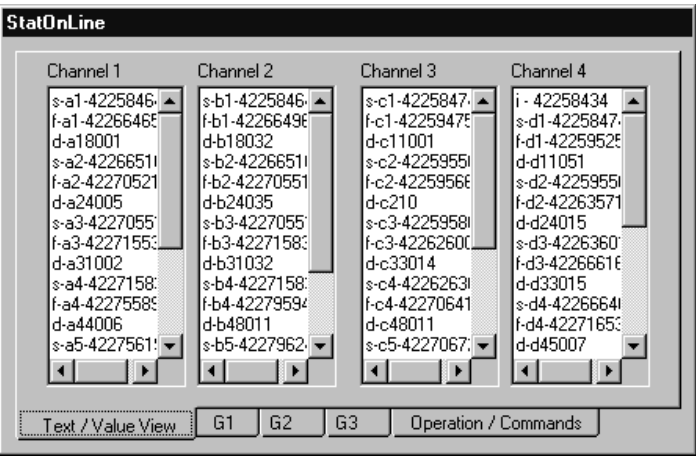

(c)

Fig. - 6.19 - Janelas da aplicação StatOnLine, apresentando as medidas de performance de uma aplicação paralela (processor farm) com 4 máquinas escravas. Visualização com blocos(a) e (b) e listagem das medidas (c).

A aplicação StatOnline fica à espera de mensagens contendo as medidas realizadas pelo componente, e uma vez que as recebe, armazena-as na memória e exibe-as, possibilitando visualizar o comportamento do sistema durante o processamento. A Figura 6.19 apresenta três janelas da aplicação StatOnline, exibindo as medidas de um sistema distribuído com estratégia processor farm, constituído de 5 máquinas (1 supervisor e 4 escravos). Em (a) temos um diagrama de blocos no qual as linhas horizontais representam as máquinas escravas, os blocos que constituem as linhas representam as tarefas executadas em função do tempo. Em (b) cada um dos gráficos (1, 2, 3 e 4) representa respectivamente cada máquina e os blocos das tarefas realizadas em cada uma, cuja duração é expressa por sua altura. Finalmente em (c) temos as listagens das medidas de tempo de 
duração, início e término, de cada tarefa.

\subsection{0 - Componente VISUAL PARA operações BÁSICAS DE PROCESSAMENTO DE IMAGENS}

A convolução de máscaras (templates) com a imagem constitui uma abordagem clássica para a operação de alguns filtros, tais como detectores de bordas (filtros passa alta, Sobel, Robert e outros), filtros de suavização (filtragem gaussiana, média da vizinhança e outros) e de realce (passa baixa) [Castleman, 1996] [Gonzalez \& Woods, 1993] [Parker, 1997]. Por se tratar de operações básicas e por sua popularidade, esses filtros são amplamente utilizados. Nessa seção apresentamos um experimento realizado para demonstrar o potencial de criação de componentes personalizados e da extrema simplicidade de desenvolvimento e operação utilizando CVMP.

Devido à simplicidade das técnicas de convolução de máscaras e a sua larga utilização, decidimos adotá-las para o experimento. A partir do componente TImage, que acompanha o Delphi, e do CVMP processor farm, foram desenvolvidos os componentes TSobelPar (mestre e escravo) e TMaskPar (mestre e escravo). Devemos lembrar que, ao invés de estarmos preocupados com as questões de performance, como é usual, tratando-se de sistemas paralelos, nesses experimentos nos preocupamos com a didática e com a máxima simplicidade de utilização do sistema.

A Figura 6.20 mostra um diagrama ilustrativo de um sistema implementado utilizando os componentes TSobelPar. Nele temos quatro aplicações, uma mestra e três escravas. A operação e programação dos componentes são simplificados, bastando arrastar e soltar os componentes no formulário da aplicação, e executar uma linha de código nas aplicações escravas (método TSobelParS.run na máquina escrava) e uma nas aplicações mestras ( método TsobelParM.run(número de máquinas) ).

Depois da execução do método na aplicação mestra é realizada a criação dos Canais Virtuais e em seguida, a aplicação mestre divide a imagem contida no componente visual TSobelParM, em tiras horizontais (no exemplo da Figura 6.20 a imagem é dividida em 4 tiras). Após essa divisão, uma das tiras permanece na aplicação mestre, enquanto as demais são transmitidas para as aplicações 


\section{CAPÍTULO 6}

escravas. Após a transmissão inicia-se a execução da convolução da máscara Sobel. As imagens dos componentes mestre e escravos são atualizadas para cada pixel resultante da convolução, apresentando de forma didática a execução paralela. Finalizado o processo de convolução em todas as aplicações (mestre e escravas), os dados resultantes são transmitidos para a aplicação mestre, a qual monta essas tiras, e exibe o resultado da convolução com a máscara Sobel.

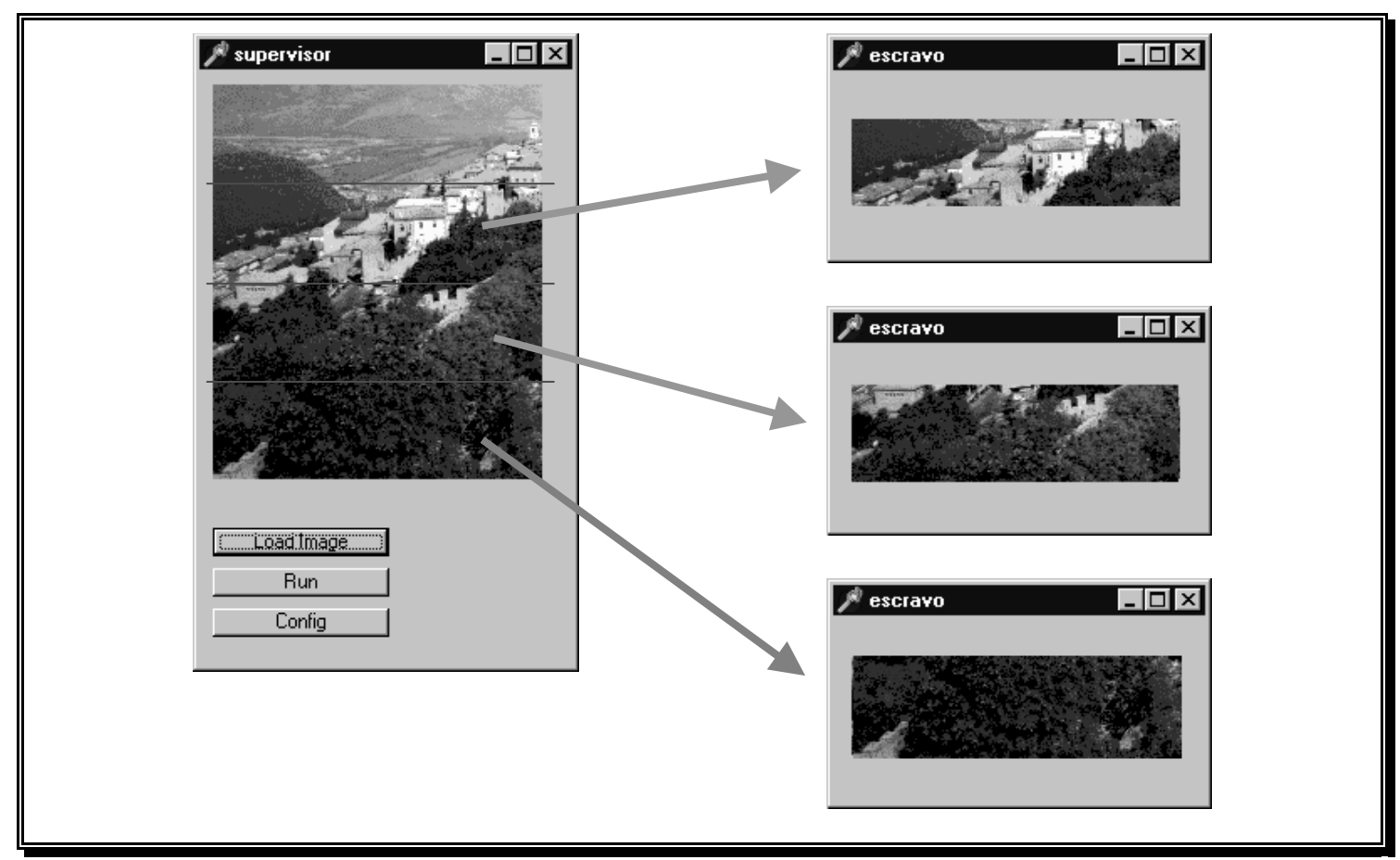

Fig. - 6.20 - Exemplo de uma aplicação paralela utilizando os componentes

TSobelPar.

Uma variação dos componentes TSobelPar são os componentes TMaskPar, que possuem um funcionamento semelhante, com a diferença de que a máscara a ser convoluída na imagem é determinada através de programação no componente mestre (TMaskParM). A matriz $(5 \times 5)$, que contém a máscara personalizada é transmitida para as aplicações escravas juntamente com as tiras da imagem, permitindo que estas realizem a convolução.

Este experimento teve caráter didático, uma vez que permitiu ao usuário a visualização da execução paralela, apresentando em cada uma das máquinas o processamento gráfico, perdendo com isso desempenho. 


\subsection{1 - PERspectivas CVMP}

O conjunto de ferramentas CVMP pode ser considerado como uma camada adicional aos protocolos de comunicação, memória compartilhada ou redes. Suas principais vantagens em relação à outras metodologias que possibilitam a computação paralela, tais como o PVM e MPI, estão na simplicidade de utilização, programação visual, encapsulamento, reutilização de código e programação orientada a objetos.

Embora o CVMP, como abordamos neste capítulo, possa estar relacionado diretamente com os protocolos de comunicação e suas primitivas (TCP/IP, NetBeui e Socket), nada impede que o CVMP seja desenvolvido sobre outras metodologias, redirecionando os métodos de comunicação para as primitivas de outras técnicas. Acreditamos que essa característica aumente o potencial do CVMP, ficando como sugestão para desenvolvimentos futuros versões do CVMP sobre PVM ou MPI. Deste modo, permitir-se-á o desenvolvimento de aplicações mistas que podem, além de se beneficiar com as amplas bases destas tecnologias, também prover a estas plataformas seus benefícios.

Uma vez que tanto o MPI quanto o PVM são voltados para o mundo Unix, e o CVMP para o mundo Windows, é necessário aguardar o lançamento do Kylix [Kylix], ambiente compatível com Delphi versão Linux, previsto para o segundo semestre de 2000, justificando assim a portabilidade do CVMP. Acreditamos que a versão CVMP para UNIX, venha trazer uma grande facilidade de desenvolvimento paralelo para essa plataforma, possibilitando ainda o desenvolvimento de sistemas paralelos heterogêneos (plataforma UNIX e Windows).

Outro aspecto interessante do CVMP é a sua versatilidade, possuindo inúmeras possibilidades para o desenvolvimento de arquiteturas paralelas, uma vez que apresenta um código simples e enxuto (componente CVMP básico com cerca de 980 linhas) e pode ser baseado em qualquer mecanismo de comunicação. Um bom exemplo de uma arquitetura não convencional que pode ser desenvolvida através de CVMP são as máquinas MIMD distribuídas baseadas em interface SCSI. Uma vez que a tecnologia de redes vem constituindo cada vez mais um gargalo, não conseguindo acompanhar a performance dos processadores atuais, as arquiteturas baseadas em interface SCSI apresentam-se como uma nova possibilidade de arquitetura paralela [Henry et al., 1998] [Mattson \& Henry, 1998] [Phillips, 1998]. 
CAPÍTULO 6 


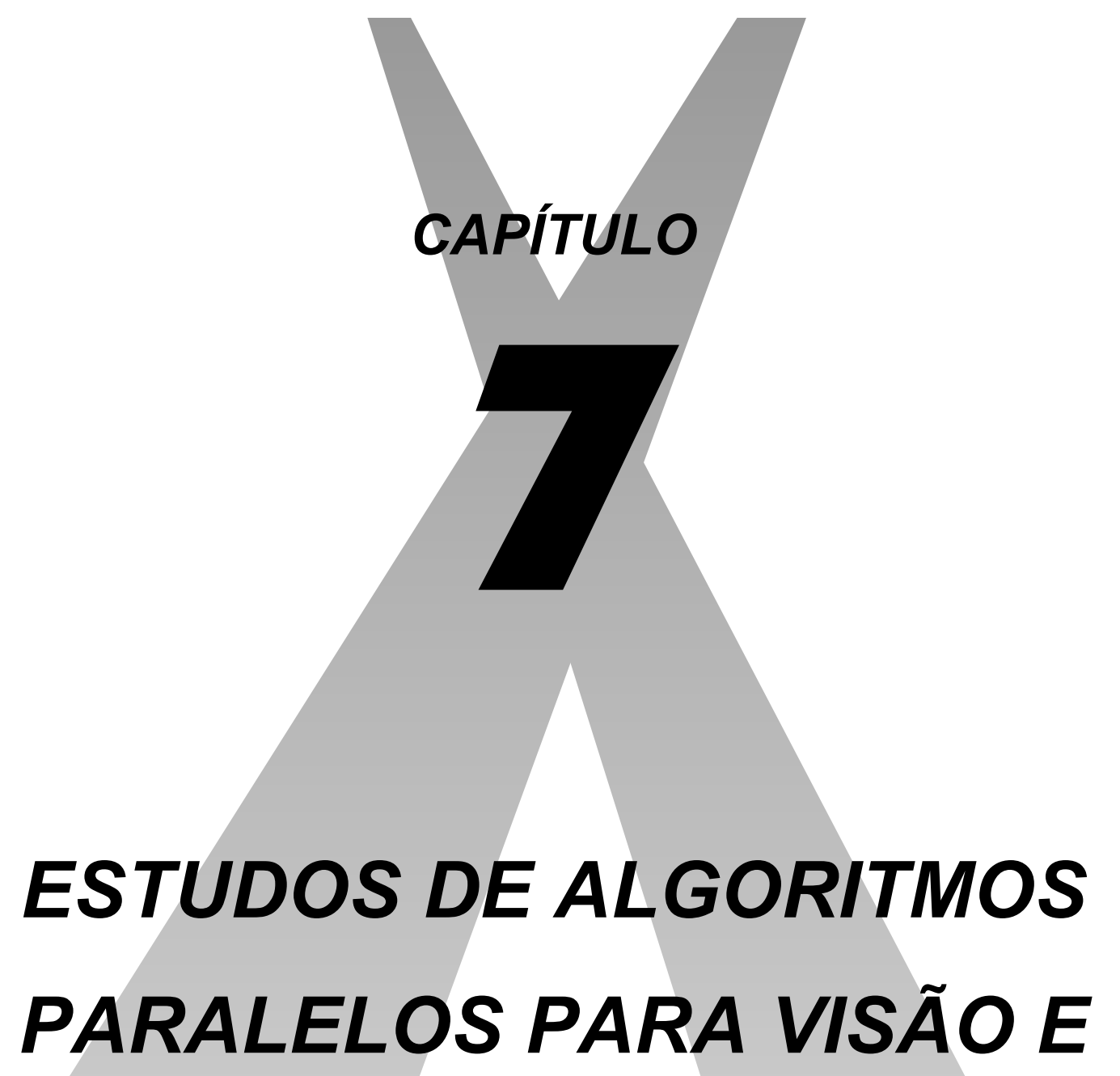

\section{SUA IMPLEMENTAÇÃO COM}

\section{CVMP}

"Is computer design driven by problems looking for solutions, or by solutions looking for problems ? The anwer is, by both."

Almasi \& Gottlieb 
CAPÍTULO 7 


\section{CAPÍTULO 7 - ESTUDOS DE ALGORITMOS PARALELOS PARA VISÃO E SUA IMPLEMENTAÇÃO COM CVMP}

\section{1 - INTRODUÇÃO}

Neste capítulo realizaremos um estudo sobre as estratégias e arquiteturas de implementação paralela de alguns algoritmos de visão computacional e processamento de imagens. Iniciaremos o estudo com operadores locais, seguindo pelo tratamento individual dos canais cromáticos em imagens, o paralelismo nos algoritmos de transformadas de Fourier 2D e continuando com estratégias de paralelismo da transformada de Hough e restauração de imagens baseados em campos aleatórios de Markov. Finalmente, encerramos o capítulo com a paralelização do cálculo da dimensão fractal de Minkowski. Todos os métodos foram implementados com as ferramentas CVMP, de forma que podem ser utilizados diretamente em outras aplicações ou mesmo convertidos para componentes personalizados, de modo a complementar o CVMP.

\section{2 - OPERADORES LOCAIS}

Definimos como operadores locais os algoritmos que atuam isoladamente em um conjunto local de pixels, de modo que não ocorra dependência de dados com os outros componentes da imagem. Assim, algoritmos locais podem estar baseados em transformações envolvendo um único pixel isoladamente ou em conjuntos de pixels locais.

As transformações em conjuntos de pixels locais são conhecidas como operadores de vizinhança, que se caracterizam pela convolução de filtros em domínio espacial [Gonzalez \& Woods, 1993]. Estas técnicas são largamente utilizadas nos algoritmos de processamento de imagens de baixo nível, através de filtros de borramento (passa baixa, filtragem mediana, etc.), filtros de nitidez (passa alta) e detectores de borda, que incluem os filtros diferenciais em geral (Sobel, Robert e Laplaciano da Gaussiana entre outros). Estas transformações podem ser 


\section{CAPÍTULO 7}

expressas como

$$
g(x, y)=T[f(x, y)]
$$

onde $f(x, y)$ é a imagem de entrada, $g(x, y)$ é a imagem resultante do processamento e $T$ é o operador de $f$, definido através de operações sobre a vizinhança dos pixels de $(x, y)$, que pode ser definida como uma matriz cujo elemento central é a coordenada $(x, y)$, conforme podemos observar a seguir:

$$
\left[\begin{array}{ccc}
(x-1, y-1) & (x, y-1) & (x+1, y-1) \\
(x-1, y) & (x, y) & (x+1, y) \\
(x-1, y+1) & (x, y+1) & (x+1, y+1)
\end{array}\right]
$$

As transformações envolvendo um único pixel podem ser expressas pela equação

$$
s=T(r)
$$

onde $s$ e $r$ são as variáveis correspondentes aos valores de nível de cinza das coordenadas de $g(x, y)$ e $f(x, y)$ respectivamente, e $T$ representa a operação a ser realizada na variável $r$. Por exemplo, sendo $T$ um operador de limiar ou binarização, a transformação realizada por $T$ é uma condicional, onde sendo $r$ maior que um limiar, então $s$ será igual a 1 e caso contrário igual a 0 . As operações locais envolvendo um único pixel, além de serem utilizadas para a binarização de imagens, são também empregadas para variações da intensidade de brilho, para alterações de coloração de uma imagem [Gonzalez \& Woods, 1993], ou ainda em conjunto com análises de histograma [Gonzalez \& Woods, 1993]. Devido à pouca demanda computacional requerida pelos métodos dessa classe (apenas uma operação por pixel da imagem), não vamos discutir suas possibilidades de paralelização.

Entretanto, os métodos de convolução no domínio do espaço, por envolverem diversas operações aritméticas para cada pixel da imagem requerem poder computacional e consequentemente tempo de execução suficiente para requererem soluções paralelas. Devemos lembrar que a demanda computacional aumenta proporcionalmente com a dimensão da máscara a ser convoluída. 


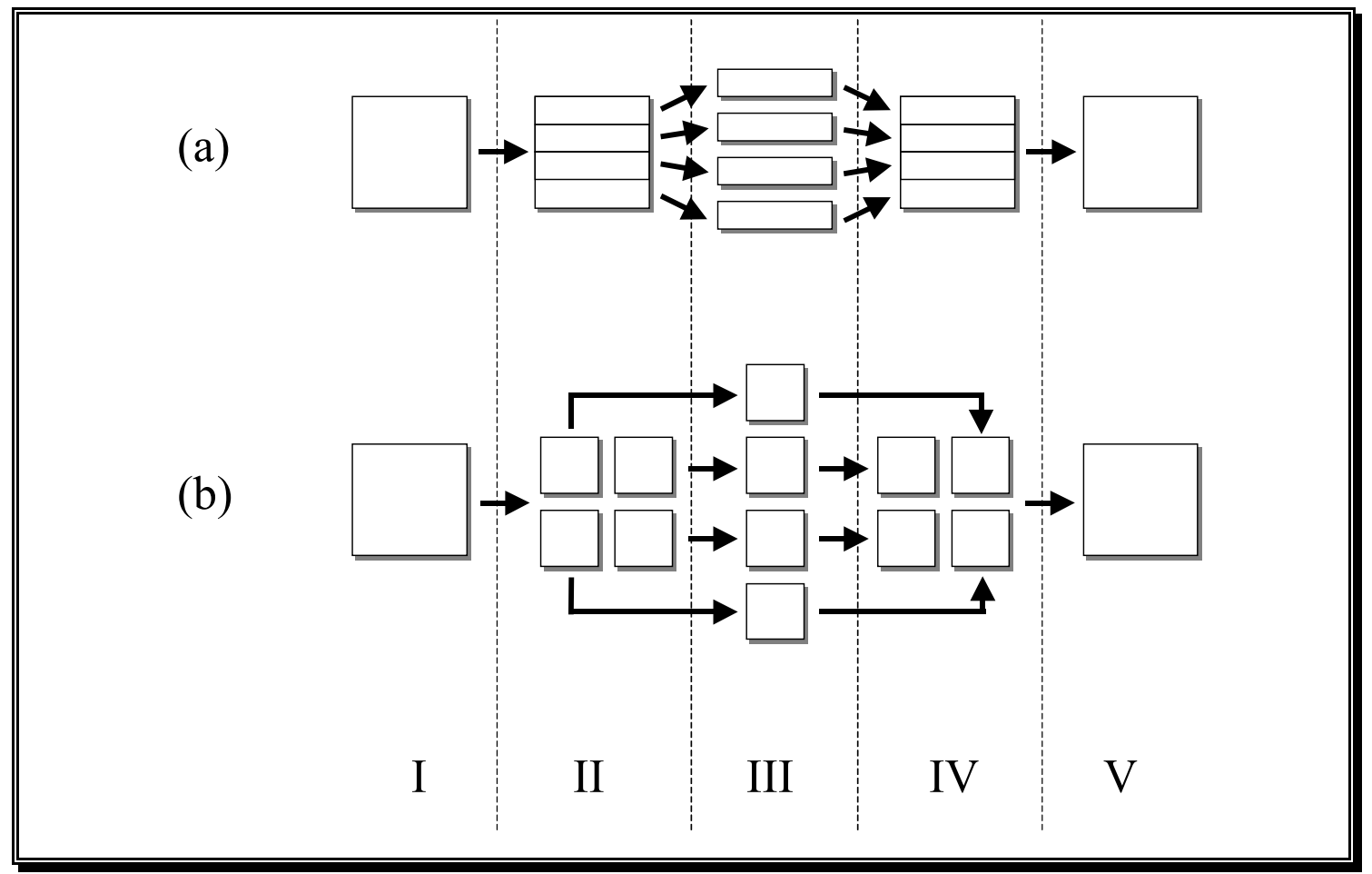

Fig. - 7.1 - Estratégia de paralelismo para operadores locais, para quatro unidades de processamento. (a) Divisão da imagem em faixas, (b) divisão da imagem em quadriláteros. As etapas I, II, III, IV e V representam respectivamente: a imagem original, divisão da imagem e sua distribuição, processamento de cada parte da imagem em uma unidade de processamento diferente, reconstrução dos resultados e resultado do processamento.

Basicamente a estratégia de paralelismo para os algoritmos operadores locais consiste na divisão da imagem em partes e em sua distribuição, de forma que cada máquina ou processador fique responsável pelo processamento em um pedaço da imagem dividida, e finalmente da união dos resultados. A Figura 7.1 contém um diagrama que ilustra essa estratégia de paralelismo com duas abordagens diferentes de divisão de imagem, formuladas para arquiteturas contendo quatro unidades de processamento. A primeira (a), consiste na divisão da imagem em tiras, que são distribuídas para as unidades de processamento e após serem processadas o resultado é reconstituído, na segunda (b), a imagem é dividida em quadriláteros. A imagem pode virtualmente ser dividida em qualquer formato, entretanto essas duas maneiras apresentam os mais óbvios e simples de implementar.

Em alguns sistemas paralelos (ex: multiprocessadores), a fragmentação da 


\section{CAPÍTULO 7}

imagem num número muito maior de porções (alta granularidade) apresenta algumas vantagens tanto em desempenho quanto em balanceamento de cargas. No entanto, devido a grande latência da comunicação via rede (computação distribuída), optamos por estratégias que utilizem pacotes com grande quantidade de dados (baixa granularidade), a fim de otimizar as transmissões de dados. Esta abordagem foi utilizada não somente nesta seção como nas demais implementações ao longo de toda a tese.

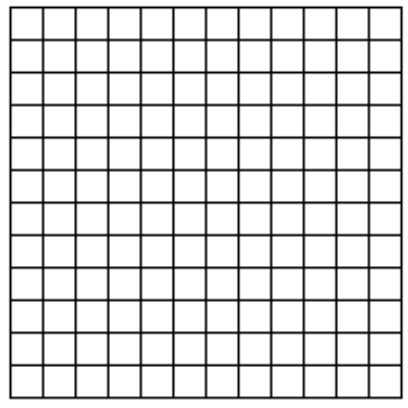

(a)
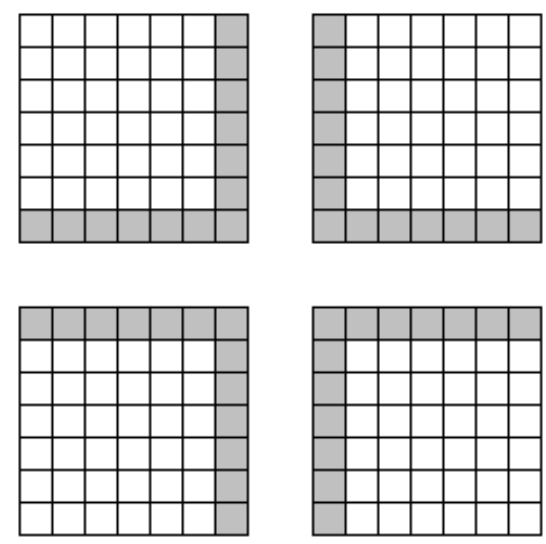

(b)

Fig. - 7.2 - Detalhes da divisão imagem resolvendo a dependência de dados para uma máscara 3×3. (a) Imagem original, (b) frações da imagem com a vizinhança dos elementos das linhas divisórias (em cinza).

O particionamento da imagem, deve levar em conta a dependência de dados ocasionada pelo filtro, uma vez que a manipulação de um pixel envolve computações referentes a sua vizinhança. Seja qual for a abordagem de divisão considerada, deve-se adotar uma metodologia a fim de embutir nas porções distribuídas a vizinhança necessária para o cálculo dos elementos das linhas divisórias. Na Figura 7.2 temos um exemplo que ilustra detalhes do processo de divisão, onde considera-se que o filtro possui dimensão de $3 \times 3$. Como podemos observar em (b), juntamente com a porção da imagem a ser dividida (de cor branca) é acrescentada a vizinhança dos elementos anexos às linhas de divisão, de modo a solucionar a dependência de dados no cálculo desses elementos.

A implementação do algoritmo, através do CVMP, pode ser realizada de inúmeras maneiras e envolvendo diferentes números de máquinas ou unidades de 
processamento. Nossa opção foi uma versão da estratégia de processor farm, onde ao invés de um processo supervisor, temos um processo mestre, que além de distribuir as tarefas para os escravos também realiza processamento. Em nossa implementação utilizamos o componente CVMP básico e o CVMP launcher para disparar os processos escravos. A Figura 7.3 mostra o arranjo esquemático dos processos, objetos CVMP e Canais Virtuais.

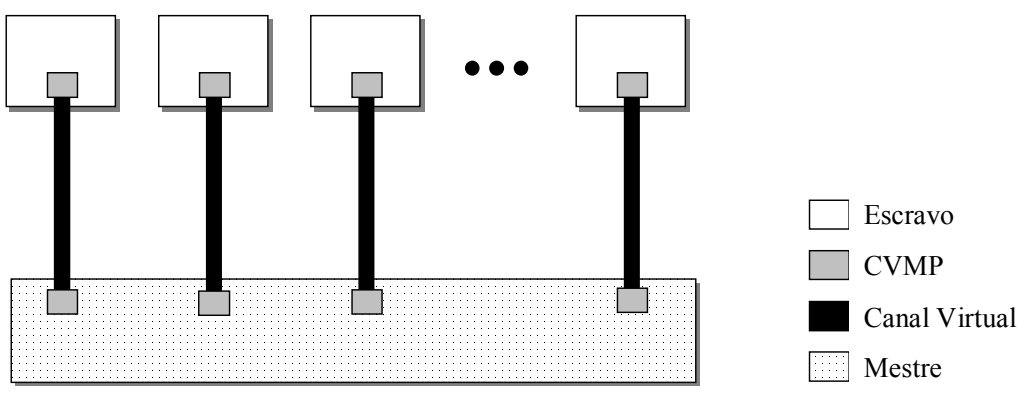

Fig. - 7.3 - Variação da arquitetura processor farm adotada para paralelismo do algoritmo dos operadores locais, onde o mestre além de distribuir as tarefas também processa uma porção da imagem.

Na Figura 7.4 temos um diagrama que ilustra as trocas de mensagens num sistema composto por 4 máquinas. O mestre, representado por $M$, particiona a imagem e envia as partes para os escravos $(E)$. A seguir ocorre o processamento paralelo de cada parte da imagem, cujo resultado retorna ao mestre, finalizando o algoritmo. Podemos observar através dos blocos de processamento que este exemplo apresenta balanceamento de carga satisfatória, uma vez que as tarefas terminam quase simultaneamente. Isso se deve ao fato do sistema possuir uma distribuição uniforme de poder computacional. O balanceamento é automático quando as unidades de processamento forem uniformes. Entretanto, em sistemas heterogêneos, ou seja, com unidades de processamento com diferentes desempenhos, o balanceamento pode ser realizado através da divisão da imagem, onde o tamanho da porção de imagem a ser processado deve ser proporcional ao poder computacional de cada unidade de processamento.

Podemos observar ainda no diagrama da Figura 7.4 três bolhas, devido ao algoritmo esperar o envio de todas as frações da imagem para iniciar o processamento. Essas bolhas podem ser eliminadas, tornando o sistema mais 


\section{CAPÍTULO 7}

eficiente, se imediatamente após o envio das porções de imagem o mestre solicitar aos escravos o processamento. No entanto, embora essa tática permita um desempenho maior, acarreta em uma necessidade de redimensionamento das frações no processo de partição da imagem, uma vez que devem ser considerados também os tempos referentes ao envio das porções da imagem no cálculo da divisão da imagem.

Vamos a seguir apresentar os resultados de um experimento realizado mediante a implementação dessa arquitetura, através dos quais poderemos analisar o comportamento do algoritmo paralelo, assim como sua performance frente ao seu análogo seqüencial. Para o experimento, utilizamos uma rede composta por 4 computadores, interligados com placas ethernet NE2000 de 10 $\mathrm{Mb} / \mathrm{s}$. Implementamos a arquitetura apresentada na Figura 7.4, com divisão igual dos componentes da imagem. Deste modo, para que não houvesse desbalanceamento de carga no sistema, as máquinas deveriam possuir performance homogênea. Para isso configuramos e ajustamos 4 máquinas para que tivessem uma performance equivalente a um microprocessador AMD K6 II com freqüência interna de $375 \mathrm{MHz}$, caracterizando assim os computadores da rede com uma performance homogênea.

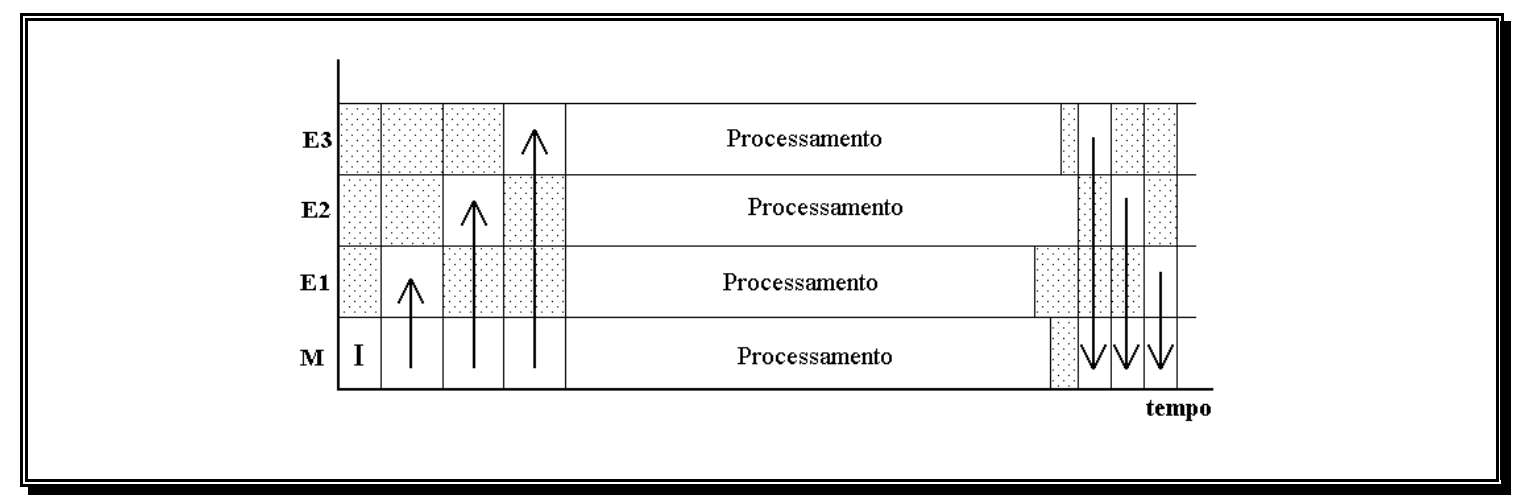

Fig. - 7.4 - Diagrama ilustrando as trocas de mensagem e o balanceamento de carga do sistema.

No experimento medimos o tempo de execução do algoritmo paralelo e seqüencial para quatro tamanhos de imagens diferentes $(250 \times 250,500 \times 500$, $750 \times 750$ e $1000 \times 1000$ pixels), sendo que para cada uma das imagens foram aplicadas operadores com máscaras de diferentes tamanhos $(3 \times 3,5 \times 5,9 \times 9,15 \times 15$, $31 \times 31,51 \times 51,71 \times 71,85 \times 85$ e 101x101 elementos). Utilizamos no experimento um dos operadores locais mais básicos que caracteriza uma filtragem passa baixa 
[Gonzalez \& Woods, 1993], conforme mostrado na Figura 7.5 através de um exemplo com dimensão $3 \times 3$, consiste no somatório dos elementos da máscara fracionada pelo número de componentes do filtro.

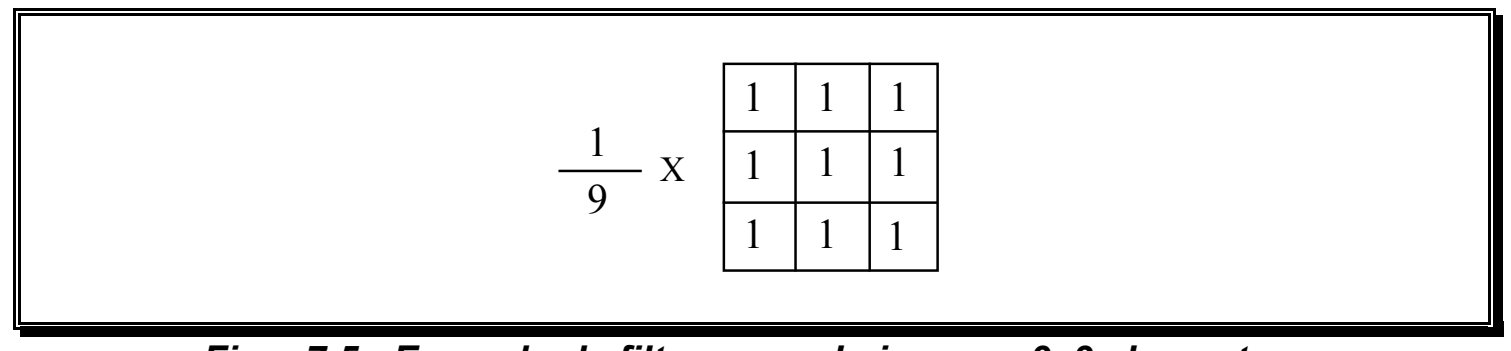

Fig. - 7.5 - Exemplo de filtro passa baixa com 3x3 elementos.
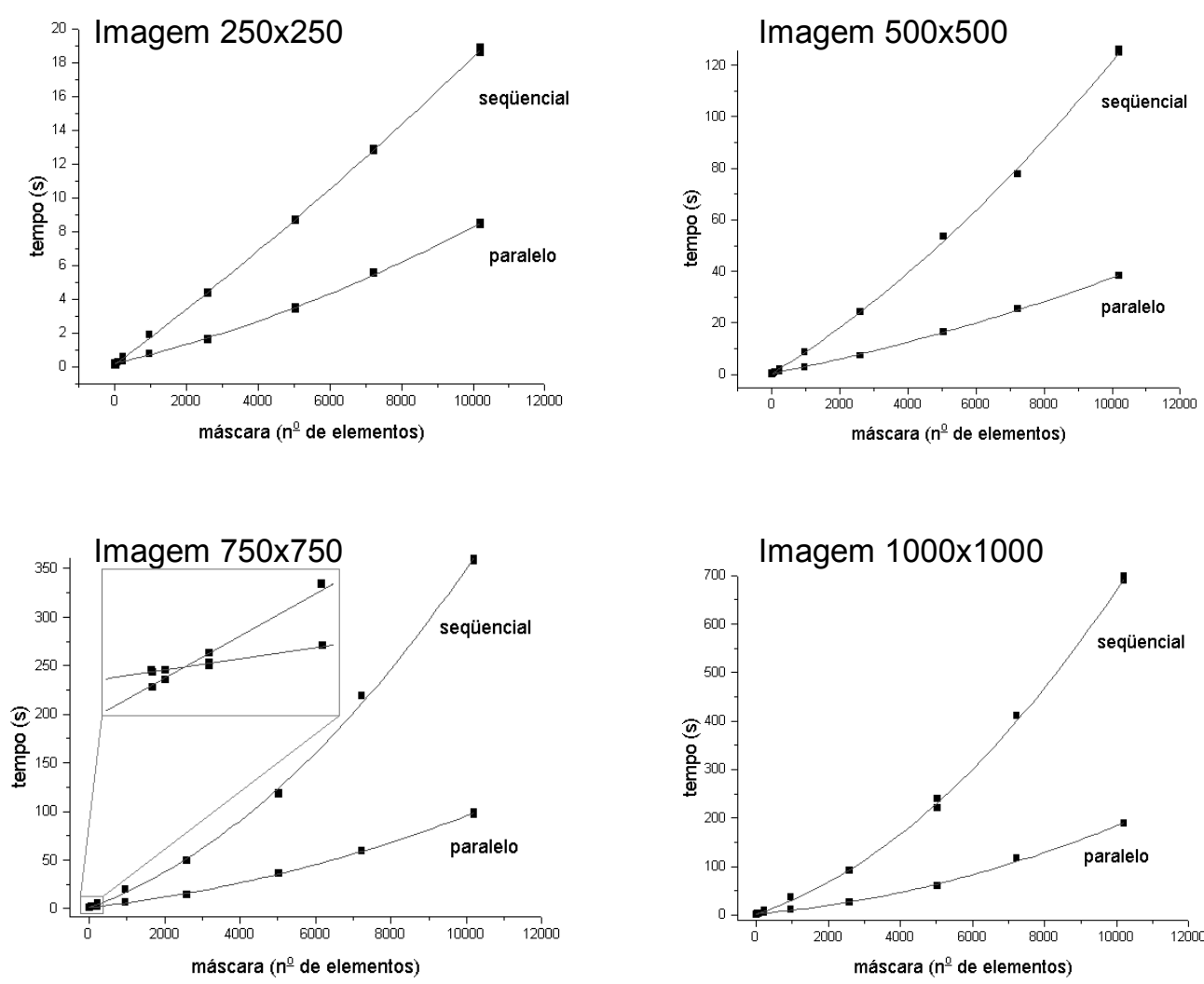

Fig. - 7.6 - Comparação entre o tempo de execução do algoritmo paralelo e seqüencial.

A Figura 7.6 apresenta quatro gráficos com os resultados do experimento, sendo que cada um deles é respectivo a um tamanho de imagem (250x250, 500x500, 750x750 e 1000x1000 pixels). Os gráficos mostram o tempo, dado em 
segundos no eixo y, e o número de elementos do filtro no eixo $\mathrm{x}$.

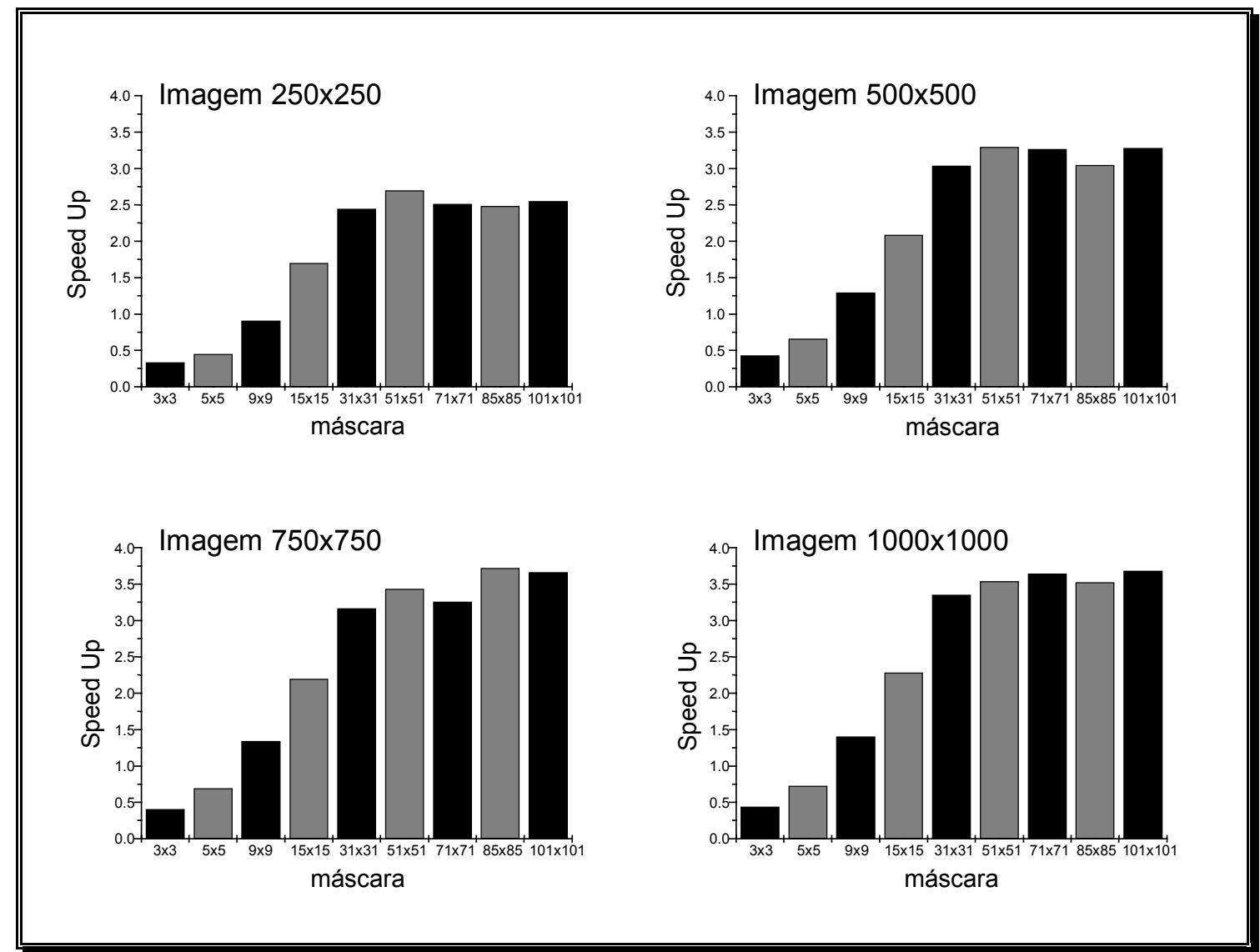

Fig. - 7.7 - Desempenho dos algoritmos paralelos.

A performance da implementação paralela frente a seqüencial aumenta à medida que caminhamos no eixo $x$. Para filtros com poucos elementos, tais como $3 \times 3$ e $5 \times 5$, o desempenho da versão paralela chega a ser inferior, conforme podemos observar na ampliação do detalhe do gráfico referente à imagem de $750 \times 750$ pixel. Para analisarmos o comportamento da performance, utilizamos da medida de Speed Up ou medida de desempenho, dada pela razão entre o tempo de execução seqüencial e o tempo de execução paralelo. Na Figura 7.7 encontramos os gráficos de desempenho, correspondentes aos da Figura 7.6. Como podemos verificar, um resultado interessante é a pequena variação de desempenho frente a dimensão da imagem. Embora a imagem 250×250 possua um desempenho médio inferior, as demais dimensões possuem características próximas, com um aumento de performance muito pequeno para as imagens de tamanho maior, indicando que o fator fundamental no desempenho é o tamanho do filtro. A partir do filtro de 15x15, a implementação paralela começa a ser justificável, atingindo um 
desempenho aproximado, que varia de 1,75 vezes (imagem $250 \times 250$ ) a 2,25 vezes superior (imagem 1000x1000). Para filtros maiores, o algoritmo paralelo implementado com 4 máquinas, atinge sua performance máxima, aproximadamente 3,5 vezes superior à versão seqüencial.

A razão da baixa performance do algoritmo paralelo para os filtros com poucos elementos pode ser compreendida através da relação entre o tempo de processamento e o tempo de transferência dos dados. Observando a Figura 7.4 podemos verificar que a base computacional do algoritmo pode ser dividida em duas partes: transmissão dos dados e processamento do operador local. $\mathrm{Na}$ transmissão de dados, temos duas etapas: a distribuição das partes da imagem a serem processadas e a transmissão do resultado para a máquina mestra. À medida que os filtros se tornam maiores, a demanda computacional para o processamento do operador local aumenta, enquanto que a demanda requerida pela transmissão de dados continua a mesma. Como os dados envolvidos na transmissão são consideráveis, essa etapa consome grande recurso computacional, especialmente em sistemas distribuídos, que possuem uma baixa banda de transferência. Para justificar o tempo desperdiçado na transmissão de dados, os recursos computacionais gastos com a processamento do operador local precisam ser maiores que estes.

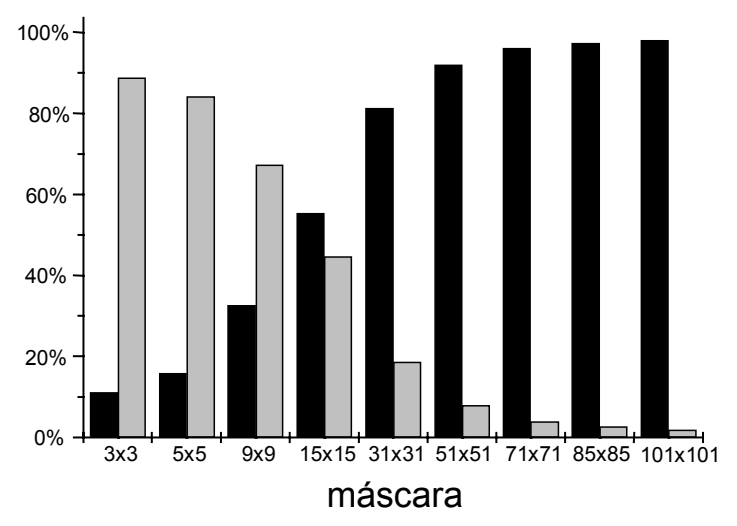

Fig. - 7.8 - Comparação entre a porcentagem de tempo consumido entre o processamento e a transmissão de dados (imagem de 500x500).

O gráfico da Figura 7.8 apresenta as porcentagens de tempo de execução 
em relação ao processamento do operador local e a transmissão de dados. Conforme podemos observar para as máscaras com poucos elementos, o percentual de demanda computacional requerido pelo processamento do operador local é pequeno, não justificando a implementação paralela. No entanto à medida que o poder computacional exigido pelo processamento aumenta, o percentual da transmissão de dados diminui, aumentando a performance do sistema.

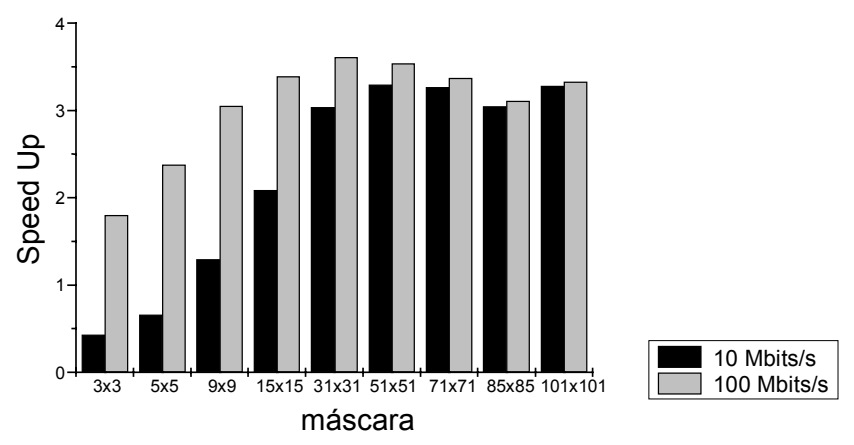

Fig. - 7.9 - Comparação entre a performance do sistema em rede de 10Mbits/s (ethernet) e 100Mbits/s (fast ethernet).

Conforme vamos observar no decorrer desse capítulo, o gargalo da grande maioria dos sistemas distribuídos para processamento de imagens e visão se encontra na transmissão de dados, uma vez que o processamento dessas áreas está relacionado com imagens. Deste modo, uma maneira de aumentar a performance dos sistemas é utilizar redes mais rápidas ou sistemas de memória compartilhada.

Na Figura 7.9 temos a comparação entre o nosso experimento executado em uma rede de 10 e 100 Mbits/s (imagem 500x500). Uma rede mais veloz fez com que a performance dos filtros menores $(3 \times 3,5 \times 5,9 \times 9$ e $15 \times 15)$ aumentasse consideravelmente, permanecendo entretanto com desempenhos próximos nos filtros de dimensão maior. Comparando este resultado com o gráfico da Figura 7.8, podemos justificar essa diferença de aumento de performance, já que à medida que os filtros aumentam, torna-se menor o gargalo constituído pela transmissão de dados. Diferente do convencional, na arquitetura apresentada nesta seção, as aplicações que envolvem grandes máscaras não justificam a utilização de redes de alto desempenho. 


\section{3 - CANAIS CROMÁtICOS}

A cor é percebida pelos primatas através da composição da percepção de três diferentes fotorreceptores, que possuem absorções máximas de onda em diferentes faixas do espectro (vermelho, verde e azul). Nos sistemas computacionais, a cor é igualmente formada pela composição de contribuições das diferentes faixas do espectro. No entanto, ao invés de funções contínuas como ocorre nos sistemas de visão natural, as representações numéricas da cor são quantizadas através de funções discretas que, em geral, possuem 256 valores.

Existem diversas representações cromáticas em sistemas computacionais, cujo princípio baseia-se na formação de um espaço de cores, que quantificam os estímulos cromáticos. Dentre os espaços de cores, existem os que combinam matiz com brilho, iluminação e contraste, ao invés de combinar as cores diretamente, como é o caso dos sistemas YIQ, YUV, HSI e HSV entre outros [Moreira, 1999] [Pratt, 1984]. As representações mais comuns e mais utilizadas são aquelas que, assim como no modelo biológico, combinam as faixas do espectro. Dentro dessa classe temos o sistema RGB, o mais difundido de todos, que é análogo ao sistema tricromático biológico, sendo formado da combinação das matizes vermelho, verde e azul. Embora a grande maioria das representações sejam compostas por três canais, existem também aquelas que não seguem esse padrão, como é o caso do sistema CMYK, sistema de representação cromática baseada na absorção e combinação de tintas na formação de cores, largamente utilizado em aplicações envolvendo impressões gráficas, cuja combinação é formada com matizes azul claro - Cyan, vermelho claro - Margenta, amarelo e preto.

Os canais de combinação dos sistemas de representações cromáticos podem ser considerados como planos ou imagens independentes. Tomemos por exemplo o sistema RGB, no qual as imagens cromáticas são formadas por três imagens em níveis de cinza, representando cada um dos planos de contribuição (azul, verde e vermelho), de forma que cada um dos planos possa ser processado com as técnicas convencionais de processamento de imagens em tons de cinza. Uma vez que cada plano pode conter informações diferenciadas, relativas às variadas absorções de espectro dos componentes da imagem, o processamento individual de cada plano possibilita a revelação de detalhes obtidos apenas na análise de um dos componentes.

Do ponto de vista do paralelismo, os planos podem ser tratados de modo 


\section{CAPÍTULO 7}

isolado uma vez que não existe dependência de dados. Isto simplifica a implementação de algoritmos cromáticos que utilizam essa abordagem. Vamos apresentar como exemplo do paralelismo explorando os canais cromáticos um detector de retas em imagens cromáticas, cujo objetivo é mais didático do que prático. Partindo da idéia que informações diferentes podem estar concentradas nos diferentes planos da imagem cromática, esse algoritmo explora os planos individualmente na expectativa de encontrar retas não detectáveis na versão monocromática da imagem.

Para cada plano cromático o algoritmo efetua a extração das bordas da imagem através do popular filtro Sobel [Sobel, 1970], e no resultado dessa operação é realizada a transformada de Hough com parametrização normal, responsável pela detecção das retas.

Implementamos o sistema distribuído utilizando 3 máquinas conectadas por rede, uma mestra e duas escravas, conforme apresentado na Figura 7.10. A máquina mestra é responsável pela aquisição da imagem cromática e pela divisão dos 3 planos e a distribuição de dois destes para as máquinas escravas. Após a distribuição dos planos é realizado o processamento dos algoritmos Sobel e Hough, simultaneamente nas três máquinas. Finalmente o resultado é retornado à máquina mestra, onde pode ser combinado com operadores lógicos.

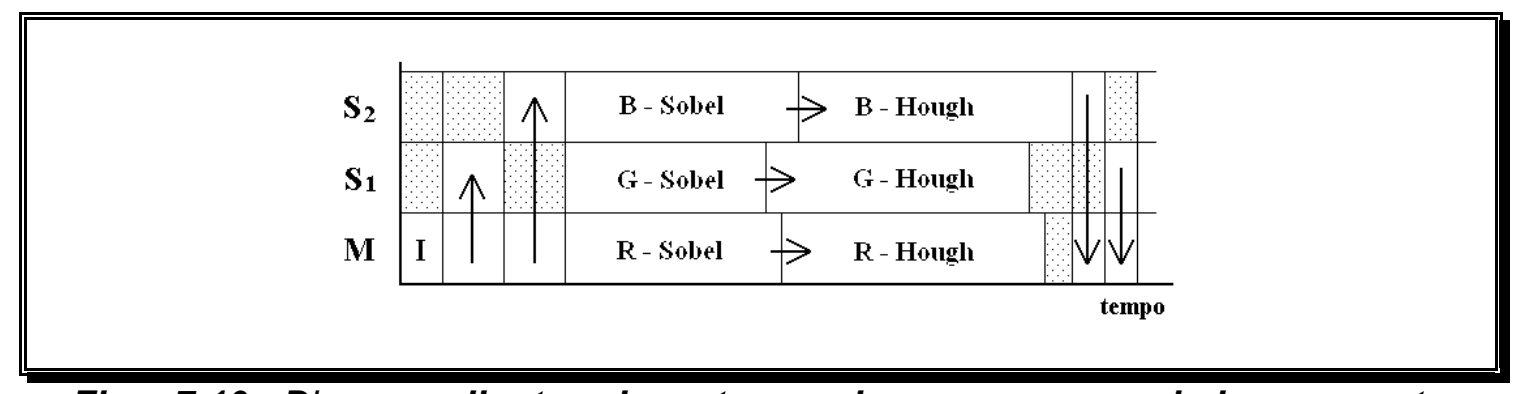

Fig. - 7.10 - Diagrama ilustrando as trocas de mensagem e o balanceamento de carga do sistema. M - máquina mestra; S1 e S2 - máquinas escravas.

Para compararmos a performance do sistema em situações distintas, implementamos três configurações diferentes: seqüencial, paralelo com duas máquinas e paralelo com três máquinas, conforme mostra a Figura 7.11. O experimento foi realizado em três redes homogêneas de computadores com três máquinas, incluindo: uma formada por computadores com processadores $486 \mathrm{dx} 4$ com freqüência interna de $100 \mathrm{MHz}$, outra com processadores Pentium MMX de $225 \mathrm{MHz}$ e a última com processadores AMD K6 II de $375 \mathrm{MHz}$. Todas as redes 
foram implementadas usando placas ethernet NE2000 de 10Mbits/s. Deste modo podemos comparar o desempenho do sistema paralelo versus sua versão seqüencial, frente a sistemas com diferentes performances, permitindo assim, avaliá-lo perante a evolução dos microprocessadores.

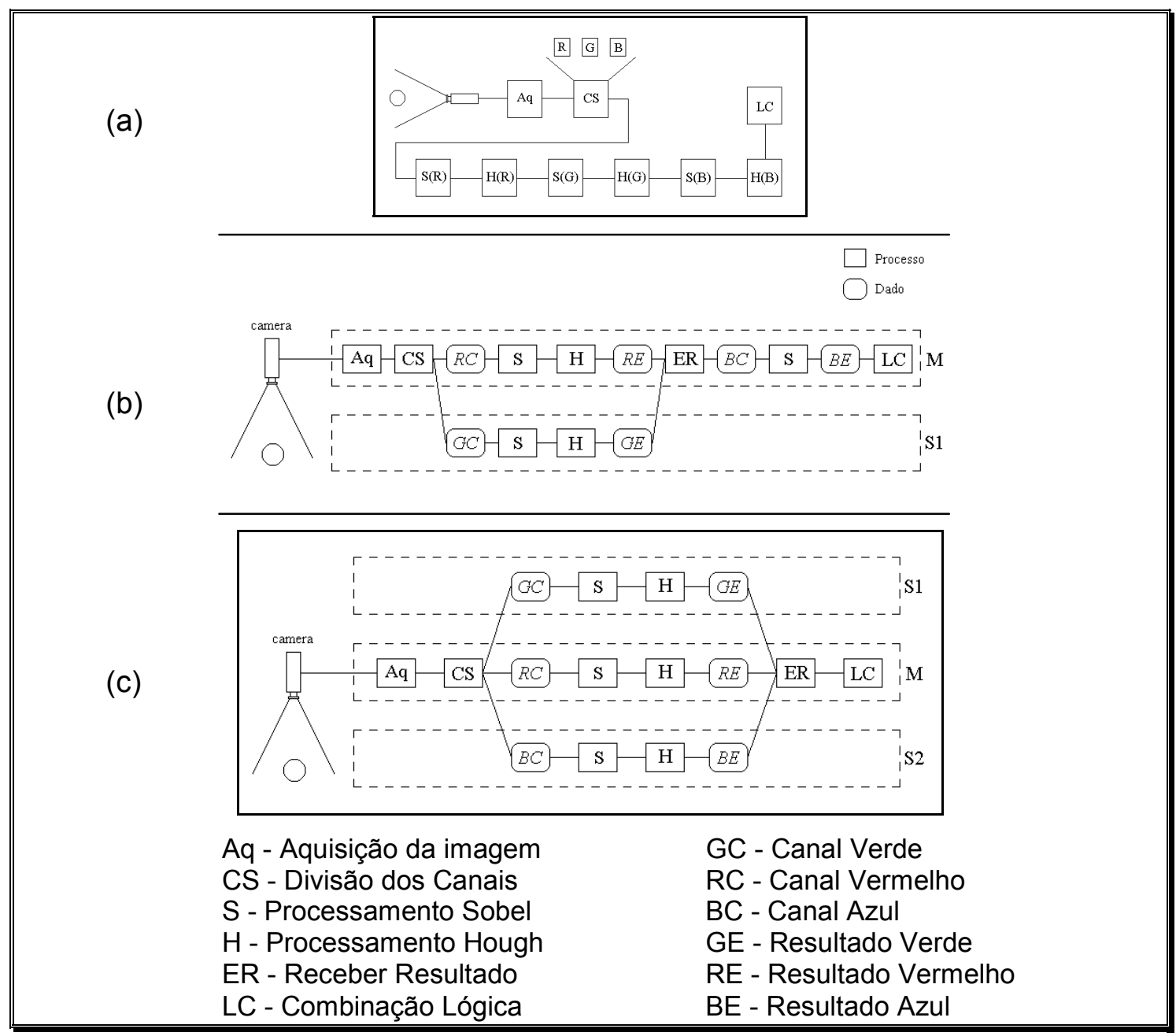

Fig. - 7.11 - Configurações do sistema: (a) seqüencial, (b) paralelo com 2 máquinas e (c) paralelo com 3 máquinas.

A Figura 7.12 (a) apresenta uma comparação entre a performance para a implementação paralela e a versão seqüencial. Nela é apresentado um gráfico do tempo de execução de cada uma das situações contra o número de pixels da imagem processada. Na Figura 7.12 (b) é apresentado um gráfico do tempo de execução em função do número de máquinas utilizadas, parametrizado pelo tamanho da imagem dado em pixels. O desempenho ou speed-up do sistema é aproximadamente uniforme para os diferentes tamanhos de imagem, ficando em 
torno de 2,5 vezes superior, para o sistema rodando em três máquinas e 1,4 vezes superior para duas máquinas, conforme podemos verificar na Figura 7.13 (a).

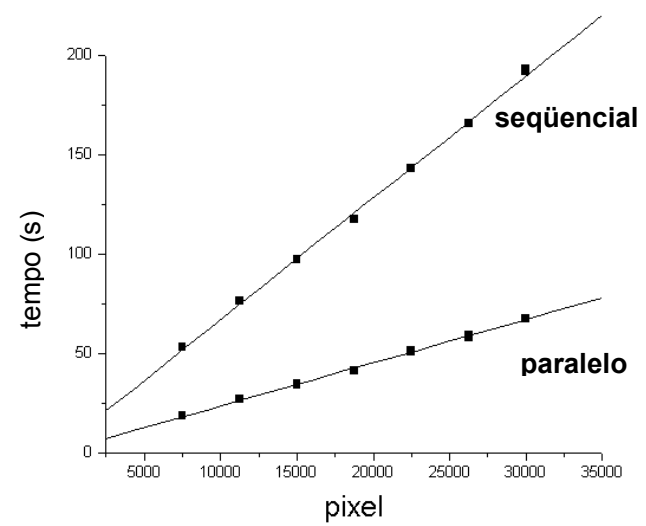

(a)

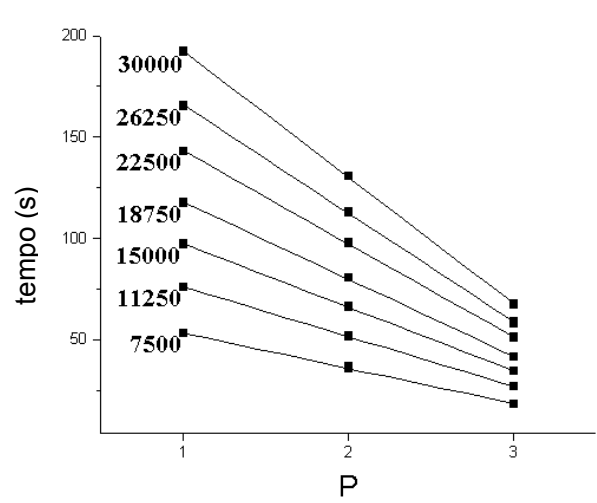

(b)

Fig. 7.12 - Tempo de execução (máquinas 486dx4-100): (a) Em relação ao número de pixels, comparação entre as versões seqüencial e paralela com 3 máquinas e (b) Em relação ao número de processadores $(P)$ parametrizado pelo número de pixels.

Os resultados do experimento realizado em redes homogêneas com diferentes microprocessadores apresentam a queda de performance da versão paralela frente à seqüencial. Isso pode ser observado através speed-up ou medida de desempenho das três diferentes situações, através dos gráficos da Figura 7.13, (a) 486dx4 100MHz, (b) Pentium MMX 225MHz e (c) AMD K6-II 375MHz. Enquanto os microprocessadores apresentam performance diferentes, a taxa de transferência da rede continua a mesma, caracterizando-a como gargalo para os processadores mais velozes. Podemos observar na Figura 7.13 ( $b$ e c) uma taxa de crescimento de performance à medida que o tamanho da imagem aumenta. Assim, embora esta arquitetura paralela tenha se tornado inviável para as imagens utilizadas no experimento, deve atingir uma performance aceitável para imagens de grandes dimensões, já que nessa situação a carga de processamento tornará maior que a de transferência. Observamos ainda que a performance do sistema em $486 \mathrm{dx} 4$ permanece constante para os diferentes tamanhos de imagem, indicando uma demanda superior para carga de processamento frente à transferência dos dados atingindo equilíbrio. 
(a)
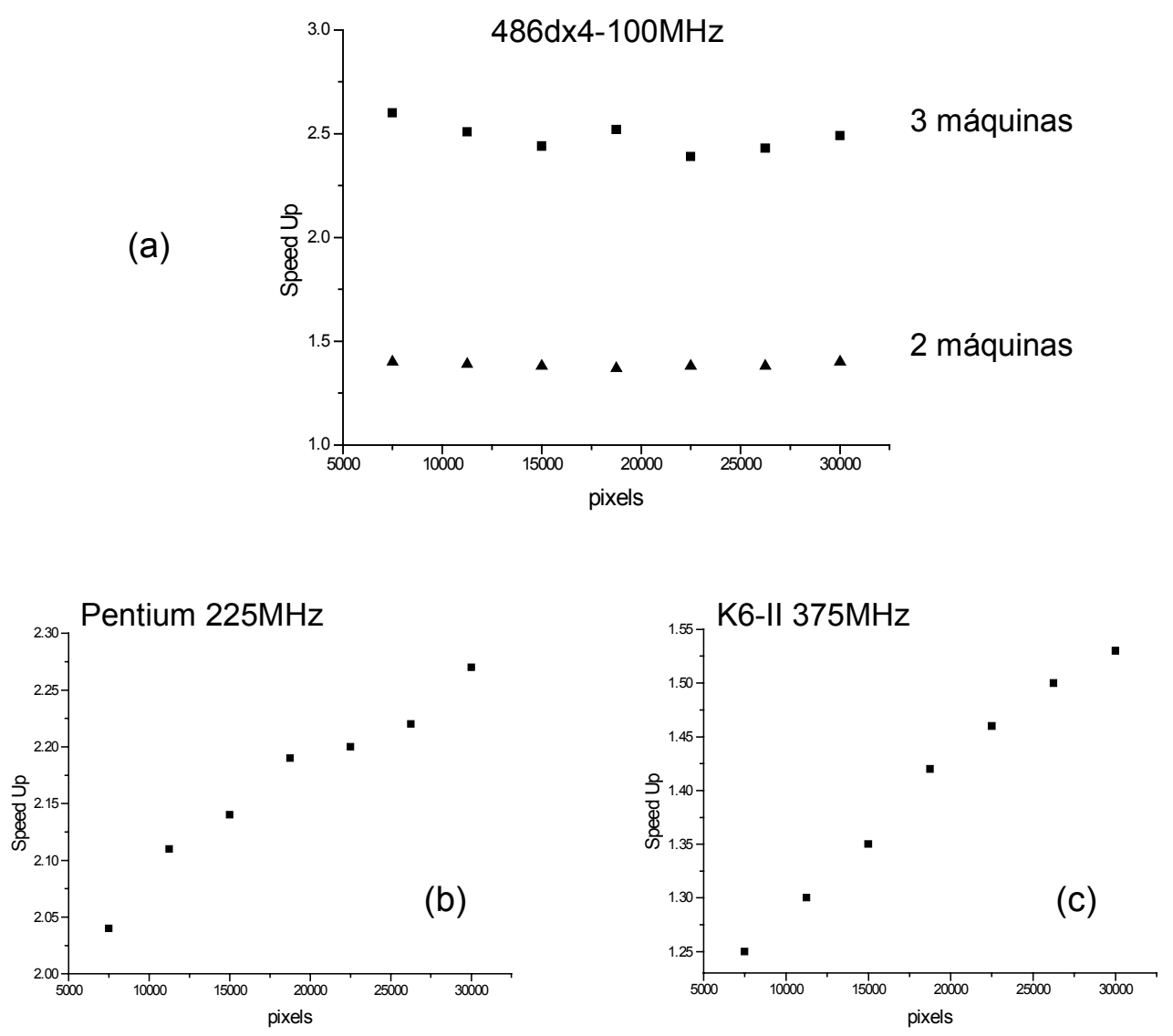

Fig. 7.13 - Gráficos de desempenho em função do número do tamanho da imagem. As redes são homogêneas e são baseadas em ethernet NE2000 com taxa de 10Mbits/s. (a) rede formada por máquinas 486dx4-100MHz, (b) Pentium $225 \mathrm{MHz}$ e (c) $\mathrm{K} 6 \mathrm{II} 375 \mathrm{MHz}$.

A Figura 14 apresenta um diagrama ilustrativo, que compara os tempos de execução das versões paralelas (3 máquinas) em cada uma das plataformas em que foi realizado o experimento. Através dele podemos observar a diminuição crescente do tempo de execução frente ao tempo de transferência de dados, justificando assim a razão pelo decréscimo de desempenho do sistema em plataformas com microprocessadores mais velozes, caracterizando a troca de mensagens como o gargalo do sistema. Como alternativas para eliminar o gargalo podemos citar: (i) Utilização de redes mais velozes. O sistema foi implementado utilizando rede ethernet NE2000 com taxa de transferência de $10 \mathrm{Mbits} / \mathrm{s}$, se a rede for substituída por uma solução com taxa de transferência superior, o tempo de transferência pode ser reduzido diminuindo o gargalo. (ii) Utilizar imagens com 


\section{CAPÍTULO 7}

dimensões bem maiores que as empregadas no experimento, aumentando o tempo proporcional de processamento (caixa preta da Figura 7.14) frente ao tempo de transferência (caixa com barras diagonais, Figura 7.14). (iii) Implementar o sistema com arquitetura de memória compartilhada. Essa solução possibilita uma grande redução do gargalo, devido à performance superior de transferência de dados entre os processos. Uma das desvantagens de sua adoção, no entanto, é a limitação de processadores nos modelos comerciais. Atualmente os sistemas de hardware (tecnologia PC) possuem um número limitado de processadores, sendo indicados, do ponto de vista da computação científica, para soluções com poucos processos paralelos, como é o caso especial do sistema apresentado nesta seção.

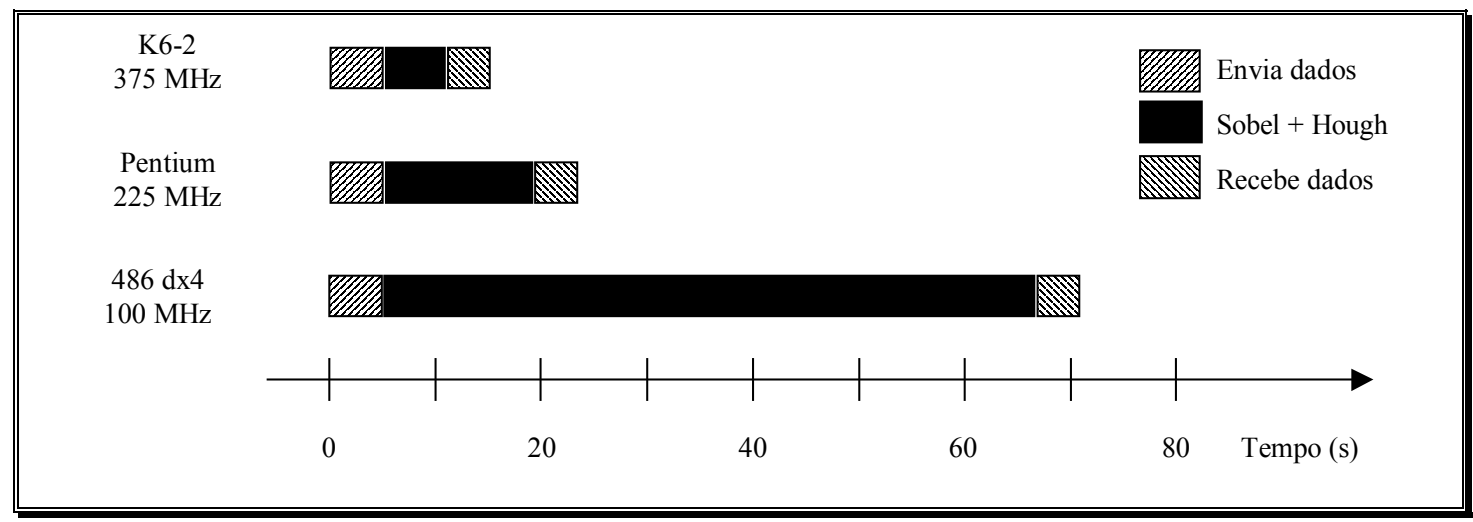

Fig. 7.14 - Comparação entre o tempo de execução do experimento em três diferentes sistemas homogêneos, em uma imagem de 30000 pixels.

\section{4 - TRANSFORMADA DE FOURIER}

Nesta seção vamos comentar a implementação paralela da transformada de Fourier rápida (FFT) de duas dimensões baseada no CVMP. A transformada de Fourier dispensa apresentações. Ela tem sido utilizada há muitos anos em processamento de sinais e imagens, tanto na teoria quanto nas aplicações, podendo ser caracterizada como uma das bases clássicas do processamento de sinais e imagens.

A transformada de Fourier e sua inversa em sua forma analítica, são dadas pelas equações 7.4 e 7.5 respectivamente, enquanto que sua forma discreta podem ser encontradas nas equações 7.6 e 7.7. Observando a transformada de Fourier discreta (TFD - Transformada de Fourier Discreta), podemos avaliar a grande carga computacional requerida para seu processamento, devido ao grande número de 
multiplicações e exponenciações. Para diminuir essa enorme carga foi elaborada a transformada de Fourier rápida (FFT - Fast Fourier Transform), um algoritmo baseado em alguns artifícios matemáticos capaz de diminuir o número de operações e agilizar o processamento [Brigham, 1988]. Embora o resultado da FFT seja uma aproximação da transformada de Fourier, e também seja limitada a vetores (ou sinais), cuja dimensão seja geralmente uma potência de 2 , sua grande performance justifica sua utilização.

$$
\begin{aligned}
& F(u)=\int_{-\infty}^{\infty} f(x) \exp [-j 2 \pi u x] d x \\
& f(x)=\int_{-\infty}^{\infty} F(u) \exp [j 2 \pi u x] d u \\
& F(u)=\frac{1}{N} \sum_{x=0}^{N-1} f(x) \exp [-j 2 \pi u x / N] \\
& f(x)=\sum_{x=0}^{N-1} F(u) \exp [j 2 \pi u x / N]
\end{aligned}
$$

\subsection{1 - TRANSFORMADA DE FOURIER 2D}

A transformada de Fourier em duas dimensões é dada pela equação:

$$
F(u, v)=\iint_{-\infty}^{\infty} f(x, y) \exp [-j 2 \pi(u x+v y)] d x d y
$$

que, quando transposta para sua forma discreta (TFD - Transformada de Fourier Discreta) resulta:

$$
F(u, v)=\frac{1}{M N} \sum_{x=0}^{N} \sum_{y=0}^{M} f(x, y) \exp \left[-j 2 \pi\left(\frac{u x}{N}+\frac{v y}{M}\right)\right]
$$

que pode ser escrita como: 


$$
F(u, v)=\frac{1}{M} \sum_{y=0}^{M} \frac{1}{N} \sum_{x=0}^{N} f(x, y) \exp \left[-j 2 \pi\left(\frac{u x}{N}\right)\right] \exp \left[-j 2 \pi\left(\frac{v y}{M}\right)\right]
$$

possibilitando a separação de um dos núcleos da equação resultando em:

$$
F(u, v)=\frac{1}{M} \sum_{y=0}^{M} F(u, y) \exp \left[-j 2 \pi\left(\frac{v y}{M}\right)\right]
$$

Esse resultado demonstra que podemos obter a TFD 2D a partir da TFD 1D, valendo o mesmo para a transformada discreta inversa, que basicamente possui como diferença apenas o sinal do expoente da exponencial. Para isso, deve-se calcular a TFD 1D de cada uma das linhas da imagem $f(x, y)$, obtendo $F(x, v)$ e depois calcular a TFD 1D de todas as colunas de $F(x, v)$, obtendo finalmente $F(u, v)$ [Brigham, 1988] [Castleman, 1996] [Gonzalez \& Woods, 1993] [Oppenheim \& Schafer, 1975]. A decomposição da TFD 2D em 1D pode ser expandida também para a FFT, neste caso, ao invés de calcular a TFD 1D de cada passo deve ser calculada a FFT [Brigham, 1988].

Classicamente a implementação do algoritmo paralelo da FFT 2D consiste nas combinações horizontais e verticais da FFT 1D, conforme apresentamos anteriormente. A Figura 7.15 apresenta um diagrama ilustrativo da implementação realizada a partir do CVMP, nela o mestre divide a imagem horizontalmente e envia cada uma das partes para os processos escravos, ficando com uma parte. Com isso, cada um dos processos realiza a FFT 1D de cada uma das linhas horizontais da sua porção de imagem e, ao final deste procedimento transmitem a parte real e imaginária do resultado para o mestre, que agora, divide os resultados verticalmente e distribui-os novamente. É então disparado o processamento vertical, em cada uma das máquinas, que consiste na FFT 1D das linhas verticais das matrizes complexas (parte real e imaginária). Finalmente os resultados (que consistem em uma matriz real e uma imaginária) são enviados para o mestre, onde são combinados formando as matrizes real e imaginária resultantes da FFT 2D da imagem. Esta e outras estratégias de paralelismo da FFT 2D podem ser encontradas em detalhes em [Chu \& George, 1999] e [Morante et al., 1999]. 


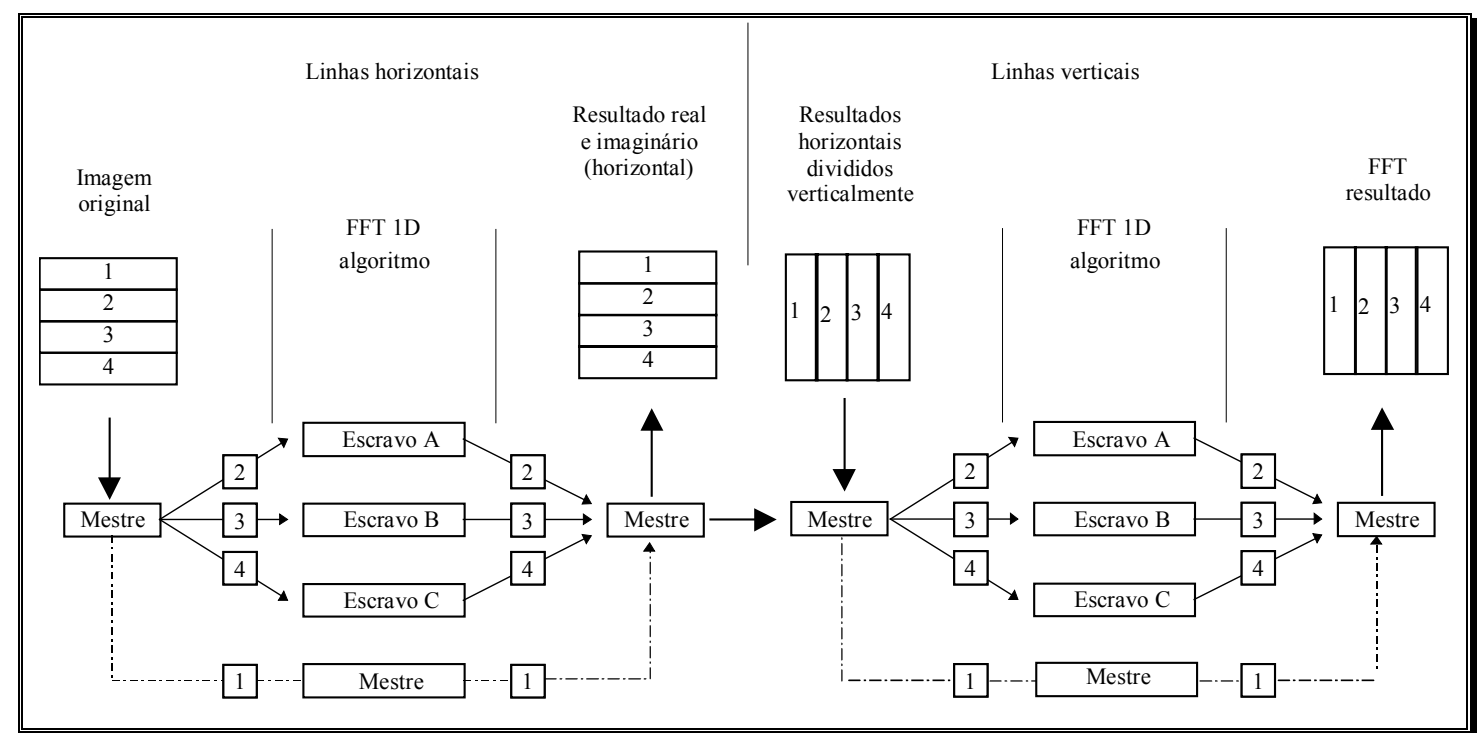

Fig. 7.15 - Estratégia de paralelismo da FFT 2D. Exemplo para 4 processos (máquinas ou processadores).

Como podemos verificar, o fluxo de dados é bastante intenso, especialmente devido a combinação dos resultados do processamento horizontal e a combinação para o processamento vertical. Entretanto, além da intensidade de trocas da estratégia de paralelização, devido à natureza dos dados, o volume transmitido aumenta demasiadamente, tornando-se um enorme gargalo no sistema. O aumento do volume dos dados ocorre devida a duas circunstâncias: (i) alteração de tipo de dado e (ii) as matrizes da transformada são complexas (uma matriz real e uma matriz imaginária).

No primeiro fator, caso estejamos aplicando a transformada de Fourier a uma imagem, e sendo a imagem de 256 níveis de cinza (usualmente utilizada em processamento de imagens), cada elemento da matriz imagem é constituída por um byte. Vamos tomar como exemplo uma imagem de $1024 \times 1024$ pixels com 256 níveis de cinza. Neste caso, o espaço de memória ocupado para armazenar a imagem é de 1 megabyte, uma vez que cada elemento da matriz imagem, é constituído por um byte $\left(256=2^{8}\right)$. A quantidade de memória é determinada pela área da imagem em pixels. Entretanto, o algoritmo da transformada oferece maior precisão em ponto flutuante. A Tabela 7.1 apresenta o espaço em bytes ocupada pelos principais tipos de variáveis presentes no Object Pascal do Delphi versão 4, como podemos ver, os espaços ocupados pelos elementos da matriz são multiplicados por 4 ou na pior das hipóteses, caso exista a necessidade de uma maior precisão, por 8 , uma vez que os tipos de variáveis que permitem 
armazenamento de ponto flutuante ocupam 4 bytes (single) ou 8 bytes (real e double). Assim, a matriz imagem 1024×1024, quando convertida para ponto flutuante, passa a ocupar 4 megabytes se for atribuída com o tipo single e 8 megabyte para os tipos real e double.

\begin{tabular}{|c|c|}
\hline Tipo & bytes utilizados \\
\hline byte & 1 byte \\
\hline integer & 4 bytes \\
\hline real & 8 bytes \\
\hline single & 4 bytes \\
\hline double & 8 bytes \\
\hline
\end{tabular}

Tabela 7.1 - Tipos de variáveis do Object Pascal (Delphi 4) e a memória utilizada.

No segundo caso, temos que considerar que a transformada de Fourier é baseada em números complexos. Deste modo, somos obrigados a duplicar os dados para constituir uma matriz complexa, através da utilização de uma matriz ponto flutuante para representar a parte real e outra para a parte imaginária. Assim, tomando o exemplo anterior, caso tivéssemos optado pelos dados do tipo single, teríamos que manipular com 8 megabytes, e 16 megabytes se tivéssemos optado pelo tipo real ou double.

Dentro da estratégia de paralelismo utilizada, temos basicamente quatro conjuntos de trocas de mensagens: (i) correspondentes a distribuição da imagem ou matriz de entrada, (ii) retorno do resultado do processamento horizontal para o mestre, (iii) redistribuição das porções verticais e (iv) envio do resultado final para o mestre. Se o algoritmo for utilizado para imagens, parte das mensagens pode ser constituída de fragmentos da imagem, diminuindo desta maneira o fluxo de dados. Com o grande volume de dados, envolvido nesses processos, o tempo de processamento gasto com as operações relacionadas a essas transferências de dados (processos de leitura, conversões e comunicação em rede) acaba sendo maior do que o tempo gasto com o processamento matemático, tornando a implementação dessa estratégia inviável em sistemas distribuídos com redes possuindo taxas de transmissão de 10 ou $100 \mathrm{Mbit} / \mathrm{s}$.

O sistema foi implementado com 4 máquinas conectadas em rede ethernet 
de 10 megabits/s. As máquinas utilizadas possuíam processadores AMD k6 II - 375 $\mathrm{MHz}$, caracterizando o sistema como homogêneo. A Figura 7.16 apresenta um diagrama ilustrativo de uma implementação utilizando quatro máquinas em sistema distribuído com rede de 10 megabits/s, mostrando o tempo estimado das trocas de mensagem e do processamento matemático, onde podemos observar o gargalo formado pelos processos envolvidos com as trocas de mensagens.

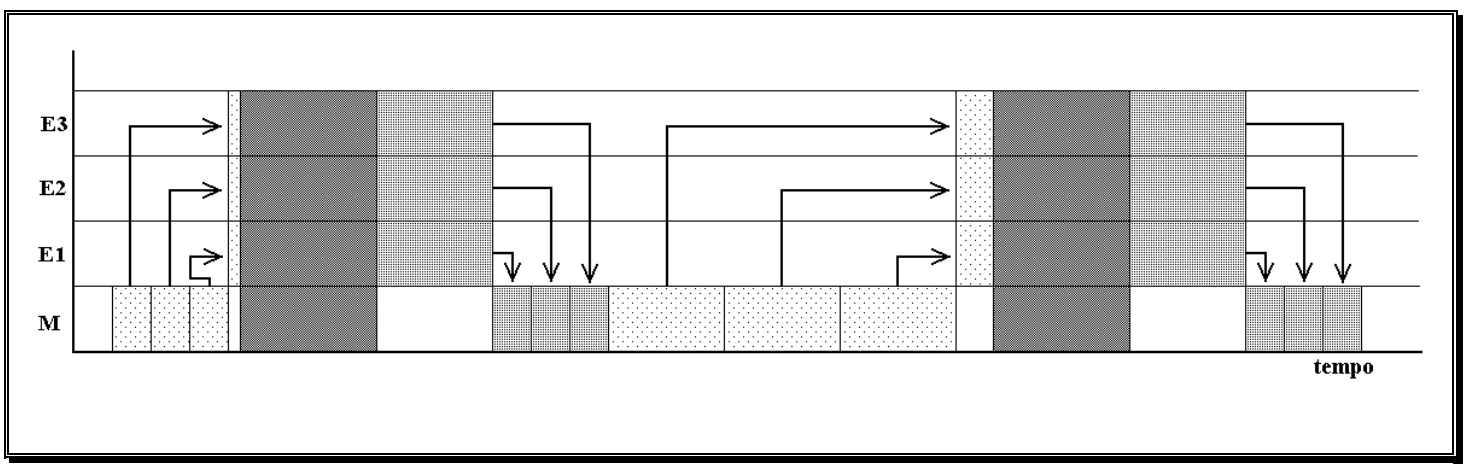

Fig. 7.16 - Estratégia de paralelismo da FFT 2D. Exemplo para 4 processos (máquinas ou processadores).

Como alternativa para a redução do grande volume de dados envolvidos nos processos de transferência, utilizamos o algoritmo LZW [Nelson, 1989] de compactação de memória. Dessa maneira, antes dos dados serem transmitidos via rede, efetuamos sua compactação na máquina local. A fim de estudar o comportamento do sistema sob diferentes situações e na tentativa de otimizar os mecanismos de troca de mensagem e consequentemente aumentar a performance da versão paralela, o sistema foi implementado de 4 diferentes maneiras:

Utilizando a memória de massa (disco rígido) para armazenar todos os dados a serem transmitidos via rede.

Utilizando memória de massa como em (i), com compactação de dados antes da transmissão.

Utilizando a memória RAM para armazenar todos os dados a serem transmitidos via rede.

Idem a anterior, com compactação dos dados antes da transmissão.

A Figura 7.17 apresenta os tempos de execução das diferentes implementações paralelas frente à versão seqüencial em 5 tamanhos diferentes de imagens (128x128, 256x256, 512x512, 1024x1024 e 2048x2048). Nela podemos 
observar a melhora de performance provocada pela compactação de dados antes da transmissão, que embora possua gastos computacionais nos processos de compactação e descompactação justifica sua utilização pela taxa de compactação, que reduziu o tamanho dos dados em cerca de $90 \%$ a $99 \%$.
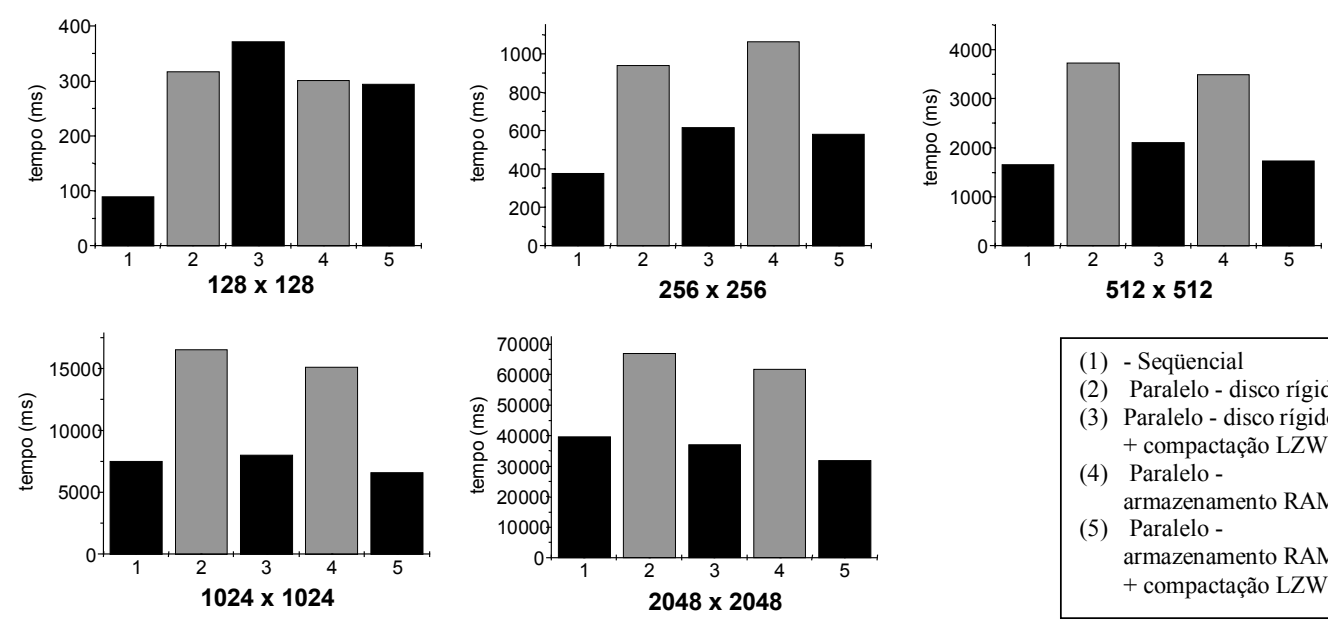

(1) - Seqüencial

(2) Paralelo - disco rígido

(3) Paralelo - disco rígido + compactação LZW

(4) Paralelo -

armazenamento RAM

(5) Paralelo -

armazenamento RAM + compactação LZW

Fig. 7.17 - Tempos de execução do sistema seqüencial (1) e modalidades paralelas (2, 3, 4 e 5) para diferentes tamanhos de imagem. As modalidades paralelas foram implementadas em sistemas distribuídos de 4 máquinas.

A Figura 7.18 apresenta a porcentagem entre o tempo gasto com o processamento matemático e o gasto com os procedimentos relacionados com as trocas de mensagens (leitura, gravação, rede, compactação e conversões). Nela podemos observar como o consumo dos recursos computacionais é maior para os processos envolvidos com a troca de mensagens do que com o envolvido com o processamento matemático, justificando uma baixa performance dessa arquitetura para sistemas distribuídos.

A Figura 7.19 apresenta a taxa de desempenho ou speed-up, dos sistemas paralelos frente ao seqüencial. Conforme podemos observar, embora a taxa de desempenho aumente gradativamente à medida que aumentam as dimensões das imagens, ela não atinge um patamar de desempenho satisfatório até a dimensão de 2048x2048. A baixa performance não justifica a utilização desta implementação paralela da FFT 2D, uma vez que com quatro máquinas, o sistema ficou na maioria dos casos mais lento que a versão seqüencial e atingiu um desempenho máximo pouco maior que esta. 


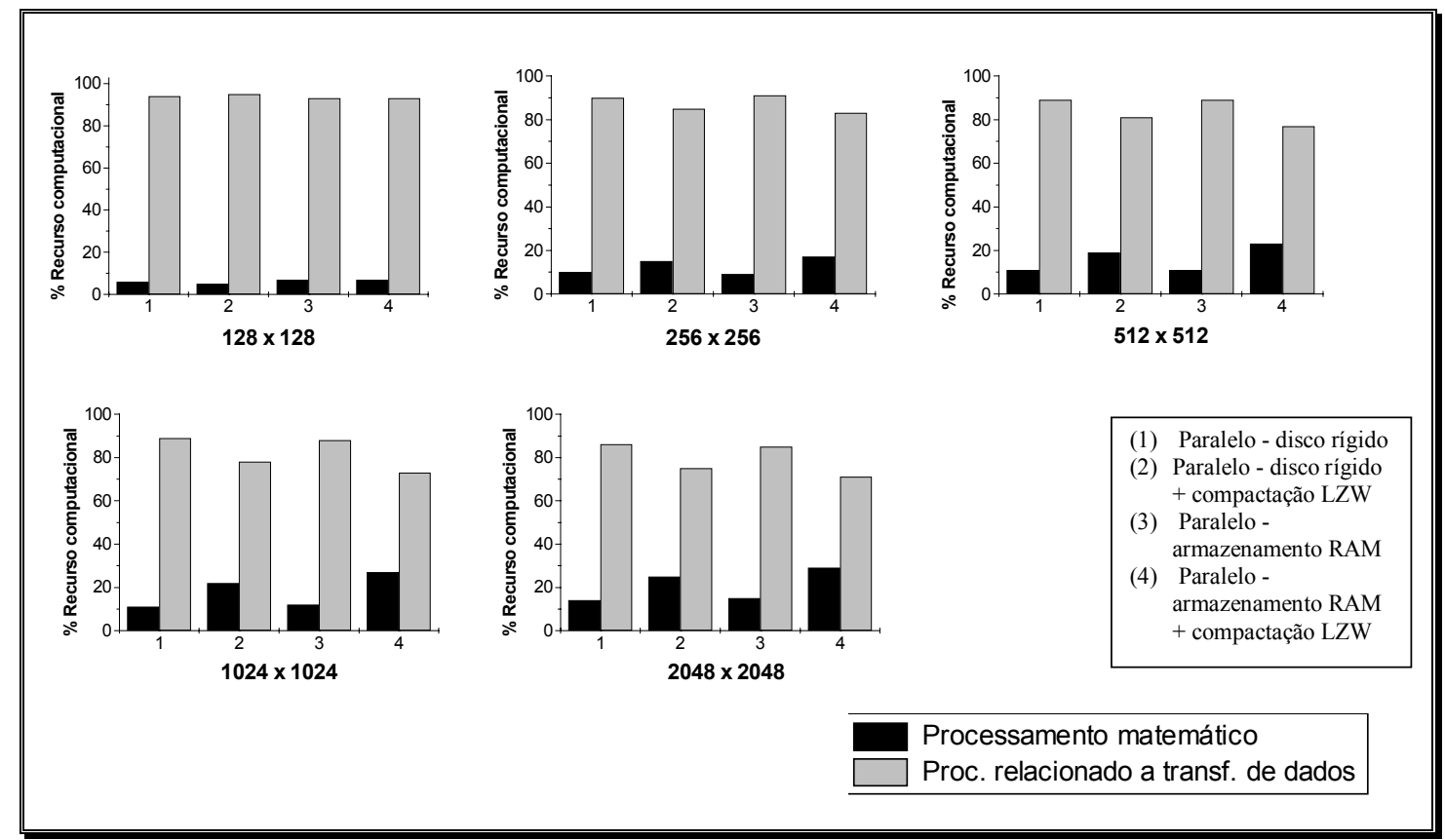

Fig. 7.18 - Porcentagem da utilização de recursos computacionais entre o processamento matemático e os processos relacionados com as transferências de dados.

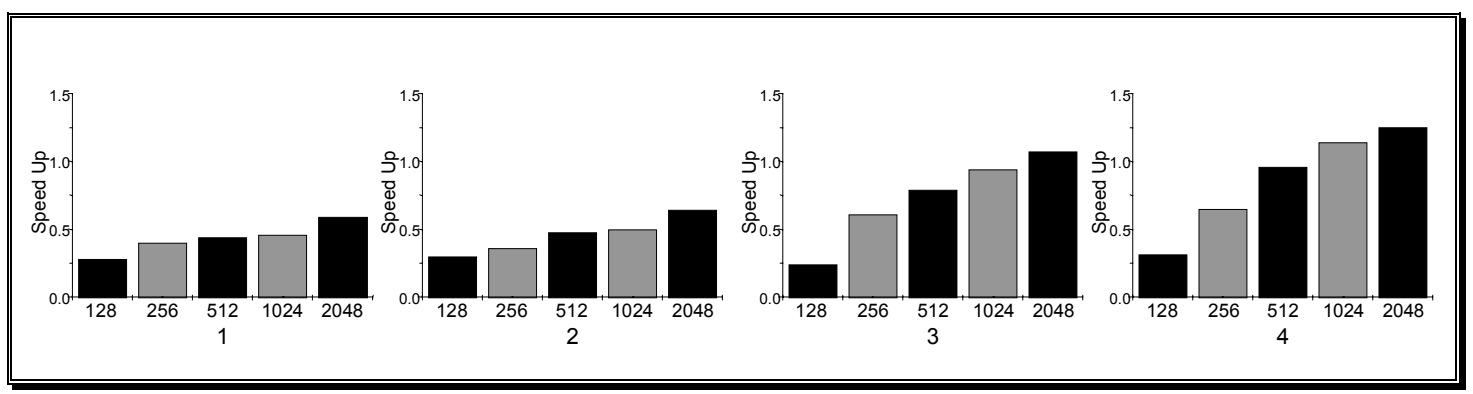

Fig. 7.19 - Gráficos da taxa de desempenho ou speed up em função do tamanho da imagem (dado pelo lado da imagem quadrada). Gráfico: (1) disco rígido, (2) disco rígido + compactação $L Z W$, (3) RAM e (4) RAM + compactação $L Z W$.

Uma vez que o gargalo do sistema está situado no grande fluxo de transferência de dados, a arquitetura paralela proposta, embora não seja promissora para sistemas distribuídos com rede convencionais, pode ser satisfatória em sistemas de memória compartilhada, uma vez que esses possuem uma velocidade muito maior na troca de mensagens. Para verificarmos sua performance em arquitetura com memória compartilhada, implementamos uma versão experimental do sistema com o CVMP memória compartilhada. Uma vez 
que não dispúnhamos de uma máquina com múltiplos processadores, realizamos a simulação utilizando a característica de multitarefa do sistema operacional. As medidas foram feitas com cautela, para não beneficiar a arquitetura compartilhada. Em algumas situações optamos para que a simulação não se beneficiasse de algumas vantagens dessa arquitetura, concluindo portanto que num sistema real podemos realizar uma implementação com algumas otimizações.

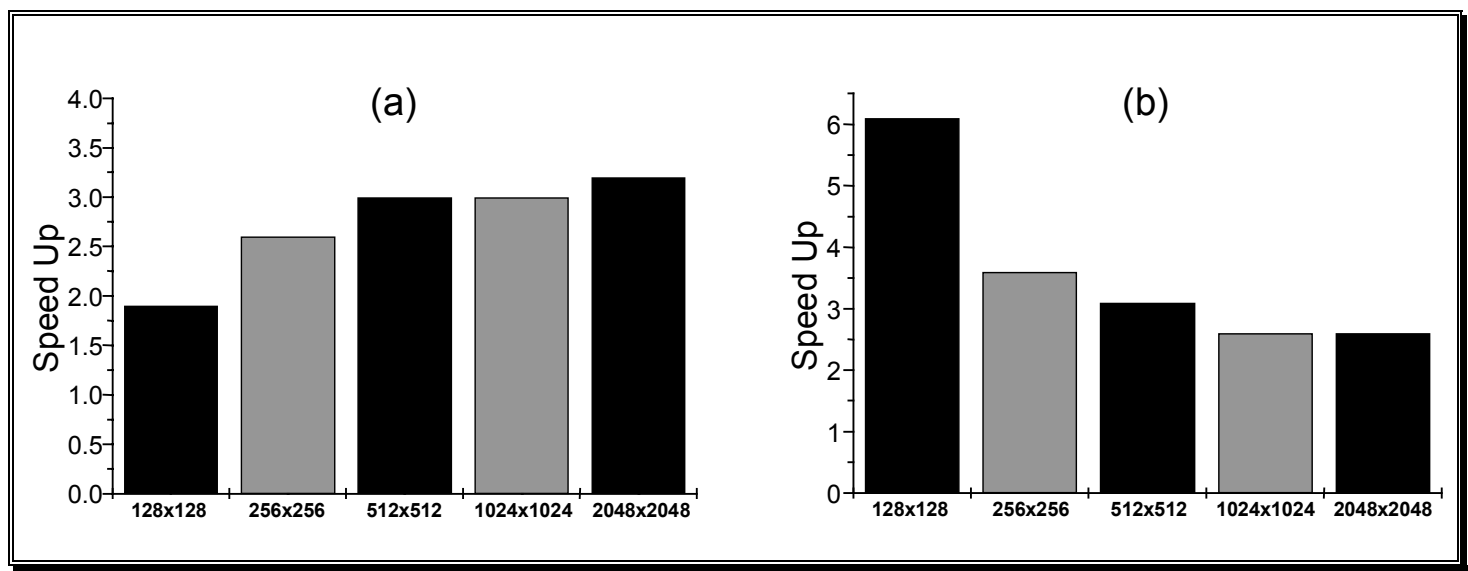

Fig. 7.20 - Gráficos da taxa de desempenho ou speed-up em função do tamanho da imagem. Simulação de uma arquitetura de memória compartilhada de 4 processadores equivalentes a AMD K6-2 $375 \mathrm{MHz}$. (a)

Desempenho memória compartilhada frente a versão seqüencial. (b) Desempenho da memória compartilhada frente ao melhor caso da arquitetura distribuída (RAM + LZW).

A Figura 7.20 apresenta os resultados da simulação. Nela temos o gráfico da taxa de desempenho ou speed up do sistema paralelo com quatro processadores de $375 \mathrm{MHz}$ e memória compartilhada. Como podemos constatar, eliminando a transferência de dados via rede e o custo dos algoritmos de compactação de dados (LZW), o sistema obteve uma grande melhora de performance. No gráfico 7.20a temos a taxa de desempenho da arquitetura compartilhada em função da versão seqüencial. A performance foi muito superior aos sistemas distribuídos, chegando a quase 3.5 de speed up, o que viabiliza a utilização da versão paralela. O gráfico $7.20 \mathrm{~b}$ mostra a taxa de desempenho da arquitetura compartilhada frente ao melhor caso da arquitetura distribuída, ou seja o caso iv (RAM + LZW), nele podemos observar que a implementação paralela em arquitetura compartilhada ficou entre 2,5 a 6 vezes mais rápida que a implementação em sistema distribuído. 


\section{5 - TRANSFORMADA DE HOUGH}

Inicialmente elaborada para calcular a trajetória de partículas em câmaras de bolhas [Hough. 1959], a transformada de Hough se tornou uma ferramenta tradicional em análise de imagens para o reconhecimento de padrões globais. A idéia básica da técnica consiste em encontrar curvas que podem ser parametrizadas, tais como segmentos de reta, polinômios, círculos, elipses e etc., em um espaço de parâmetros (arranjo acumulador). Embora possa ser utilizada em dimensões maiores, sua principal utilização consiste na localização de padrões em duas dimensões [Schalkoff, 1989] [Duda \& Hart, 1972].

Dentre os padrões globais disponíveis para a transformada de Hough, o mais amplamente difundido e utilizado é o segmento de reta (provavelmente devido a importância dessa modalidade em visão e processamento de imagens), sendo muitas vezes generalizada à transformada de Hough como uma técnica de detecção de retas. Nesta seção vamos nos concentrar apenas nessa modalidade da transformada de Hough.

Os segmentos de reta encontrados em uma imagem podem ser parametrizados como:

$$
\rho=x \cos \theta+y \operatorname{sen} \theta
$$

onde $\rho$ é a distância perpendicular até a origem e $\theta$ o ângulo com sua normal (Figura 7.21). Deste modo, os pontos co-lineares $\left(x_{i}, y_{i}\right)$, onde i varia de 1 a $N$, são transformados em $\mathrm{N}$ curvas senoidais

$$
\rho=x_{i} \cos \theta+y_{i} \operatorname{sen} \theta
$$

no plano $(\rho, \theta)$, que se intersecionam no ponto $(\rho, \theta)$, conforme podemos observar na Figura 7.21. 
(a)

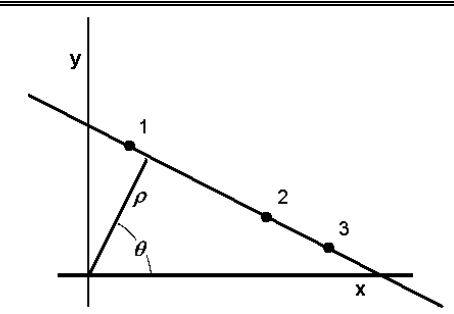

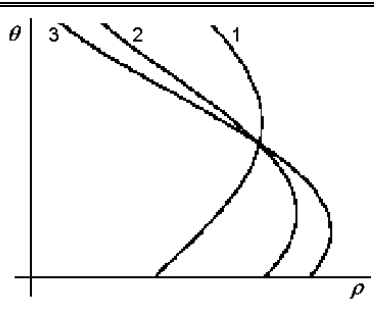

(b)

Fig. 7.21 - Demonstração dos principais elementos envolvidos na parametrização de retas para a transformada de Hough. (a) Espaço de coordenadas original. (b) Espaço de Hough.

O plano $(\rho, \theta)$, é parametrizado em uma estrutura conhecida como arranjo acumulador. Trata-se de uma matriz cujas linhas e colunas são parametrizadas em função de $\rho$ e $\theta$, onde para cada ponto do plano original são incrementados os elementos correspondentes a curva senoidal dada por (7.12). Assim, as retas ou os pontos colineares da imagem, se apresentam na forma de picos no arranjo acumulador, sendo caracterizados como máximos locais. A Figura 7.22 apresenta uma imagem com o seu respectivo espaço de Hough.

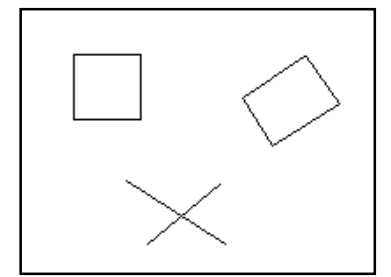

(a)
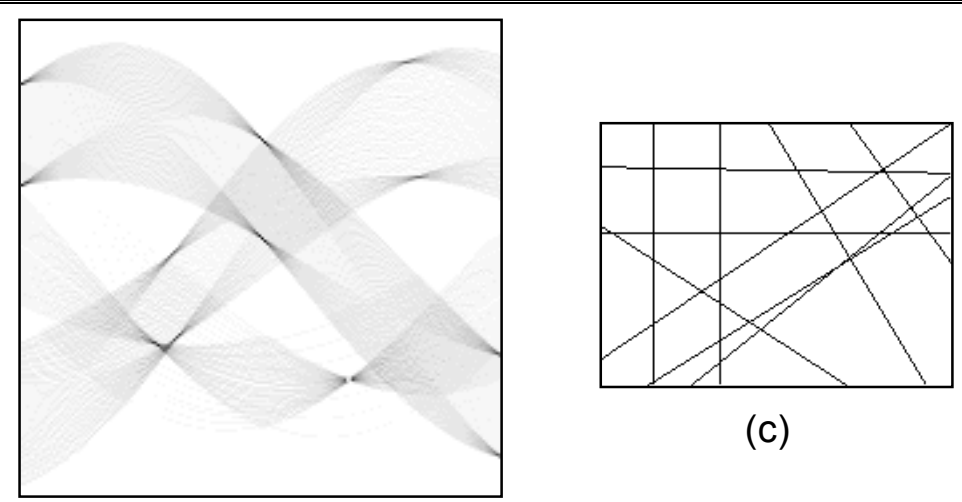

(c)

(b)

Fig. 7.22 - Detecção de retas através da transformada de Hough. (a) Imagem original, (b) Arranjo acumulador (espaço de Hough) e (c) Retas detectadas (com backmapping).

Cada ponto da imagem, corresponde a uma curva senoidal no espaço de Hough, que parametrizada incrementa o espaço acumulador, permitindo na técnica, ser processado isoladamente. Deste modo, a transformada de Hough pode ser entendida como uma série de operações locais, já que não ocorre dependência de 
dados entre os elementos da imagem. Baseado nisso, podemos paralelizar o algoritmo através da divisão da imagem original, ficando cada elemento de processamento responsável por um fragmento, onde no final do processamento o arranjo acumulador de cada unidade de processamento deverá ser somado constituindo o arranjo acumulador resultante da transformada. Informações adicionais sobre estratégias de paralelismo na transformada de Hough podem ser encontrados em [Guil \& Zapata, 1997] e [Thazhuthaveetil \& Shah, 1991].

A Figura 7.23 exibe um diagrama que ilustra essa arquitetura para quatro unidades de processamento, onde a imagem é dividida em 4 e enviada para cada processador. Cada fragmento da imagem é então processado, gerando o seu respectivo espaço de Hough, parametrizado em um arranjo acumulador. No final, os elementos dos arranjos acumulador correspondentes a cada porção da imagem são somados, gerando o resultado final.

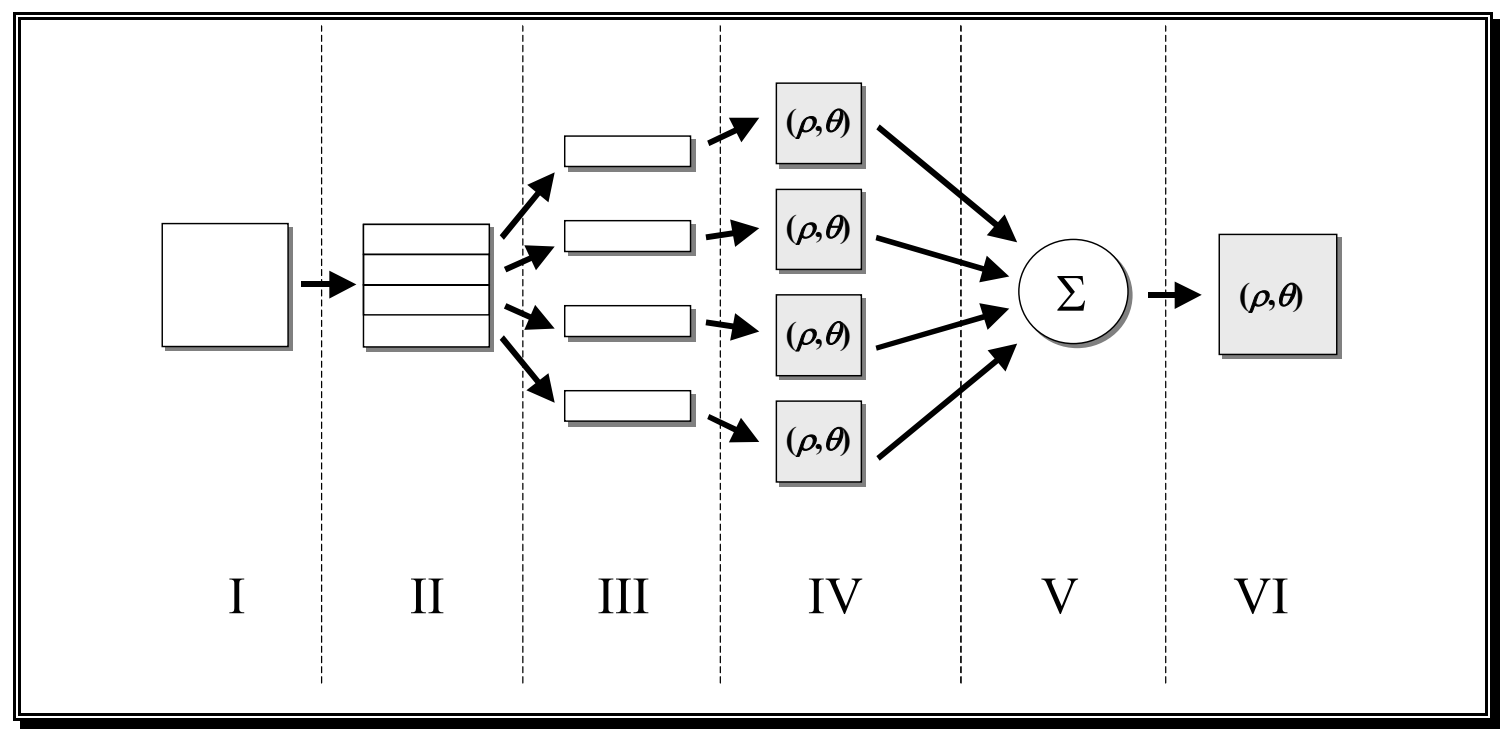

Fig. - 7.23 - Estratégia de paralelismo para a transformada de Hough. As etapas I, II, III, IV, V e VI representam respectivamente: a imagem original, divisão da imagem e sua distribuição, processamento de cada fragmento da imagem, arranjos acumulador resultante do processamento de cada fragmento, somatório dos elementos dos arranjos acumulador e arranjo acumulador resultante.

Implementamos versões do sistema, com 2, 3 e 4 unidades de processamento diferentes. A Figura 7.24 mostra um exemplo do diagrama de fluxo de dados e execução para a versão com quatro processadores, nela temos um 


\section{CAPÍTULO 7}

processo mestre e quatro escravos, onde cada processo está alojado em uma unidade de processamento distinta. O mestre é responsável pela divisão da imagem principal, e sua distribuição para as máquinas escravas, que juntamente com o mestre irão processar um dos fragmentos da imagem. Após o término da execução os arranjos acumuladores, resultantes do processamento, são enviados à máquina mestra, que realizará o somatório dos elementos de cada arranjo, constituindo desse modo a resultado final.

Adotamos os arranjos acumuladores com dimensões equivalentes às imagens. Desta maneira, eles foram parametrizados de forma a possuir um número de elementos muito próximo ao número de pixels da imagem. Usualmente a transformada de Hough é aplicada sobre imagens binárias resultantes de detecções de bordas, portanto empregamos imagens de 1 bit de profundidade como entrada do sistema, diminuindo assim o tráfego de mensagens. Para as matrizes que armazenam os arranjos acumulador, adotamos o tipo de variável word, que apresenta dois bytes para o armazenamento, de modo que o arranjo acumulador ocupa uma memória de cerca de 16 vezes o tamanho das imagens correspondentes.

Além de versões para diferentes quantidades de elementos de processamento, vamos apresentar o desempenho para diferentes modalidades de arquitetura que obedecem à mesma estratégia de paralelização: (i) sistema distribuído com rede ethernet de $10 \mathrm{Mb} / \mathrm{s}$, (ii) sistema distribuído com rede fast ethernet de $100 \mathrm{Mb} / \mathrm{s}$ e (iii) sistema memória compartilhada.

Todas as modalidades de sistemas foram implementadas utilizando processadores AMD K6 II com $375 \mathrm{MHz}$. O sistema de memória compartilhada foi simulado.

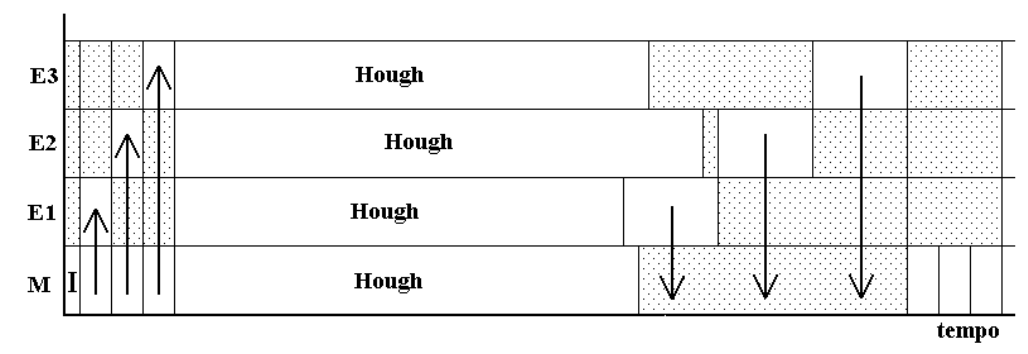

Fig. - 7.24 - Diagrama ilustrando as trocas de mensagem e o balanceamento de carga do sistema. 
A Figura 7.25 apresenta três gráficos, com os tempos de execução dos sistemas em função do número de processadores. Cada um dos gráficos é referente a um tamanho de imagem utilizada no experimento $(250 \times 250,500 \times 500$ e 750x750 pixels). Diferente do que seria previsível, o tempo de execução da modalidade sistema distribuído de $10 \mathrm{Mb} / \mathrm{s}$, ao invés de diminuir aumenta, à medida que o sistema é acrescido de unidades de processamento. Isso pode ser observado nos gráficos referentes as imagens de 250×250 e 500×500 pixels, ao passo que essa situação não ocorre nas imagens de $750 \times 750$ pixels. Esse fato é explicado pelo gargalo da transferência de dados. Conforme é apresentado na Figura 7.23, enquanto a imagem é dividida e distribuída para as unidades de processamento, o mesmo não ocorre com o arranjo acumulador. Embora as máquinas processem apenas um fragmento da imagem, o resultado obtido é um arranjo acumulador não fragmentado, ou seja, com a mesma dimensão da versão seqüencial. Com isso, as mensagens a serem retornadas para a máquina mestra, aumentam proporcionalmente ao número de processadores escravos, uma vez que não se fragmentam.

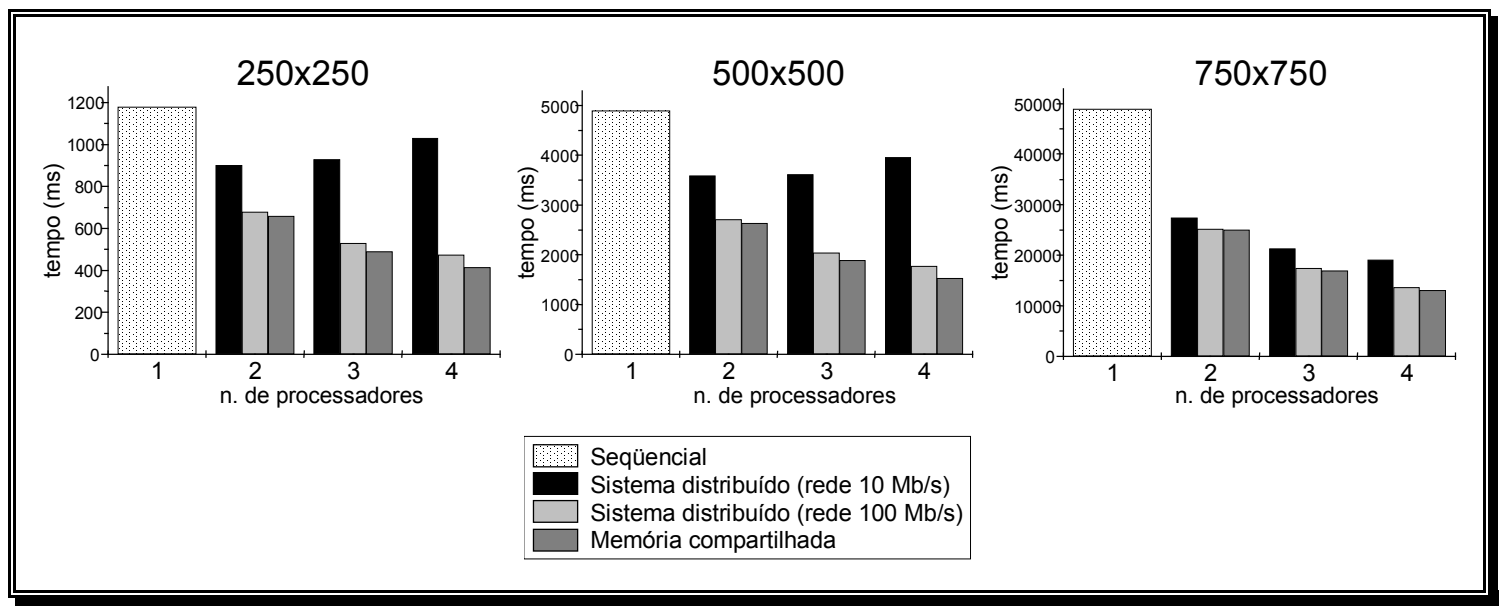

Fig. - 7.25 - Gráficos do tempo de execução em função do número de processadores, com suas respectivas modalidades de implementação. Cada gráfico é definido mediante um tamanho de imagem.

Embora ocorra uma situação semelhante com as outras modalidades, essa situação não é observada de forma tão nítida, devido ao fato do gargalo de transferência estar reduzido em relação ao sistema distribuído de $10 \mathrm{Mb} / \mathrm{s}$. O mesmo fato ocorre nesse sistema no processamento de imagens de $750 \times 750$ pixels, uma que o tempo de processamento aumenta consideravelmente em 
relação ao tempo de transferência, fazendo com que o gargalo diminua.

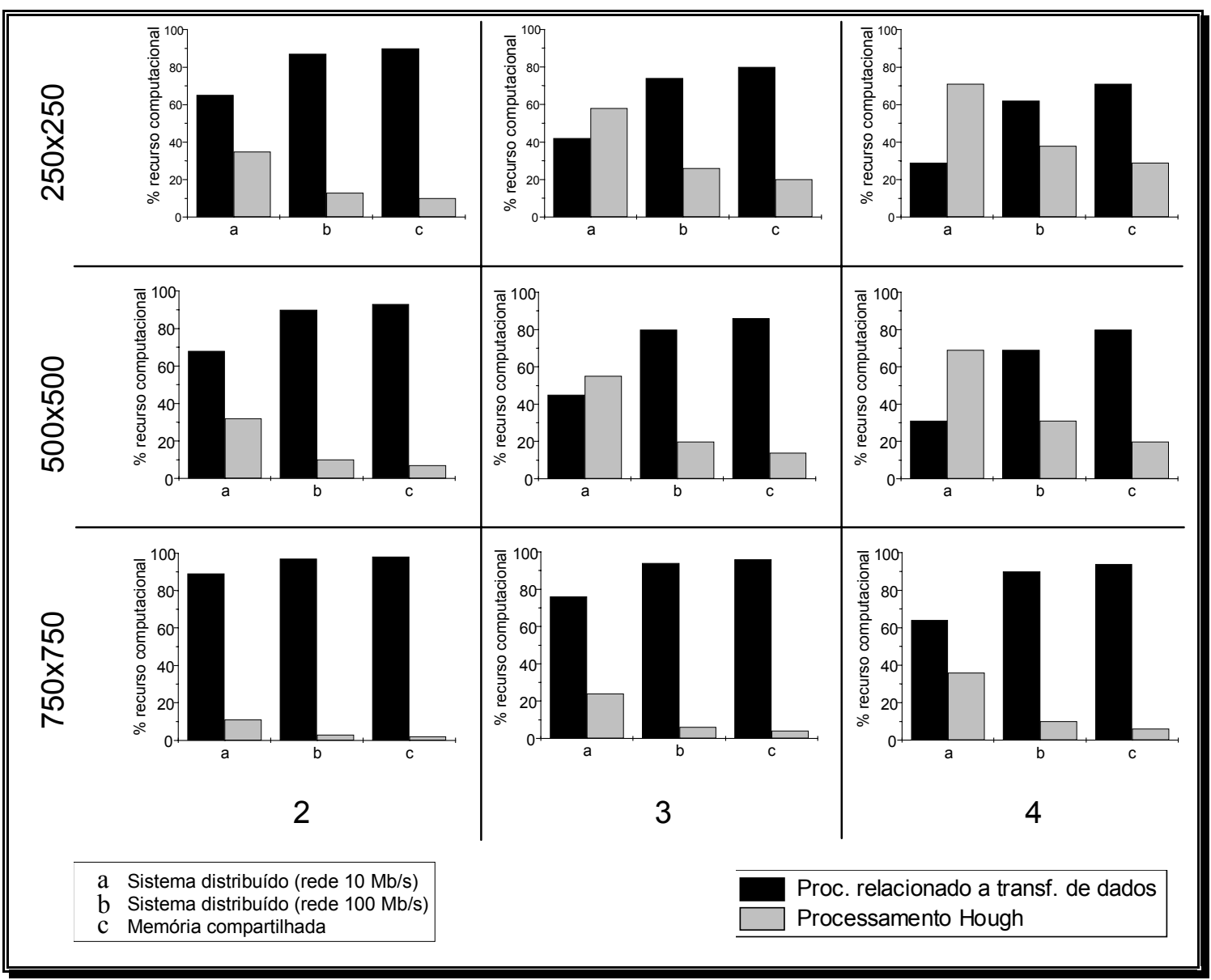

Fig. - 7.26 - Porcentagem da utilização de recursos computacionais entre o processamento da técnica e os processos relacionados com as transferências de dados. As linhas horizontais contém os gráficos relacionados ao tamanho da imagem, enquanto que as linhas verticais os números de processadores.

A Figura 7.26 apresenta a porcentagem entre o tempo gasto com 0 processamento da técnica e com os procedimentos relacionados com as trocas de mensagens. Nela podemos observar a situação descrita anteriormente, que fica bem nítida com os sistemas distribuídos de $10 \mathrm{Mb} / \mathrm{s}$. Como podemos observar a porcentagem relativa ao tempo gasto com a troca de mensagem se torna maior a medida que aumentam os processadores. Com isso podemos concluir que essa arquitetura não favorece a utilização de sistemas massivamente paralelos, já que o aumento no número de processadores resulta igualmente num aumento do volume de mensagens, que deverá atingir um limite nos sistemas distribuídos de $100 \mathrm{Mb} / \mathrm{s}$ 
semelhante ao dos sistemas de $10 \mathrm{Mb} / \mathrm{s}$ a partir de um determinado número de processadores.

As taxas de desempenho ou speed-up dos sistemas são mostradas nos gráficos da Figura 7.27. Através deles são determinadas as performances de cada modalidade frente à versão seqüencial. Conforme podemos observar, a arquitetura apresentou um bom desempenho para diferentes quantidades de unidades de processamento, com exceção dos sistemas distribuídos baseados em redes de ethernet de $10 \mathrm{Mb} / \mathrm{s}$, que apresentaram uma performance pequena para as imagens de $250 \times 250$ e 500x500 pixels, especialmente com 3 ou 4 processadores.

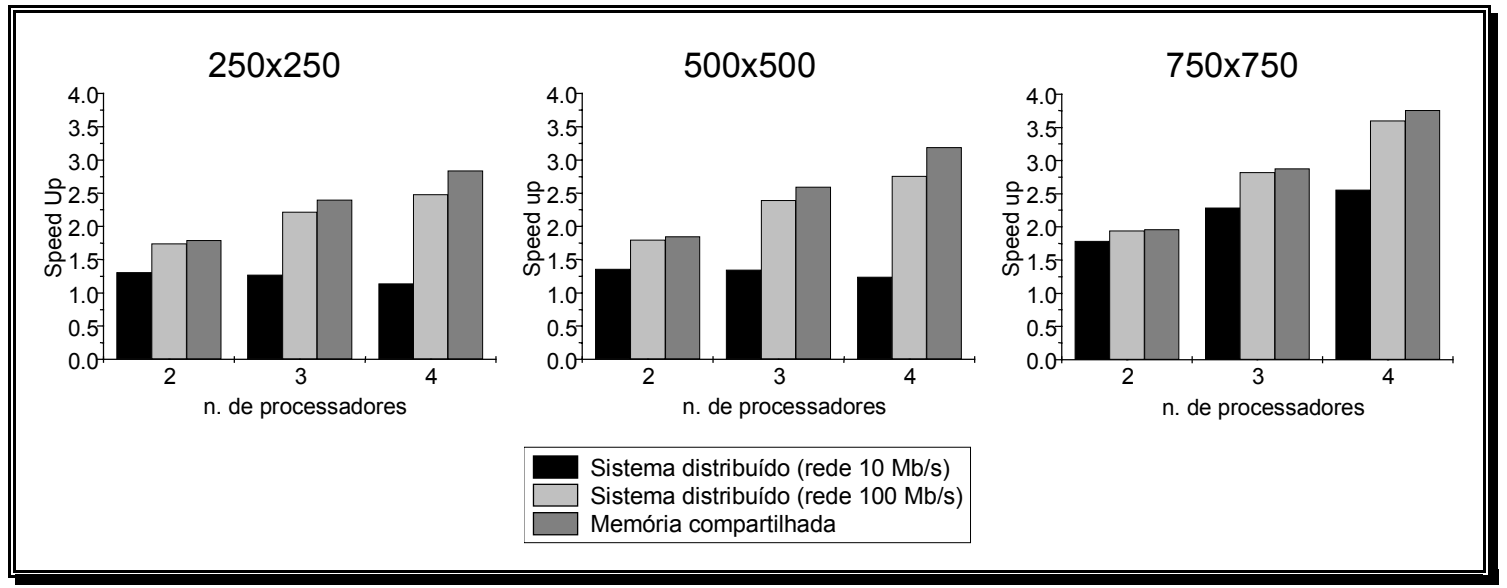

Fig. - 7.27 - Gráficos da taxa de desempenho ou speed up em função do número de processadores. Os gráficos apresentam as três modalidades implementadas no experimento. Cada gráfico é correspondente a um tamanho de imagem.

Devido às baixas performances obtidas com os sistemas distribuídos baseados em ethernet, decidimos explorar alguns mecanismos que possibilitassem a diminuição da carga de mensagens e consequentemente a ampliação do gargalo, de modo a aumentar o desempenho. O maior gargalo encontrado no sistema, se encontra na transferência dos arranjos acumuladores dos processos escravos, resultantes do processamento de cada fragmento de imagem para o processo mestre, portanto a solução estaria na redução do tamanho dos arranjos acumulador. Na tentativa de reduzir o tamanho dos arranjos acumulador, adotamos duas estratégias: (i) compactação LZW e (ii) lista de picos.

$\mathrm{Na}$ primeira estratégia, utilizamos o algoritmo de compactação de dados para diminuir o volume dos dados do arranjo antes de ser transmitido para o 


\section{CAPÍTULO 7}

processo mestre. Deste modo, embora seja acrescida uma carga computacional, devido ao processamento do algoritmo LZW [Nelson, 1989], esperamos que seu tempo de execução seja menor que o tempo de transferência do arranjo sem compactação.

Como sabemos, muitas das informações contidas no arranjo acumulador não são utilizadas pelas maiorias das aplicações (detecção de retas), deste modo, os interesses estão concentrados nos picos, que caracterizam os maiores conjuntos de pontos colineares, ou seja, as retas da imagem. Considerando essa abordagem, elaboramos a segunda estratégia, que consiste na criação de uma lista ou vetor contendo as coordenadas do plano de Hough e seu conteúdo apenas as células que ultrapassam um determinado valor (limiar). Não exploramos as heurísticas para a determinação do limiar, no entanto este foi definido como a décima quinta parte do maior elemento do arranjo.

A Figura 7.28 apresenta comparações entre as duas estratégias frente à versão experimentada nesta seção. Nela temos o tempo de execução da versão de 4 máquinas conectadas via ethernet. Como podemos observar, as duas alternativas que utilizamos para a redução dos gargalos tiveram um bom resultado, aumentando consideravelmente a performance comprometida da transformada de Hough distribuída em rede ethernet $10 \mathrm{Mb} / \mathrm{s}$.

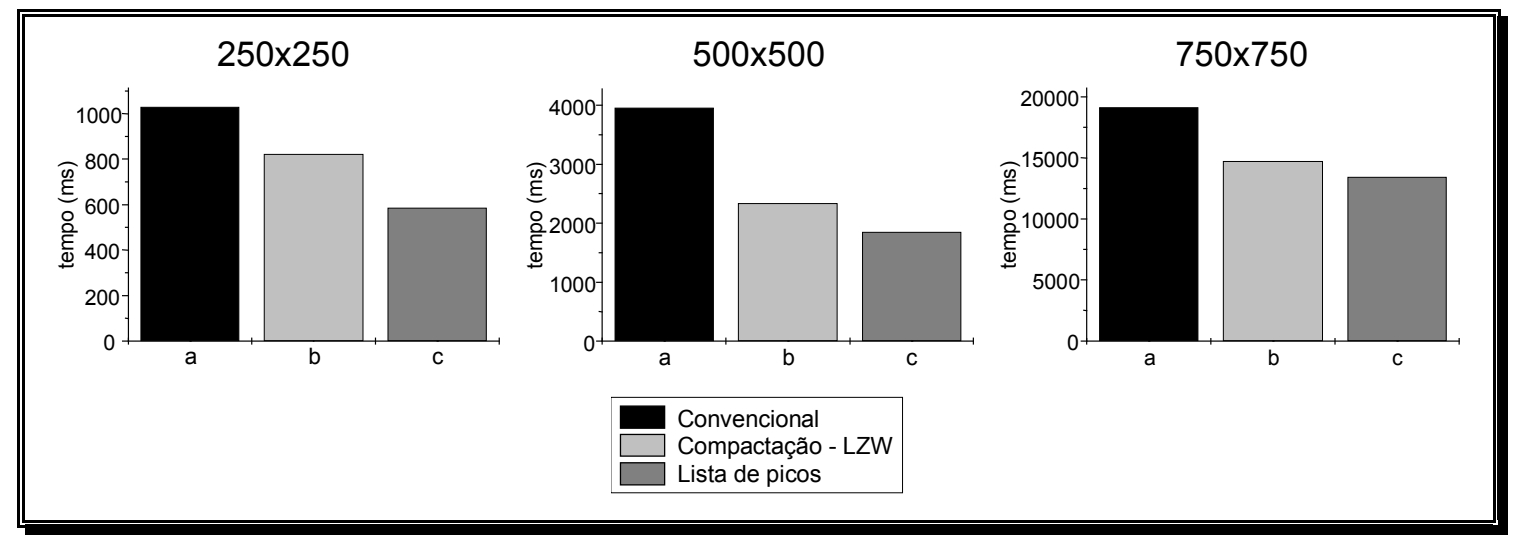

Fig. - 7.28 - Gráficos apresentando o tempo de execução relacionados com o tamanho da imagem, apresentando uma comparação entre as diferentes versões de implementação paralela para os sistemas distribuídos com rede ethernet $10 \mathrm{Mb} / \mathrm{s}$. 


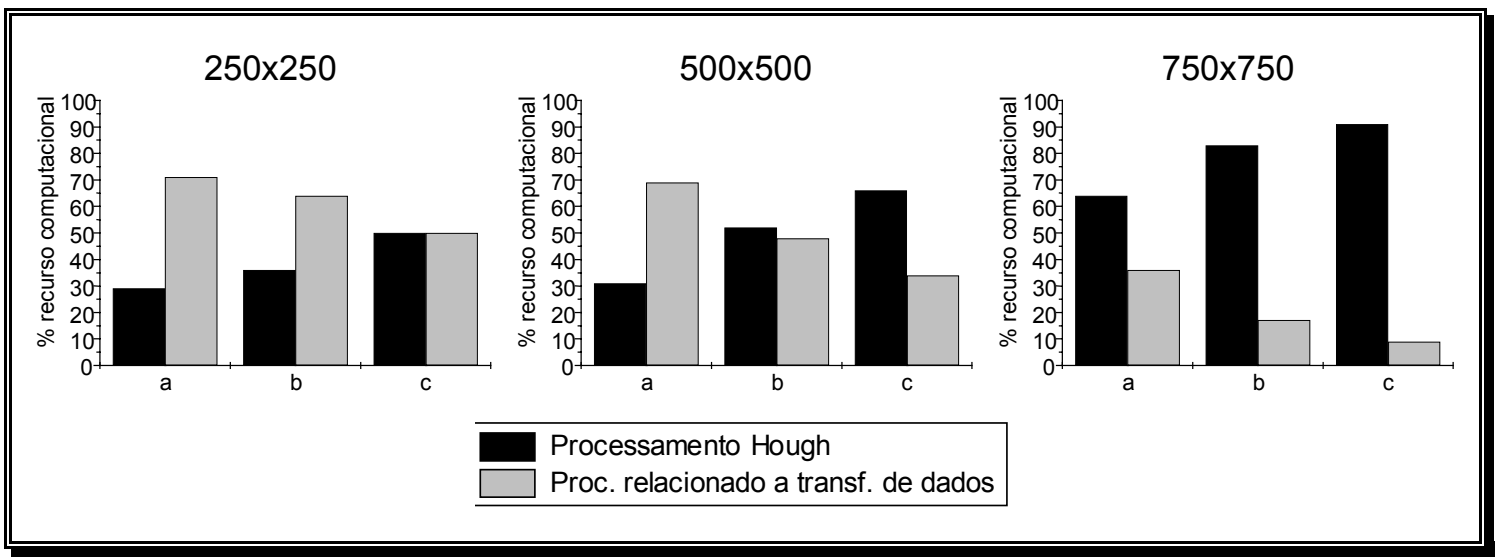

Fig. - 7.29 - Porcentagem da utilização de recursos computacionais entre o processamento da técnica e os processos relacionados com as transferências de dados (e afins: compactação e lista de picos). (a) Sistema distribuído $10 \mathrm{Mb} / \mathrm{s}$, (b) Sistema distribuído com compactação e (c) Sistema distribuído com lista de picos.

O aumento de performance é explicado pela redução no volume dos dados a serem transferidos, como mostra a Figura 7.29. Embora as duas alternativas (i) e (ii) reduzam o volume dos arranjos acumulador com uma taxa próxima (aproximadamente $85 \%$ do tamanho original), a compactação por LZW (i) é computacionalmente mais custosa e a lista de picos (ii) apresentou um melhor desempenho do sistema distribuído. A Figura 7.30 apresenta as taxas de desempenho ou speed-up, comparando as implementações paralelas.

Embora a lista de picos (ii) tenha apresentado um resultado melhor na eliminação dos gargalos, e consequentemente na performance, devido à redução dos dados do arranjo acumulador; essa alternativa não pode ser utilizada pela totalidade das aplicações da transformada, uma vez que algumas destas podem envolver uma exploração maior dos dados presentes no arranjo acumulador. A compactação por LZW, entretanto, não altera o conteúdo do arranjo acumulador, permitindo portanto sua utilização em toda a gama de aplicações, uma vez que apresenta resultado idêntico ao da transformada de Hough.

Apresentamos nesta seção algumas estratégias e implementações para a transformada de Hough paralela enfocando a detecção de retas. No entanto, estas podem ser estendidas para outras curvas parametrizadas no espaço de Hough, mediante algumas adaptações. 


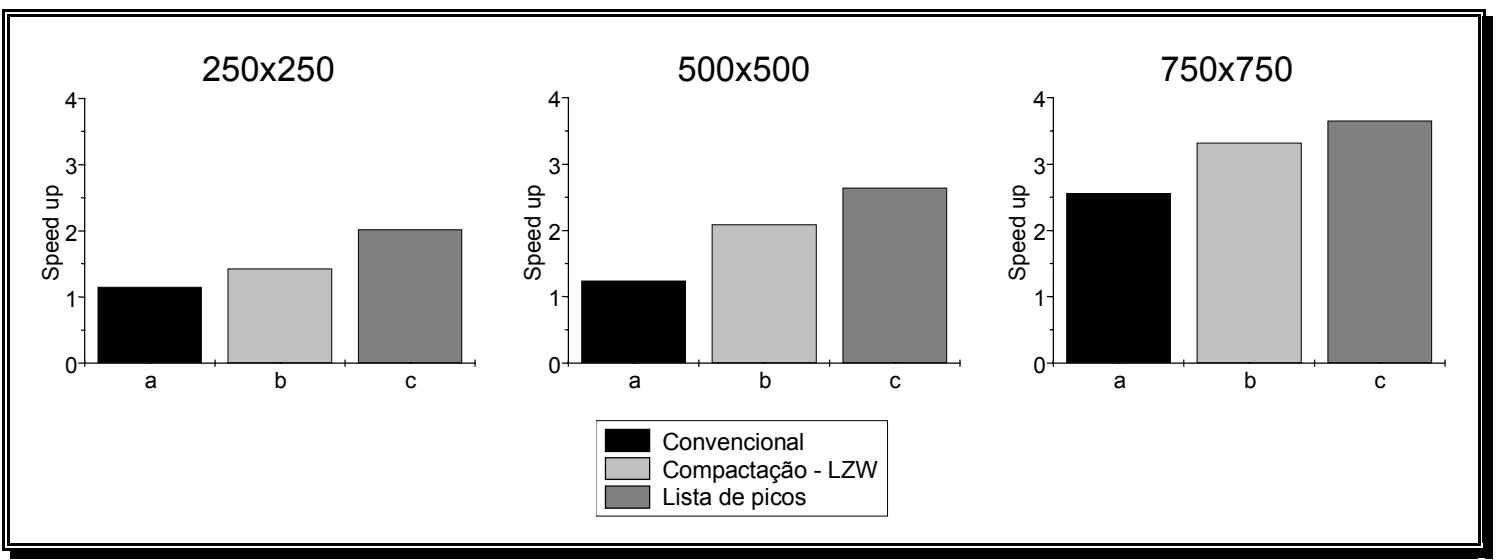

Fig. - 7.30 - Gráficos da taxa de desempenho ou speed up. Cada gráfico é correspondente a um tamanho de imagem.

\subsection{1 - RASTREAMENTO DO ARRANJO ACUMULADOR (BACKMAPPING)}

Um grande problema na transformada de Hough se encontra na localização dos picos do arranjo acumulador, uma vez que estes correspondem às curvas as quais a técnica espera detectar realmente. A grande dificuldade reside na característica local de cada pico, sendo este um problema ainda não resolvido por completo pela ciência. Devido às limitações no processo de localização dos picos locais, como resultado da transformada podem ser apresentadas diversas falsas curvas, provocadas pela interferência de pontos colineares entre diferentes curvas, entre segmentos com poucos pixels e até mesmo o ruído presente na imagem.

Um avanço na direção da solução desse problema foi publicado em 1986 por Gerig e Klein [Gerig \& Klein, 1986], que introduziram um passo adicional à transformada de Hough, denominado de backmapping (rastreamento). A técnica de backmapping consiste na criação de um novo arranjo acumulador, onde a transformada é novamente calculada para cada ponto da imagem. Para este novo espaço, contudo, somente são computadas as células que correspondem aos valores máximos de cada uma das senóides do arranjo original. Deste modo, essa abordagem corresponde a um reforço aplicado à transformada de Hough, na tentativa de localizar os picos locais e reduzir os picos causados pelos pontos 
colineares de curvas distintas, ruídos, interferência entre objetos e segmentos com poucos pontos.

Devido ao novo cálculo da transformada aliado a buscas contínuas de pontos máximos para as curvas do espaço de Hough, correspondentes a cada ponto da imagem, essa técnica é bastante dispendiosa, consumindo grande poder computacional, motivando portanto seu paralelismo.

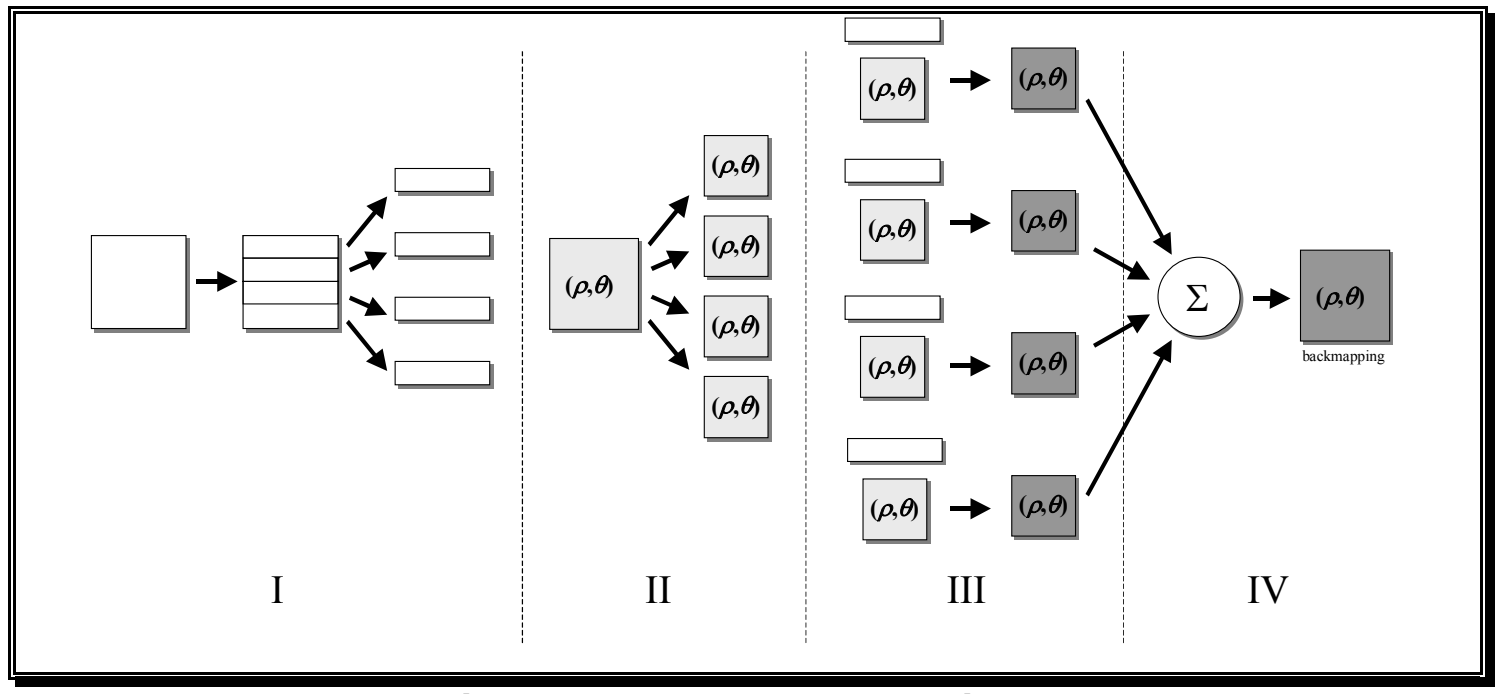

Fig. - 7.31 - Estratégia de paralelismo para a técnica de rastreamento

(backmapping), para quatro unidades de processamento. I - Divisão da imagem e distribuição dos fragmentos, II - Distribuição do arranjo acumulador resultante da transformada de Hough, III - Processamento do backmapping a partir dos dados dos fragmentos da imagem e do arranjo acumulador , IV transmissão do arranjo acumulador gerado pelo rastreamento para o processo mestre, onde os elementos de cada arranjo serão somados constituindo o resultado da técnica.

Através de algumas adaptações à estratégia de paralelismo apresentada na Figura 7.23, desenvolvemos uma estratégia para paralelizar o algoritmo de rastreamento (backmapping). Podendo ou não ser utilizada em conjunto com a versão paralela da transformada de Hough, descrita em 7.5, o paralelismo da técnica de rastreamento consiste basicamente na distribuição do arranjo acumulador, obtido na transformada de Hough para os processos envolvidos na computação, e na fragmentação da imagem original, e sua distribuição, ou no caso da transformada de Hough paralela, na utilização dos fragmentos da imagem original já processada. A Figura 7.31 exibe um diagrama contendo as definições 


\section{CAPÍTULO 7}

para paralelização da técnica para quatro elementos de processamento, que pode ser expandida facilmente. Após serem distribuídos os fragmentos da imagem (fig. 31 - I) e distribuídos os resultados da transformada de Hough para os elementos de processamento, são então realizadas o processamento do rastreamento simultaneamente para cada um dos fragmentos da imagem, produzindo um novo arranjo acumulador. Assim como na versão paralela da transformada de Hough, os arranjos são transmitidos para a unidade mestre, através do somatório deste constituíra o resultado final.

Implementamos a versão paralela da técnica utilizando sistema distribuído em rede ethernet de $10 \mathrm{Mb} / \mathrm{s}$, com quatro máquinas possuindo processadores semelhantes AMD K6 II - $375 \mathrm{MHz}$. A Figura 7.32 apresenta o tempo de processamento da versão seqüencial e das paralelas para dois tamanhos de imagem diferentes (250x250 e 500x500 pixels).

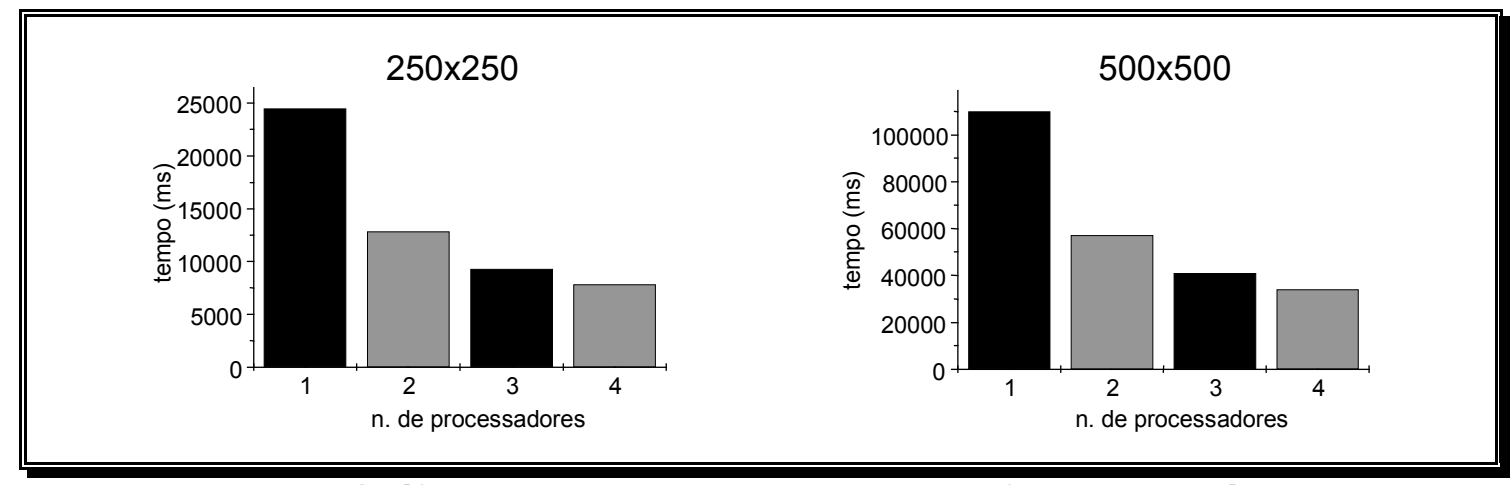

Fig. - 7.32 - Gráficos do tempo de execução em função do número de processadores.

Na Figura 7.33 temos os gráficos da porcentagem de utilização de recursos computacionais entre o processamento referente à técnica backmapping e aos processos relacionados com as transferências de dados. Embora possua um fluxo de dados muito maior do que a transformada de Hough, a porcentagem de recursos gastos com a transferência dos dados é menor. Já a técnica de backmapping é mais dispendiosa que a transformada de Hough, uma vez que além de conter os mesmos cálculos necessários da transformada, são realizados operações para obtenção dos pontos de máximo valor do arranjo acumulador para cada ponto analisado da imagem. Devido ao grande poder computacional requerido pelos cálculos, a transferência de dados não se torna um gargalo crítico para as versões paralelas. 


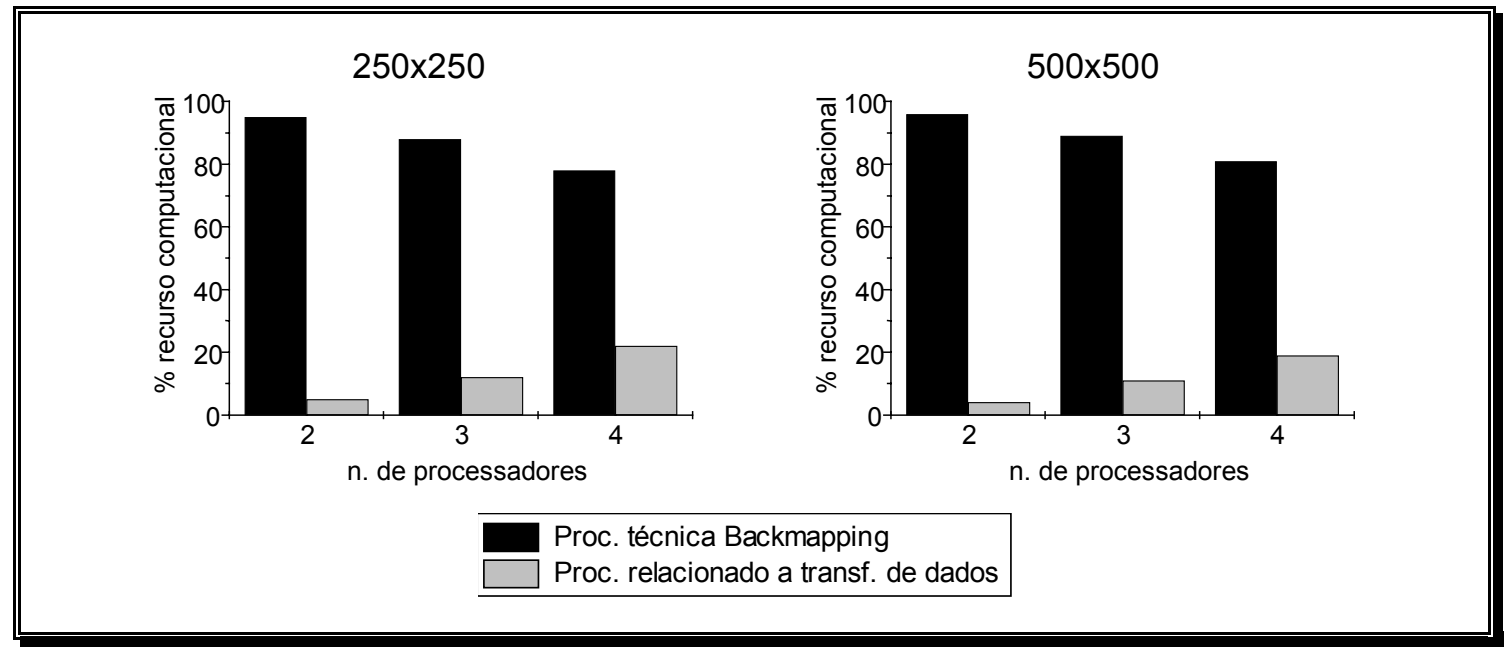

Fig. - 7.33 - Porcentagem da utilização de recursos computacionais entre 0 processamento da técnica e os processos relacionados com as transferências de dados.

A porcentagem de recursos gastos com a transferência de dados, entretanto, vai aumentando proporcionalmente com o número de processos (processadores), uma vez que os arranjos acumuladores não são fragmentados. Com isso, embora a performance aumente com o acréscimo de elementos de processamento no sistema, aumenta também o gargalo, de modo que a razão entre o número de processadores e o ganho de performance diminua. Na Figura 7.34 são apresentados os gráficos de taxa de desempenho ou speed-up em função do número de processadores.

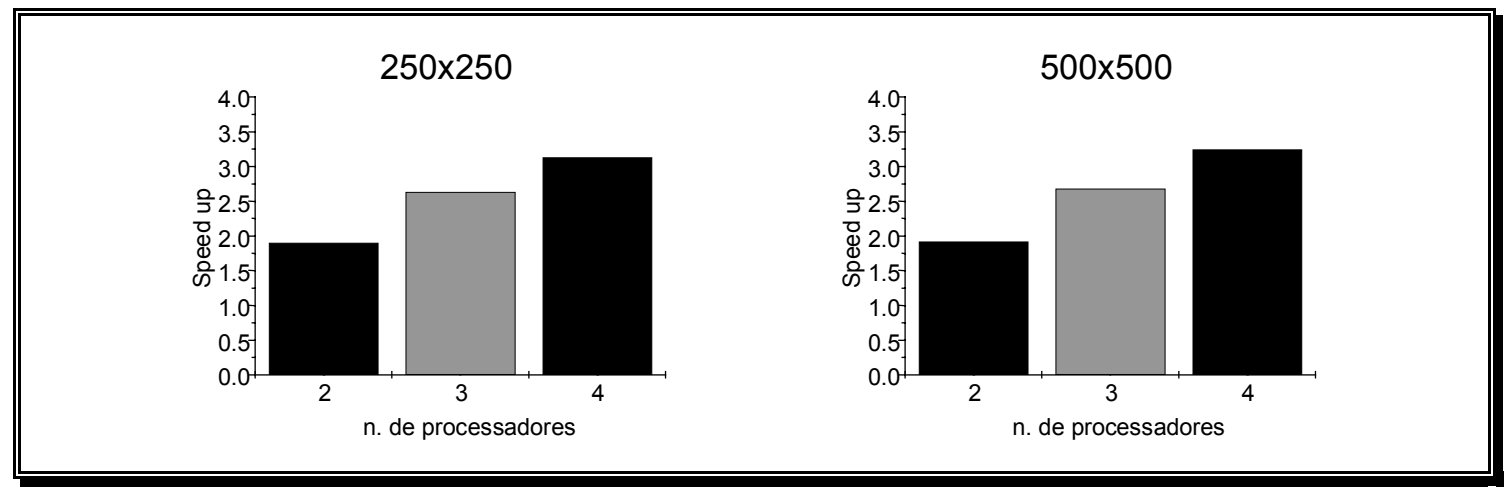

Fig. - 7.34 - Taxa de desempenho em função do número de processadores. 


\section{6 - REStauRAÇÃo de IMAgenS BASEADO EM CAMPOS RANDÔMICOS MARKOVIANOS}

Uma aplicação bastante comum em processamento de imagens é a eliminação de ruídos de uma imagem. Diversos fatores, tais como interferência em sistemas de aquisição de imagem, ruído em sistemas de comunicação, sistemas de imagem por satélite, sistema de aquisição de imagens médicas (ultra-som), etc., podem ocasionar a adição de ruídos a imagem, de forma a poluí-la. Os algoritmos de restauração de imagens são técnicas que permitem a redução do ruído ou em alguns casos até mesmo sua completa eliminação.

Nesta seção vamos apresentar a paralelização do algoritmo de restauração de imagens baseado em campos aleatórios de Markov, desenvolvido no decorrer deste doutorado. A nova técnica [Bruno \& Costa, 2000] consiste em uma modificação dos campos aleatórios de Gibbs operando no modo condicional iterativo (ICM) [Chellappa \& Jain, 1993].

A primeira abordagem da técnica classifica o campo aleatório de Markov como um caso específico da teoria da regularização [Poggio et al., 1985]. A regularização de um problema "ill-posed" pode ser compreendida em termos da equação $A z=y$, onde $z$ é a solução procurada, $y$ é o dado original, e $A$ é o operador linear. Uma possível solução consiste em achar $z$ que minimiza $\Omega(z)$ na Equação 7.12, onde $\|\mathrm{Pz}\|$ é o estabilizador funcional.

$$
\Omega(z)=\|A z-y\|^{2}+\lambda\|P z\|^{2}
$$

Enquanto o primeiro termo da Equação 7.12 expressa a discrepância entre os dados originais e a solução, o segundo termo indica o sucesso da solução $z$ no critério de regularização expresso pelo operador $P$. Através de variações no parâmetro $\lambda$ é possível controlar o grau de similaridade do dado original e do resultado do processo de regularização. Para a técnica de restauração de imagem $P$ é considerado linear. Aplicando o conceito em termos práticos, a Equação 7.13 ilustra essa situação com respeito a dois termos funcionais, onde $f(x, y)$ é a imagem original e $g(x, y)$ é a solução procurada. O primeiro termo força a similaridade entre a imagem original e a imagem modificada, o segundo termo conhecido como "membrana", impõe um certo grau de "borramento", controlado pelo parâmetro $\lambda$, 
sobre a solução esperada $g(x, y)$.

$$
F_{\lambda}(x, y)=\iint_{\text {image }}\left[|f(x, y)-g(x, y)|^{2}+\lambda^{2} \cdot|\nabla g(x, y)|^{2}\right] d x d y
$$

Embora o conceito dos campos aleatórios de Markov (MRF) não seja novo, sua aplicação em processamento de imagem e visão computacional foi apenas recentemente explorada [Bruno \& Costa, 2000]. Basicamente, os campos aleatórios de Markov, são extensões de grandes dimensões da clássica abordagem da cadeia de Markov. Deste modo, ele assume que o valor de um dado ponto da imagem é influenciado somente pelo seu vizinho imediato. Pelo estabelecimento de uma conexão entre os campos aleatórios de Markov (locais) e a distribuição de Gibbs (global) dada pela mecânica estatística, o teorema de Hammersley-Clifford permitiu um significado essencial para o cálculo das probabilidades das possíveis configurações em MRF [Li, 1995] [Kindermann and Snell, 1980] [Chellappa \& Jain, 1993]. Mais especificamente, a probabilidade de uma dada configuração (dentro de um conjunto finito de valores quantificados), freqüentemente parametrizados pelo decréscimo de temperatura, é fornecida pela probabilidade da densidade de massa da distribuição de Gibbs [Geman \& Geman, 1984], que é determinada pela temperatura e pela energia definida pelos potenciais de cliques. Embora grandes vizinhanças sejam possíveis, aplicações em análise e processamento de imagem, tipicamente consideram cliques com conexões de 4 ou 8 vizinhos em torno do pixel. A abordagem MRF permite muitas possibilidades na incorporação de contextos ao processamento de imagens, provavelmente uma das mais típicas seja na restauração de imagens.

Considerando que unir as distribuições em um MRF é uma tarefa particularmente complicada, uma abordagem alternativa denominada de modo condicional iterativo (ICM) foi proposta por Besag [Besag, 1986]. Duas hipóteses são assumidas no ICM: (i) as observações $d_{i}$ são independentes e cada observação possui a mesma densidade condicional conhecida $p\left(d_{i} \mid f_{i}\right)$, que depende somente de $f_{i}$; e (ii) cada rótulo depende somente de um rótulo vizinho. A Equação 7.14 apresenta um critério simplificado de classificação que consiste na maximização da probabilidade, onde $S$ é o conjunto de sítios e $N_{\mathrm{i}}$ são as vizinhanças no sítio $i$ [Li, 1995]. 


\section{CAPÍTULO 7}

$$
P\left(f_{i} \mid d, f_{S-\{i\}}\right) \propto p\left(d_{i} \mid f_{i}\right) \cdot P\left(f_{i} \mid f_{N_{i}}\right)
$$

A técnica assume que as imagens binárias foram corrompidas por ruído Gaussiano, com um parâmetro conhecido. Somente dois valores de cliques são considerados, com pesos iguais, de forma a favorecer a uniformidade. Assim, a Equação 7.14 produz o seguinte critério de classificação:

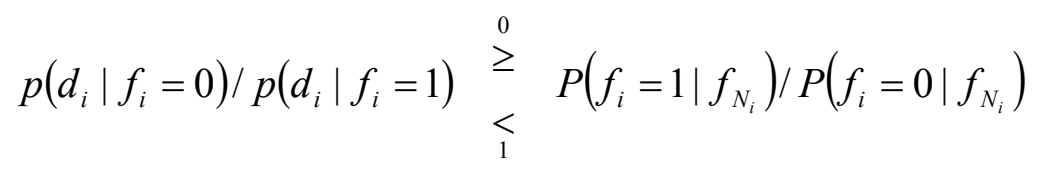

Como pode ser verificado, os primeiros termos da condição de 7.15 , refletem o modelo da imagem e o modelo do ruído, e o segundo termo expressa a influência contextual do vizinho com adjacência imediata, que são similares ao primeiro e segundo termos da Equação 7.13.

Uma versão mais flexível do critério descrito anteriormente é obtida por pesos adicionais, na forma de parâmetros $\alpha$, conforme podemos observar a seguir:

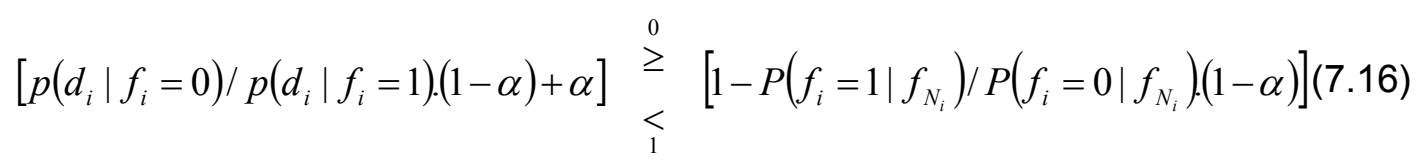

Agora, as influências relativas do modelo imagem/ruído e a coação contextual podem ser continuamente variadas em termos do parâmetro $\alpha$. A Tabela 7.2 ilustra alguns critérios que são obtidos em função de diferentes valores de $\alpha$. Enquanto para $\alpha=0$ a condição é exclusivamente governada pelo modelo imagem/ruído, para $\alpha=1$ somente a coação contextual é refletida. A condição original dada por 7.15 é obtida para $\alpha=0,5$. Diferentes influências são obtidas para valores de $\alpha \in[0,1]$. Alguns resultados experimentais são apresentados na Figura 7.35, que claramente apresentam a flexibilidade permitida pela técnica. 


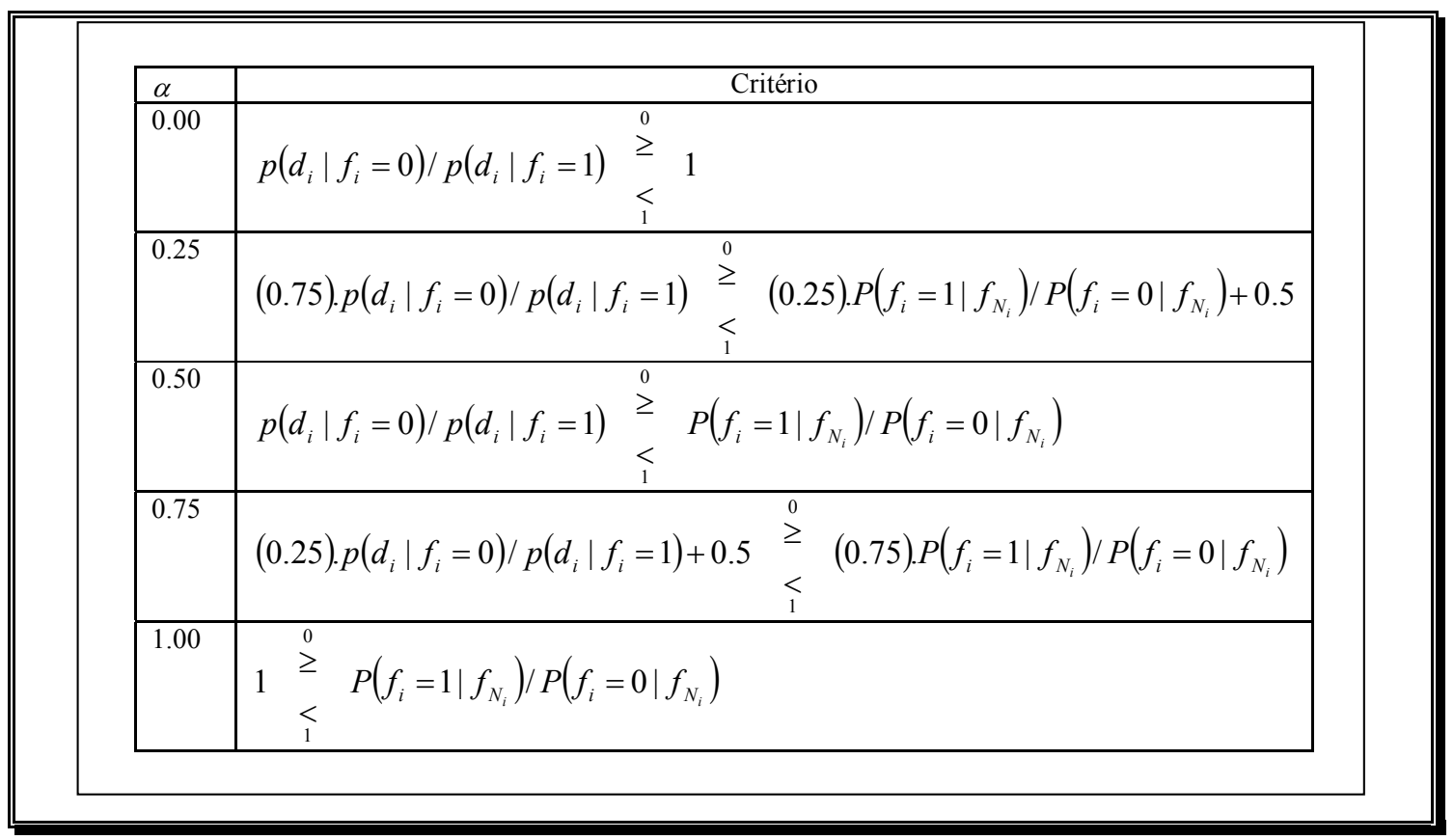

Tabela 7.2 - Exemplos de critérios obtidos em termos de $\alpha$.

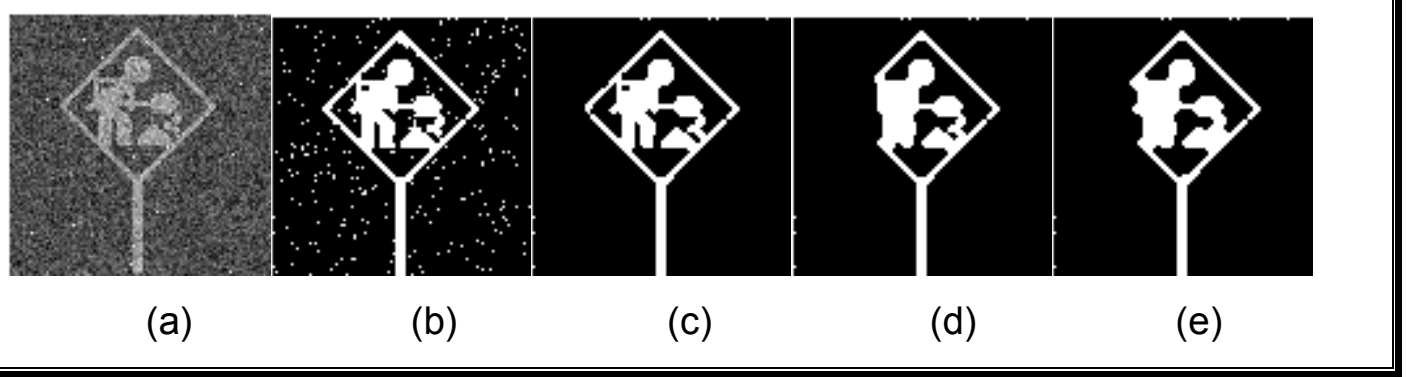

Fig. - 7.35 - Resultados da técnica de restauração - (a) Imagem original $100 \times 100$ corrompida por um ruído gaussiano com $\sigma^{2}=0,5$. Os resultados são respectivos a $\alpha=0,3$ (b), $\alpha=0,5$ (c), $\alpha=0,7$ (d) e $\alpha=0,9$ (e).

\subsection{1 - ESTRATÉGIA DE PARALELISMO}

Diferente das técnicas apresentadas anteriormente neste capítulo, o algoritmo de restauração de imagens baseado em campos aleatórios de Markov é um método iterativo, que se repete continuamente até que ocorra a convergência numérica. Do ponto de vista do paralelismo, esse fato acrescenta uma complexidade à estratégia, uma vez que a troca de mensagens entre os processos ocorre diversas vezes de forma a atualizar os dados a cada iteração, o que torna o 


\section{CAPÍTULO 7}

problema bastante interessante.

A Figura 7.36 apresenta as bases da estratégia de paralelização para quatro elementos de processamento, onde a imagem é dividida pelo processo mestre, que distribui cada parte desta para os processos escravos, ficando com um fragmento. Após a distribuição, cada processo executa o algoritmo MRF, que consiste de uma série de iterações, envolvendo troca de mensagens e atualização de dados, que serão discutidos adiante. Uma vez tendo convergido a técnica, os resultados são enviados para o mestre, que une os fragmentos, formando o resultado sobre a imagem original.

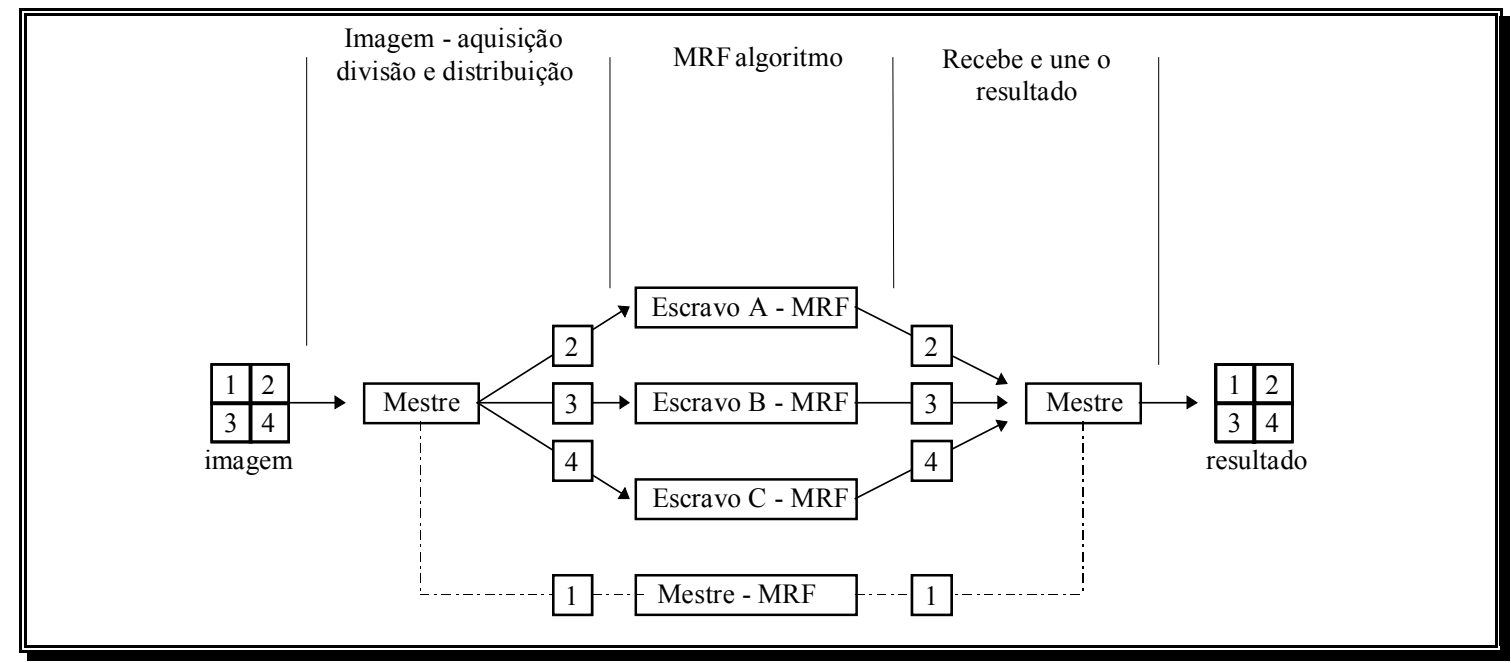

\section{Fig. - 7.36 - Estratégia básica de paralelismo da técnica MRF.}

Nesta técnica (MRF), cada elemento é calculado considerando os cliques envolvendo a vizinhança dos 8 pontos em torno de cada pixel. Embora distâncias maiores sejam também verificadas, essa situação ocorre ao longo do tempo (iterações) através de propagação entre os elementos vizinhos. Deste modo, para cada iteração ocorre a dependência de dados entre os limites da divisão da imagem. Para solucionar essa dependência de dados e atualizar as porções de imagem em cada elemento de processamento, permitindo assim a propagação de informações ao longo de toda a imagem, foram implementadas três estruturas de atualização de dados, duas na forma de vetores e a última sendo um único ponto. $A$ Figura 7.37 apresenta a configuração das estruturas de atualização para a parte 1 da imagem. Como podemos observar, o vetor vertical é composto pelos pixels da borda da parte 3 , ocorrendo o mesmo com o vetor horizontal, que é associado à parte 2. A pequena estrutura de atualização, caracterizada como um ponto, é 
composta pelo pixel do canto superior esquerdo da parte 4.

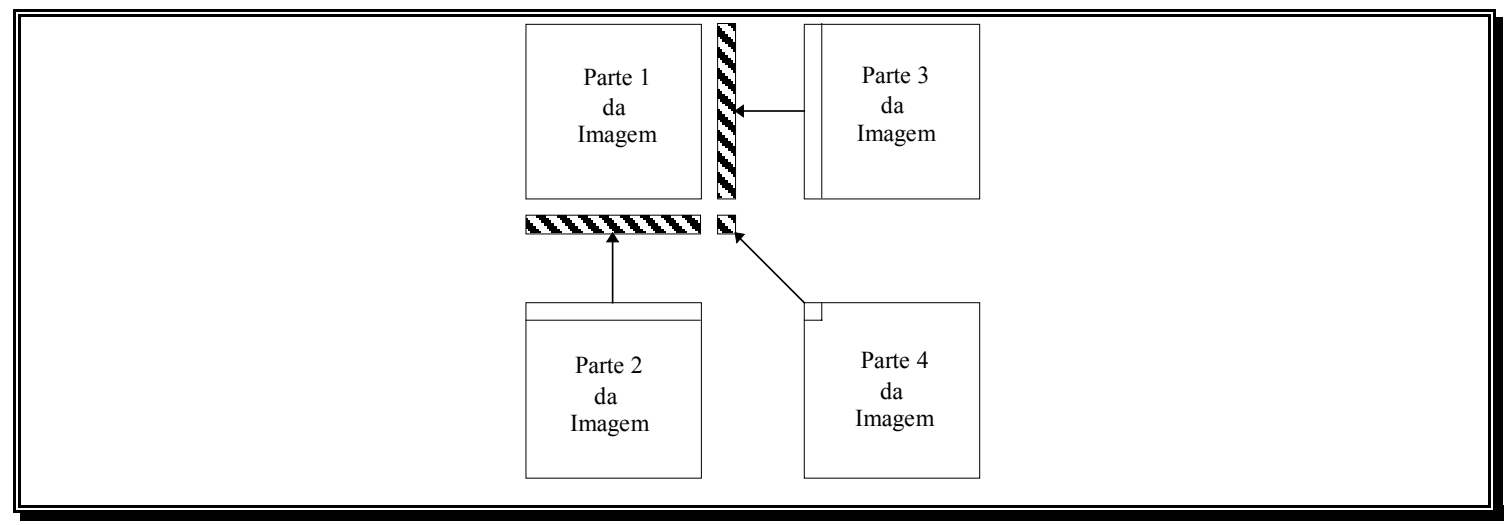

Fig. - 7.37 - Estratégia básica de paralelismo da técnica MRF.

A incorporação das estruturas de atualização permite que todas as iterações sejam calculadas em concorrência, resolvendo a questão da dependência de dados e permitindo a convergência da técnica e a propagação dos dados através das vizinhanças. Para tanto, os módulos paralelos devem trocar as informações contidas nas estruturas de atualização após cada iteração do algoritmo MRF. A Figura 7.38 ilustra a troca de informações através das estruturas de atualização, nela são apresentados quatro módulos, representados pelas caixas numeradas, com suas respectivas estruturas de atualização, representadas pelas caixas preenchidas. Diferente da Figura 7.36, aqui não há distinção entre os processos mestre e escravo.

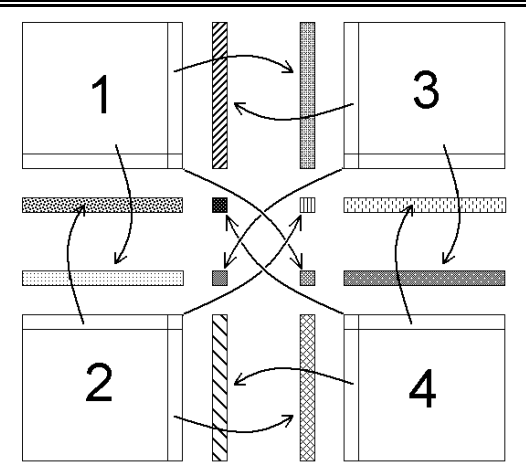

Fig. - 7.38 - Diagrama de transferência das estruturas de atualização.

Nesta arquitetura, o balanceamento de carga é definido pela quantidade de pontos a serem processados. Neste caso, em sistemas heterogêneos, ou seja, 


\section{CAPÍTULO 7}

aqueles em que as unidades de processamento possuem diferentes poderes computacionais, devem ser atribuídas porções de imagem proporcionais à performance de cada uma das unidades de processamento do sistema. Embora a Figura 7.38 apresente um diagrama limitado em apenas quatro unidades de processamento, sem a preocupação com o balanceamento de carga, a arquitetura permite um conjunto virtualmente infinito de configurações.

A Figura 7.39 apresenta algumas possibilidades de configurações da arquitetura para 6 e 9 unidades de processamento, que demonstram que a arquitetura pode ser estendida facilmente para qualquer número de elementos de processamento. $\mathrm{O}$ balanceamento de carga do sistema pode ser realizado alojando mais de um módulo da imagem em uma única unidade de processamento. Essa abordagem é mostrada na Figura 7.40, onde são apresentados três exemplos envolvendo balanceamento de carga em sistemas heterogêneos. Os módulos agrupados em caixas estão alojados em um único elemento de processamento, permitindo desse modo uma distribuição irregular da carga computacional ao longo do sistema.

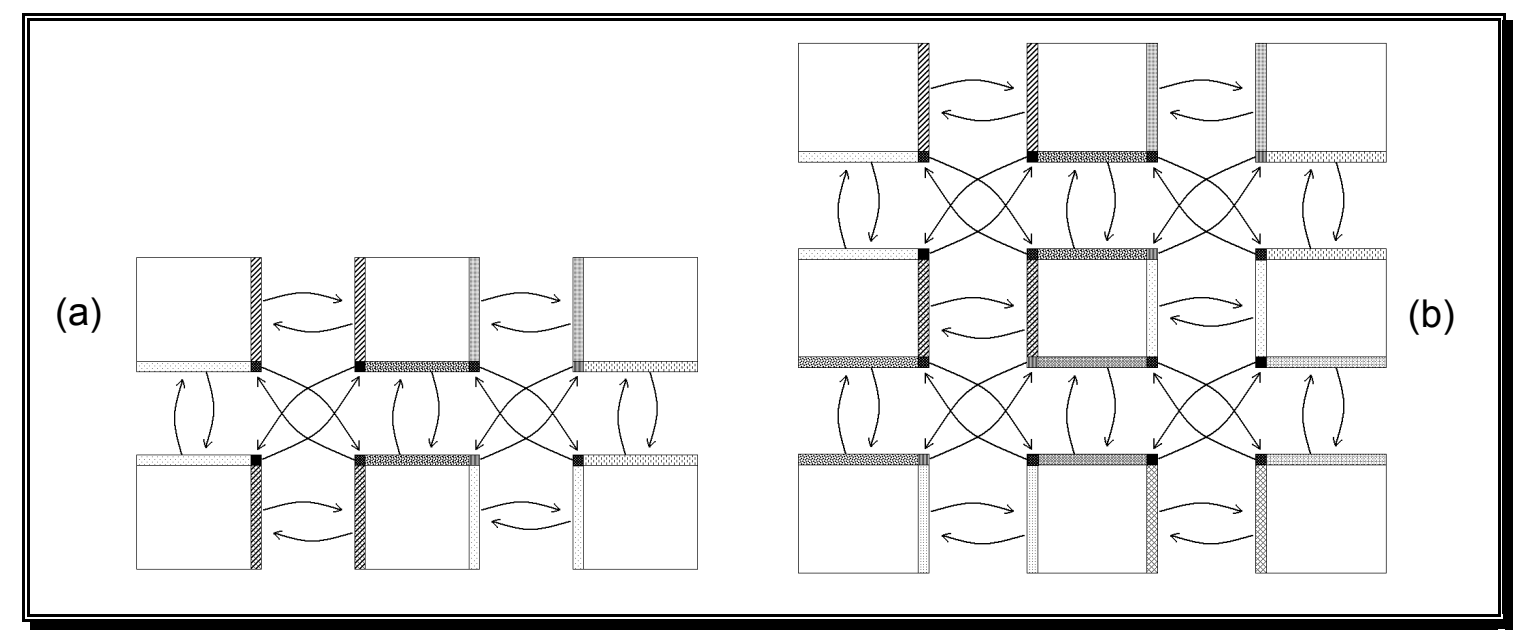

Fig. - 7.39 - Diagrama de transferência das estruturas de atualização para 6 (a) e 9 (b) elementos de processamento. 
(a)
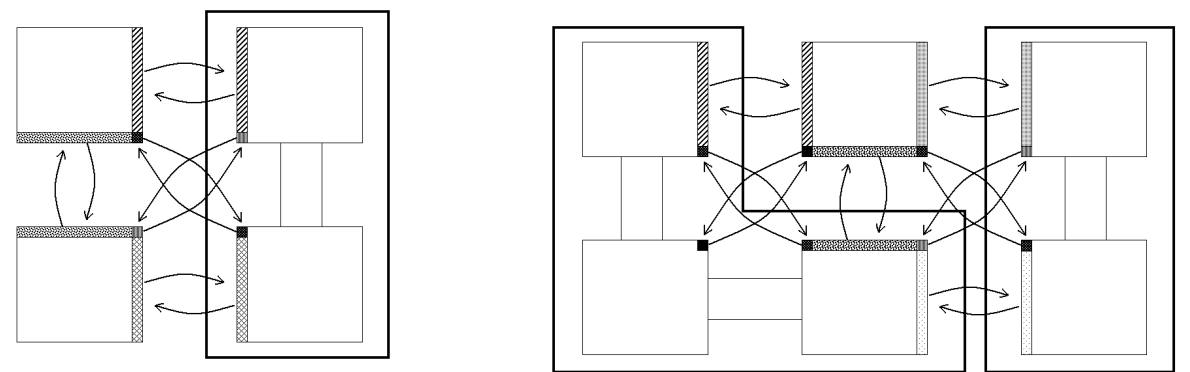

(b)

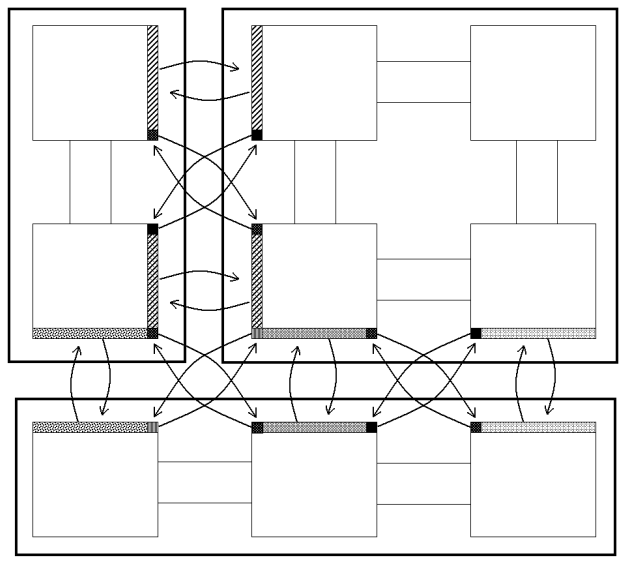

(c)

Fig. - 7.40 - Exemplos de balanceamento de carga, com 3 elementos de processamento heterogêneos.

Nesta técnica, o número de iterações depende do nível de ruído e da estrutura da imagem. Em alguns casos a convergência não é garantida. Assim, o processamento pode ser finalizado pelos eventos seguintes: (a) não ocorrendo modificação em nenhum dos módulos (convergência); ou (b) o número de iterações ultrapassa um limiar pré-estabelecido. Devemos observar também que cada módulo envia suas três estruturas de atualização para os outros módulos e essas estruturas são necessárias para a próxima iteração. Quando um módulo é finalizado, ele fica inativo até a próxima iteração. Se algum dado foi alterado (através das estruturas de atualização), então o módulo inicia outra iteração; caso contrário, envia sua estrutura e aguarda os próximos dados. 


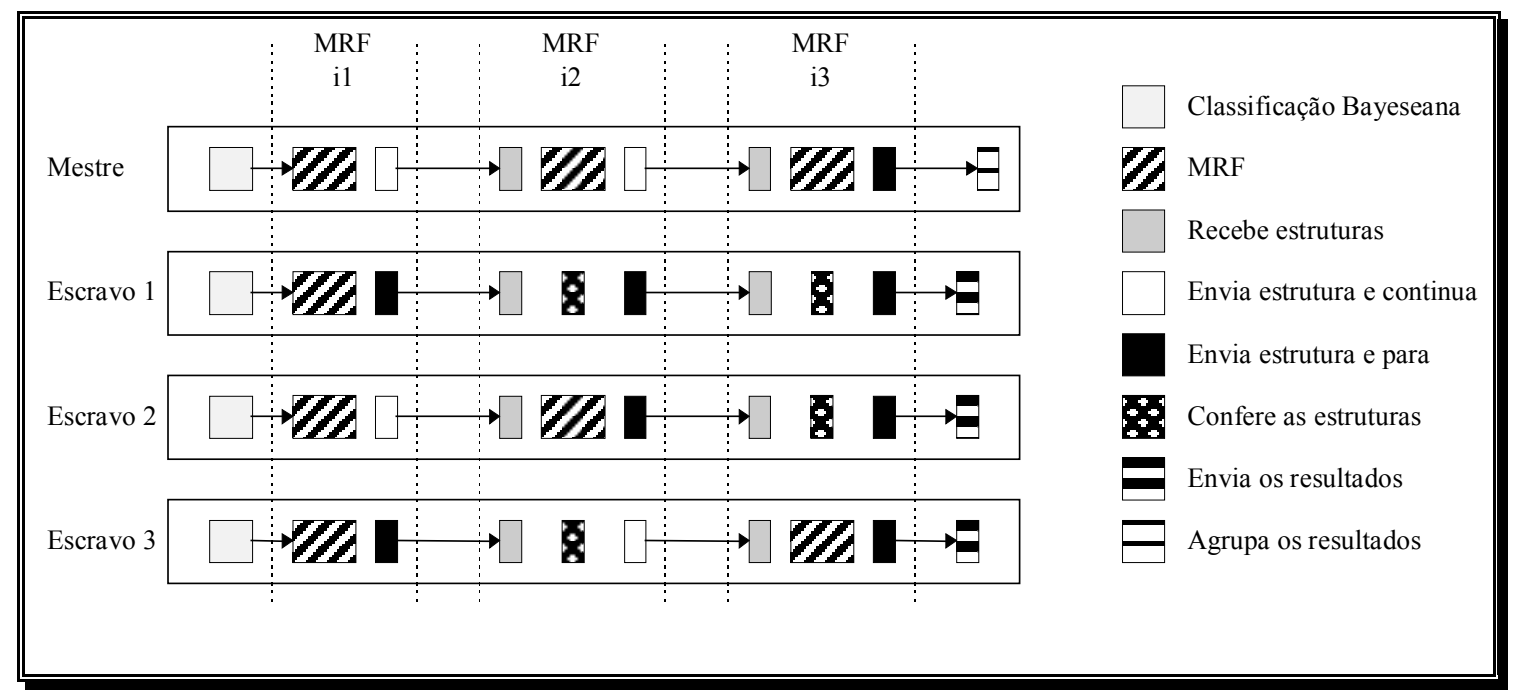

Fig. - 7.41 - Diagrama de execução do algoritmo MRF paralelo, para quatro elementos de processamento.

A Figura 7.41 apresenta um diagrama que representa a arquitetura em execução para quatro elementos de processamento. O primeiro passo da técnica é a classificação Bayeseana realizada pelo mestre, que é então distribuída. A partir destes dados são iniciadas as iterações do MRF. O número de iterações do algoritmo MRF é variável, e devido a sua natureza estocástica não existe uma maneira de prever com precisão como será executado. Cada módulo pode parar em tempos diferentes, como pode ser observado, os módulos escravos 1 e 3 terminam na primeira iteração e o módulo 2 termina na segunda iteração. No entanto, a qualquer iteração, um módulo parado pode voltar a ativa mediante alterações na estrutura de atualização. Isto pode ser observado no módulo escravo 3 , que recebe um dado diferenciado na iteração 2 , sendo forçado a processar mais uma iteração. A tarefa de verificar o fim do algoritmo fica a cargo do mestre, que ao final de cada iteração recebe uma mensagem do estado de cada módulo, finalizando o processamento quando todos os módulos tiverem convergido. Após a finalização do algoritmo, todos os resultados são enviados para o mestre, que os combina formando o resultado final.

\subsection{2 - IMPLEMENTAÇÃO E RESULTADOS}

A estratégia de paralelismo para o algoritmo de restauração de imagens baseado em campos randômicos markovianos desenvolvida durante este doutorado foi implementada em sistemas distribuídos através do CVMP. Nesta 
seção vamos apresentar os resultados experimentais da implementação paralela da técnica em quatro máquinas conectadas por rede ethernet de $10 \mathrm{mb} / \mathrm{s}$. No primeiro experimento, utilizamos máquinas com diferentes performances, que resultam em um sistema não balanceado. Deste modo, as máquinas mais velozes precisam esperar pelas mais lentas para continuar o processamento. Embora essa abordagem leve a uma performance baixa, ela é ainda interessante para ilustrar algumas características do sistema. Utilizamos no primeiro experimento uma imagem binária de $200 \times 200$ pixels.

A Figura 7.42 apresenta um diagrama caracterizando a execução do sistema, enquanto que a Figura 7.43 mostra um diagrama correspondente à transferência de dados. As máquinas utilizadas no experimento foram: uma Pentium de $150 \mathrm{MHz}$ como mestre, um Pentium de $90 \mathrm{MHz}$ como escravo $\mathrm{A}$, um Pentium $133 \mathrm{MHz}$ como escravo B e um Pentium $150 \mathrm{MHz}$ como escravo C. O grande número de bolhas encontrado no diagrama da Figura 7.42 é devido especialmente às máquinas mais velozes, que tiveram que esperar pela vagarosa máquina de $90 \mathrm{MHz}$.

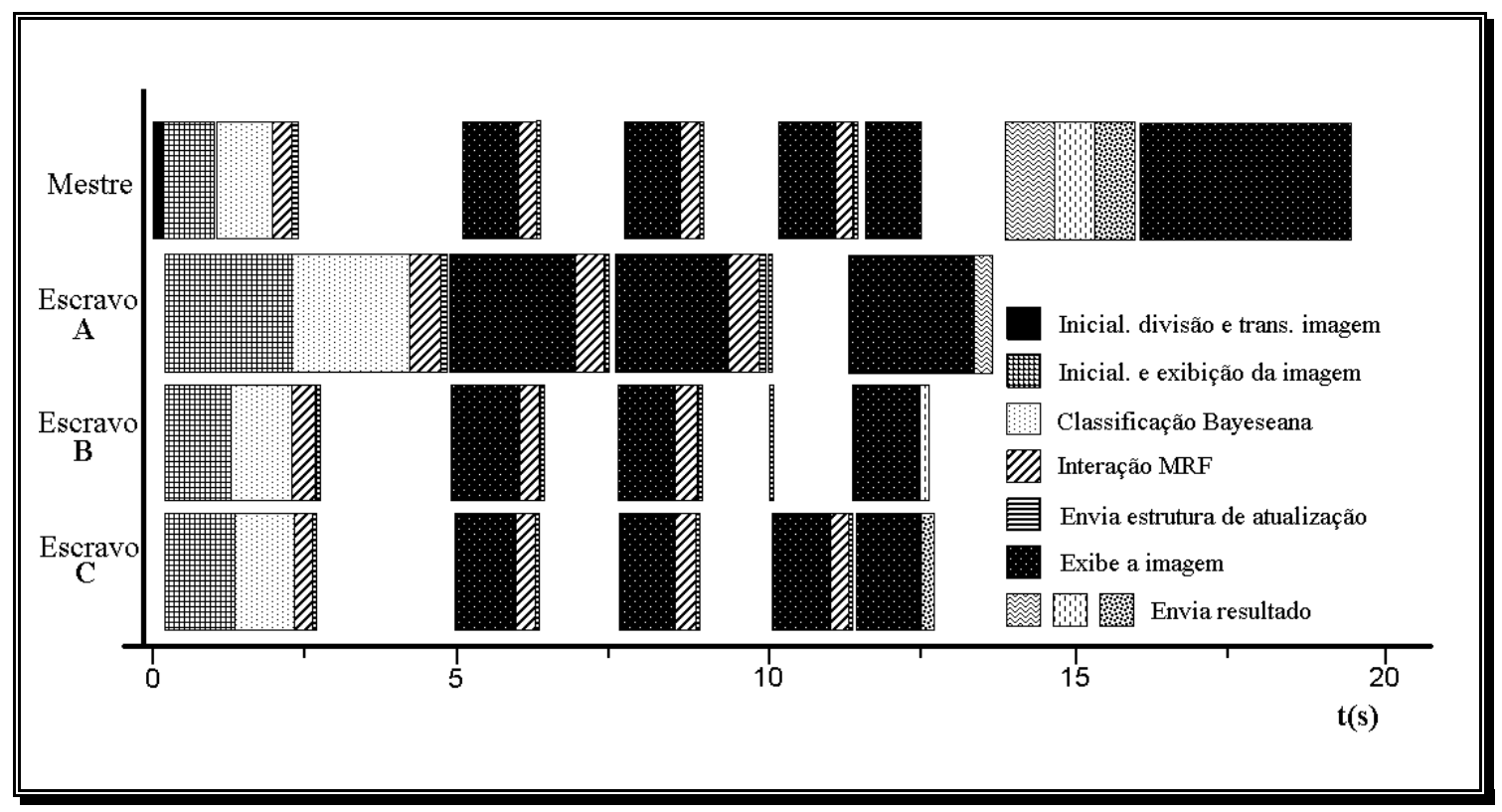

Fig. - 7.42 - Diagrama de execução do algoritmo MRF paralelo em um sistema heterogêneo. 


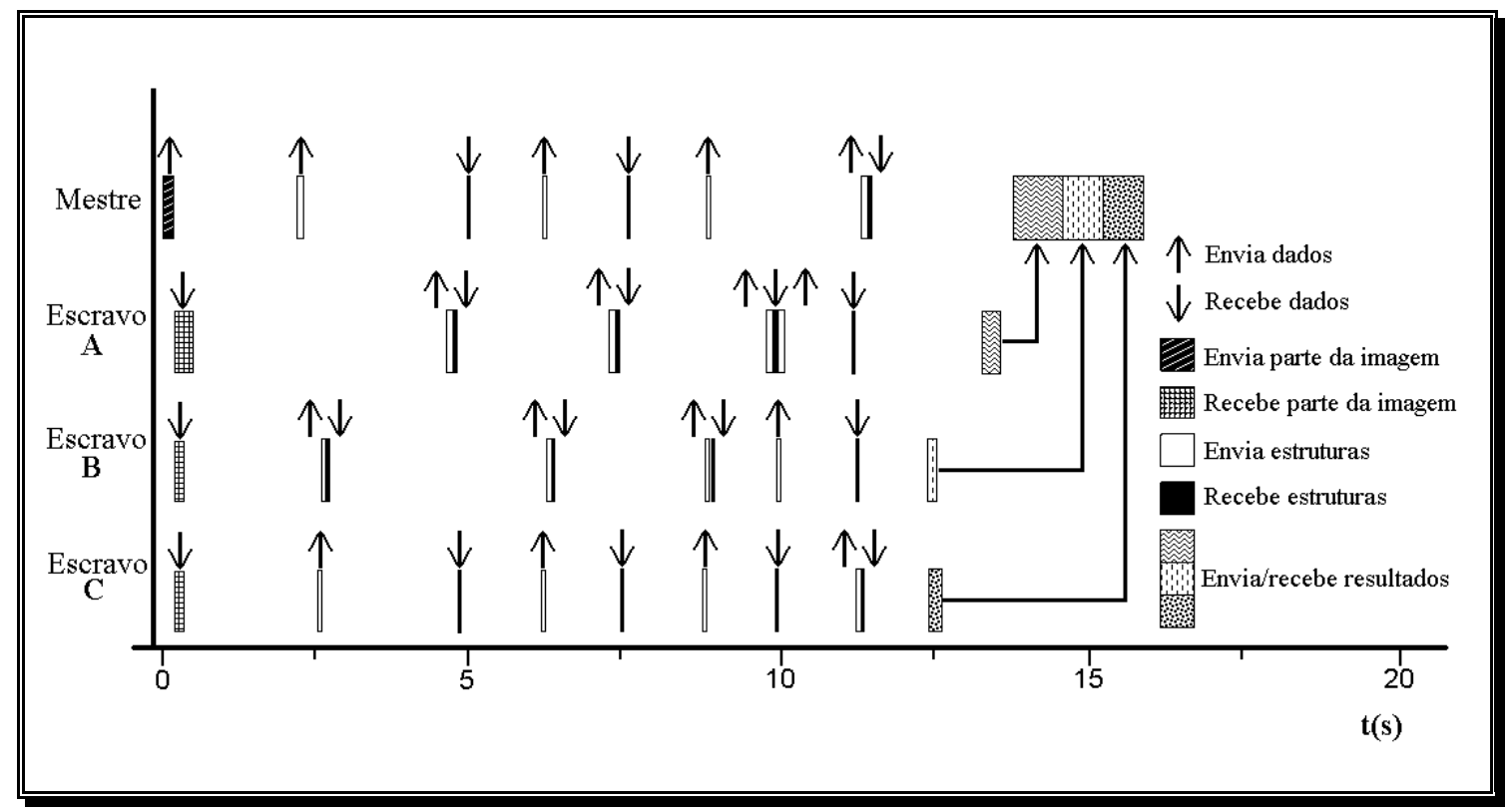

Fig. - 7.43 - Diagrama da troca de mensagens.

Observando ainda os diagramas das Figuras 7.42 e 7.43 podemos verificar a dificuldade de estabelecer a performance real do sistema, uma vez que o sistema não é previsível quanto ao número de iterações. No experimento apresentado o mestre e o escravo C tiveram 3 iterações, enquanto os escravos A e B apenas duas.

Para extrairmos medidas de desempenho mais consistentes, escolhemos situações em que tanto a versão seqüencial quanto a paralela tiveram quatro iterações. Realizamos esse experimento em sistema distribuído homogêneo com quatro máquinas Pentium 133 Mhz conectadas com rede padrão ethernet de 10 $\mathrm{mb} / \mathrm{s}$. A Figura 7.44a apresenta o gráfico de tempo de execução das versões seqüencial e paralela para quatro máquinas. Conforme pode ser observado, a performance do sistema paralelo aumenta à medida que aumenta o tamanho da imagem, tornando-se 3,5 vezes mais rápido que a versão seqüencial nas imagens de $700 \times 700$ pixels (ver Figura 7.44b). 


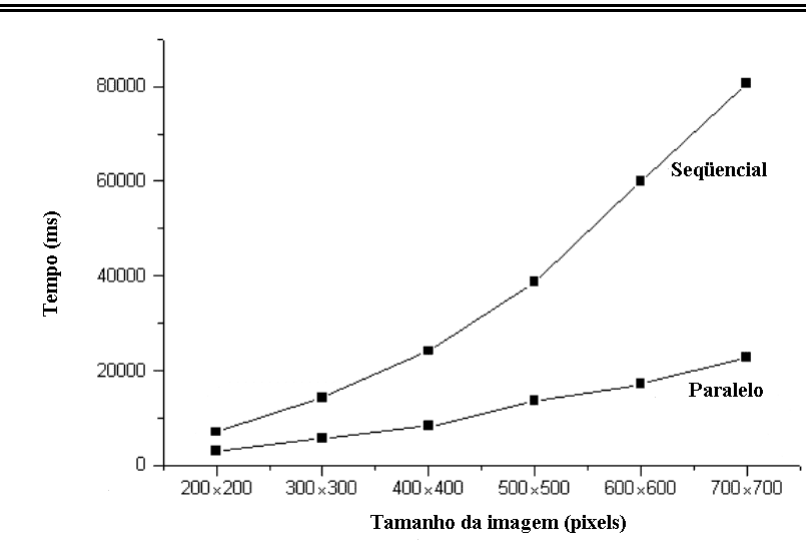

(a)

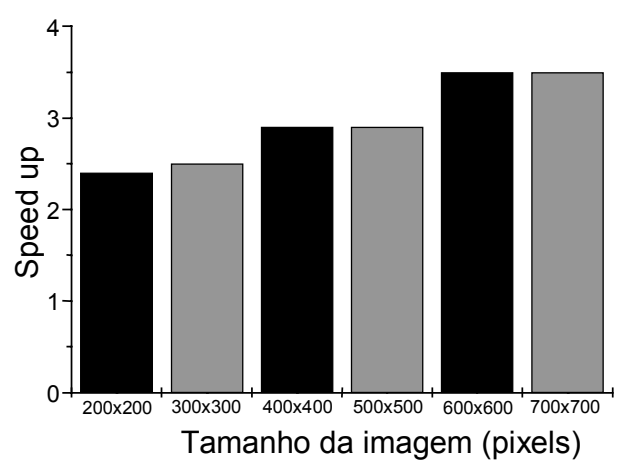

(b)

Fig. - 7.44 - Comparações de performance entre a versão paralela e seqüencial. (a) Gráfico do tempo de execução em função do tamanho de imagem. (b) Gráfico da taxa de desempenho em função do tamanho de imagem.

\section{7 - DIMENSÃO FRACTAL}

Muitas formas na natureza são tão complexas e irregulares que são difíceis e até mesmo impossíveis de serem expressas e analisadas pela geometria euclideana. Através de estudos sobre a auto-similaridade e irregularidade, Mandelbrot [Mandelbrot, 1977] introduziu a geometria fractal, que apresentou uma nova maneira de considerar tais formas. Através da geometria fractal, um grande número de objetos naturais, que vão de neurônios a nuvens, pode ser modelado e melhor compreendido. A Figura 7.45 apresenta dois exemplos de fractais, onde o primeiro é o triângulo de Sierpinski [Stanley, 1986] e o segundo uma forma de Mandrelbrot [Mandelbrot, 1983].

A idéia de dimensão fractal surgiu na tentativa de se determinar uma medida de complexidade para formas como as da Figura 7.45. Embora inicialmente dedicado à geometria fractal, o conceito da dimensão fractal rapidamente se espalhou, permitindo sua aplicações em diversas áreas tais como: ciência dos materiais, geologia, visão computacional [Biswas et al., 1998], neuromorfologia [Costa, 1996][Coelho, 1998], etc.

Diversas técnicas para estimar a dimensão fractal foram descritas na literatura [Caserta et al., 1995] [Clark, 1986] [Kaye, 1989] [Kaye, 1994] [Smith et al., 1996], das quais a mais popular para processamento de imagens e provavelmente 
também a mais simples é a de contagem de caixas [Peitgen \& Saupe, 1988] [Falconer, 1990].

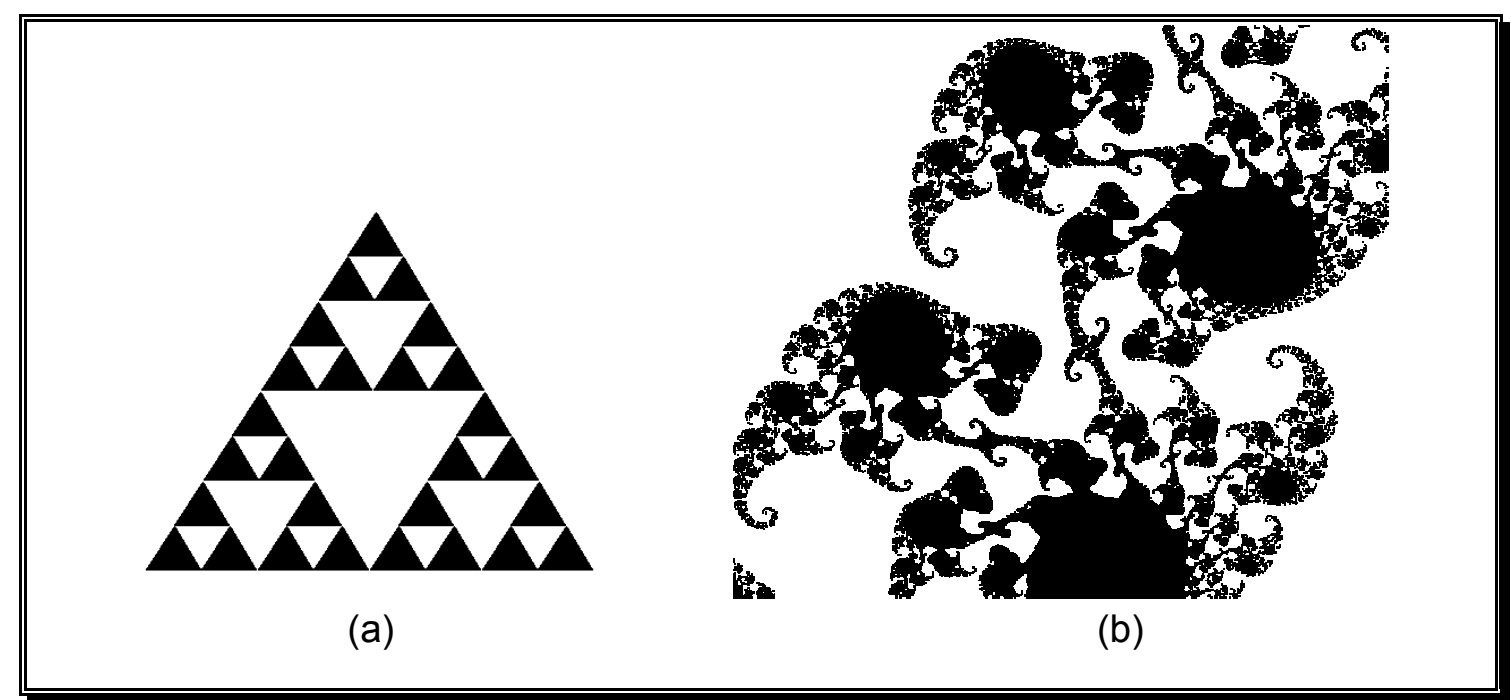

Fig. - 7.45 - Dois exemplos de fractais, triângulo de Sierpinski (a) e Mandelbrot

(b).

Vamos nos limitar ao método de salsichas de Minkowski [Tricot, 1995]. O método para cálculo da dimensão fractal conhecido como de salsichas de Minkowski, produz uma estimativa da dimensão de Bouligand-Minkowski [Coelho, 1998]. A técnica essencialmente se baseia na convolução de círculos com diferentes raios $r$ na imagem. Com o resultado da convolução de cada círculo, calcula-se a área $A$ ocupada pelos pixels significantes (não nulos). Projetam-se então os pontos obtidos pelos pares $r$ e $A_{r}$ em um gráfico $\log (r) \times \log (A)$. Usualmente os pontos irão caracterizar uma reta, que pode ser determinada através de regressão linear. A dimensão fractal é obtida pela inclinação desta reta.

A paralelização da técnica é bastante simples, uma vez que não ocorre a dependência de dados durante a concorrência, e pode ser implementado diretamente com o componente Processor Farm do CVMP, simplificando muito a sua implementação (ver 6.8). Deste modo, através do CVMP, define-se uma arquitetura Processor Farm. O processo mestre distribui uma cópia da imagem para todos os escravos, e a seguir distribui para cada processo escravo uma tarefa, enviando um determinado valor de raio $r$. A tarefa se constitui na convolução de um círculo de raio $r$ (determinado pelo mestre) e na determinação da área do resultado $A_{r}$, que é enviada para o mestre assim que calculada. $O$ mestre supervisiona o conjunto de escravos e, à medida que as tarefas vão sendo executadas, novas são 
atribuídas aos escravos desocupados, até que sejam calculados todos os $A_{r}$, definidos pelo número de raios determinados pelo mestre. Assim que todos os resultados são obtidos, o mestre realiza a regressão linear dos pontos $\left(r, A_{r}\right)$ em $\log (r) \times \log (A)$ e inclinação da reta obtida finalmente determina a dimensão fractal da imagem.

Uma das vantagens da utilização dessa abordagem é o balanceamento de carga automático, possibilitando a utilização de um conjunto heterogêneo de elementos de processamento sem a necessidade de realizar qualquer alteração na implementação. Para explorar essa versatilidade, implementamos a técnica em um sistema distribuído em rede de padrão ethernet de $10 \mathrm{Mb} / \mathrm{s}$, com 4 máquinas baseadas no processador AMD K6 II com freqüências distintas: 200, 250, 300 e 375 $\mathrm{MHz}$. Na máquina mais veloz $375 \mathrm{MHz}$, foi alojado o processo mestre e um escravo.

Utilizamos como método para a convolução, a multiplicação do disco com a imagem no domínio da freqüência de Fourier [Brigham, 1988]. Deste modo, o processo de convolução se caracteriza basicamente pela FFT da imagem e do disco, o produto complexo de seus domínios complexos, e sua FFT inversa, constituindo o resultado da operação de convolução.

Realizamos o experimento para uma imagem binária de $512 \times 512$ pixels. $\mathrm{O}$ número de discos utilizados foi de 32 , com raios variando em 2. A Figura 7.46 apresenta o diagrama de execução, obtido através das ferramentas de estatística do CVMP. Devido ao pequeno fluxo de dados nas trocas de mensagens em rede, o sistema possui uma ótima performance (observe a pequena quantidade de bolhas). Uma prova da excelente performance está no fato de que o sistema paralelo com quatro máquinas heterogêneas (200 MHz, $250 \mathrm{MHz}, 300 \mathrm{MHz}$ e $375 \mathrm{MHz}$ ) é aproximadamente 2,7 vezes mais rápido que a versão seqüencial executada na máquina mais veloz $(375 \mathrm{Mhz})$. 


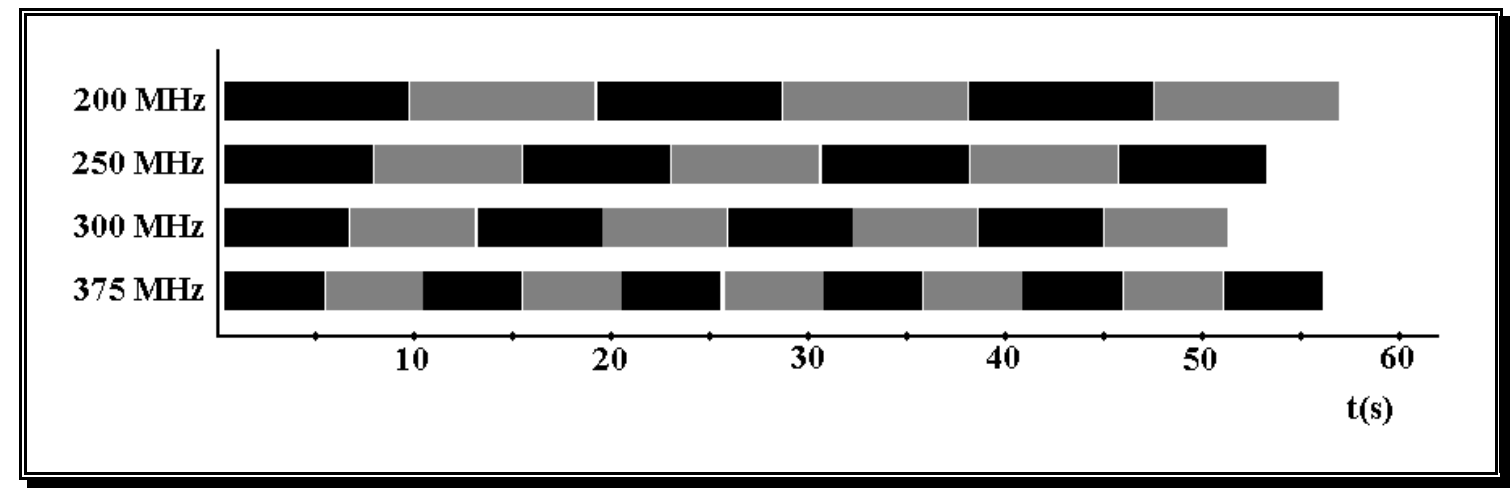

Fig. - 7.46 - Diagrama de execução para 4 máquinas.

O CVMP Processor Farm pode ser utilizado em muitas outras aplicações de processamento de imagens e visão computacional. Os problemas de multi-escala [Cesar, 1997], especificamente os bidimensionais, possuem uma metodologia de implementação idêntica à dimensão fractal de Minkowski descrita nesta seção, bastando apenas substituir no processo de convolução os discos de raio variado por gaussianas com diferentes desvios padrão. 


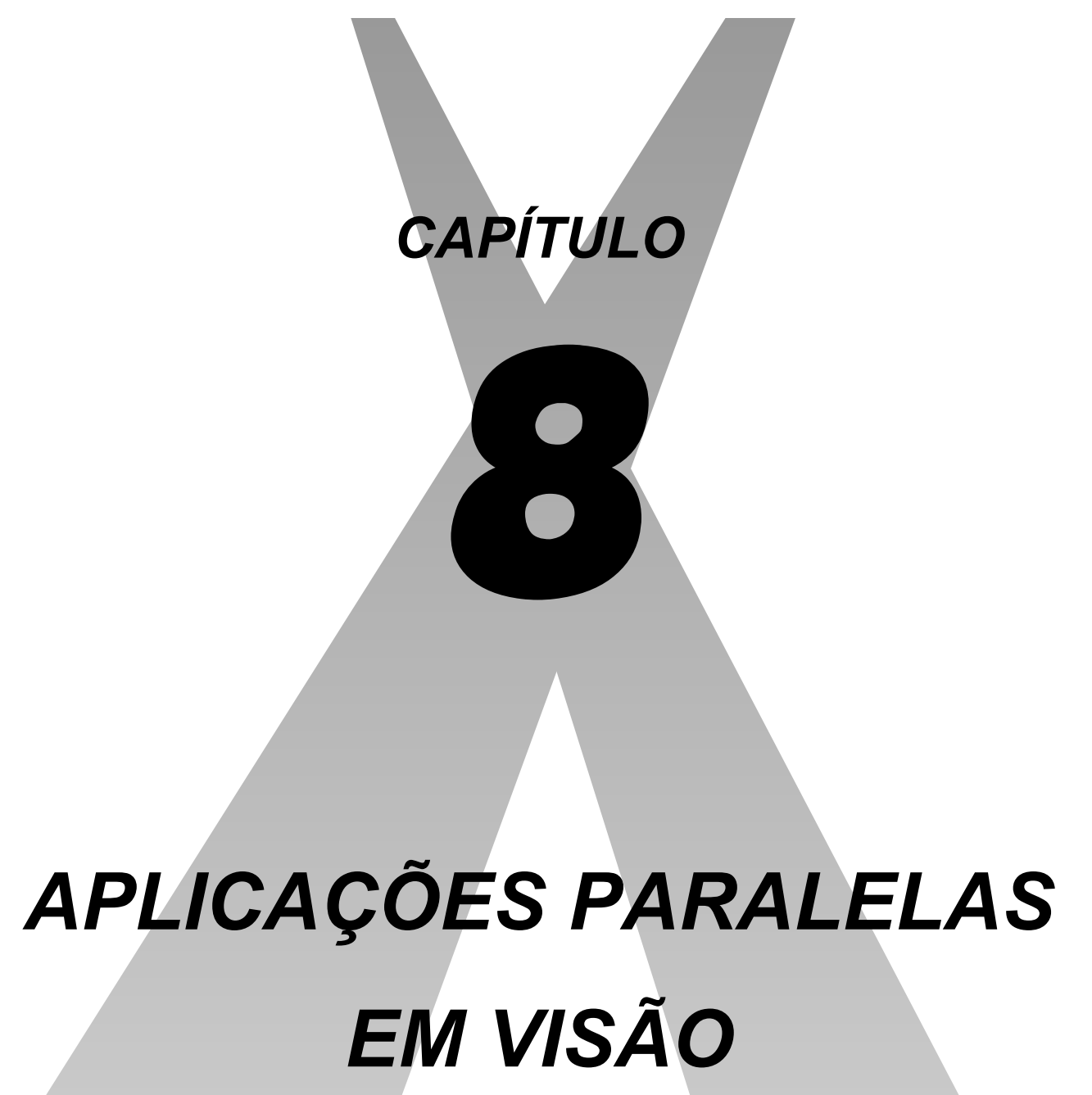

"Never trust a computer you can't throw out a window."

Steve Wozniak 
CAPÍTULO 8 


\section{CAPÍTULO 8 - APLICAÇÕES PARALELAS EM VISÃO}

\section{1 - INTRODUÇÃO}

No capítulo anterior vimos algumas estratégias de paralelismo e implementações de métodos para visão computacional e processamento de imagens. Neste capítulo iremos apresentar 3 aplicações inéditas desenvolvidas no CVRG. A primeira a ser discutida é um protótipo do Cyvis-1, que utiliza o paralelismo como ferramenta de integração de informações, neste caso os atributos visuais cor e estéreo. Como segunda aplicação temos um experimento do projeto इynergos, na qual, através de psicofísica, é desenvolvido um modelo matemático para complexidade de imagens, baseado no padrão da percepção humana. Finalizamos o capítulo apresentando o projeto TreeVis, um sistema paralelo de reconhecimento de plantas arbóreas.

\section{2 - INTEGRAÇÃO DE COR E ESTÉREO NO PROJETO CYVIS-1}

Podemos caracterizar a computação paralela como uma ciência cujo objetivo fundamental, senão único, é a performance. Deste modo, seu emprego dentro da temática da visão artificial seria o desenvolvimento de estratégias e arquiteturas para reduzir o tempo de execução dos algoritmos e métodos envolvidos nesta atividade. A natureza, entretanto, adota o paralelismo de modo versátil. Conforme discutimos no Capítulo 4, além de ser fundamental para o desempenho do processamento de informações nos sistemas biológicos, realizado por um conjunto de estratégias de paralelização de massa e multinível (4.7), a natureza encontrou também no paralelismo a chave vital para seus mecanismos de integração de informações, através da qual desenvolve um papel fundamental na integração dos atributos visuais, modularizados no córtex visual [Zeki, 1993].

Uma das bases do sistema de visão artificial Cyvis-1, apresentado no 


\section{CAPÍTULO 8}

Capítulo 5, é o modelo de especialização funcional do córtex visual dos primatas, proposto por Zeki e Ship [Zeki \& Shipp, 1988]. Segundo este modelo, o sistema visual é organizado em módulos independentes, onde cada módulo é responsável pelo processamento especializado de um atributo visual. Durante o processamento das informações, cada módulo pode permutar informações com outros módulos, ocorrendo a colaboração entre os diferentes atributos visuais. Esta abordagem caracteriza a integração de múltiplos estágios (Seção 5.2.1.8), que conta como princípio básico a integração dos atributos visuais.

Diferentemente de todas as abordagens de paralelismo apresentadas nesta tese, onde, de forma tradicional, o paralelismo atuou como uma ferramenta de performance, iremos apresentar nesta seção uma proposta de integração entre atributos visuais, na qual o CVMP é utilizado para exercer a integração, através da troca de informações. A forma como os atributos visuais distintos podem cooperar para atingir um determinado objetivo, embora ainda seja uma lacuna dentro da visão artificial, constitui uma das colunas fundamentais do projeto Cyvis-1. Deste modo estaremos apresentando o primeiro passo desse projeto, onde temos um sistema de visão artificial baseado na integração das informações provenientes de atributos visuais distintos, no caso: cor e estéreo.

Os atributos são especificados no sistema como módulos ou subsistemas, possuindo cada um sua própria meta de resultados. O módulo cor é responsável pela segmentação das imagens adquiridas pelo sistema, fornecendo informações referentes às regiões e suas bordas, enquanto o módulo estéreo utiliza as informações providas pelo atributo cor para determinar uma representação mais abstrata da cena. Assim, o sistema representa os objetos não apenas a partir das informações de regiões e bordas (2D), mas também da informação de profundidade, caracterizando a reprodução da estrutura dos objetos de forma tridimensional.

O sistema proposto foi desenvolvido com 0 intuito de realizar 0 reconhecimento de objetos poliédricos. Um dos módulos do sistema é responsável pela identificação dos objetos (cubos e pirâmides).

Conforme já comentamos, uma das características do projeto Cyvis-1 é o trabalho cooperativo entre diversos pesquisadores. Além de prover o paralelismo de forma simples, eliminando a restrição de que somente especialistas em computação paralela sejam capazes de desenvolver aplicações paralelas, permite que os demais pesquisadores também possam implementar sistemas paralelos, 
mesmo que sejam complexos. O CVMP atua, ainda, como uma ferramenta de integração entre os pesquisadores, que podem desenvolver módulos em máquinas individuais que se conectam e integram formando o sistema como um todo.

Podendo ser definido como o primeiro protótipo do Cvyis-1, o sistema de integração entre cor e estéreo apresentado neste capítulo foi desenvolvido pelo trabalho cooperativo de três doutorandos do Grupo de Visão Cibernética. Alan Salvany Felinto [Moreira et al., 1999] foi responsável pela implementação do módulo de estéreo e Jander Moreira [Moreira, 1999] pelo módulo de cor. A participação do autor, além do CVMP, base de desenvolvimento paralelo do sistema, envolveu a colaboração no planejamento e estruturação do sistema.

\subsection{1 - ESTRUTURAÇÃO DO SISTEMA}

Embora, o projeto Cyvis-1 incorpore diversos atributos visuais, assim como uma série de sofisticados recursos de visão (conforme discutido no Capítulo 5), seu primeiro protótipo é bastante limitado, baseando-se essencialmente na integração entre os atributos de cor e estéreo. A integração entre os atributos conforme idealizada no Cyvis-1, requer a colaboração em diversos níveis hierárquicos de processamento, além de permitir também que o processamento percorra o caminho de execução em ambos os sentidos (top-down e botton-up) de forma a permitir a utilização de informações de alto nível. A integração entre os atributos é uma tarefa difícil e pouco explorada. Deste modo, o primeiro protótipo, embora apresente a execução em apenas um único sentido (botton-up) e um limitado mecanismo de integração, que ocorre em apenas uma etapa hierárquica, constitui um importante passo para os estudos dos mecanismos de integração entre os atributos e, consequentemente, para o projeto Cyvis-1.

O sistema cor/estéreo, cuja estrutura básica é mostrada pelo diagrama de blocos da Figura 8.1, é composto por seis módulos, ou subsistemas: aquisição de imagens, segmentação por cor, análise de formas, reconhecimento de objetos e controle geral. O sistema foi implementado com padrões distribuídos, utilizado de forma que cada um dos módulos pode ser alojado em uma máquina distinta. $\mathrm{O}$ CVMP é responsável pela conexão e troca de mensagens entre os módulos. 


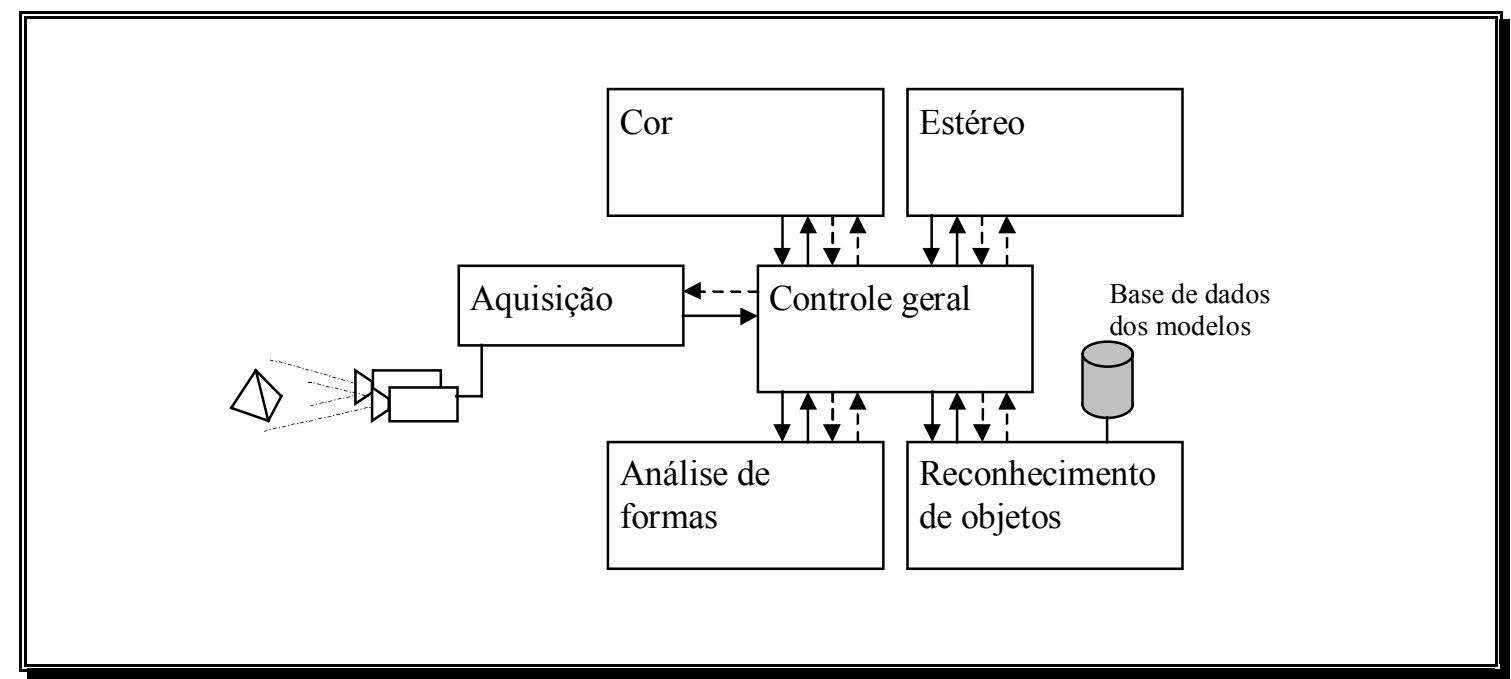

Fig. - 8.1 - Sistema de integração entre cor e estéreo, segundo sua estrutura modular [Moreira, 1999].

\subsubsection{1 - MÓDULO DE AQUISIÇÃO}

A aquisição de imagens é realizada através de duas câmeras digitais (CCD). As imagens são adquiridas em pares, com as câmeras posicionadas a uma distância conhecida, sem convergência, ou seja, os eixos de captura são paralelos. O módulo de aquisição é independente e autônomo, alojado em uma máquina que possui dispositivo para aquisição de imagens.

Quanto ao seu funcionamento, o módulo fica aguardando mensagens de outros módulos, solicitando serviços. Toda vez que o módulo recebe uma solicitação, é realizada a aquisição das imagens, transmitidas para o módulo solicitante na forma de mapas de bits. Ao final do processo, o módulo envia uma mensagem indicando ao módulo solicitante que o serviço foi efetuado com êxito e volta ao estado de espera.

\subsubsection{2 - MÓDULO DE COR}

O módulo de cor é responsável pela segmentação de uma das imagens do par estéreo. A técnica utilizada é conhecida como mapa auto-organizável. Trata-se de uma técnica baseada em redes neurais, consistindo na segmentação das imagens através de regiões, formadas por agrupamentos de pixels. A técnica é descrita em detalhes por Moreira em sua tese de doutorado [Moreira, 1999]. No sistema as duas imagens (esquerda e direita do par estéreo) são utilizadas para o treinamento do mapa auto-organizável. Após a convergência da técnica, são 
obtidas as classes identificadas, que segmentam a imagem em regiões. Com base nas regiões, são determinadas as fronteiras, gerando seu mapa de bordas. A segmentação ocorre em apenas uma das imagens, uma vez que as informações detectáveis nesse nível são irrelevantes para o módulo de estéreo.

\subsubsection{3 - ANÁLISE DE FORMAS}

A análise de formas é baseada na detecção das retas do mapa de bordas, uma vez que os objetos poliédricos podem ser modelados a partir das retas que constituem suas arestas. A detecção de retas é feita a partir da transformada de Hough, discutida na Seção 7.5. A partir dela, são encontradas as retas que passam sobre os pontos colineares da imagem. Conforme vimos nas Seções 7.5 e 7.5.1, na transformada de Hough as retas detectadas são representadas como picos no espaço de Hough. No entanto, os pontos colineares e ruídos na imagem geram um grande número picos, tornando praticamente impossível a obtenção somente das retas de interesse. Para solucionar este problema, foi introduzido o backmapping ou rastreamento, uma técnica complementar para solucionar esse problema.

Através da combinação entre a transformada de Hough e do backmapping, o módulo de análise obtém as retas da imagem, na tentativa de localizar as arestas dos objetos. Entretanto, o módulo análise de formas necessita não apenas conhecer a equação das retas da imagem, mas também determinar seus segmentos, ou seja, a posição onde as retas começam e terminam. Para determinar os segmentos de retas, foi utilizada uma técnica proposta por Costa \& Sandler [Costa \& Sandler, 1993], a qual permitem obter os segmentos de reta mediante o resultado do backmapping, e eliminar as retas consecutivas e coincidentes. Assim é realizada a análise de formas, que consiste na determinação dos segmentos de retas contidos no mapa de bordas.

\subsubsection{4 - ESTÉREO}

O módulo de estéreo efetua o cálculo de profundidade para cada uma das extremidades dos segmentos de retas determinados pelo módulo de análise de formas. O cálculo de profundidade é realizado a partir das disparidades localizadas entre os dois pares de imagem adquiridos pelo sistema. A disparidade é determinada a partir dos pontos conjugados ou de correspondência. Os pontos 


\section{CAPÍTULO 8}

conjugados são pares de coordenadas (uma coordenada para cada imagem do par estéreo) relacionadas ao mesmo ponto físico da cena na qual foi realizada a aquisição pelo par de câmeras [Shirai, 1987].

Dentre os diversos métodos para determinar os pontos conjugados (correlação, diferenças quadráticas mínimas, transformadas de Gabor, entre outros [Theimer \& Mallot, 1994] [Faugeras, 1996] [Qian, 1997]), foi adotado para a implementação do módulo de estéreo o método das janelas quadradas. Nessa abordagem, dado um ponto em uma imagem, é centrada uma janela quadrada com um tamanho determinado. A busca do ponto conjugado consiste na localização da janela correspondente, a outra imagem do par estéreo. A similaridade é determinada pelo conteúdo das janelas. Para solucionar algumas ambigüidades, é realizada a mudança sistemática do tamanho das janelas, conforme indicado por Shirai [Shirai, 1987]. A comparação entre as janelas é realizada apenas nas regiões determinadas pela linha epipolar, calculada através da geometria das câmeras, determina a região provável do ponto conjugado. A calibração das câmeras do sistema foi realizada mediante os procedimentos propostos por Tsai [Tsai, 1987].

\subsubsection{5 - RECONHECIMENTO DE OBJETOS}

O universo de objetos para qual o sistema foi proposto é constituído de 3 entidades: cubo, tetraedro e prisma (ver Figura 8.2). Cada um dos objetos é construído em alumínio, apresentando dimensões conhecidas, onde cada face possui uma cor uniforme distinta, que permite a segmentação por região cromática. O sistema foi idealizado a fim de identificar os objetos tridimensionais, sob qualquer posição na cena, sendo tolerante a rotação e translação dos objetos no espaço.

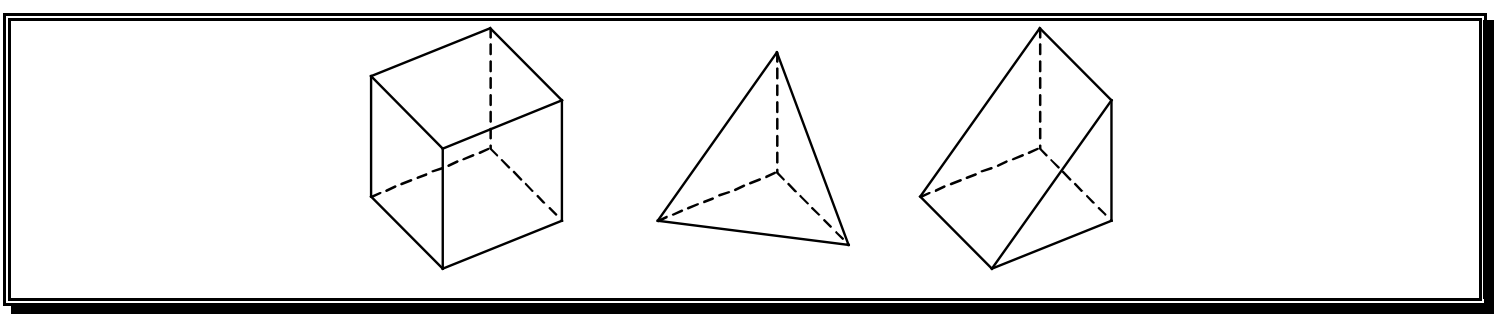

Fig. - 8.2 - Modelo de arestas dos objetos que constituem o universo de reconhecimento do sistema (cubo, tetraedro e prisma).

O módulo de reconhecimento faz uso de uma base de dados contendo os modelos dos objetos, que correspondem a um conjunto de segmentos de retas 
contendo extremidades especificadas por coordenadas tridimensionais. O sistema de busca e reconhecimento é realizado mediante a comparação dos modelos da base de dados frente às informações extraídas da cena. A identificação do objeto se faz através de uma verificação exaustiva, que visa emparelhar o modelo da cena com o da base de dados. As escalas das descrições dos objetos não são consideradas, uma vez que ocorre a normalização dos segmentos antes do início da comparação. O emparelhamento é realizado mediante rotações e translações do modelo da base, a fim de possibilitar a identificação dos objetos tridimensionais para qualquer posicionamento espacial. Para cada emparelhamento, um erro geral é calculado, o qual será descrito na Seção 8.2.3. Com base nesse cálculo é realizado o reconhecimento do objeto.

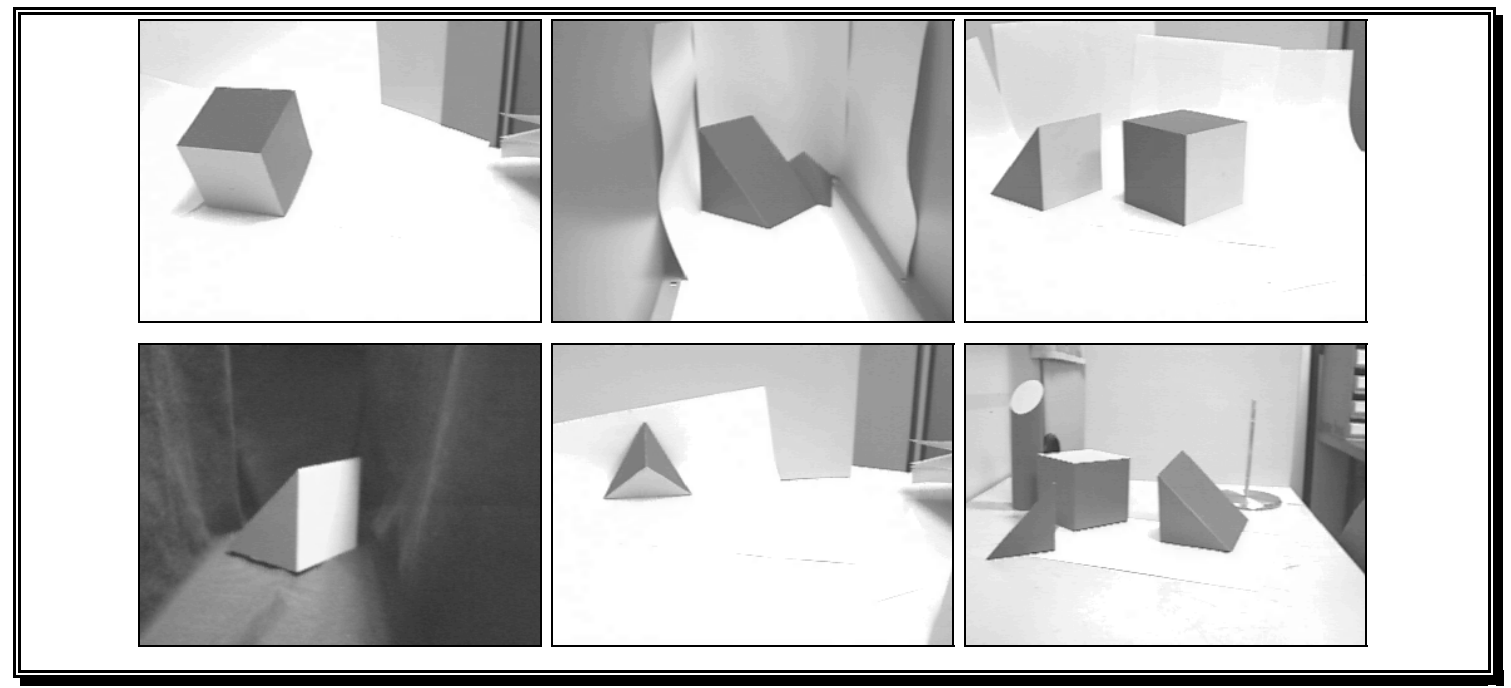

Fig. - 8.3 - Exemplos de cenas reais, nas quais o sistema realizou a identificação dos objetos [Moreira, 1999].

A cena na qual os objetos são posicionados é real, contendo em muitas situações um grande número de segmentos de retas detectáveis que não pertencem aos objetos (fundo de cena), ou ainda pertencentes a outros objetos posicionados na cena, que não fazem parte do universo de reconhecimento. Podem ocorrer ainda situações em que surgem alguns segmentos de retas pertencentes aos objetos de reconhecimento, que não satisfazem o modelo de reconhecimento poliédrico. Através de comparações com o modelo e limites de erro, o sistema elimina as informações indesejáveis, desconsiderando-as, permitindo assim a criação de um modelo poliédrico e o reconhecimento de objetos em cenas reais e complexas. A Figura 8.3 apresenta algumas imagens adquiridas pelo sistema, na 
qual podemos observar a complexidade da cena.

\subsubsection{6 - CONTROLE GERAL}

O módulo controle geral é responsável pela supervisão dos demais módulos, assim como pelo controle do fluxo de informações. Toda a comunicação entre módulos é realizada pelo controle central. Conforme podemos observar na Figura 8.1, não existe conexão entre módulos que não passem pelo controle central. Todas as decisões, seqüências de operações, ciclo de execução e controle de dependência de dados do sistema são realizados sob a sua determinação, de modo que os demais módulos podem ser considerados como escravos ao seu comando. Deste modo o controle central promove a hierarquia e integração dos módulos que compõem o sistema.

\subsection{2 - CRITÉRIO DE AVALIAÇÃO}

Nesta seção vamos descrever o critério de avaliação utilizado para a realização do reconhecimento dos objetos. Implementado no módulo de reconhecimento, o critério de avaliação realiza a comparação entre o modelo do objeto, ou seja, o modelo retirado das imagens adquiridas pelos sistemas e o modelo da base de dados. O reconhecimento ocorre quando a discrepância entre os modelos, determinada pelo cálculo de erro, é a menor dentre as comparações com os modelos da base ou ainda se o erro for menor que um determinado limite pré-estipulado. O cálculo do erro é estabelecido pelo erro médio quadrático entre as distâncias das extremidades correspondentes de todos os segmentos emparelhados do modelo do objeto da imagem e da base de dados. A Equação 8.1 apresenta o cálculo de erro, onde $N$ indica o número de extremidades de segmentos, $m o_{i}$ e $m b_{i}$ representam os pontos conjugados no espaço do modelo objeto da imagem e do modelo da base, respectivamente, e $D(\cdot)$ é a função de distância euclidiana.

$$
\varepsilon_{q}=\frac{1}{N} \sum_{i=1}^{N}\left[D\left(m o_{i}, m b_{i}\right)\right]^{2}
$$

Embora o cálculo do erro estabeleça uma metodologia objetiva de comparação entre os modelos, existem algumas situações em que o cálculo do erro 
não é capaz de reconhecer os objetos com precisão, sendo necessário adicionar outras considerações ao critério de avaliação. Uma dessas situações ocorre devido à similaridade entre os objetos do universo de classificação. Como podemos observar na Figura 8.2, tanto o tetraedro como o prisma podem ser consideradas como objetos poliédricos formados a partir de cortes planares em cubos. Se tomarmos um cubo e fizermos um corte por um plano que passa por arestas opostas, teremos como resultado um prisma, assim como se o plano passar por três vértices não compartilhados pela mesma face e que não contenha uma diagonal, teremos um tetraedro.

Deste modo se o analisador de formas detectar somente três segmentos de reta, conforme apresentado na Figura 8.4, e se utilizarmos esse modelo diretamente no emparelhamento e testarmos a seguir o critério de avaliação através do cálculo de erro, podem ocorrer falsos reconhecimentos devido à similaridade entre os vértices. Nesta situação, o erro médio quadrático $\varepsilon_{q}$ seria muito próximo, praticamente idêntico, impossibilitando um reconhecimento eficaz.

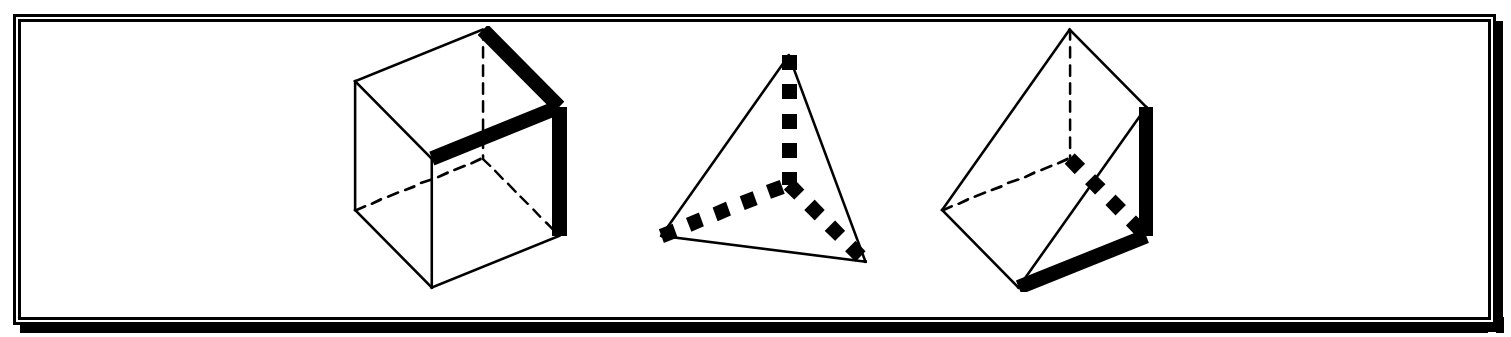

\section{Fig. - 8.4 - Modelo de arestas dos objetos que constituem o universo de reconhecimento do sistema (cubo, tetraedro e prisma).}

Para solucionar este problema, foi introduzida uma semântica na qual é ponderado o número de segmentos detectados como peso adicional ao critério de avaliação. Deste modo, é considerado o número total de arestas visíveis ao invés do total de arestas. O número total de arestas visíveis para os poliedros que constituem o universo de reconhecimento é de 9,6 e 8 respectivamente para o cubo, tetraedro e prisma.

$$
\varepsilon_{e}=k \frac{N_{v}-N_{o}}{N_{v}}
$$

Com base nesse novo contexto, foi introduzido o erro relativo ao 


\section{CAPÍTULO 8}

emparelhamento de bordas, conforme indicado na Equação 8.2, onde $N_{v}$ e $N_{0}$ indicam, respectivamente, o número de arestas visíveis do modelo e o número de arestas (segmentos) da imagem que foram emparelhados. $O$ fator $k$ é um fator de correção da magnitude do erro, para que tenha a mesma variação máxima que o erro quadrático médio $\varepsilon_{q}$. O erro $\varepsilon_{e}$ estabelece a razão entre a falha no emparelhamento esperado (número de arestas visíveis não relacionadas a arestas da imagem) e a expectativa inicial (número de arestas visíveis).

$$
\varepsilon=h \varepsilon_{q}+(1-h) \varepsilon_{e}
$$

O erro total, definido pela Equação 8.3 , consiste na ponderação entre os erros $\varepsilon_{q}$ e $\varepsilon_{e}$, através do parâmetro $h$. O erro $\varepsilon$ permite a distinção entre os modelos de objetos da base de dados e o modelo do objeto das imagens a ser reconhecido, caracterizando desse modo o critério de avaliação do módulo de reconhecimento de objetos.

\subsection{3 - FUNCIONAMENTO GERAL E RESULTADOS}

O sistema é constituído de 6 módulos autônomos e independentes, distribuídos pelas máquinas que compõe a rede. Usualmente, uma máquina aloja mais de um módulo. Nos experimentos realizados no laboratório utilizou-se geralmente três máquinas compor o sistema. Nesta configuração uma das máquinas aloja somente o módulo de aquisição, o qual necessita de hardware especial (aquisição de imagens), enquanto que os módulos de cor, forma e controle partilham a segunda máquina e os demais módulos, ou seja, estéreo e reconhecimento, utilizam a máquina restante.

Embora o sistema apresente arquitetura e estrutura paralela, havendo autonomia e independência entre os módulos que o compõe, o paralelismo foi utilizado para integração, não tendo sido especificamente exploradas as possibilidades de aumento de performance. Deste modo, o sistema apresenta uma cadeia de execução seqüencial. Supervisionados pelo controle geral, os módulos vão sendo executados um após o outro seguindo um determinado fluxo de 
execução. O ciclo inicia-se com a aquisição dos pares de imagem. Para isso o módulo de controle solicita ao módulo de aquisição que cumpra sua tarefa preestabelecida, ou seja, efetuar a aquisição do par de imagens através das duas câmeras do sistema.

Uma vez realizada a aquisição das imagens, o controle central solicita ao módulo cor que realize a segmentação de uma das imagens do par estéreo. Como resultado da segmentação por cor é produzido um mapa de bordas da imagem, através da classificação da imagem pelo método dos mapas auto-organizáveis [Moreira, 1999]. Para as configurações dos mapas auto-organizáveis foi adotado: mapas de dimensões 32x32, vizinhança circular inicial com raio de 25,6 (equivalente a $80 \%$ da dimensão do mapa), taxa de aprendizado inicial de $60 \%$, taxas de decaimento de $0,05 \%$ para o aprendizado e para o raio da vizinhança e foi adotado um erro de 10-4 estipulado para a verificação da convergência [Moreira, 1999]. A Figura 8.5 apresenta os resultados de segmentação do módulo cor, em comparação com clássico método de gradiente Sobel [Sobel, 1970], nela temos uma das imagens do par estéreo, adquirido pelo sistema (esquerda), com o respectivo resultado de segmentação pelo método dos mapas auto-organizáveis (centro) e Sobel (direita).

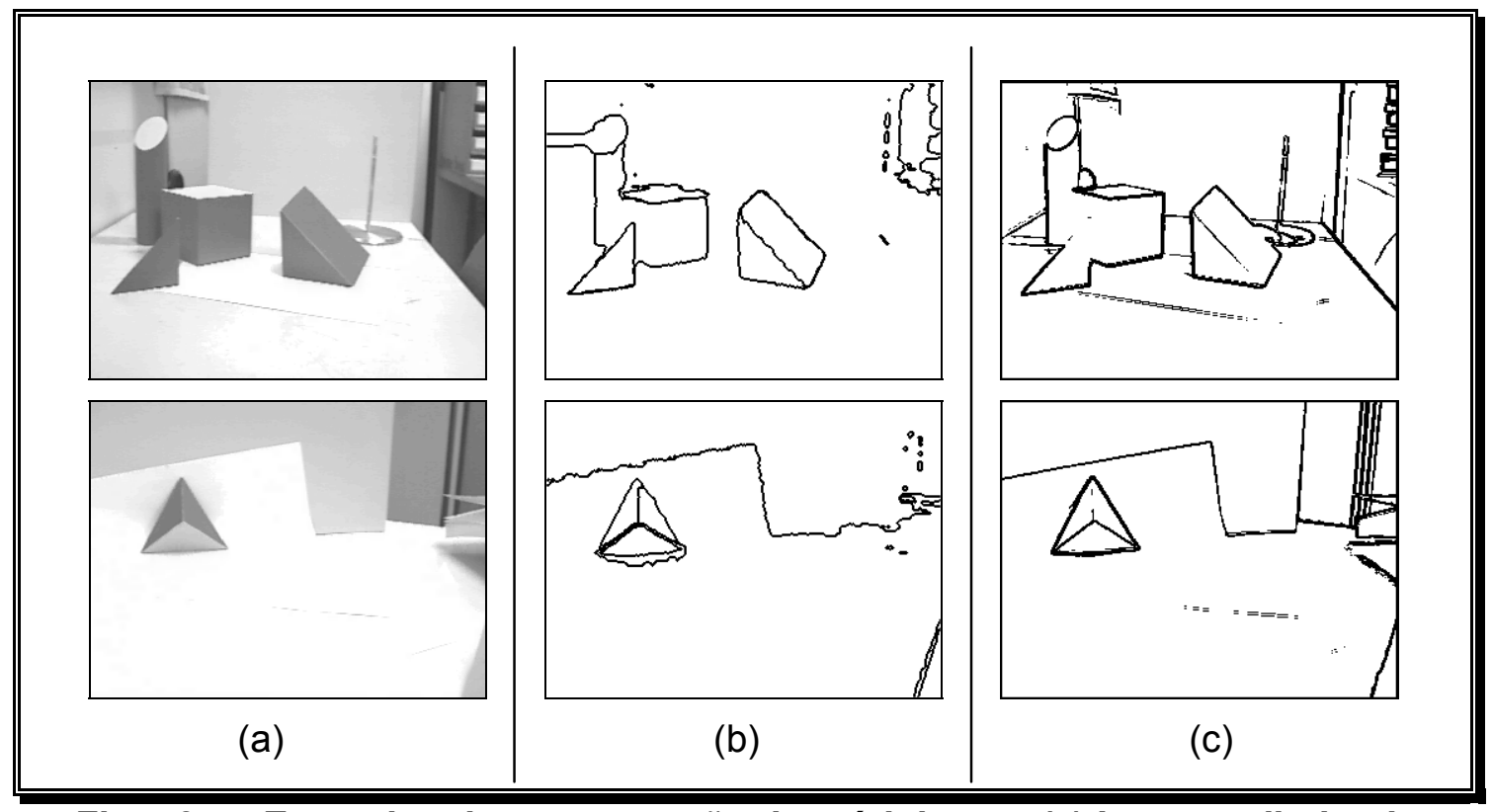

Fig. - 8.5 - Exemplos de segmentação do módulo cor. (a) Imagem direita do par estéreo, adquirida pelo módulo de aquisição. (b) Resultado da segmentação do módulo cor (Mapas auto-organizáveis). (c) Segmentação por Sobel com finalidade comparativa.

Uma vez gerado o mapa de bordas pela segmentação do módulo de cor, o 


\section{CAPÍTULO 8}

módulo de controle envia uma mensagem para o módulo de análise de formas, para este que o processe. Baseado na transformada de Hough e backmapping, o módulo de análise de formas tem como função extrair os segmentos de retas da imagem. A Figura 8.6 contém os segmentos detectados para uma mesma cena, sob diferentes pontos de vista.

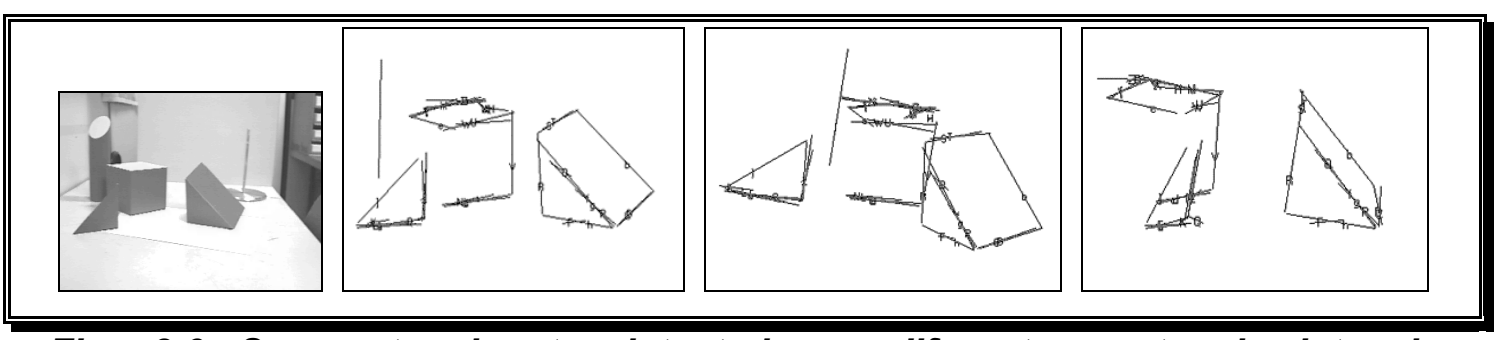

Fig. - 8.6 - Segmentos de retas detectados em diferentes pontos de vistas de uma mesma cena (figura a esquerda).

A próxima etapa do ciclo de execução do sistema é a tarefa do módulo estéreo. Finalizada a análise de formas, o módulo de controle geral solicita que o módulo estéreo inicie o processamento, que consiste basicamente na determinação da profundidade das extremidades dos segmentos de reta detectados. Através das coordenadas das extremidades dos segmentos de retas, o módulo estéreo localiza o conjugado e pelo cálculo de disparidade é determinada sua profundidade. A determinação da profundidade, entretanto, não é sempre possível, devido a fatores como as diferenças de perspectiva, que causam oclusões parciais, ou introduzem reflexos diferenciados e a imprecisão dos segmentos, além de reflexos nas cores e determinadas sombras, que acarretam em imprecisões no mapa de bordas.

Estas situações fazem com que as bordas e os segmentos detectados não fiquem precisamente localizados nas posições reais dos objetos. Desse modo, as coordenadas das extremidades dos segmentos podem coincidir com o a base ou com o fundo da cena. Deste modo o valor da profundidade calculado se torna relativo ao fundo da cena ou sua base, deturpando as dimensões e posições dos objetos de interesse. Para evitar modelos incorretos, se os pontos conjugados de uma das extremidades do segmento de reta não for determinado de modo adequado, o segmento é excluído do modelo do objeto.

Além da exclusão pela falta de determinação correta do conjugado, ocorrem situações em que os segmentos não são emparelhados com o modelo da base, sendo nestes casos também eliminados. Os segmentos desconsiderados dessa 
forma pertenciam ao fundo da imagem, reflexos, sombras, ou outros objetos da imagem.

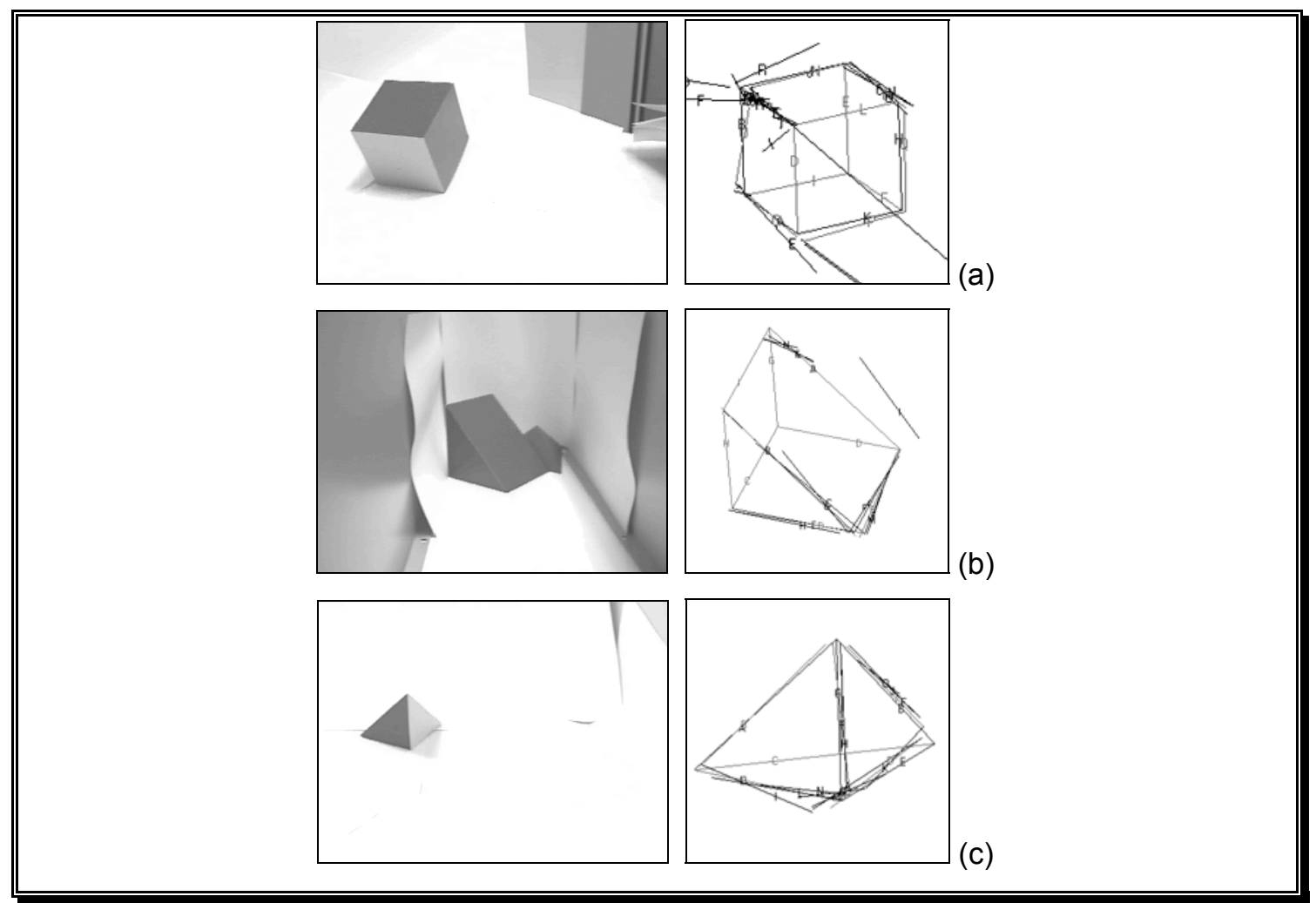

Fig. - 8.7 - Exemplos de reconhecimento de objetos. Na coluna esquerda é apresentada a imagem direita do par estéreo e na coluna direita, o modelo obtido do objeto sobreposto ao modelo reconhecido do banco de dados.

Finalizado o processamento do módulo estéreo, o controle central determina a execução da última etapa do processamento, tarefa realizada pelo módulo de reconhecimento, o qual compara o modelo do objeto da imagem com os modelos da base de dados, identificando a comparação que apresente o menor erro (definido na Equação 8.3). A Figura 8.7 apresenta três resultados do processo de reconhecimento, ilustrando cada um dos objetos do universo de reconhecimento. $\mathrm{Na}$ coluna esquerda temos as imagens adquiridas pela câmera direita e na coluna direita seus respectivos modelos (sobreposição objeto e banco de dados).

Para o primeiro experimento (Figura 8.7 a), o objeto utilizado foi um cubo, reconhecido através da identificação de 6 arestas, com um erro $\varepsilon=7,0 \times 10^{-3}$. No segundo experimento (Figura $8.7 \mathrm{~b}$ ), o prisma foi reconhecido com um erro $\varepsilon=$ $7,4 \times 10^{-3}$. E finalmente o tetraedro (Figura $8.7 \mathrm{c}$ ) foi identificado com um erro $\varepsilon=$ 


\section{CAPÍTULO 8}

$1,2 \times 10^{-2}$. Experimentos similares foram realizados em cerca de 20 cenas, com diversas condições de iluminação, fundo e quantidade de objetos diferentes, que diagnosticando que o sistema ainda possui um índice considerável de reconhecimentos incorretos. Nos casos onde o sistema reconheceu os objetos corretamente, os erros apresentados oscilaram em valores próximos aos da Figura 8.7. Maiores detalhes sobre o funcionamento do sistema, técnicas utilizadas e resultados podem ser obtidos na tese de doutorado de Moreira [Moreira, 1999].

\subsection{4 - SISTEMA DISTRIBUÍDO E PARALELISMO}

O sistema foi implementado em arquitetura distribuída, sobre a plataforma Windows/Delphi e com a ferramenta de paralelismo CVMP. Graças à sua arquitetura distribuída, todos os módulos que compõe o sistema são independentes, podendo ser dispostos em máquinas diferentes (conectadas por redes) ou ainda na mesma máquina (multitarefa). Conforme comentamos anteriormente, embora possua todos os requintes da arquitetura paralela, na qual os módulos do sistema são autônomos, separados e independentes, o fluxo de execução ocorre de forma seqüencial, uma vez que o objetivo do sistema prima a integração.

Quanto ao controle, os módulos do sistema podem ser divididos em dois grupos: supervisor e escravos. O grupo dos escravos, é composto por todos os módulos com exceção do módulo de controle central. Basicamente, os módulos escravos podem ser considerados como sistemas independentes, que ficam aguardando o recebimento de ordens, através de troca de mensagens (CVMP). Uma vez recebida a tarefa, o módulo a executa de forma autônoma e independente, retornando o resultado do processamento, e voltando ao estado de vigília, ao qual permanece até que seja requisitada uma nova tarefa.

O módulo supervisor do sistema é o módulo controle geral. Sua finalidade é supervisionar e controlar todos os demais módulos, atribuindo tarefas aos escravos, através de trocas de mensagens, recebendo as respostas e coordenando o ciclo de execução do sistema. Embora essa estrutura paralela permita a execução simultânea entre módulos, a concorrência não ocorre, parcialmente devido à dependência de dados entre módulos e também pelo esforço generalizado do projeto na integração.

Mesmo tendo uma forte dependência de dados entre os módulos, que 
impossibilita a execução simultânea, devido a sua arquitetura paralela e distribuída, pode ser facilmente incorporado ao sistema diversos aspectos de paralelismo, que proporcionam concorrência e consequentemente melhoram a performance. Essas estratégias de paralelismo, que não implicam grandes modificações no sistema, podem ser divididas em duas abordagens: (i) Paralelizar o processamento interno de cada módulo e (ii) Adaptar o sistema para processamento intermitente, e adicionar mecanismos de paralelismo temporal ("pipeline") entre os módulos.

$\mathrm{Na}$ primeira situação (i), os módulos do sistema, responsáveis por processamento de cor, estéreo e análise de formas, podem ser substituídos por uma versão paralela. Deste modo, visto a independência entre os módulos e sua autonomia, os módulos de processamento poderiam ser paralelos, possuindo dessa forma sub-módulos. Estes seriam alojados em diferentes máquinas, no caso do modelo distribuído ou em diferentes processadores, no caso de máquinas multiprocessadas. No caso específico, do módulo de análise formas, a paralelização dos processamentos referentes a transformada de Hough e backmapping, foram implementados via CVMP nesse trabalho, e encontram-se exemplificados nas Seções 7.5 e 7.51 .

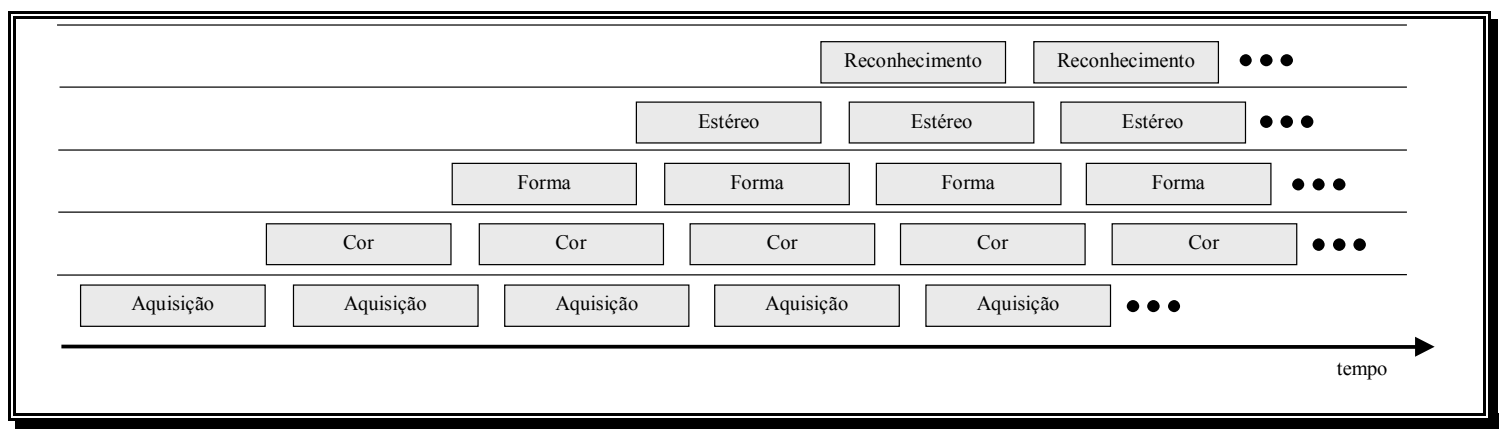

Fig. - 8.8 - Exemplo de pipeline de 5 estágios entre os módulos do sistema (aquisição, cor, forma, estéreo e reconhecimento).

Na segunda abordagem (ii) é proposta a adição de paralelismo temporal ao sistema, na forma de pipeline entre os módulos. Para essa abordagem o sistema deveria funcionar em intermitência, ou seja, estar sempre adquirindo, processando e analisando as imagens provenientes das câmeras. Nesse caso, conforme mostra a Figura 8.8, o sistema seria baseado em estrutura pipeline de 5 estágios, e enquanto a seqüência de execução de uma cena (aquisição do par de imagens, processamento de cor, processamento de formas, processamento estéreo e reconhecimento de padrões) estivesse sendo realizada, novas seqüências já 
iniciariam o processamento simultaneamente.

\subsection{5 - INTEGRAÇÃO ENTRE PESQUISADORES}

O primeiro protótipo do Cyvis-1 consolidou o CVMP como uma plataforma amigável e versátil, através da qual pesquisadores do Grupo de Pesquisa em Visão Cibernética puderam tornar paralelas suas aplicações, promovendo uma maior performance e a possibilidade de visão em tempo real. Além de permitir a adição ao contexto da visão artificial, toda a filosofia de integração, modularidade e independência, exigida pelos modelos mais complexos do córtex, em especial a especialização funcional proposta por Zeki e Ship [Zeki \& Shipp, 1988], possibilitando novos estudos científicos nessa área.

Neste protótipo tivemos a oportunidade e a satisfação de trabalhar juntamente com dois pesquisadores do grupo, especialistas em visão e processamento de imagens: Jander Moreira, na época do projeto, doutorando especialista em cor, e Alan Salvany Felinto, doutorando especialista em estéreo. Além do desenvolvimento do primeiro protótipo do Cyvis-1, a colaboração dos dois colegas foi fundamental para estudos do CVMP, tais como simplicidade de utilização, validação e também as características de herança (OOP) da ferramenta, que foram validadas através do desenvolvimento de um objeto herdado do Tcvmp, para utilização específica no protótipo (ver Seção 6.6.2).

Esse trabalho, em especial, ilustrou uma nova forma de integração entre os pesquisadores no desenvolvimento de sistemas de visão, através da ferramenta CVMP. A integração é propiciada devido à independência e autonomia entre os diferentes módulos do sistema, presentes nos sistemas distribuídos ou paralelos. Graças a estas características, cada módulo se comporta como uma caixa preta, seguindo a mesma filosofia do conceito de programação orientada a objetos [Cox, 1986]. Nesse caso, os pesquisadores não precisam conhecer os detalhes sobre a técnica ou implementação dos módulos, uma vez que basta enviar uma mensagem e aguardar a resposta do processamento do módulo.

Essa abordagem facilita muito o trabalho cooperativo, uma vez que concentra os esforços de cada indivíduo no desenvolvimento de uma parte específica do sistema. A independência e autonomia modular, aliadas ao alojamento distribuído de cada módulo, propiciou um ambiente de desenvolvimento bastante interessante no nosso laboratório, em que cada pesquisador ficou 
responsável por uma máquina, na qual estava alojado um módulo específico do sistema. Com isso, os colaboradores do projeto puderam trabalhar simultaneamente em máquinas distintas e, a qualquer momento, testar a integração de sua parte com todo o sistema. Para isso, enquanto trabalhavam no desenvolvimento, os pesquisadores disponibilizaram uma versão do módulo, sendo executado em multitarefa em suas máquinas. Assim, tanto o módulo quanto a máquina poderiam ser utilizados para testes pelos outros módulos, ao mesmo tempo em que a máquina estava sendo utilizada para o desenvolvimento de novas versões do seu respectivo módulo.

Graças ao ambiente de desenvolvimento e teste distribuído, foi possível o trabalho cooperativo e simultâneo para a implementação do primeiro protótipo do projeto Cyvis-1, que exemplificou não apenas a utilização do paralelismo para a integração de atributos visuais em sistemas de visão artificial, mas também a integração e harmonização do trabalho de pesquisa de pesquisadores do Grupo de Pesquisa em Visão Cibernética.

\section{3 - LYNERGOS - INVESTIGAÇÃO DA PERCEPÇÃO HUMANA NA COMPLEXIDADE DAS FORMAS}

No Capítulo 5 discutimos o projeto $\Sigma$ ynergos, um sistema baseado na sinergia, conceito através do qual a associação simultânea de diversos fatores contribuem para uma ação coordenada, cujo objetivo fundamental é a implementação de um poderoso e versátil laboratório de visão computacional, para auxiliar o desenvolvimento e a validação de técnicas, sistemas e experimentos em visão. Nesta seção, vamos apresentar um experimento psicofísico realizado através do projeto $\Sigma$ ynergos, no qual diversos paradigmas, em especial Internet, sistemas distribuídos, computação paralela, inteligência artificial e visão biológica, são utilizados de forma integrada para investigar a percepção humana na complexidade das formas e com base nessa investigação, desenvolver um modelo matemático/computacional dessa sensação humana [Bruno et al., 2000].

\subsection{1 - O EXPERIMENTO PSICOFÍSICO}

A percepção visual humana envolve processos altamente complexos e não 


\section{CAPÍTULO 8}

lineares, organizados em uma estrutura hierárquica [Marr, 1982] [Zeki, 1993], se inicia com a conversão do sinal físico (luz) em estímulo nervoso e termina com sua completa caracterização e descrição (sensação do estímulo). Deste modo, para cada estímulo físico em uma dada modalidade sensitiva, será criada uma percepção correspondente, a qual na maioria das vezes obedece a uma dependência não linear. Em psicofísica, esse tipo de correspondência pode ser caracterizado e modelado em termos da lei de Fechner, dada pela Equação 8.4, onde $c$ é uma constante proporcional, $P$ é a intensidade do estímulo físico e $S$ é a magnitude subjetiva [Barlow \& Mollom, 1982].

$$
S=c \log P
$$

Para investigar como os parâmetros da lei de Fechner podem se relacionar com a percepção humana na complexidade das formas, planejamos um experimento que consiste em apresentar uma série de imagens para um indivíduo, que avaliará a imagem atribuindo-Ihe uma nota de 1 a 10. Para que o experimento se torne estatisticamente representativo, um grande número de imagens deve ser considerado, com a natureza mais divergente possível (ex: fotografia de um escritório, fotografia de um elefante, etc.).

Uma fonte de imagens vasta e bastante variada é a própria Internet. Através do módulo de Internet e do WebWorm, que será discutido mais adiante, o $\Sigma$ ynergos é capaz de montar uma base de dados de imagens variadas, que são organizadas e apresentadas ao espectador para a realização do experimento. Os resultados obtidos podem ser então comparados com funções definidas por valores medidos. Nesse trabalho optou-se por duas funções: (i) combinações lineares das características, dada pela Equação 8.5 e (ii) combinações lineares do logaritmo das características (devido a lei de Fechner), expressa na Equação 8.6. O fator de influência, determinado pelo parâmetro bias é necessário para possibilitar eventuais deslocamentos do hiperplano definido pela função de suas coordenadas de origem, caso seja preciso.

$$
\begin{aligned}
S_{C, 1} & =\sum_{i=1}^{N_{f}} a_{i} f_{i}+\text { bias } \\
S_{C, 2} & =\sum_{i=1}^{N_{f}} a_{i} \log \left(f_{i}\right)+\text { bias }
\end{aligned}
$$


Os resultados obtidos pela análise humana são então relacionados com os resultados obtidos através da análise de complexidade de alguns métodos computacionais, os quais serão discutidos a seguir. Desta forma, é determinada a combinação linear, que ditará o modelo computacional mais próximo do comportamento humano.

Em termos computacionais, boas aproximações para as combinações lineares são aquelas que apresentem o menor número de fatores possível. Uma aplicação direta para essa consideração seria a possibilidade de utilização dos modelos em tempo real, onde, quanto menor o número de fatores considerados, menores serão os recursos computacionais requeridos e consequentemente, mais rápido será o sistema.

\subsection{2 - WEBWORM}

A construção do banco de imagens é realizada através de uma coleta de imagens dos mais variados assuntos, extraídas da Internet. Deste modo, coletando imagens ao acaso pela Internet estaremos garantindo que as imagens apresentadas no experimento psicofísico possuirão natureza amplamente variada, não apresentando características em comum (que poderiam ocorrer caso as imagens fossem recolhidas de algum banco de dados específico e obtidas por alguma pessoa ou grupo de pessoas). Para permitir a aquisição das imagens foi desenvolvido um aplicativo, incorporado ao módulo Internet do $\Sigma$ ynergos, o qual denominamos de WebWorm, cujo funcionamento básico consiste em acessar páginas HTML e trazer as imagens.

O WebWorm é uma aplicação desenvolvida em Delphi, que através de sockets (winsock) [Dumas, 1995], se conecta com o porto 80 (servidor Web) através das máquinas pela Internet, estabelecendo comunicação com os servidores WWW. O WebWorm opera um navegador Netscape, através do mecanismo sendkey do Windows, fazendo com que o Netscape abra as páginas HTML requisitadas. 


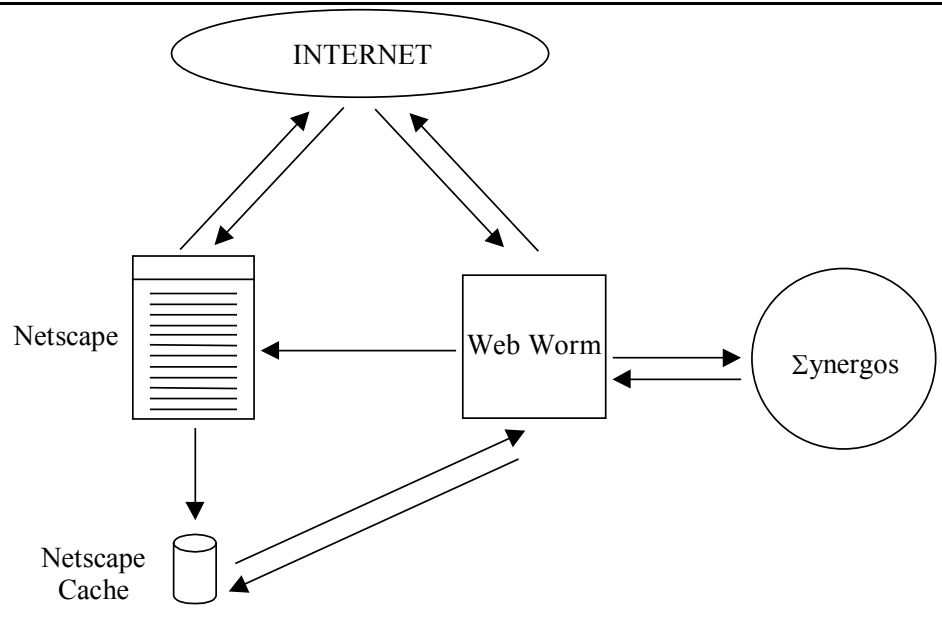

Fig. - 8.9 - Diagrama apresentado as interações do WebWorm.

A Figura 8.9 apresenta um diagrama esquemático contendo sua estrutura de funcionamento. Após carregar uma página HTML, o WebWorm analisa o código e monta duas listas, a primeira, denominada de lista de espera, contendo os ponteiros para outras páginas HTML e a outra com as imagens do documento HTML. Feito isso, o aplicativo apaga todos os arquivos do diretório cache do Netscape e solicita a este que a página em questão seja carregada. Uma vez que a página e todas as suas imagens (arquivos GIF, JPEG, BMP e etc.) são carregadas, o WebWorm, transfere as imagens (.JPG) do diretório cache do Netscape para um diretório de entrada de imagens do $\Sigma$ ynergos.

O processo é repetido para todas as páginas na lista de espera, de modo que o WebWorm é capaz de percorrer automaticamente todas as páginas apontadas por um determinado sítio (site), podendo deste modo percorrer milhares de páginas. Esse processo é encerrado quando um determinado nível de profundidade de acesso foi alcançado. A Figura 8.10 ilustra um exemplo do processo de navegação. Nesse caso a página inicial apresenta três ponteiros (hyperlinks) para três outras páginas, que por sua vez, são conectadas a quatro, três e uma páginas respectivamente. Se o WebWorm for instruído para percorrer apenas um nível de profundidade, serão carregadas apenas as imagens da página inicial; para dois níveis, as imagens das páginas correspondentes ao primeiro e segundo nível e assim sucessivamente.

Nessa abordagem nós assumimos que o WebWorm realiza uma busca cega na Internet, iniciada a partir de uma determinada página. Assim, para que se torne mais interessante, iniciamos a busca a partir da página resultante de determinada 
pesquisa em um mecanismo de busca como o AltaVista ou Yahoo (com as chaves "photo" e "pictures").

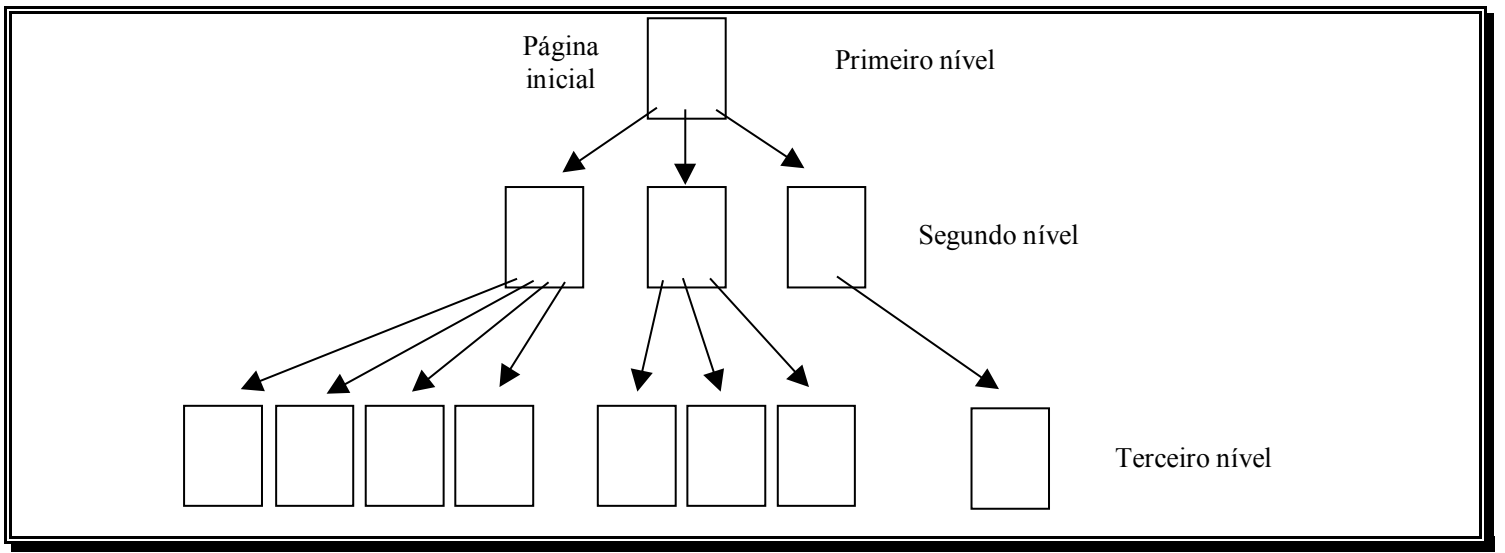

Fig. - 8.10 - Exemplo de navegação do WebWorm.

A vasta maioria das imagens utilizadas na Internet utiliza dois formatos de imagens: JPEG e GIF. Uma vez que as imagens GIF não apresentam canais de cores reais $(R G B)$ devido ao mecanismo de paleta (cores indexadas) incorporado ao formato, consideramos apenas as imagens JPEG, que em geral apresentam canais de cores reais (24bits - RGB), transferindo somente imagens com a terminação JPG para o diretório de entrada do $\Sigma$ ynergos. Sendo todas as imagens das páginas com formato JPEG consideradas, temos uma grande variedade de figuras utilizadas na Internet, tais como botões, banners, texto em formato gráfico, propaganda e outros. A tarefa de separar imagens específicas é realizada pelo इynergos, que analisa cada uma das imagens do diretório de entrada, considerando sua dimensão, complexidade, e estrutura do histograma (imagens sintéticas são caracterizadas por apresentar histogramas bem definidos), a fim de filtrar apenas as imagens desejadas, no caso do experimento, imagens fotográficas.

\subsection{3 - MÉTODOS CONSIDERADOS}

Conforme mencionamos, os dados extraídos do experimento psicofísico deverão ser correlacionados com modelos matemáticos para analisar e medir a complexidade das imagens. Nesse trabalho, escolhemos 4 métodos para obtenção de medidas de complexidade: (i) Entropia dos níveis de cinza [Gonzalez \& Woods, 1993], (ii) Tempo de decaimento multi-escala da variância da distribuição dos níveis de cinza da imagem (variância do histograma) [Bruno et al., 2000], (iii) circularidade 


\section{CAPÍTULO 8}

[Bruno et al.,2000] e (iv) dimensão fractal por salsicha de Minkowski [Tricot, 1995]. O estudo desses métodos como medidas de complexidade foi realizado através de diversos experimentos conduzidos pelo Grupo de Pesquisa em Visão Cibernética, voltados particularmente para a análise morfológica de neurônios, onde a complexidade tem sido considerada por neurocientistas como uma importante característica para classificar neurônios [Cesar \& Costa, 1998] [Costa \& Velte, 1999] [Costa, 1996] [Coelho, 1998].

O conceito entropia usualmente empregado em processamento de imagens [Gonzalez \& Woods, 1993] é baseado na distribuição de probabilidade dos níveis de cinza da imagem (histograma). Dentro deste contexto, a entropia é uma medida de desorganização ou incerteza sobre a distribuição, podendo ser empregada como uma forma de caracterização da complexidade da imagem. A natureza do método, entretanto, enfoca a complexidade sobre o ponto de vista da variação de brilho na imagem, uma vez que é analisada apenas a freqüência de cada nível de cinza e a distribuição espacial dos pontos ao longo da imagem não influencia o cálculo da entropia.

O tempo de decaimento da variância multi-escala da distribuição dos níveis de cinza foi escolhido devido ao seu potencial de refletir a estrutura espacial da imagem. Embora, assim como a medida de entropia, a variância também seja determinada a partir da distribuição da freqüência dos níveis de cinza da imagem, a condição multi-escala engajada no tempo de decaimento faz com que seja incorporada a natureza da estrutura e complexidade espacial da medida.

Uma outra medida importante, na tentativa de quantificar a complexidade de imagens, é a circularidade, determinada pela razão do quadrado do perímetro da forma por sua área. Deste modo, estima-se a circunferência como a forma mais simples, e por complexas as formas que apresentam irregularidade, especialmente a concavidade. Finalmente a dimensão fractal, calculada nesse experimento pelo método da salsichas de Minkowski (ver Seção 7.7), também se caracteriza como uma forma clássica para a quantificação da complexidade.

\subsection{4 - O EXPERIMENTO VIA WEB}

O experimento foi disponibilizado na Internet de modo que qualquer pessoa do planeta possa realizá-lo. A primeira página do experimento do Eynergos contém as instruções básicas para a sua operação e um formulário solicitando os dados do 
usuário (nome, e-mail, profissão e grau de instrução), assim como um botão prosseguir. Assim que o usuário pressiona o botão o experimento é inicializado, conforme vamos narrar. Cada imagem do experimento é apresentada na porção central da janela por um período fixo de tempo. Após o seu desaparecimento é exibida uma janela solicitando ao usuário uma nota de 0 a 10 (através de uma interface "combo box") para indicar o seu grau de complexidade (nenhuma informação sobre o conceito de complexidade é dada). Uma vez que todas as imagens tenham sido apresentadas e avaliadas pelo indivíduo, a página do experimento, que foi implementada em HTML e JavaScript, envia o resultado para um cgi-bin (Commom gateway interface) especial armazenado no servidor (experimento), que disponibiliza os dados do experimento para o $\Sigma$ ynergos. No mesmo instante, os dados do indivíduo, sua avaliação e a média de sua avaliação em relação aos outros experimentos é apresentada.

\subsection{5 - AlgoritMo GenÉtico PARALELO - ANÁlise E MODELAGEM DOS DADOS EXPERIMENTAIS}

Os dados coletados dos experimentos psicofísicos podem ser processados a qualquer momento pelo $\Sigma$ ynergos, a fim de se obter um modelo matemáticocomputacional da percepção humana da complexidade de imagens. Os resultados apresentados a seguir foram obtidos a partir do experimento psicofísico realizado por nove pessoas através da Internet. Para obter os coeficientes da combinação linear e logarítmica das características de complexidade extraídas das imagens (Subseção 8.3.3) correlacionadas à percepção humana, foi utilizada uma versão distribuída do algoritmo genético [Goldberg, 1989] [Bruno et al., 2000], o qual comentaremos a seguir.

A computação evolucionária, da qual se destaca o algoritmo genético, tem se tornado uma interessante alternativa para a otimização de problemas combinatórios e complexos. Os algoritmos genéticos codificam as soluções potenciais de um problema específico em uma estrutura de dados inspirada em cromossomos. A partir de regras de evolução genética inspiradas na natureza, tais como reprodução, mutação, crossover, adaptação e outras, é definido o melhor conjunto de parâmetros (indivíduos) que mais se adaptam (mais otimizados) a um determinado problema. Do ponto de vista computacional, o algoritmo genético é uma técnica custosa que, entretanto, apresenta um bom potencial de 


\section{CAPÍTULO 8}

implementação paralela. Sua inspiração se encontra na própria natureza, onde além dos indivíduos coexistirem em paralelo, ocorre o mesmo com diversos ambientes e nichos.

A versão paralela do algoritmo genético foi implementada através de CVMP para plataforma distribuída. Devido à natureza do problema, foi adotada a estratégia de paralelismo processor farm. Conforme vimos no Capítulo 6, a estratégia processor farm, é amplamente utilizada em diversas situações e o CVMP possui um conjunto de ferramentas específicas para essa arquitetura, provendo sua programação de forma visual, simplificando bastante a sua implementação.

Nesta concepção, o sistema é constituído de dois conjuntos de processos: Mestre e Escravo. O processo mestre, é responsável por coletar e redistribuir as populações durante a execução, além de gerar as populações iniciais e supervisionar os processos escravos. Já os processos escravos são responsáveis pelo processamento da evolução das populações. Na abordagem adotada, o mestre gera uma população através de parâmetros aleatórios, e a distribui para os processos escravos. No final de um determinado número pré-fixado de gerações (especificados por um parâmetro de controle), são selecionados os indivíduos mais adaptados, resultantes do processamento evolutivo de cada escravo e enviados para o mestre, que promove uma nova população baseada nesses indivíduos e redistribui para os escravos. Esse ciclo se mantém até que a convergência préestipulada seja atingida. A Figura 8.11 apresenta um diagrama ilustrativo sobre a estratégia básica de funcionamento do algoritmo genético paralelo utilizado. Nela temos o processo mestre e o conjunto de processos escravos. As tarefas que o mestre atribui aos escravos disponíveis são populações a serem evoluídas por um determinado número de gerações, o escravo retorna ao mestre um determinado número de indivíduos melhor adaptados. 


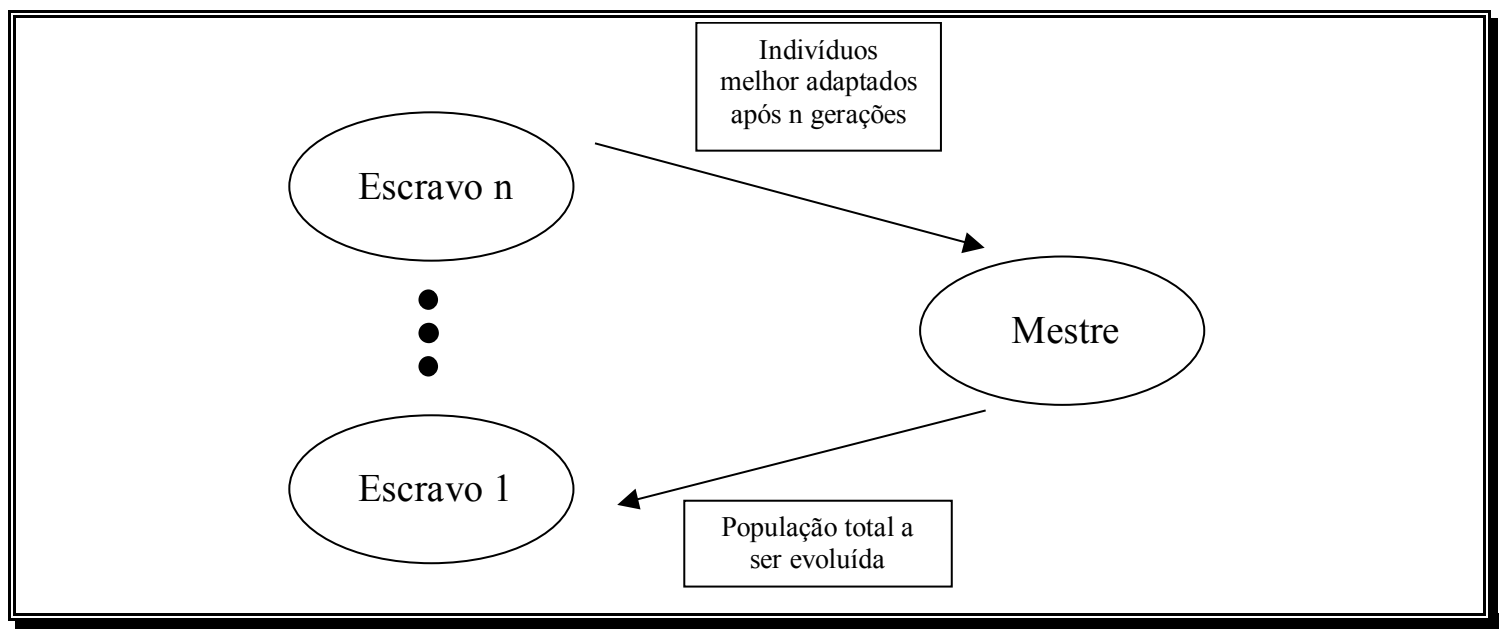

Fig. - 8.11 - Diagrama ilustrativo da estratégia de paralelismo do algoritmo genético distribuído com arquitetura CVMP processor farm.

$\mathrm{Na}$ implementação do algoritmo genético foi gerada uma população inicial de 200 indivíduos, criados de forma aleatória e ordenados em ordem crescente mediante à sua adaptação (fitness), dada pela distância euclidiana entre os parâmetros de complexidade definida pelos métodos matemáticos e o valor da função determinada pela análise humana. A cada geração, os 100 indivíduos com as melhores taxas de adaptação são submetidos ao cross-over e a mutação, a fim de produzir outros 100 indivíduos e compor a população total. Os 20 indivíduos com a menor adaptação, são também mantidos para garantir a diversidade. Maiores detalhes sobre o algoritmo utilizado no experimento podem ser obtidas em [Bruno et al., 2000].

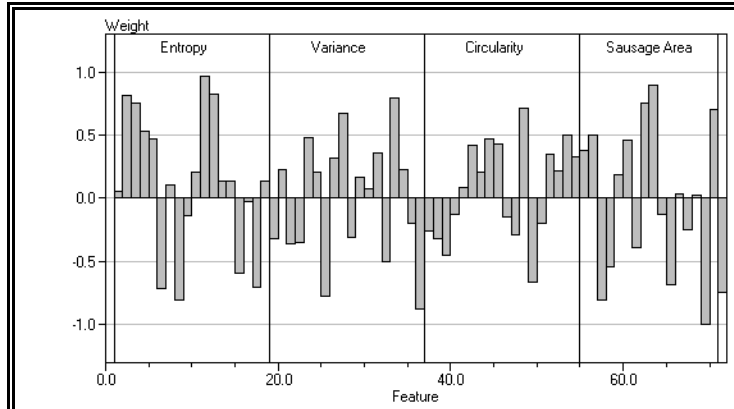

(a)

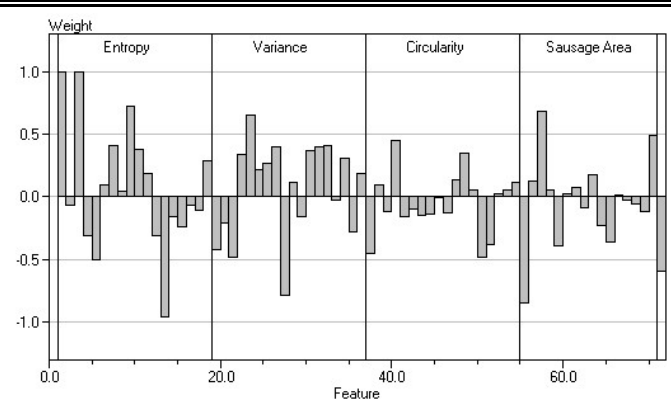

(b)

Fig. - 8.12 - Resultados da correlação do algoritmo genético para os modelos de complexidade utilizados. Referente a combinação linear (a) e logarítmica (b). 
A Figura 8.12 apresenta os resultados do algoritmo genético mostrando o melhor ajuste das características dos modelos matemáticos utilizados em função da análise humana, onde a Figura 8.12a corresponde ao ajuste para o modelo de combinação linear (Equação 8.5) e a Figura 8.12b ao modelo logaritmo (Equação 8.6). A taxa de adaptação foi normalizada no intervalo [-1;1]. Somente os coeficientes maiores do que 0,5 foram considerados no algoritmo genético de modo a reduzir o número de características do modelo final [Bruno et al., 2000].

Uma vez definido os coeficientes válidos (maiores que 0,5 ou menores que $0,5)$, podemos analisar a otimização realizada pelo algoritmo genético e chegar ao modelo de características através da Figura 8.12. Dos 71 coeficientes extraídos originalmente (18 entropia, 18 tempo de decaimento, 18 circularidade e 17 Minkowski), os modelos finais reduziram esse número para 22 (Figura 8.12a) e 8 (Figura 8.12b), respectivamente para a combinação linear e logarítmica, o que indica que o modelo logarítmico demonstrou ser mais efetivo. Das 8 características resultantes do modelo, 4 são de entropia (3 positivas e uma negativa), 2 são de tempo de decaimento da variância (uma positiva e uma negativa) e 2 de Minkowski (uma positiva e uma negativa). Curiosamente, nenhum coeficiente de circularidade foi definido no modelo logarítmico, o que pode indicar uma predominância de textura maior que a forma na percepção de complexidade humana. O modelo obtido pode ser utilizado em análises de imagens e aplicações em visão computacional, onde são necessários obter medidas de complexidade aproximadas à percepção humana.

\subsection{6 - EFICIÊNCIA DA IMPLEMENTAÇÃO PARALELA}

Do ponto de vista do paralelismo e do CVMP, a implementação paralela do algoritmo genético possibilitou a comprovação da eficácia e dos benefícios da utilização do CVMP processor farm. Basicamente, encontramos cinco pontos que consolidaram a utilização do CVMP processor farm, demonstrados através da implementação do algoritmo genético paralelo: (i) simplicidade de utilização, (ii) estratégias de paralelismo prontas para uso, (iii) utilização genérica, (iv) balanceamento de carga automático e (v) alta performance.

A Figura 8.13 apresenta três gráficos contendo o tempo de execução do algoritmo genético paralelo. Nos gráficos, cada um dos blocos representam as tarefas realizadas pelos processos escravos, que consistem em executar um 
determinado número de gerações (8.13a e 8.13c - 20 gerações ; 8.13b - 50 gerações). Em todos os exemplos, o sistema distribuído foi constituído de máquinas heterogêneas, com diferentes performances, o que coloca a prova seu balanceamento de carga. Nos gráficos (a) e (b) foram utilizadas quatro máquinas conectadas com rede ethernet $10 \mathrm{Mb} / \mathrm{s}$. Em cada uma das máquinas foi executado um processo escravo, e na máquina mais veloz foi também incorporado o processo mestre, executado em concorrência através de multitarefa. No gráfico (c) foram utilizadas três máquinas conectadas através de fast ethernet $100 \mathrm{Mb} / \mathrm{s}$. O tempo despendido com a troca de mensagens entre os processos é muito pequeno, comparado com o tempo de processamento de cada uma das tarefas, de modo que, a diferença de velocidade entre os sistemas de rede é praticamente desconsiderada.

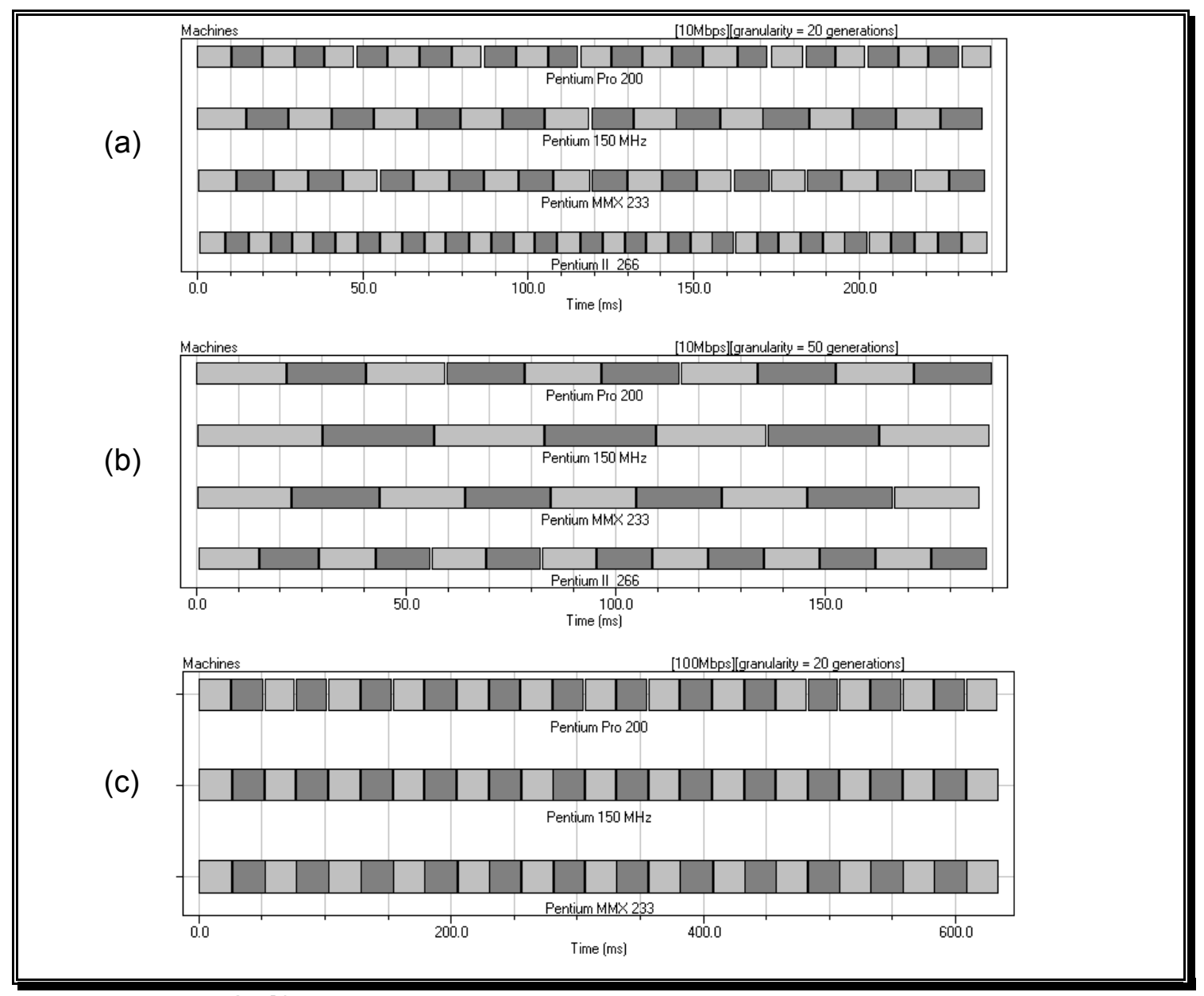

Fig. - 8.13 - Gráficos apresentando o tempo de execução da implementação paralela do algoritmo genético. 
A eficiência do balanceamento de cargas do sistema pode ser observada pela ausência de bolhas, demonstrando uma ótima utilização do hardware (eficiência), acarretando diretamente em boa performance. Embora a determinação precisa da performance do sistema seja dificultada devido à natureza aleatória, tanto na configuração inicial quanto na execução do algoritmo genético, ela pode ser estipulada de forma aproximada pela qualidade do balanceamento de cargas e pela baixa demanda computacional requerida pelas trocas de mensagens. Deste modo, se as máquinas utilizadas no sistema forem homogêneas, a taxa de desempenho vai estar muito próxima ao número de máquinas utilizadas.

\subsection{7 - GERAÇÃO AUTOMÁtICA DE RELATÓRIOS NA WEB}

Usualmente os experimentos conduzidos no $\Sigma$ ynergos produzem um grande conjunto de gráficos, dados numéricos e texto [Bruno et al., 1998] [Bruno et al., 2000]. Uma das funções do módulo Internet do इynergos é a produção de relatórios automáticos dos resultados obtidos nos experimentos, de modo a auxiliar a organização, a apresentação e visualização dos dados. Os resultados são gerados em HTML, possibilitando sua utilização em um grande número de aplicativos, assim como sua publicação direta na Internet.

\section{4 - TREEVIS - UM SISTEMA PARALELO DE VISÃO PARA ANÁLISE E RECONHECIMENTO ARBÓREO}

O levantamento de espécies arbóreas em florestas, além de ser um dos alicerces para o estudo e pesquisa científica em diversas áreas da ciência associadas à botânica, apresenta ainda importância vital para a manutenção e preservação ecológica, assim como para a economia florestal (cultivo, explorativismo, matéria prima para remédios, etc.). Sua importância se acentua nas florestas tropicais e equatoriais, que se caracterizam pela grande divergência de famílias e espécies de árvores, muitas das quais ainda não foram exploradas e se mantém objetos de pesquisa científica.

Nesta seção será introduzida a proposta TreeVis, através da qual é proposto um sistema para o reconhecimento automático de espécies arbóreas baseado na 
análise sistemática de suas folhas. Além de prover o reconhecimento automático, o TreeVis, conta com um banco de dados, que armazena o modelo matemático do espécime e também sua descrição fotográfica, oferecendo uma alternativa aos herbários tradicionais. Também será descrito o primeiro protótipo do sistema TreeVis, implementado neste trabalho, o qual conta com uma arquitetura paralela para melhorar a performance do reconhecimento automático. A seção será finalizada com alguns dados experimentais de reconhecimento arbóreo de algumas espécies vegetais brasileiras (mata atlântica e cerrado) realizadas a partir do protótipo TreeVis.

\subsection{1 - LEVANTAMENTO ARBÓREO E OS HERBÁREOS}

A exploração desenfreada dos recursos naturais, a destruição dos habitats e a extinção de inúmeras espécies animais e vegetais, vem acontecendo nos últimos séculos sem a preocupação real da humanidade. Neste final de século entretanto, uma vez que estamos próximos de um ponto crítico, esses temas vem atraindo a atenção de diversos segmentos da sociedade, não sendo mais apenas um mero debate científico a respeito de um futuro distante. Toda essa atenção ao desgaste incontrolável da biosfera e a perda dos recursos genéticos nela presente, nos mostra que um dos grandes desafios de nosso tempo converge para o estudo e a compreensão da biodiversidade, para que além de conhecermos, possamos ainda resgatar, preservar e manejar alguns desses recursos, garantindo sua continuidade para o deleite das gerações futuras.

As florestas tropicais e equatoriais são as regiões que apresentam a maior e mais exuberante diversidade biológica do planeta. Coincidentemente estão presentes em países emergentes, sem planos consistentes de preservação ecológica ou de levantamento sistemático da vegetação, distribuídos na América Latina, África e sudeste asiático. Dentre esses países podemos destacar o Brasil, que possui a flora arbórea mais diversificada do mundo, cuja falta de direcionamento técnico e conscientização ecológica na exploração dos recursos florestais vem acarretando danos irreparáveis, onde muitas espécies ainda desconhecidas ou pouco estudadas correm sério risco de desaparecer.

As bases para o estudo da biodiversidade, sobretudo no reino vegetal, consistem na taxonomia e no inventário. A taxonomia vegetal é uma ciência que encontra um ponto fundamental em botânica, sendo responsável pela síntese, 


\section{CAPÍTULO 8}

organização, classificação, identificação e nomenclatura das plantas. É baseada fundamentalmente na Morfologia e na Anatomia, e recebe informações adicionais, enriquecendo seus processos de classificação, obtidas através do desenvolvimento de pesquisas em outras áreas, entre elas podemos destacar a Citologia, Fisiologia, Ecologia, Fitogeografia, Paleobotânica, Fitoquímica e a Genética. [Joly, 1993] [Stace, 1984] [Stuessy, 1990] [Lorenzi, 1992].

Simultaneamente à classificação, surge a necessidade de realizar o inventário das espécies, através do qual é possível efetuar o reconhecimento de espécies catalogadas. O inventário botânico é realizado essencialmente através dos herbários. Os herbários se caracterizam por uma coleção científica de exemplares de ramos férteis (galhos com folhas, podendo possuir flores ou frutos característicos), coletados na natureza, prensados, dessecados e montados sobre papel cartão. Associados a cada exemplar existe uma ficha padronizada, contendo todas as informações sobre o espécime, com o rigor da taxonomia. Nos herbários podem ser armazenados grande quantidade de espécimes, que deverão ser alojadas em locais adequados à sua preservação, permitindo sua conservação por longo período de tempo (da ordem de séculos). Os exemplares devem ser arranjados segundo o critério botânico, a fim de auxiliar a localização e estudos [Peixoto \& Barbosa, 1998].

Deste modo, os herbários constituem a mais importante ferramenta de trabalho do botânico, através dos quais podem ser examinados e estudados, espécimes procedentes de diferentes locais e ecossistemas. Através de seu auxílio, o botânico pode comparar um exemplar na natureza com centenas de espécimes classificadas por especialistas e deste modo realizar sua identificação. Através da pesquisa de campo e da utilização de ferramentas como o herbário, é realizado o levantamento arbóreo de uma região, que consiste na especificação e na identificação das espécimes de árvores ali encontradas. O levantamento arbóreo é de importância vital para o estudo dos habitats e ecossistemas, assim como para a eventual descoberta de novas espécimes, auxiliando o desenvolvimento da pesquisa científica.

\subsubsection{1 - COLETA E TRATAMENTO DAS AMOSTRAS}

O levantamento arbóreo é uma árdua tarefa, na qual todas as fases devem ser realizadas através de trabalho manual. A primeira etapa do processo consiste na pesquisa de campo. Nessa fase é realizada a coleta dos exemplares que serão 
identificados. Como exemplares, são coletados ramos férteis, ou seja, galhos com folhas e, caso estejam presentes flores e frutos. Coletado o material, esse deve ser preparado para que se conserve até a próxima etapa da pesquisa, que consiste na comparação e identificação desses espécimes com o material do herbário, uma vez que essas etapas são separadas por dias e as vezes até mesmo por meses [Fernandes, 1997] [Lorenzi, 1992].

O material coletado, recebe um tratamento similar aquele executado para a formação do herbário, ou seja, os ramos são prensados e dessecados. Além da conservação, o tratamento também pode auxiliar na identificação do material, uma vez que este terá aspecto semelhante aos espécimes do herbário [Peixoto \& Barbosa, 1998].

\subsubsection{2 - CLASSIFICAÇÃO ATRAVÉS DE HERBÁRIOS}

De posse do material coletado em campo, é realizada a identificação através do herbário. Nessa fase também o trabalho é exercido de forma manual. Caso o botânico tenha alguma pista a respeito da família ou da espécie do exemplar, a pesquisa é direcionada e a comparação é realizada com as pranchas previamente escolhidas para este fim. No entanto em muitas situações, especialmente se o botânico não for um profundo conhecedor de determinada espécie ou região, a busca deverá ser realizada através de comparações com um universo muito maior de pranchas.

A comparação consiste em colocar o material coletado ao lado da prancha do herbário e realizar a identificação visual das semelhanças e diferenças entre ambas. Uma vez localizada a prancha que apresenta a maior semelhança com o espécime coletado, é realizada a identificação. Esse processo, além de trabalhoso e demorado, requer um vasto treinamento ao botânico, de forma a minimizar os erros decorrentes de falsas identificações.

\subsection{2 - OS HERBÁRIOS BRASILEIROS}

Os herbários são repositórios de material científico, contendo a documentação florística de um país. Suas informações constituem a fonte primária para a botânica, através das quais podem ser realizados trabalhos taxônomicos, evolutivos, ecológicos, biogeográficos, etnobotânicos e estudos de biodiversidade, sendo ainda uma importante ferramenta e fonte de dados para o planejamento do 


\section{CAPÍTULO 8}

desenvolvimento sustentável [Peixoto \& Barbosa, 1998].

Os países desenvolvidos possuem herbários praticamente completos, através dos quais são preparadas listas de espécies ameaçadas de extinção, de valor medicinal, ornamental, produtoras de frutos comestíveis e muitas outras. Entretanto, eles não contam com uma rica flora tropical e uma exuberante biodiversidade, como é a situação de alguns países em desenvolvimento, em especial o Brasil, que não tem feito o mesmo devido à falta de recursos, informações e pela complexidade da tarefa.

Inúmeros estudos realizados sobre espécies brasileiras promissoras certificam o valor da flora nativa, sobre diferentes aspectos, e trazem à tona o quanto custa o desconhecimento do conjunto dessas espécies para a sociedade moderna. A falta de informações sobre as espécies nativas se dá, predominantemente, à diversidade e riqueza da flora, ao pequeno número de botânicos especializados que possam estudá-las e ao longo e trabalhoso processo de levantamento florístico. Esta situação torna-se mais crítica diante da rapidez com que está desaparecendo a vegetação natural e do longo período de treinamento exigido para formar um especialista em taxonomia.

\begin{tabular}{|c|c|c|}
\hline Estado & $\mathrm{N}^{\circ}$ de Herbários & Exemplares \\
\hline RJ & 11 & 912.632 \\
\hline SP & 16 & 750.765 \\
\hline RS & 15 & 437.230 \\
\hline PR & 8 & 349.537 \\
\hline PA & 3 & 326.778 \\
\hline DF & 4 & 281.474 \\
\hline MG & 11 & 228.143 \\
\hline BA & 7 & 210.027 \\
\hline AM & 3 & 206.092 \\
\hline PE & 6 & 184.338 \\
\hline SC & 4 & 111.200 \\
\hline PB & 2 & 31.500 \\
\hline CE & 4 & 23.612 \\
\hline GO & 1 & 22.001 \\
\hline ES & 3 & 21.800 \\
\hline MS & 4 & 18.548 \\
\hline AL & 2 & 16.232 \\
\hline MT & 1 & 14.014 \\
\hline PI & 1 & 9.930 \\
\hline AP & 1 & 8.000 \\
\hline AC & 2 & 7.822 \\
\hline SE & 1 & 6.930 \\
\hline RN & 2 & 5.257 \\
\hline MA & 1 & 2.777 \\
\hline
\end{tabular}

Tabela 8.1 - Herbários brasileiros e números de exemplares [Peixoto \&

Barbosa, 1998]. 
O Brasil conta com 113 herbários ativos, que guardam um acervo de 4.187.154 espécimes vegetais, segundo a Sociedade Brasileira de Botânica (SBB) (1997) [Peixoto \& Barbosa, 1998]. Embora em uma primeira instância esse número possa parecer significativo, ele reflete uma pequena fração da biodiversividade florística brasileira (sem considerar que muitas espécies se repetem em diferentes herbários). A Tabela 8.1 apresenta uma listagem contendo o número de herbários e as espécies catalogadas em cada estado brasileiro, e a Tabela 8.2 apresenta a lista dos herbários que mais detêm informações.

\begin{tabular}{|c|c|c|c|}
\hline Estado & Sigla & Instituição & Exemplares \\
\hline RJ & R & Museu Nacional do Rio de Janeiro & 375.000 \\
\hline RJ & RB & Jardim Botânico do Rio de Janeiro & 344.812 \\
\hline SP & SP & Instituto de Botânica de São Paulo & 317.000 \\
\hline PR & MBM & Museu Botânico Municipal de Curitiba & 255.000 \\
\hline DF & UB & Universidade de Brasília & 208.000 \\
\hline AM & INPA & Instituto de Pesquisas da Amazônia & 200.000 \\
\hline PA & IAN & EMBRAPA, Amazônia Oriental & 164.000 \\
\hline PA & MG & Museu Paraense Emílio Goeldi & 159.778 \\
\hline SP & SPF & Universidade de São Paulo & 142.827 \\
\hline RS & RS & Instituto Anchietano de Pesquisas & 120.000 \\
\hline RS & ICN & Universidade Federal do Rio Grande do Sul & 118.000 \\
\hline RS & HAS & Fundação Zoobotânica do Rio Grande do Sul & 108.300 \\
\hline
\end{tabular}

Tabela 8.2 - Os doze herbários brasileiros que mais detêm informações

[Peixoto \& Barbosa, 1998].

\subsection{3 - A PROPOSTA TREEVIS}

Levando em conta a importância do levantamento arbóreo e suas dificuldades, fomos motivados a idealizar um sistema cujo intuito é propiciar ao botânico taxonomista mais um recurso para auxiliar seu trabalho na identificação dos espécimes. Além da busca em herbários tradicionais ser uma tarefa bastante exaustiva, podemos citar alguns fatores que restringem sua utilização tais como: (i) Pequeno número de herbários, que em geral estão localizados em locais distantes do pesquisador, (ii) Dificuldade de replicação da base científica de modo a democratizar seu acesso, uma vez que os herbários são constituídos de exemplares retirados da natureza, (iii) Perda de informações essenciais durante o tratamento dos exemplares (cor e detalhes da textura) e (iv) longo treinamento na formação de especialistas realmente capazes de realizar a identificação.

Esta proposta não visa a substituição dos herbários tradicionais, mas sim 


\section{CAPÍTULO 8}

adicionar mais um complemento ao conjunto de metodologias de identificação vegetal, permitindo acelerar o trabalho de reconhecimento (reconhecimento automático) e facilitar o acesso à informações, uma vez que os sistemas digitais são facilmente replicáveis, podendo ser distribuídos para diversas universidades, laboratórios e institutos de pesquisa.

Dentro desta motivação surgiu a proposta do sistema TreeVis, cujo nome é derivado do inglês "Tree Vision System". Trata-se de um sistema capaz de armazenar, classificar e organizar dados científicos e realizar a identificação automática de espécies, funcionando como um herbário digital. Diferente dos herbários tradicionais, onde são colecionados ramos férteis, o TreeVis concentra nas folhas todo o sistema de informações e identificação dos exemplares.

O processo de reconhecimento através das folhas é uma tarefa complicada e audaciosa, concretizando um verdadeiro desafio para um sistema de reconhecimento. Isso acontece devido à natureza dos vegetais. Embora conservem algumas características fundamentais, as folhas apresentam uma grande variação. Essas variações ocorrem dentro de um único indivíduo, onde a maturidade ou mesmo a formação das folhas, faz com que essas tenham grandes variações quanto ao tamanho, coloração, textura, formato, etc., e também entre indivíduos diferentes (da mesma espécie). Indivíduos diferentes de uma mesma espécie localizados nas mesmas regiões podem apresentar diferenças nas suas folhas (como influência do solo) e, para dificultar ainda mais o processo, indivíduos de uma mesma espécie localizados em diferentes regiões ou ecossistemas, podem ainda conter folhas diferentes, refletindo o resultado de refinamento genético ou até mesmo mutações.

Para vencer os desafios impostos pela complexa tarefa do reconhecimento de folhas, a proposta TreeVis está baseada em fundamentos que apresentam grande potencial para a solução do problema: (i) exploração sistemática das características das folhas através de um vasto número de atributos visuais, (ii) sinergismo, (iii) análise estatística e (iv) metodologia de utilização.

A exploração do maior número possível de informações (características) (i), fornece um contexto maior para a identificação. Devido ao grande universo de espécies e as grandes variações dentro de uma mesma classe, surge a necessidade de extrair grandes quantidades de informações, a fim de se conseguir dados suficientes para realizar uma classificação estatística. Esta abordagem, além de possuir motivação biológica, é também abordada em diversos sistemas 
artificiais. O sistema de visão dos primatas por exemplo, associa diversos atributos, e através de sua combinação extrai uma incrível quantidade de características para realizar o reconhecimento. Encontramos também alguns sistemas de visão artificial com amplas bases de conhecimento que adotam essa estratégia para efetivar o reconhecimento de objetos, entre eles podemos citar a proposta Cyvis-1, bastante discutida nesta tese e o Seemore [Mel, 1997], sistema capaz de reconhecer um grande número de objetos bidimensionais, tridimensionais e flexíveis (cabo de telefone, tecido, etc.), fundamentalmente baseado na extração de um grande e variado número de características de diferentes atributos (cor, forma, textura, complexidade, etc.). Estreitamente ligado a essa estratégia encontramos o item (ii), onde podemos considerar que a combinação das características resulta em um sinergismo de atributos, onde a associação destas é muito mais rica do que a soma individual de cada parte.

A análise estatística (iii) é um dos pontos fundamentais da proposta. Em primeiro lugar, através dela é realizada a classificação e consequentemente o reconhecimento. Em segundo lugar, é a abordagem estatística que ditará a metodologia de comparação e identificação. Por exemplo, através do bom senso estatístico, o sistema não processa o reconhecimento baseado em uma única folha (tanto no aprendizado quanto na busca), ao contrário disso são processadas diversas folhas (cerca de 10) de um mesmo espécime a fim de compensar suas grandes variações, convergindo para uma média.

Finalmente é na metodologia de utilização (iv) ou seja nos procedimentos técnicos realizados pelo botânico que se encontra um outro ponto fundamental do sistema. A ele competirá a normalização da coleta de folhas, ou seja, as folhas deverão pertencer a uma média, não podendo ser coletados exemplares que contradigam a média do vegetal, tanto no tamanho, coloração ou forma. O botânico ainda deverá levar em conta questões como doenças ou outros aspectos que possam alterar as características das folhas do vegetal, e também se preocupar com a questão da maturidade, colhendo folhas sempre com maturidade média.

\subsection{4 - PROTÓTIPO TREEVIS}

Neste trabalho implementamos o primeiro protótipo do sistema TreeVis, no qual todos os métodos e técnicas utilizadas para a extração de características das amostras foram ajustados e configurados especificamente para a caracterização de 


\section{CAPÍTULO 8}

plantas arbóreas. O sistema foi implementado em Delphi para a plataforma Windows. Devido à grande quantidade de características extraídas das imagens, assim como pela resolução das imagens, o sistema consome considerável recurso computacional. Deste modo, ele foi implementado com recursos de paralelismo, através da utilização de CVMP, onde foi adotada a arquitetura de computação distribuída.

A fim de avaliar, foram realizados experimentos com 59 espécies reais, das quais a maior parte é constituída de espécies de plantas arbóreas nativas da Mata Atlântica (reconhecida como a floresta mais ameaçada do planeta). Embora o resultado obtido tenha sido satisfatório, muito ainda deve ser feito para obter uma versão operacional, ou seja, que permita a utilização do TreeVis como uma ferramenta de trabalho para os botânicos.

Nas próximas subseções iremos descrever o protótipo, abordar sua implementação paralela e apresentar alguns resultados obtidos.

\subsection{5 - DESCRIÇÃO DO SISTEMA TREEVIS}

O sistema TreeVis, conforme apresentado no diagrama em blocos da Figura 8.14, é composto por seis módulos: Extração de características, Controle central, Treinamento e identificação, Análise estatística, Base de dados e Estrutura de amostragem.

As informações são adquiridas pelo sistema através de um dispositivo de digitalização de imagens. Neste sistema foi adotado um "Scanner de mesa" comercial, que permite digitalizar imagens com até 9600 DPI (pontos por polegada "dot per inch"). Uma vez que as folhas possuem diferentes informações em cada um dos lados, o sistema necessita que sejam adquiridas as imagens referentes aos dois lados da folha, que podem ser a grosso modo definidos, como lado de sol (exposto a luz solar direta) e lado de sombra (lado oposto). Deste modo cada amostra é representada através de um par de imagens. Além dessas informações, o sistema utiliza também uma imagem, adquirida através da ampliação de uma determinada região da folha, para a análise da textura de sua organização celular. Discutiremos sobre ela na Subseção 8.4.5.1.1. As imagens dos dois lados da folha, mais a imagem para análise de textura, constituem os dados de entrada do sistema, denominados de amostras. É denominada de Estrutura de amostragem, a amostra ou o conjunto de amostras a ser analisado. 


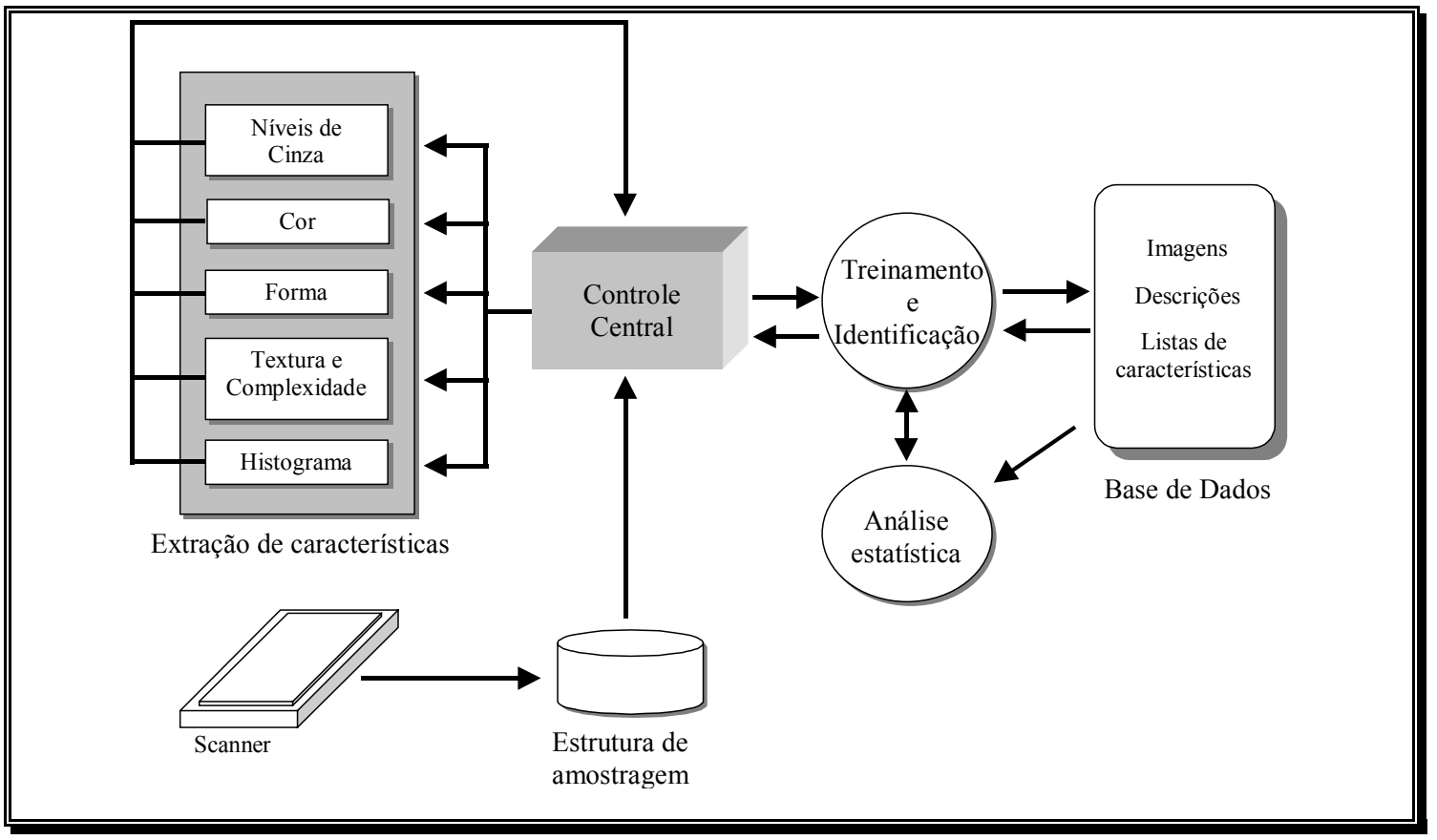

Fig. - 8.14 - Diagrama em blocos apresentando os módulos que compõe o sistema TreeVis, e suas respectivas conexões.

Nesta descrição não abordaremos da implementação paralela do sistema, a qual será discutida na Subseção 8.4.6, limitaremos por enquanto ao sistema na sua forma seqüencial. A partir da estrutura de amostras, pode ser solicitada uma análise, e deste modo o sistema inicia sua execução. O módulo Controle central envia as imagens que constituem cada uma das amostras da estrutura de amostragem para o módulo Extração de características. Este módulo é dividido em vários submódulos, cada um contendo uma família de métodos e técnicas de visão e processamento de imagens, responsáveis pela extração do conjunto de características da imagem (vetor de características).

O sistema possibilita duas modalidades de identificação: Estática e dinâmica. $\mathrm{Na}$ identificação estática, o módulo Controle central aguarda até que todas as características sejam extraídas, e então as envia para o módulo Treinamento e Identificação, que através de busca e comparação com a base de dados realiza a identificação da amostra.

A identificação dinâmica possibilita o reconhecimento da amostra em um tempo menor, aumentando a performance do sistema. Para essa modalidade o sistema tenta fazer o reconhecimento da amostra à medida em que é realizado o processamento e a extração das características. Uma vez que os métodos e as 


\section{CAPÍTULO 8}

técnicas de processamento de imagens e extração de características possuem tempo de processamento diferentes, à medida que os mais velozes (ex: área, histograma, etc.), extraem as características da imagem, estas são enviadas para o módulo de controle. O módulo de controle por sua vez, envia as característica parciais ao módulo Treinamento e identificação, que realiza uma busca no sistema de base de dados, obtendo uma lista das prováveis espécies, contendo a classe da espécie provável e o seu correspondente vetor de características. Esta lista é enviada para o módulo Análise estatística, o qual é baseado no cálculo da matriz de covariância, que permite determinar quais características apresentam as melhores discriminações entre as espécies da lista, podendo consequentemente classificá-las enquanto parte do módulo Extração de características executa o processamento.

O sistema termina a execução quando finaliza a análise e processamento de cada uma das amostras da Estrutura de amostragem. Conforme comentamos anteriormente, a estrutura de amostragem pode conter uma ou mais amostras de uma mesma planta arbórea. A utilização de um maior número de amostras, faz com que o sistema possa se munir de recursos adicionais no processo de classificação, permitindo uma identificação mais acurada.

Como resultado da identificação é apresentada ao usuário uma lista (com cerca de 4 elementos) ordenada com as espécies mais prováveis. Selecionando o item da lista, são mostradas informações referentes à espécie, contendo as imagens de uma amostra (os dois lados da folha e a ampliação de análise de textura) e seus respectivos nomes popular, científico e família.

O processo de treinamento do sistema consiste basicamente na inserção de novos espécimes à base de dados, sendo bastante similar ao do processo de identificação estática. Deve ser armazenado um grupo de amostras referente à espécie a ser inserida. Quanto maior o número de amostras, maior a chance de se obter um bom treinamento. É então solicitado ao sistema a inserção da espécie. O usuário deve preencher a ficha de identificação contendo o nome científico e a família da planta arbórea, assim como escolher uma amostra para caracterizá-la no processo de identificação (exibir ao usuário no resultado). Deste modo, como no processo de identificação, o módulo Controle central envia as imagens do primeiro elemento da Estrutura de amostragem para o módulo de Extração de características, o qual realiza o processamento e a extração das características, resultando em um vetor. O vetor de características é então enviado para o módulo Treinamento e identificação, que aguarda uma mensagem do módulo Controle 
central, indicando que todas as amostras da Estrutura de amostragem foram processadas. Neste momento, o módulo Treinamento e identificação, realiza o cálculo da média dos vetores, e armazena-o no módulo Base de dados, juntamente com as informações sobre o espécime fornecidas pelo usuário.

Tanto no treinamento quanto na identificação, a perícia técnica do usuário é fundamental, sendo o responsável pela determinação das folhas a serem amostradas. Lembrando mais uma vez, o material coletado para a amostragem deve refletir a característica média das folhas da planta arbórea, especialmente no que se refere à cor (maturidade), forma e dimensão. A qualidade do exemplar também é outro fator importante, uma vez que folhas com pragas, ou danificadas por insetos, vão descaraterizar o modelo obtido através do sistema TreeVis.

Nas próximas subseções vamos descrever com maiores detalhes cada um dos módulos que compõe o sistema TreeVis.

\subsubsection{1 - ESTRUTURA DE AMOSTRAGEM}

O módulo Estrutura de amostragem é responsável pelo armazenamento das amostras a serem processadas. As amostras devem pertencer a uma mesma planta arbórea, ou ser provenientes de diferentes indivíduos da mesma espécie. $\mathrm{O}$ módulo funciona como uma estrutura de dados na forma de fila (FIFO - first in first out), disponibilizando as amostras para o módulo Controle central. O número de amostras necessárias para o funcionamento do sistema TreeVis é variável, podendo ir de uma única amostra até virtualmente quantas o usuário desejar utilizar. Diferentes amostras determinam uma média ao modelo das amostras, deste modo, quanto maior o número de amostras, maior a estimativa de que o modelo resultante vai estar mais próximo do modelo mais representativo da média das folhas desta espécie. Assim, a utilização de um número maior de amostras é fundamental para o bom treinamento de uma espécie.

\subsubsection{1 - Amostras}

As amostras são formadas por duas imagens principais e uma imagem adicional, que pode ou não ser utilizada no sistema. Uma vez que as folhas apresentam dois lados, com diferentes naturezas, fica bastante óbvio, que o sistema deve explorar essa característica. Portanto as imagens principais das amostras são constituídas através da aquisição de cada um dos lados da folha (lado de sol e de sombra). O lado de sol é discriminado como lado A e o de sombra 


\section{CAPÍTULO 8}

de lado $B$.

As imagens utilizadas no sistema são quadradas com lado de 512 pixels (potência de $2\left(2^{9}=512\right)$ ) para facilitar os métodos que utilizam a transformada rápida de Fourier - FFT. Esta dimensão foi escolhida por fornecer uma boa resolução. Experimentos realizados com resoluções menores, (128x128 e 256x256) não apresentaram resultados satisfatórios. Embora não tenhamos realizado testes detalhados, acreditamos que imagens maiores (ex: 1024x1024 ou 2048x2048) poderão apresentar melhores resultados, ficando como sugestão para experimentos e futuras versões do TreeVis. Cada imagem (lado A ou lado B) deve conter apenas uma folha, a qual deve estar orientada em $90^{\circ}$, ou seja em posição vertical, com a extremidade da folha localizada na parte superior da imagem. A orientação é realizada a partir da nervura principal da folha, conforme mostra a Figura 8.15.

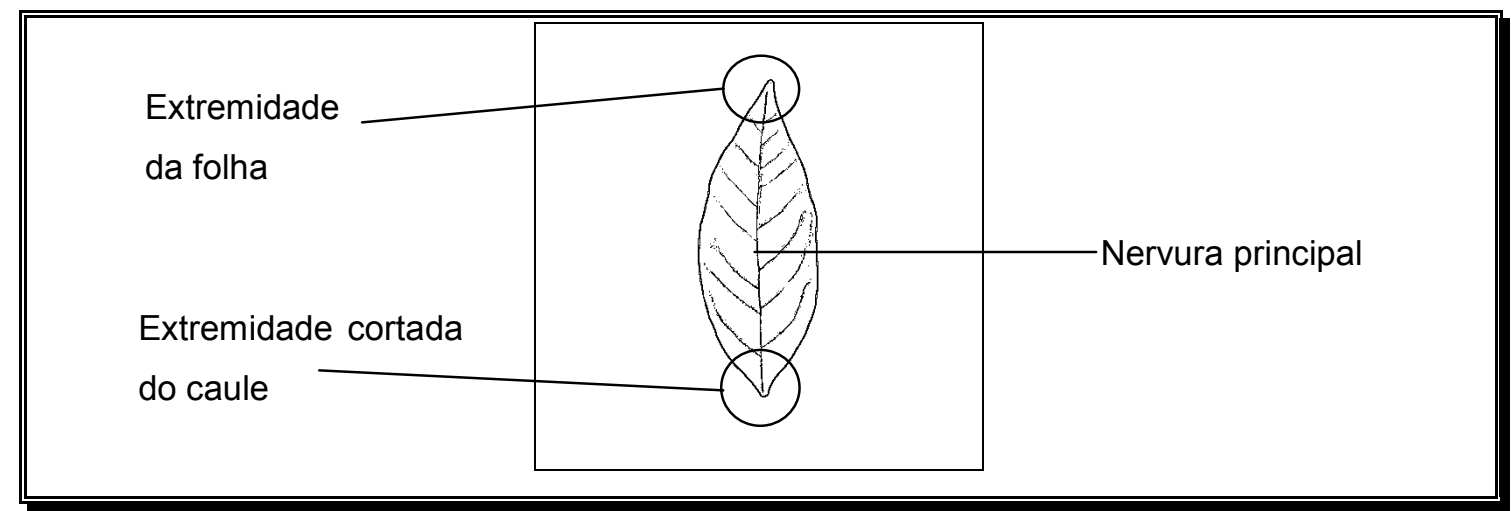

Fig. - 8.15 - Exemplo do alinhamento da imagem, na qual a nervura principal da folha deverá estar orientada na vertical.

A aquisição das imagens de ambos os lados da folha é realizada com cerca de 200 DPI (pontos por polegada - dot per inch). No entanto na grande maioria dos casos, a imagem deve ser reduzida, a fim de que toda a folha caiba na imagem (ver Figura 8.15). O fator de redução é dado em porcentagem do tamanho original da imagem, e deve ser adicionado à amostra, para que com ele o sistema possa realizar os cálculos para compensar a redução.

Além das imagens principais (os dois lados da folha), é realizada também a digitalização de uma terceira imagem, a qual denominamos imagem ampliada de textura, através da qual é realizada análise da organização (textura) celular. A Figura 8.16 mostra o procedimento de digitalização desta imagem. Com o lado de sol da folha, orientado no Scanner, é selecionada uma pequena janela quadrada de 
0,341 polegadas de lado, a qual deve ser adquirida com uma resolução de 1500 DPI, resultando em uma imagem de $512 \times 512$ pixels. A janela deve sempre ser posicionada na porção direita da folha, entre as nervuras.

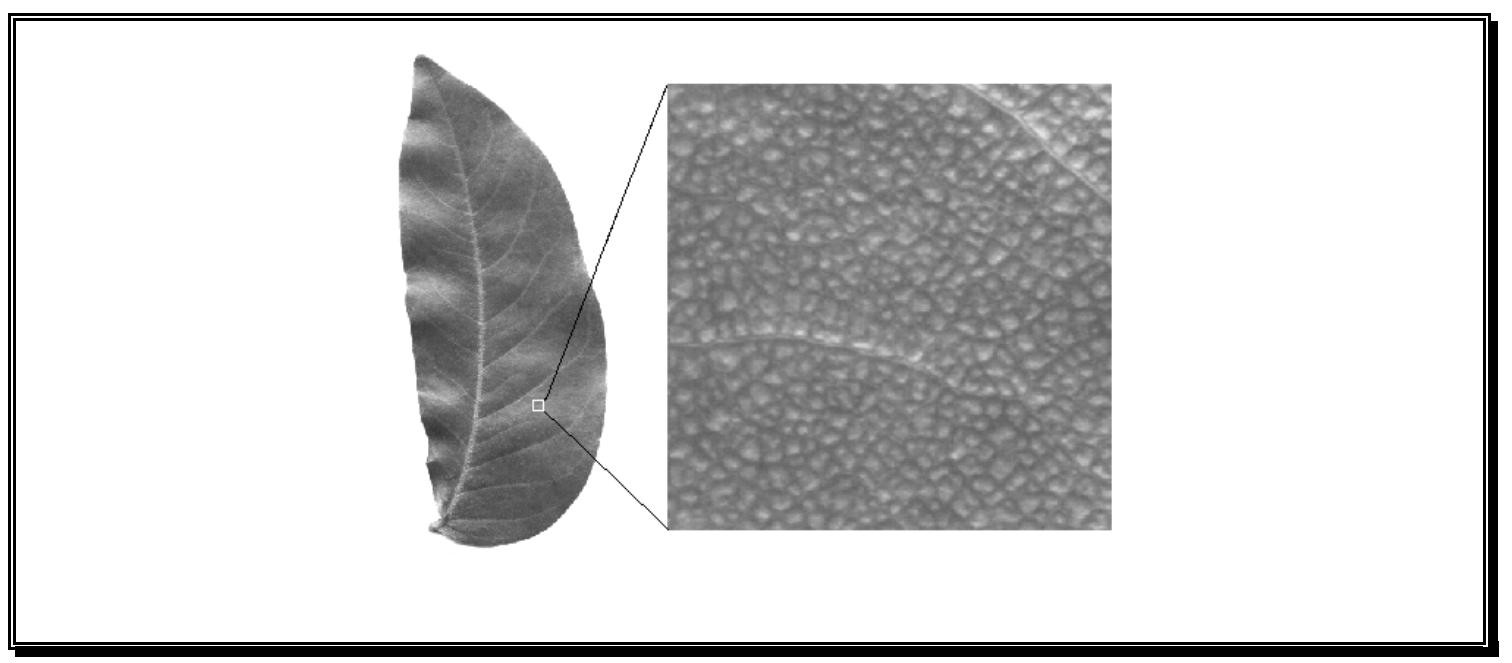

Fig. - 8.16 - Procedimento para aquisição da imagem ampliada de textura.

Neste exemplo foi utilizada a folha da Hymenea courbaril (Jatobá).

A Figura 8.17 mostra as imagens que compõe uma amostra completa, da Ormosia arborea (olho de cabra), apresentadas no ambiente gráfico do sistema TreeVis.

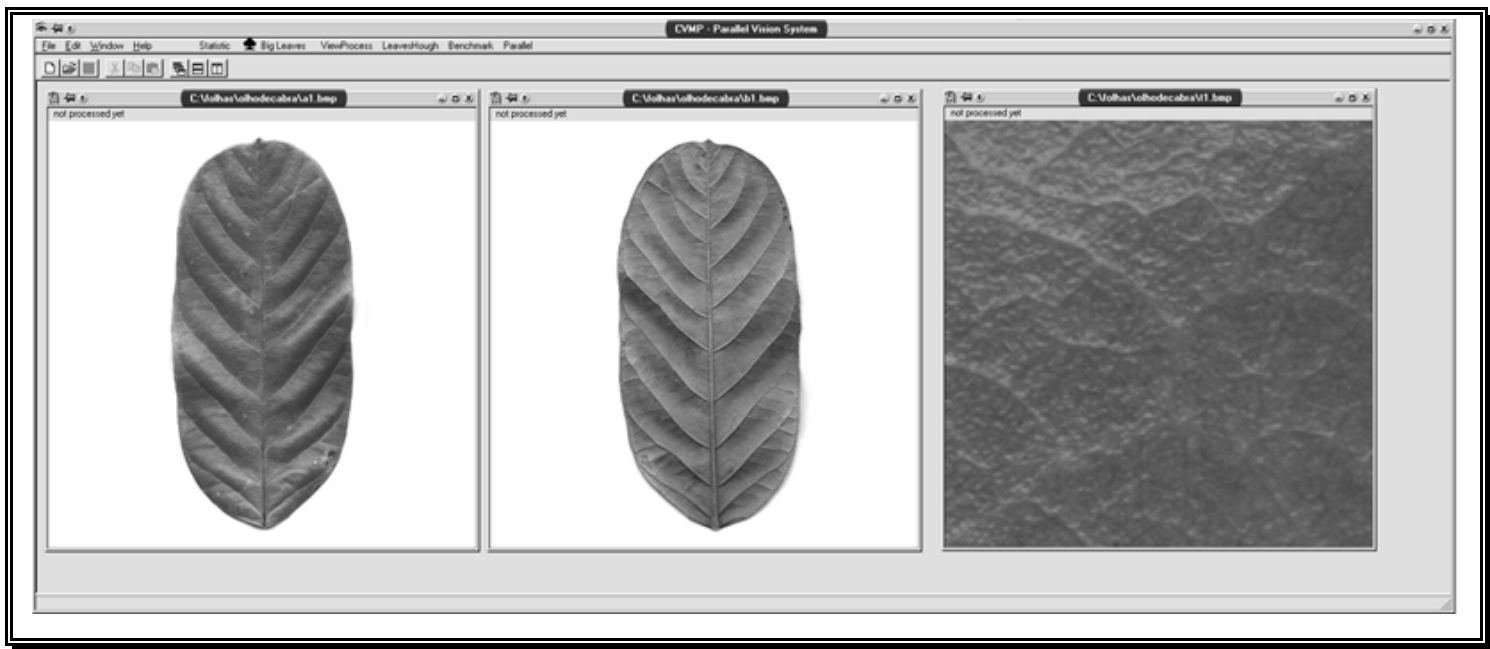

Fig. - 8.17 - Amostra completa da Ormosia arborea (olho de cabra), no ambiente gráfico do sistema TreeVis. Da esquerda para a direita: lado A (sol), lado B (sombra) e imagem ampliada de textura. 
As amostras devem passar pelo processo de digitalização, o mais breve possível após sua coleta, a fim de não perderem suas propriedades vitais (cor e textura). As folhas devem ser lavadas e mantidas em água a fim de se manterem conservadas. É recomendado que algumas horas antes do processo de digitalização as folhas sejam ligeiramente prensadas, a fim de evitar que surjam dobras quando colocadas no Scanner.

As amostras estão limitadas à folhas simples, tratando as plantas com folhas compostas ou palmadas da mesma forma, ou seja é considerado apenas um de seus elementos na constituição da amostra. As plantas com folhas compostas como o caso do Pau-Brasil ou palmadas como a Paineira, perdem importantes informações a respeito de sua composição, uma vez que o sistema considera apenas uma de suas componentes e despreza a sua estrutura. Uma sugestão para considerar essas estruturas é, nas futuras versões do sistema, incorporar essas informações, como parte integrante das amostras. Neste caso, usuário entraria com informações adicionais a respeito do espécime, indicando se a folha é simples, composta ou palmada, e no caso das palmadas, ainda poderia ser incorporado como característica de classificação o número médio de elementos que as compõem. Com base nestas informações o sistema poderia eliminar grande parte da base de dados, no processo de identificação, direcionado a pesquisa para as espécies pertencentes a estes grupos.

\subsubsection{2 - BASE DE DADOS}

No módulo Base de dados são armazenadas as informações referentes às amostras treinadas pelo TreeVis. Para cada amostra são armazenados os dados de identificação da espécie, fornecidos pelo usuário, contendo seu nome científico e vulgar, e a sua família. Uma amostra (lado A, lado B e ampliação de textura) é também armazenada, de forma a auxiliar o usuário na confirmação visual do veredicto providenciado pelo sistema. Além das informações fornecidas pelo usuário, é armazenado também o vetor das características extraídas pelo TreeVis, através do qual a espécie é modelada.

\subsubsection{3 - CONTROLE CENTRAL}

No módulo Controle central reside o coração do sistema. Nele é implementada a interface gráfica com o usuário (GUI), permitindo que o usuário 
opere o sistema, efetue a identificação e treinamento das amostras, entre com a descrição das espécies (treinamento), compare o resultado visualmente, e também realize a visualização de algumas das técnicas e métodos de processamento de imagens e visão utilizadas no TreeVis. A Figura 8.18, exibe o ambiente gráfico com o usuário do sistema TreeVis, exemplificando alguns dos recursos de visualização das técnicas e métodos do TreeVis.

Além de prover a interface gráfica com o usuário, a visualização científica e a operação do sistema, o módulo Controle central também controla, gerência e supervisiona todos os demais módulos.

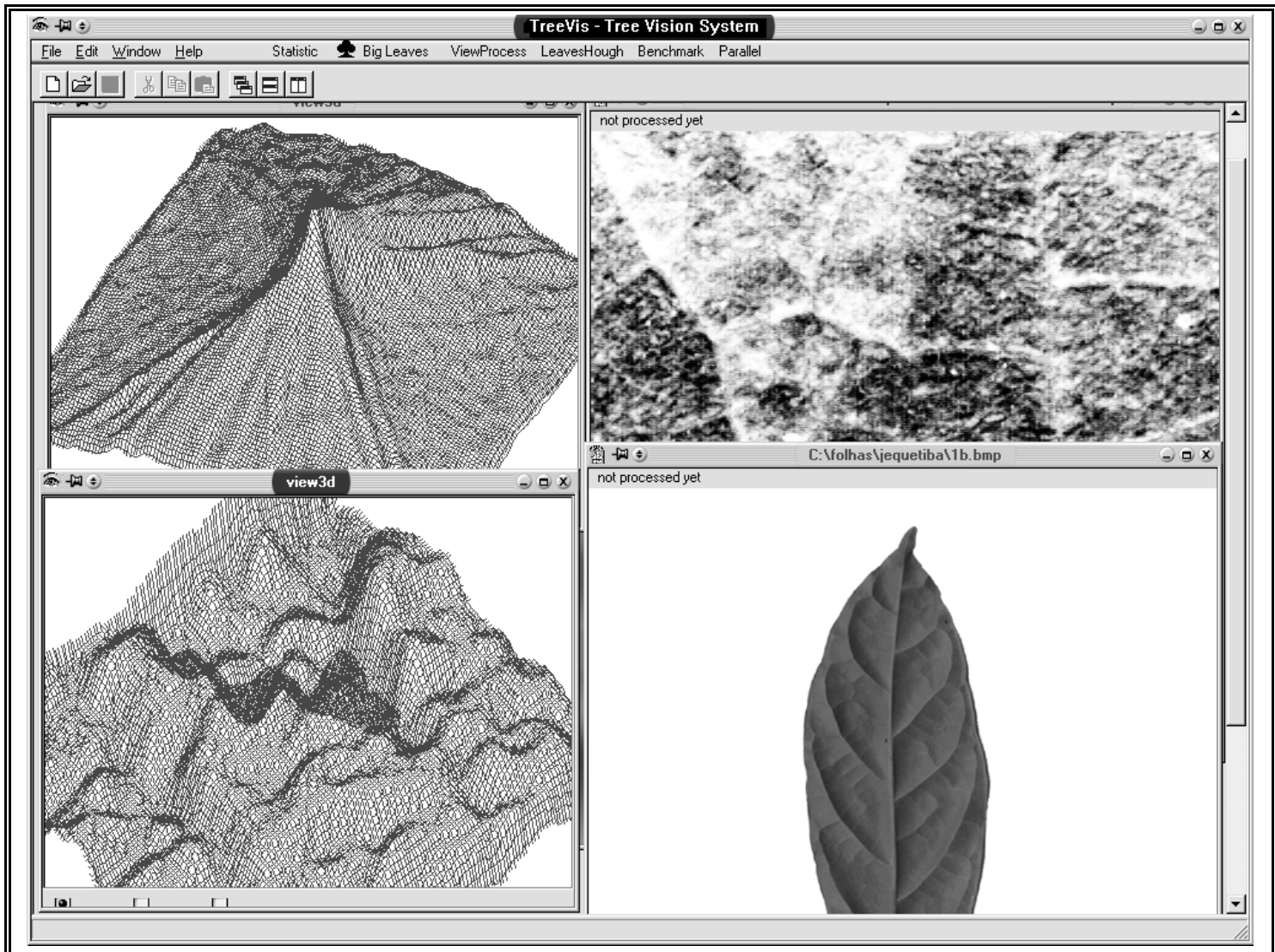

Fig. - 8.18 - Ambiente gráfico com o usuário do TreeVis. Exemplo de visualização de técnicas e métodos de processamento de imagens e visão.

\subsubsection{4 - EXTRAÇÃO DE CARACTERÍSTICAS}

Através do módulo Extração de características o TreeVis extrai o modelo de representação da amostra, que nada mais é do que um vetor de 165 elementos, contento todas as características determinadas pelo sistema. Este módulo é 
dividido em 5 submódulos: níveis de cinza, cor, forma, textura/complexidade e histograma. Os submódulos agrupam as técnicas e métodos utilizados para a extração das características, em função de sua natureza. O módulo Extração de características envia em tempo de execução do elemento do modelo de representação para o Controle central, possibilitando desta forma a operação do sistema em caráter de classificação dinâmica.

\subsubsection{1 - Níveis de Cinza}

Nesse módulo somente é processado o lado A da amostra, uma vez que o processamento aqui realizado leva somente em conta o formato da folha, a partir de sua binarização (que é o mesmo em ambos os lados). Dessa imagem são extraídas três características: área da folha, perímetro e circularidade (razão entre a área e o perímetro ao quadrado).

\subsubsection{2 - Cor}

O módulo cor é composto por dois conjuntos de características: cromaticidade e cromaticidade multiescala. No primeiro caso, é realizado o cálculo da cromaticidade para cada componente cromático ( $R, G$ e B) [Moreira, 1999]. Esse procedimento é realizado em ambos os lados da folha (lado A e B), uma vez que cada lado possui sua própria natureza cromática. As Equações 8.7, 8.8 e 8.9 expressam o cálculo de cromaticidade para cada um dos componentes cromáticos da imagem, onde $r, g$ e b é o valor do componente cromático de cada pixel, e n é o número de pontos pertencentes a folha. Devemos lembrar que somente são computados nesses cálculos os pixels pertencentes à folha.

$$
\begin{aligned}
& C(r)=\frac{\sum_{i=1}^{n}\left(\frac{r_{i}}{r_{i}+g_{i}+b_{i}}\right)}{n} \\
& C(g)=\frac{\sum_{i=1}^{n}\left(\frac{g_{i}}{r_{i}+g_{i}+b_{i}}\right)}{n}
\end{aligned}
$$




$$
C(b)=\frac{\sum_{i=1}^{n}\left(\frac{b_{i}}{r_{i}+g_{i}+b_{i}}\right)}{n}
$$

Os cálculos para a cromaticidade multiescala são realizados da mesma maneira, sendo considerados os dois lados da imagem, que no entanto sofrem convoluções com Gaussianas de diferentes desvios padrão (5 desvios-padrão ao todo).

\subsubsection{3 - Forma}

O módulo forma analisa o contorno da folha (imagem binarizada) e também seu interior, através das nervuras. No primeiro caso, o sistema utiliza o algoritmo de extração de contorno [Cesar, 1997] (Figura 8.19b). Com base no modelo de contorno são calculadas 15 características, das quais, 3 consistem na energia de dobramento (bending energy) multi-escala [Cesar, 1997] e as outras 12 nos descritores de Fourier 1D do contorno [Castleman, 1996] [Gonzalez \& Woods, 1993]. Uma vez que ambos os lados da folha possuem o mesmo contorno, somente é considerado o lado $\mathrm{A}$.

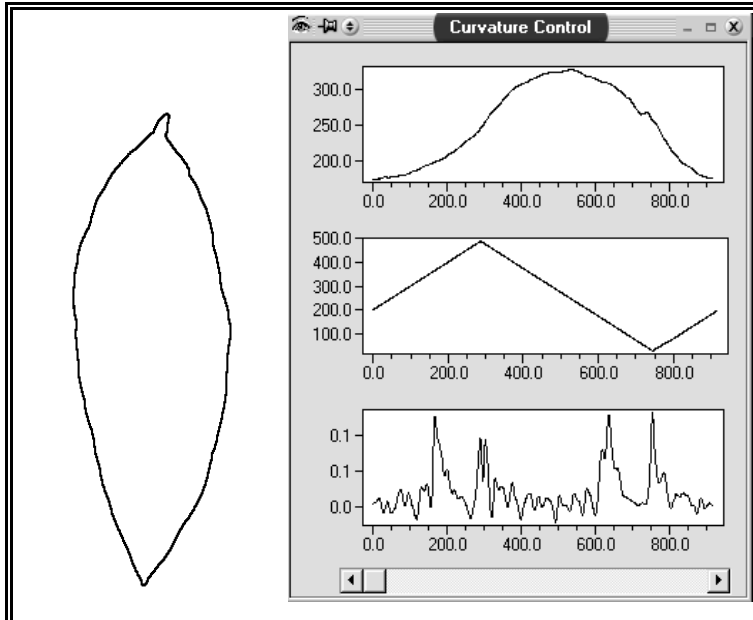

(a)

(b)

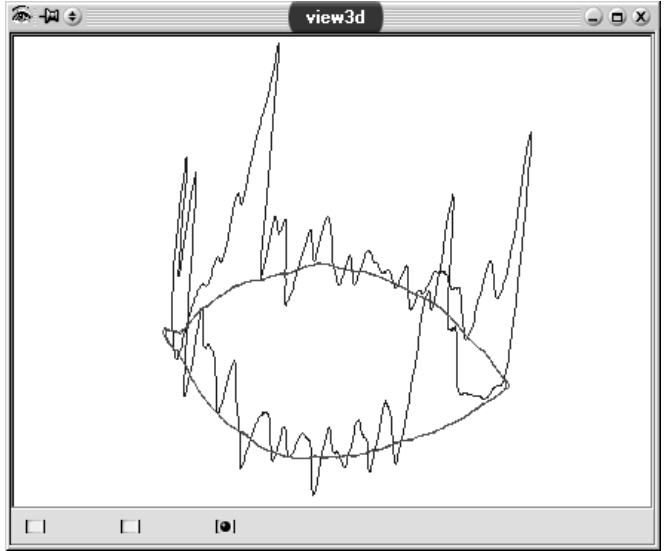

(c)

Fig. - 8.19 - Visualização do cálculo de curvatura. Contorno da folha da Cariniana estrellensis (Jequitibá), obtida através da detecção de bordas da imagem binarizada. (b) Janela de controle, apresentando a projeção do contorno no eixo $x$, y e o gráfico de curvatura. (c) Projeção do gráfico de curvatura sobre o contorno (3D).

A Figura 8.19 ilustra a visualização do cálculo de curvatura, onde a figura (a) 
apresenta o contorno de uma folha, obtido através da detecção de borda (Sobel) da imagem binarizada, a figura (b) apresenta as projeções do contorno nos eixo x e y e o gráfico de curvatura e a figura (c) exibe a projeção do gráfico de curvatura de forma perpendicular sobre o contorno (visualização 3D).

Para a análise das nervuras é utilizada a transformada de Hough com backmapping, em ambos os lados da folha (lado A e lado B), uma vez que em determinadas espécies podem surgir diferenças entre as estruturas de cada lado. $A$ nervura principal é desconsiderada no cálculo, que utiliza apenas as demais nervuras (ver Figura 8.20b). Através delas são obtidas 7 características, sendo que uma é referente ao ângulo de orientação das nervuras e as 6 restantes referentes ao número de retas obtidas, dentro de 6 dimensões pré-especificadas (definidas pelo sistema). A Figura 8.20 ilustra a imagem da folha segmentada exibindo seu contorno e nervuras (a) ,as nervuras consideradas na análise (b) e um exemplo mostrando o ângulo avaliado (c).

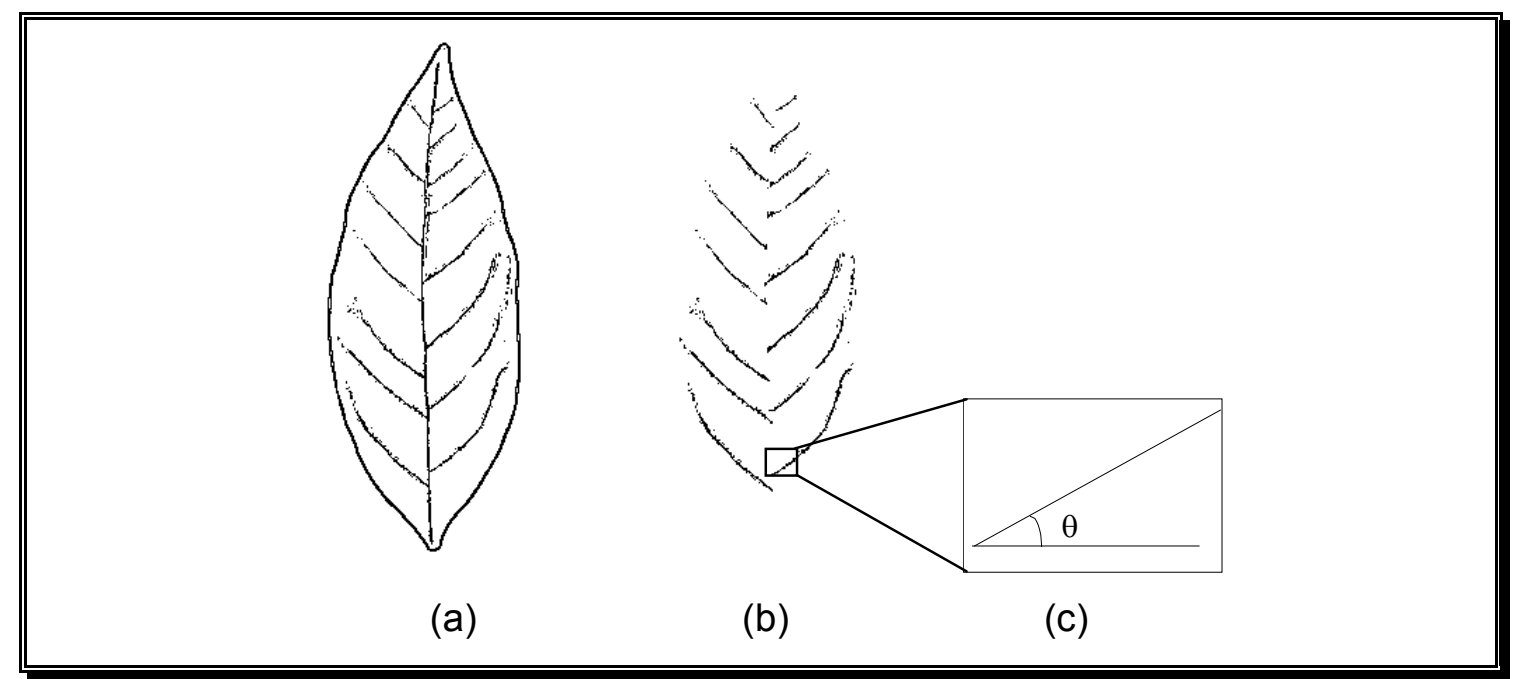

Fig. - 8.20 - Nervuras da folha, consideradas na transformada de Hough. Imagem segmentada (a), nervuras consideradas para a transformada (b) e referência do ângulo determinado pela análise (c).

\subsubsection{4 - Textura e complexidade}

No módulo Textura e complexidade são agrupados alguns métodos para medir a complexidade e a textura da folha, extraindo desse modo características. Como medidas de complexidade e de textura, o módulo utiliza a dimensão fractal (box counting), efetuada em cada um dos lados da folha, totalizando suas 
características e a contagem de pontos de cruzamento por zero da transformada de Marr-Hildreth para 4 diferentes desvios-padrão (multi-escala) [Gonzalez \& Woods, 1993] [Marr,1982] [Parker, 1997], totalizando 5 características. Embora o módulo seja denominado Textura e complexidade, ele não é o único módulo a tratar deste atributo, uma vez que o módulo Histograma também apresenta medidas relativas que, devido à natureza dos métodos, foram agrupadas nele.

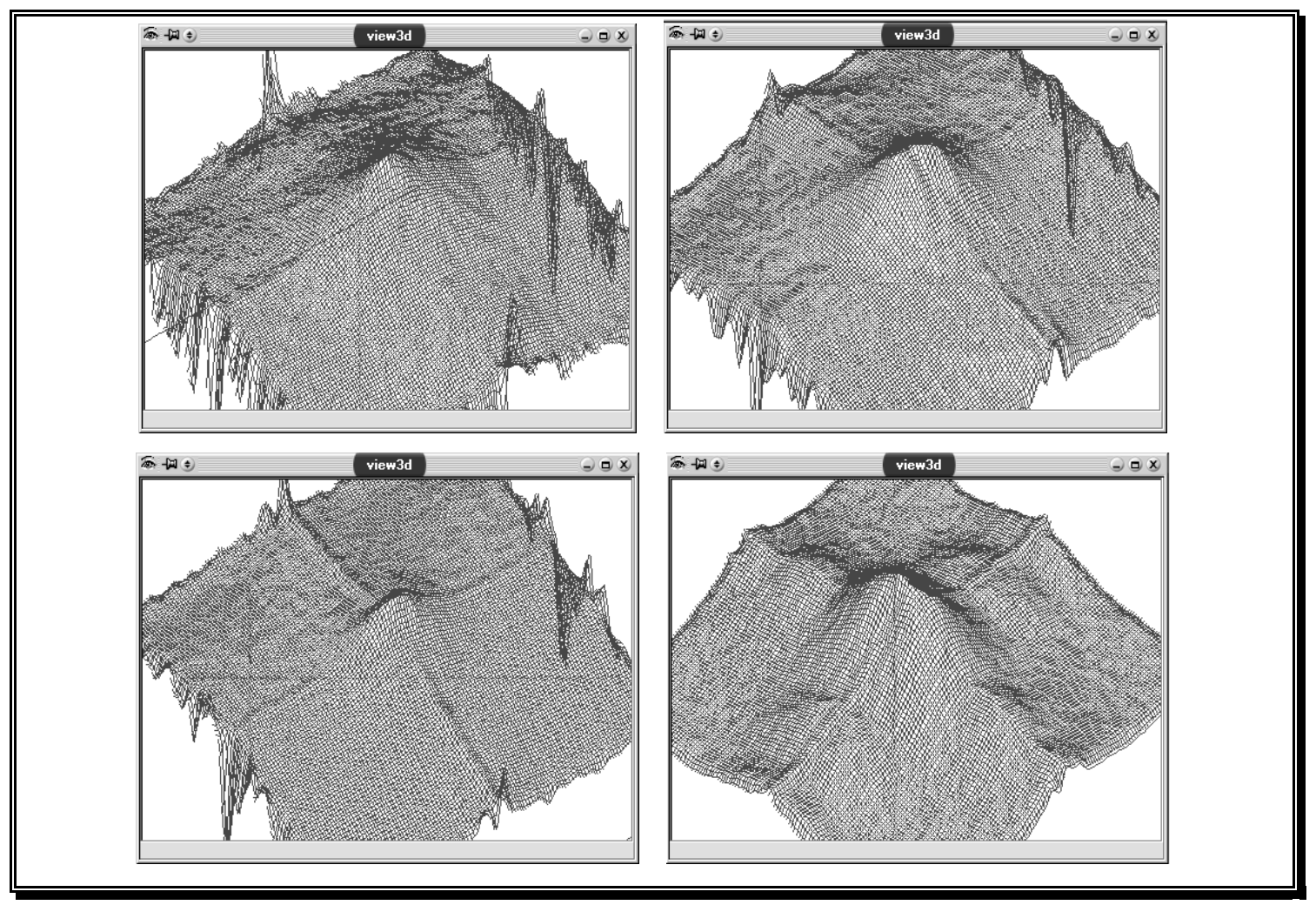

Fig. - 8.21 - Visualização do domínio da freqüência (real) da imagem de ampliação de textura de 4 espécies diferentes, apresentando as diferenças que caracterizam os descritores.

Dentre os submódulos de extração de características, Textura e complexidade é o único a utilizar a imagem ampliada de textura. Para analisar e extrair as características da imagem ampliada de textura, é utilizado os descritores da transformada de Fourier 2D da imagem [Gonzalez \& Woods, 1993]. Os descritores utilizados são os radiais, e totalizam 15 características. A Figura 8.21 apresenta a visualização do domínio (real) da freqüência de 4 espécies distintas de plantas arbóreas. Através delas podemos observar a variação na forma dos gráficos, a qual é descriminada pelos descritores, caracterizando o modelo de classificação por textura. 


\subsubsection{5 - Histograma}

Este módulo, embora extraia características relacionadas com a complexidade e a textura das folhas, recebe a denominação de Histograma, devido às técnicas utilizadas serem todas baseadas no histograma da imagem. Nele basicamente são realizadas dois tipos de medidas: cálculo do desvio-padrão da distribuição do histograma e cálculo da entropia do histograma [Gonzalez \& Woods, 1993]. Assim como no módulo Cor, somente são considerados os pixels pertencentes à folha para a elaboração do histograma. Uma vez que ambos os lados da folha possuem diferentes textura, os dois são considerados pelo módulo.

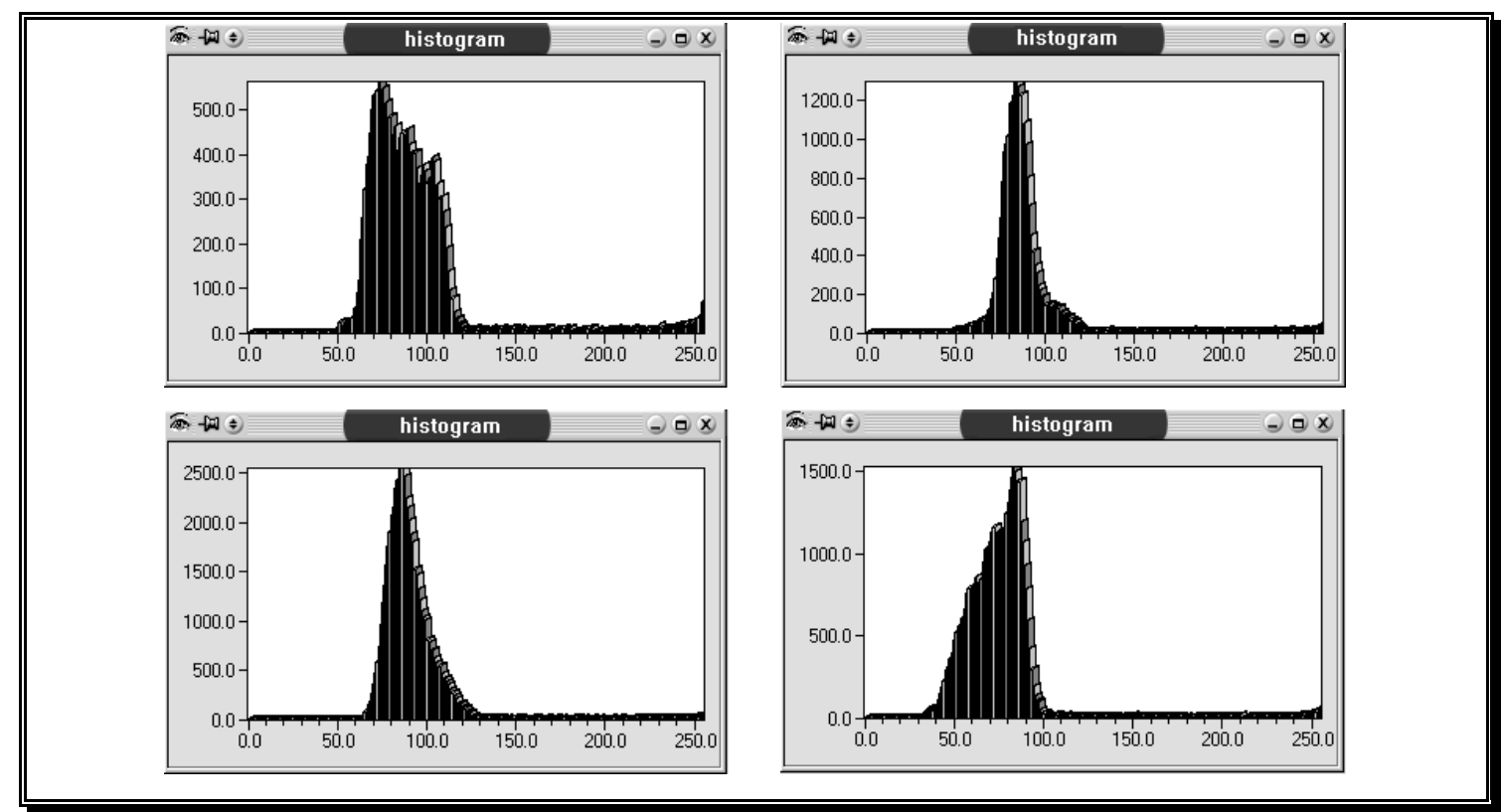

Fig. - 8.22 - Histogramas de folhas de 4 diferentes espécies, ilustrando a variação presente na distribuição dos histogramas.

Os cálculos são realizados para níveis de cinza e para cada um dos componentes cromáticos ( $R, G$ e $B)$. No primeiro caso, a imagem cromática da folha é convertida para níveis de cinza através da média dos componentes cromáticos. A partir dos níveis de cinza são computados 4 características para o desvio-padrão, das quais uma é realizada para a imagem padrão e as outras três para a imagem após sofrer convolução com Gaussianas de diferentes desviospadrão (multi-escala). A mesma estratégia é realizada para o cálculo da entropia, onde também, são extraídas 4 características. 
Cada um dos componentes cromáticos é considerado como um canal ou plano da imagem, sendo computados para cada um deles ( $R, G$ e $B)$ as mesmas características obtidas na imagem de níveis de cinza. Deste modo, o número total de características extraídas pelo módulo é de 32 para cada lado da folha, totalizando 64 .

A Figura 8.22 ilustra a variação de histograma ocorrida entre 4 diferentes espécies de folhas. O histograma foi obtido através da imagem de níveis de cinza.

\subsubsection{5 - TREINAMENTO E IDENTIFICAÇÃO}

Tanto o treinamento quanto o reconhecimento são processos centrados no módulo Treinamento e identificação com base no vetor de características que, como vimos, é calculado através do módulo Extração de características.

Para o módulo Treinamento e identificação o processo de treinamento consiste em calcular o vetor médio a partir do vetor de características de cada amostra processada. Para isso o módulo recebe o vetor de características do Controle central após a amostra ser processada pelo módulo de Extração de características. Ao final do processamento de todas as amostras, o módulo realiza a média dos vetores, obtendo o vetor de característica responsável pelo modelo da espécie. O vetor é armazenado juntamente com as informações de identificação da espécie adicionada ao sistema, na Base de dados.

$O$ reconhecimento pode ser efetuado de dois modos: dinâmico e estático. A identificação estática é realizada após serem extraídas as características das amostras. Compete ao módulo de treinamento e identificação realizar a comparação entre o modelo da amostra a ser classificada e os modelos armazenados na Base de dados. A comparação é realizada em duas etapas. A primeira seleciona uma lista de prováveis espécies, e na segunda etapa, esta lista é refinada. Na primeira etapa, apenas 63 das 165 características são consideradas. $O$ modelo da primeira etapa de classificação é definido como um ponto num espaço de 63 dimensões. A lista de prováveis espécies é obtida através da distância euclidiana entre os dois modelos, sendo consideradas as espécies que apresentaram a menor distância ao modelo analisado (são inseridas na lista as espécies que possuem distância menor que o limiar estipulado pelo sistema). 0 refinamento da lista é realizado utilizando as outras 102 caraterísticas. É calculada a distância euclidiana (102 dimensões) entre os modelos da lista da primeira etapa, efetuando seu refinamento e obtendo deste modo a lista de identificação, que pode 


\section{CAPÍTULO 8}

possuir um ou mais elementos ordenados segundo a probabilidade de identificar o modelo analisado.

O processo de identificação dinâmica é uma tentativa de aumentar a performance do reconhecimento. Diferentemente do processo de reconhecimento estático, que aguarda até que todas as características sejam extraídas para iniciar a comparação, a identificação dinâmica, é um processo simultâneo à extração de características. Isto é permitido devido a comunicação entre os módulos Extração de características, Controle Central e Treinamento e identificação, que permitem que cada característica extraída seja enviada para o módulo de identificação. Com base nelas, o módulo realiza uma busca no banco de dados, e monta uma lista com que se enquadram no perfil do modelo incompleto. Esta lista é enviada então para o módulo Análise estatística, que retorna outra lista, indicando quais são as características mais importantes para classificar as espécies da lista que recebeu. Com base nessa informação o módulo solicita ao Controle central para que sejam priorizados métodos cujas características foram destacadas. O processo de identificação dinâmica finaliza quando as características extraídas, montarem um modelo que, mesmo incompleto, satisfaça as condições estabelecidas pelo sistema, determinando o reconhecimento.

O processo de identificação dinâmica é um modo experimental de operação do TreeVis, que em certas situações consegue obter uma boa performance devido à limitação da extração de características, como por exemplo no caso das espécies com características marcantes, cuja identificação é realizada mesmo no modelo incompleto. Apresenta também situações onde não promove aumento de performance, como é o caso das espécies com características medianas, que não possibilitam uma boa identificação com modelos incompletos. A principal desvantagem na utilização do reconhecimento dinâmico está nos erros de identificação que o método acarreta. Assim, a identificação dinâmica deve ser considerada pelo menos a uma primeira instância, como uma alternativa de reconhecimento aberta ao estudo científico dentro do projeto TreeVis.

\subsubsection{6 - ANÁLISE ESTATÍSTICA}

O módulo Análise estatística tem a exclusiva finalidade de dar suporte ao módulo de treinamento e identificação, quando é realizado reconhecimento dinâmico. Basicamente sua função é determinar as características mais divergentes dentro de um conjunto de vetores de características, de modo a tornar possível a 
classificação de modelos incompletos com razoável precisão.

O principal mecanismo utilizado no módulo é o cálculo da matriz de covariância (Equação 8.10). Através da covariância, é possível diagnosticar o grau de similaridade entre as características dos modelos.

$$
\Lambda_{a, b}=\frac{1}{N}\left(x_{a}(i)-\bar{x}_{a}\right)\left(x_{b}(i)-\bar{x}_{b}\right)
$$

Determinada a matriz de covariância, o módulo Análise estatística, procura pelos menores elementos da matriz, correlacionados com as características já extraídas pelo sistema, montando uma lista das características que possuem a maior chance de caracterizar o reconhecimento do modelo. O módulo conta também com uma tabela, indicando o tempo médio de duração para a extração das características. Com base na tabela e na lista de características, é elaborada uma nova lista, a qual é ordenada através da divergência da característica e de seu tempo de processamento, visando o aumento da performance no reconhecimento.

\subsection{6 - IMPLEMENTAÇÃO PARALELA}

Como ocorre usualmente em sistemas de visão, o TreeVis requer grande demanda computacional, possuindo portanto um elevado tempo de execução (Pentium II $400 \mathrm{MHz}$ ). A fim de melhorar a performance e consequentemente reduzir seu tempo de execução, foi realizada a implementação paralela do TreeVis, através de CVMP, possibilitando sua execução em sistemas distribuídos.

Os módulos do sistema TreeVis possuem razoável autonomia e independência, permitindo a exploração de paralelismo. No entanto, o gargalo do sistema reside no módulo Extração de características, uma vez que concentra as diversas técnicas e métodos de processamento de imagem e visão, que são inúmeras vezes mais lentas que os processos localizados nos demais módulos. Deste modo, a estratégia de paralelismo adotada explorou a concorrência de seus submódulos.

Foram incorporadas três estratégias de paralelismo ao sistema: (i) replicação dos módulos Extração de características, (ii) implementação paralela deste módulo e (iii) a combinação das duas estratégias anteriores.

No primeiro caso a estratégia aproveita a necessidade do sistema a 
múltiplas amostras. Assim, com a replicação dos módulos Extração de características, cada amostra é direcionada para um dos módulos, que as processa simultaneamente. A estratégia utilizada foi a fazenda de processadores, através da utilização do CVMP processor farm. Conforme mostrado na Figura 8.23, o sistema fica dividido entre mestre e escravos. Cada módulo escravo é constituído por um módulo de extração de características, ficando no módulo mestre todo o restante do sistema. O Controle central, principal unidade do mestre, fica incumbido de supervisionar, controlar e distribuir as tarefas (amostras) para os escravos. Essa estratégia possui como vantagem o balanceamento automático, podendo ser utilizado um conjunto de máquinas heterogêneas, sem a necessidade de ser realizado qualquer tipo de balanceamento de carga. A estratégia apresenta uma boa performance dependendo do número de amostras utilizadas, quanto maior o número destas melhor o resultado. Quando o número de amostras é consideravelmente maior que o número de processadores, a taxa de desempenho obtido se torna um fator próximo do número de unidades de processamento (escravos) do sistema, uma vez que o tempo gasto com o processamento é muito maior que o gasto na transferência dos dados.

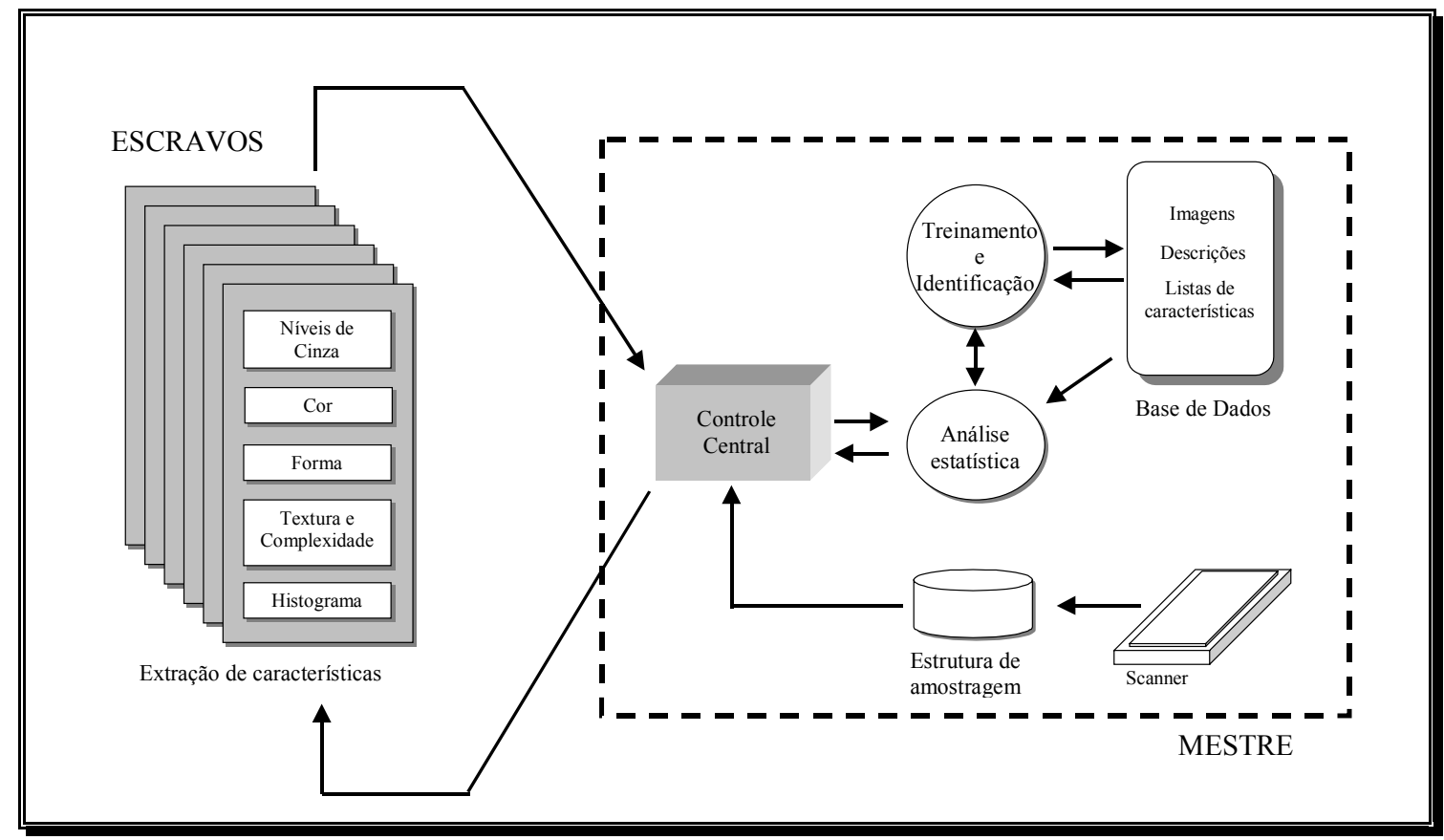

Fig. - 8.23 - TreeVis com a estratégia de paralelismo processor farm.

No segundo caso, é explorado o paralelismo dentro do módulo, através de concorrência entre seus submódulos e também através da implementação paralela 
dos métodos e técnicas (Capítulo 7). A exploração do paralelismo consiste na divisão do módulo Extração de características em partes, executando-as em concorrência. Devido à independência e autonomia de seus submódulos, a divisão do módulo de extração de características é uma tarefa simples. Contudo a dificuldade reside no balanceamento de cargas do sistema. Em sistemas homogêneos, as partes deverão possuir a mesma demanda computacional, ao passo que em sistemas heterogêneos, elas deverão possuir cargas proporcionais às máquinas em que serão executadas. Implementamos duas diferentes configurações dessa estratégia, uma dividindo o módulo em três partes e a outra em seis, ambas voltadas para sistemas distribuídos homogêneos (3 e 6 máquinas iguais).

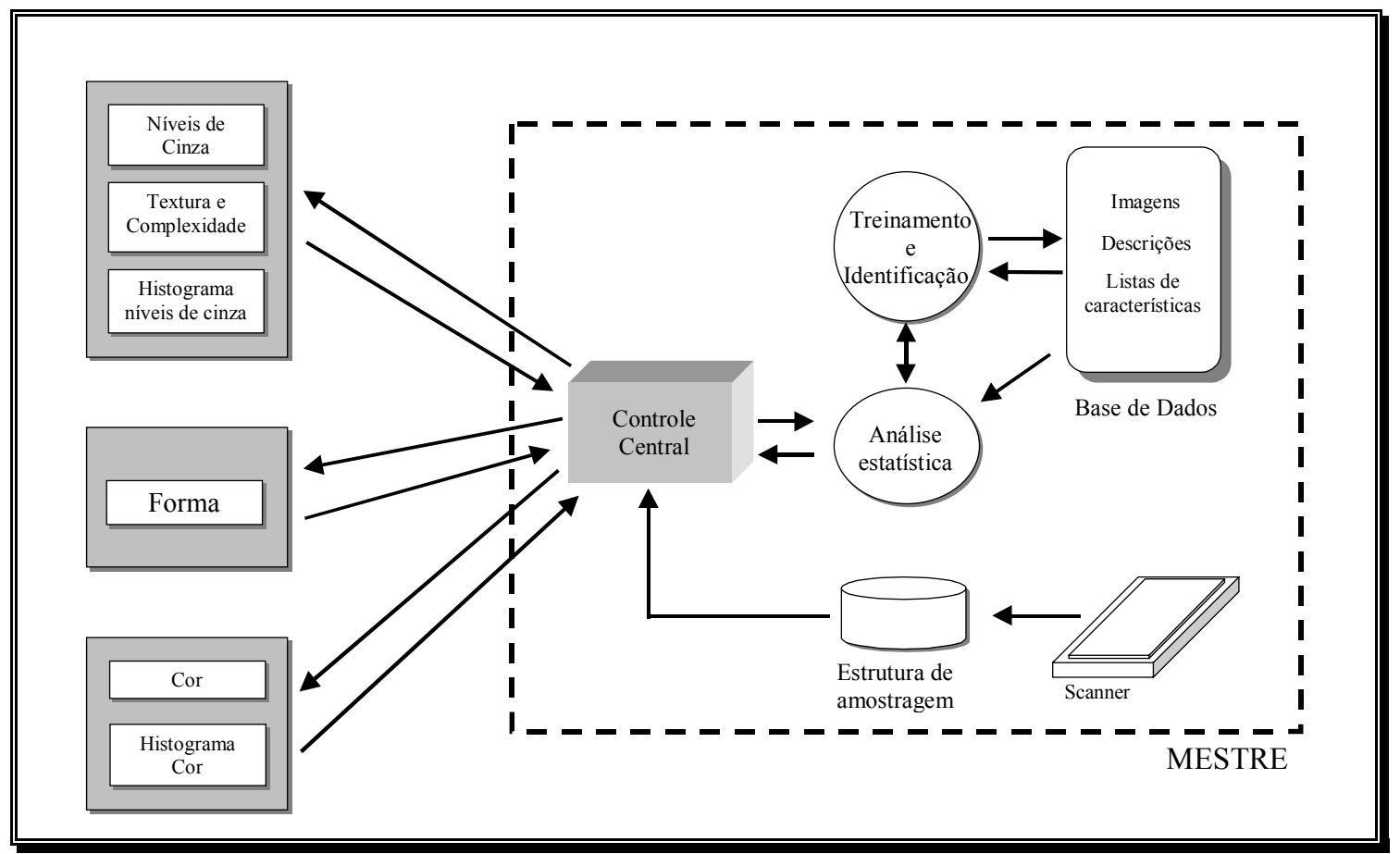

Fig. - 8.24 - TreeVis - Exploração de paralelismo através da partição do módulo Extração de características em 3 partes, executadas simultaneamente em processadores diferentes.

A Figura 8.24 contém um diagrama ilustrativo da versão na qual o módulo de extração de características é dividido em 3 partes com performances aproximadamente equivalentes. Nesta abordagem, somente o submódulo responsável pelas medidas relativas a histogramas foi particionado, a fim de aproveitar as convoluções com a gaussiana (multi-escala) realizados no módulo de 
Cor nos histogramas multi-escala cromáticos. Através desta configuração o TreeVis fica especificado para sistemas distribuídos constituídos de 3 máquinas homogêneas. Cada uma das máquinas deverá executar um dos fragmentos do módulo de extração de características. O módulo mestre, responsável pela supervisão e controle do sistema, é alojado (multitarefa) juntamente com o fragmento que agrupa os submódulos: Niveis de cinza, Textura e complexidade e histograma de níveis de cinza; uma vez que este possui o menor tempo de execução.

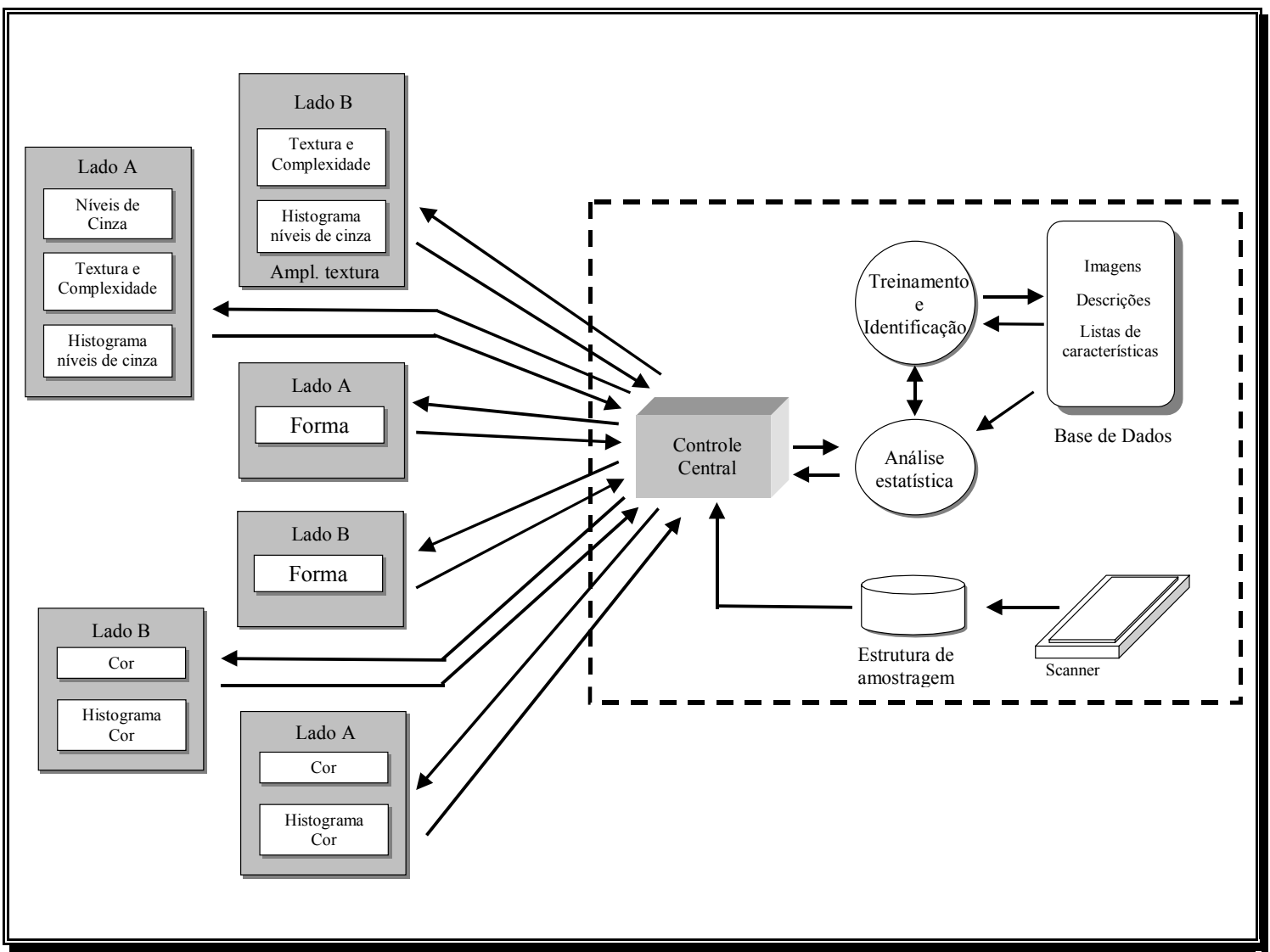

Fig. - 8.25 - TreeVis - Exploração de paralelismo através da partição do módulo Extração de características em 6 partes, executadas simultaneamente em processadores diferentes.

Na Figura 8.25 é apresentada a versão do sistema para seis máquinas. Neste caso, cada uma das partes da fragmentação anterior (Figura 8.24) foi dividida em duas partes, correspondentes aos lados da amostra. Devido à sua natureza, o módulo de extração de características pode ser ainda dividido em muitos outros fragmentos, podendo até mesmo atingir níveis de paralelismo nos métodos e 
técnicas de processamento de imagens e visão (como Hough por exemplo), possibilitando configurações para sistemas distribuídos com maior quantidade de máquinas. Neste trabalho à divisão do módulo foi realizada em até seis partes.

A terceira estratégia (iii) de paralelismo consiste na combinação das estratégias processor farm (i) e fragmentação do módulo de extração de caraterísticas (ii). Nesse caso, o sistema possui as duas configurações, e dependendo do número de amostras utilizadas escolhe uma ou outra configuração para executar o sistema. Em sistema homogêneos, a primeira estratégia (i) apresenta uma performance melhor que a (ii), quando o número de amostras é múltiplo do número de processadores ou quando o número de amostras é grande e próximo ao múltiplo dos processadores. A segunda, entretanto, possui performance superior que a primeira, quando o número de amostras é menor que o número de processadores, ou quando o número de amostras é muito diferente do múltiplo do número de processadores.

\subsubsection{1 - RESULTADOS EXPERIMENTAIS}

Nesta subseção vamos apresentar duas séries de experimentos que comparam a performance das versões paralelas do TreeVis frente à sua versão seqüencial. Em todos os experimentos foram utilizados sistemas distribuídos homogêneos constituídos por máquinas AMD K6 II - $375 \mathrm{MHz}$ conectadas via rede ethernet (padrão NE-2000) de $10 \mathrm{Mb} / \mathrm{s}$. Na primeira série de experimentos foram utilizadas 3 máquinas e na segunda foi realizada a simulação de 6 máquinas. Cada série de experimentos contém duas experiências, uma voltada para a estratégia de paralelismo processor farm (i) e a outra para a estratégia (ii) (fragmentação do módulo de extração de características).

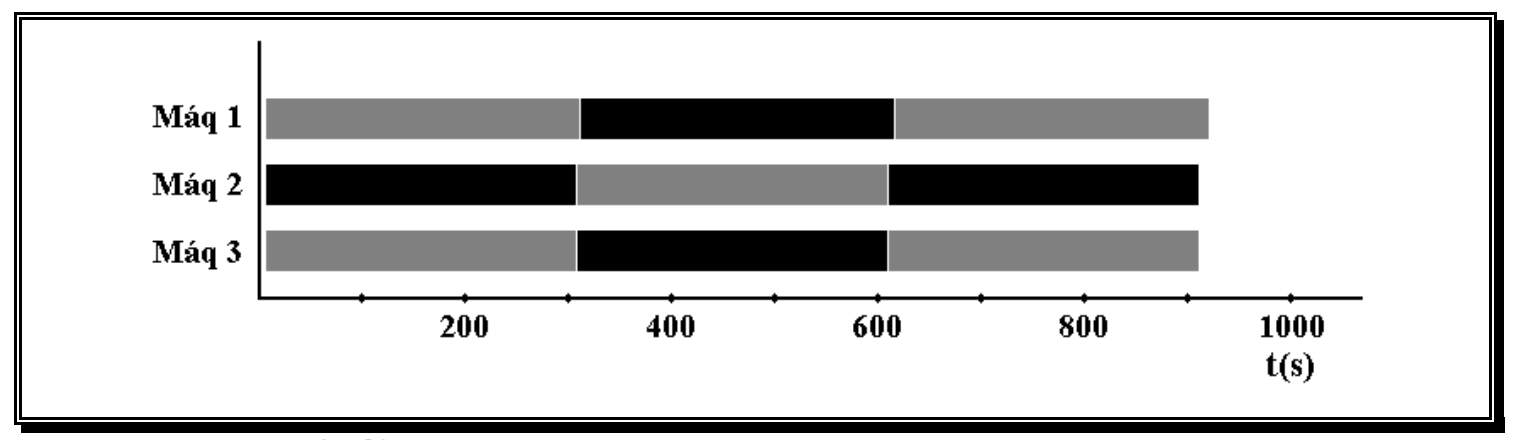

Fig. - 8.26 - Gráfico do tempo de execução da versão paralela (processor farm). Nove amostras foram processadas. 
No primeiro experimento da primeira série foi realizado o reconhecimento de um espécime constituído por 9 amostras. O experimento consistiu na comparação entre a performance da versão paralela (processor farm) frente a versão seqüencial. A Figura 8.26 apresenta os resultados obtidos no experimento, nela temos um gráfico do tempo de execução da versão paralela do sistema (processor farm). Como pode ser observado, não ocorreram bolhas na execução e o tempo gasto com a transferência de dados foi praticamente desprezível, de modo que a taxa de desempenho (speed-up) do sistema paralelo ficou próxima do número de processadores (3).

Na Figura 8.27 é mostrado o gráfico do tempo de execução da versão paralela do TreeVis (explorando o paralelismo do módulo de extração de características), comparada com sua versão seqüencial. Na Figura 8.27 a temos o resultado do processamento de três amostras. Na máquina 1 foram executados os submódulos de cor e histograma cromático, além do mestre. Na máquina 20 submódulo Forma e na máquina 3 os submódulos de níveis de cinza, textura e complexidade e, histograma de níveis de cinza. Na Figura 8.27b o tempo de execução seqüencial de uma amostra.

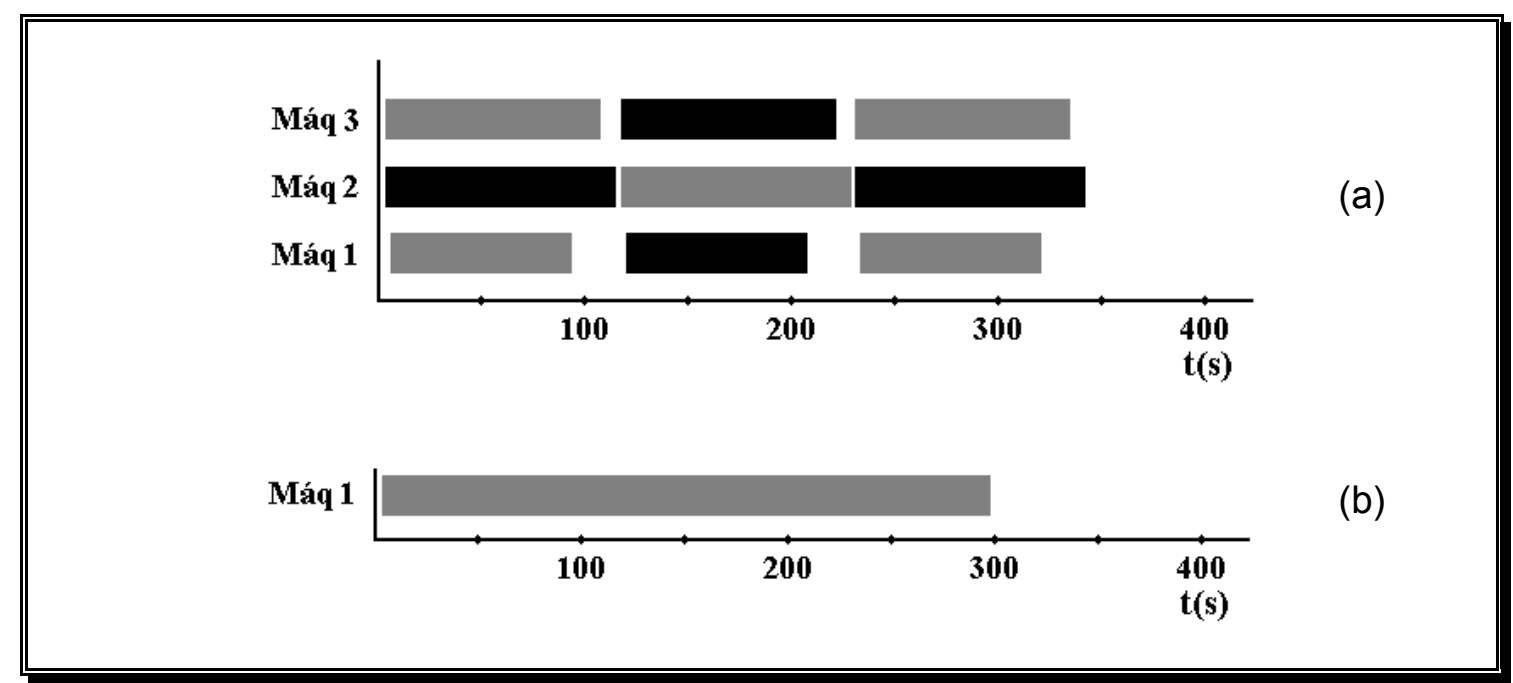

Fig. - 8.27 - Gráficos do tempo de execução, comparando as versões paralela e seqüencial do TreeVis. (a) Execução de três amostras na versão paralela (fragmentação do módulo de extração de características). (b) Execução de uma amostra na versão seqüencial.

Embora esta estratégia paralela apresente uma performance superior à versão seqüencial, obtendo uma máxima taxa de desempenho (Speed-up) de 
aproximadamente 2,7, devido a seu balanceamento de carga, não tão equilibrado quanto na implementação anterior (processor farm), apresentou uma performance menor. Devemos, entretanto, lembrar que para situações onde o número de amostras não é igual ao múltiplo do número de máquinas, surgem bolhas e a performance da implementação processor farm cai, fazendo com que a estratégia de exploração do módulo de extração de características apresente um desempenho superior, uma vez que não possui limitações quanto ao número de amostras.

As Figuras 8.28 e 8.29 apresentam a segunda série de experimentos, na qual são utilizadas versões paralelas (processor farm e fragmentação do módulo de extração de caraterísticas) configuradas para sistemas distribuídos compostos de seis máquinas. Seus resultados são proporcionais aos obtidos nos experimentos anteriores. Na versão processor farm, a taxa de desempenho ficou novamente muito próxima ao número de processadores utilizados (6). A versão seguinte, entretanto, apresentou uma pequena queda da taxa de desempenho, proporcionalmente ao experimento anterior (fig. 8.27), ficando em torno de 4,6. Isso se deve a um desequilíbrio no balanceamento de cargas do sistema, que no entanto pode ser melhorado através de uma nova configuração.

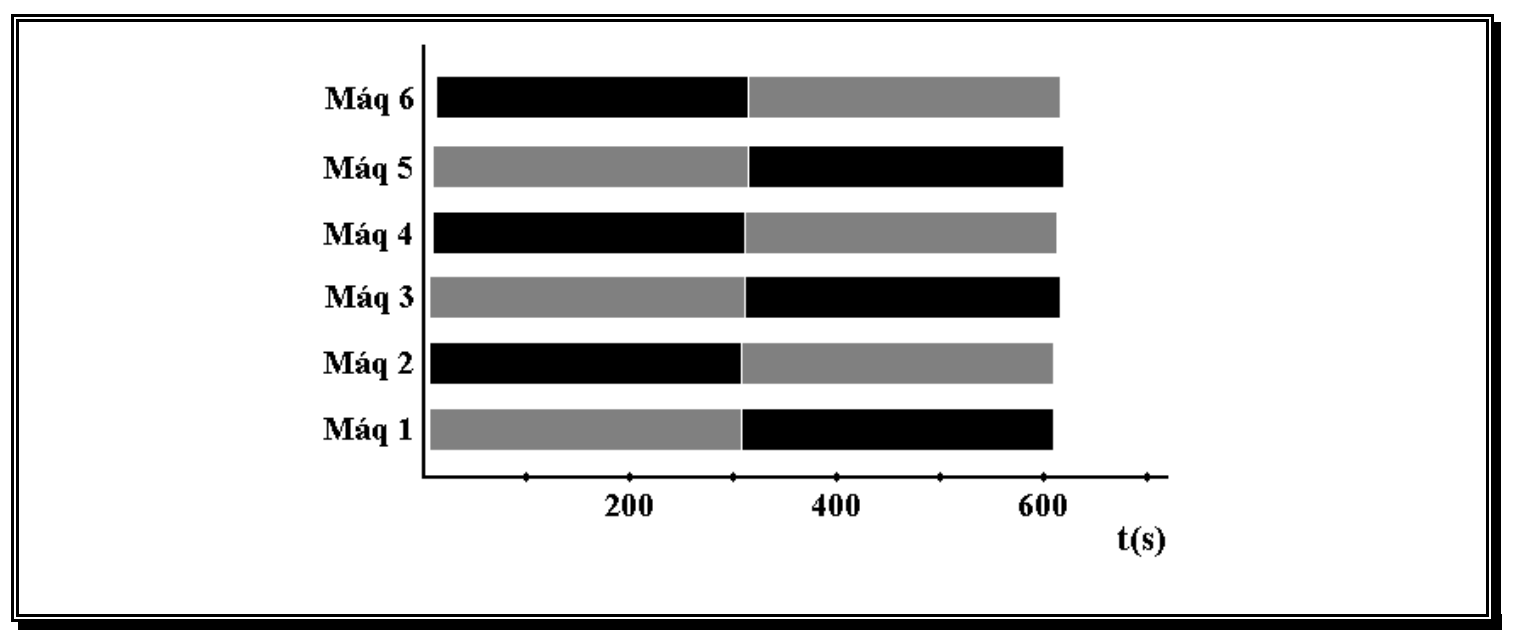

Fig. - 8.28 - Gráfico do tempo de execução da versão paralela (processor farm) em sistema distribuído com 6 máquinas. Doze amostras foram processadas. 

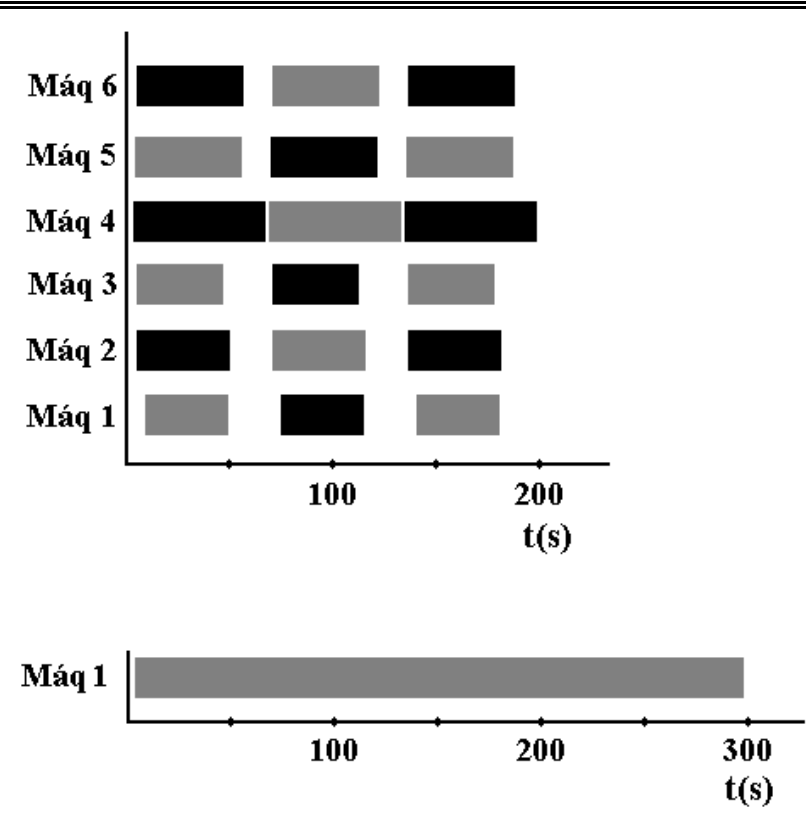

Fig. - 8.29 - Gráficos do tempo de execução, comparando as versões paralela e seqüencial do TreeVis. (a) Execução de três amostras na versão paralela (fragmentação do módulo de extração de características). (b) Execução de uma amostra na versão seqüencial.

\subsection{7 - RECONHECIMENTO DE PLANTAS ARBÓREAS}

A Tabela 8.3 apresenta a listagem das espécies utilizadas nos experimentos realizados com o TreeVis. Estas espécies caracterizam a flora brasileira, sendo nativas da mata atlântica (maior parte) e do cerrado. Além desta, utilizamos ainda, cerca de 30 espécies não catalogadas, contendo plantas ornamentais e frutíferas exóticas e nativas, a fim de somar 59 categorias na base de conhecimento do sistema. Com bases nessas amostras, pudemos realizar experimentos para a condução do projeto (métodos, técnicas, características, etc.).

A avaliação do sistema TreeVis é uma tarefa bastante difícil, uma vez que o processo de reconhecimento depende de um grande número de fatores (coleta dos dados, escolha da amostra, diferença entre indivíduos da mesma espécie, etc.). Embora não disponhamos do controle desses parâmetros, ficando como sugestão para trabalhos futuros, realizamos um experimento a fim de avaliar, mesmo que de maneira bastante aproximada, o desempenho do sistema no reconhecimento das espécies. 


\begin{tabular}{|c|c|c|}
\hline Família & Denominação científica & Denominação popular \\
\hline ANACARDIACEAE & Schinus terebinthifolius Raddi & Aroeira pimenteira \\
\hline ANACARDIACEAE & Tapirira guianensis Aubl. & Peito de pomba \\
\hline APOCYNACEAE & Rauwolfia sellowii & Casca d'anta \\
\hline BIGNONIACEAE & Tabebuia impetiginosa (Mart.) Standl. & Ipê roxo \\
\hline BIGNONIACEAE & Tabebuia vellosoi (Tol.) & Ipê amarelo \\
\hline BIGNONIACEAE & Tabebuia roseo-alba (Ridl.) Sand. & Ipê Branco \\
\hline BOMBACACEAE & Pseudobombax grandiflorum Mart. \& Zucc. & Imbiruçú \\
\hline BOMBACACEAE & Eriotheca candoleana & Paina da mata \\
\hline BOMBACACEAE & Chorisia speciosa (St. Hil.) & Paineira \\
\hline BORAGINACEAE & Patagonula americana $\mathrm{L}$. & Guaiuvira \\
\hline BORAGINACEAE & Cordia sellowiana Cham. & Chá de bugre \\
\hline BORAGINACEAE & Cordia trichotoma (Vell.) & Louro pardo \\
\hline CECROPIACEAE & Cecropia cineria & Embaúba \\
\hline FABACEAE & Platycianus regnelli Benth. & Pau Pereira \\
\hline FABACEAE & Miroxyon peruiferum (L.) Harms. & Cabreúva \\
\hline LECYTHIDACEAE & Cariniana estrellensis (Raddi) Kuntze & Jequitibá \\
\hline LEGUMINOSAE & Caesalpinia echinata $\mathrm{L}$. & Pau-brasil \\
\hline LEGUMINOSAE & Hymenea courbaril L. & Jatobá \\
\hline LEGUMINOSAE CAESALPINOIDEAE & Bauhinia forficata (Link) & Pata de Vaca \\
\hline LEGUMINOSAE-PAPILONOIDEAE & Ormosia arborea (Vell.) Harms & Olho de cabra \\
\hline MELASTOMACEAE & Tibouchina pranulosa (Cogn.) & Quaresmeira \\
\hline MELASTOMACEAE & Tibouchina mutabilis (Cong.) & Manacá da Serra \\
\hline MYRTACEAE & Syzyngium jambolanum & Jambolão \\
\hline MYRTACEAE & Eugenia Uniflora (L) & Pitanga \\
\hline MYRTACEAE & Psidium cattleianum (Sabine) & Araçá \\
\hline MYRTACEAE & Psidium guajava (L.) & Goiabeira \\
\hline MYRTACEAE & Eugenia pyriformis (Camb.) & Uvaia \\
\hline MYRTACEAE & Myrciaria trunciflora (Berg) & Jabuticabeira \\
\hline NYCTAGINACEAE & Bougainvillea glabra (Choisy) & Primavera \\
\hline
\end{tabular}

Tabela 8.3 - Espécies utilizadas no experimento.

Conquanto o sistema necessita de várias amostras para efetuar um treinamento satisfatório, no experimento, realizamos o treinamento das espécies a partir de uma única amostra, a qual julgamos caracterizar a planta. Efetuado o treinamento das 59 espécies, realizamos o reconhecimento de 283 amostras. Assim como no treinamento, o reconhecimento também exige que diversas amostras sejam utilizadas para classificar uma espécie de forma satisfatória. Entretanto, visando colocar o sistema em um situação extrema, efetuamos o reconhecimento através de amostras constituídas por apenas uma folha. Dentre as 283 amostras, foram identificas corretamente 226, sendo que o sistema cometeu 57 erros no reconhecimento, estabelecendo uma margem de erro de aproximadamente $20 \%$. 
CAPÍTULO 8 


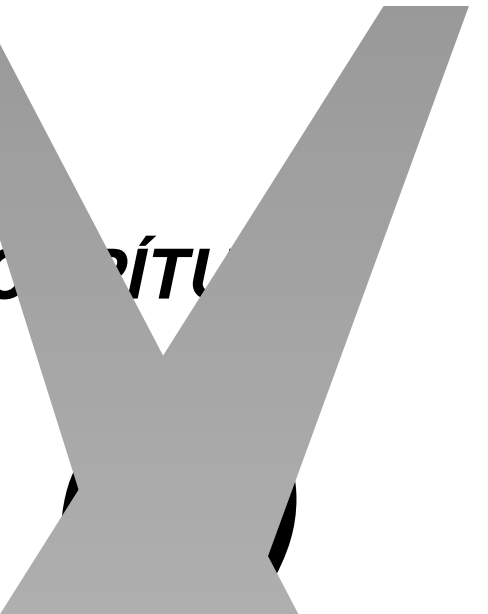

serience, the best creative work is never done when one $\mathrm{i}$

A 
CAPÍTULO 9 


\section{CAPÍTULO 9 - CONCLUSÃO}

\section{1 - COMENTÁRIOS FINAIS E CONTRIBUIÇÕES}

Discutimos nesta tese uma série de aspectos relacionados ao paralelismo em visão natural e artificial. Uma vez que o paralelismo em visão artificial está diretamente relacionado à Computação Paralela, iniciamos a abordagem a partir de uma revisão dos conceitos fundamentais dessa área, tanto do ponto de vista da arquitetura (hardware) quanto da programação (software), com o intuito de fornecer aos leitores uma base substancial em Computação Paralela, permitindo uma melhor interação e compreensão aos assuntos tratados no decorrer da tese. Em visão natural, após realizarmos uma revisão de visão biológica, partimos para uma discussão sobre o sistema de visão dos primatas sob o ponto de vista do paralelismo, onde abordamos vários aspectos, dos quais podemos destacar: (i) modularidade do córtex visual, (ii) especialização funcional, (iii) independência dos módulos e atributos, (iv) distribuição das informações ao longo do caminho visual, (v) independência e autonomia do caminho parvo e magno celular, (vi) arquitetura de paralelismo multiníveis, (vii) mapeamento das informações nas áreas corticais e (viii) a integração dos sinais, módulos e atributos visuais.

A integração entre o paralelismo em visão natural e artificial ocorre com a abordagem do projeto Cyvis-1. Fortemente inspirado na visão biológica, o Cyvis-1, apresenta diversas características baseadas no paralelismo dos sistemas de visão natural, que nos permitiu analisar, discutir e sugerir diversos aspectos do paralelismo natural que podem contribuir para a eficiência e o realismo dos sistemas de visão artificial. Entre os aspectos levantados e discutidos, podemos destacar: (i) modularidade, (ii) hierarquia, (iii) especialização funcional, (iv) cooperação entre subsistemas, (v) representação da informação em vários níveis de conhecimento, (vi) distribuição de informações em arquitetura paralela de visão, (vii) integração de atributos e módulos concorrentes, (viii) granularidade de pacotes entre os níveis hierárquicos, (ix) supervisão e controle dos processos visuais, (x) processamento visual em tempo real, etc. Realizamos também uma série de comparações e análises críticas entre o projeto Cyvis-1 e outros sistemas de visão encontrados na literatura, que apresentam alguns aspectos semelhantes. 


\section{CAPÍTULO 9}

Neste trabalho verificamos que o paralelismo é inerente à visão natural, constituindo a base de sua arquitetura e podendo possibilitar uma série de benefícios aos sistemas de visão artificial. No entanto, constatamos que o paralelismo é pouco explorado em visão computacional, estando praticamente ausente se considerarmos sua importância, constituindo assim, uma lacuna no estudo da visão. Acreditamos que as razões para a ausência de paralelismo na visão artificial estão fundadas na própria Ciência da Computação, sendo esta o alicerce do estudo da visão artificial. Qualquer um que já tenha um dia desenvolvido e implementado um algoritmo paralelo, sabe das inúmeras dificuldades no desenvolvimento de software paralelo. A programação concorrente é uma tarefa árdua e complicada que, além de requerer um profundo conhecimento no assunto, exige um trabalho muito maior que o realizado nas soluções seqüenciais. Estas dificuldades são acentuadas pela escassez de ferramentas computacionais amigáveis e intuitivas, baseadas na interação homem-máquina, para o desenvolvimento de aplicações paralelas.

Além do perfil científico e tecnológico no projeto Cyvis-1, devemos levar em conta o trabalho humano envolvido sob o ponto de vista do desenvolvimento e implementação. Estando o Cyvis-1 fortemente inspirado nos benefícios do paralelismo em visão, surge à tona as dificuldades da programação concorrente. Uma vez que o Cyvis-1 é um projeto complexo, modular e de longa duração, que abrange diferentes especializações em visão (atributos visuais) e portanto possui vários pesquisadores envolvidos, surgem também as questões da manutenção e reutilização de código e da integração e cooperação entre os pesquisadores. Um dos principais objetivos deste trabalho foi apresentar as soluções para estes problemas e assim propor uma plataforma de desenvolvimento para o projeto Cyvis-1.

A fim de atender as necessidades de paralelismo do Cyvis-1 e dos demais projetos de nosso grupo (Cybernetic Vision Research Group), introduzimos uma nova plataforma de desenvolvimento de programação concorrente denominada CVMP (Cybernetic Vision Message Passage). Baseado em programação orientada a objetos, interface homem-máquina, engenharia de software e programação visual, o CVMP é uma proposta para facilitar e simplificar o desenvolvimento de programas paralelos, seja através de sistemas distribuídos ou máquinas multiprocessadores. Através do CVMP, qualquer programador com um conhecimento reduzido em Computação Paralela pode desenvolver com facilidade suas próprias aplicações 
paralelas. Além da facilidade de utilização, o CVMP também apresenta recursos para a reutilização de código, permitindo que as estruturas e algoritmos possam ser reaproveitados, agilizando o desenvolvimento de sistemas.

Dentre os componentes que compõem o CVMP, o CVMP processor farm, em especial, ilustra as possibilidades de reutilização de código, facilidade e simplicidade no desenvolvimento de aplicações paralelas. Este componente possui encapsulados todos os recursos necessários para o desenvolvimento de uma aplicação paralela baseada na estratégia processor farm, permitindo que o programador desenvolva um programa concorrente de forma visual.

Diferente da programação seqüencial, na programação concorrente é necessário ao programador analisar a execução do programa, de modo a localizar os gargalos do sistema e efetuar o balanceamento de cargas, permitindo ampliar a sua performance e eficiência. Uma grande limitação dos ambientes de desenvolvimento paralelo está na falta de suporte para tais análises, tornando-as uma tarefa árdua e difícil a ser realizada pelo programador. A fim de suprir essas limitações e auxiliar o programador nas análises estatísticas dos programas concorrentes, o CVMP apresenta ferramentas de análise estatística, que permitem o monitoramento e a análise dos programas em duas diferentes modalidades: dados analisados após o término dos processos ou em tempo de execução.

O CVMP foi desenvolvido para ser utilizado na plataforma Delphi/C++ Builder (Windows NT/9X), aproveitando os recursos computacionais destes ambientes de desenvolvimento (OOP, programação visual, etc.), e permitindo que os programadores utilizem as linguagens e os ambientes seqüenciais a que estão familiarizados no desenvolvimento das aplicações paralelas. Entretanto, graças a sua concepção, o CVMP se comporta como uma camada adicional de software, que gerencia as primitivas de comunicação do sistemas operacional, podendo, deste modo, atuar em sistemas distribuídos ou multiprocessadores (memória compartilhada). Devido a essa característica, o CVMP pode ser desenvolvido de modo a utilizar sistemas de troca de mensagens já existentes, tais como o PVM ou MPI, permitindo um desenvolvimento simples, amigável, e os benefícios da OOP (programação visual, reutilização de código, etc.).

Outra característica do CVMP, devido a sua versatilidade, é a possibilidade de fornecer a base para o desenvolvimento de novas arquiteturas paralelas. Uma vez que o CVMP apresenta um código simples e enxuto (componente CVMP básico com cerca de 980 linhas) e pode ser baseado em qualquer mecanismo de 


\section{CAPÍTULO 9}

comunicação, ele pode ser utilizado como plataforma de desenvolvimento de software para novas arquiteturas. Um bom exemplo para essa aplicação, seriam as arquiteturas baseadas em interface SCSI [Henry et al., 1998] [Mattson \& Henry, 1998] [Phillips, 1998] que, por estarem em desenvolvimento, podem não apresentar dispositivos de comunicação prontos para utilizarem por exemplo ferramentas convencionais de desenvolvimento paralelo (MPI, PVM, etc.). Uma vez que o CVMP pode ser facilmente adaptado a qualquer mecanismo de comunicação, ele pode fornecer a base para o desenvolvimento para novas arquiteturas paralelas.

No decorrer do trabalho, observamos que os problemas que afligiam o desenvolvimento do Cyvis-1 não estavam apenas limitados ao seu universo, mas sim poderiam preencher de certo modo a lacuna do paralelismo em visão, e também de diversas outras áreas científicas que demandam soluções paralelas. Deste modo, a proposta CVMP não apenas cumpriu seus objetivos iniciais como também possibilitou um vasto campo de utilização, abrindo inúmeras perspectivas para esta proposta. Voltaremos a este assunto na seção 9.3, na qual são discutidos seus desenvolvimentos futuros.

Uma vez definida a proposta de paralelismo, um dos objetivos foi avaliar, analisar e validar o CVMP, nos aspectos de funcionalidade, performance e utilização. Esse objetivo foi satisfeito através de uma série de implementações de algoritmos de visão computacional e de processamento de imagens. Foram implementados diversos algoritmos clássicos na área, tais como operadores locais, transformada de Hough, transformada de Fourier e outros. Em cada um dos casos foi discutida a arquitetura e abordagem paralela, assim como analisada a performance e eficiência da versão paralela dos algoritmos frente à seqüencial. Os algoritmos foram analisados através dos módulos de estatística do CVMP, os quais permitiram um estudo sobre seu comportamento, eficiência e performance, gerando resultados que validaram a proposta e demonstraram sua performance e potencial para desenvolvimento de aplicações paralelas. Dentro dessa análise foi ainda introduzida uma nova técnica de paralelismo para um novo algoritmo de segmentação de imagens baseado em campos aleatórios de Markov [Bruno \& Costa, 2000].

Finalizando o trabalho, foram apresentadas 3 aplicações reais de visão artificial que utilizam diferentes conceitos de paralelismo. Tais aplicações não apenas concluem a validação da ferramenta de desenvolvimento paralelo desenvolvida no decorrer deste doutorado, como também demonstram diferentes 
vantagens na utilização de paralelismo em sistemas de visão, tais como: aumento de performance, integração entre atributos visuais, modularidade, independência modular e integração entre pesquisadores. Duas dessas aplicações foram desenvolvidas em conjunto com outros membros do grupo de Visão Cibernética, assim permitindo avaliarmos o paralelismo e o CVMP como integradores de trabalho. A integração entre pesquisadores ocorre devido à natureza do paralelismo, que exige uma estrutura modular e independente e que propicia o trabalho cooperativo. Quanto ao CVMP, a possibilidade de utilizá-lo em projetos cooperativos reais foi de grande valia para comprovar sua simplicidade de utilização (manuseio amigável), facilidade, interação homem-máquina, integrar pesquisadores em trabalhos paralelos cooperativos e reutilização de código. Deste modo, os ótimos resultados obtidos com o CVMP na implementação destas 3 aplicações foi uma convincente maneira de demonstrar que os objetivos da proposta foram satisfeitos.

Todas as 3 aplicações discutidas nesta tese são inéditas, constituindo por si só contribuições originais. A primeira delas contém uma proposta para a integração de atributos visuais (cor e estéreo) dentro do projeto Cyvis-1, a partir do paralelismo. Desenvolvida por Jander Moreira e Alan Salvany Felinto, em colaboração com autor, o sistema foi implementado em CVMP, tendo como finalidade a identificação de objetos poliédricos cromáticos através da integração entre os atributos visuais cor e estéreo. Aqui foi apresentado o primeiro protótipo do sistema Cyvis-1, e diferente das outras duas aplicações, o paralelismo é visto como um agente de integração, uma vez que a implementação não objetiva a performance de processamento. Além da integração dos atributos visuais, a aplicação ilustrou também o paralelismo como fonte de modularização e consequentemente como base de apoio para o trabalho cooperativo.

$\mathrm{Na}$ segunda aplicação foi implementado um experimento no projeto इynergos. Desenvolvido em colaboração com Luís Augusto Consularo e Roberto Cesar Marcondes Jr. [Bruno et al., 2000], a aplicação constitui um experimento para um modelo de complexidade baseado na percepção humana. Através de um experimento psicofísico, são coletados dados que refletem a percepção de complexidade humana. O modelo é baseado em 4 técnicas de medidas de complexidade: (i) Entropia dos níveis de cinza, (ii) Tempo de decaimento multiescala da variância da distribuição dos níveis de cinza da imagem (variância do histograma), (iii) circularidade e (iv) dimensão fractal por salsichas de Minkowski. 
Com base nos dados do experimento psicofísico, as técnicas são otimizadas através de um algoritmo genético paralelo, implementado através do CVMP processor farm. Neste experimento, o paralelismo foi utilizado para aumentar a performance do processo de otimização realizado pelo algoritmo genético. A performance da implementação paralela foi bastante satisfatória, apresentando uma taxa de desempenho próxima ao número de processadores utilizados.

Na terceira aplicação foi introduzida uma proposta do autor, de um sistema de visão paralela para o reconhecimento automático de plantas arbóreas. A fim de desenvolvermos uma aplicação real para visão paralela, procuramos identificar um problema de relevância, onde pudéssemos contribuir para sua solução. Em botânica, é de extrema importância o estudo da biodiversidade, sendo assim é vital o levantamento arbóreo das florestas tropicais, uma vez que estas apresentam a maior biodiversidade do planeta. Foi introduzida nesta tese a proposta de um sistema, que fornece aos botânicos uma ferramenta complementar aos tradicionais herbários. Intitulado TreeVis, o sistema de visão em questão extrai uma série de atributos de folhas de plantas arbóreas e, através de classificador estatístico, procura identificar o espécime, funcionando como um herbário automático. $O$ sistema é baseado em uma arquitetura paralela, utilizada para aumentar o desempenho dos processos de treinamento e reconhecimento. Através de uma heurística especial, tomada a partir do número de amostras a ser processada, o sistema escolhe qual estratégia de paralelismo realiza a tarefa com a melhor performance. Os resultados obtidos comprovaram mais uma vez o potencial do CVMP no fornecimento das bases computacionais para o desenvolvimento de paralelismo, mesmo em situações complexas.

\section{2 - SíNTESE DAS PRINCIPAIS CONTRIBUIÇÕES}

Embora inter-relacionados, os assuntos abordados nesta tese podem ser divididos em três modalidades, relacionadas da seguinte forma: (i) discussão do paralelismo em visão natural e artificial; (ii) proposta CVMP e (iii) aplicações paralelas reais em visão artificial. Seguindo essa divisão, foi montada a tabela 9.1 , que apresenta a síntese das principais contribuições de cada modalidade. 


\begin{tabular}{|c|c|}
\hline ABORDAGEM & CONTRIBUIÇÕES \\
\hline $\begin{array}{l}\text { Discussão do } \\
\text { paralelismo em visão } \\
\text { natural e artificial }\end{array}$ & $\begin{array}{l}\text { - Revisão bibliográfica crítica e abrangente de computação paralela. } \\
\text { - Discussão do sistema de visão cortical dos primatas sob o ponto de } \\
\text { vista do paralelismo. } \\
\text { - Levantamento das principais questões, adotadas no sistema de visão } \\
\text { - Los primatas, que podem aperfeiçoar os sistemas de visão artificial. } \\
\text { - Levantamento de sistemas de visão e comparação com o Cyvis-1. } \\
\text { - Discussão das abordagens de paralelismo no projeto Cyvis-1 } \\
\text { - Levantamento das possíveis contribuições fornecidas pelo } \\
\text { paralelismo em visão artificial. }\end{array}$ \\
\hline Proposta CVMP & $\begin{array}{l}\text { - Proposta de um conjunto de ferramentas para o desenvolvimento de } \\
\text { aplicações paralelas, com base na simplicidade de utilização } \\
\text { (manuseio amigável), facilidade, programação visual e reutilização de } \\
\text { código - CVMP (Cybernetic Vision Message Passage). } \\
\text { - Desenvolvimento, implementação e validação da proposta CVMP. } \\
\text { - Ferramentas para a análise estatística de programas concorrentes. } \\
\text { - Implementação e avaliação do desempenho de diversos algoritmos } \\
\text { de visão e processamento de imagens. } \\
\text { - Técnica de paralelismo para um novo algoritmo de segmentação de } \\
\text { imagens baseado em campos aleatórios de Markov. }\end{array}$ \\
\hline $\begin{array}{l}\text { Aplicações paralelas } \\
\text { reais em visão artificial }\end{array}$ & 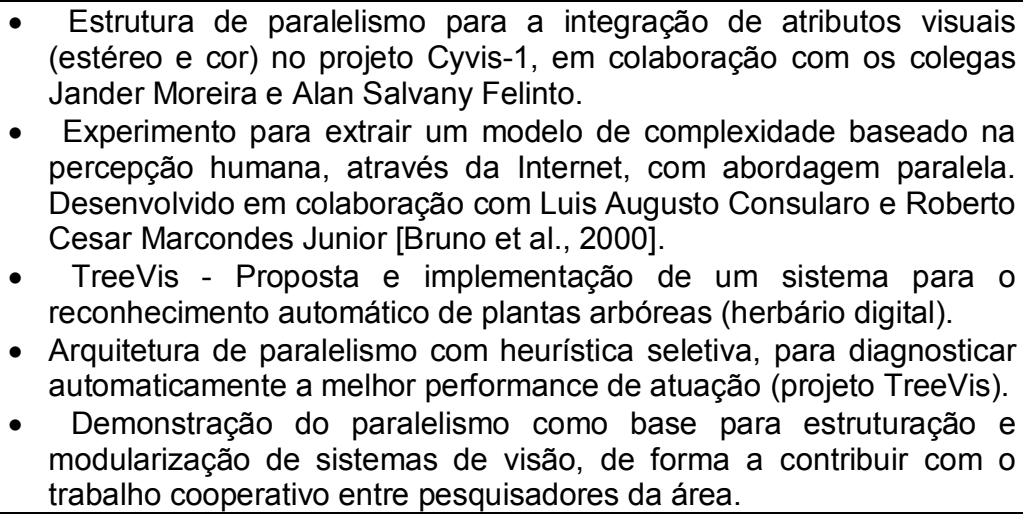 \\
\hline
\end{tabular}

Tabela 9.1 - Síntese das principais contribuições desta tese. 


\section{3 - PESQUISAS FUTURAS}

Uma das características dos trabalhos multidisciplinares está na diversidade de direções que eles motivam, possibilitando perspectivas tanto para sua continuidade quanto para o surgimento de novas linhas de pesquisa. Como seria de se esperar, as contribuições desta tese proporcionam diversos caminhos para estudos futuros, complementações do trabalho e novas linhas de pesquisa. Vamos fazer algumas sugestões para a continuidade deste trabalho, obedecendo a divisão modular apresentada na seção anterior: (i) estudos de paralelismo em visão natural e artificial; (ii) proposta CVMP e (iii) aplicações paralelas reais em visão artificial. Estaremos tecendo um breve comentário em cada um dos itens das subseções seguintes.

\subsection{1 - ESTUDOS DE PARALELISMO EM VISÃO NATURAL}

\section{E ARTIFICIAL}

(i) Acompanhar o desenvolvimento da neurociência: O córtex visual ainda é muito pouco compreendido, tornando sua pesquisa uma área fértil e produtiva, da qual provêm com freqüência considerada, novos modelos, teorias e descobertas. Deste modo, o estudo do paralelismo em visão é uma tarefa contínua, que exige o acompanhamento constante do desenvolvimento da neurociência e áreas relacionadas.

(ii) Experimentos em modelos corticais artificiais: Modelos corticais artificiais contribuem para a compreensão dos mecanismos corticais. $O$ estudo do paralelismo no córtex visual através de simuladores neurológicos pode elucidar questões e apresentar novas abordagens para sistema paralelos de visão artificial.

(iii) Caracterização do paralelismo em visão: Os estudos e implementações de paralelismo em sistemas de visão artificial, realizados neste trabalho, podem ser aprimorados e estendidos a fim de se obter uma caracterização mais formal e genérica do paralelismo em visão artificial. Através da implementação e estudo de diversos sistemas de visão artificial, poderão ser estimadas estatísticas para o comportamento do fluxo de mensagem, dependência de dados e gargalos, ao longo da hierarquia do processamento visual. 


\subsubsection{PROPOSTA CVMP:}

(i) Validar a versão CVMP multiprocessadores: Embora tenha sido implementado e discutido o componente CVMP para máquinas multiprocessadores, a sua validação foi realizada através de simulações, utilizando o mecanismo de multitarefa, ficando como uma tarefa para futuros desenvolvimentos do CVMP a sua avaliação e validação mais concreta em máquinas realmente multiprocessadas.

(ii) Portar o CVMP para UNIX: Acreditamos que seria de grande importância portar a ferramenta CVMP para o sistema operacional UNIX, especialmente por este constituir uma plataforma particularmente utilizada no desenvolvimento de aplicações paralelas. Uma versão UNIX das ferramentas CVMP traria benefícios tanto para a proposta CVMP, através de sua divulgação, críticas e eventualmente contribuições do mundo UNIX, assim como para a própria comunidade UNIX, que possui como uma de suas principais deficiências a ausência de ferramentas que priorizem a interação homem-máquina e o manuseio amigável e intuitivo. A viabilização do CVMP para UNIX, se tornará possível e será justificada com o lançamento do ambiente de desenvolvimento Delphi para Linux, o Kylix, previsto para o segundo semestre de 2000.

(iii) Desenvolver o CVMP sobre plataformas PVM ou MPI: O CVMP pode ser desenvolvido para atuar sobre uma plataforma de troca de mensagens já estabelecida. Uma linha de pesquisa que deve ser considerada como continuidade deste trabalho é o desenvolvimento de versões CVMP sobre as plataformas PVM ou MPI. Uma vez que existe uma série de trabalhos científicos para essas plataformas, este desenvolvimento traria inúmeros benefícios para a proposta CVMP, ampliando seus recursos e possibilidades de desenvolvimento paralelo. Do mesmo modo, essa linha de pesquisa poderá proporcionar uma série de contribuições, levando para estas plataformas os benefícios CVMP (desenvolvimento visual, manuseio amigável, reutilização de código, desenvolvimento OOP, etc.).

(iv) Novas arquiteturas: O CVMP pode ser considerado como uma camada extra de software sobre as primitivas de comunicação, que pode utilizar virtualmente qualquer mecanismo ou plataforma para troca de mensagens. Assim, uma interessante linha de pesquisa na qual pode ser utilizada essa proposta seria o desenvolvimento de novas arquiteturas paralelas. Uma das dificuldades nesse tipo de projeto se encontra na base de plataformas de desenvolvimento de software. 


\section{CAPÍTULO 9}

Uma vez que as tradicionais plataformas de desenvolvimento paralelo necessitam "drivers" e bibliotecas específicas, o CVMP pode ser bastante promissor nesta área, uma vez que possui um código simples e enxuto, que pode ser facilmente adaptado a virtualmente qualquer mecanismo de comunicação. Um prova disto está no início de seu desenvolvimento. Antes de ser implementado para redes de computadores, o CVMP possuiu uma versão experimental que implementava máquinas paralelas através de comunicação com o porto paralelo (LPT, porta de impressora).

(v) Encapsular outras estratégias de paralelismo: Um grande sucesso na proposta CVMP foi o encapsulamento da estratégia de paralelismo processor farm. Através deste componente, o desenvolvimento de aplicações paralelas baseadas nesta estratégia se tornou uma tarefa simples e objetiva, uma vez que o componente apresenta encapsulado todo o mecanismo envolvido nesta abordagem. No entanto, apenas uma estratégia de paralelismo foi encapsulada fazendo parte do conjunto de ferramentas CVMP, ficando como sugestão para futuros desenvolvimentos a incorporação de novos componentes que encapsulem outras abordagens de paralelismo.

(vi) Desenvolver objetos para métodos de visão computacional e processamento de imagens: Uma das características da proposta CVMP é permitir a criação de componentes personalizados, que encapsulam métodos e técnicas. Embora tenham sido realizados estudos sobre alguns algoritmos de visão, apenas duas técnicas foram encapsuladas, gerando componentes prontos para utilização. De forma a auxiliar o desenvolvimento de aplicações paralelas, seria interessante a criação de diversos componentes com diferentes técnicas de processamento e visão computacional encapsuladas.

(vii) Aperfeiçoar o módulo de estatística: Uma das limitações das ferramentas de estatística apresentadas nesta tese, especialmente a versão em tempo real, está no seu condicionamento à máquina, ou seja, não foi desenvolvido uma versão da ferramenta que possibilita concentrar em um único módulo a análise de comportamento de todas as máquinas da rede. Embora esse tipo de abordagem possa acarretar uma sobre carga de mensagens na rede, diversas situações justificam sua utilização. 


\subsection{3 - APLICAÇÕES PARALELAS REAIS EM VISÃO ARTIFICIAL}

\subsubsection{1 - PROJETO CYVIS-1}

(i) Incorporação de novos atributos visuais: No protótipo desenvolvido no grupo, apenas duas modalidades visuais foram consideradas. A proposta do Cyvis-1, entretanto, é baseada na integração de diversos atributos visuais. Portanto, novas pesquisas deverão ser realizadas, especialmente na estrutura de comunicação e representação de informações, a fim de permitir que atributos adicionais sejam acrescentados no sistema.

(ii) Reestruturação do sistema priorizando a performance: Embora o paralelismo tenha sido utilizado no sistema enfocando os estudos de integração de atributos visuais, representação de dados e trabalho corporativo, sua reestruturação visando ampliar a performance e independência de dados entre os módulos seria bastante interessante, uma vez que este é um dos principais objetivos da Computação Paralela.

(iii) Inserção de novas estratégias de comunicação e fluxo inverso de dados: $O$ projeto Cyvis-1 prevê várias etapas de comunicação realizadas entre os atributos visuais em diferentes níveis hierárquicos do processamento, assim como o fluxo de informações nos dois sentidos ("top-down" e "botton-up"). Pesquisas deverão ser realizadas a fim de incorporar tais características ao sistema.

\subsubsection{2 - PROPOSTA TREEVIS}

(i) Avaliação do protótipo (identificação das plantas arbóreas): A avaliação do protótipo TreeVis, realizada nesta tese, foi bastante sucinta. Apresentamos apenas um resultado para uma situação extrema do sistema (pior situação), que embora tenha mostrado bons resultados, não relatou com a devida determinação científica sua validação. Pretendemos realizar novos experimentos a fim de determinar de maneira mais acurada as características do protótipo, contendo resultados para as situações extremas e para as situações onde o sistema se apresente mais promissor (maior quantidade de amostras por espécie) e também, se possível, com um número maior de espécies arbóreas. 
(ii) Realização de estudo abrangente da natureza e diversidade morfológica das folhas: Para implementar o primeiro protótipo do TreeVis, adotamos algumas metodologias para a extração de características, que embora tenham sido escolhidas experimentalmente através de análises em alguns tipos de folhas, a pesquisa realizada não foi suficientemente abrangente e acurada da forma exigida pelo problema. Para a continuidade da proposta TreeVis seria necessária, uma vasta e abrangente investigação sobre as características morfológicas das folhas de plantas arbóreas, de modo a definir de maneira mais precisa quais as metodologias e medidas se adequam melhor ao processo de classificação das espécies. Devido à divergência das espécies, acreditamos que deverão ser acrescidas muitas técnicas de processamento e visão, a fim de obter bons resultados em bases com centenas ou milhares de espécies.

(iii) Desenvolvimento de novos protótipos, dando continuidade a proposta: $O$ reconhecimento automático de plantas arbóreas é um problema que está longe de ser resolvido na sua íntegra. O protótipo apresentado nesta tese contém apenas os primeiros passos para uma solução. Muito trabalho e pesquisa ainda são necessários, sugerindo numerosos outros protótipos para consolidar uma ferramenta consistente e definitiva para que o TreeVis possa vir a ser utilizado como um herbário digital.

(iv) Adaptação e extensão do sistema para outros problemas em ciência teórica e aplicada: Embora voltado para a botânica, o ambiente e as estruturas de paralelismo desenvolvidas no protótipo TreeVis podem ser adaptadas e estendidas para outros problemas em ciência teórica e aplicada incluindo, por exemplo, mineração de dados em engenharia biomolecular (genética). 


\section{BIBLIOGRAFIA}

[Almasi \& Gottlieb, 1994] ALMASI, G. S.; GOTTLIEB, A. Highly Parallel Computing. 2.ed. California, The Benjamin/cummings Publishing, 1994.

[Amorin et al.,1988] AMORIN, C. L.; BARBOSA, V. C.; FERNANDES, E. S. T. Uma introdução à computação paralela e distribuída. VI Escola de Computação, Campinas, UNICAMP, 1988.

[Andrews \& Schneider, 1983] ANDREWS, G. R.; SCHNEIDER, F. B. Concepts and Notations for Concurrent Processing. ACM Computing Surveys, v.15 pp3-43, 1983.

[Atkin, 1987] ATKIN, P. Performance Maximization. Technical note 17, Inmos Ltd., Bristol, 1987.

[Baber et al., 1993] BABER, C. ; HOYES, T. ; STANTON, N. A. Comparison of GUls and CUls: appropriate ranges of actions and the ease of use. Displays, v14, n4, pp207-215, 1993.

[Ballard \& Brown, 1982] BALLARD, D. H ; BROWN, C. M. Computer Vision. Prentice-Hall, 1982.

[Barlow \& Mollom, 1982] BARLOW, H. B. ; MOLLON, J. D. The Senses, Cambridge University Press, 1982.

[Bem-Ari, 1990] BEM-ARI, M. Principles of Concurrent and Distributed Programming. New York, Prentice Hall, 1990.

[Benchmark] http://webopedia.internet.com/TERM/b/benchmark.html

[Bennett, 1997] BENNETT, G. Designing TCP/IP Internetworks. John Wiley \& Sons, 1997.

[Besag, 1986] Besag, J. On the statistical analysis of dirty pictures. J. Roy. Statist.Soc. B, 48(3):259-302, 1986.

[Biswas et al., 1998] BISWAS, M. K. ; GHOSE, T. ; GUHA, S. ; BISWAS, K. K. Fractal dimension estimation for texture images: A parallel approach. Pattern Recognition Letters, 19(1998) pp.309-313, 1998.

[Blasdel, 1986] BLASDEL, G. Differential imaging of ocular dominance and orientation selectivity in monkey striate cortex. Nature, 321:579-585, 1986.

[Bogni \& Marrone, 1991] BOGNI, C. J.; MARRONE, L. Arquitectura de 
Computadoras. Rio de Janeiro, V Escola Brasileiro - Argentina de Informática, 1991.

[Bonhoeffer \& Grinvald, 1991] BONHOEFFER, T. ; GRINVALD, A. Iso-orientation domains in cat visual cortex are arranged in pinwheel-like patterns. Nature, 353: 429-431, 1991.

[Bonner, 1995] BONNER, P. Programação Visual: Promessa/Realidade Windows Computing, v. 2, n.1, p.64-6, 68, 70, 72, 74-5, 1995.

[Braham, 1996] BRAHAM, R. Toward an artificial eye, IEEE Spectrum, p.20-29, May 1996.

[Braitenberg \& Braitenberg, 1979] BRAITENBERG, V ; BRAITENBERG, C. Geometry of orientation columns in the visual cortex. Biological Cybernetics, 33:179-186. 1979.

[Brawer, 1989] BRAWER, S. Introduction to Parallel Programming. San Diego, CA (USA), Academic Press, 1989.

[Breton, 1991] BRETON, Philippe História da Informática São Paulo, Ed. UNESP, 1991

[Brigham, 1988] BRIGHAM, E. O. The Fast Fourier Transform and its Applications. Prentice Hall, 1988.

[Broca, 1861] BROCA, P. P. Perte de la parole, ramollisement chronique et destructuion partielle du lobe antérieure gauche du cerveau. Bull. Soc. Anthropol, v. 2, pp. 235-238.

[Bruce \& Green, 1990] BRUCE, V. ; GREEN, P. Visual perception: physiology, psychology and ecology 2ed. London, Lawrence Erlbaum Associates, 1990.

[Bruno \& Costa, 1996] BRUNO, O. M. ; COSTA, L da F. Towards Cost-Effective and Versatile Real-Time Vision Based on a Distributed System of Personal Computers. IEEE Proceedings - II Workshop on Cybernetic Vision. São Carlos, Brasil, 1996.

[Bruno \& Costa, 1997] BRUNO, O. M.; COSTA, L. da F. Versatile Real-Time Vision Based on a Distributed System of Personal Computers. Proceedings Third IEEE International Conference on Engineering of Complex Computer Systems. Como, Itália, 1997.

[Bruno \& Costa, 2000] BRUNO, O. M.; COSTA, L. da F. Effective Image Segmentation with Flexible ICM-Based Markov Random Fields in a Distributed Systems of Personal Computers. Real-Time Imaging, artigo 
submetido e aceito, aguardando publicação.

[Bruno et al., 1998] BRUNO, O. M., CESAR Jr., R.M., CONSULARO, L.A., and COSTA, L. F. Automatic feature selection for biological shape classification in Lynergos. Proceedings 1998 International Symposium on Computer Graphics, Image Processing and Vision, Rio de Janeiro, RJ, IEEE Computer Society Press, pp 363-370, 1998.

[Bruno et al., 2000] BRUNO, O. M., CESAR Jr., R.M., CONSULARO, L.A., and COSTA, L. F. Eynergos - Synergetic Vision Research. Real Time Journal, artigo submetido e aceito, aguardando publicação.

[Bruno, 1995] BRUNO, O. M. Sistema Automatizado de Medidas TSC em

Plataforma GUI Dissertação de Mestrado, IFSC - USP, 1995.

[Bruno, 1999] BRUNO, O. M. Exame de qualificação, IFSC-USP, 1999.

[Calvert, 1997] CALVERT, C. Borland C++ Builder unleashed. Sams, 1997.

[Calvert, 1999] CALVERT, C. Delphi 4 unleashed. Sams, 1999.

[Cantoni \& Lombardi, 1999] CANTONI, V. ; LOMBARDI, L. Visual attention in artificial systems. Proceedings 1999 I International Seminar on Bioelectronic Interfaces and III Workshop on Cybernetic Vision, Campinas, Brazil, 1999.

[Cantù,1995] CANTÙ, M. Mastering Delphi Sybex, 1995

[Caserta et al., 1995] CASERTA, F. ; ELDRED, W. D. ;FERNANDEZ, E. ; HAUSMAN, R. E. ; STANFORD, L. R. ; BULDEREV, S. V. ; SCHWARZER, S. ; STANLEY, H. E. Determination of fractal dimension of physiologically characterized neurons in two and three dimensions. Journal of Neuroscience Methods. 56, pp. 133-144, 1995.

[Castleman, 1996] CASTLEMAN, K.R. Digital Image Processing, Prentice-Hall, Englewood Cliffs, NJ, 1996.

[Cesar \& Costa, 1998] CESAR Jr., R.M. and COSTA, L. F. Neural cell classification by wavelets and multiscale curvature, Biological Cybernetics, v.79, n.4, pp.347-360, 1998.

[Cesar, 1997] CESAR Jr., R. M. Análise Multi-escala de formas bidimensionais. Tese de doutorado, IFSC - USP, 1997.

[Chappell, 1998] CHAPPELL, L. A. Novell's Guide to Lan/Wan Analysis : Ipx/Spx. Novell Press, 1998.

[Chellappa \& Jain, 1993] CHELLAPPA, R. ; JAIN, A, (eds.). Markov Random Fields. Academic Press, 1993. 
[Chu \& George, 1999] CHU, E. ; GEORGE, A. Inside the FFT Black Box: Serial and Parallel Fast Fourier Transform Algorithms. CRC Press LLC, 1999.

[Clark, 1986] CLARK, N. N. Three Techniques for Implementing Digital Fractal Analysis of Particle Shape .Powder Technology. 46, 1986.

[Codenoti \& Leoncini, 1994] CODENOTI, Bruno ; LEONCINI, Mauro.. Introducing to Parallel Processing. New York, Addison-Wesley, 1994.

[Coelho, 1998] COELHO, R. C. Síntese, modelagem e simulação de estruturas neurais morfologicamente realísticas. Tese de doutorado, IFSC - USP, 1998.

[Consularo \& Costa, 1998] CONSULARO, L. A. ; COSTA, L. da F. MATCOM Integrates MATLAB Resources Into Standalone Applications. Computers in Physics, v12 n5 p460, 1998.

[Consularo et al., 1999] CONSULARO, L. A. ; CESAR JR, R. M. ; COSTA, L. da F. इynergos and its application to contour segmentation. Proceedings 1999 I International Seminar on Bioelectronic Interfaces and III Workshop on Cybernetic Vision, Campinas, Brazil, 1999.

[Costa \& Sandler, 1993] COSTA, L. da F. ; SANDLER, M. B. Effective detection of digital bar segments with Hough transform. CVGIP: Gr. Models Imge Process: v.55, n.3, pp.180-191, 1993.

[Costa \& Slaets, 1991] COSTA, L. da F. ; SLAETS, J. F. W. On the efficiency of parallel pipelined architectures, IEEE Transactions on Signal Processing, 39(9):2086-2089, 1991.

[Costa \& Velte, 1999] COSTA, L. F. and VELTE, T. Automatic characterization and classification of ganglion cells from the salamander retina, Journal of Comparative Neurology, v.404, n.1, pp.33-51, 1999

[Costa et al., 1994] COSTA, L. da F. ; RODA, V. O. ; KÖBERLE, R. A biologicallyinspired system for visual pattern recognition. Proceedings - IEEE International Symposium on Industrial Electronics, Santiago, Chile, 1994.

[Costa, 1996] COSTA, L. da F. Novas perspectivas em neuromorfologia e neuromodelagem, Tese de livre-docência, IFSC - USP, 1996.

[Cox, 1986] COX, Brad J. Object-Oriented Programming - AN Evolutionary Approach. New York, Addison-Wesley, 1986.

[Darwin, 1859] DARWIN, C. R. On the Origin of Species by Means of Natural Selection - The Preservation of Favored Races in the Struggle for Life, London, 1859 (disponível em http://www.literature.org/authors/darwin- 
charles/the-origin-of-the-species/index.html).

[Deatz, 1997] DEATZ, G. Sharing memory. Delphi Informant, v.3, n.11, 1997.

[Dowling, 1992] DOWLING, J. E. Neurons and networks - An introduction to neurocience. The Belknap Press of Harvard University Press, 1992.

[Duda \& Hart, 1972] DUDA, R. O. ; HART, P. E. Use of the Hough transformation to detect lines and curves in pictures. Comunications of the ACM, v.15, n.1, pp11-15, 1972.

[Duda \& Hart, 1973] DUDA, R. O. ; HART, P. E. Pattern classification and scene analysis. John Wiley and Sons, Inc., New York, 1973.

[Dumas, 1995] DUMAS, A. Programando winsock. Axcel Books, 1995.

[Duncan, 1990] DUNCAN, R. A Survey of Parallel Computer Architectures. Computer IEEE, v23, n 2, p 5-16, 1990.

[Etter, 1995] ETTER, D. M. Introduction to MATLAB for engineers and scientists. Prentice-Hall, 1995.

[Faber et al., 1987] FABER, V ; LUBECK, O. M. ; WHITE, A. B. Jr. Comments on the paper "Parallel efficiency can be greater than unity", Parallel Computing, 4:209-210, 1987.

[Falconer, 1990] FALCONER, K. Fractal Geometry-Mathematical Foundations and Applications. John Wiley \& Sons, 1990.

[Faugeras, 1996] FAUGERA, O. Three-dimensional computer vision: a geometric viewpoint. MIT Press, $2^{\text {nd }}$ ed. 1996.

[Fernades et al., 1993] FERNANDES, Edil S. T.; AMORIN, Cláudio, L. de Arquiteturas Paralelas Avançadas. Embalse, VI Escuela Brasileño Argentina de Informática, 1993.

[Fernades, 1997] FERNANDES, I. Taxonomia e fitogeografia de Cyatheaceae e Dicksoniaceae nas Regiões Sul e Sudeste do Brasil. Tese de doutorado, IB (Instituto de Botanica) USP, 1997.

[Flynn, 1966] FLYNN, M. J., Very High Speed Computing Systems Proc.IEEE Vol 54, p 1901-9, 1966

[Flynn, 1972] FLYNN, M. J. Some Computer Organizations and Their Effectiveness. IEEE Trans. Comput. C-21 p948-60, 1972

[Foster, 1995] FOSTER, I. Designing and Building Parallel Program - Concepts and Tools for Parallel Software Engineering. New York, Addison-Wesley, 1995.

[Fritsch \& Hitzig, 1870] Fritsch, G. ; Hitzig, E. Uber die elektriche erregbakeit des 
grosshirns. Arch. F. Anat. Physiol. U. Wiss. Med., v.37, pp. 300-332.

[Gazzaniga, 1998] GAZZANIGA, m. S. The split brain revisited Scientific American v. 279 , n. 1, p 34-39, July, 1998.

[Gehani, 1988] GEHANI, N. Ed. ; MCGETTRICK, A. Ed. Concurrent Programming. Wokingham, England, Addison-Wesley, 1988.

[Geist et al., 1996] GEIST, BEGUELIN, DONGARRA, et al. PVM: Parallel Virtual Machine, A User's Guide and Tutorial for Parallel Computing, MIT Press, 1996.

[Geman \& Geman, 1984] GEMAN, S. ; GEMAN, D. Stochastic relaxation, Gibbs distributions, and the Bayesian restoration of images. IEEE Transactions on Pattern Analysis and Machine Intelligence, vol. PAMI-6, n.6, november 1984.

[Gerig \& Klein, 1986] GERIG, G. \& KLEIN, F. Fast contour identification through efficient Hough transform and simplified interpretation strategy. In: Proc. 8th Int. Conference on Pattern Recognition, vol. 1, pp. 498-500, Paris, France, October 27-31, 1986.

[Gimarc \& Milutinovic, 1987] GIMARC, C. E.; MILUTINOVIC, V. M. A survey of RISC processors and computers in the mid-1980s. IEEE Computer, 20(9), p59-69, Sep. 1987.

[GNOME] www.gnome.org

[Goldberg, 1989] GOLDBERG, D. E. Genetic algorithms in search, optimization, and machine learning, Addison-Wesley, 1989.

[Goldstein, 1989] GOLDSTEIN, E. B. Sensation and Perception. Wadsworth Publish Company, 1989.

[Goldstine, 1993] GOLDSTINE. Herman H. The Computer from Pascal to Von Neumann. Princeton, Princeton University Press, 1993.

[Gomes et al., 1999] GOMES, C. ; BUNKS C. ; CHANCELIER, J. ; STEER, S. ; NIKOUKHAH, R. Engineering and scientific computing with Scilab. Springer Verlag, 1999.

[Gonçalves, 1999] GONÇALVES, S. E. Reconhecimento Visual Atencional. Tese de doutorado, COPPE, UFRJ, 1999.

[Gonzalez \& Woods, 1993] GONZALEZ, R. C. ; WOODS, R. E. Digital Image Processing. Addison-Wesley, 1993.

[Gregory, 1987] GREGORY, S. Parallel Logic Programming in PARLOG, AddisonWesley, 1987. 
[Grimes, 1997] GRIMES, R. Professional DCOM programming. Wrox Press, 1997. [Guil \& Zapata, 1997] GUIL, N.; ZAPATA, E. L. Fast Hough transform on multiprocessors: A branch and bound approach. Journal of Parallel and Distributed Computing, 45(1):82-89, August 1997.

45(1):82-89, 25 August 1997. [BibTeX entry]

[Hayes, 1990] HAYES, Frank From TTY to VUI. Byte, p205-211, Ap. 1990.

[Henry et al., 1998] HENRY, G. ; FAY, P. ; COLE, B. ; MATTSON, T. G. The performance of the Intel TFLOPS supercomputer. http://developer.intel.com/technology/itj/q11998/articles/art_2.htm , 1998.

[Hockney \& Jesshope, 1988] HOCKNEY, R. W.; JESSHOPE, C. R. Parallel Computers 2. Philadelphia, IOP, 1988

[Hodges, 1992] HODGES, Andrew Alan Turing: The Enigma London, Vintage, 1992.

[Hough, 1959] HOUGH, P. V .C. Machine Analysis of Bubble Chamber Pictures. International Conference on High Energy Accelerators and Instrumentation, CERN, 1959.

[Hubel \& Wiesel, 1977] Functional architecture of macaque monkey visual cortex. Ferrier Lecture, Proc. R. Soc. Lond. B. 198:1-59.

[Hubel et al., 1977] HUBEL, D. H.; WIESEL, T. N.; STRYKER, M. P. Orientation columns in macaque monkey visual cortex demonstrated by the 2deoxyglucose autoradiograph technique. Science, 269:328-330.

[Hubel, 1995] HUBEL, D. H. Eye, brain and vision Scientific American Library, 1995.

[Hudak, 1989] HUDAK, P. Functional Programming Languages, ACM Computing Surveys, v. 21, pp359-411, 1989.

[Hundert, 1995] HUNDERT, E. M. Lessons from an optical illusion: On nature and nurture, knowledge and values. Harvard University Press, 1995.

[Hurson et al., 1993] HURSON, A. R. ; PAKZAD, S. H. ; CHENG, J. ObjectOriented Database Management Systems: Evolution and Performance Issues, Computer, v.26, n. 2, p. 48-60, 1993.

[Hwang et al., 1984] HWANG, Kai; BRIGGS, Fayé A. Computer Architecture and

Parallel Processing. New York, McGraw-Hill, 1984.

[Inmos, 1988] INMOS Limited. Transputer Reference Manual. New York, Prentice Hall, 1988.

[Inmos, 1988b] INMOS Limited. Occam2 Programming Manual, Prentice Hall, 1988. 
[Inmos, 1989] Transputer Applications Notebook - Architecture and Software. Inmos, 1989.

[Joly, 1993 JOLY, A. B. Botânica - Introdução à taxonomia vegetal. Companhia Editora Nacional, 11 edição, 1993.

[Julesz, 1995] JULESZ, B. Dialogues on perception. The MIT Press, 1995.

[Kaye, 1989] KAYE, B. H. Image Analysis Techniques for Characterizing Fractal

Structures. from The Fractal Approach to Heterogeneous Chemistry (D. Avnir, editor). John Wiley \& Sons Ltd., 1989.

[Kaye, 1994] KAYE, B. H. A Random Walk Through Fractal Dimensions: $2^{\text {nd }}$ Edition. New York, VCH Publishers, 1994.

[Kindermann and Snell, 1980] KINDERMANN, R. ; SNELL, J. L. Markov random fields and their applications. Contemporary Mathematics, American Mathematical Society, 1980.

[Konopka, 1997] Konopka, R. Developing custom Delphi 3 components. Scottsdale, Arizona (USA), The Coriolis Group, 1997.

[Kosslyn, 1996] KOSSLYN, S. M. Image and Brain: The resolution of the imagery debate. The MIT Press, 1996.

[Kovács, 1996] KOVÁCS, Z. L. Redes neurais artificiais: Fundamentos e aplicações. São Paulo, Edição Acadêmica, 1996.

[Kovács, 1997] KOVÁCS, Z. L. O cérebro e a sua mente: Uma introdução à neurociência computacional. São Paulo, Edição Acadêmica, 1997.

[Krishnamurthy, 1989] KRISHNAMURTHY, E. V. Parallel Processing: Principles and practice. Sydney, Addison-Wesley, 1989.

[Kung et al., 1987] KUNG, S. Y. et al. Wavefront Array Processors - Concept to Implemention. Computer IEEE, 20(7), p18-33, Jun. 1987.

[Kylix] http://www.borland.com/about/press/2000/kylixkickstart.html , Abril, 2000.

[Leventhal, 1988] LEVENTHAL, Lance Lance Leventhal's 80386 Programming Guide Toronto, Bantam Book, 1988.

[Levine \& Shefner, 1991] LEVINE, M. W. ; SHEFNER, J. M. Fundamentals of sensation and perception. Brooks/Cole Publishing, 1991.

[Levine, 1985] LEVINE, M. D. Vision in man and machine. N. York, McGraw-Hill, 1985.

[Li, 1995] LI, S. Z. Markov random field modeling in computer vision. SpringerVerlag, 1995.

[Livingstone \& Hubel, 1988] LIVINGSTONE, M. ; HUBEL, D. Segregation of form, 
color, movement and depht: anatomy, physiology and perception. Science, v.240 p.740-749, 6 May 1988.

[Lorenzi, 1992] LORENZI, H. Árvores brasileiras: Manual de identificação e cultivo de plantas arbóreas nativas do Brasil. Editora Plantarum, 1992.

[Machado, 1993] MACHADO, A. B. M. Neuroanatomia funcional. 2.ed. São Paulo, Atheneu, 1993.

[Mandelbrot, 1977] MANDELBROT, B. B. Fractals: Form, Chance and Dimension. W. H. Freeman and Company, 1977.

[Mandelbrot, 1983] MANDELBROT, B. B. The fractal geometry of nature. W. H. Freeman and Company, 1983.

[Marr, 1982] MARR, D. Vision - A computational investigation into the human representation and processing of visual information. New York, W. H. Freeman and Company, 1982.

[Mattson \& Henry, 1998] MATTSON, T. G. ; HENRY, G. An overview of the Intel TFLOPS supercomputer.

http://developer.intel.com/technology/itj/q11998/articles/art_1.htm , 1998.

[McCulloch \& Pitts, 1943] MCCULLOCH, W. ; PITTS, W. A logical calculus of the ideas immanent in nervous activity. Bulletin of Mathematical Biophysics, 1943.

[Mel, 1997] MEL, B. W. SEEMORE: Combining color, shape, and texture histogramming in a neurally inspired approach to visual object recognition. Neural Computation, v.9 pp.777-804, 1997.

[Morante et al., 1999] MORANTE, S. ; ROSSI, G. ; SALINA, G. A parallel fast Fourier transform. International Journal of Modern Physics C, Vol. 10, No. 5, pp. 781-805, 1999.

[Moreira et al., 1999] MOREIRA, J. ; FELINTO, A. S. ; COSTA, L. F. Cyvis-1: Integration of Color and Stereo. International Workshop on SyntheticNatural Hybrid Coding on 3D imaging. Santorini, Greece, September 1517, 1999.

[Moreira, 1999] MOREIRA, J. Uma proposta de estruturação e integração de processamento de cores em sistemas artificiais de visão. Tese de doutorado, IFSC - USP, 1999.

[Mullender et al., 1990] MULLENDER, S. J.; ROSSUM, G.; TANENBAUM, A. S.; RENESSE, R.; STAVEREN, H. Amoeba: A Distributed Operating System for the 1990s. IEEE Computer, vol. 23, pp. 44-53, May 1990. 
[Naiditch, 1995] NAIDITCH, D. Rendezvous with Ada 95, John Wiley \& Sons, 1995.

[Nazif \& Levine, 1984] NAZIF, A. M. ; LEVINE, M. D. Low level image segmentation: An expert system. IEEE Transactions on Pattern Analysis and Machine Intelligence. V.PAMI-6, n.5, September, 1984.

[Nelson, 1989] NELSON, M. LZW data compression. Dr. Dobb's Journal, October 1989.

[Oppenheim \& Schafer, 1975] OPPENHEIM, A.V. ; SCHAFER, R.W. Digital Signal Processing, Prentice Hall, 1975.

[Pacheco, 1997] PACHECO, Peter. Parallel Programming with MPI, Morgan Kaufmann, 1997.

[Parker, 1997] PARKER, J. R. Algorithms for Image Processing and Computer Vision. John Wiley \& Sons, 1997.

[Peddie, 1992] PEDDIE, Jon Graphical User Interfaces and Graphic Standards. New York, McGraw Hill, 1992.

[Peitgen \& Saupe, 1988] PEITGEN, H. O. ; SAUPE, D. The science of fractal images. Springer-Verlag, New York, 1988.

[Peixoto \& Barbosa, 1998] PEIXOTO, A. L. ; BARBOSA, M. R. V. Os herbários brasileiros e a flora nacional: Desafios para o século 21. Sistemas de informação sobre biodiversidade/biotecnologia para o desenvolvimento sustentável, 1998. - http://www.bdt.org.br/oea/sib/

[Penrose, 1989] PENROSE, R. The emperor's new mind: Concerning computers, minds, and the laws of physics. Oxford University Press, 1989.

[Petzold \& Yao, 1996] PETZOLD, C. ; YAO P. Programming Windows 95. Redmond, Microsoft Press, 1996

[Pfister, 1995] PFISTER, G. F. In Search of Clusters, New York, Prentice Hall, 1995.

[Phillips, 1998] PHILLIPS, B. Have storage area networks coming out of age? IEEE Computer, p10-12, July, 1998.

[Poggio \& Weinshall, 1993] POGGIO, T. ; WEINSHALL, D. The MIT vision machine: Progress in the integration of vision modules. In: CHELLAPA, R. ; JAIN, A. Markov random fields: Theory and application. Academic Press, Boston, 1993.

[Poggio et al., 1985] Poggio, T. ; Torre, T. ; Koch, C. Computational vision and regularization theory. Nature, 317:314-319, 1985.

[Pratt, 1984] PRATT, T. W. Programming Languages - Design and Implementation, New York, Prentice Hall, 1984. 
[Preece et al., 1994] PREECE, J. ; ROGERS, Y. ; SHARP, H. ; BENYON, D. Human-Computer interaction. Addison-Wesley, 1994.

[Pressman, 1988] PRESSMAN, R. Software Engineering. New York, McGraw Hill, 1988.

[PVM] Parallel Virtual Machine - Home-Page. http://www.epm.ornl.gov/pvm/pvm_home.html

[Qian, 1997]Qian, N. Physiological computation of binocular disparity. Vision Res., 37(13):1811-1827, 1997

[Quinn, 1987] QUINN, M. J. Designing efficient algorithms for parallel computers.

[Richter, 1995] RICHTER, J. Advanced Windows. Microsoft Press, 1995.

[Rolls et al., 1994] ROLLS, E. T ; TOVEĖ, M. J. ; PURCELL, D. G. ; STEWART A. L. ; AZZOPARDI, P. The responses of neurons in the temporal cortex of primates and face identification and detection. Experimental Brain Research, n. 101, p473-484, 1994.

[Rosenberry et al., 1992] ROSENBERRY, W.; KENNEY, D.; FISHER, G.

Understanding DCE. Sebastopol, O'Reilly, 1992.

[Ryan, 1992] RYAN, B. Built for speed Byte, p123-129, Feb. 1992.

[Schalkoff, 1989] SCHALKOFF, R. F. Digital image processing and computer vision. John Wiley and Sons, 1989.

[Schmidt, 1980] SCHMIDT, R. F. Fisiologia Sensorial. EDUSP, 1980.

[Shapley \& Perry 1986] SHAPLEY, R. ; PERRY, V. Cat and monkey retinal ganglion cells and their visual functional roles. Trends in Neuroscience, v9 p.229-235, 1986.

[Shirai, 1987] SHIRAI, Y. Three-dimensional computer vision. Springer-Verlag, 1987.

[Smith et al., 1996] SMITH, T. G. ; LANGE, G. D. ; MARKS, W. B. Fractal Methods and results in cellular morphology - dimensions, lacunarity and multifractals. Journal of Neuroscience Methods. 69, pp.123-136, 1996

[Snow, 1992] SNOW, C. R. Concurrent Programming. Cambridge, Cambridge University Press, 1992.

[Sobel, 1970] SOBEL, I. E. Camera models and machine perception. Ph.D. Thesis, Stanford University, 1970.

[Spufford \& Uglow, 1997] SPUFFORD, F. ; UGLOW, J. Cultural Babbage Technology, Time and Invention London, Faber and Faber, 1997.

[Stace, 1984] STACE, C. A. Plant Taxonomy and Biosystematics, London, Edward 
Arnold, 1984.

[Stanley, 1986] STANLEY, H. E. Form: An introduction to self-similarity and fractal behavior, in: STANLEY, H. E. ; OSTROWSKY, N. On Growth and form Fractal and non-fractal patterns in physics. Martinus Nijhoff Publishers, Dordrecht, The Netherlands, p. 21-53, 1986.

[Stuessy, 1990] STUESSY, T. F. Plant Taxonomy (The systematic Evaluation of Comparative data). New York, Columbia University Press, 1990.

[Tabak, 1990] TABAK, Daniel RISC systems Taunton, Research Studies Press, 1990.

[Tanenbaum, 1989] TANENBAUM, Andrew S. Computer Networks. Englewood Cliffs, Prentice-Hall, 1989.

[Tanenbaum, 1990] TANENBAUM, Andrew S. Structured Computer Organization. Upper Saddle River, Prentice-Hall, 1990.

[Tanenbaum, 1992] TANENBAUM, Andrew S. Modern Operating Systems. Englewood Cliffs, Prentice-Hall, 1992.

[Tanenbaum, 1995] TANENBAUM, Andrew S. Distributed Operating Systems. Englewood Cliffs, Prentice-Hall, 1995.

[Thazhuthaveetil \& Shah, 1991] THAZHUTHAVEETIL, M.J. ; A.V. SHAH Parallel Hough transform algorithm performance. Image and Vision Computing, volume 9 (1991), number 2, pp. 88-92, 1991.

[Theimer \& Mallot, 1994] THEIMER, W. M., MALLOT, H. A. Phase-based binocular vergence control and depth reconstruction using active vision. CVGIP: Image Understanding. 60(3):343-358. November 1994.

[Tovée, 1996] TOVÉE, M. J. An introduction to the visual system. Cambridge University Press, 1996.

[Tricot, 1995] TRICOT, C. Curves and Fractal Dimensions. Springer-Verlag, Paris, 1995.

[Tsai, 1987] TSAI, R. A versatile camera calibration technique for high accuracy 3D machine vision metrology using off-the-shelf TV and lenses. IEEE Journal of Robotics and Automation, 3(4):323-344, August 1987

[Unger, 1958] UNGER, S. H. A computer oriented towards spatial problems. Proceedings Inst. Radio Engineering, USA, 1958.

[Voorhees \& Poggio, 1988] VOORHESS, H. ; POGGIO, T. Computing texture boundaries from images. Nature, v.333 p364-367, 1988.

[Wilder, 1993] WILDER, F. A guide to the TCP/IP protocol suite. Artech House, 
1993.

[Williams, 1994] WILLIAMS, A. OLE 2.0 and DDE distilled: A programmer's crash course. Addison-Wesley, 1994.

[Zeki \& Shipp, 1988] ZEKI, S. ; SHIPP, S. The functional logic of cortical connections, Nature, v.355, p311-317, September 1988.

[Zeki, 1993] ZEKI, S. A vision of the brain. Blackwell Science, 1993.

[Zuffo, 1978] ZUFFO, J. A. Fundamentos da arquitetura e organização dos microprocessadores. São Paulo, Edit. Edgard Blücher, 1978. 